\title{
Fluid inclusion analyses of Bedded Halite from the Neoproterozoic Browne Formation of Central Australia to Determine Parent Water Origin and $\mathrm{pH}$
}

\author{
Jeremiah A. Bernau
}

Follow this and additional works at: https://researchrepository.wvu.edu/etd

\section{Recommended Citation}

Bernau, Jeremiah A., "Fluid inclusion analyses of Bedded Halite from the Neoproterozoic Browne Formation of Central Australia to Determine Parent Water Origin and pH" (2017). Graduate Theses, Dissertations, and Problem Reports. 5192.

https://researchrepository.wvu.edu/etd/5192

This Thesis is protected by copyright and/or related rights. It has been brought to you by the The Research Repository @ WVU with permission from the rights-holder(s). You are free to use this Thesis in any way that is permitted by the copyright and related rights legislation that applies to your use. For other uses you must obtain permission from the rights-holder(s) directly, unless additional rights are indicated by a Creative Commons license in the record and/ or on the work itself. This Thesis has been accepted for inclusion in WVU Graduate Theses, Dissertations, and Problem Reports collection by an authorized administrator of The Research Repository @ WVU. For more information, please contact researchrepository@mail.wvu.edu. 
Fluid inclusion analyses of bedded halite from the Neoproterozoic Browne Formation of central Australia to determine parent water origin and $\mathrm{pH}$

\author{
Jeremiah A. Bernau \\ Thesis submitted to the \\ Eberly College of Arts and Sciences \\ at West Virginia University
}

in partial fulfillment of the requirements for the degree of

Master of Science in

Geology

Kathleen C. Benison, Ph.D., Chair

Jaime Toro, Ph.D.

Dorothy Vesper, Ph.D.

Department of Geology and Geography

Morgantown, West Virginia

2017

Keywords: fluid inclusions, halite, waters, central Australia, Browne Formation, petrography, laser Raman spectroscopy, freezing-melting microthermometry, $\mathrm{pH}$, saline, microbes

Copyright 2017 Jeremiah A. Bernau 


\title{
Abstract
}

\section{Fluid inclusion analyses of bedded halite from the Neoproterozoic Browne Formation of central Australia to determine parent water origin and $\mathrm{pH}$}

\author{
Jeremiah Bernau
}

The depositional origin of the Neoproterozoic Browne Formation of Australia is unclear. The Browne Formation consists of red-siliciclastic mudstone and siltstone (red beds), bedded and displacive halite and gypsum, and dolomitized stromatolites. Environmental interpretations of the Browne Formation range from a marginal marine lagoon to a playa lake deposit (Grey and Blake, 1999; Hill et al., 2000; Haines et al., 2004; Spear, 2013).

Primary fluid inclusions in Browne Formation bedded halite are the oldest known surface water remnants (Spear et al., 2014). Prior major-ion ratio analysis of these inclusions indicates that the Browne Formation formed from waters with unusually low sulfate concentrations. These waters differed significantly from modern seawater (Spear et al., 2014).

This study tested the non-marine interpretation of the Browne Formation via geochemical analyses. A non-marine interpretation is supported by the sedimentological characteristics it shares with geochemically distinct evaporites and red beds from acid-saline-continental settings $(\mathrm{pH}<1$; Benison and Goldstein, 2002). This thesis is the first examination of primary fluid inclusions from bedded halite from the Neoproterozoic Browne Formation through detailed fluid inclusion petrography, freezing-melting microthermometry, and laser Raman spectroscopy.

This thesis found that the Browne Formation inclusions are geochemically distinct. Freezing-melting attempts to determine major-ion composition and salinity were unsuccessful, this rare outcome indicates high inclusion salinity, and possible low $\mathrm{pH}$. Efforts to determine $\mathrm{pH}$ through laser Raman spectroscopy were unsuccessful and do not indicate low pH $(<1)$. Furthermore, no spectra of solutes or solids indicative of $\mathrm{pH}$ were detected. However, Raman analysis did detect anhydrite, disordered graphite, iron oxides, and several unidentified solids. Inclusion solids include exceptionally well-preserved suspect microbial life, including prokaryotes, spherules similar to Dunaleilla algae, and possible algal mats.

This study found no conclusive data of marine or non-marine Browne Formation parent waters. There is no diagnostic evidence of acid parent waters in the Browne Formation. Due to its unique freezing-melting and laser Raman characteristics, the Browne Formation may be a geologically unique evaporite deposit. 


\section{Acknowledgements}

This research would not have been possible without the guidance, support, advice, edits, and most importantly, the inspiration of my advisor, Dr. Kathleen Benison. Kathy introduced me to the world of fluid inclusions as a doorway to seeing into the past. For that, I now have this thesis, and so much more, to share.

My lab group has been there every step of the way, from starting this project, to problemshooting the laser Raman spectrometer, to lending an eye to my edits. Thank you, Sofia, for bringing joy and community to our group and our department. You have enriched my time at West Virginia University. Lynnette, you have helped ground my research and commiserated with me over the pain of looking at very small things. Thank you for your humor and advice.

I would like to thank my committee members, Dr. Vesper and Dr. Toro, for humbling me while still inspiring me to find new approaches to find solutions.

The Geological Survey of Western Australia provided samples for this thesis. Thank you, Heidi Allen, Kath Gray, Peter Haines, and Roger Hocking for aiding in their collection and documentation.

All science is based upon constructive criticism, and I thank Dr. Tim Lowenstein for sharing his insights with me on this project.

The Shared Research Facilities at West Virginia University enabled much of this research through to access to their Laser Raman Spectrometer for analyses. Thank you Weiqiang Ding for teaching me how to use this device and helping to fix it when things went awry.

Funding from the American Association of Petroleum Geologists Grants-in-Aid Program, the Milton Tidd and Doris E. Heald Award, the Carl del Signore Foundation Graduate Scholarship, and the Bob and Beverly Shumaker Fund made this project possible and greatly enriched it.

Finally, I would like to thank my family for setting me on the path of strong academics. I thank my parents for the Magic School Bus books I received so long ago in second grade, and my aunt Louise for supporting an inquisitive mind. Finally, I would like to thank my siblings for their unwavering support and their congenial competition that helped bring me to where I am today. 


\section{Contents}

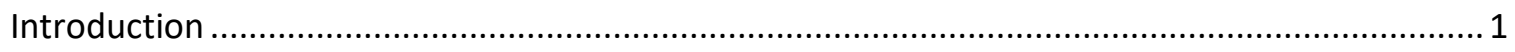

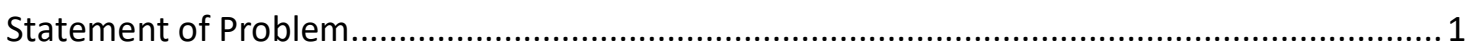

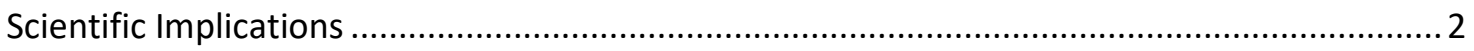

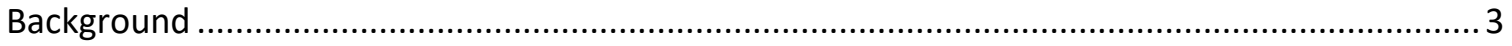

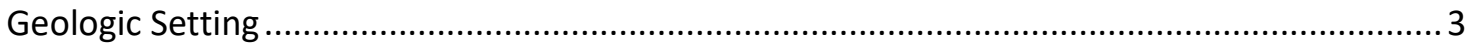

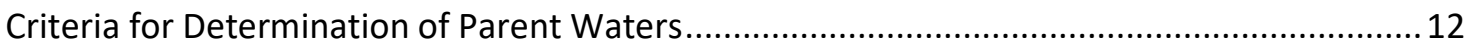

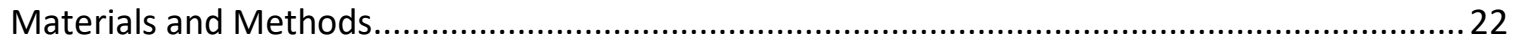

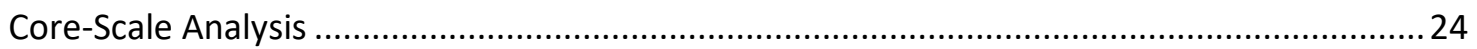

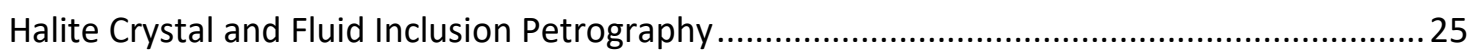

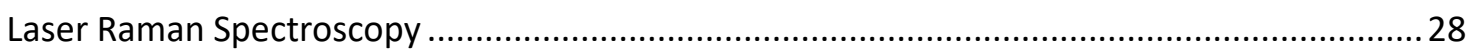

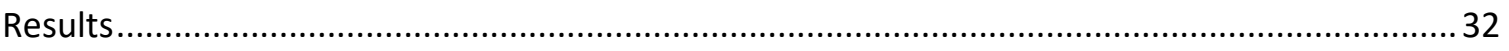

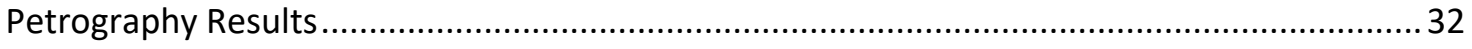

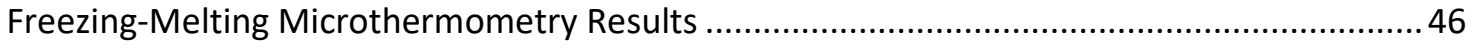

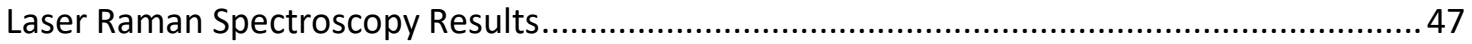

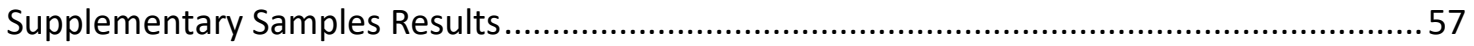

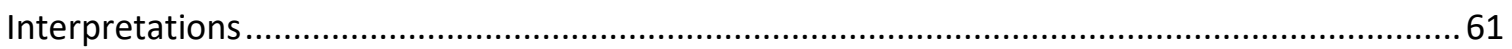

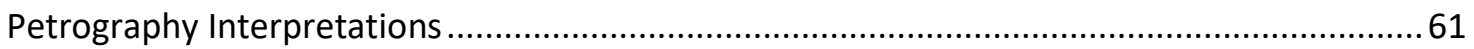

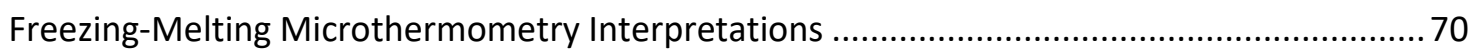

Laser Raman Spectroscopy Data Interpretation ................................................................ 71

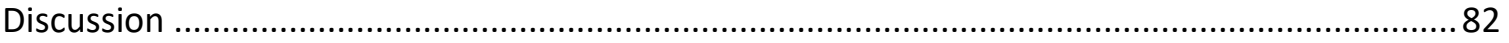

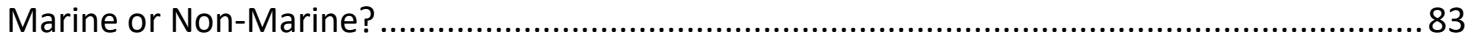

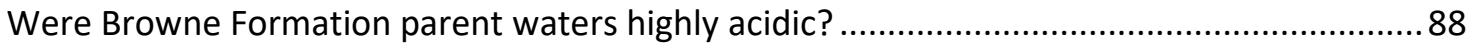

Were Brown Formation parent waters weird? .....................................................................96

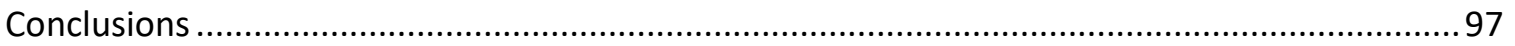

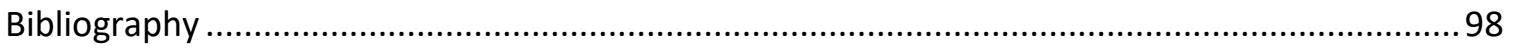

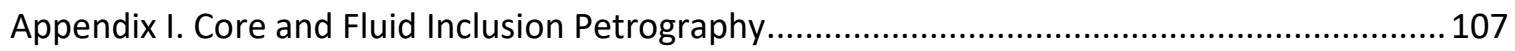

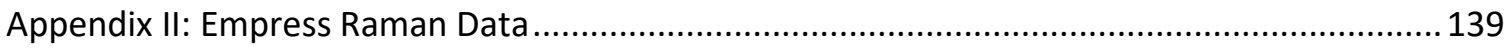

Appendix III. Raman Spectra of Supplementary Samples...................................................... 191

Appendix IV. Can Raman spectra of aqeous iron complexes be a pH proxy? .............................219 


\section{List of Tables}

Table 1. Criteria diagnostic of marine vs. non-marine classification as set out by Brennen et al., 2013; Hardie, 1984; Benison and Goldstein, 2002; \& Bowen and Benison, 2009. .........17

Table 2. Minerals mentioned in this study and their chemical formulas. ...............................20

Table 3. Explanation of sample name scheme, signifigance of name parts........................26

Table 4: Criteria for rating suitability of halite chip for fluid inclusion analyses for this study. .....27

Table 5: Sample halite chips from Empress 1A core that were examined for fluid inclusions. ...37

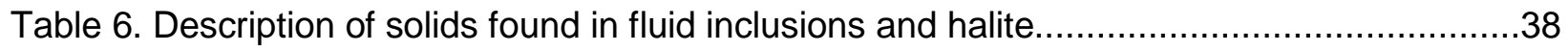

Table 7: Areas of Raman spectra analysis in Empress 1A core ......................................48

Table 8: Guide to Raman peak naming conventions ................................................49

Table 9. Distribution of Raman peaks across sampling interval $\left(237-861 \mathrm{~cm}^{-1}\right) \ldots \ldots \ldots \ldots \ldots \ldots . \ldots 1$

Table 10. Distribution of Raman peaks over sampling intervals $\left(870-1182 \mathrm{~cm}^{-1}\right) \ldots \ldots \ldots \ldots \ldots \ldots . \ldots . \ldots \ldots 2$

Table 11. Distribution of Raman peaks across sampling interval $\left(1237-3070 \mathrm{~cm}^{-1}\right) \ldots \ldots \ldots \ldots . \ldots 3$

Table 12. Identification of solids found in fluid inclusions and halite. .................................66

Table 13: Compounds (and their associated Raman peaks) used to determine $\mathrm{pH} . . . \ldots \ldots \ldots . . . .71$

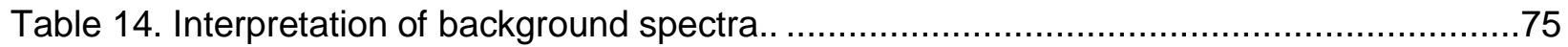

Table 15. Interpretation of Raman peaks of fluid inclusions from 237 to $993 \mathrm{~cm}^{-1} \ldots \ldots \ldots \ldots \ldots . \ldots . \ldots . \ldots$

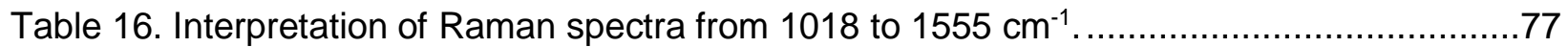

Table 17. Interpretation of Raman peaks from 1604 to $3070 \mathrm{~cm}^{-1} . \mathrm{d}$. ................................78

Table 18: Browne formation characteristices compared with criteria indicative of marine or

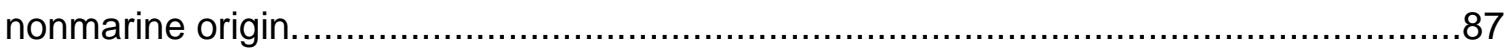

Table 19. Past changes in seawater chemistry as compared with the modeled parent waters of the Browne Formation. .88

\section{List of Figures}

Figure 1. The geographic and stratigraphic setting of the Neoproterozoic Browne Formation.... 4 Figure 2: Generalized stratigraphic column of Empress 1A core lithology in the lower part of the Browne Formation $(1522-1462$ m), after Spear, 2013 ..................................... 7

Figure 3. Depiction of a typical depositional sequence in a shallow saline pan...................... 8

Figure 4. Chart of bromide concentration and sulfur isotopic variations in the Browne Formation

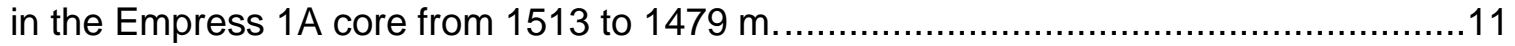


Figure 5: Schematic illustrations of types of salt deposition in an ephemeral saline lake, and examples of primary and secondary fluid inclusions.

Figure 6. Depiction of evaporative divides of seawater with corresponding mineral assemblages.

Figure 7. Map of geographic distribution of analogs used for petrographic/geochemical comparison. .23

Figure 8: Empress 1A sampling intervals from 1520.85-1480.7 m (intervals 1-10), core material

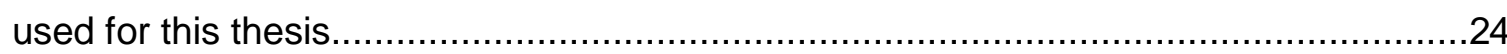

Figure 9: Illustration of phase changes in fluid inclusions during freezing-melting 30

Figure 10. Chart with effect of baseline removal and spectral smoothing in easing Raman spectra interpretation.

Figure 11. Images demonstrating different intervals of core sampling and examination.

Figure 12. Images of halite crystals and fluid inclusion growth bands in halite chip E.4.Z.1.P. ..35

Figure 13. Image of bedded halite the Browne Formation (sample E.4.B.1.P)...... .39

Figure 14. Images of globular fluorescing solids fluid inclusions from zone $E$ of interval 2 (1520.22-1520.0 m).

Figure 15. Images of globular fluorescing solids fluid inclusions from zone $E$ of interval 2 (1520.22-1520.0 m).

Fig. 16. Images of small globular solids in primary fluid inclusions in sample E.4.B.1.P, these solids did not fluoresce under UV illumination.

Figure 17. Image of opaque cubic solid inclusions $(100-600 \mu \mathrm{m})$ found in or near to primary fluid

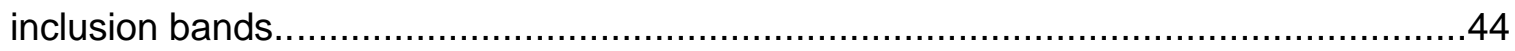

Figure 18. Images of unusual solids found in thick slab from interval 10, zone E. ..................46

Fig. 19: Images of fluid inclusions during freezing-melting attempt with sample E.1297.Z.1.P

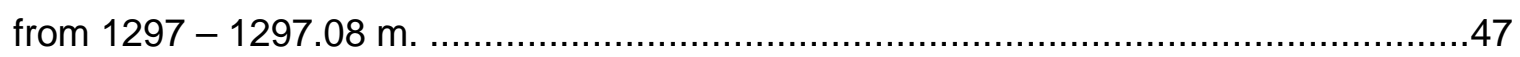

Figure 20: Chart of Raman spectra of potential contamination sources..............................49

Figure 21. Images of areas of targeted Raman collection and chart of corresponding spectra. .50

Figure 22. Chart of Raman spectra of synthetic fluid inclusions with $\mathrm{pH}$ ranging from 0 to 6 (Benison, 1997).

Figure 23. Chart of short Raman scans $\left(400-1700 \mathrm{~cm}^{-1}\right)$ of solids in fluid inclusions in bedded

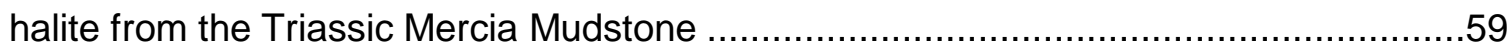

Figure 24. Chart of Raman spectra from aqueous phase of reference fluid inclusions 60 
Figure 25. Chart of reference Raman spectra of natural modern waters from locations with varying $\mathrm{pH}$ and salinity.

Figure 26. Chart of long Raman scans of reference waters and fluid inclusions.

Figure 27. Figure of diversity of Raman spectra collected from Browne Formation halite samples.

Fig. 28. Chart of Raman spectra from the anhydrite and jarosite collected at different laser frequencies. .74

Figure 29. Figure of Browne Formation Raman spectra consistent with anhydrite from inclusions in samples from different sampling intervals................................................ 80

Figure 30. Figure of Raman spectra of solids from Browne Formation halite fluid inclusions.....82

Figure 31. Chart of changes in seawater composition over time. .89 


\section{Introduction}

\section{Statement of Problem}

Primary fluid inclusions in bedded halite in the Neoproterozoic Browne Formation of Australia from the Empress $1 \mathrm{~A}$ core represent unaltered remnants of the oldest known surface waters (Fig. 1; Spear et al., 2014). Past research into these fluid inclusions used cryogenic electron microscopy energy dispersive X-ray spectrometry (cryo-SEM-EDS) to determine the fluid's major ion ratios $\left(\mathrm{Ca}^{2+}, \mathrm{Mg}^{2+}, \mathrm{K}^{+}, \mathrm{S}, \mathrm{Na}^{+}, \mathrm{Cl}^{-}\right.$; Spear et al., 2014). This prior research determined that Browne Formation parent waters highly differed from modern seawater and had depleted $\mathrm{SO}_{4}{ }^{2-}$ and $\mathrm{K}^{+}$concentrations. Other prior study includes analysis of inclusion gases from the Browne Formation indicate a paleoatmospheric oxygen content of roughly half of present-day values (Blamey et al., 2016).

The depositional environment of the Browne Formation is unclear and debated. The Browne Formation consists of red-siliciclastic mudstone and siltstone (red beds), bedded and displacive halite, bedded anhydrite (after gypsum?), and dolomitized stromatolites. A marine interpretation of the Browne Formation is based upon non-diagnostic criteria, such as stromatolites, large extent of evaporites, bromine concentrations, and sulfur and strontium isotopic values (Grey and Blake, 1999; Hill et al., 2000; Spear, 2013). Many of these geochemical characteristics of marine deposits overlap with those of some lake deposits (Hardie, 1984; Bowen and Benison, 2009). Therefore, these data do not unequivocally support a marine origin.

Based upon sedimentological features, the Browne Formation has been interpreted as a marginal marine lagoon or ephemeral lake deposit (Haines et al., 2004). A non-marine interpretation is further supported by the Browne Formation's sedimentological similarity with 
red beds and evaporites that formed in acid-continental settings (Benison and Goldstein, 2002). Finally, no evidence excludes a non-marine deposition.

This master's thesis is the first study to use detailed petrography, microthermometry, and laser Raman spectroscopy to characterize Browne Formation primary fluid inclusions. These analytical techniques were used to answer two questions: (1) was this Neoproterozoic environment marine or non-marine? If non-marine, (2) was its parent water acid?

\section{Scientific Implications}

Determination of a marine or non-marine origin directly affects the interpretation and application of data collected from that deposit. If a deposit is marine, then information collected from that deposit may help interpretation of global ocean fluctuations. If, however, a deposit is non-marine, its interpretations may be locally limited and do not apply to furthering study of oceanic fluctuations. However, they would advance understanding continental settings.

Studies of parent water $\mathrm{pH}$ of evaporite deposits are rare. This may be because acidsaline deposits are not common in the geologic record. Most research assumes evaporite deposits are neutral or alkaline. Acid-saline deposits only form as a result of specific climactic, geographic, and geologic conditions (Long and Lyons, 1992; Benison and Bowen, 2015). This study is the first investigation of the $\mathrm{pH}$ of Browne Formation parent waters. Study of acid-saline systems may hint at the limitations of extreme weathering and geochemistry, as well as climactic and habitability factors (Benison and Bowen, 2013, 2015). Acid-saline deposits share sedimentological and geochemical characteristics with some Martian strata and terrestrial analogs may offer insights into these systems (Squyres et al., 2004; Benison and Bowen, 2006).

\section{Background}

\section{Geologic Setting}




\section{Tectonic Setting of the Officer Basin}

The Empress 1A core was drilled in the western Officer Basin in central Australia (Stevens and Apak, 1999). This semi-emergent broad structural shelf has remained tectonically stable since the Neoproterozoic and is unaffected by deformation (Carlsen et al., 2003; Haines et al., 2004; Simeonova and lasky, 2005). During the Neoproterozoic, this region was located in the Northern Hemisphere near the Equator (Fig. 1C; Scotese, 2009).

After the breakup of Rodinia about $1 \mathrm{Ga}$, the Centralian Superbasin formed in the Australian craton (Shaw et al., 1991; Myers et al., 1996; Hill et al., 2000). The Centralian Superbasin is a collection of several basins, which the Officer Basin is part of, that covered $\sim 2$ million $\mathrm{km}^{2}$ in central Australia during the Neoproterozoic. There are two hypotheses about basin connectivity in the Neoproterozoic Centralian Superbasin. The first is that the superbasin was well connected with laterally continuous deposits across the superbasin. The other hypothesis is that the superbasin had little or no connectivity in the Neoproterozoic. Thus the parent waters of these basins may differ (Stewart, 1979; Lindsay, 1987).

Deposits in the Centralian Superbasin date from the Neoproterozoic to the Cambrian Period. The first interval of large, regionally extensive evaporite deposits in the superbasin is known as Supersequence 1. This is one of three regional supersequences defined by major tectonic events and associated unconformities. Correlation of Supersequence 1 has been attempted through isotopic and geochemical data (Hill et al., 2000). Through sedimentologic, isotopic, and geochemical data, some researchers conclude that the Browne Formation and other deposits in the Centralian Superbasin, such as the Gillen Member of the Bitter Springs Formation in the adjacent Amadeus Basin, are coeval evaporite deposits (Hill et al., 2000). 


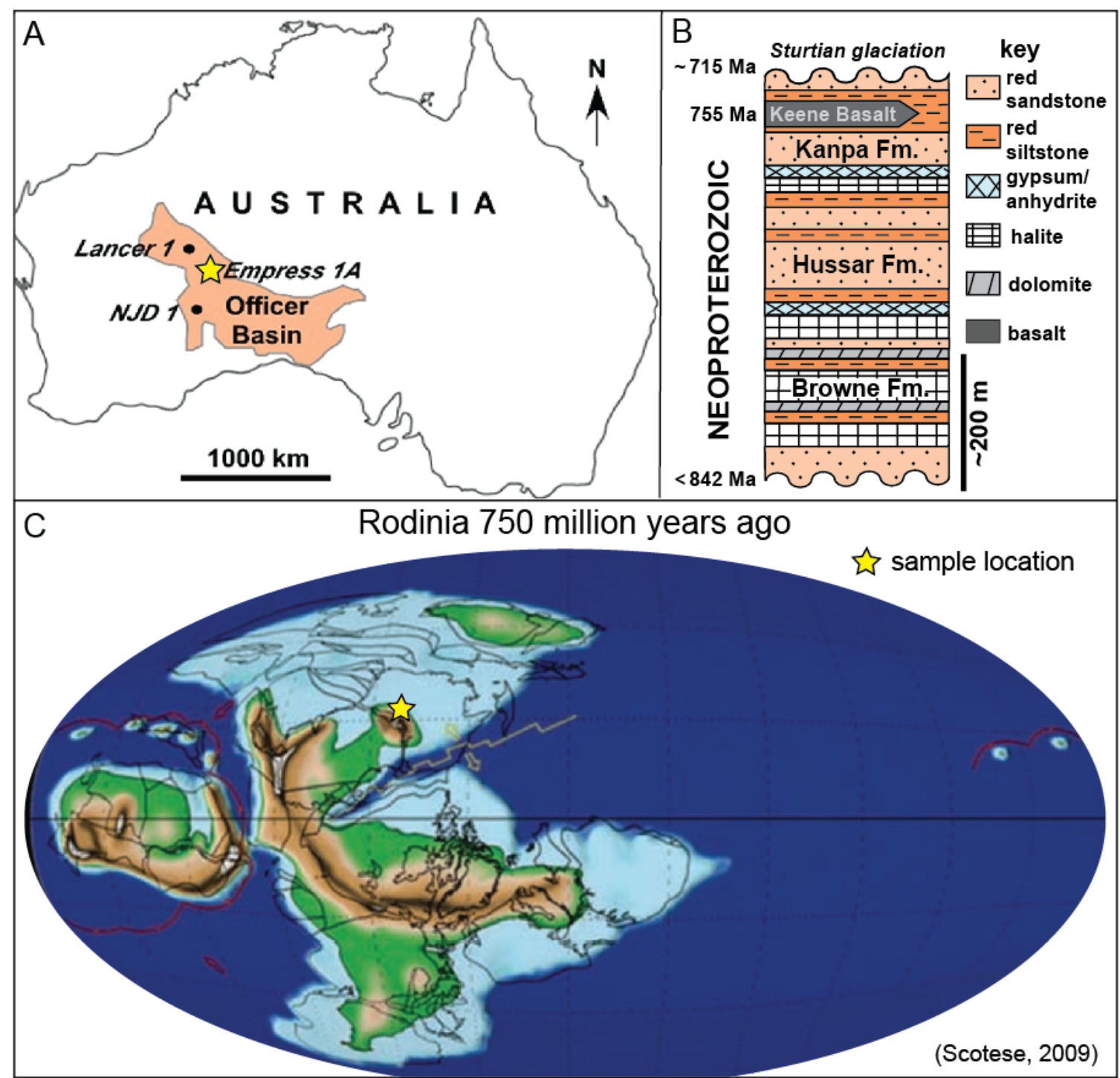

Figure 1. The geographic and stratigraphic setting of the Neoproterozoic Browne Formation. (A) The Officer Basin of central Australia with the Empress 1A, Lancer 1, and NJD 1 cores noted. Cores contain the Browne Formation. (B) Generalized Stratigraphy of the Buldya Group. The lowest formation in the Buldya Group, the Browne Formation, consists of red beds, halite, and dolomite. Image courtesy of K. Benison (modified from Hocking, 2002; Grey et al., 2005; Grey et al., 2011). (C) The approximate location of Australia, north of the equator, during the deposition of the Browne Formation (modified from Scotese, 2009). Note: The Browne Formation may have been deposited tens of millions of years prior to its presence at this location $\sim 750$ million years ago, therefore this paleolocation is very imprecise.

Stratigraphy of the Browne Formation and Adjacent Deposits

The Browne Formation is part of a depositional package knowns as the Buldya Group (Fig. 1B, Grey et al., 2005). At the Empress 1A core, the Buldya Group is $~ 1040 \mathrm{~m}$ thick (4841524 m; Stevens and Apak, 1999). The Buldya Group consists of, from base to top, the Browne, 
Hussar, and Kanpa Formations (Fig. 1A; Grey et al., 2005; Spear, 2013;). Regionally, the Buldya Group is classified as part of the geographically extant Supersequence 1 (Hill et al., 2000). An unconformity bounds the lower Buldya Group from older volcanic rocks that were deformed before $824 \mathrm{Ma}$ (Fig. 1B; Grey et al., 2005). The Keene basalt ( $755 \pm 3 \mathrm{Ma})$ at the Lancer 1A core provides a clear age delineation in the upper portion of the Buldya Group (Fig. 1B; Grey et al., 2005). Detrital zircons in the upper Kanpa Formation, aged at $725 \mathrm{Ma}( \pm 11 \mathrm{Ma})$, indicate Buldya Group deposition until at least 725 Ma (Grey et al., 2005). Glacial deposits of the Sturtian Ice Age ( 717 Ma) overlie the Buldya Group (Grey et al., 2011; Spence et al., 2016). Some researchers date the Browne Formation to roughly $815 \pm 15$ Ma based upon stable-isotope stratigraphy and biostratigraphic correlations with Neoproterozoic deposits in Australia, Canada, Norway, and Namibia (Hill et al., 2000; Macdonald et al., 2010; SwansonHysell et al., 2015). Paleocurrent indicators and sedimentological features indicate that the Officer Basin received inflow waters from the south and clastic material from the northeast during the deposition of the Buldya Group (Stevens and Apak, 1999). The Buldya Group is present in four cores drilled in the Officer Basin: the Empress 1A, the Lancer 1, Hussar 1, and the NJD cores (Fig. 1A; Stevens and Apak, 1998; Haines et al., 2004; Hocking, 2002).

The Buldya Group represents a range of depositional environments (Haines et al., 2004; Grey et al., 2005; Spear et al., 2014). The Browne Formation consists of displacive and bedded halite and red beds (Fig. 2). It has been interpreted as shallow saline water depositional setting. The Hussar Formation consists of anhydrite nodules, sandstone, dolostone, and mudstone (Haines et al., 2004). The Buldya Group has been interpreted as a marginal marine lagoon deposit with changing depositional conditions from high to low energy (Haines et al., 2004). The upper part of the Buldya Group, the Kanpa Formation, consists of stromatolitic dolostone, sandstone, and claystone. It has been interpreted as a shallow marine to coastal deposit 
(Haines et al., 2004). The Keene Basalt, a collection of at least five lava flows, is part of the upper Kanpa Formation (Grey et al., 2005). Mineralogy of the upper part of the Kean Basalt indicates weathering in an arid environment (Grey et al., 2005).

\section{Sedimentology of the Browne Formation}

Evaporites exist throughout the Browne Formation (Fig. 2). Randomly oriented displacive halite in red mudstone and red beds are the most abundant lithologies in the Browne Formation in the Empress 1A, Lancer 1, Hussar 1, and NJD cores (Stevens and Apak, 1999; Benison, personal communication). Very limited work has been done on red beds in the Browne Formation. Bedded halite consisting of cumulates, chevrons, and efflorescent crusts represent a minority of the Browne Formation (Spear, 2013; Fig. 3).

The Browne Formation consists of several subsequences. A lower red mudstone and evaporite succession is documented in the Empress 1A, Lancer 1, and Hussar 1 cores. The middle succession is dominated by stromatolitic dolostone and red mudstone. The upper succession of the Browne Formation varies regionally, it consists of evaporites in the Hussar 1 and Empress $1 \mathrm{~A}$ cores, and sandstone in the Lancer 1 core.

\section{Empress 1A Core, Prior Work}

The Empress 1A core (latitude 2703'13.3" S, longitude 2509'24.3" E) was drilled in the summer of 1997 from the surface to 1624.6 meters depth by the Geological Survey of Western Australia (GSWA; Stevens and Apak, 1999). The Survey collected geochemical, palynological, paleontological, and sedimentological information from the core. Based upon sedimentology, Stevens and Apak (1999) concluded large shallow lakes or a restricted inland sea deposited the Browne Formation (1521.8 to $1247.1 \mathrm{~m}$ depth). The overlying Hussar Formation was interpreted as deposition in a reducing lagoonal or subtidal environment. 


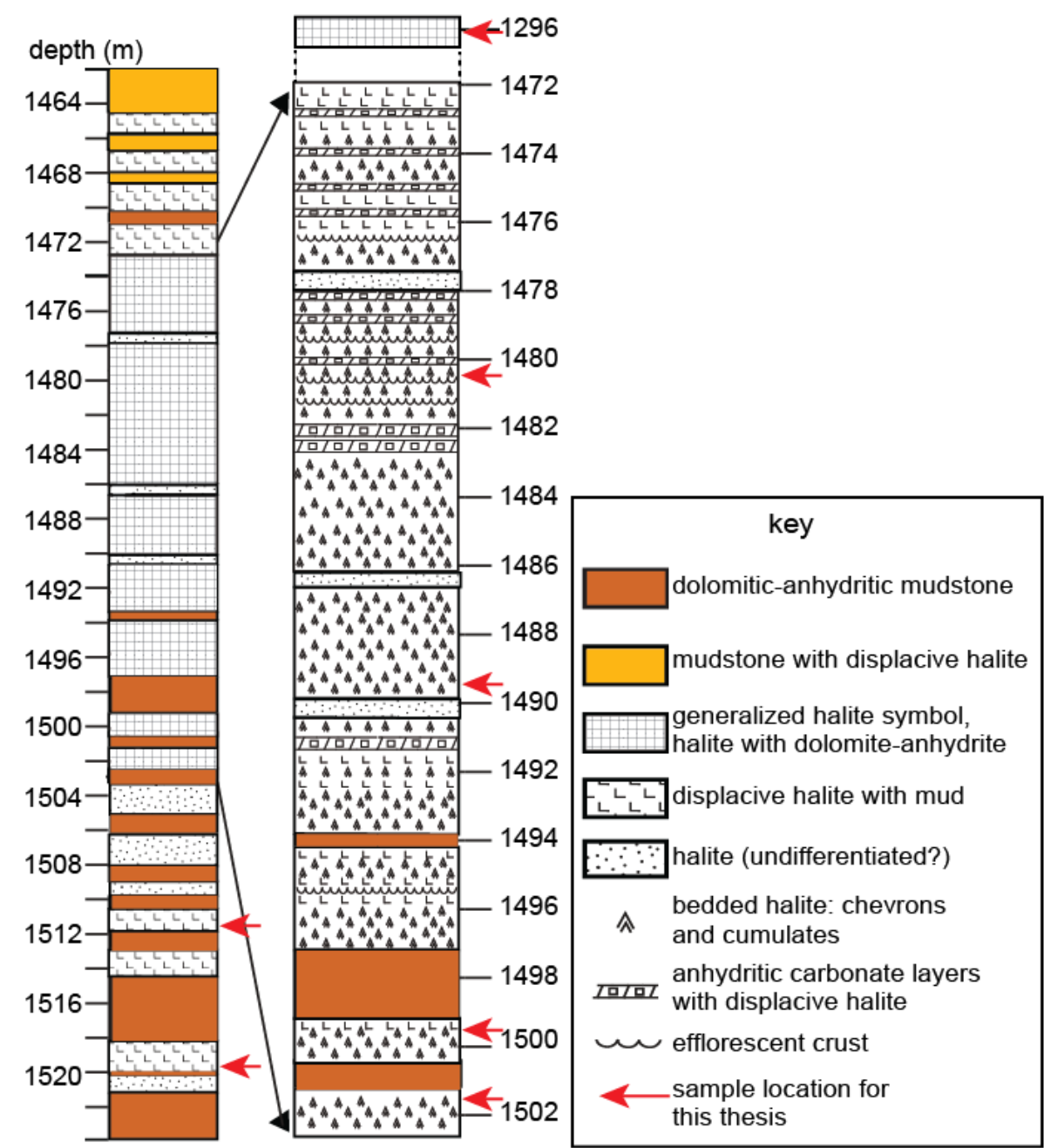

Figure 2: Generalized stratigraphic column of Empress 1A core lithology in the lower part of the Browne Formation (1522 - $1462 \mathrm{~m}$ ), after Spear, 2013. Some halite described in this core is not well distinguished as either bedded or displacive. This interval does not have the full extent of the Browne Formation, which in this core which spans from 1521.8 to $1247.1 \mathrm{~m}$ (Stevens and Apak, 1999). The upper portions of the Browne Formation not shown here include halite (displacive?), interbedded with mudstone (1351-1247.1 $\mathrm{m})$, sandstone (1365-1351 m), dolomite (1403.7-1365 m), and halite (bedded?) interbedded with mudstone (1462-1403.7 m; Stevens and Apak, 1999). The red arrows show sample locations used for this study. Note: sample locations are on both parts of the stratigraphic column.

Palynological and paleontological analyses are limited in the Browne Formation. Only one of three palynological samples $(1602.3 \mathrm{~m})$ had acritarchs that were "too degraded to be identified" (Stevens and Apak, 1999). Other portions of the Browne Formation have only finely disseminated organic material. The upper portion of the Browne Formation (1385.5 - $1368.3 \mathrm{~m}$; 
12 samples) has an 18 meter thick pink dolomite deposit with stromatolites classified as

Acaciella australica (Stevens and Apak, 1999). Based upon this type of stromatolite, authors concluded the paleoenvironment had moderately quiet water and low clastic input, and was below wave base to occasionally emergent.

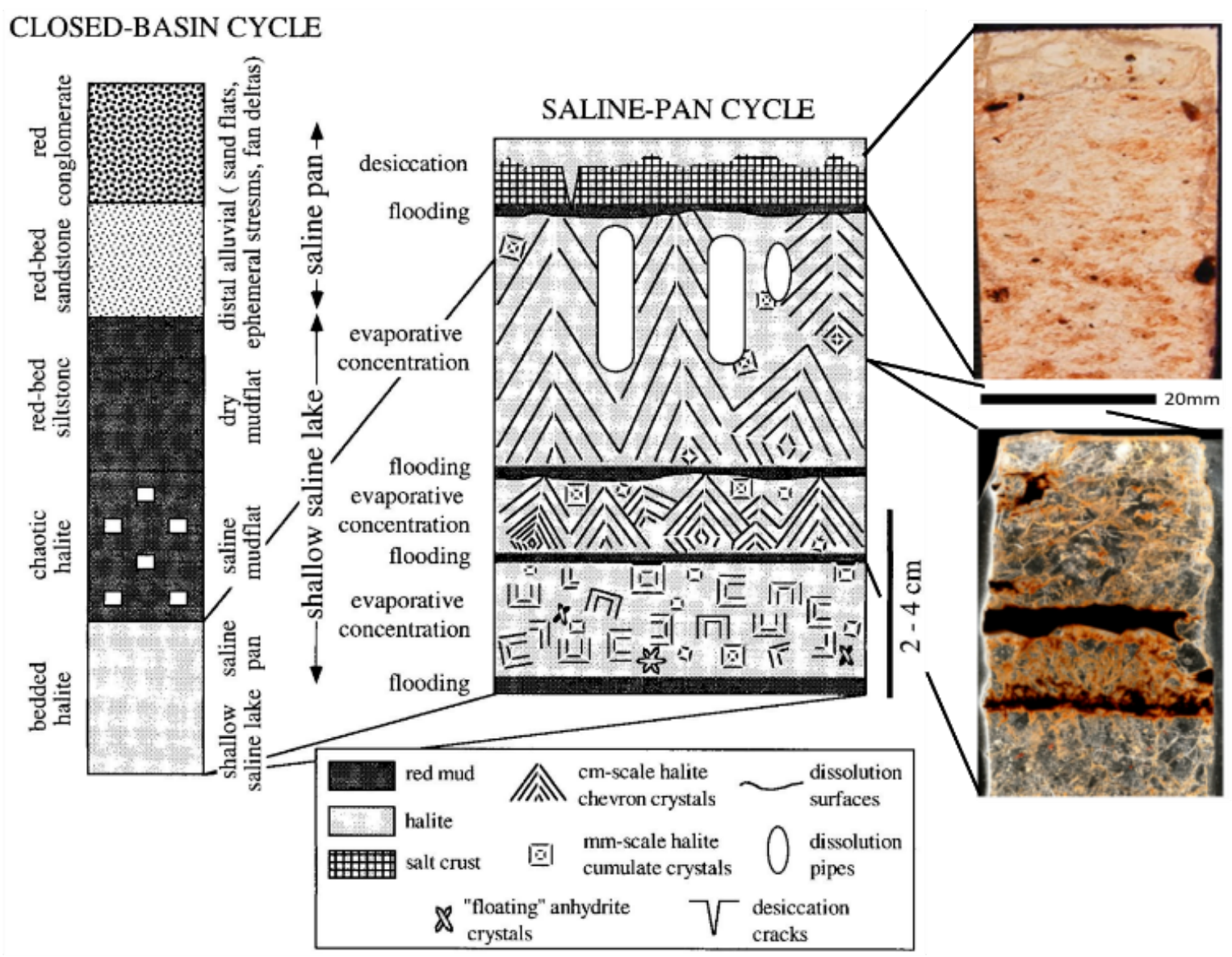

Figure 3. Depiction of a typical depositional sequence in a shallow saline pan. On the left is a schematic of a closed basin-cycle. In the middle diagram shows a saline pan cycle deposit. On the right are thick sections of the Browne Formation that indicate intervals of flooding, evaporative concentration, and desiccation. Dessication is characterized by an finely crystaliine efflourescent crust that formed as waters wicked to the surface (Smoot and Lowenstein, 1991). Images modified from Benison and Goldstein (2000) and Spear (2013). Upper right image from Empress 1A core, $1477 \mathrm{~m}$. Lower right image from Empress $1 \mathrm{~A}$ core, $1500 \mathrm{~m}$.

Spear (2013) collected and examined bedded halite samples from the lower portions of the Browne Formation in the Empress 1A core $(\sim 1522-1462 \mathrm{~m})$ and Lancer 1 core $(\sim 1472-$ $1438 \mathrm{~m})$. Using these samples, she analyzed core petrography and mineralogy, and determined 
major ion-composition of primary fluid inclusions, halite bromide content, and anhydrite sulfur isotopic values (Spear, 2013). Spear's analysis concluded that the Browne Formation was a marine deposit with parent waters that highly differed from modern seawater.

Spear's mineralogical and petrographic analysis of bedded halite from the Browne Formation used X-ray diffraction (XRD; 24 samples), environmental scanning electron microscopy (ESEM; 11 samples), thin sections (at least 4 samples), and thick sections (unknown number of samples; Spear, 2013). Petrographic analysis found blocky, very fine, and lath-shaped anhydrite in association with dolomite (no primary gypsum detected). Dolomite in lower portions of the Browne Formation was laminated, fine-grained, silty to micritic, and halite cemented. Spear concluded that detrital quartz and potassium feldspar grains were eolian. Spear also detected traces of hematite and ilmenite in halite. Spear identified areas of "clear, fluid inclusion free" halite, displacive halite in association with siliciclastic muds, and bedded halite consisting of cumulates, chevrons, dissolution surfaces (Spear, 2013).

Spear described depositional fabrics in halite in a stratigraphic column representative of her measured section of the Browne Formation in the Empress 1A core (Fig. 2; some of these rock type classifications do not have detailed descriptions). No further information about the measured section was provided. Based upon sedimentological features, Spear (2013) divided the lower portion of the Browne Formation in the Empress 1A core $(1525-1460 \mathrm{~m})$ into three depositional regimes. The first regime $(1525-1503 \mathrm{~m})$, of dolomite and anhydrite with some displacive halite and sandstone, was interpreted as a marginal marine, shallow lagoon environment. The second regime (1503 - $1473 \mathrm{~m})$, of bedded halite with chevron and cumulate crystals, dissolution surfaces, and ephemeral crusts with thin sandy beds and draping dolomitic and anhydrite mud layers, was interpreted as an ephemeral marine saline pan or shallow lagoon. The third regime (1473 - $1460 \mathrm{~m})$, of displacive halite and mudstone, was interpreted as 
a salt pan mudflat environment. Spear believes these features are indicative of cyclical basin shallowing and desiccation (Spear, 2013). These sedimentary features are also present in shallow saline pans (Fig. 3).

Spear measured the sulfur isotopic concentrations of anhydrite crystals (primary gypsum pseudomorphs?) in association with bedded halite. Empress $1 \mathrm{~A}$ samples had an average of $\delta^{34} \mathrm{~S}$ value of $15.3 \%$ (14.8-15.9\%o range; 25 samples from 1502 to $1479 \mathrm{~m}$; Fig. 4). These values did not discernably differ from the Lancer 1 core (2 samples, $\delta^{34} \mathrm{~S} 15.1$ and $15.5 \%$; Spear, 2013). Spear considers the Gillen Member in the Amadeus Basin to be coeval with the Browne Formation. Average sulfur isotope values from the Gillen Member, when adjusted for non-marine deposition and diagenesis, are similar to Browne Formation values at $\delta^{34} \mathrm{~S} 17.6 \%$ (adjusted range of 15.3 to 20.1\%; Spear, 2013).

Bromide concentrations were collected from the Browne Formation halite (8 samples from 1502 to $1479 \mathrm{~m}$ ). The highest bromide levels were near the base of the Browne Formation (1502 m) at 122 ppm. Concentrations steadily decreased upsection to 73 ppm (1479 m; Fig. 4; Spear, 2013). Two samples from the Lancer core had similar bromide concentrations at 107 and 111 ppm (Spear, 2013). Spear interpreted the decreasing trend in bromide concentration as resulting from the addition of dilute water into the system and the syndepositional dissolution and recycling of existing halite.

Spear determined the ratios of major ions $\left(\mathrm{Ca}^{2+}, \mathrm{Mg}^{2+}, \mathrm{K}^{+}, \mathrm{S}, \mathrm{Na}^{+}, \mathrm{Cl}^{-}\right)$of 42 unaltered primary fluid inclusions from the Browne Formation ( 7 beds in the Empress $1 \mathrm{~A}$ core, 2 beds in the Lancer 1 core) through cryo-SEM-EDS analysis (Timofeeff et al., 2000; Spear et al., 2014). Due to the halite host, sodium and chloride concentrations found via this method may not be accurate. All measured sulfur was assumed to be in a sulfate form (Spear et al., 2014). 
Inclusion sulfate concentrations were below detection limits (30 mmol). This data was used to derive original Browne Formation parent water sulfate concentrations of $>3 \mathrm{mmol}$ or $10 \%$ of modern seawater levels (Spear et al., 2014). Spear concluded that depleted sulfate levels indicate a parent brine with initial $\mathrm{Ca}^{2+}$ concentrations in excess of sulfate and bicarbonate concentrations. Spear found low inclusion $\mathrm{K}^{+}$concentrations. These low $\mathrm{K}^{+}$concentrations were interpreted as parent waters depleted in potassium, or removal of $\mathrm{K}^{+}$by deposition of and later dissolution of potassium salts.

Figure 4. Chart of bromide concentration and sulfur isotopic variations in the Browne Formation in the Empress 1A core from 1513 to 1479 m. Bromide concentrations decrease upsection. Sulfur isotopes fluctuate with no clear trends (Figure from Spear, 2013). Sulfur values reported versus VCDT (Vienna Canyon Diablo Troilite).

Primary fluid inclusions from the Browne Formation in the Empress $1 \mathrm{~A}$ core were the focus of a paleoatmospheric study (Blamey et al., 2016). Matchhead sized halite samples with primary fluid inclusions with gas bubbles were crushed in bursts in a vacuum. Released gases were run through a mass spectrometer. Inclusion gases had an average oxygen content of $10.9 \%$, roughly half of present-day values (Blamey et al., 2016). The consistency of the amount of gas released by each crush burst was used as an indicator of homogeneity and steady depositional environment. Only two of six samples had a steady release of gas (Blamey et al., 2016).

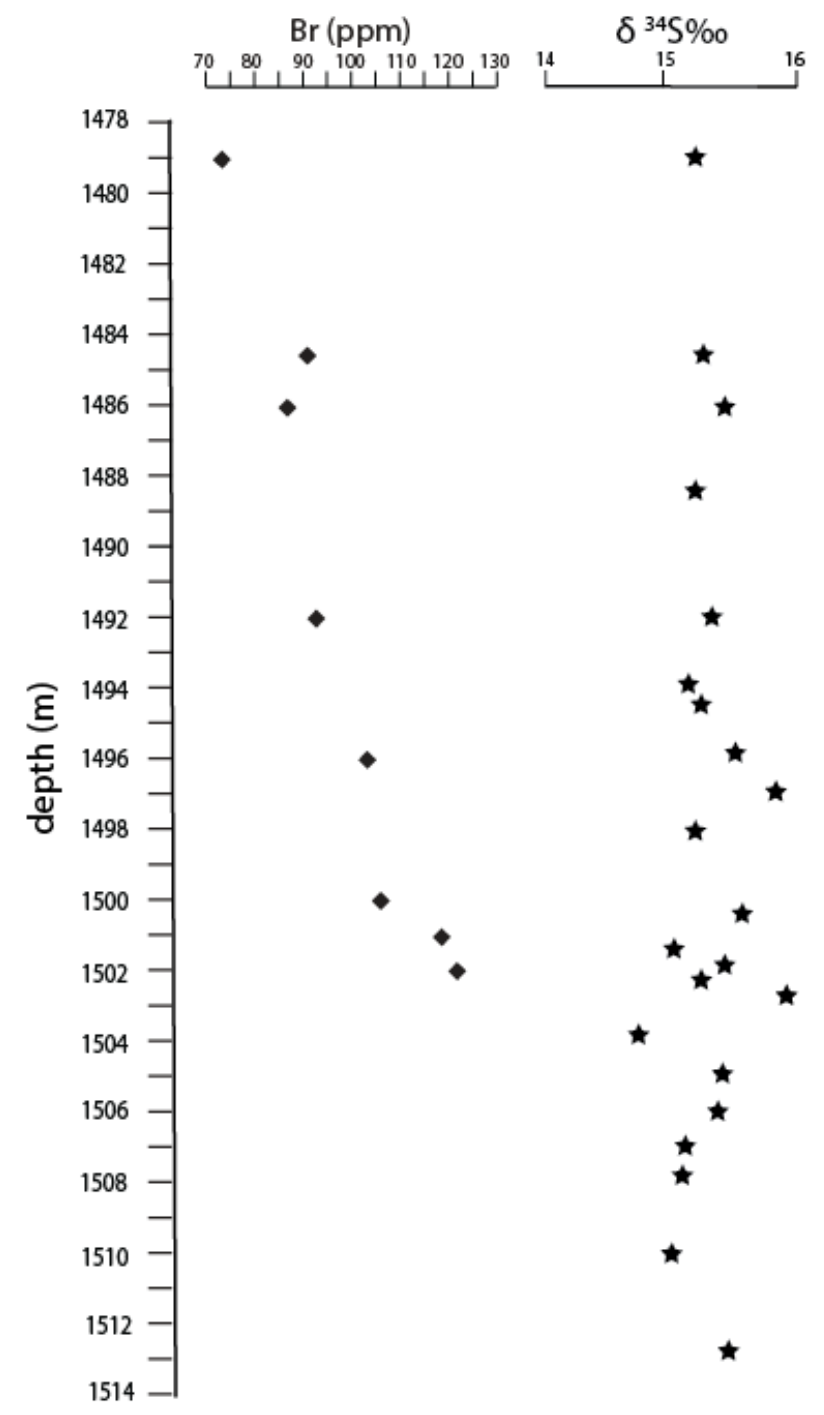




\section{Criteria for Determination of Parent Waters}

Petrographic characteristics of halite deposits are used to find sample suitability for fluid inclusion analysis. This is a key part in determining an evaporite's parent water, $\mathrm{pH}$, and marine or non-marine origin. Sedimentological, geochemical, and fluid inclusion criteria are used to find a non-marine or marine classification. The characteristics of and conditions necessary to identify and form acid-saline deposits are another important element of this thesis.

\section{Halite and Fluid Inclusion Petrography}

\section{Types of halite crystals}

Halite crystals can form from surface water and groundwater. There are several types of halite crystals. Bedded halite formed from surface water consists of cumulate and/or chevron crystals. Cumulate halite consists of millimeter-scale inverted pyramidal to cubic crystals that may connect to form cumulate rafts (Fig. 5; Hovorka, 1987). Chevron halite consists of chevronshaped crystals that are generally larger than one centimeter wide and tall (Lowenstein and Hardie, 1985).

Some halite crystals are minute. Efflorescent crusts are white opaque layers consisting of microscopic crystals of halite and other minerals (Smoot and Castens-Seidell, 1994). Fluid inclusions in efflorescent crusts are too small to see $(<1 \mu \mathrm{m})$.

Early diagenetic halite occurs in two forms. Vug-filling clear halite cement may fill the voids between crystals in bedded halite and other materials, it is massive and has no crystalline shape (Casas and Lowenstein, 1989; Schreiber and El Tabakh, 2000). Displacive halite consists of cubic crystals surrounded by siliciclastics (Casas and Lowenstein, 1989). Fluid inclusions in displacive halite are groundwater. 


\section{Halite Growth Conditions}

The different types of halite crystals are from different depositional stages. Bedded halite from shallow lakes may evidence the flooding, evaporative concentration, and desiccation stages of a saline lake cycle (Lowenstein and Hardie, 1985). The evaporative stage of an ephemeral saline lake cycle marks the highest rate of bedded halite growth from cumulate and chevron halite. Cumulates form at the air-water interface and later sink and settle to the bottom (Shearman, 1970; Hovorka, 1987). These crystals may serve as the nucleation point for further halite growth. In shallow bodies of water $(<0.5 \mathrm{~m})$ bottom-growth halite forms chevron crystals (Arthurton, 1973; Shearman, 1978). During the desiccation stage of an ephemeral saline pan cycle, features such as polygonal fractures and ridges, mud-halite filling microkarst pits, and efflorescent halite crusts may form (Lowenstein and Hardie, 1985).

Diagenetic processes may alter bedded halite (Fig. 3). Very early diagenetic processes occur from dilute water input during the flooding stage. Dilute water may create truncated surfaces and vugs in the bedded halite (Lowenstein and Hardie, 1985). Interstitial halite may form in vugs (Casas and Lowenstein, 1989; Schreiber and El Tabakh, 2000).

Displacive halite grows from saline groundwaters in siliciclastic sediment in the shallow subsurface. As crystals grow they push the sediment host material aside (cm depth; Casas and Lowenstein, 1989). Displacive halite is typically clear.

\section{Halite Fluid Inclusions}

Fluid inclusions in halite are trapped waters. Bedded halite has halite crystals defined by primary fluid inclusion growth bands that form during crystal precipitation. Primary fluid inclusions form during periods of rapid crystal growth. As such, they outline and define stages of prior growth (Goldstein and Reynolds, 1994). Primary inclusions form as flaws in crystal lattices propagate and eventually heal, creating voids with negative crystal habit (cubic for halite). 
These inclusions entrap adjacent liquids, solids, and gases. Primary halite fluid inclusions contain past surface water. The gas in inclusions may be from the air-surface interface or may be gases that upwelled from the subsurface. The crystals in inclusions may be solids in surface waters that were trapped by growing halite (accidental daughter crystals), or they may have crystallized after inclusion formation (true daughter crystals). Fluid inclusions can also trap microorganisms, including bacteria, archaea, algae, and fungi, as well as organic compounds (Benison et al., 2008; Schubert et al., 2009). Only bedded halite that contains unaltered primary fluid inclusions should be used in paleoenvironmental studies (Benison et al., 1998; Benison and Goldstein, 1999; Conner and Benison, 2013).

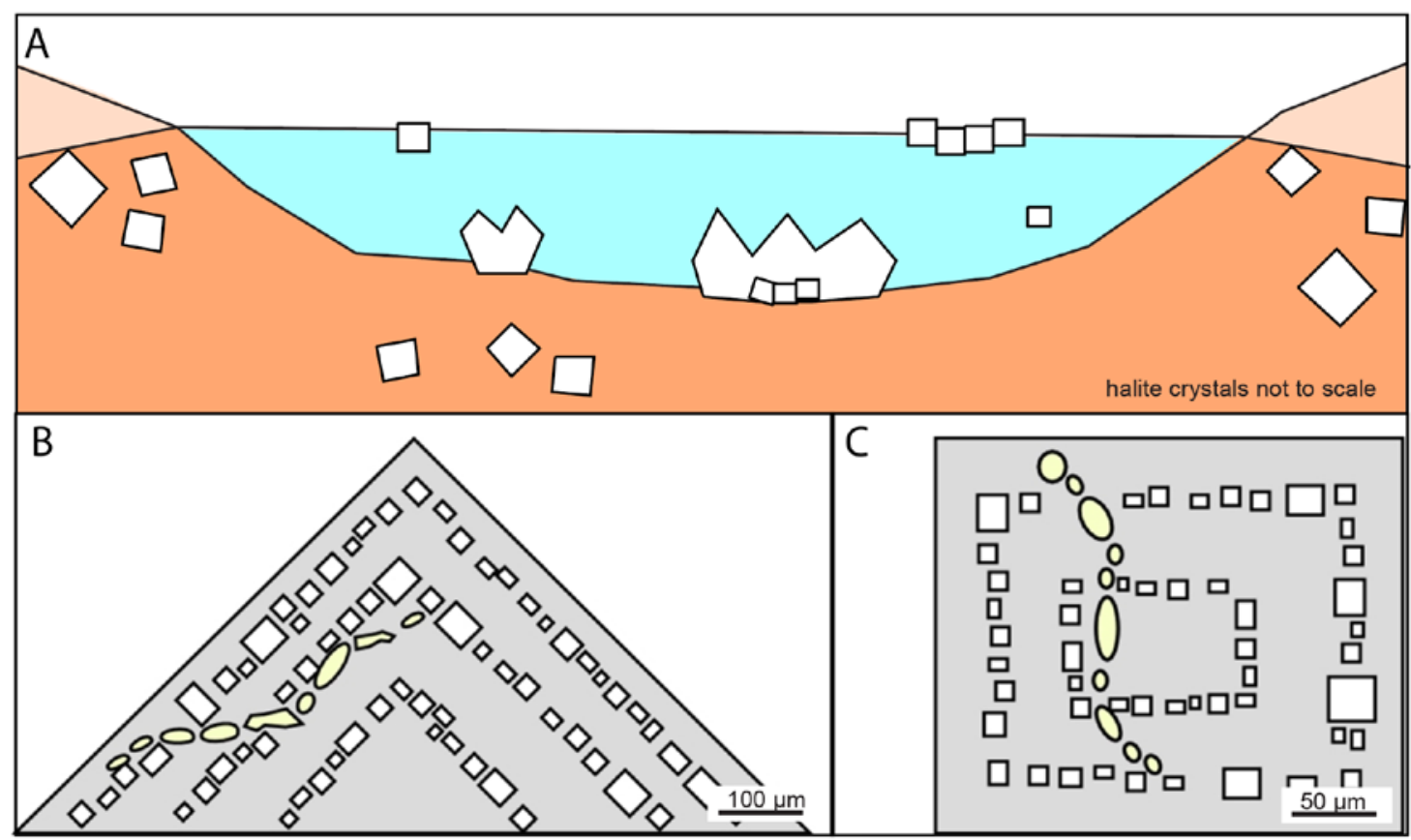

Figure 5: Schematic illustrations of types of salt deposition in an ephemeral saline lake, and examples of primary and secondary fluid inclusions. (A) Cross-section of cumulate crystals and rafts that grow at the air-water interface until eventually sinking to the bottom. If the waters are shallow $(<0.5 \mathrm{~m})$ then these crystals may serve as the nuclei for bottom growth chevron crystals. Small halite crystals may also form in suspension and settle out of the water. The red-orange area designates a briny water table with displacive halite cubes growing in the sediment subsurface. (B) Chevron halite as viewed in crosssection. White boxes outline fluid inclusions aligned along growth bands. The off-yellow ellipses represent a secondary fluid inclusion assemblage that cross cuts primary growth bands, likely formed along a healed fracture. (C) Cumulate chevron with fluid inclusion growth bands as viewed from above. Note that the cumulate crystals are much smaller than chevron crystals (image courtesy of K. Benison). 
Primary inclusions align along growth bands composed of alternating cloudy inclusionrich intervals and clear inclusion-poor intervals (Goldstein and Reynolds, 1994). Inclusion poor intervals form during periods of slow crystal growth. These inclusion assemblages outline crystal shapes. For example, fluid inclusion growth bands appear like chevrons growing in the upward direction in chevron halite. Displacive and interstitial halite do not have primary fluid inclusions.

Later stages of diagenesis may alter or create inclusions. Inclusion stretching or leaking is indicative of diagenesis due to heating and/or pressure (Goldstein, 2003). When deformation occurs, it alters the shape and volume of inclusions. This may cause inclusions to shift from single-phase, to two-phase liquid-vapor inclusions with consistent liquid-vapor ratios.

Diagenesis may also cause secondary fluid inclusion assemblages to form. Secondary inclusions are a diagenetic feature. They are identified by their shape (elliptical) and relation to other inclusions. They form as healed fractures consisting of curved planes that cut across primary inclusion assemblages. All halite types may contain secondary inclusions. Large isolated inclusions with negative crystal habit may also exist, these are unsuitable for fluid inclusions analysis because of uncertainty in their fluid origin (Roedder et al., 1987; Stein and Krumhansl, 1988).

\section{Marine vs. Non-Marine Origin}

In the absence of marine fossils, determination of a marine origin in evaporites requires the fulfillment of many criteria (Hardie, 1984). Mineralogical, sedimentological, isotopic, geochemical, and fluid inclusion criteria must be consistent with contemporaneous marine deposits for a marine classification. Table 1 discusses criteria used to differentiate marine and non-marine evaporite deposits. A brine's composition determines mineralogy, geochemistry, and fluid inclusion composition. Non-marine brines from meteoric, hydrothermal, diagenetic, and/or volcanogenic sources may vary greatly. Some non-marine brine compositions are 
distinct from seawater composition, while some non-marine brine compositions are similar to seawater composition (Brennan et al., 2013).

\section{Sedimentology and Mineralogy}

Sedimentological features assist in determining if deposits are marginal marine or nonmarine (Hardie, 1984; James et al., 1984). Both tidally influenced marginal marine and nonmarine ephemeral lakes or saline pans have sedimentary structures such as mud cracks and wave ripples. Diagnostic properties of tidal flats include marine fossils, tidal bundles, and associated marine lithofacies, such as reefal carbonates. In contrast, diagnostic properties of a continental environment include non-marine fossils and continental lithofacies, such as paleosols (James et al.,1984). Clear challenges exist in identifying non-marine sedimentological characteristics in the Precambrian due to the absence of non-marine (or marine) fossils and poorly developed paleosols at that time (Retallack et al., 2015).

Figure 6. Depiction of evaporative divides of seawater with corresponding mineral assemblages. The final brine composition is determined by variations within the parent brine composition (Hardie, 1984).

Seawater chemistry has known elemental ratios ( $\mathrm{Na}-\mathrm{K}-\mathrm{Mg}-\mathrm{Ca}-\mathrm{Cl}-\mathrm{SO}_{4}$ brine), this limits the resulting mineral precipitates (Fig. 6). Minerals such as epsomite and

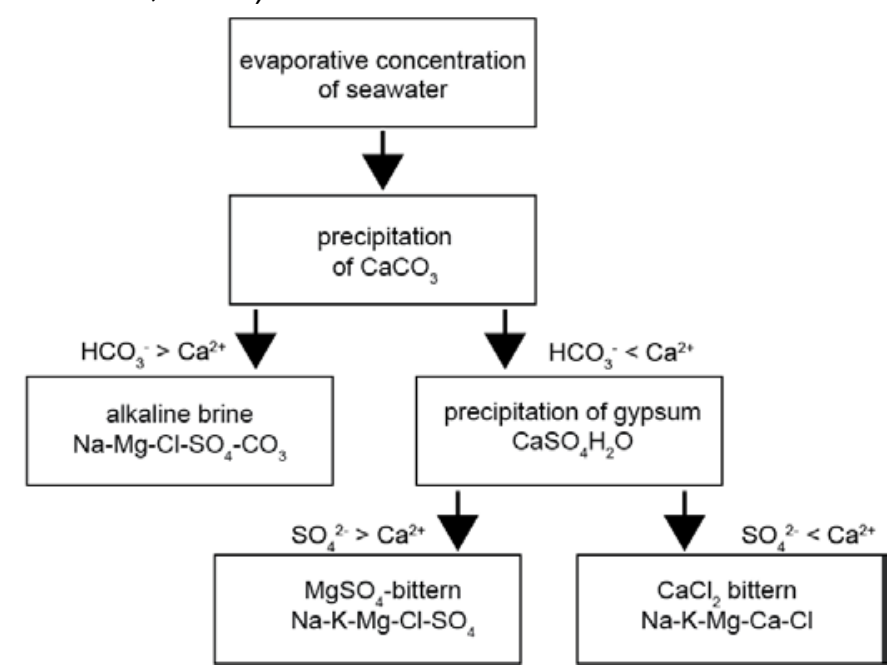
thenardite are consistent, but not diagnostic, of marine input. These mineral assemblages may be present in non-marine deposits. Parent brines with elemental ratios that differ from marine waters, however, result in unique non-marine mineral assemblages. For example, the presence of nahcolite and calcium chloride in the absence of epsomite and thenardite is non-marine. The minerals discussed in this thesis, and their chemical formulas, are outlined in Table 2. 
Table 1. Criteria diagnostic of marine vs. non-marine classification as set out by Brennen et al., 2013; Hardie, 1984; Benison and Goldstein, 2002; \& Bowen and Benison, 2009.

\begin{tabular}{|c|c|c|c|c|}
\hline \multicolumn{2}{|c|}{ criteria } & marine & non-marine & interpretive challenges \\
\hline \multicolumn{2}{|c|}{$\begin{array}{l}\text { deposits and } \\
\text { fossils }\end{array}$} & $\begin{array}{l}\text { marine lithofacies and/or marine } \\
\text { fossils below, interbedded with, } \\
\text { or above evaporites }\end{array}$ & $\begin{array}{l}\text { continental deposits and/or } \\
\text { continental fossils below, } \\
\text { interbedded with, or above } \\
\text { evaporites }\end{array}$ & $\begin{array}{l}\text { some basins and evaporites } \\
\text { change from being marine to } \\
\text { non-marine. (e.g. the } \\
\text { Mediterranean) }\end{array}$ \\
\hline \multicolumn{2}{|c|}{$\begin{array}{l}\text { Br- concentration of } \\
\text { halite }\end{array}$} & $\begin{array}{l}\text { halite with } \mathrm{Br}^{-}>40 \mathrm{ppm} \text {. Halite } \mathrm{Br}^{-} \\
\text {concentrations should increase } \\
\text { upsection. }\end{array}$ & $\begin{array}{l}\text { halite with } \mathrm{Br}-<40 \mathrm{ppm} \text { is } \\
\text { continental/cannot form from } \\
\text { simple seawater evaporation. } \\
\mathrm{Br}-\text { concentrations that decrease } \\
\text { upsection indicate seawater } \\
\text { caused halite recycling or non- } \\
\text { marine waters }\end{array}$ & $\begin{array}{l}\text { non-marine brines have a } \\
\text { large range of } \\
\mathrm{Br}-\text { concentrations } \\
(0-3,000 \mathrm{ppm}) \text {, so some non- } \\
\text { marine brine } \mathrm{Br} \text { - overlaps with } \\
\text { marine } \mathrm{Br} \text { - range }\end{array}$ \\
\hline \multicolumn{2}{|c|}{ mineralogy } & $\begin{array}{l}\text { primary and postdepositional } \\
\text { minerals and mineral } \\
\text { successions limited by parent } \\
\text { water ( } \mathrm{Na}-\mathrm{K}-\mathrm{Mg}-\mathrm{Ca}-\mathrm{Cl}-\mathrm{SO}_{4} \text { ), } \\
\text { minerals such as } \mathrm{MgSO}_{4} \text { and } \\
\mathrm{Na}_{2} \mathrm{SO}_{4} \text { are consistent with } \\
\text { marine input (but not diagnostic) }\end{array}$ & $\begin{array}{l}\text { minerals such as } \mathrm{Na}_{2} \mathrm{CO}_{3}, \mathrm{KCl} \\
\text { and } \mathrm{CaCl}_{2} \text { in the absence of } \\
\mathrm{CaCO}_{3}, \mathrm{Na}_{2} \mathrm{SO}_{4} \text {, and } \mathrm{MgSO}_{4} \\
\text { indicate non-marine parent brine } \\
\text { (in modern deposits) }\end{array}$ & $\begin{array}{l}\text { The main mineralogy for } \\
\text { deposits with either parent } \\
\text { water is gypsum and halite. } \\
\text { Marine type minerals may be } \\
\text { present in non-marine } \\
\text { deposits. }\end{array}$ \\
\hline \multicolumn{2}{|c|}{$\begin{array}{l}\delta^{34} \mathrm{~S} \text { of waters and } \\
\text { sulfate minerals }\end{array}$} & $\begin{array}{l}\delta^{34} \mathrm{~S} \text { of Cenozoic seawater is }+20 \\
\text { to }+23 \% \text {, and Cenozoic marine } \\
\text { evaporites have this isotope } \\
\text { range }\end{array}$ & $\begin{array}{l}\delta^{34} S \text { of sulfate minerals }<+20 \text { or } \\
>+23 \% \text { are not from pristine } \\
\text { modern seawater }\end{array}$ & $\begin{array}{l}\text { Some modern lakes have } \delta^{34} \mathrm{~S} \\
\text { concentrations within } 20 \text { - } \\
23 \% . \text { The } \delta^{34} \mathrm{~S} \text { of acid-saline } \\
\text { lakes in Western Australia are } \\
17-18.6 \% \text { in water and } 18.9- \\
20.4 \% \text { in sulfate minerals. }\end{array}$ \\
\hline \multicolumn{2}{|c|}{$\begin{array}{l}{ }^{87} \mathrm{Sr} / 86 \mathrm{Sr} \text { of sulfates } \\
\text { and carbonates }\end{array}$} & $\begin{array}{l}\text { sulfates and carbonates have } \\
87 \mathrm{Sr} / 86 \mathrm{Sr} \text { within range of } 0.7077 \\
\text { to } 0.7091 \text { (seawater composition } \\
\text { from } \sim 40 \mathrm{Ma} \text { to present) }\end{array}$ & $\begin{array}{l}\text { sulfates and carbonates with } \\
\text { radiogenic }{ }^{87} \mathrm{Sr} /{ }^{86} \mathrm{Sr} \text { values } \\
>0.7091 \text { are not from pristine } \\
\text { seawater }\end{array}$ & $\begin{array}{l}\text { some non-marine sulfates and } \\
\text { carbonates have values < } \\
0.7091 \text {; while some marine } \\
\text { deposits have }>0.7091 \\
87 \mathrm{Sr} / 86 \mathrm{Sr} \text { (Permian Salado and } \\
\text { Rustler Formations) }\end{array}$ \\
\hline \multirow{5}{*}{ 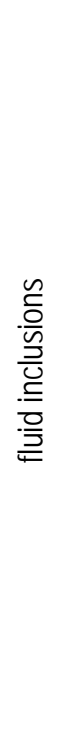 } & \multirow[t]{2}{*}{ brines } & $\begin{array}{l}\text { consistent fluid inclusion brine } \\
\text { compositions in coeval basins } \\
\text { (same evaporation paths) }\end{array}$ & $\begin{array}{l}\text { different brine types for coeval } \\
\text { inclusions indicate that parent } \\
\text { water from a non-marine or a } \\
\text { mixed source }\end{array}$ & $\begin{array}{l}\text { fluctuations in seawater } \\
\text { chemistry may occur with } \\
\text { dilute seawater input }\end{array}$ \\
\hline & & $\begin{array}{l}\mathrm{Na}-\mathrm{K}-\mathrm{Mg} \text {-Ca-Cl-SO} \\
4 \\
\mathrm{Cl}^{-} \mathrm{SO}_{4} \text { brine in ma-K-Mg- }\end{array}$ & $\begin{array}{l}\text { brines that are not } \mathrm{Na}-\mathrm{K}-\mathrm{Mg}-\mathrm{Ca}- \\
\mathrm{Cl}^{-} \mathrm{SO}_{4} \text { to } \mathrm{Na}-\mathrm{K}-\mathrm{Mg}-\mathrm{Cl}-\mathrm{SO}_{4} \text { type } \\
\text { brines }\end{array}$ & $\begin{array}{l}\text { non-marine brine may have } \\
\mathrm{Na}-\mathrm{K}-\mathrm{Mg}-\mathrm{Ca}-\mathrm{Cl}-\mathrm{SO}_{4} \text { to } \mathrm{Na}-\mathrm{K}- \\
\mathrm{Mg}-\mathrm{Cl}-\mathrm{SO}_{4} \text { brine type }\end{array}$ \\
\hline & $\mathrm{pH}$ & $\begin{array}{l}\text { neutral to alkaline fluid inclusion } \\
\mathrm{pH}\end{array}$ & $\begin{array}{l}\text { non-marine waters } \mathrm{pH} \text { may } \\
\text { range from }<1.9 \text { up to } 12.4\end{array}$ & $\begin{array}{l}\text { like marine brines, non-marine } \\
\text { brines may be neutral to } \\
\text { alkaline }\end{array}$ \\
\hline & $\begin{array}{l}\text { evaporation } \\
\text { paths }\end{array}$ & $\begin{array}{l}\text { fluid inclusion brine composition } \\
\text { from a basin follows evaporation } \\
\text { paths on concentration crossplots }\end{array}$ & $\begin{array}{l}\text { scatter on concentration } \\
\text { crossplots indicates non-marine } \\
\text { or mixed source brine }\end{array}$ & $\begin{array}{l}\text { non-marine brines may follow } \\
\text { evaporation paths on } \\
\text { concentration crossplots }\end{array}$ \\
\hline & $\begin{array}{l}\text { overlapping } \\
\text { evaporation } \\
\text { paths }\end{array}$ & $\begin{array}{l}\text { fluid inclusion brines from } \\
\text { contemporaneous, } \\
\text { geographically separated basins } \\
\text { must have overlapping } \\
\text { evaporation paths }\end{array}$ & $\begin{array}{l}\text { evaporation paths that do not } \\
\text { overlap indicate different parent } \\
\text { waters in the basins }\end{array}$ & $\begin{array}{l}\text { non-marine basins may have } \\
\text { same evaporation paths as } \\
\text { marine basins }\end{array}$ \\
\hline
\end{tabular}




\section{Elemental and Isotopic Geochemistry}

High bromide concentration (> $40 \mathrm{ppm}$ ) is traditionally considered an indicator of marine origin. As a conservative ion that is not incorporated into most mineral precipitates, brine bromide concentration tends to increase as water evaporates. Typical seawater halite deposits have bromide concentrations of 70 ppm (first halite deposited) to 200 ppm (last halite deposited; Valyashko, 1956; Holser and Kaplan, 1966). However, some modern marine halite deposits have bromide concentrations as low as 40 ppm (Bloch, 1953). An upward decreasing trend in bromide is indicative of non-marine input or syndepositional recycling of halite deposits from dilute waters (Brennan et al., 2013). Some non-marine deposits, such as the Green River Formation and acid-saline lakes in Western Australia, have much lower or higher bromide concentrations than those observed in seawater (0 to $~ 941 \mathrm{ppm} \mathrm{Br}$; Bowen and Benison, 2009). So, only low bromide concentrations (<40 ppm) are indicative of a non-marine origin (Hardie, 1984).

The isotopic composition of sulfur in unaltered sulfate minerals may be indicative of parent brine origin (Hardie, 1984; Brennan et al., 2013). Sulfate minerals that have $\delta^{34} S$ values consistent with modern seawater ( +20 to $+23 \%$ for Cenozoic) may come from seawater. Nonmarine deposits, however, can share the same $\delta^{34} \mathrm{~S}$ values as marine deposits $(21.8-22.5 \%$; Playa et al., 2007). A consistent value for $\delta^{34} S$ throughout a formation suggests a non-varying source of parent water.

The ${ }^{87} \mathrm{Sr} /{ }^{86} \mathrm{Sr}$ ratio in sulfates and carbonate minerals is another corroborative tool (Hardie, 1984; Brennan et al., 2013). Strontium may be substituted for calcium in minerals because of its chemical similarity. Strontium ratios of Cenozoic seawaters are well defined ( 0.7077 to $\left.0.7091{ }^{87} \mathrm{Sr} /{ }^{86} \mathrm{Sr}\right)$. A deviation from this ratio is indicative of non-marine input, but non-marine deposits may fall within this ratio. In general, low ratios indicate seawater or mafic- 
rock derived strontium and high ratios indicate felsic igneous rock derived strontium (continental, non-marine waters). Modern nonmarine lake brines have a large ${ }^{87} \mathrm{Sr} /{ }^{86} \mathrm{Sr}$ range that overlaps with the ${ }^{87} \mathrm{Sr} /{ }^{86} \mathrm{Sr}$ marine range.

\section{Fluid Inclusion Analyses}

As remnants of surface waters, fluid inclusions yield snapshots into depositional water chemistry. Modern seawater begins as a Na-K-Mg-Ca-Cl-SO brine and develops into a Na-KMg-Cl-SO 4 brine (Hardie, 1984). In marine deposits, inclusion chemistry should be consistent

with seawater evaporative paths on concentration crossplots. Crossplots show changes in brine chemistry as evaporation increases and minerals precipitate (principles related to Figure 6). Inconsistent concentrations on these crossplots indicates mixed brine sources (Brennan et al., 2013). As marine input implies little variation in inclusion chemistry over time, large fluctuations are indicative of a non-marine origin. In ancient deposits, a marine designation requires brine chemistry evaporation paths that are consistent between contemporaneous, geographically separated basins. Inclusion $\mathrm{pH}$ is also indicative of parent water origin. Non-marine brines may match marine brines in $\mathrm{pH}$, however, extreme $\mathrm{pH}$, such as $<1$, is indicative of non-marine origin (Benison et al., 1998). Any brine with a pH less than 7 is non-marine because seawater $\mathrm{pH}(8.3$ $\mathrm{pH}$ ) increases with evaporation.

\section{Characteristics and environments of formation of acid-saline deposits}

Acid-saline brines vary greatly, but all strongly differ from modern seawater (Benison and Bowen, 2015). Low pH in acid-saline ephemeral lakes is attributed to sulfide oxidation and ferrohydrolysis of ancient rocks and soil. Acidity increases and decreases through floodingevaporation-desiccation cycles in arid climates (Long and Lyons, 1992; Benison et al., 2007). Acidophilic microbes may also influence low pH conditions through geochemical cycles (Bowen and Benison, 2009; Conner and Benison, 2013). 
Benison and Goldstein (2002) described key mineralogical, sedimentological, and fluid inclusion features for the recognition of acid red beds and evaporites. Modern and ancient acid brine deposits have red beds and no carbonates. Any detected carbonates acid-saline deposits must be diagenetic replacement minerals (for example, gypsum replaced by calcite or dolomite; Benison and Goldstein, 2002). Acid environments may have rare mineral assemblages. Most commonly, they include iron oxides and the sulfate minerals alunite and jarosite. Other acid precipitates include kaolinite, opal, natroalunite, alunogen, jurbanite, basluminite, rostite, natrojarosite, schwertmannite, halotrichite, melanterite, and copiapite (Table 2; Benison and Goldstein, 2002). The geologic record rarely preserves many of these sulfate minerals as they weather to gypsum and hematite. They may, however, be preserved as solid inclusions in halite or gypsum, or as accidental daughter crystals within fluid inclusions in halite or gypsum. Fluid inclusion analyses of bedded halite may also reveal characteristics of the parent water chemistry. Acid waters would likely contain bisulfate (if $\mathrm{pH}<1$ ) and elevated aluminum, iron, and silicon concentrations (Benison and Goldstein, 2002).

Table 2. Minerals mentioned in this study and their chemical formulas.

\begin{tabular}{|c|c|}
\hline mineral name & chemical formula \\
\hline actinolite & $\mathrm{Ca}_{2}(\mathrm{Mg}, \mathrm{Fe})_{5} \mathrm{Si}_{8} \mathrm{O}_{22}(\mathrm{OH})_{2}$ \\
\hline afwillite & $\mathrm{Ca}_{3}\left(\mathrm{SiO}_{3} \mathrm{OH}\right)_{2} \cdot 2\left(\mathrm{H}_{2} \mathrm{O}\right)$ \\
\hline alum $(\mathrm{K})$ & $\mathrm{KAI}\left(\mathrm{SO}_{4}\right)_{2} \cdot 12\left(\mathrm{H}_{2} \mathrm{O}\right)$ \\
\hline aluminite & $\mathrm{Al}_{2} \mathrm{SO}_{4}(\mathrm{OH})_{4} \cdot 7\left(\mathrm{H}_{2} \mathrm{O}\right)$ \\
\hline aluminum sulfate & $\mathrm{Al}\left(\mathrm{SO}_{4}\right)_{3}$ \\
\hline alunite (ammonium alunite) & $\mathrm{NH}_{4} \mathrm{Al}_{6}\left(\mathrm{SO}_{4}\right)_{2}(\mathrm{OH})_{6}$ \\
\hline alunite (hydronium alunite) & $\mathrm{H}_{3} \mathrm{O}^{+} \mathrm{Al}_{3}\left(\mathrm{SO}_{4}\right)_{2}(\mathrm{OH})_{6}$ \\
\hline alunite (k-alunite) & $\mathrm{KAl}_{3}\left(\mathrm{SO}_{4}\right)_{2}(\mathrm{OH})_{6}$ \\
\hline alunite (natroalunite) & $\mathrm{NaAl}_{3}\left(\mathrm{SO}_{4}\right)_{2}(\mathrm{OH})_{6}$ \\
\hline alunogen & $\mathrm{Al}_{2}\left(\mathrm{SO}_{4}\right)_{3} \cdot 17\left(\mathrm{H}_{2} \mathrm{O}\right)$ \\
\hline analcime & $\mathrm{NaAlSi}_{2} \mathrm{O}_{6} \cdot \mathrm{H}_{2} \mathrm{O}$ \\
\hline anhydrite & $\mathrm{CaSO}_{4}$ \\
\hline aragonite & $\mathrm{CaCO}_{3}$ \\
\hline basaluminite (felsőbányaite) & $\mathrm{Al}_{4}(\mathrm{OH})_{10} \cdot 4\left(\mathrm{H}_{2} \mathrm{O}\right)$ \\
\hline bassanite & $\mathrm{CaSO}_{4} \cdot 0.5\left(\mathrm{H}_{2} \mathrm{O}\right)$ \\
\hline bischofite & $\mathrm{MgCl}_{2} \cdot 6\left(\mathrm{H}_{2} \mathrm{O}\right)$ \\
\hline blödite & $\mathrm{Na}_{2} \mathrm{Mg}\left(\mathrm{SO}_{4}\right)_{2} \cdot 4\left(\mathrm{H}_{2} \mathrm{O}\right)$ \\
\hline calcite & $\mathrm{CaCO}_{3}$ \\
\hline carnallite & $\mathrm{KCl} \cdot \mathrm{MgCl}_{2} \cdot 6\left(\mathrm{H}_{2} \mathrm{O}\right)$ \\
\hline
\end{tabular}




\begin{tabular}{|c|c|}
\hline copaipite & $\mathrm{Fe}^{2+}\left(\mathrm{Fe}^{3+}\right)_{4}\left(\mathrm{SO}_{4}\right)_{6}(\mathrm{OH})_{2} \cdot 20\left(\mathrm{H}_{2} \mathrm{O}\right)$ \\
\hline dickite (kaolinite) & $\mathrm{Al}_{2} \mathrm{Si}_{2} \mathrm{O}_{5}(\mathrm{OH})_{4}$ \\
\hline dolomite & $\mathrm{CaMg}\left(\mathrm{CO}_{3}\right)_{2}$ \\
\hline epsomite & $\mathrm{MgSO}_{4} \cdot 7 \mathrm{H}_{2} \mathrm{O}$ \\
\hline gaylussite & $\mathrm{Na}_{2} \mathrm{Ca}\left(\mathrm{CO}_{3}\right)_{2} \cdot 5\left(\mathrm{H}_{2} \mathrm{O}\right)$ \\
\hline gibbsite (norstrandite) & $\mathrm{Al}(\mathrm{OH})_{3}$ \\
\hline glauberite & $\mathrm{Na}_{2} \mathrm{Ca}(\mathrm{SO} 4)_{2}$ \\
\hline goethite & $\mathrm{Fe}^{3+} \mathrm{O}(\mathrm{OH})$ \\
\hline graphite & $\mathrm{C}$ \\
\hline gypsum & $\mathrm{CaSO}_{4} \cdot 2\left(\mathrm{H}_{2} \mathrm{O}\right)$ \\
\hline halite & $\mathrm{NaCl}$ \\
\hline halotrichite & $\mathrm{FeAl}_{2}\left(\mathrm{SO}_{4}\right)_{4} \cdot 22\left(\mathrm{H}_{2} \mathrm{O}\right)$ \\
\hline hematite & $\mathrm{Fe}_{2} \mathrm{O}_{3}$ \\
\hline hydrobasaluminite & $\mathrm{Al}_{4}\left(\mathrm{SO}_{4}\right)(\mathrm{OH})_{10} \cdot 15\left(\mathrm{H}_{2} \mathrm{O}\right)$ \\
\hline iron(III) chloride & $\mathrm{Fe}^{3+} \mathrm{Cl}_{3}$ \\
\hline jarosite (k-jarosite) & $\mathrm{KFe}^{3+}{ }_{3}(\mathrm{OH})_{6}\left(\mathrm{SO}_{4}\right)_{2}$ \\
\hline jarosite (natrojarosite) & $\mathrm{NaFe}_{3}\left(\mathrm{SO}_{4}\right)_{2}(\mathrm{OH})_{6}$ \\
\hline jurbanite & $\mathrm{AlSO}_{4}(\mathrm{OH}) \cdot 5\left(\mathrm{H}_{2} \mathrm{O}\right)$ \\
\hline kaolinite & $\mathrm{Al}_{2} \mathrm{Si}_{2} \mathrm{O}_{5}(\mathrm{OH})_{4}$ \\
\hline kieserite & $\mathrm{MgSO}_{4} \mathrm{H}_{2} \mathrm{O}$ \\
\hline leonite & $\mathrm{K}_{2} \mathrm{Mg}\left(\mathrm{SO}_{4}\right)_{2} \cdot 4\left(\mathrm{H}_{2} \mathrm{O}\right)$ \\
\hline lepidocrocite & $\mathrm{Fe}^{3+} \mathrm{O}(\mathrm{OH})$ \\
\hline magnesite & $\mathrm{MgCO}_{3}$ \\
\hline magnetite & $\mathrm{Fe}^{2+} \mathrm{Fe}^{3+} 2 \mathrm{O}_{4}$ \\
\hline melanterite & $\mathrm{FeSO}_{4} \cdot 7\left(\mathrm{H}_{2} \mathrm{O}\right)$ \\
\hline mirabilite & $\mathrm{Na}_{2} \mathrm{SO}_{4} \cdot 10\left(\mathrm{H}_{2} \mathrm{O}\right)$ \\
\hline montmorillonite & $(\mathrm{Na}, \mathrm{Ca})_{0.33}(\mathrm{Al}, \mathrm{Mg})_{2}\left(\mathrm{Si}_{4} \mathrm{O}_{10}\right)(\mathrm{OH})_{2} \cdot \mathrm{nH} 2 \mathrm{O}$ \\
\hline nahcolite & $\mathrm{NaHCO}_{3}$ \\
\hline nontronite (clay) & $\left(\mathrm{CaO}_{0.5}, \mathrm{Na}\right)_{0.3} \mathrm{Fe}^{3+}{ }_{2}(\mathrm{Si}, \mathrm{Al})_{4} \mathrm{O}_{10}(\mathrm{OH})_{2} \cdot \mathrm{n}\left(\mathrm{H}_{2} \mathrm{O}\right)$ \\
\hline opal & $\mathrm{SiO}_{2} \cdot \mathrm{n}\left(\mathrm{H}_{2} \mathrm{O}\right)$ \\
\hline paulingite-k & $\left(\mathrm{Na}_{2}, \mathrm{~K}_{2}, \mathrm{Ca}, \mathrm{Ba}\right)_{5} \mathrm{Al}_{10} \mathrm{Si}_{35} \mathrm{O}_{90} \cdot 45(\mathrm{H} 2 \mathrm{O})$ \\
\hline pentahydrite & $\mathrm{MgSO}_{4} \cdot 5 \mathrm{H}_{2} \mathrm{O}$ \\
\hline polyhalite & $\mathrm{K}_{2} \mathrm{Ca}_{2} \mathrm{Mg}\left(\mathrm{SO}_{4}\right) 4 \cdot 2\left(\mathrm{H}_{2} \mathrm{O}\right)$ \\
\hline pyrite & $\mathrm{FeS}_{2}$ \\
\hline quartz & $\mathrm{SiO}_{2}$ \\
\hline rostite & $\mathrm{Al}\left(\mathrm{SO}_{4}\right)(\mathrm{OH})_{0.8} \mathrm{~F}_{0.2} \cdot 5\left(\mathrm{H}_{2} \mathrm{O}\right)$ \\
\hline rozenite & $\mathrm{Fe}^{2+} \mathrm{SO}_{4} \cdot 4\left(\mathrm{H}_{2} \mathrm{O}\right)$ \\
\hline schlossmacherite & $\left(\mathrm{H}_{3} \mathrm{O}\right) \mathrm{Al}_{3}\left(\mathrm{SO}_{4}\right)_{2}(\mathrm{OH})_{6}$ \\
\hline schwertmannite & $\mathrm{Fe}_{8} \mathrm{O}_{8}(\mathrm{OH})_{6}\left(\mathrm{SO}_{4}\right) \cdot n\left(\mathrm{H}_{2} \mathrm{O}\right)$ \\
\hline starkeyite & $\mathrm{MgSO}_{4} \cdot 4\left(\mathrm{H}_{2} \mathrm{O}\right)$ \\
\hline sylvite & $\mathrm{KCl}$ \\
\hline tachyhydrite & $\mathrm{CaMg}_{2} \mathrm{Cl}_{6} \cdot 12\left(\mathrm{H}_{2} \mathrm{O}\right)$ \\
\hline thenardite & $\mathrm{Na}_{2} \mathrm{SO}_{4}$ \\
\hline zaherite & $\mathrm{Al}_{12}(\mathrm{OH})_{26}\left(\mathrm{SO}_{4}\right)_{5} \cdot 20\left(\mathrm{H}_{2} \mathrm{O}\right)$ \\
\hline
\end{tabular}




\section{Materials and Methods}

\section{Browne Formation Samples}

For this thesis, halite-rich portions of the Empress 1A core at the Geological Survey of Western Australia (GSWA) Core Repository in Perth were photographed, slabbed, and bagged for shipment to West Virginia University on January 13, 2015 by Kathleen Benison. Portions of the Lancer $1 \mathrm{~A}$ core were also observed and sampled during this period. The NJD core at the GSWA Core Repository in Kalgoorlie was examined and sampled by Kathleen Benison in 2011. There is little recoverable primary halite in the NJD core due to drilling and storage methods. Due to GSWA restrictions on the amount sampling permitted, only a small portion of the full Browne Formation from the Empress $1 \mathrm{~A}$ core is the subject of this thesis. The main sample interval for this thesis spans from 1520.85-1480.7 m (intervals 1-10). See Figure 2 and Figure 8 for the sampling intervals. These 10 samples consist of $128 \mathrm{~cm}$ of core, only $3.3 \%$ of the core from 1520.85-1480.7 m. An additional sample $(8.1 \mathrm{~cm})$ was collected from $\sim 1297 \mathrm{~m}$.

\section{Supplementary Samples}

This thesis also analyzed fluid inclusions and waters from marine and non-marine modern and ancient evaporites for comparison purposes and to serve as lab "knowns" (Fig. 7). Synthetic halite samples of known pH and chemistry were used as standards (Benison, 1997). All Raman spectra, from both the Browne Formation and supplementary samples, were collected with the same Raman spectrometer. These spectra were used for comparison purposes and to find sources of data error.

The reference halite samples with fluid inclusions come from diverse saline environments. Samples come from the Silurian Salina Formation of Michigan, Permian Opeche Shale of North Dakota, Permian Nippewalla Group of Kansas, Triassic Mercia Mudstone of Northern Ireland, and modern Great Salt Lake of Utah. The Silurian Salina Formation is a 
marine halite (Satterfield et al., 2005). The Permian Opeche Shale and Nippewalla Group are acid-saline ephemeral lake deposits (Benison et al., 1998). The Triassic Mercia Mudstone is an ephemeral lake deposit with moderately low pH (2-4; Andeskie, 2016; Eichenlaub, 2016). Great Salt Lake is an alkaline lake.

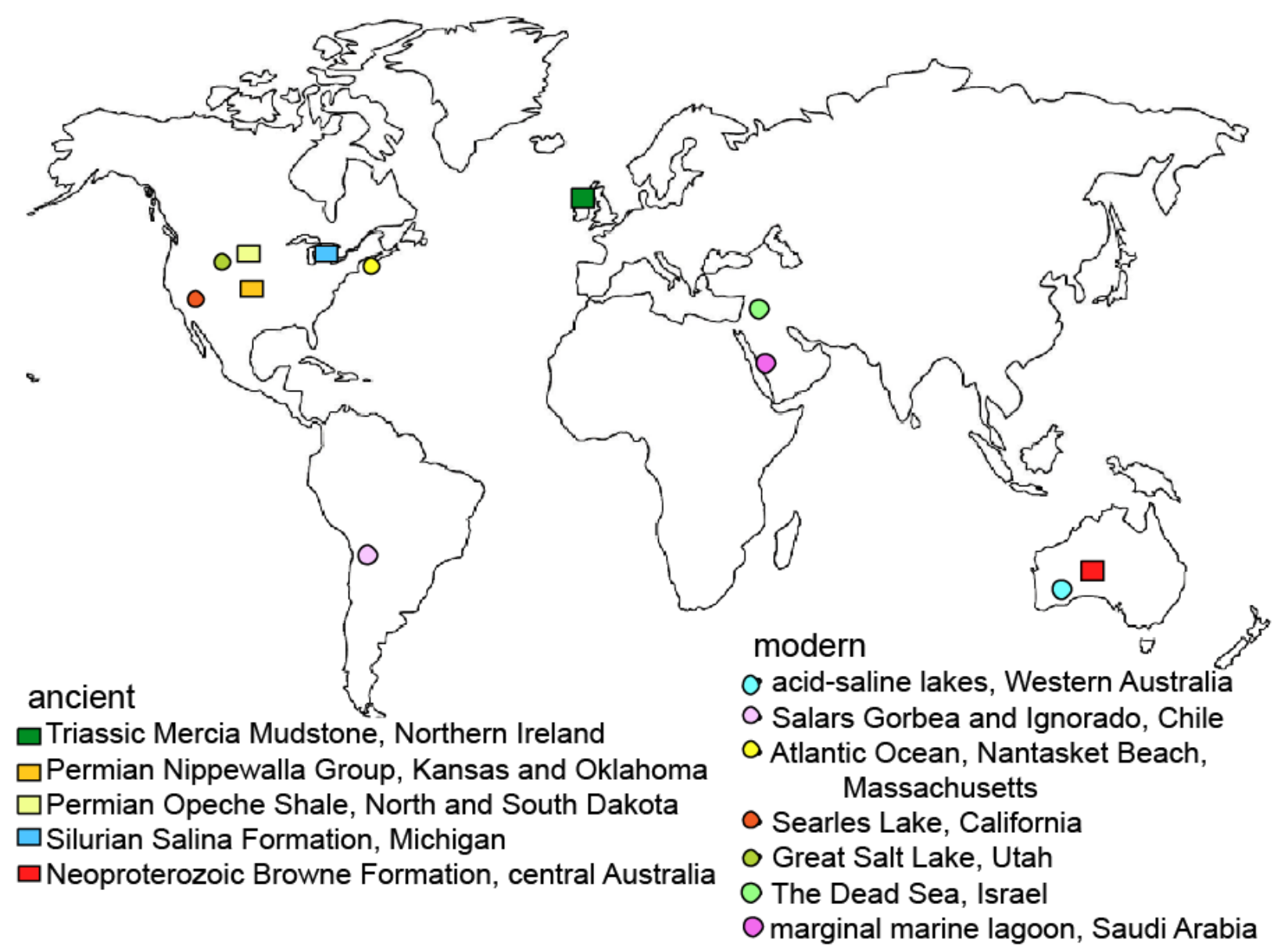

Figure 7. Map of geographic distribution of analogs used for petrographic/geochemical comparison.

Natural waters used as solutions of known chemistry and $\mathrm{pH}$ include marine and nonmarine samples. Samples from natural waters used in this study include Searles Lake, California; Great Salt Lake, Utah; Atlantic Ocean, Massachusetts; Salar Gorbea, Chile; and acid-saline lakes from Western Australia. Searles Lake in California is an alkaline saline lake (Winters et al., 2013). Great Salt Lake is an alkaline non-marine lake. The modern Atlantic 
Ocean water is slightly alkaline and is the most dilute sample used in this thesis. Salar Gorbea is an acid-saline lake in Chile that precipitates gypsum (Karmanocky and Benison, 2016). Acidsaline lake samples from Western Australia varied in $\mathrm{pH}$ and salinity (Benison et al., 2007;

Bowen and Benison, 2009).

\section{Core-Scale Analysis}

Ten "intervals" of core were

examined for this study (Fig. 8;

ranging in length from 6 to $22 \mathrm{~cm}$ ).

Each interval is a continuous piece

of core that may have several beds.

Core-scale analysis identified areas

for halite sampling. Different areas

of sampling and examination are

named as "zones". Each zone is

consists of a halite rich region

separated from other zones

physically by color changes, or by

interceding mud layers.

Figure 8: Empress 1 A sampling intervals from 1520.85-1480.7 m (intervals 1-10), core material used for this thesis. An interval is a continuous piece of core that was available for this study. These 10 collected samples consist of $128 \mathrm{~cm}$ of core, only 3.3\% of

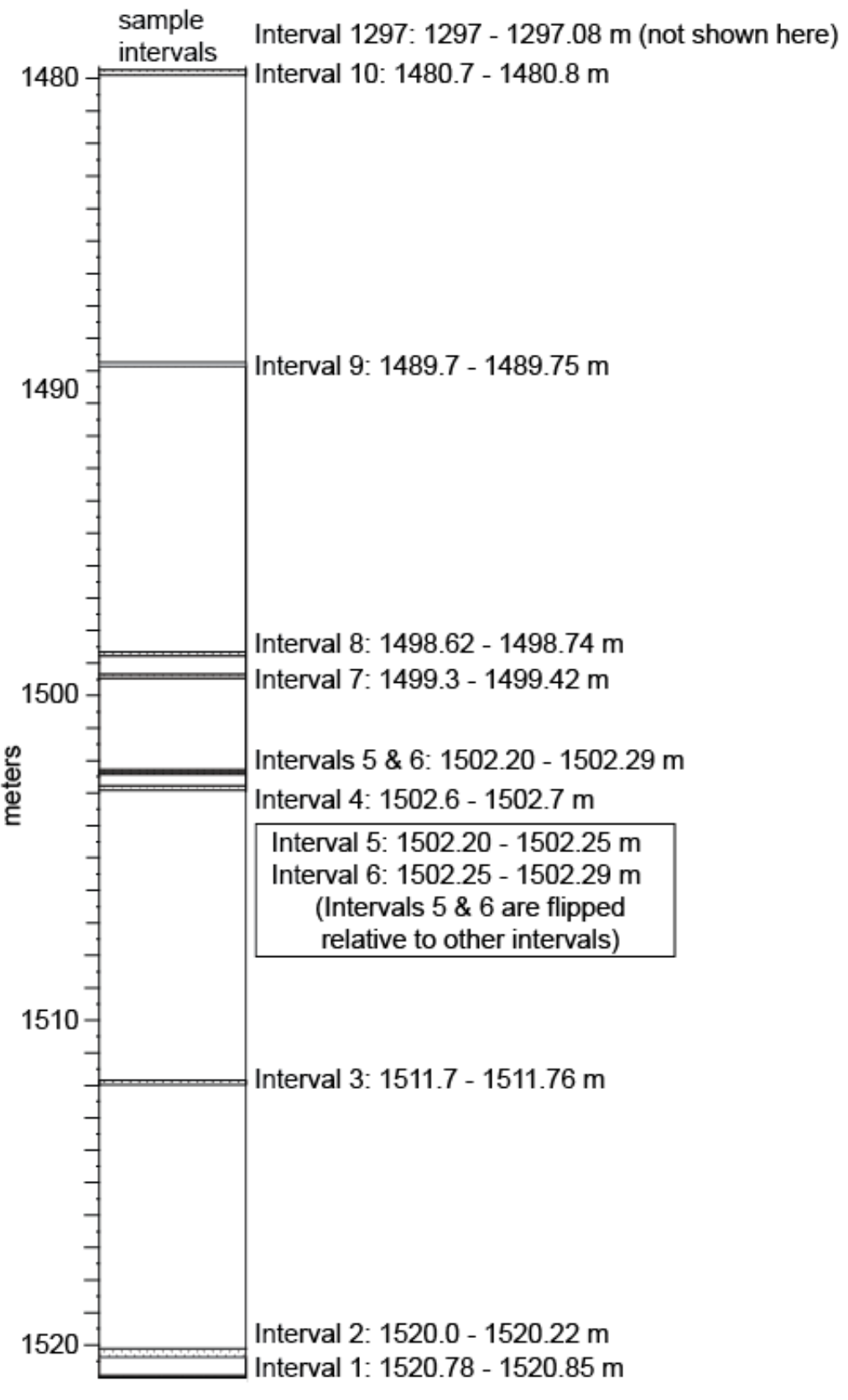
this section. Interval 1 consists of sandstone and was not examined closely for this study. An additional sample $(8.1 \mathrm{~cm})$ is from $\sim 1297 \mathrm{~m}$. Areas shown in white were not samples for this study. 
Empress 1A evaporite intervals (Fig. 8) were examined at West Virginia University. Core intervals with halite and/or gypsum/anhydrite were polished, photographed, scanned, and examined for sedimentary structures and diagenetic features. Core-scale observations were made from the rough slabbed surface of the core, and then from the polished slab surface. Polishing may bring out details not seen in the rough slab, such as chevrons. Rock color (Munsell-color), type, and mineralogy were recorded (Munsell, 1912). Mineralogy, depositional and diagenetic features were used to delineate beds and sampling zones for fluid inclusion analysis. Beds were defined by changes in color, lithology, and crystal shape, size, and orientation. Part of one core was made into a thick section for closer analysis.

This project focused upon evaporite areas. Mud intervals adjacent to evaporites were noted for depositional features, such as color, relation to halite and gypsum/anhydrite, reaction with dilute hydrochloric acid, the presence of laminations, and other sedimentary structures. Halite was noted for features such as color, crystal shape, and relation to mud layers. Halite was separated into three groupings: bedded, displacive, and interstitial.

\section{Halite Crystal and Fluid Inclusion Petrography}

Halite chips (2-8 mm wide) were collected from each interval from halite-rich "zones" to gauge crystal type and preservation (Fig. 11). Each zone had several halite chips collected from it. An abbreviated sample name notation was used to record samples and their details (Table 3).

Chips were sampled with a razor blade, manually sanded to a thickness of $\sim 0.5 \mathrm{~mm}$, and polished for optical resolution. Halite chips were sanded and polished with progressively finer grit sandpaper, with grit values of $220,400,600,1200,2000,3000,5000$, and 7000 . (Grit size is inversely proportional to its value. For example, a grit of 220 consists of particles that are $68 \mu \mathrm{m}$ on average, a grit of 3,000 consists of particles that are $6 \mu \mathrm{m}$ on average.) 
Table 3. Explanation of sample name scheme, signifigance of name parts.

\begin{tabular}{|l|l|l|}
\hline \multicolumn{2}{|l|}{ explanation of sample names (Ex: E.8.A.2.P.B.1.1) } \\
\hline $\begin{array}{l}\text { section } \\
\text { of name }\end{array}$ & what it refers to & what it refers to here \\
\hline E & core name & Empress \\
\hline 8 & sample interval, see Figure 8 & interval 8 comes from 1498.47-1498.62 m \\
\hline A & $\begin{array}{l}\text { sample interval in this section of core (Fig. 11, } \\
\text { part B) }\end{array}$ & $\begin{array}{l}\text { first interval, see the core diagram to locate } \\
\text { sample location }\end{array}$ \\
\hline 2 & sample number from that interval & this is the second chip saved from this interval \\
\hline P & primary (P), secondary (S), or massive & this samples has primary fluid inclusions \\
\hline
\end{tabular}

Optical petrography was conducted with two microscopes, an Olympus SZX10 and an Olympus BX53 microscope. Each microscope used plane transmitted, reflected, and polarized light and a digital camera with SPOT 5 imaging software. The Olympus SX10 binocular microscope had a magnification range of 6.3 to $63 x$. The Olympus BX53 microscope had a magnification range of 20 to $2000 x$ and is equipped with a UV-vis light.

During microscopy, different lighting forms, such as transmitted, cross polarized (XPL), plane polarized (PPL), ultra-violet (UV), and reflected light were used to identify features within halite chips. Samples were first observed with unfiltered transmitted white light. Samples were then examined with one and then two polarization filters to differentiate between isotropic halite and anisotropic anhydrite and other minerals. Reflected light was used to examine any opaque solids. Finally, UV-vis light (excitation by combined $330 \mathrm{~nm}$ UV and $385 \mathrm{~nm}$ visible) was used to examine samples.

Halite chips were examined for mineralogy, halite crystal type, and fluid inclusion assemblages. Minerals were noted by type and association with crystal type. Fluid inclusion assemblages were used to identify halite crystal type. Inclusions assemblages were split into primary and secondary groupings. Primary halite fluid inclusion assemblages were further characterized for their suitability for analyses by their size and the presence of absence of other minerals. Primary fluid inclusion size, shape, and contents (liquid, gas, and/or solids) were 
noted. Halite chips were rated on their suitability for fluid inclusion analyses based upon of the presence and abundance of unaltered primary fluid inclusions (Table 4). Highly suitable samples had primary fluid inclusions assemblages with clear growth bands and large (>50 $\mu \mathrm{m})$ primary fluid inclusions.

Table 4: Criteria for rating suitability of halite chip for fluid inclusion analyses for this study.

\begin{tabular}{|l|l|}
\hline rating & criteria for rating \\
\hline 0 & massive, no inclusions seen or full or secondary fluid inclusions, may have solid inclusions \\
\hline 1 & rare small potentially primary fluid inclusions \\
\hline 2 & suspect primary fluid inclusions, many secondary fluid inclusions \\
\hline 3 & has primary fluid inclusions, some $>50 \mu \mathrm{m}$ \\
\hline 4 & may have primary fluid inclusion growth bands, many primary inclusions \\
\hline 5 & excellent, clear growth bands, many large $(>50 \mu \mathrm{m})$ primary fluid inclusions \\
\hline
\end{tabular}

Primary fluid inclusions and opaque solids were examined under a 330 and 385 nm UVvis light source for fluorescence. Primary fluid inclusions with unidentified solids were examined with UV-vis at magnifications up to 2000x. The presence and color of, or absence of, fluorescence was noted to evaluate the type of solids. This study examined fluid inclusions for evidence of life such as the presence of globular solids ( $<1$ to $\sim 10 \mu \mathrm{m})$ that fluoresced blue, yellow, yellow/green, or orange red (suspect prokaryotes, algae, or beta-carotene; Nadeau et al., 2008; Benison and Karmanocky, 2014; Conner and Benison, 2013).

\section{Fluid Inclusion Microthermometry}

This study used fluid inclusion microthermometry to determine inclusion salinity and major ion composition (Fig. 9; Goldstein and Reynolds, 1994). Microthermometry was performed with a Fluid Inc. U.S. Geological Survey-modified gas flow heating-cooling stage mounted on an Olympus BX53 microscope. The stage was calibrated to $\pm 0.1^{\circ} \mathrm{C}$ with an ice water bath $\left(0{ }^{\circ} \mathrm{C}\right)$ and synthetic $\mathrm{CO}_{2}$ inclusions (melting burst at $-56.6{ }^{\circ} \mathrm{C}$ ) at least semiannually.

During freezing-melting a halite sample is placed in the stage, and cooled with liquid nitrogen (to as low as $-190{ }^{\circ} \mathrm{C}$ ) until inclusions are frozen. The sample is slowly warmed to room 
temperature and the subsequent phase changes and the temperatures at which they occur at are recorded (Goldstein and Reynolds, 1994; Fig. 9). The eutectic temperature, or temperature of first melting, is recorded as an indicator the major ion composition (Davis et al., 1990; Goldstein and Reynolds, 1994). The temperature at which all ice was fully melted was used to interpret salinity (Goldstein and Reynolds, 1994). The presence of solids other than ice is used to refine inclusion composition (Davis et al., 1990; Jagniecki and Benison, 2010). The presence of other changes, such as alteration of inclusion walls (Fig. 9), is noted, as this may indicate very low pH (Jagniecki and Benison, 2010).

\section{Laser Raman Spectroscopy}

This study collected laser Raman spectra from inclusion fluids, solids, and vapor, adjacent halite, and solid inclusions in the Browne Formation and supplementary samples. Spectra from the glass slide that holds halite chips during analysis were gathered to identify potential sources of spectral contamination and to ensure that spectra were representative of fluid inclusions and their contents.

Laser Raman spectroscopy is a non-destructive, in-situ method used to detect and identify covalently-bonded compounds (solids, liquids, or gases). Raman spectroscopy is well suited to the study of fluid inclusions in halite. Halite has very weak Raman spectra, as such, it does not affect detection of inclusion liquid (Frezzotti et al., 2012).

Laser Raman spectroscopy uses a single wavelength light source (laser) to measure a molecular bond's unique Raman scattering. Most light interacts with molecules by being absorbed and then emitted at the same frequency (Rayleigh scattering; Frezzotti et al., 2012). However, the vibrational energy held between a molecule's covalent bonds may alter the frequency of a small portion of emitted light. This is Raman scattering (Raman, 1928). This 
offset frequency, measured in wavenumber locations $\left(\mathrm{cm}^{-1}\right)$, is determined by the unique bond energy of molecules and may be influenced by intermolecular interactions, such as hydrogen bonds. With the exception of fluorescing compounds, regardless of the light source's frequency, a molecule's unique Raman spectra does not change. For example, bisulfate will have peaks at 892 and $1054 \mathrm{~cm}^{-1}$, irrespective of laser frequency.

\section{Laser Raman Spectra Collection}

This study used a Renishaw Indian CRL 381 MCF-Raman microscope (WH B20B) equipped with a $532 \mathrm{~nm}$ green laser in the WVU shared research facility. This device has a one micron resolution, enabling study of very small solids and inclusions. The spectrometer was calibrated with a silicon standard $\left(521 \mathrm{~cm}^{-1}\right)$ at the beginning and end of every period of use. The spectrometer and all samples were held at $21^{\circ} \mathrm{C}$ during analysis. Polished halite chips were placed on a clean glass slide. Raman spectra were also collected from the glass slide to characterize sources of spectral contamination. Halite near inclusions, fluid inclusions and, if present, solids and gases in inclusions, were targeted for spectral analysis. The target area was identified and focused upon with 40x and 100x long-working distance objectives. The 40x objective was primarily used in this study. Spectra were collected at 100 percent laser power unless weaker power was necessary, as was in the case of rare strong spectra which saturated the detector. During analysis, the strong Raman spectra of water confirmed if a laser was focused on a fluid inclusion. Both long $\left(100\right.$ to $\left.\geq 3700 \mathrm{~cm}^{-1}\right)$ and short $\left(100\right.$ to $\left.\geq 1700 \mathrm{~cm}^{-1}\right)$ spectra were collected from target areas. Repeated spectral acquisitions averaging at least two minutes in cumulative time were gathered to reduce the noise signals in spectra. Peak wavenumbers were then identified with the laser Raman spectrometer's software or with SpectraGryph 1.1 spectroscopy software. Wavenumbers of peaks were rounded to the nearest whole number. Very weak peaks were identified by comparison between spectral accumulations 
to confirm their presence.

Figure 9: Illustration of phase changes in fluid inclusions during freezing-melting. Neutral $\mathrm{NaCl}$ fluid inclusions (A) undergo different phase changed during freezing-melting than acid-saline inclusions (B),

A

Freezing/Melting of Synthetic Neutral $\mathrm{NaCl}-\mathrm{H}_{2} \mathrm{O}$ Fluid Inclusions

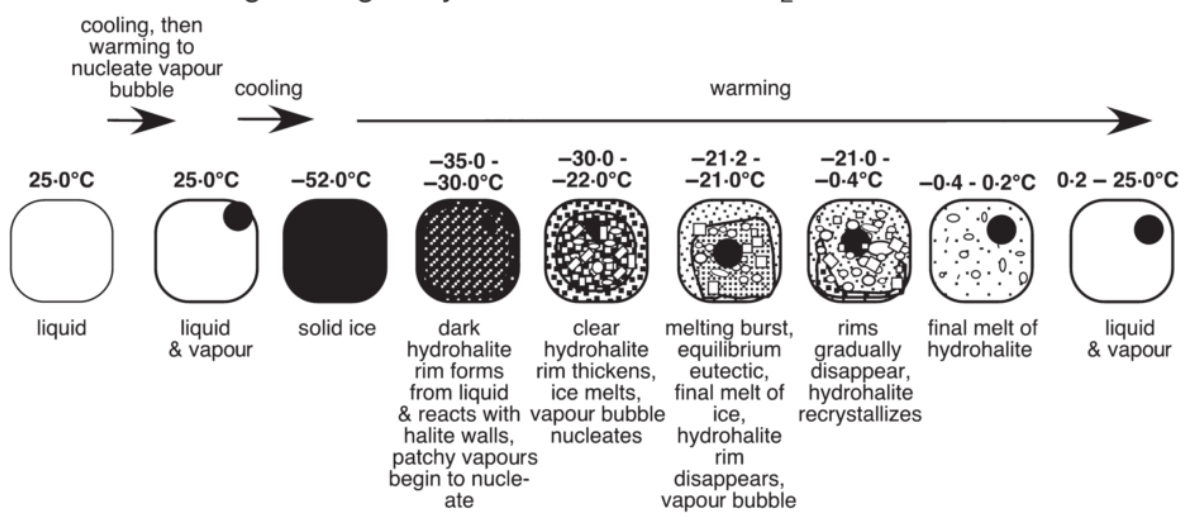

B

Freezing/Melting of Natural Acid Saline Fluid Inclusions

cooling, then
warming to

warming to

$\begin{gathered}\text { nucleate vapour } \\ \text { bubble }\end{gathered}$
$\longrightarrow$

Freezing/Melling of Natural Acid Saline Fluid Inclusions

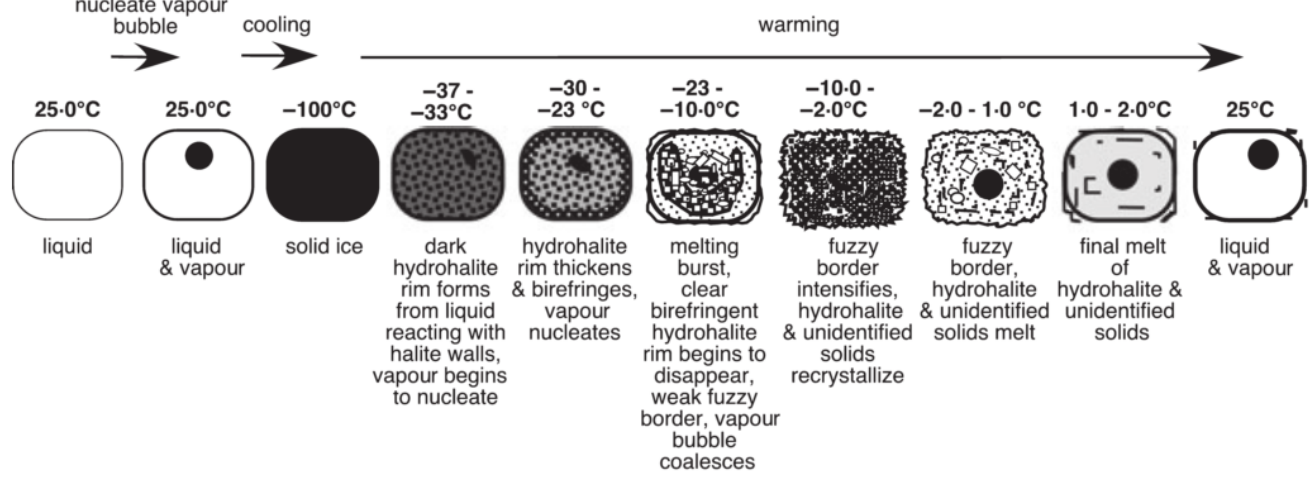

c Freezing/Melting of Synthetic Neutral and Natural Acid Saline Fluid Inclusions

\section{Synthetic Neutral}

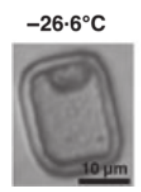
clear
hydrohalite rim,
melted ice melted ice,
vapour bubble

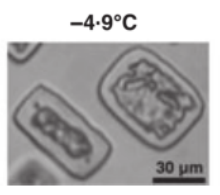

dissolved/no rim, centralized ecrystallization
hydrohalite

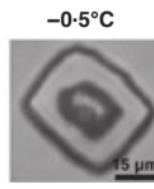

final melt of hydrohalite
Natural Acid
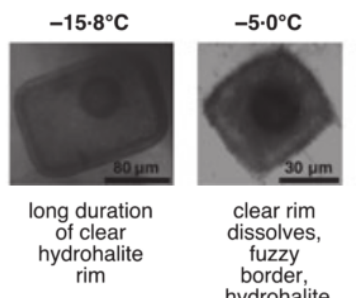

clear rim

dissolves,

fuzzy

border,

hydrohalite

$$
\begin{gathered}
\text { unidentifie } \\
\text { solids }
\end{gathered}
$$

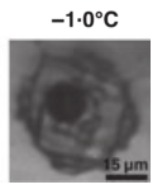

approaching

final melt,

"building

begins
block" border
b

recrystallize

which have "fuzzy" inclusion walls during melting. (C) Images of phase changes during freezing-melting in neutral and acid inclusions (image from Jagniecki and Benison, 2010) 
Laser Raman Spectral Processing and Identification

Spectral contamination can hinder interpretation. Contamination comes from several sources. Cosmic rays cause very sharp random spikes in the spectra. Fluorescence from partially opaque materials leads to large humps in the specta. Other sources of contamination are interference from outside light sources and the machine's charge coupled device (CCD) light detector. Poor focus may also lead to high noise to signal ratios.

Spectra were processed with SpectraGryph 1.1 spectroscopy software. Peaks from cosmic rays were removed. Spectra were then smoothed to reduce the noise-to signal ratio. Baseline data were subtracted to remove spectral contamination from fluorescence and to ease interpretation. Figure 10 demonstrates how processing spectra eases interpretation.

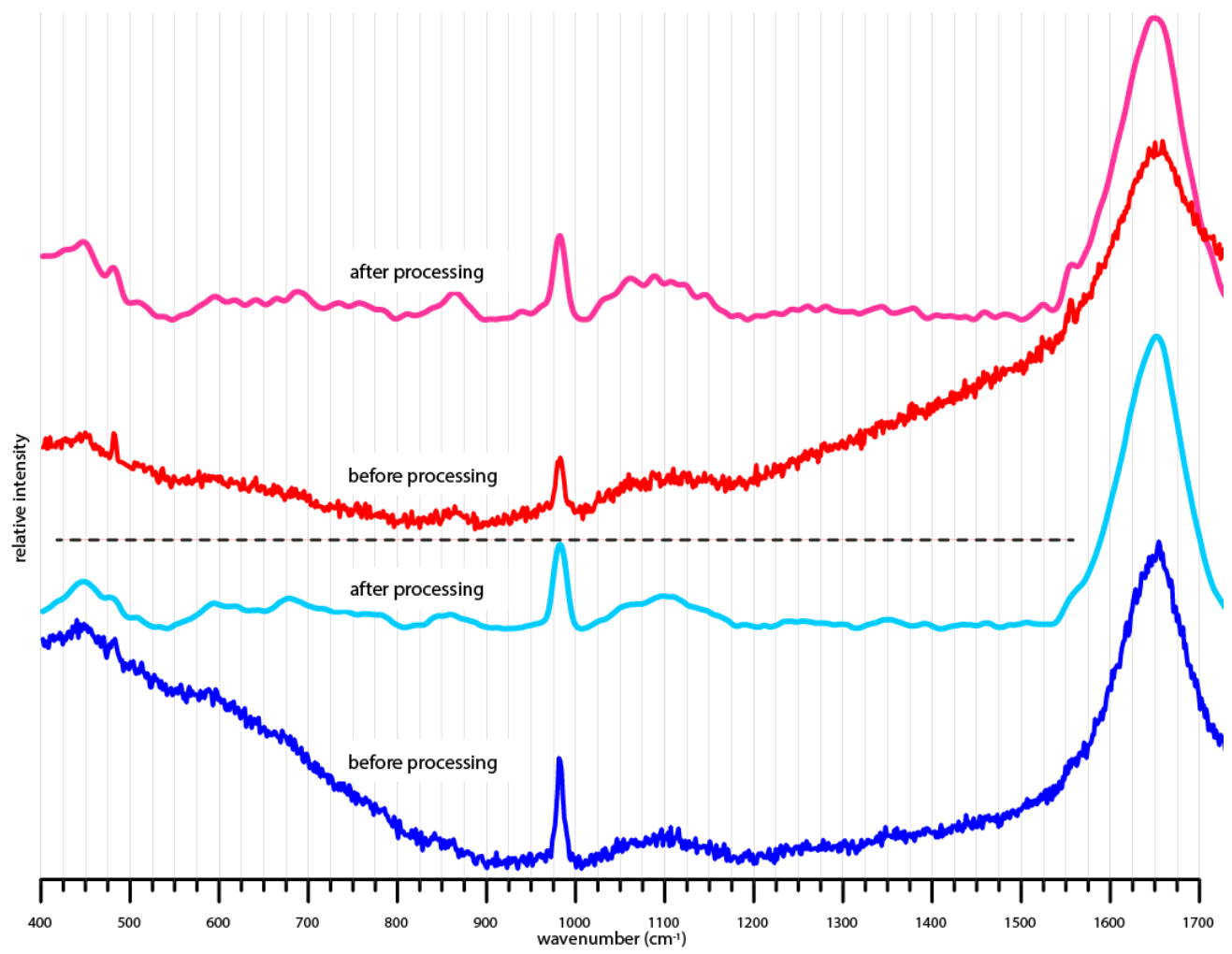

Figure 10. Chart with effect of baseline removal and spectral smoothing in easing Raman spectra interpretation. Note that the baseline removal enables existing peaks to be highlighted and accentuates peaks that were difficult to detect. While smoothing removes noise, it also blunts detected peaks. The blue and red spectral sets demonstrate varying degrees of noise and fluorescence. 


\section{Results}

\section{Petrography Results}

Core

All 10 of the studied intervals contained at least one layer of bedded halite. Most intervals included chevron halite crystals and mud. Some intervals transitioned from mud-rich, halite-poor beds to halite-rich and mud-poor beds and vice versa. No mud reacted with dilute hydrochloric acid. Muddy areas were present as isolated lenses with regular to irregular shapes, or as distinct layers that either truncated or draped halite crystals. Mud was present in several areas as isolated lenses or with no clear shape. Some mud had angular irregular shapes defined by halite crystals. In some intervals, mud lenses transitioned from large rounded shapes to angular shapes. Distinct mud layers ranged from millimeter to centimeter scale in thickness. Several mud layers transitioned in color. Noted mud color transitions include greenish gray to reddish brown, red to light greenish gray, dark reddish gray to dark reddish brown, and dark reddish gray to light red. Other noted mud colors include gray, light gray, dark gray, greenish gray, light greenish gray, red, and pink. (Detailed discriptions of the core with Munsell colors are included in Appendix I.)

Displacive halite was either totally or partially bordered by mud with angular edges. This classification was corroborated by lack of primary inclusions in halite chips. Displacive halite was lighter in color than other halite, and was never red. Displacive halite had mud lenses with angular edges.

Halite-rich areas varied in color and crystal shape. Halite-rich portions had other evaporite minerals that were difficult to discern at the core-scale. At the core-scale crystal shape was difficult to discern unless the halite was adjacent to a mud-rich interval which outlined crystal edges. Mud layers outlined chevrons as well as blocky halite inclusions surrounded by 
mud. Several halite-rich areas transitioned in color with no intervening mud-layers between color changes. One interval has halite that transitions in color from pink, to dusky red, to light red (Fig. 11B). Other noted halite colors include reddish yellow, dusky red halite, light red, reddish gray, reddish brown, brown, and light gray. Portions of halite intervals were sampled for examination under the microscope in order to differentiate crystal types and preservation. Red halite was more likely to contain bedded halite than other colors of halite.

\section{Crystal Types and Fluid Inclusion Assemblages}

Sixty chips were analyzed from 10 intervals and over 34 zones (Table 5; an interval is a continuous piece of core; a zone is a subdivision of an interval). The majority of these zones represent distinct halite beds. Zones listed as "Z" come from before this system was standardized, so their precise stratigraphic sampling location is less certain. Of the 60 analyzed chips only 16 (27\%) were found to be highly suitable for analysis (rating of 5 or 4; Table 4). Detailed discriptions of halite chips are included in Appendix I.

Petrographic examination of halite chips revealed the presence of fluid inclusion growth bands, anhydrite crystals, hematite rich-areas, detrital quartz, and detrital halite grains. Well preserved samples had easily identified chevrons and cumulates (Fig. 12). Cumulate crystals were recognized by their size (mm-scale), the presence of primary fluid inclusions assemblages, and their association with other crystals as a cumulate raft. Chevrons were identified by their larger size. Some chevrons had dissolution surfaces (Fig. 13). Differentiating between small chevrons and cumulate crystals was challenging due to the small size of the halite chip. A few halite chips contained no fluid inclusions or only secondary fluid inclusions (Fig. 13B). Some opaque reflective solids that fluoresce are present in healed fractures. The thick slab made for this study had a gypsum/anhydrite crystal splay with cumulate halite crystals and thin brown (likely hematite mud) layers. 


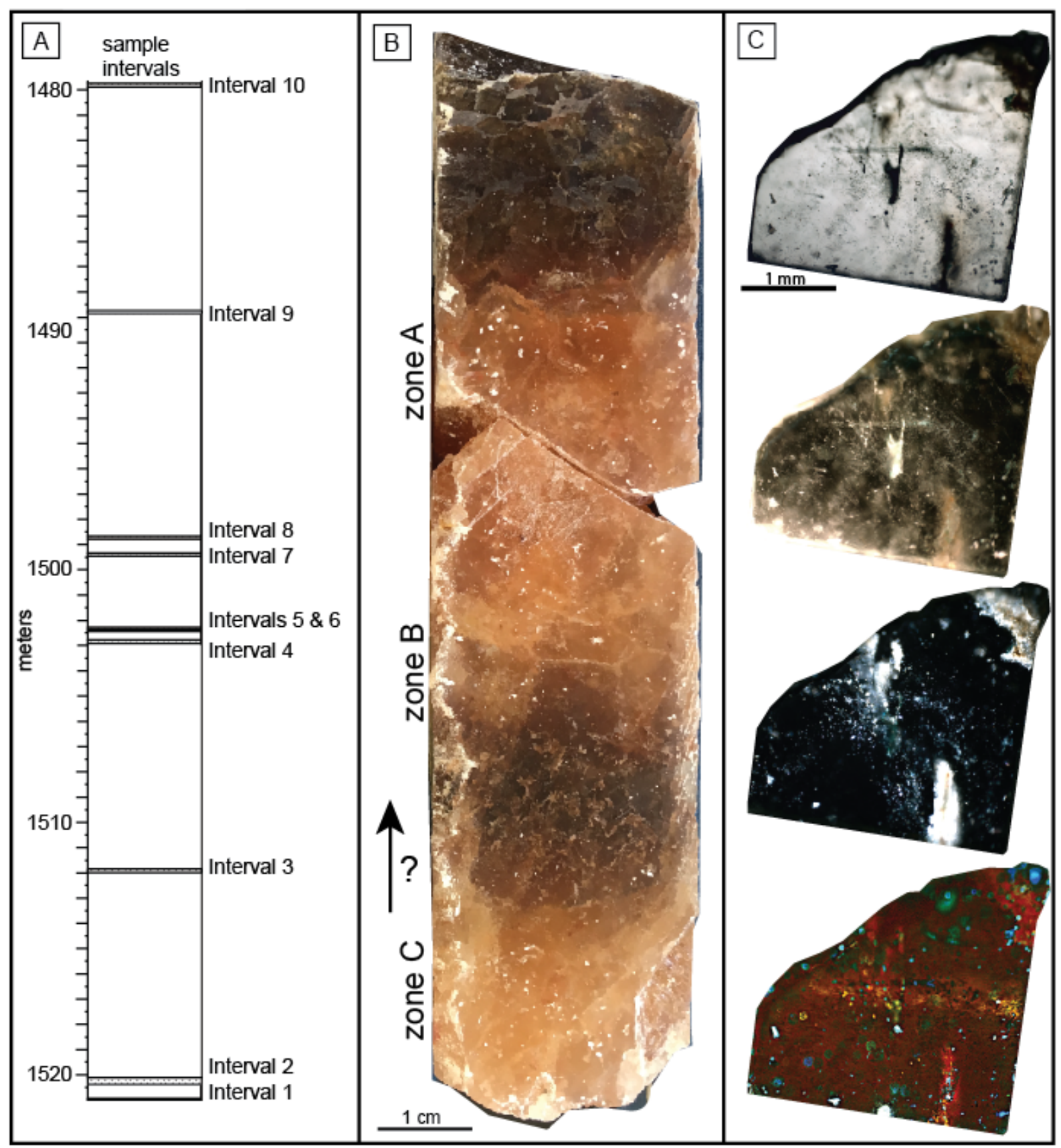

Figure 11. Images demonstrating different intervals of core sampling and examination. (A) Portions of the Empress $1 \mathrm{~A}$ core in the Browne Formation that were sampled for this study. Each interval is a continuous section of core that was sampled for this study. (B) Interval 8 (1498.74 - $1498.62 \mathrm{~m}$; $11.7 \mathrm{~cm}) \mathrm{contains}$ bedded halite with several distinct layers and chevrons. Sampling intervals in different beds are demarcated by zones $A, B$, and $C$. Image of polished core in daylight. (C) Halite chip collected from a zone examined in microscope under different lighting (Sample: E.4.B.1.P). Uppermost image of halite chip in plane polarized light provides a general overview of the sample. Middle-upper image in reflected light shows opaque reflective solids. Middle-lower image in cross polarized light shows halite (black) and anhydrite (white/yellow). Lowest image in UV-vis illuminations shows areas with suspect organic compounds. 


\section{Fluid Inclusion Petrography}

Primary fluid inclusion assemblages were noted in all 10 intervals. Primary inclusions had negative crystal habit (cubic) and were present in association with other primary inclusions. There were abundant inclusions that ranged from 15-40 $\mu \mathrm{m}$ in samples well-suited for fluid inclusion analysis. Very large primary inclusions $(40-100 \mu \mathrm{m})$ were also present in a few samples. Inclusions containing liquid (L), liquid-vapor (L-V), liquid-vapor-solid (L-V-S), liquidsolid (L-S), and liquid-vapor-solid-solid (L-V-S-S) were noted in most sampling intervals. While some small inclusions contained gas bubbles, only large inclusions consistently had gas bubbles. Many inclusions had solids (Fig. 13D - F). There was no consistent solid-liquid ratio in inclusions. In roughly half of the samples the majority inclusions had acicular to tabular solids.

Samples where all fluid inclusions had no solids were rare.

Figure 12. Images of halite crystals and fluid inclusion growth bands in halite chip E.4.Z.1.P, from Empress $1 A$, Interval 4, 1502.7$1502.6 \mathrm{~m}$, zone $A$. (A) on the top part of the sample, this area is replete with primary inclusions.(B) Another part of the chevron has very large fluid inclusions (C). Chip contains cumulate crystal connected in a raft and sourrounded by mud. This appears to have been the nucleation point for a chevron. Black arrow points to the up direction.

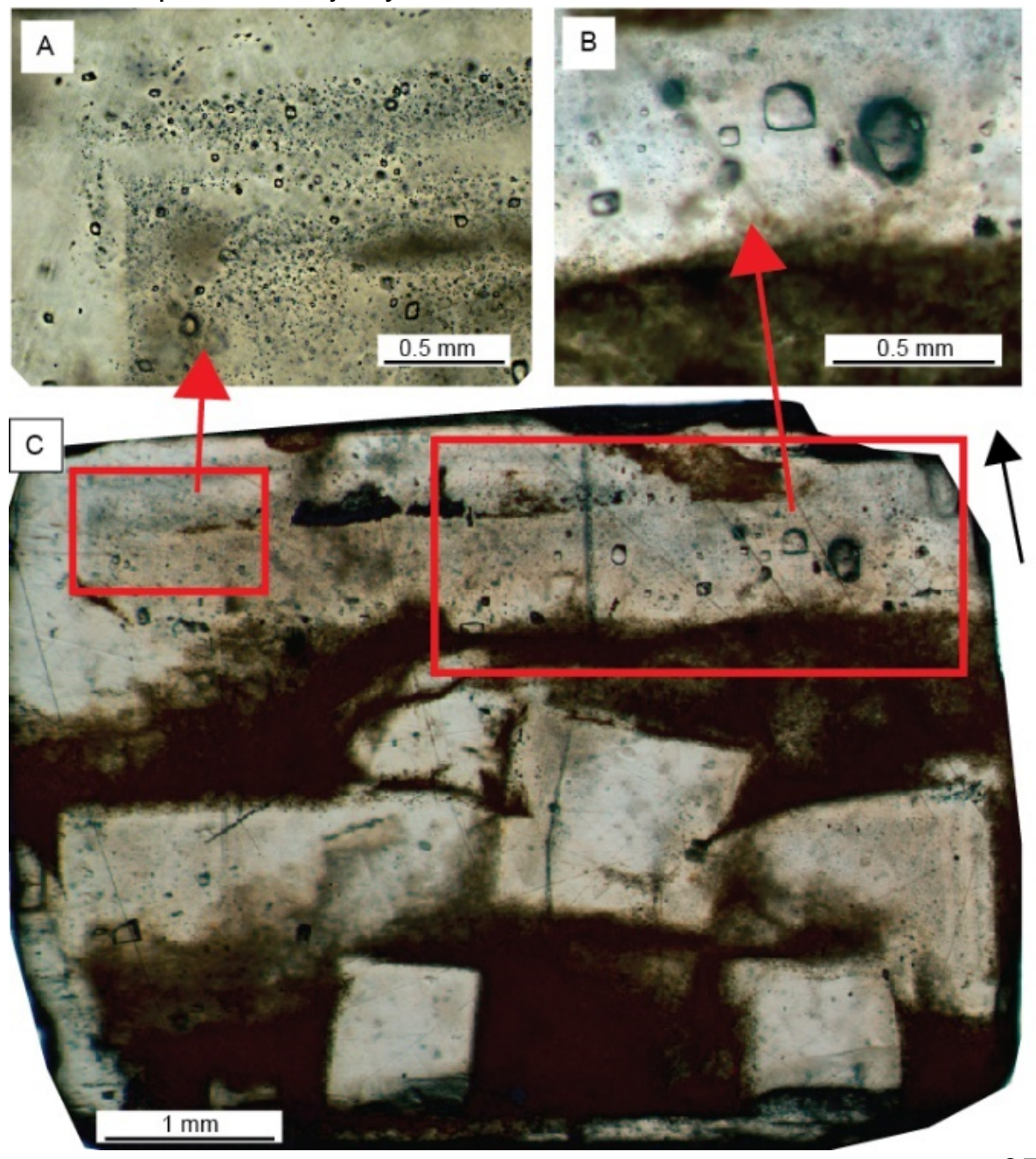


Primary inclusions were only noted if they were adjacent to other primary inclusions. Some primary inclusion assemblages had abundant inclusions, but inclusion growth bands that were not easily identified. This is the most typical kind primary fluid inclusion assemblage seen in this thesis. This type of assemblage was often seen in association with dissolution areas and clear halite cement. Excellent halite chip samples had fluid inclusion growth bands separated by cloudy, inclusion rich areas of fast growth and clear inclusion-poor areas of slow growth.

Other types of fluid inclusions were present. These inclusions were large and isolated (sometimes cubic), or elliptical and elongated. Large isolated cubic inclusions were present in many samples and were present both in association with primary inclusion areas and in areas with very few inclusions. These isolated inclusions often had very high gas to water ratios.

Elliptical secondary inclusions were present in every halite sample. Secondary inclusion assemblages cut through clear halite and areas with primary fluid inclusions. Secondary inclusions often contained acicular solids, and sometimes contained gasses.

\section{Solids in Halite and Inclusions}

Table 6 describes identified solids. Solids found in fluid inclusions include fluorescing spherules (<1 to $10 \mu \mathrm{m}$; fluoresce in response to $330 \mathrm{~nm}$ and $385 \mathrm{~nm}$ light), acicular and tabular birefringent crystals with low relief (several appeared striated), and angular orange-red solids $(\sim 5 \mu \mathrm{m})$. Solids found in the halite matrix include acicular and tabular (several appeared striated) birefringent low relief crystals, opaque cubic solids that may fluoresce (50 - $600 \mu \mathrm{m})$, and subrounded orange-red solids, present in a cluster or mass $(10-50 \mu \mathrm{m})$. 
Table 5: Sample halite chips from Empress 1A core that were examined for fluid inclusions.

\begin{tabular}{|c|c|c|c|c|}
\hline interval & $\begin{array}{l}\text { sample } \\
\text { depth }(m)\end{array}$ & zone & sample name(s) & $\begin{array}{l}\text { primary/secondary inclusions and sample } \\
\text { rating for suitability for inclusion analysis } \\
\end{array}$ \\
\hline \multirow[t]{5}{*}{2} & \multirow{5}{*}{$\begin{array}{l}1520- \\
1520\end{array}$} & A & E.2.A.S,P? & primary, 1 \\
\hline & & $\mathrm{B}$ & E.2.B.S & secondary, 0 \\
\hline & & C & E.2.C.1.P & primary, 2 \\
\hline & & $\mathrm{D}$ & E.2.D.1.P & primary, 2 \\
\hline & & $\mathrm{E}$ & E.2.E.1.P, E.2.E.2.P & primary, 5; primary, 4 \\
\hline \multirow[t]{2}{*}{3} & \multirow{2}{*}{$\begin{array}{l}1511.7- \\
1511.7 \\
\end{array}$} & $A$ & E.3.A.S & secondary, 0 \\
\hline & & $B$ & E.3.B.1.P & primary, 2 \\
\hline \multirow[t]{5}{*}{4} & \multirow{5}{*}{$\begin{array}{l}1502.7- \\
1502.6\end{array}$} & A & E.4.A.1.P, E.4.A.2.P & primary; 5; primary, 3 \\
\hline & & $\mathrm{B}$ & E.4.B.1.P, E.4.B.2.P & primary, 5 ; primary, 4 \\
\hline & & $\mathrm{C}$ & E.4.C.2.P, E.4.C.1.P & primary; 2 ; primary, 1 \\
\hline & & $\mathrm{D}$ & E.4.D.1.P, E.4.D.2.P & primary, 4; primary, 2 \\
\hline & & Z & E.4.Z.1.P, E.4.Z.2.P & primary, 5; primary, 5 \\
\hline \multirow[t]{3}{*}{5} & \multirow{3}{*}{$\begin{array}{l}1502.25- \\
1502.2\end{array}$} & $\mathrm{~B}$ & E.5.B.S & secondary, 0 \\
\hline & & $\mathrm{C}$ & E.5.C.1.P, E.5.C.2.P, E.5.C.3.P & primary, 4; primary, 3; primary, 2 \\
\hline & & Z & E.5.Z.1.P & primary, 2 \\
\hline \multirow[t]{3}{*}{6} & \multirow{3}{*}{$\begin{array}{l}1502.29- \\
1502.25\end{array}$} & $\mathrm{~A}$ & E.6.A.1.P, E.6.A.2.P & primary, 2; primary, 3 \\
\hline & & $\mathrm{B}$ & E.6.B.1.P & primary, 2 \\
\hline & & C & E.6.C.1.P & primary, 2 \\
\hline \multirow[t]{3}{*}{7} & \multirow{3}{*}{$\begin{array}{l}1499.42- \\
1499.3\end{array}$} & A & E.7.A.1.P, E.7.A.2.P & primary, 4; primary, 2 \\
\hline & & $\mathrm{B}$ & E.7.B.S & secondary, 0 \\
\hline & & Z & E.7.Z.2.P & primary, 3 \\
\hline \multirow[t]{4}{*}{8} & \multirow{4}{*}{$\begin{array}{l}1498.74- \\
1498.62\end{array}$} & A & E.8.A.1.P, E.8.A.2.P, E.8.A.5.P & primary, 4; primary, 5; primary, 3 \\
\hline & & $\mathrm{B}$ & E.8.B.S & secondary, 0 \\
\hline & & $\mathrm{C}$ & E.8.C.1.P, E.8.C.P.2.P & primary, 2; primary, 2 \\
\hline & & Z & E.8.Z.1.P & primary, 4 \\
\hline \multirow[t]{4}{*}{9} & \multirow{4}{*}{$\begin{array}{l}1489.75- \\
1489.7\end{array}$} & $\mathrm{~A}$ & E.9.A.1.P & primary, 4 \\
\hline & & $\mathrm{B}$ & E.9.B.1.P & primary, 3 \\
\hline & & $\mathrm{C}$ & E.9.C.1.P & primary, 2 \\
\hline & & Z & E.9.Z.1 & solid inclusion, 0 \\
\hline \multirow[t]{7}{*}{10} & \multirow{7}{*}{$\begin{array}{l}1480.8- \\
1480.7\end{array}$} & $\mathrm{~A}$ & E.10.A.- & no inclusions, 0 \\
\hline & & $\mathrm{B}$ & E.10.B.1.P, E.10.B.6.P & primary, 2; primary, 2 \\
\hline & & $\mathrm{C}$ & E.10.C.S & secondary, 0 \\
\hline & & C-D & E.10.CD.1.S & secondary, 1 \\
\hline & & $\mathrm{D}$ & E.10.D.- & no inclusions, 0 \\
\hline & & $\mathrm{E}$ & E.10.E.1. P?, E.10.E.2. S & primary, 1; secondary, 0 \\
\hline & & Z & E.10.Z.S & secondary, 0 \\
\hline \multirow[t]{4}{*}{1297} & \multirow[t]{4}{*}{$\begin{array}{l}1297- \\
1297\end{array}$} & A & $\begin{array}{l}\text { E.1297.A.1.S, E.1297.A.2.S, } \\
\text { E.1297.A.3.P }\end{array}$ & secondary, 0; secondary, 0; primary, 3 \\
\hline & & $\mathrm{B}$ & E.1297.B.1.S & secondary, 0 \\
\hline & & $\mathrm{C}$ & E.1297.C.1.S & secondary, 0 \\
\hline & & Z & $\begin{array}{l}\text { E.1297.Z.1.P, E.1297.Z.7.P, } \\
\text { E.1297.Z.8.P }\end{array}$ & Primary, 4; primary, 4; primary, 4 \\
\hline
\end{tabular}


Table 6. Description of solids found in fluid inclusions and halite.

\begin{tabular}{|c|c|c|}
\hline $\begin{array}{l}\text { distinct solid } \\
\text { type }\end{array}$ & description, size, shape, optical properties & $\begin{array}{l}\text { image (additional images show features } \\
\text { or illumination in UV) }\end{array}$ \\
\hline $\begin{array}{l}\text { globular } \\
\text { solid }\end{array}$ & $\begin{array}{l}\text { colorless or brown globular solids ( }>3 \text { to } 10 \\
\mu \mathrm{m}) \text { that fluoresce pale yellow to blue }\end{array}$ & \\
\hline small cocci & $\begin{array}{l}\text { isolated colorless cocci that fluoresce pale } \\
\text { blue }(0.25 \text { to } \sim 1 \mu \mathrm{m}) \text {, likely to be the only } \\
\text { solid in an inclusion. } \\
\text { clumps of cocci }(0.25 \text { to } \sim 1 \mu \mathrm{m}) \text { that are } \\
\text { brown in plane polarized light and fluoresce } \\
\text { pale blue, seen with other solids in an } \\
\text { inclusion }\end{array}$ & 5 \\
\hline $\begin{array}{l}\text { opaque } \\
\text { cubic solid } \\
\text { inclusion }\end{array}$ & $\begin{array}{l}\text { opaque cubic solids that may fluoresce } \\
\text { electric blue ( } 50-600 \mu \mathrm{m}) \text {, adjacent or } \\
\text { present in a primary fluid inclusion } \\
\text { assemblages }\end{array}$ & \\
\hline $\begin{array}{l}\text { subrounded } \\
\text { orange-red } \\
\text { solids }\end{array}$ & $\begin{array}{l}\text { subrounded orange-red solid }(10-50 \mu \mathrm{m}) \text {, } \\
\text { present in a cluster or mass }\end{array}$ & \\
\hline $\begin{array}{l}\text { red angular } \\
\text { solid }\end{array}$ & $\begin{array}{l}\text { red-orange angular solid ( } \sim 5 \mu \mathrm{m}) \text {, only } \\
\text { observed in one sample, likely related to } \\
\text { subrounded orange-red crystals in halite } \\
\text { matrix }\end{array}$ & \\
\hline $\begin{array}{l}\text { acicular } \\
\text { solid }\end{array}$ & $\begin{array}{l}\text { slightly higher relief than halite, birefringent } \\
\text { acicular solid }(2-50 \mu \mathrm{m}) \text {, present in as } \\
\text { singular solid inclusion or as a mass, also } \\
\text { present in halite matrix }\end{array}$ & \\
\hline $\begin{array}{l}\text { tabular to } \\
\text { tabular } \\
\text { striated sold }\end{array}$ & $\begin{array}{l}\text { slightly higher relief than halite, birefringent } \\
\text { tabular solid }(2-50 \mu \mathrm{m}) \text {, present in as } \\
\text { singular solid inclusion or as a mass of } \\
\text { solids, also present in halite matrix, shape } \\
\text { may vary while still being tabular }\end{array}$ & \\
\hline
\end{tabular}




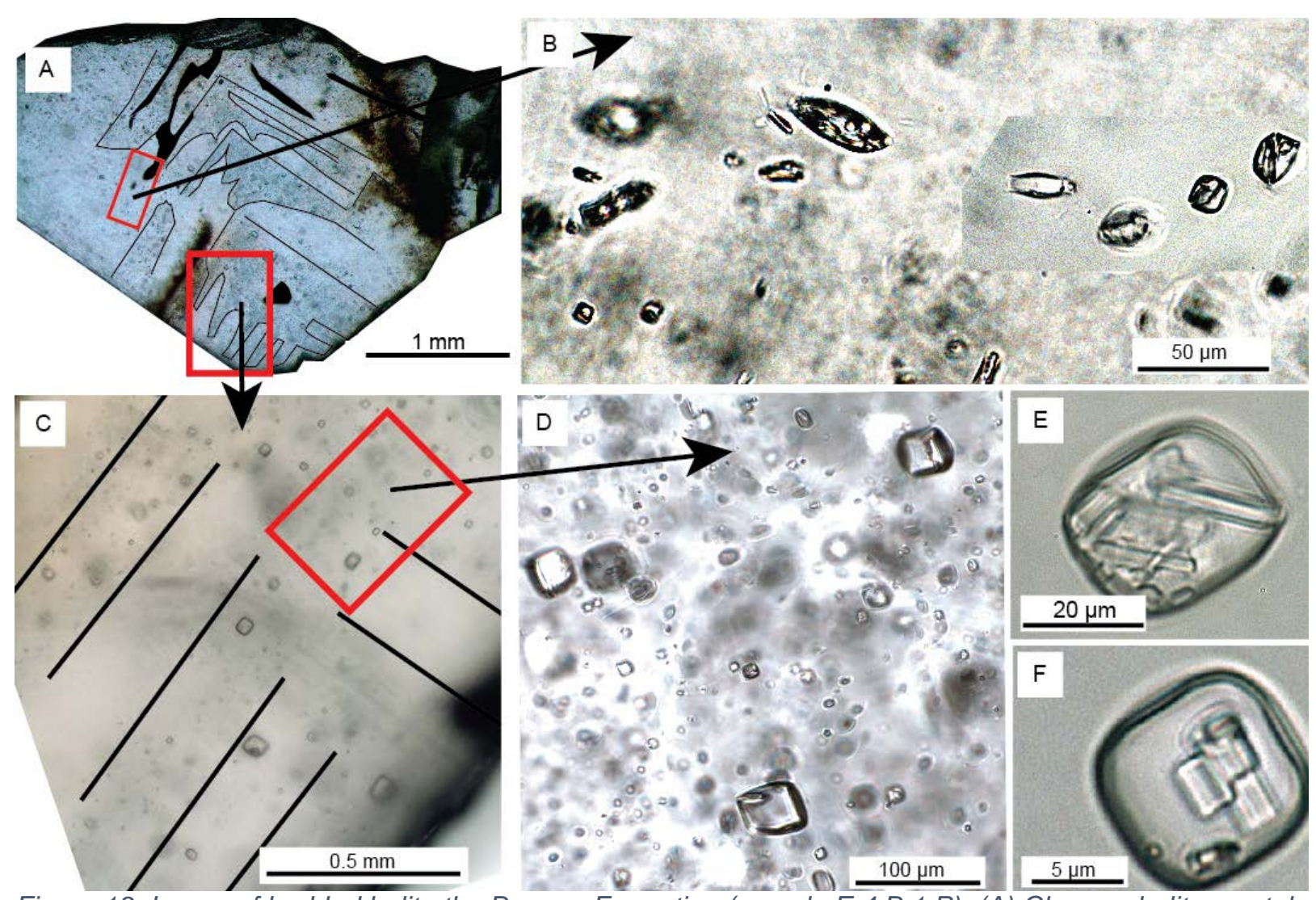

Figure 13. Image of bedded halite the Browne Formation (sample E.4.B.1.P). (A) Chevron halite crystal containing growth bands of primary fluid inclusions and (B) secondary inclusions. This chevron also has dissolution surfaces. (C\&D) This thesis focused on primary fluid inclusion assemblages consisting of inclusions with negative crystal habit located along growth bands. Lines added to highlight growth bands. (E\&F) Some primary inclusion have with multiple solids that are (E) acicular or (F) tabular and spherule.

Petrographic Description of Sampling Intervals

Interval $2(1520.22-1520.0 \mathrm{~m})$

The upper part of Interval $2(1520.22-1520.0 \mathrm{~m})$ is largely halite with poor preservation of primary depositional features (zones A-B). The lower portions of this segment has bedded halite (zones C-E). Bedded halite is seen at the mud halite contact, it consists of chevrons with well-preserved primary fluid inclusion assemblages. Halite crystals are not truncated by mud at the lower mud-halite contact zones. Fluid inclusions become larger from the middle to the bottom of the interval (C-E). Many primary fluid inclusions in this part have solids, vapor bubbles are not common in these inclusions. 
Interval 2 (1520.22 - $1520.0 \mathrm{~m})$ has the highest frequency and diversity of fluorescing solids (Fig. 14 and Fig. 15). A portion of these solids occur in inclusions that also have tabular to acicular solids. The unusual fluorescing solids are (1) colorless globular solids (>3 to $10 \mu \mathrm{m})$ that fluoresce pale yellow, (2) brown globular solids (>3 to $10 \mu \mathrm{m}$ ) that fluoresce pale yellow, (3) isolated colorless cocci $(0.25$ to $\sim 1 \mu \mathrm{m})$ that fluoresce pale blue, usually the only solid in an inclusion, (4) clumps of brown cocci $(0.25$ to $\sim 1 \mu \mathrm{m})$ that fluoresce pale blue, (5) opaque cubic solid inclusions (50 to $200 \mu \mathrm{m}$ ), that may fluoresce blue, present in primary inclusion areas.

Interval 3 (1511.76-1511.7 m)

Interval $3(1511.76-1511.7 \mathrm{~m})$ consists of massive reddish yellow halite with isolated mud lenses. Only one sample had a small area with a primary fluid inclusions assemblage. Other sampled portions only yielded halite with secondary inclusions. Primary inclusions do not have any solids. A minority of inclusions have vapor bubbles. No fluorescing solids were detected.

\section{Interval 4 (1502.7 - $1502.6 \mathrm{~m})$}

The yellowish red to dark reddish gray halite in Interval 4 (1502.7 - 1502.6 m) has several thin mud layers. The bottommost mud layer appears crystalline. Most zones in this sample have well preserved primary fluid inclusions. Several zones have clear to suspect chevrons; a suspect cumulate raft was also found. The middle area (zone C) did not have many large primary inclusions. Most inclusions in this interval have acicular to tabular/cubic solids, vapor bubbles are rare in small to medium inclusions, no solids in primary inclusions fluoresced. Sample E.4.Z.2.P was examined via freezing-melting microthermometry. Attempts to make inclusions freeze in this sample were unsuccessful.

Globular solids were rare, but present, in primary fluid inclusions from Interval 4 (1502.7 - $1502.6 \mathrm{~m})$. These small cocci shaped solids were light brown to colorless, $\sim 1$ to $2 \mu \mathrm{m}$ in size, 
and did not fluoresce (Fig. 16). Microscopic examination of halite next to bedded halite (sample E.4.B.1.P, Fig. 13) shows the presence of subrounded angular grains (20-15 um) that are optically similar to halite (Fig. 13C). This sample also had a "spine" of red opaque noncrystalline solids surrounded by birefringent acicular to tabular crystals followed by massive halite.
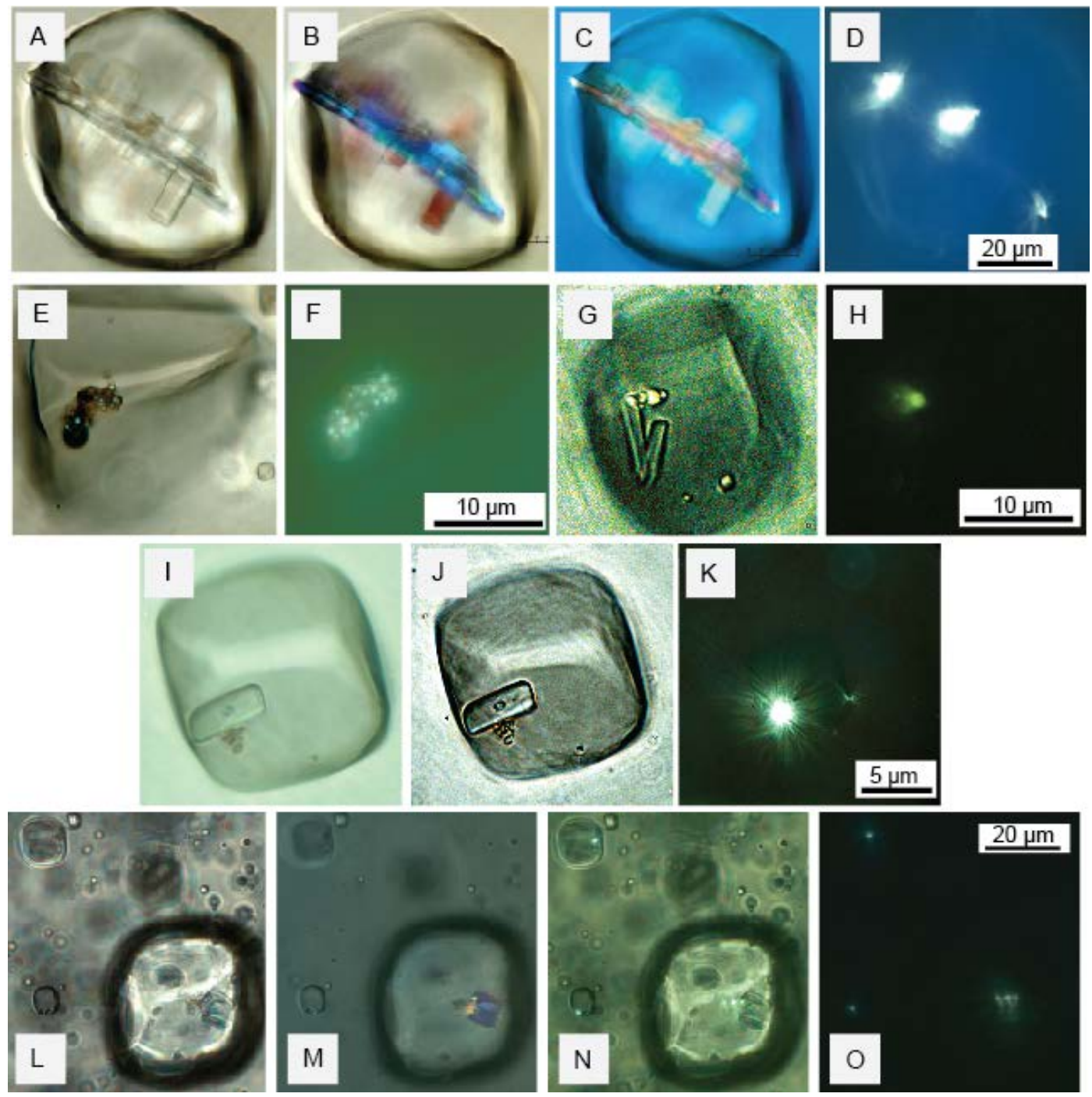

Figure 14. Images of globular fluorescing solids fluid inclusions from zone $E$ of interval 2 (1520.22-1520.0 m). (A-D) primary fluid inclusion E.2.E.1.P.B.2 under different lighting, (A) PPL, (B-C) XPL, (D) UV. (E-F) suspect secondary fluid inclusion E.2.E.1.P.D.1 under different lighting, (E) PPL+UV, (F) UV. (G-H) primary fluid inclusion location E.2.E.1.P.B.9 under different lighting, (G) PPL+UV, (H) UV. (I-K) inclusion location E.2.E.1.P.C.5 under different lighting, (I) PPL, (J) PPL+UV, (K) UV. (L-O) inclusion location E.2.E.1.P.A.7 under different lighting, (L) PPL, (M) XPL, (N) UV and PPL, (O) UV. 


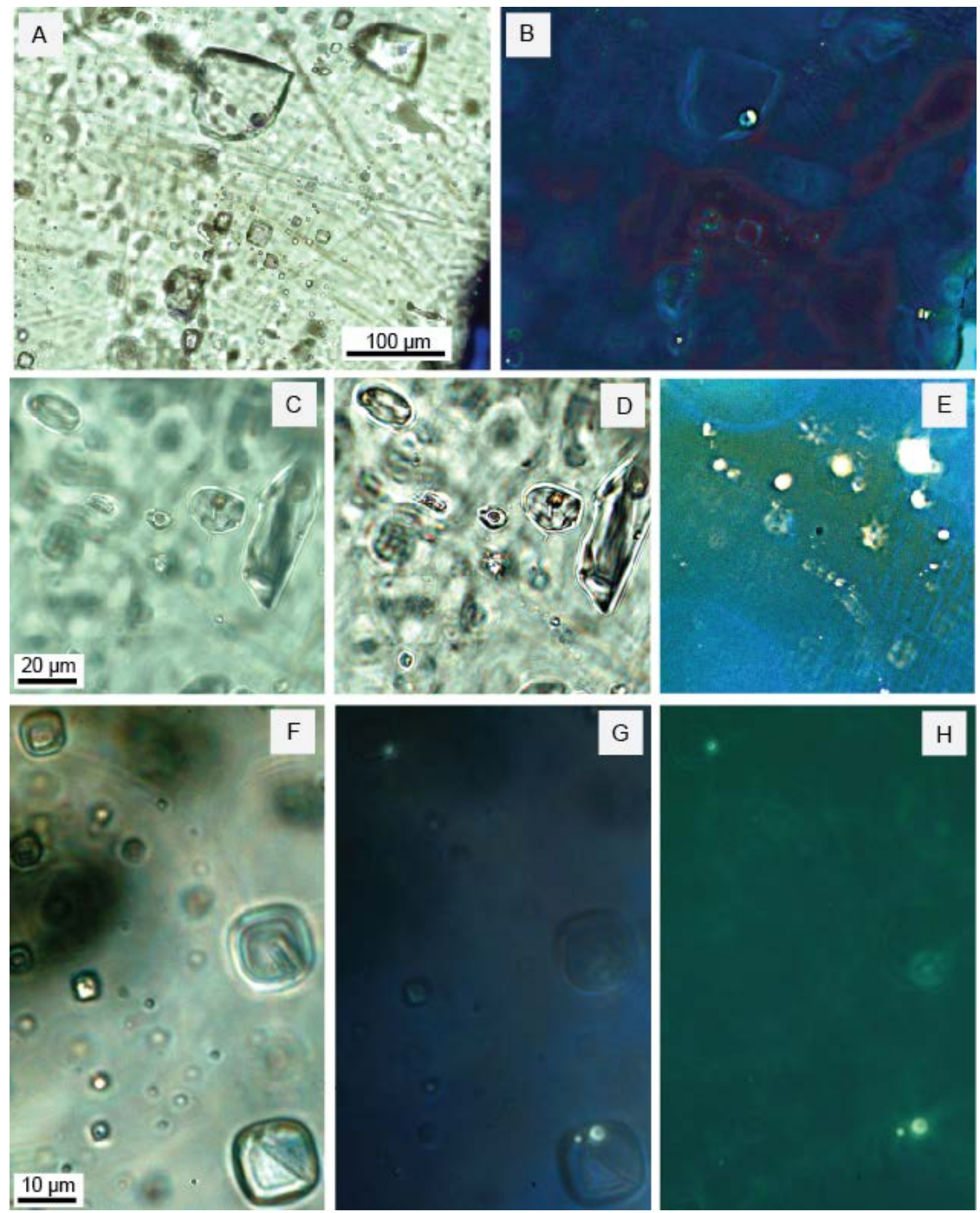

Figure 15. Images of globular fluorescing solids fluid inclusions from zone E of interval 2 (1520.22-1520.0 $m)$. (A-B) fluid inclusion assemblage with fluorescing solids, inclusion assemblage location E.2.E.2.A.P.B under different lighting, (A) PPL, (B) UV illumination, note the light blue fluorescence on the edge in the crystal in the lower right of the images, this is from processing, and not a primary feature. (C-E) secondary fluid inclusion assemblage with brown fluorescing globular solids. Inclusion locations E.2.E.2A.B.3-5 under different lighting, (C) PPL, (D) XPL, (E) UV. (F-H) Primary fluid inclusions with acicular solids and fluorescing globular solids, inclusion location E.2.E.2.P.A.9.2, under different lighting, (F) PPL, (G) PPL+UV, (H) UV. 


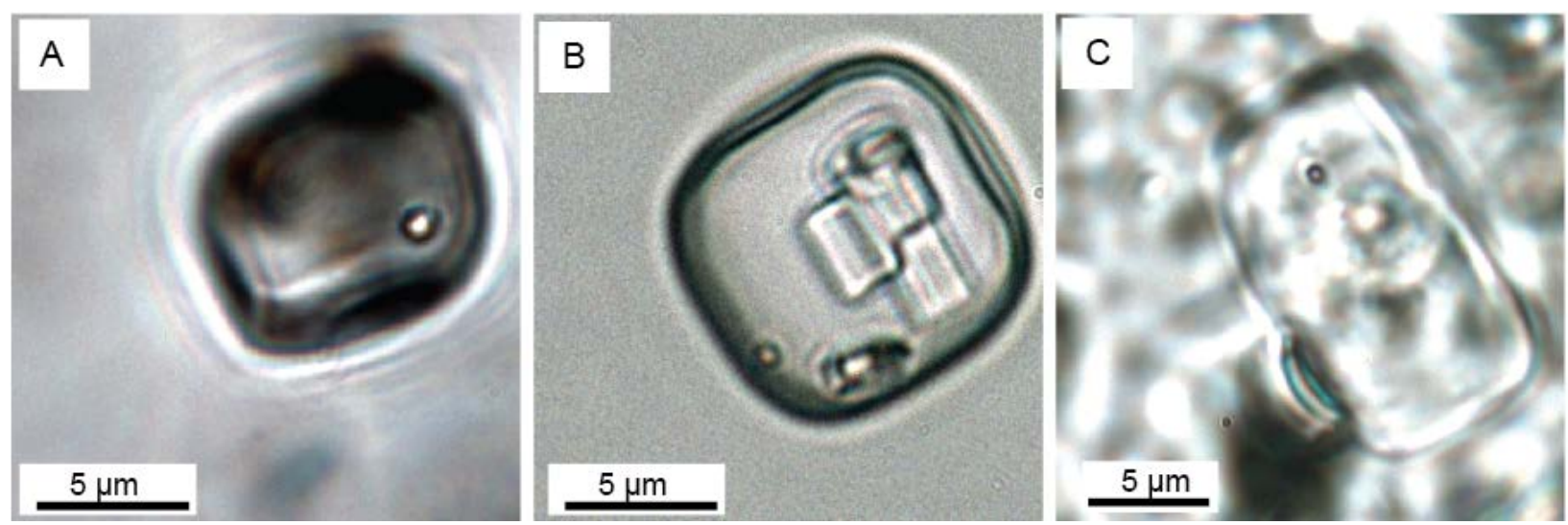

Fig. 16. Images of small globular solids in primary fluid inclusions in sample E.4.B.1.P, these solids did not fluoresce under UV illumination. (A) Inclusion with $1 \mu \mathrm{m}$ globular solid. (B) $<1 \mu \mathrm{m}$ solid in inclusion with tabular solids. (C) $<1 \mu \mathrm{m}$ solid in inclusion. Note: images $A$ and $C$ courtesy of $K$. Benison. (Similar solids also seen in sample E.4.C.2.P).

Interval 5 (1502.25 - $1502.2 \mathrm{~m})$

Good halite preservation is rare in Interval $5(1502.25-1502.2 \mathrm{~m})$. This interval consists of blocky brown halite surrounded by gray mud. In the upper part of Interval 5, blocky halite with mud may be displacive halite as there are only secondary fluid inclusions noted in this region. Only the lower area (zone C) has well preserved halite with faint primary fluid inclusion assemblages consisting of chevrons. These small primary inclusions do not have daughter crystals, although there are solid inclusions in this part (zone C).

Interval 6 (1502.29-1502.25 m)

Interval $6(1502.29-1502.25 \mathrm{~m})$ is contiguous with interval 5 . The lower part of this sample (zones B-C) has several thin layers of mud. Halite crystals are also interfiled with mud. The lower part has areas with very few suspect primary inclusions. The upper part (zone A) is largely halite with isolated mud intervals with irregular shapes and sharp angles. This upper part has small primary fluid inclusions with daughter crystals. Only large inclusions have gas bubbles. 
Interval $6(1502.29-1502.25 \mathrm{~m})$ has cubic solid inclusions found in or near to primary fluid inclusions bands, these solids are 100 to $600 \mu \mathrm{m}$ in size (Fig. 17). Portions of these opaque inclusions fluoresce an electric blue under UV illumination. Interval 8 has similar solids (seen in sample E.8.C.1.P).

Figure 17. Image of opaque cubic solid inclusions (100-600 $\mu \mathrm{m})$ found in or near to primary fluid inclusion bands. (Image from sample E.6.C.1.P).

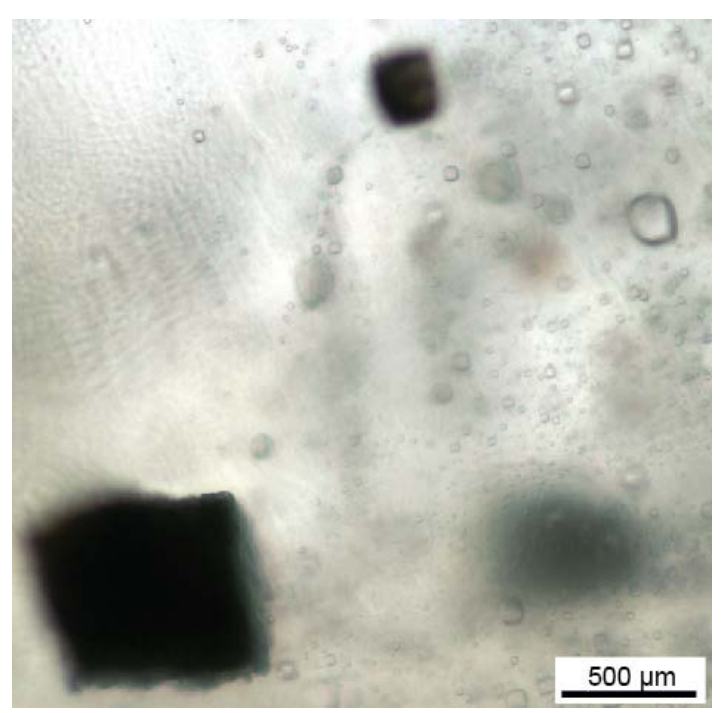

Interval 7 (1499.42-1499.3 m)

Interval 7 transitions from a muddy layer at the bottom to dusky red halite interfiled with mud (zone B). The lower area does not have any primary fluid inclusions. Mud in this area transitions from subrounded to angular edges to large rounded shapes. There is a sharp transition from a fine mud layer to massive red halite with isolated gray mud lenses (zone A).

The upper area consists of halite with chevrons with growth bands consisting of small (<20 um) fluid inclusions. Many inclusions have cubic to tabular inclusions. Some solids appear striated. Vapor is only present in large fluid inclusions.

\section{Interval 8 (1498.74 - 1498.62 m)}

Interval 8 consists of several halite beds with marked changes in color from pink to dusky red, to light red halite near the top. The lowest zone has bedded halite that is poorly preserved. It has primary fluid inclusions, but clear growth bands are not easily evident. The middle of the core (zone B), near the dusky red halite layer, does not have any primary fluid inclusions. Finally, the top of the core (zone A), beneath the mud layer, faintly outlines chevrons. Examination of halite chips reveals that this upper zone consists of halite with growth bands. These inclusions have acicular solids, vapor bubbles are only seen in large fluid inclusions. 
Several rare inclusions appear to be all vapor (in sample E.8.A.1.P). Interval 8 contains opaque cubic solid inclusions (100 to $600 \mu \mathrm{m}$ ). These solids fluoresce an electric blue under UVillumination and are located in or near to primary fluid inclusions bands.

\section{Interval 9 (1489.75-1489.7 m)}

Interval 9 is mud-rich at the bottom. The mud-halite contact consists of many sharp angles outlining halite crystals. The bottom area (zone C) transitions from displacive halite with mud to a halite rich and mud poor bed (bedded halite). The lower bedded halite has small primary fluid inclusions. A thin mud layer separates the lower and middle areas (zones $\mathrm{C}$ and B). The middle layer (zone B) consists of bedded red halite with many primary fluid inclusions. Primary fluid inclusions have cocci-shaped solids that do not fluoresce, but appear to be birefringent. A minority of inclusions in this bed have vapor bubbles. The upper and middle halite layers are separated by a mud layer (mud transitions from light to dark red color). This muddy halite zone has well preserved primary inclusions with tabular and acicular daughter crystals, vapor bubbles are only present in large inclusions.

\section{Interval $10(1480.8-1480.7 \mathrm{~m})$}

Interval 10 consists of several sampling zones. This interval consists of reddish brown to reddish yellow halite rich layers with small muddy intervals. A thick slab made from the lower part of this interval (zones E and D) has gypsum/anhydrite crystal splays, cumulate halite crystals, and a thin brown (likely hematite) layer. Primary inclusions also have red angular solids (Table 6). There is a clump of small (20-100 um) abraded grains in this zone that are not isotropic and have weak relief (quartz). A fracture in the thick section from the lower part of the core (zone E) has opaque solids that fluoresce deep royal blue. Halite chips from this zone have many secondary inclusions and a few have solid cubic inclusions, with high birefringence and relief. Only a layer near the top of the interval (zone B) consistently yields samples with primary 
fluid inclusions, these small inclusions outline growth bands in faint chevrons.

Interval $10(1480.8-1480.7 \mathrm{~m})$ has

unusual solids that have a border defined by

opaque red (iron oxide?) material (Fig. 18).

These solids ranged from $200-400 \mu \mathrm{m}$ in

size and are roughly triangular. One has rough

spiky borders, while another has rounded

globular shape.

Figure 18. Images of unusual solids found in thick slab from interval 10, zone E. Illuminated by $(A)$

white light, $(B)$ cross polarized light (C) plane white light (D) plane white light.
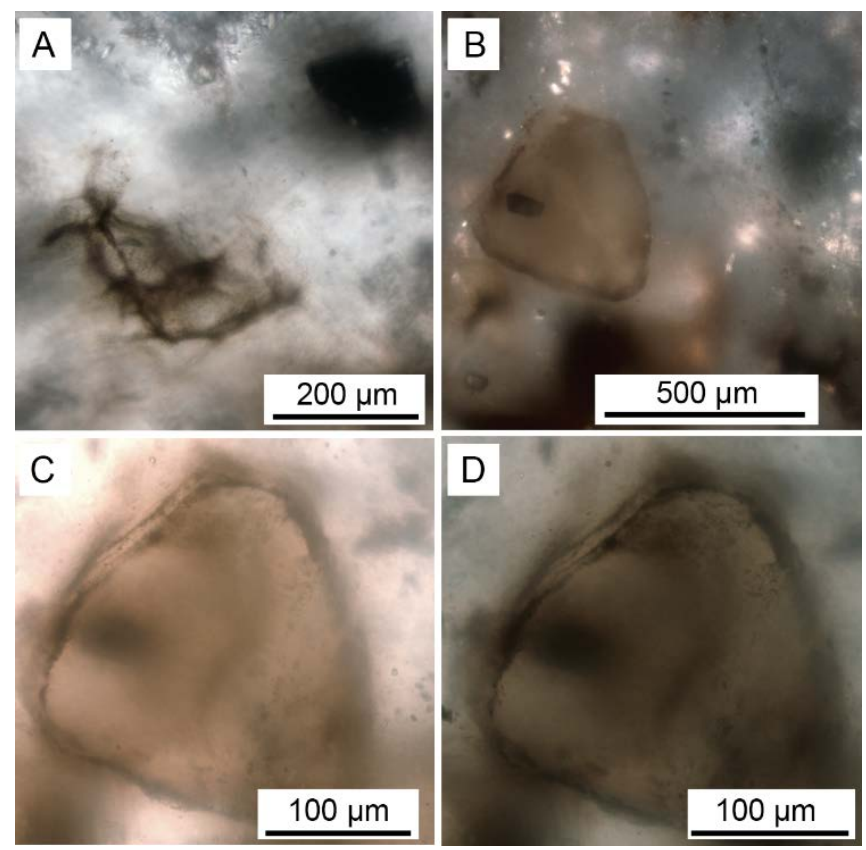

\section{Interval 1297 (1297.08-1297.0 m)}

Interval 1297 consists of blocky light gray halite and both red and light gray mud with light gray halite crystals. Large secondary fluid inclusions are present in all parts of this interval. Zone A has areas with primary fluid inclusion assemblages with large inclusions, these inclusions are primarily all liquid, some inclusions have acicular solids and vapor bubbles.

\section{Freezing-Melting Microthermometry Results}

Samples of chevron crystals for microthermometry were selected for optically clarity and large fluid inclusion size. Samples with large inclusions $(20-60 \mu \mathrm{m})$ from bedded halite from Empress $1 \mathrm{~A}$ core samples were cooled to $-190{ }^{\circ} \mathrm{C}$ for over three minutes (two sampling intervals, three samples: E.4.Z.2.P [two freezing-melting attempts], E.1297.Z.1.P [two freezingmelting attempts], and E.1297.Z.8.P [one freezing-melting attempt]). Despite these low temperatures, fluid inclusions never froze (Fig. 19). 
Fig. 19: Images of fluid inclusions during freezing-melting attempt with sample E.1297.Z.1.P from $1297.08-1297.0 \mathrm{~m}$. Note that there are no textural changes that would be indicative of freezing in any of the images.

\section{Laser Raman Spectroscopy Results}

Over 170 Raman spectra were collected from 10 intervals comprising of 17 zones of the Empress $1 \mathrm{~A}$ core (Table 7). Of the 20 halite chips examined through Raman spectroscopy, only spectra from the aqueous phase of fluid inclusions from ones zone (5.C) did not yield any water peaks. Large primary fluid inclusions (>20 $\mu \mathrm{m})$ were targeted for Raman analysis, as their greater volume increased spectral strength. Inclusions from 1502.25 - 1502.2 m (5.C) appear to be too small to yield useful spectra (<15 $\mu \mathrm{m})$. Appendix II discusses individual spectra of liquids and solids within inclusions, their peaks, and interpretations. To ensure a standard description of spectral peaks, this study used the Raman peak naming convention decribed in Table 8.
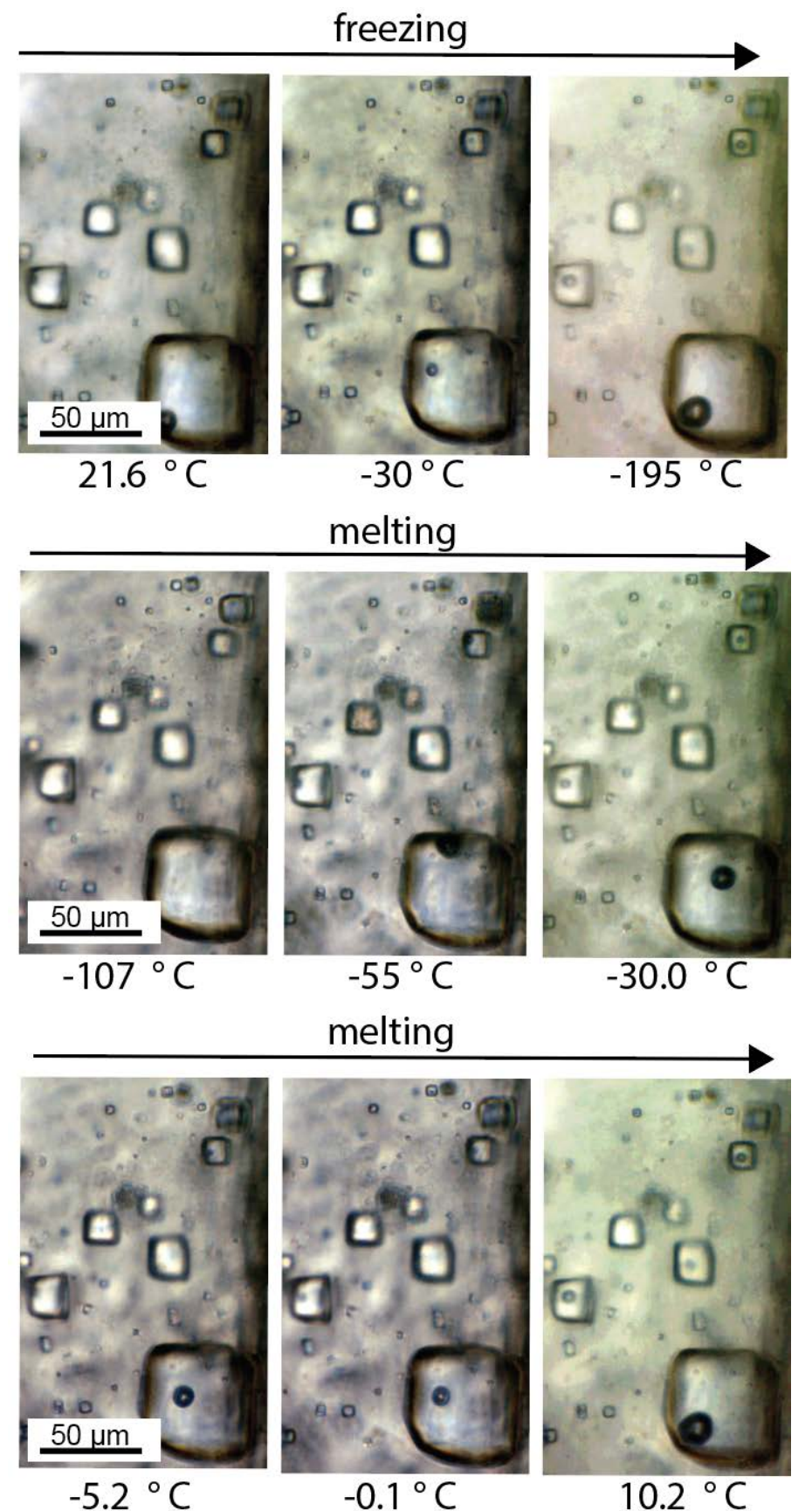

$-0.1^{\circ} \mathrm{C}$ 
Table 7: Areas of Raman spectra analysis in Empress 1A core

\begin{tabular}{|c|c|c|c|c|}
\hline $\begin{array}{l}\text { sample } \\
\text { interval }\end{array}$ & core depth $(m)$ & \begin{tabular}{|l|}
$\begin{array}{l}\text { zones examined } \\
\text { (zone name[s] }\end{array}$ \\
\end{tabular} & $\begin{array}{l}\text { number of halite chips examined } \\
\text { (chip name) }\end{array}$ & $\begin{array}{l}\text { Raman spectra } \\
\text { collected }\end{array}$ \\
\hline 2 & 1520 & $1(E)$ & 2 (E.2.E.1.P, E.2.E.2.P) & 13 \\
\hline 3 & 1511.7 & $1(\mathrm{~B})$ & 1 (E.3.B.1.P) & 5 \\
\hline 4 & $1502.7-1502.6$ & $4(A, B, D, Z)$ & $\begin{array}{l}5 \text { (E.4.A.1.P, E.4.B.1.P, E.4.D.1.P, } \\
\text { E.4.Z.1.P, E.4.Z.2.P) }\end{array}$ & 39 \\
\hline 5 & $1502.25-1502.2$ & $1(\mathrm{C})$ & 1 (E.5.C.1.P) & 4 \\
\hline 6 & $1502.29-1502.25$ & $1(\mathrm{~A})$ & 1 (E.6.A.2.P) & 8 \\
\hline 7 & 1499.42 - 1499.3 & $2(A, Z)$ & 2 (E.7.A.1.P, E.7.Z.2.P) & 33 \\
\hline 8 & $1498.74-1498.62$ & $2(A, Z)$ & 2 (E.8.A.2.P, E.8.Z.1.P) & 33 \\
\hline 9 & $1489.75-1489.7$ & $3(A, B, Z)$ & 3 (E.9.A.1.P, E.9.B.1.P, E.9.Z.1) & 19 \\
\hline 10 & $1480.8-1480.7$ & $1(\mathrm{E})$ & 1 (E.10.E.2. S) & 4 \\
\hline 1297 & $\sim 1297$ & $1(\mathrm{Z})$ & 2 (E.1297.Z.1.P, E.1297.Z.\&.P) & 14 \\
\hline Total: & not applicable & 17 & 20 & 172 \\
\hline
\end{tabular}

Background spectra from the glass sample holder and halite were seen in Raman spectra collected from fluid inclusions (Fig. 20). In addition to peaks from the glass slide $\sim 478$, $\sim 561, \sim 775, \sim 993, \sim 1024$, and $\left.\sim 1099 \mathrm{~cm}^{-1}\right)$, halite spectra has several peaks $(\sim 127, \sim 278$, $\left.\sim 352, \sim 484, \sim 1077,1555, \sim 2442, \sim 3413 \mathrm{~cm}^{-1}\right)$. Only the source of a portion of the peaks from these background spectra were accounted for.

\section{Summary of Peak Distribution over Empress 1A Sampling Intervals}

The presence or absence of peaks or peak groups was recorded for all zones to find if there were any trends between different halite beds (Table 9, Table 10, and Table 11). Observed peaks could vary greatly in a small area, depending upon the target of Raman spectra collection (Fig. 21). Peaks in these tables are not representative of all Raman spectra of inclusions from each interval, but are present in at least some scans for each interval. Broad peaks could be a combination of two smaller peaks. Raman peaks that were close to recorded peaks, but not a perfect match, are listed in white on these tables. 
Table 8: Guide to Raman peak naming conventions

\begin{tabular}{|c|c|c|}
\hline \multicolumn{3}{|c|}{ name template (strength + width + certainty) } \\
\hline $\begin{array}{l}\text { strength } \\
\text { (optional) }\end{array}$ & width & $\begin{array}{l}\text { certainty } \\
\text { (optional) }\end{array}$ \\
\hline \multirow{3}{*}{ w (weak) } & S (sharp: easily found, may be stronger than water peak) & \multirow{6}{*}{$\begin{array}{c}? \\
\text { (could be noise) }\end{array}$} \\
\hline & s (sharp: taller than it is wide) & \\
\hline & B (large broad: > $100 \mathrm{~cm}^{-1}$ breadth) & \\
\hline \multirow{3}{*}{ v (very) } & b (broad: >15 cm-1 breadth, not sharp) & \\
\hline & m (medium sharp peak) & \\
\hline & sh (shoulder on a larger peak) & \\
\hline
\end{tabular}

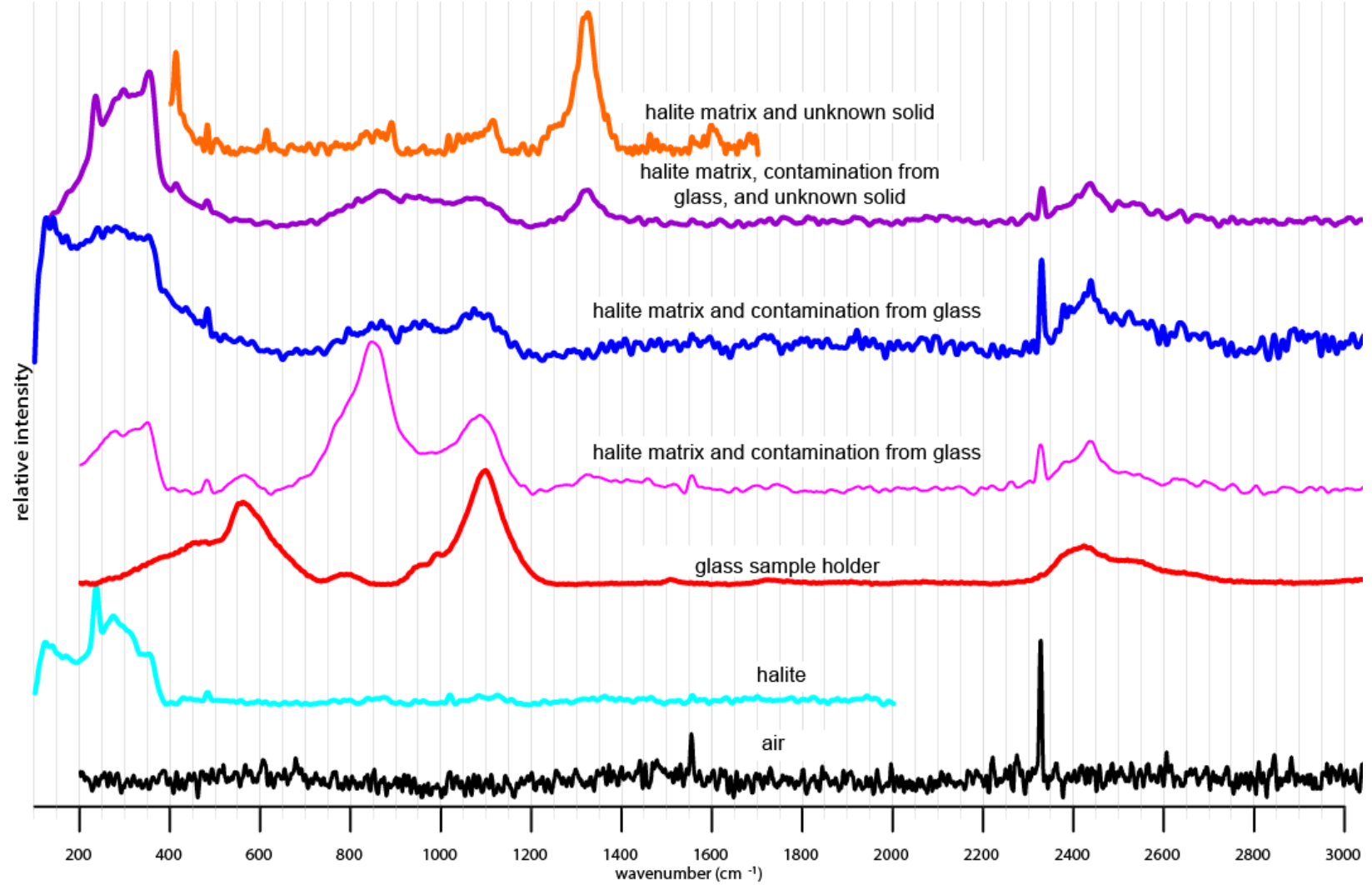

Figure 20: Chart of Raman spectra of potential contamination sources. The bottommost scan is representative of the influence of the atmosphere, peaks for oxygen $\left(\sim 1555 \mathrm{~cm}^{-1}\right)$ and nitrogen $(\sim 2333$ $\left.\mathrm{cm}^{-1}\right)$ are present. The next spectra (red) is of the underlying glass slide that samples are placed upon. This spectra correlated to spectral references of glass and opal. The peaks from $\sim 200-400 \mathrm{~cm}^{-1}$ are indicative of the present of salt. Other large broad peaks in the upper spectra have an unidentified source but do not originate in fluid inclusions.

Except for Raman spectra from intervals 5 and 10 (which are not fluid inclusion spectra), all intervals have Raman peaks at $\sim 237, \sim 484, \sim 1650$, and $\sim 2331 \mathrm{~cm}^{-1}$ (from spectra targeting inclusions fluid). All intervals, except intervals 3 and 5, had peaks at $\sim 1018, \sim 1115$, and $\sim 1131$ 
$\mathrm{cm}^{-1}$ (from spectra targeting solids in inclusions and inclusion fluid). Over half of the intervals have peaks at $\sim 413$ (weak sharp), 861 (very broad), 1099 (very broad), 1237-1254 (broad), 〜1321-1326 (broad), 1464 (sharp), 1604 (sharp and/or broad), 2424 (very broad), and $\sim 2930$ (very broad) $\mathrm{cm}^{-1}$ (from spectra targeting inclusion fluid). Peaks at $\sim 735$ (weak sharp), $\sim 845$ (sharp), 888 (weak broad), $\sim 993$ (sharp), 1087 (weak sharp), and $\sim 3070$ (sharp) cm-1 are present in several intervals (from spectra targeting inclusion fluid). A group of peaks at $\sim 708, \sim 890$, and $\sim 1180 \mathrm{~cm}^{-1}$ is also present in a minority of intervals (from spectra targeting inclusion fluid). No strong peaks were present at $\sim 1054 \mathrm{~cm}^{-1}$ in any interval. No strong peaks were present at any interval from $\sim 982-988 \mathrm{~cm}^{-1}$.

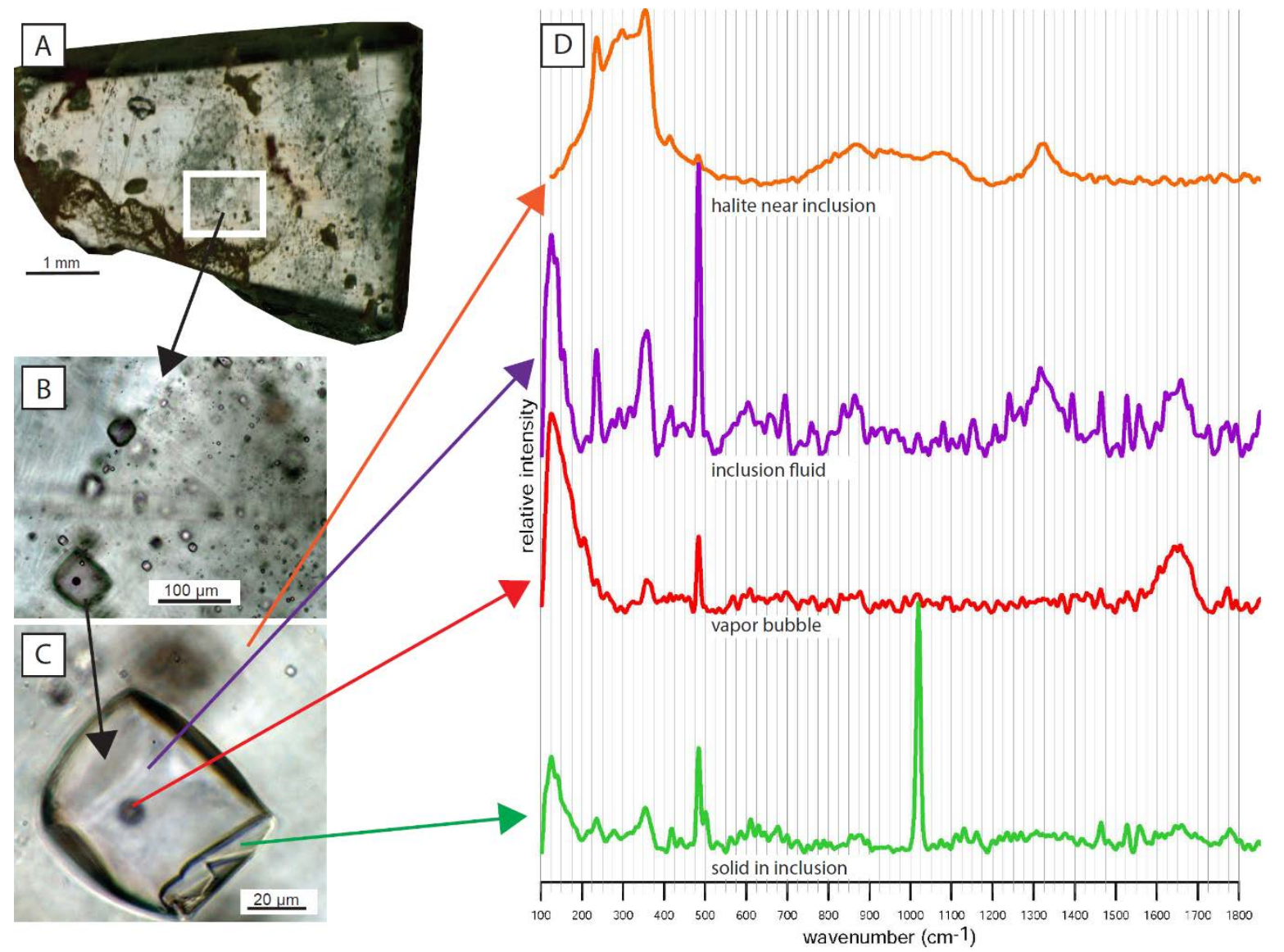

Figure 21. Images of areas of targeted Raman collection and chart of corresponding spectra. (A). This sample from interval 8, 1498.74-1498.62 m, contains (B) primary fluid inclusion assemblages with (C) am inclusion with gas, a solid, and liquid. (D) Raman spectra were collected from areas both in and near the inclusion. 
Table 9. Distribution of Raman peaks across sampling interval $\left(237-861 \mathrm{~cm}^{-1}\right)$, green " $X$ " shows

presence in an interval, red "no" shows absence, and entries that are not shaded in may be the same

peek, but were inconclusive. Note peak strength abbreviations: $s=$ sharp, ws $=$ weak sharp, $b=$ broad, $B$

= very broad.

\begin{tabular}{|c|c|c|c|c|c|c|c|c|c|c|c|c|c|c|c|c|}
\hline \multicolumn{17}{|c|}{ Raman peaks $\left(\mathrm{cm}^{-1}\right)$} \\
\hline 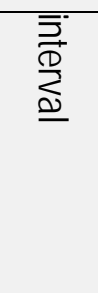 & $\begin{array}{l}\text { No } \\
\text { 임 }\end{array}$ & $\frac{\dot{N}}{\tilde{w}}$ & \begin{tabular}{l}
1 \\
$\tilde{U}$ \\
$\infty$ \\
\multirow{n}{\infty}{}
\end{tabular} & $\begin{array}{l}\stackrel{1}{w} \\
\text { ज̃ } \\
\stackrel{0}{\sigma}\end{array}$ & $\begin{array}{l}1 \\
\stackrel{p}{\omega} \\
\sum \\
\xi\end{array}$ & $\begin{array}{l}\frac{1}{N} \\
\frac{N}{n}\end{array}$ & $\begin{array}{l}\frac{1}{p} \\
\infty \\
+\infty \\
\tilde{n}\end{array}$ & 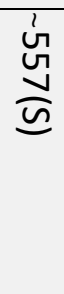 & 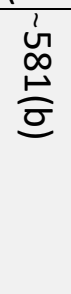 & $\begin{array}{l}\frac{1}{0} \\
\frac{u}{n}\end{array}$ & 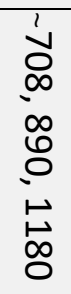 & 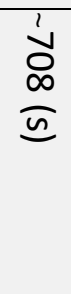 & $\frac{1}{w}$ & $\begin{array}{l}\frac{1}{b} \\
\frac{p}{n}\end{array}$ & $\begin{array}{l}1 \\
\infty \\
+ \\
\mathbb{N} \\
\underline{n}\end{array}$ & $\begin{array}{l}\stackrel{1}{\infty} \\
\stackrel{\sigma}{\ominus} \\
\text { Ш0 }\end{array}$ \\
\hline 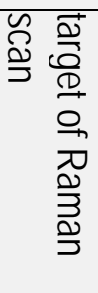 & & 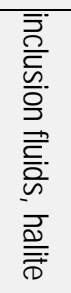 & 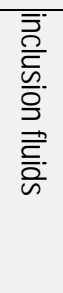 & 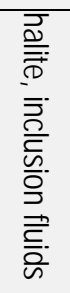 & 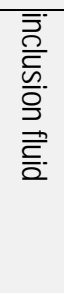 & 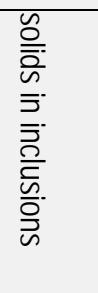 & 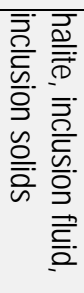 & 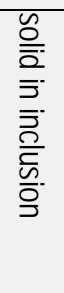 & 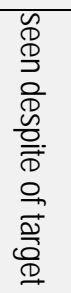 & 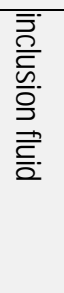 & 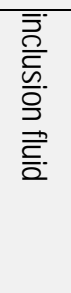 & 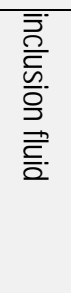 & 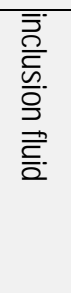 & 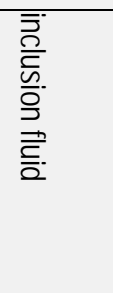 & 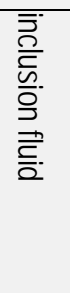 & 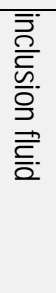 \\
\hline 2 & $E$ & $x$ & no & $x$ & no & no & $x$ & no & no & no & no & no & no & $x$ & no & $x$ \\
\hline 3 & $\mathrm{~B}$ & $x$ & no & $x$ & no & no & $x$ & no & no & $x$ & no & no & no & no & $x$ & $x$ \\
\hline \multirow{4}{*}{4} & $A$ & no & no & no & no & no & $x$ & no & no & no & no & no & no & no & no & $x$ \\
\hline & $B$ & no & no & no & no & no & no & no & no & no & no & no & no & no & no & no \\
\hline & $D$ & $x$ & $x$ & $x$ & $x$ & no & $x$ & no & no & no & no & no & no & no & no & $x$ \\
\hline & $Z$ & $x$ & $x$ & $x$ & $x$ & 472(b) & $x$ & no & $x$ & no & $x$ & $x$ & $x$ & no & $x$ & no \\
\hline 5 & C & no & no & no & no & no & $x$ & no & no & no & no & no & no & $x$ & no & no \\
\hline 6 & $A$ & $x$ & $x$ & $x$ & no & no & $x$ & no & no & no & no & no & no & $790(b)$ & no & no \\
\hline \multirow[t]{2}{*}{7} & $A$ & $x$ & $x$ & $x$ & $x$ & $x$ & $x$ & no & $x$ & $x$ & $x$ & $x$ & $x$ & no & no & $x$ \\
\hline & $Z$ & $x$ & $x$ & $x$ & $x$ & no & $x$ & $x$ & $x$ & no & $x$ & $x$ & $x$ & no & $x$ & $x$ \\
\hline \multirow{2}{*}{8} & $A$ & $x$ & $x$ & $x$ & $x$ & no & $x$ & $x$ & no & no & no & no & no & no & $x$ & $x$ \\
\hline & $Z$ & $x$ & no & $x$ & no & no & $x$ & no & no & no & no & no & no & no & no & $x$ \\
\hline \multirow{3}{*}{$\begin{array}{l}9 \\
\text { (zone } \\
\mathrm{Z} \text { is a } \\
\text { solid) }\end{array}$} & $A$ & $x$ & no & $x$ & no & no & $x$ & no & no & no & no & no & no & no & no & $x$ \\
\hline & $B$ & $x$ & no & $x$ & no & no & $x$ & no & no & no & $x$ & $x$ & no & no & no & $x$ \\
\hline & $Z$ & no & no & no & $x$ & no & no & no & no & no & no & no & no & no & no & no \\
\hline $\begin{array}{l}10 \\
\text { (solids) }\end{array}$ & $E$ & no & no & no & no & no & $x$ & no & no & no & no & no & no & no & no & no \\
\hline 1297 & Z & $x$ & no & $x$ & $x$ & no & $x$ & $x$ & $x$ & no & $x$ & $x$ & no & no & $x$ & $x$ \\
\hline
\end{tabular}


Table 10. Distribution of Raman peaks across sampling intervals $\left(870-1182 \mathrm{~cm}^{-1}\right)$, green " $X$ " shows presence in an interval, red "no" shows absence, and entries that are not shaded in may be the same peek, but were inconclusive. Note peak strength abbreviations: $s=$ sharp, vS = very sharp, ws = weak sharp, vws = very weak sharp, vwb = very weak broad, $B=$ very broad, $w B=$ weak very broad.

\begin{tabular}{|c|c|c|c|c|c|c|c|c|c|c|c|c|}
\hline \multicolumn{13}{|c|}{ Raman peaks $\left(\mathrm{cm}^{-1}\right)$} \\
\hline 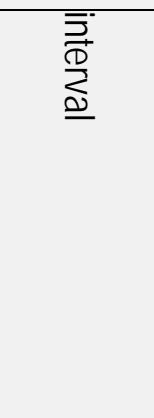 & 음 & 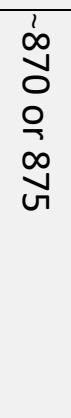 & 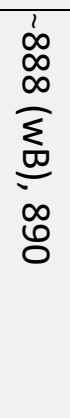 & $\begin{array}{l}\text { bे } \\
\dot{0}\end{array}$ & $\begin{array}{l}\dot{b} \\
\stackrel{\omega}{\omega} \\
\underline{\omega}\end{array}$ & $\begin{array}{l}\dot{l} \\
\dot{0} \\
\sigma \\
\text { o } \\
\text { ஸे }\end{array}$ & 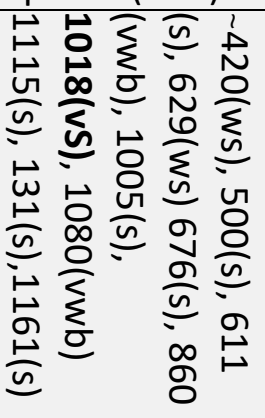 & 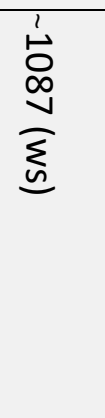 & 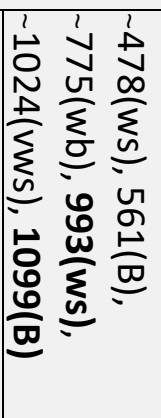 & 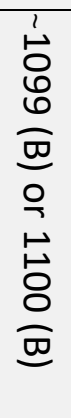 & 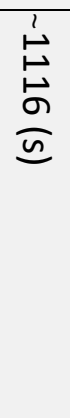 & 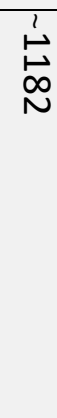 \\
\hline 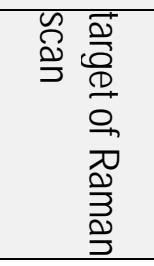 & & 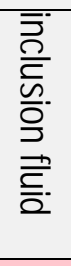 & 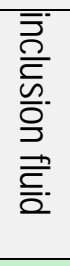 & 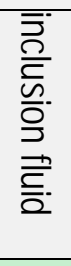 & 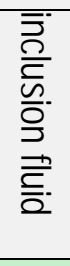 & 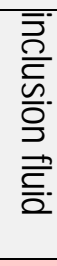 & 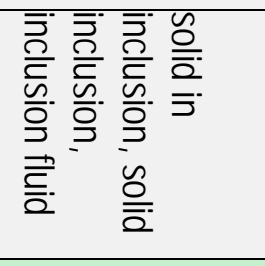 & 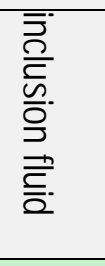 & 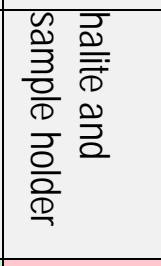 & 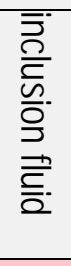 & 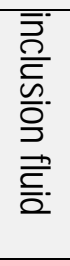 & 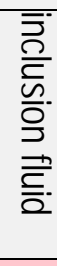 \\
\hline 2 & $\mathrm{E}$ & no & $x$ & $x$ & $x$ & no & $x$ & $x$ & no & no & no & no \\
\hline 3 & B & $x$ & no & no & no & no & no & no & no & no & $x$ & $x$ \\
\hline \multirow{4}{*}{4} & $A$ & no & no & no & no & no & $x$ & no & no & no & no & no \\
\hline & $\mathrm{B}$ & no & no & no & no & no & no & no & no & no & no & no \\
\hline & $\mathrm{D}$ & no & no & no & no & no & $x$ & no & no & no & no & no \\
\hline & Z & no & $x$ & $x$ & $x$ & no & $x$ & no & no & no & $x$ & $x$ \\
\hline 5 & C & no & no & no & no & no & no & $x$ & no & $x$ & no & no \\
\hline 6 & $A$ & no & no & no & no & no & $x$ & no & no & $x$ & no & no \\
\hline \multirow{2}{*}{7} & A & no & $x$ & no & $x$ & no & $x$ & no & $x$ & $x$ & $x$ & $x$ \\
\hline & Z & no & $x$ & no & no & no & $x$ & $x$ & no & $x$ & $x$ & $x$ \\
\hline \multirow{2}{*}{8} & A & $x$ & no & no & no & no & $x$ & $x$ & no & $x$ & $x$ & no \\
\hline & Z & no & no & no & no & no & $x$ & no & no & no & $x$ & no \\
\hline \multirow{3}{*}{$\begin{array}{l}9 \text { (zone Z } \\
\text { is a solid) }\end{array}$} & A & no & no & no & no & no & $x$ & no & no & no & no & no \\
\hline & $B$ & no & $x$ & no & no & no & $x$ & no & no & $x$ & $x$ & $x$ \\
\hline & Z & no & no & no & no & no & $x$ & no & no & no & no & no \\
\hline 10 (solids) & $E$ & no & no & no & No & no & $x$ & $x$ & no & no & no & no \\
\hline 1297 & Z & no & $x$ & $x$ & $x$ & no & $x$ & 1084 & $x$ & $x$ & no & $x$ \\
\hline
\end{tabular}


Table 11. Distribution of Raman peaks across sampling interval $\left(1237-3070 \mathrm{~cm}^{-1}\right)$, green " $X$ " shows presence in an interval, red "no" shows absence, and entries that are not shaded in may be the same peek, but were inconclusive. Note peak strength abbreviations: $s=$ sharp, ws = weak sharp, vws = very weak sharp, $b=$ broad, $w b=$ weak broad, $B=$ very broad, $w B=$ weak very broad.

\begin{tabular}{|c|c|c|c|c|c|c|c|c|c|c|c|c|c|}
\hline \multicolumn{14}{|c|}{ Raman peaks $\left(\mathrm{cm}^{-1}\right)$} \\
\hline 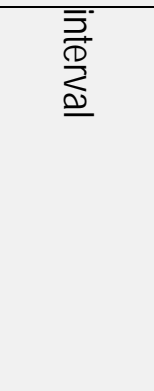 & $\begin{array}{l}\text { No } \\
\text { ㅇ }\end{array}$ & 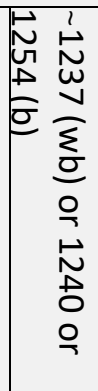 & 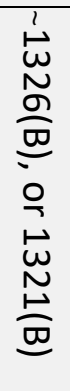 & $\begin{array}{l}\stackrel{1}{\omega} \\
\stackrel{\omega}{v} \\
\stackrel{\varpi}{\sigma}\end{array}$ & 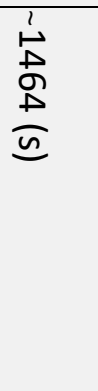 & 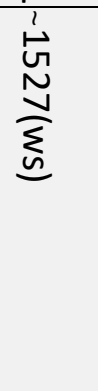 & 点 & 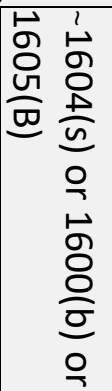 & 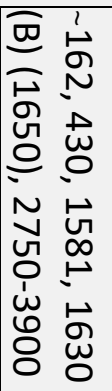 & $\underset{\underset{w}{\omega}}{\stackrel{L}{w}}$ & $\begin{array}{l}\stackrel{N}{N} \\
\stackrel{N}{ \pm} \\
\stackrel{D}{D}\end{array}$ & $\begin{array}{l}\stackrel{1}{\omega} \\
\text { w } \\
\text { 이 }\end{array}$ & $\begin{array}{l}\stackrel{\text { w }}{\circ} \\
\stackrel{J}{0} \\
\stackrel{0}{n}\end{array}$ \\
\hline 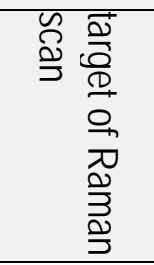 & & 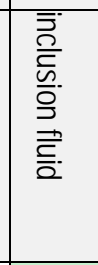 & 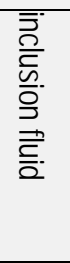 & 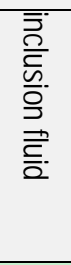 & 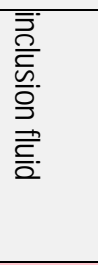 & 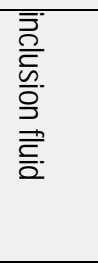 & 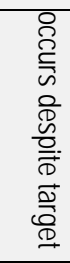 & 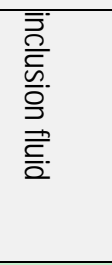 & 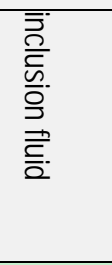 & 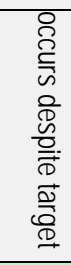 & $\begin{array}{l}\overline{\overline{\bar{D}}} \\
\overline{\bar{E}} \\
\overline{\mathrm{D}} \\
\overline{\bar{D}} \\
\overline{\vec{D}} \\
\overline{\bar{c}}\end{array}$ & 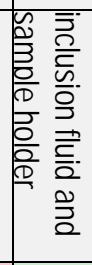 & 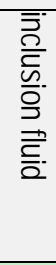 \\
\hline 2 & $E$ & $x$ & no & $x$ & no & 1523 & no & $x$ & $x$ & $x$ & no & $x$ & $x$ \\
\hline 3 & B & $x$ & no & no & no & no & $x$ & $x$ & $x$ & $x$ & $x$ & $x$ & no \\
\hline \multirow{4}{*}{4} & $A$ & $x$ & no & no & no & no & no & no & $x$ & $x$ & no & no & no \\
\hline & $B$ & $x$ & no & no & no & no & no & no & $x$ & $x$ & no & $x$ & no \\
\hline & $D$ & no & $x$ & no & 1468 & no & no & no & $x$ & $x$ & $x$ & no & no \\
\hline & Z & $x$ & $x$ & $x$ & $x$ & 1533 & $x$ & $x$ & $x$ & $x$ & no & no & $x$ \\
\hline 5 & C & no & no & no & no & no & no & no & no & no & $x$ & no & no \\
\hline 6 & $A$ & no & $x$ & no & no & no & no & no & $x$ & $x$ & $x$ & no & no \\
\hline \multirow{2}{*}{7} & $A$ & $x$ & $x$ & $\mathrm{x}$ & $x$ & $x$ & $x$ & $x$ & $x$ & $x$ & $x$ & $x$ & no \\
\hline & Z & $x$ & $x$ & $x$ & $x$ & no & no & $x$ & $x$ & $x$ & $x$ & $x$ & no \\
\hline \multirow{2}{*}{8} & A & $x$ & $x$ & no & $x$ & $x$ & $x$ & no & $x$ & $x$ & $x$ & no & no \\
\hline & Z & no & no & no & $x$ & no & $x$ & no & $x$ & $x$ & no & no & no \\
\hline \multirow{3}{*}{$\begin{array}{l}9 \\
\text { (zone } Z \text { is a } \\
\text { solid) }\end{array}$} & A & no & no & no & no & no & $x$ & no & $x$ & $x$ & $x$ & no & no \\
\hline & $B$ & $x$ & $x$ & $x$ & $x$ & $x$ & $x$ & $x$ & $x$ & $x$ & $x$ & $x$ & no \\
\hline & Z & no & no & no & no & no & no & no & $x$ & $x$ & $x$ & $x$ & no \\
\hline 10 (solids) & $E$ & no & no & no & no & no & no & no & $x$ & $x$ & $x$ & $x$ & no \\
\hline 1297 & Z & no & $x$ & no & $x$ & no & $x$ & $x$ & $x$ & $x$ & $x$ & $x$ & $x$ \\
\hline
\end{tabular}




\section{Laser Raman Spectroscopy Results by Sampling Interval}

Interval 2 (1520.22-1520.0 m)

Some spectra from Interval $2(1520.22-1520.0 \mathrm{~m})$ have a broad weak peak at $~ 888$ $\mathrm{cm}^{-1}$. Several scans from this interval have the broad peak at $\sim 3440 \mathrm{~cm}^{-1}$ but do not have peaks at $\sim 1650 \mathrm{~cm}^{-1}$, the same spectra have very broad peaks at $\sim 1605 \mathrm{~cm}^{-1}$. Spectra with peaks at both $\sim 1605$ and $\sim 1650 \mathrm{~cm}^{-1}$ were noted. Broad peaks at $\sim 1272$ and $\sim 1377 \mathrm{~cm}^{-1}$ are present in several spectra.

Globular solids (5-12 $\mu \mathrm{m})$ were scanned in several inclusions, the resulting spectra from these scans was noisy and showed evidence of fluorescence. A scan of a globular solid (E.2.E.1.P.A.1.3B_gloubular) has strong peaks at $\sim 794,992,1019$, and $1113 \mathrm{~cm}^{-1}$. Other scans of globular solids have peaks at $\sim 504,1019,1113$, and $1160 \mathrm{~cm}^{-1}$. The Raman spectrometer did not successfully scan one globular solid at 100 or 50 percent laser power, but scanned successfully at 10 percent.

\section{Interval 3 (1511.76-1511.7 m)}

All peaks from Interval $3(1511.76-1511.7 \mathrm{~m})$ are noisy. There is a sharp peak at 845 in one scan that does not show up in other intervals. There is a weak sharp peak present in four of the five spectra here at $\sim 880 \mathrm{~cm}^{-1}$. A weak broad peak at $\sim 1237 \mathrm{~cm}^{-1}$ is in all spectra from this interval. Two broad peaks are present in two scans at $\sim 1375$ and $\sim 1460 \mathrm{~cm}^{-1}$. There is a broad peak at $\sim 2930 \mathrm{~cm}^{-1}$ in a noisy spectrum. Like those seen at interval 2 , there are peaks at $\sim 1605$ $\mathrm{cm}^{-1}$ present in all spectra from interval 3. There is a strong peak at $-3070 \mathrm{~cm}^{-1}$ for all long spectra in this interval.

\section{Interval 4 (1502.7 - $1502.6 \mathrm{~m})$}

Interval 4 (1502.7 - 1502.6 m) has many spectra with only broad peaks at $\sim 1650$ and $-3440 \mathrm{~cm}^{-1}$. Other spectra from this interval have many broad peaks and sharp peaks. There 
are strong peaks at $\sim 417,500,1018$, and $1132 \mathrm{~cm}^{-1}$ in many of these samples. Many of the scanned inclusions appeared to be all water and have no solids when visually examined, but had had sharps peaks in their spectra indicative of a solid. There are strong broad peaks at $\sim 470 \mathrm{~cm}^{-1}$ in this interval. There is a sharp peak at $\sim 557 \mathrm{~cm}^{-1}$ and a broad peak at $\sim 581 \mathrm{~cm}^{-1}$ in several spectra. Weak sharp peaks at $\sim 870$ and $930 \mathrm{~cm}^{-1}$ are present in two spectra from Interval 4.

Three broad peaks occur in the $-1200-1600 \mathrm{~cm}^{-1}$ range in Interval 4 . A weak, very broad peak $\mathrm{a} \sim 1320 \mathrm{~cm}^{-1}$ is present in many scans from this interval. Very broad peaks at $\sim 1380$ and $1570 \mathrm{~cm}^{-1}$ were also detected.

Interval 5 (1502.25 - $1502.2 \mathrm{~m})$

The spectra from Interval 5 (1502.25 - $1502.2 \mathrm{~m}$ ) are very noisy. Small inclusion size made it difficult to collect good spectra from this interval. One long scan had a broad peak at $\sim 3400 \mathrm{~cm}^{-1}$. All spectra in this interval had very broad peaks at $\sim 1090 \mathrm{~cm}^{-1}$, and weak broad peaks at $\sim 570$ and $795 \mathrm{~cm}^{-1}$.

Interval 6 (1502.29 - 1502.25 m)

Interval 6 (1502.29 - 1502.25 m) has sharp peaks at 418, 677, 1020 (very strong), 1115,1130 , and $1160 \mathrm{~cm}^{-1}$ in many spectra. Some spectra have sharp peaks at $\sim 418,677$, 1115 and $1131 \mathrm{~cm}^{-1}$, but no sharp peak at $\sim 1020 \mathrm{~cm}^{-1}$. All spectra have a very broad peak at $\sim 1320 \mathrm{~cm}^{-1}$.

Interval 7 (1499.42 - 1499.3 m)

All spectra from Interval $7(1499.42-1499.3 \mathrm{~m})$ have a peak at $\sim 484 \mathrm{~cm}^{-1}$. One spectrum has a very strong sharp peak at $\sim 484 \mathrm{~cm}^{-1}$. Many spectra have sharp peaks at $\sim 1018$, 1130 , and $1160 \mathrm{~cm}^{-1}$. Many spectra also have peaks at $\sim 705(\mathrm{~s}), 735(\mathrm{ws}), 890$, and $1113 \mathrm{~cm}^{-1}$. 
There are very broad peaks present at $\sim 1254,1326$, and $1464 \mathrm{~cm}^{-1}$ in different spectra.

Interval 8 (1498.74 - 1498.62 m)

There are several peaks in spectra from Interval 8 (1498.74 - $1498.62 \mathrm{~m})$. Sharp peaks at $\sim 420,1019$, and $1131 \mathrm{~cm}^{-1}$ occur together. Very weak broad peaks at $\sim 846$ and $875 \mathrm{~cm}^{-1}$ occur together, as do weak sharp peaks at $\sim 1465$ and $1527 \mathrm{~cm}^{-1}$. Very broad peaks occur at -861, 1100, and $1330 \mathrm{~cm}^{-1}$. A fluid inclusion that had a solid, when scanned in the aqueous part, yielded several sharp peaks, including one at $\sim 1018 \mathrm{~cm}^{-1}$ (Fig. 21). When the vapor bubble in this inclusion was targeted and scanned, this peak at $\sim 1018 \mathrm{~cm}^{-1}$ was no longer present.

Interval 9 (1489.75 - $1489.7 \mathrm{~m})$

Spectra from targeting fluid in inclusions with tabular solids in Interval 9 (1489.75 $1489.7 \mathrm{~m}$ ) have sharp peaks at $\sim 420,1019$, and $1132 \mathrm{~cm}^{-1}$. Sharp peaks at $\sim 708,890,1114$, and $1180 \mathrm{~cm}^{-1}$ occur in spectra without the $\sim 1019 \mathrm{~cm}^{-1}$ peak. Broad peaks at $\sim 1100$ and 1325 $\mathrm{cm}^{-1}$ occur in this interval. A broad peak at $\sim 1600 \mathrm{~cm}^{-1}$ occurs in spectra with and without the broad peak at $1650 \mathrm{~cm}^{-1}$.

Interval 10 (1480.8 - $1480.7 \mathrm{~m})$

Spectra of cubic to tabular solid inclusions in halite are represented in Interval 10 (1480.8 - $1480.7 \mathrm{~m})$. Spectra contain a strong peak at $\sim 484 \mathrm{~cm}^{-1}$. Sharp peaks at $\sim 502,1018$, 1113 and $1131 \mathrm{~cm}^{-1}$ occur in several spectra. A weak sharp peak occurs at $\sim 1087 \mathrm{~cm}^{-1}$ in several spectra.

Interval $1297(1297.08-1297.0 \mathrm{~m})$

Spectra from Interval 1297, $(-1297.08-1297.0 \mathrm{~m})$ have sharp peaks at $\sim 420,1020$, and $1113 \mathrm{~cm}^{-1}$. Other spectra have weak peaks at $\sim 890$ and $1180 \mathrm{~cm}^{-1}$. There are broad peaks at $\sim 1100,1245,1380,1600$ and $2930 \mathrm{~cm}^{-1}$ in several spectra. 


\section{Supplementary Samples Results}

\section{Synthetic samples}

Synthetic halite fluid inclusions with $\mathrm{pH}$ ranging from 0 to 6 , and with varying amounts of sulfate, were used as reference samples to ensure equipment detected sulfate and bisulfate peaks (Fig. 22). Raman spectra were collected from the aqueous phase of fluid inclusions. Peaks $\sim 986$ and $\sim 620 \mathrm{~cm}^{-1}$ are indicative of sulfate in solution. Peaks at $\sim 422, \sim 586, \sim 890$, $\sim 1053$, and $\sim 1202 \mathrm{~cm}^{-1}$ are indicative of bisulfate in solution (Rudolph and Mason, 2001). The presence of a peak at $\sim 1054 \mathrm{~cm}^{-1}$ is indicative of a pH below 1. If a peak at $\sim 890 \mathrm{~cm}^{-1}$ is present, it is indicative of a pH below 0 (Benison, et al., 1998). Low sulfate concentrations (<2000 ppm) are not detectable via laser Raman spectroscopy.

\section{Reference Samples}

Reference Raman spectra of natural modern waters from locations with varying $\mathrm{pH}$ and salinity were collected. Several spectra were collected by Eichenlaub (2016). Additional spectra available from the Mercia Mudstone, so its spectra were used to deepen understanding of the equipment and possible spectral contamination sources (Fig. 23; Eichenlaub, 2016). Mercia Raman spectra were collected from inclusion fluid and solids within fluid inclusions. Spectra from the Mercia show the presence of diverse solids, solutes, and spectral contamination.

Raman spectra were collected from ancient surface waters (aqueous phase of primary fluid inclusions from bedded halite) and modern surface waters (aqueous phase of primary fluid inclusions from bedded halite and glass vials containing water samples; Fig. 24, Fig. 25, and Fig. 26). Fluid inclusions from Permian Opeche Shale and Nippewalla group show evidence of high sulfate the low pH. Fluid inclusions from Great Salt Lake, Utah have high sulfate. Inclusions from Silurian Salina Formation do not have sulfate peaks. Spectra might be influenced by solids in adjacent halite, or in the fluid inclusion. 


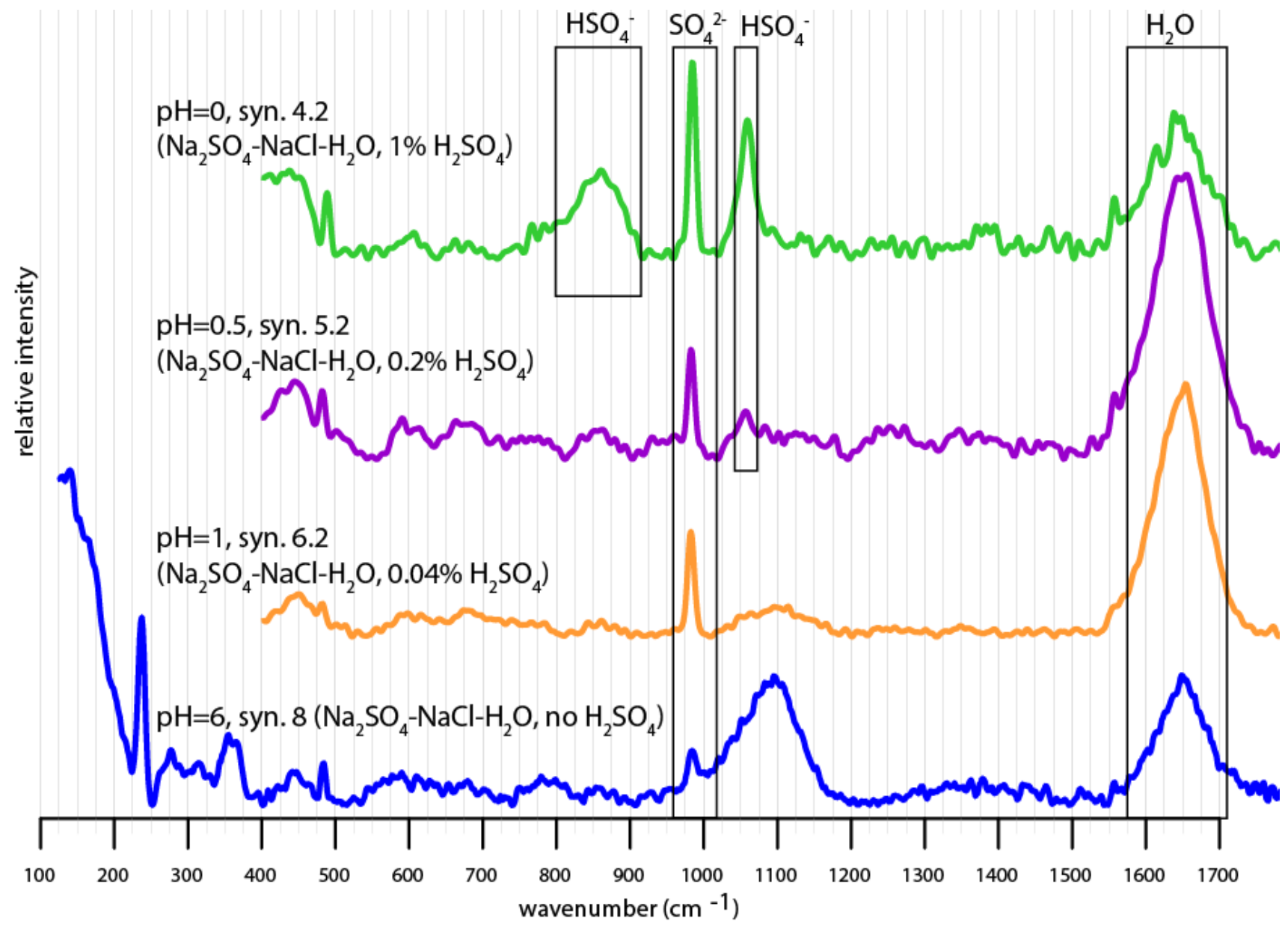

Figure 22. Chart of Raman spectra of synthetic fluid inclusions with $\mathrm{pH}$ ranging from 0 to 6 (Benison, 1997). Peaks $\sim 986$ and $\sim 620 \mathrm{~cm}^{-1}$ are indicative of sulfate in solution. Peaks at $\sim 422, \sim 586, \sim 890, \sim 1053$, and $\sim 1202 \mathrm{~cm}^{-1}$ are indicative of bisulfate in solution (Rudolph and Mason, 2001). The presence of a peak at $\sim 1054 \mathrm{~cm}^{-1}$ is indicative of a pH below 1. If an additional peak at $\sim 890 \mathrm{~cm}^{-1}$ is present, it is indicative of a pH below 0 (Benison, et al., 1998). This technique will not detect sulfate in concentrations below 2000 ppm. Note: the notation syn \#.\# is indicative of which samples were used from Benison's thesis (1997).

Most samples from modern saline waters had strong sulfate peaks, several other peaks were present in these spectra. For example, peaks at $\sim 880 \mathrm{~cm}^{-1}$ are present in spectra from acid-saline brines from Salar Gorbea. The most dilute sample, modern seawater, had weak sulfate spectra, likely because of low sulfate concentrations. Only a minority of spectra from the Mercia Mudstone detected sulfate. Those spectra typically had a strong peak associated with anhydrite ( $1018 \mathrm{~cm}^{-1}$; curiously, this peak was broad and other anhydrite peaks were not present, indicating an aqueous origin.) 


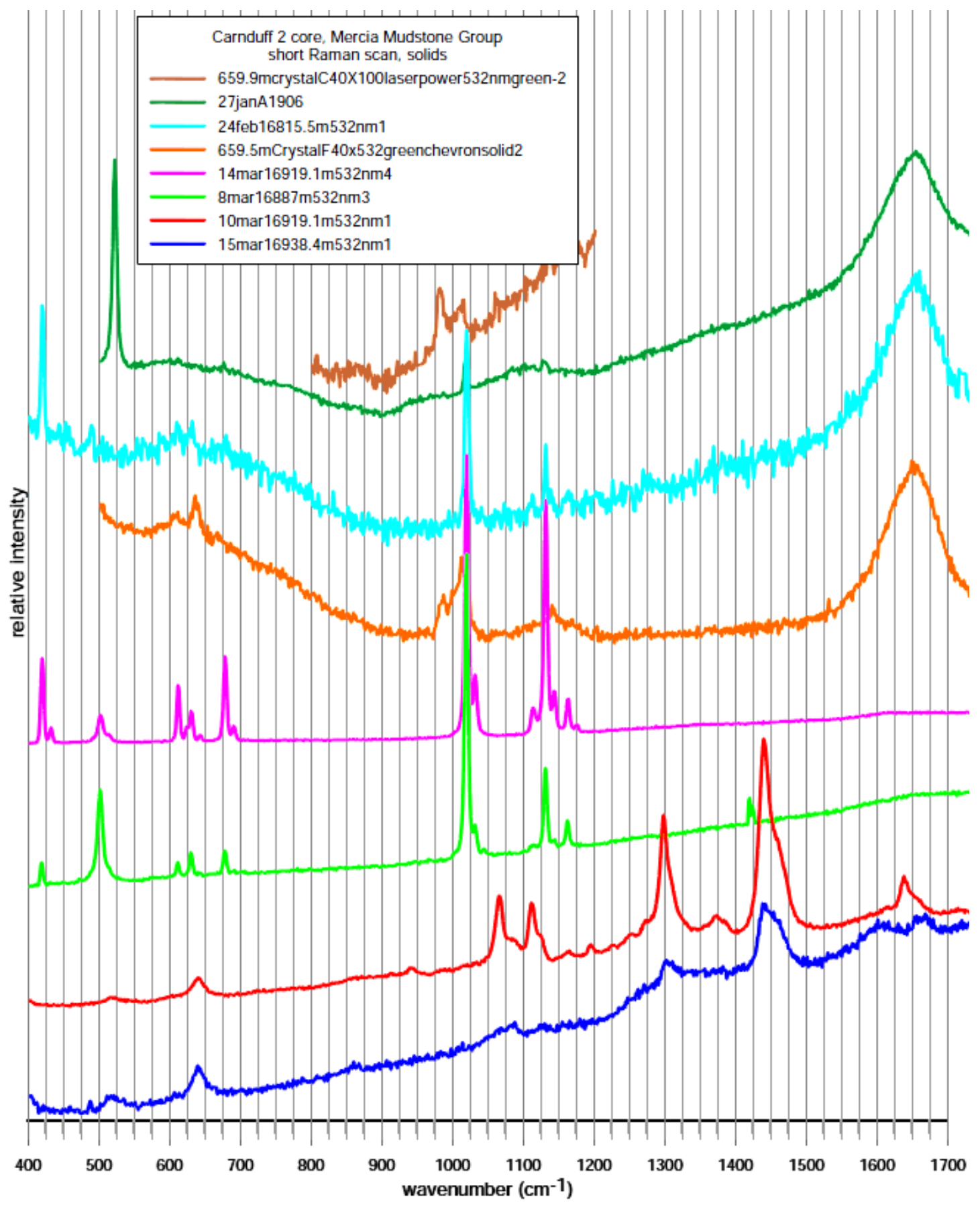

Figure 23. Chart of short Raman scans $\left(400-1700 \mathrm{~cm}^{-1}\right)$ of solids in fluid inclusions in bedded halite from the Triassic Mercia Mudstone (Eichenlaub, 2016). Solids are identified as anhydrite, suspect alunite, other solids are unidentified. 


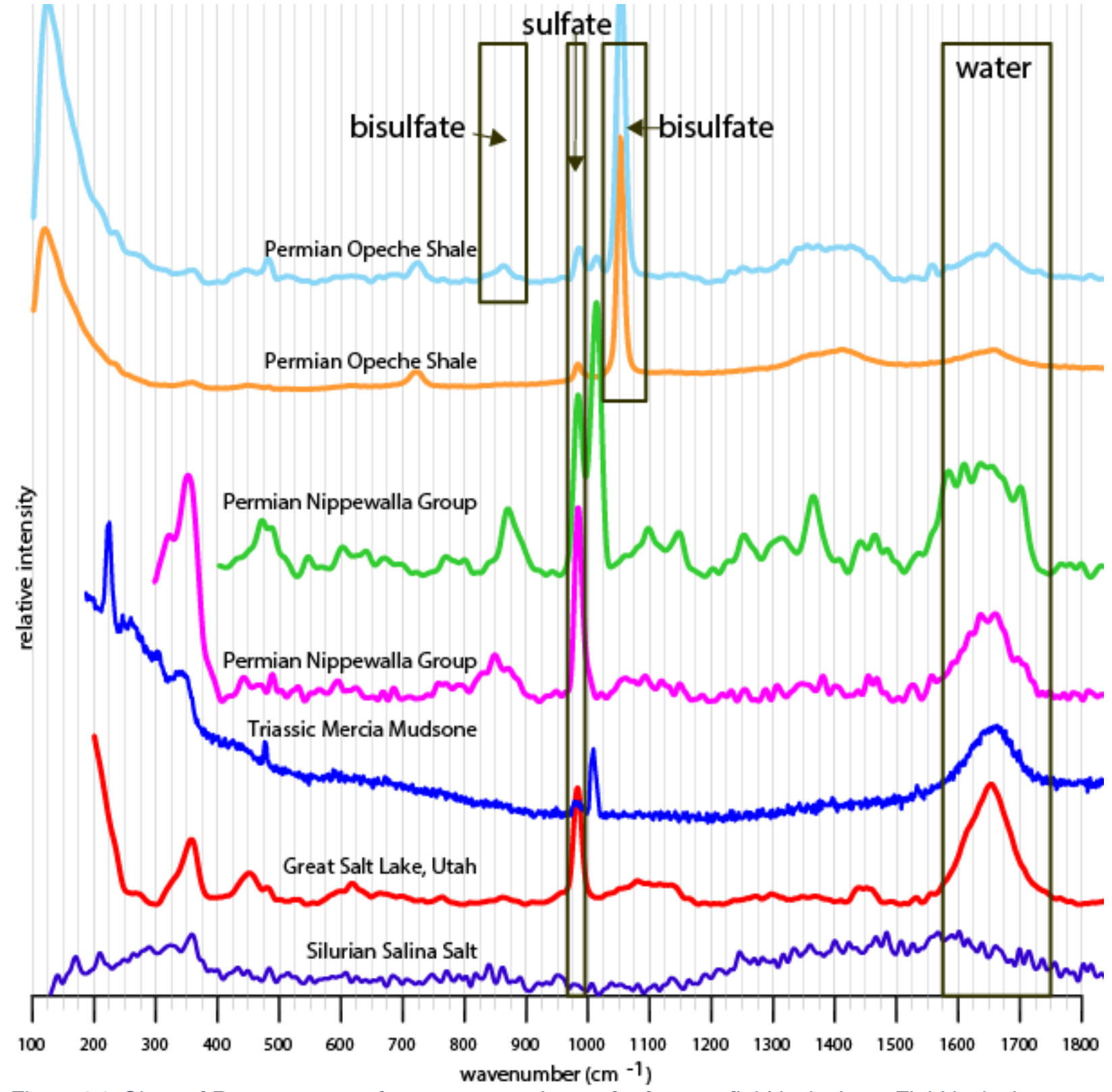

Figure 24. Chart of Raman spectra from aqueous phase of reference fluid inclusions. Fluid inclusions from Permian Opeche Shale and Nippewalla Group show evidence of high sulfate and low $\mathrm{pH}$. Fluid inclusions from Great Salt Lake, Utah, have high sulfate. Spectra of aqueous phase of inclusion from Silurian Salina Formation does not show the presence of sulfate. Note: spectra may be influenced by solids in adjacent halite, or in the fluid inclusion. Several spectra collected by Eichenlaub (2016). Note the mixed spectral quality seen here. 


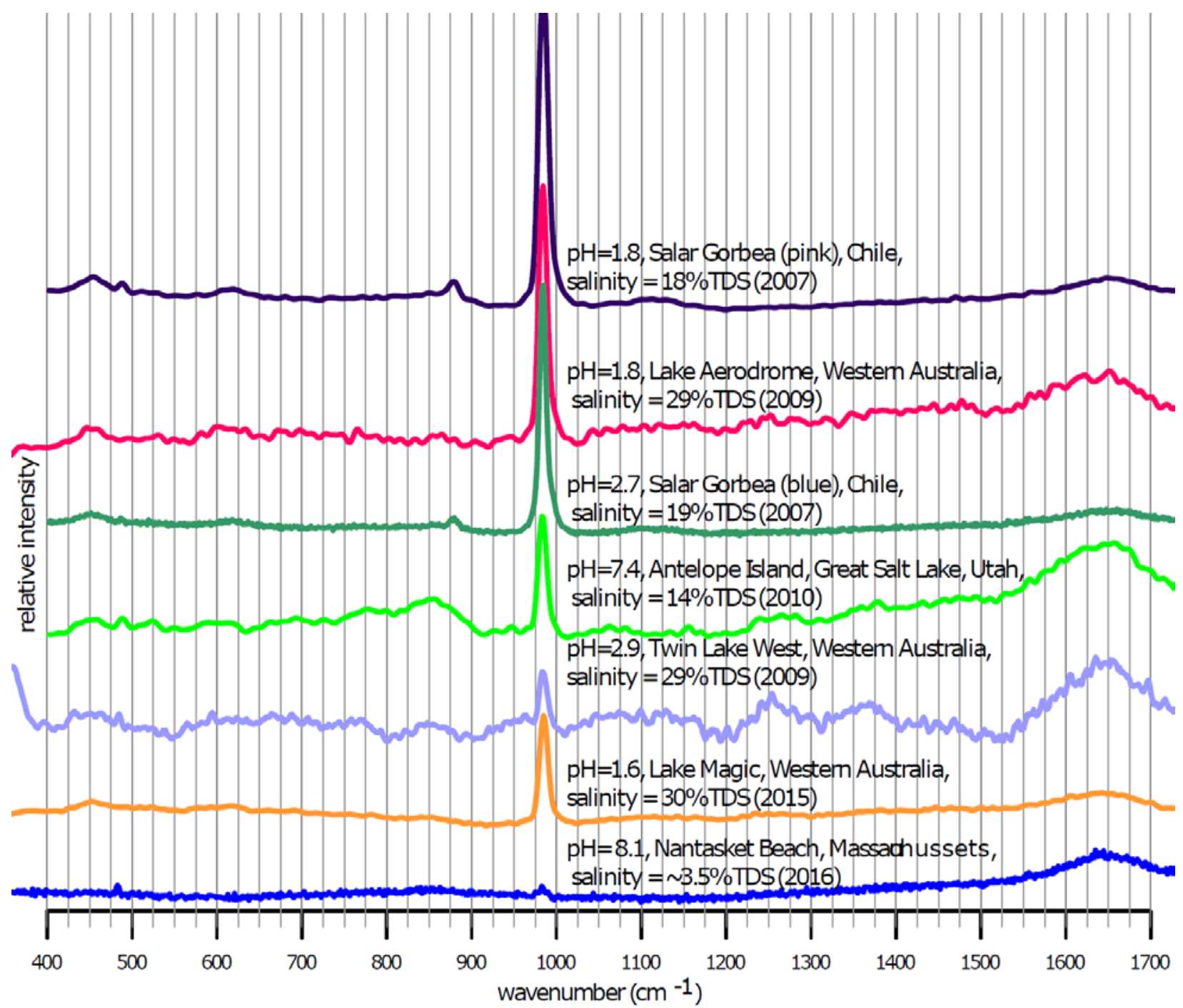

Figure 25. Chart of reference Raman spectra of natural modern waters from locations with varying $\mathrm{pH}$ and salinity. All spectra have sulfate peaks. Samples from Salar Gorbea have peaks at $\sim 880 \mathrm{~cm}^{-1}$. Several spectra collected by Eichenlaub (2016)

\section{Interpretations}

\section{Petrography Interpretations}

\section{Core}

Halite, based on its association with mud and the presence or absence of primary fluid inclusions, was separated into three groupings: bedded, displacive, and interstitial cement. The higher occurrence of red halite in bedded halite indicates bedded halite formed often during oxidizing periods. Bedded halite formed during periods of desiccation in shallow saline waters. 


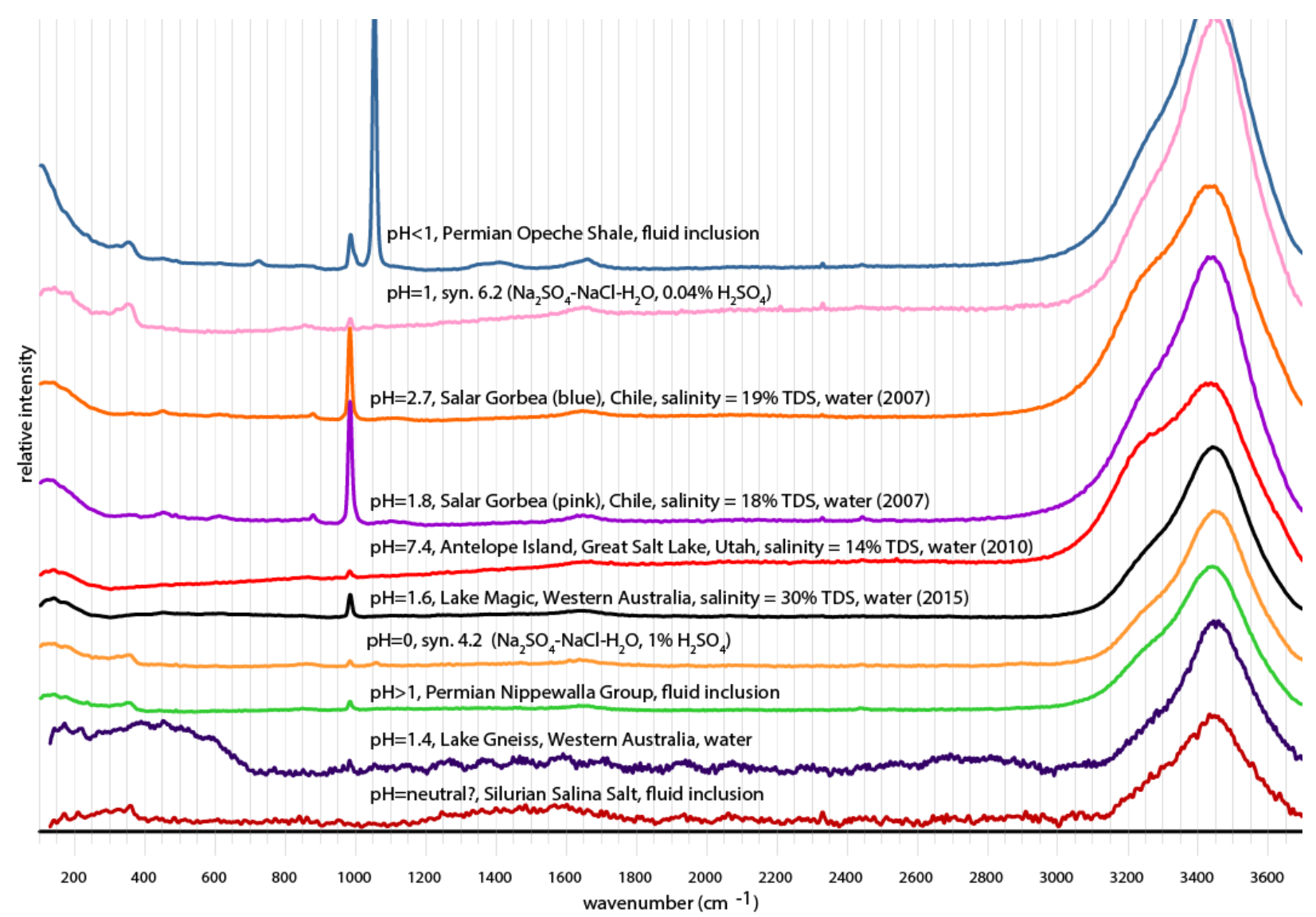

Figure 26. Chart of long Raman scans $\left(100-3700 \mathrm{~cm}^{-1}\right)$ of reference waters and fluid inclusions. Some spectra collected by Eichenlaub (2016). The broad peak at $\sim 3400 \mathrm{~cm}^{-1}$ has been used in other studies to detect bicarbonate, however the change in this peak from bicarbonate is very similar to the change in peak caused by increased salinity (Sun and Qi, 2011).

Clear interstitial cement formed after input of dilute waters into the shallow saline system. This water dissolved some of the bedded halite, creating vugs. The vugs were later filled by the clear halite cement.

Displacive halite formed in the shallow subsurface from saline groundwater. Displacive halite in association with bedded halite indicates periods where crystal growth transitions from being surface water dominated to groundwater dominated. Portions where the volume of displacive halite is greater than the mud it displaced indicate conditions stable enough for large displacive crystal growth. 
The mud's lack of reaction with dilute hydrochloric acid suggests the absence of carbonates. Crystals that are truncated and covered by mud indicate periods of dilute water input with mud. An alternative source of mud is precipitation from parent waters. Mud that drapes crystals shows sediment input (eolian?) with no brine dilution. Changes in mud color within beds reveals changing depositional conditions. Transitions from oxidizing to reducing environment may have occurred to cause changes in mud from red to light greenish gray color change could also be associated with different sources of sediment input or precipitation from waters.

\section{Crystal Types}

Each of the 10 intervals from the Empress $1 \mathrm{~A}$ core has some bedded halite consisting of chevron crystals, only two layers had definitive cumulate crystals. Browne Formation bedded halite was formed by waters that were shallow, $\mathrm{Na}-\mathrm{Cl}-\mathrm{Ca}-\mathrm{SO}_{4}$-rich and underwent both evapoconcentration and flooding. Cumulates can form at any water depth, but chevrons grow in shallow waters (depth of $\sim 0.5$ m or less; Arthurton, 1973). Dissolution surfaces indicate dilute water input. Anhydrite shows this system was saturated with respect to gypsum/anhydrite. Displacive halite crystals indicate saline groundwaters. Interstitial halite indicates saline waters filling vugs.

\section{Fluid Inclusion Petrography}

Petrography shows that primary fluid inclusion assemblages were not altered during deposition. These primary inclusions are still representative of shallow saline surface waters trapped during halite growth. No consistent vapor-liquid ratios are present, inclusions did not lose their negative crystal shape, or appear altered, showing that inclusions were not stretched or deformed. Gas bubbles that are typically found in larger inclusions are likely trapped air or are gases that rose from the subsurface during inclusion growth. The abundant acicular and 
tabular solids in inclusions indicate a parent brine saturated with gypsum/anhydrite.

Several solids were identified in Browne Formation fluid inclusions. Fluorescing solids are identified as suspect organic material including algae, prokaryotes, and organic-sulfate material. Orange red solids are identified as iron oxides (Table 12). Acicular and tabular solids are identified as anhydrite.

\section{Interpretation of Solids, Suspect Microbial Life}

Primary fluid inclusions in bedded halite from the Browne Formation contain several forms of suspect life. Some intervals contain many examples of suspect life (Interval 2, 1520.0 1520.22 m; Fig. 14 and Fig. 15; Interval 4, 1502.6 - 1502.7 m). Other intervals contain only a few examples of suspect life (Interval 9, 1489.75 - 1489.7,Fig. 16; Interval 6, 1502.29 - 1502.25 m, Interval 8, 1498.74 - 1498.62 m; Interval 10. 1480.8 - 1480.7 m).

Small spherule solids were identified in transmitted light and fluoresce blue, yellow, and yellow/green. The colorless to brown globular solids that fluoresce pale yellow (>3 to $10 \mu \mathrm{m}$ ), are similar to Dunaliella algae. The isolated colorless cocci that fluoresce pale blue and are 0.25 to $\sim 1 \mu \mathrm{m}$ in size, are likely prokaryotes. Clumps of brown cocci $(0.25$ to $\sim 1 \mu \mathrm{m})$ that fluoresce pale blue, and occur in inclusions with other solids, are also likely prokaryotes. The small light brown cocci $(\sim 1-2 \mu \mathrm{m})$ that did not fluoresce are also likely prokaryotes. Many fluorescing materials may have biodegraded due to their age. These spherule solids are similar to algae and prokaryotes (Mormile and Storrie-Lombardi, 2012; Conner and Benison, 2013; Benison and Karmanocky, 2014). These observations are similar with microorganisms seen in other deposits, such as prokaryotes, which are seen as 1-3 $\mu \mathrm{m}$ cocci that fluoresce green-blue; and Dunalleila algae, which are seen as 5-10 $\mu \mathrm{m}$ spherules that fluoresce blue (Conner and Benison, 2013). 
Large opaque cubic fluorescing solids located near to primary fluid inclusion bands are seen in several intervals $(100-600 \mu \mathrm{m})$. Portions of these opaque inclusions fluoresce an electric blue under UV illumination (Fig. 17). These resemble solids identified as remnants of algal mats as seen in halite samples from Western Australia (Benison et al., 2008).

Suspect life, resembling acritarchs, are only present in one interval (Interval 10; 1480.8 $1480.7 \mathrm{~m}$ ). These unusual solids have border defined by opaque red (iron oxide?) material (Fig. 18). These solids ranged from $200-400 \mu \mathrm{m}$ in size and are roughly triangular, one with rough spiky borders, the other with a globular rounded shape. They were identified as suspect acritarchs. Kath Grey identified degraded acritarchs in samples from the Brown Formation (Stevens and Apak, 1999). Experts offered mixed opinions whether these solids are fossils or are from another source. Reed Wicander (palynologist, Central Michigan University) believes that these may be lifeforms. Wicander indicated that the angular spiky triangular solid could be a mat-building blue-green algae. The globular triangular solid could be a palynomorph with a thick cell wall, but may also be an inclusion (Reed Wicander, personal communication). Franca Oboh-Ikuenobe (palynologist, Missouri S\&T) believes these are not acritarchs (personal communication). Paul Strother (cryptospore specialist, Boston College) believes that these are not microfossils and may be an organic matter coating or "speared in-between mineral grains" (personal communication). Therefore, they are considered suspect microorganisms.

The Lancer 1 core, located $\sim 200 \mathrm{~km}$ northwest, intersects the Buldya Group and the Browne Formation. The Kanpa Group in the Lancer 1 core has megascopic alga Chuaria sps, which consists of dark carbonaceous disks (Haines et al, 2004). This indicates that (in addition to stromatolites) life was present in this region during the deposition of the Browne Formation and adjacent deposits (Haines et al., 2004). 
Table 12. Identification of solids found in fluid inclusions and halite.

\begin{tabular}{|c|c|c|}
\hline $\begin{array}{l}\text { distinct solid } \\
\text { type }\end{array}$ & $\begin{array}{l}\text { interpretation (rationale and } \\
\text { references) }\end{array}$ & $\begin{array}{l}\text { image (additional images show new features } \\
\text { or illumination in UV) }\end{array}$ \\
\hline globular solid & $\begin{array}{l}\text { Dunaliella algae(?) (size, fluorescence } \\
\text { color; Mormile and Storrie-Lombardi, } \\
\text { 2012; Conner and Benison, 2013; } \\
\text { Benison and Karmanocky, 2014) }\end{array}$ & \\
\hline small cocci & $\begin{array}{l}\text { prokaryotes (size, fluorescence color; } \\
\text { Conner and Benison, 2013) }\end{array}$ & \\
\hline $\begin{array}{l}\text { opaque cubic } \\
\text { solid } \\
\text { inclusion }\end{array}$ & $\begin{array}{l}\text { suspect organic-sulfate material, hairy } \\
\text { blobs (Shape, size, fluorescence, } \\
\text { Benison et al., 2008) }\end{array}$ & \\
\hline $\begin{array}{l}\text { subrounded } \\
\text { orange-red } \\
\text { solids }\end{array}$ & $\begin{array}{l}\text { iron oxide (based upon color, likely } \\
\text { composition) or suspect carotenoids } \\
\text { (similarity with those seen in core from } \\
\text { Death Valley; Winters et al.,2013) }\end{array}$ & \\
\hline $\begin{array}{l}\text { red angular } \\
\text { solid }\end{array}$ & $\begin{array}{l}\text { iron oxide (based upon color, crystal } \\
\text { shape, and likely composition) }\end{array}$ & \\
\hline acicular solid & $\begin{array}{l}\text { anhydrite (based upon optical } \\
\text { properties and Raman spectra) }\end{array}$ & \\
\hline $\begin{array}{l}\text { tabular to } \\
\text { tabular } \\
\text { striated sold }\end{array}$ & $\begin{array}{l}\text { anhydrite (based upon optical } \\
\text { properties and Raman spectra) }\end{array}$ & \\
\hline
\end{tabular}




\section{Petrographic Interpretation of Sampling Intervals}

Interval 2 (1520.22-1520.0 m)

The mud layers in Interval $2(1520.22-1520.0 \mathrm{~m})$ may have contributed to the preservation of the primary fabric in the halite. Chevron halite here indicates deposition in shallow saline waters. Bedded halite is truncated by horizontal mud layers. This indicates that crystals may have dissolved when dilute waters carrying mud entered the system.

Many fluid inclusions from this interval have solids. These solids are not consistent in their size or presence across inclusions, so they are likely accidental daughter crystals that existed in water prior to being trapped in fluid inclusions. The globular solids that fluoresce yellow may be organic. Their presence with accidental anhydrite daughter crystals in inclusions shows these solids were in suspension and trapped during halite formation.

\section{Interval 3 (1511.76-1511.7 m)}

The massive halite in Interval $3(1511.76-1511.7 \mathrm{~m})$ is largely, but not completely, recrystallized. There are area with small primary fluid inclusions, indicating bedded halite. This

interval was deposited as bedded halite, partially dissolved and replaced by interstitial halite and possibly displacive halite. The small isolated mud lenses indicate a period of little detrital input. The reddish yellow color likely comes from iron.

\section{Interval 4 (1502.7 - $1502.6 \mathrm{~m})$}

The crystalline appearance of the lowest mud layer in Interval 4 (1502.7 - $1502.6 \mathrm{~m})$ indicates that this mud may contain halite and other evaporites. This interval consists of wellpreserved bedded halite with chevrons and cumulates. This interval was deposited in shallow saline waters. The cubic and acicular daughter crystals (likely accidental due to their uneven distribution across inclusions) likely share the same composition as they are optically similar. 
The subrounded angular grains in a sample from zone B (sample E.4.B.1.P) are likely detrital halite given their optical similarity to halite. This suggests areas of surface exposure of halite as well as available surface exposure to round and abrade halite crystals. The red "spine" in this sample is likely a hematite mud(?) that became a nucleation spot for the acicular to tabular anhydrite crystals before the area returned to halite deposition.

Interval 5 (1502.25 - $1502.2 \mathrm{~m})$

Interval 5 (1502.25 - $1502.2 \mathrm{~m}$ ) has bedded halite with chevrons formed by surface water. This interval was deposited in shallow saline waters. A slow growth rate is interpreted from the small fluid inclusion size in chevrons. The part of this interval consisting of displacive halite suggests saline mudflat deposition.

Interval $6(1502.29-1502.25 \mathrm{~m})$

Interval 6 (1502.29 - $1502.25 \mathrm{~m})$ consists of bedded halite interfiled with mud layers. This interval was deposited in shallow waters with intermittent siliciclastic sediment input. The small, likely accidental, daughter crystals indicate deposition in a brine saturated with anhydrite. The vapor bubbles in large inclusions indicate deposition at the air-water interface, where bubbles were trapped by growing halite.

Interval 7 (1499.42 - 1499.3 m)

The lower part (zone B) of Interval 7 (1499.42 - 1499.3 m) contains partial dissolution, possibly associated with a pulse of sediment holding dilute water. This lower part has mud in both layers and deposited within the halite, indicating a period of both sediment input and halite deposition. The sharp transition to red halite shows the removal of mud from waters while leaving iron (in suspension?). This upper layer bedded halite with chevrons indicates this interval was deposited in shallow saline waters. Chevrons had had a lower growth rate, given their small inclusions. Vapor in large inclusions suggest crystal growth at the air-water interface. 


\section{Interval 8 (1498.74-1498.62 m)}

Interval 8 (1498.74 - $1498.62 \mathrm{~m})$ has little mud, but the bedded halite has several color transitions. This interval was deposited in shallow saline waters. This suggests changes in water chemistry during deposition of sediment. The dusky red halite had few inclusions, indicating a period of slow deposition, or recrystallization. The upper and lower part (Zones A and C) have bedded chevron halite, indicating shallow saline waters. Finally, the mud interval had blocky halite and mud, indicating mud deposition after or with crystal formation. The solids in primary inclusions from zone A indicate deposition in a brine with anhydrite crystals in solution. Vapor bubbles seen only in primary inclusions indicate deposition at the air-water interface.

\section{Interval 9 (1489.75-1489.7 m)}

Interval 9 (1489.75 - $1489.7 \mathrm{~m})$ transitions from periods of halite deposition with high mud input to periods of little mud input and halite deposition. The lower part of the core (zone C) consists of bedded halite consisting of chevrons, indicating deposition in shallow saline surface waters. The mud layer between the lower and middle bedded halite indicates siliciclastic input or precipitation from waters. The middle layer consists of bedded halite with fluid inclusions containing abundant solids, such as anhydrite and suspect microbes; this increased frequency of solids possibly indicates changes to the parent brine. The uppermost part of bedded halite (Zone A) was deposited in a period of little mud input, but parent water from the period still had anhydrite crystals in suspension. The vapor bubbles in large primary inclusions from this interval indicate deposition at the air-water interface.

\section{Interval $10(1480.8-1480.7 \mathrm{~m})$}

Interval $10(1480.8-1480.7 \mathrm{~m})$ represents a period of evaporite deposition with bedded gypsum and cumulate halite with small periods of mud/hematite input in the lower part. This interval transitions to bedded chevron halite, indicating deposition in shallow saline surface 
waters. Primary fluid inclusions are rare in the upper part of this interval, indicating partial dissolution of bedded halite and emplacement of clear halite cement.

The presence of red crystalline solids in fluid inclusions indicates that parent water contained and possibly precipitated iron oxides. There was also input of quartz, this may be eolian in origin. The blue fluorescing opaque solids in a fracture may be an organic compound that moved through this system during oil migration. The crystals in the upper zones of halite may have grown at a slow rate, given the small size of their primary inclusions.

\section{Interval $1297(1297.08-1297.0 \mathrm{~m})$}

Interval 1297 (1297.08 - $1297.0 \mathrm{~m}$ ) largely consists of displacive halite with some mud. This indicates halite deposition in the shallow subsurface. This bottom of this interval contains a small layer of bedded halite with primary fluid inclusions. This indicates a period of shallow surface waters. Some mud appears to have halite inclusions that differ from the displacive halite, indicating possible pseudomorphs or partial dissolution of salt. The majority of fluid inclusions in the bedded halite do not contain any solids, indicating few solids in parent waters during halite growth.

\section{Freezing-Melting Microthermometry Interpretations}

Despite prolonged periods at low temperatures, no fluid inclusions froze from any of the three samples in the Empress 1A core (E.4.Z, and E.1297.Z). Spear (2014) indicates that Empress inclusions contain more calcium than present-day marine inclusions. Lowenstein and Bodnar (personal communication; Vanko et al., 1998) indicate that inclusions with high calcium concentrations may be difficult to freeze. Other studies indicate that this inability to freeze may be related to low pH and/or high salinity (Benison, 2013). 


\section{Laser Raman Spectroscopy Data Interpretation}

Identification of the molecular source of all Raman peaks was attempted. To constrain $\mathrm{pH}$, Raman peaks were compared with Table 13, a compilation of substances known to exist within certain pH ranges (Benison et al., 1998; Frezzotti et al., 2012). For example, the solids alunite and jarosite, and the solute bisulfate, are only stable at low pH.

Table 13: Compounds (and their associated Raman peaks) used to determine pH. Note peak strength abbreviations: $s$ = sharp, vS = very sharp, ws = weak sharp, vws = very weak sharp.

\begin{tabular}{|c|c|c|c|c|}
\hline compound & spectra peaks $\left(\mathrm{cm}^{-1}\right)$ & $\begin{array}{l}\text { observed in } \\
\text { the Browne } \\
\text { Formation? }\end{array}$ & associated pH & reference(s) \\
\hline bicarbonate $\left(\mathrm{HCO}_{3}\right)$ & 1017(vs), $1360(\mathrm{~b})$ & no & 6 to 10 & (Frezzotti et al., 2012) \\
\hline calcite $\left(\mathrm{CaCO}_{3}\right)$ & $\begin{array}{l}\text { 156(s), 284(s), 711(s), } \\
1085(\mathrm{vS}), 1435(\mathrm{vws})\end{array}$ & no & $>6$ & (Frezzotti et al., 2012) \\
\hline $\begin{array}{l}\text { acid metal sulfates } \\
\text { (alunite) }\end{array}$ & $\begin{array}{l}200(\text { ws), 235(s),248 } \\
373,389481,489, \\
505,563608,644, \\
644,773,961,989, \\
9991014,1026,1049, \\
1051,1083,1194 \\
1228\end{array}$ & no & $<2$ to 4 & $\begin{array}{l}\text { (Frost and Wills, 2006; } \\
\text { Jagniecki and Benison, } \\
\text { 2010) }\end{array}$ \\
\hline sulfate $\left(\mathrm{SO}_{4}^{2}\right)$ & 620,986 & no & $\begin{array}{l}\text { not } \mathrm{pH} \\
\text { dependent }\end{array}$ & (Benison et al., 1998) \\
\hline bisulfate $\left(\mathrm{HSO}_{4}^{-1}\right)$ & $\begin{array}{l}422,586,890,1053, \\
1202\end{array}$ & no & $<1$ & (Benison et al., 1998) \\
\hline
\end{tabular}

Spectra of solids were compared with a database of mineral Raman spectra likely to exist in an ephemeral saline lake (most minerals on Table 2; Appendix III; Armbruster and Micaela Danisi, 2015). Solids used for this database have at least two forms of mineral identification, such as X-ray diffraction, chemical analysis, and confirmed chemical composition with electron microprobe. Mineral database spectra were made with $532 \mathrm{~nm}$ lasers, if possible. This eliminated differences that may have made spectra more difficult to interpret (Fig. 28). Spectra were compared with published articles. Raman spectra reference samples were also used the characterize spectra collected from the Browne Formation. 
Interpreting Raman spectra of complex natural waters can be challenging. Figure 27 demonstrates a range of observed spectra from Browne Formation samples. Even if the compound producing a spectrum cannot be definitively identified, its spectra may be correlated with functional groups. For example, $\mathrm{H}_{2} \mathrm{O}$ has broad peaks centered around $\sim 1640$ and $\sim 3400$ $\mathrm{cm}^{-1}$ (Auer and Skinner, 2008). The broad peak at $\sim 3400$ is associated with the OH functional group. The wavenumber here is so high due to the small mass of the hydrogen atom. This peak is broad because of the interactions occurring during hydrogen bonding. The broad peak at $-1640 \mathrm{~cm}^{-1}$ is lower because of the heavier oxygen atom in this spectra relating to the $\mathrm{HOH}$ bend. If $\sim 3400 \mathrm{~cm}^{-1}$ peak is present, but not the $\sim 1640$ peak, then the scanned compound may have an $\mathrm{OH}$ group, but not an $\mathrm{HOH}$ functional group. Similarly, if the $\mathrm{OH}$ group bonds with a metal ion, such as gibbsite $\left[\mathrm{Al}(\mathrm{OH})_{3}\right]$ the bending mode(s) will be observed at a lower frequency $\left(\sim 924 \mathrm{~cm}^{-1}\right)$ than in $\mathrm{H}_{2} \mathrm{O}$ (Ruan et al., 2001). OH has stretching vibrational peaks $<600 \mathrm{~cm}^{-1}$. In $\mathrm{H}_{2} \mathrm{O}$ these peaks are at $\sim 162$ and $\sim 430 \mathrm{~cm}^{-1}$ (Frezzotti et al., 2012).

Raman spectra of solids and solutes differ. Raman spectra of minerals have sharp peaks corresponding exactly to specific bonds in the mineral. Spectra of unordered solids, including many organic molecules have broader peaks. Raman peaks for covalent bonds in aqueous phases can shift in wavenumber slightly due to the influence of other ions in solution. Substance in aqueous phases tend to have broad peaks because of how they interact with water's hydrogen bonds. 


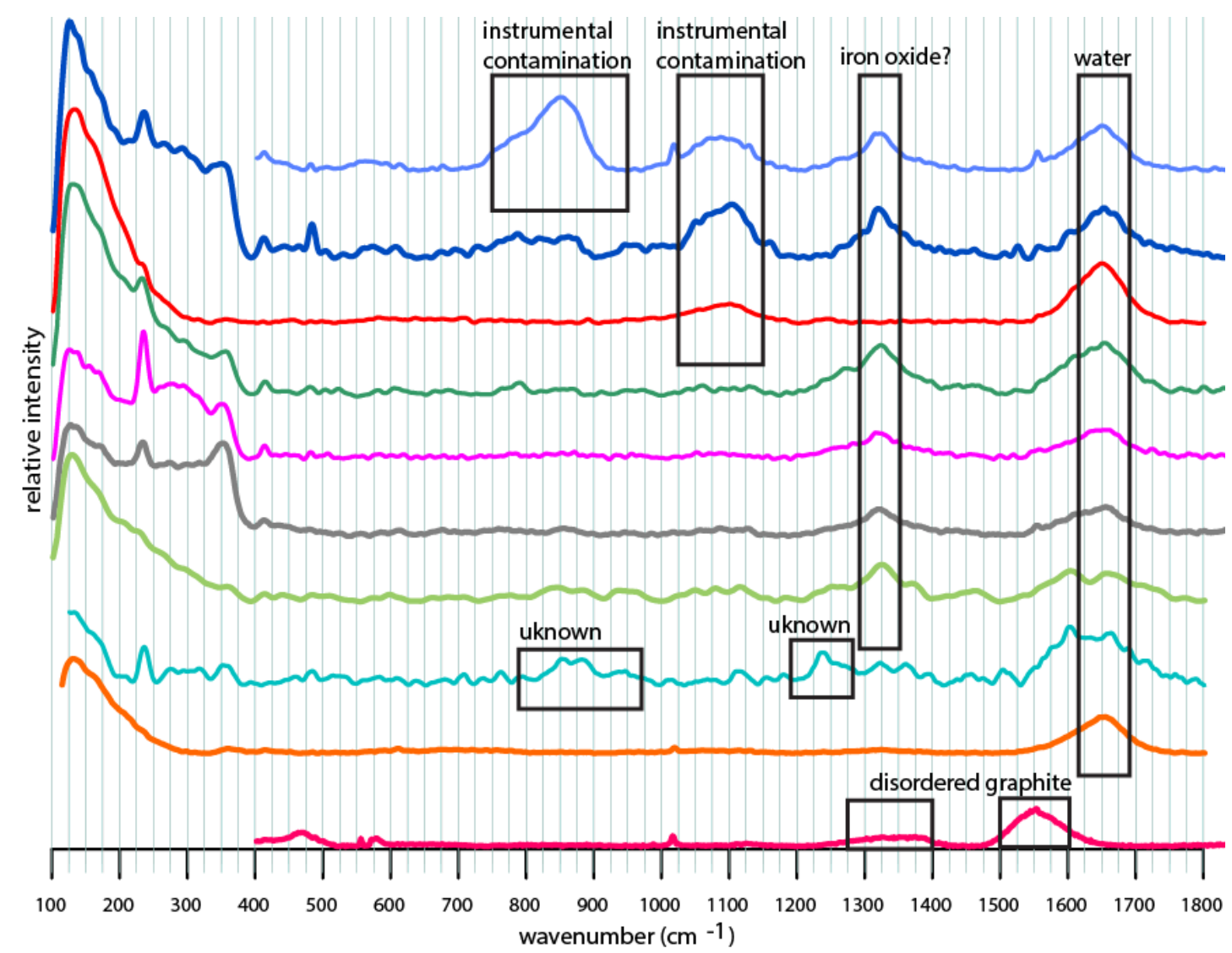

Figure 27. Figure of diversity of Raman spectra collected from Browne Formation halite samples. Spectra (from top to bottom) are from samples E.8.A.2; E.8.A.2.P; E.1297.Z.1.P; E.6.A.2.P; E.8.A.2.P; E.4.D.1.P; E.9.B.1.P; E.3.B.1.P; E.4.Z.1.P; and E.4.Z.1.P.

Data was interpreted using the following process

1. Find unique peaks and confirm that they are not noise by comparing their presence (or lack thereof) with other spectra from the Empress core, background spectra (Table 14), and reference samples.

2. Determine if peaks are likely from a solid or solute.

3. Compare peaks with mineral database, see if they are a good match.

4. If not a good match with one of documented minerals, do a search through collected reference papers.

5. If still no match, enter data (either full spectra, or a clipped part) into interpretative peakmatching software, if decent match, use this to find potential functional groups affecting spectra occurring here.

6. Do a search of reference databases, considering more likely, simpler chemistries associated with evaporates and simple carbon compounds. 
7. Identify suspect functional groups in unidentified spectral peaks.

The process outlined above was used to find peaks in spectra. This process ensured analysis was robust and the source of Raman peaks was from the target area, and not from equipment or background spectra in the host material. Table 15, Table 16, and Table 17 have interpretations of spectra from Empress $1 \mathrm{~A}$ inclusions.

Fig. 28. Chart of Raman spectra from the anhydrite and jarosite collected at different laser frequencies. Changing frequency affects the height and presence of peaks in Raman spectra. The upper three spectra were collected from the same anhydrite sample at laser frequencies 514, 532, and $780 \mathrm{~nm}$. Small peaks differ markedly between spectra. The lower two spectra of jarosite, collected at laser frequencies 532 and $780 \mathrm{~nm}$, demonstrate variation between laser frequencies and collected spectra.

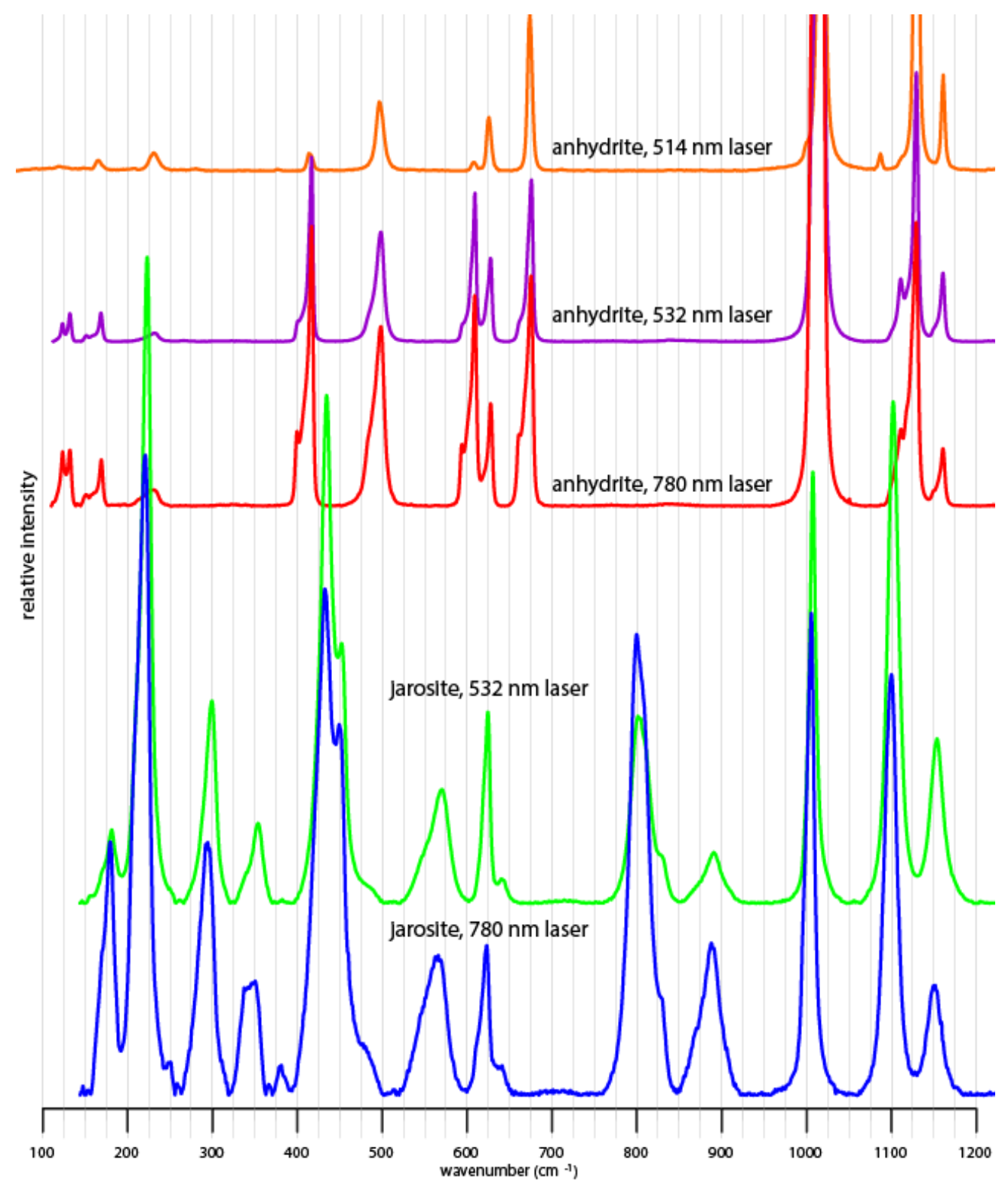


Table 14. Interpretation of background spectra. Peak strength abbreviations: $s=$ sharp, ws = weak sharp, $b=$ broad, $B=$ very broad.

\begin{tabular}{|c|c|c|}
\hline scan name & comments & peaks and interpretation $\left(\mathrm{cm}^{-1}\right)$ \\
\hline $\begin{array}{l}\text { E.7.Z.2.P.A.7.4_HALITE } \\
\text { NEAR IT }\end{array}$ & $\begin{array}{l}\text { unknown - may be related to iron oxide, } \\
\text { peaks similar to to those of ochre } \\
\text { (anhydrous iron(III)-oxide; iron oxide } \\
{\left[\mathrm{Fe}_{2} \mathrm{O}_{3}\right] \text { along with clay and other varied }} \\
\text { natural minerals). }\end{array}$ & $\begin{array}{l}431(\mathrm{~s}), 460,482,503,615(\mathrm{~s}) \\
\text { red ochre?, 670, 833, 859, 892, } \\
\text { 1017, 1041(ws), 1116, 1326(B) } \\
\text { red ochre?, 1463, 1558, 2329, } \\
2941,3429\end{array}$ \\
\hline \multicolumn{3}{|c|}{$\begin{array}{l}\text { Spectra } \\
\text { E.7.Z.2.P.A.7.4_HALITE (in } \\
\text { black) compared with } \\
\text { reference spectra of red } \\
\text { ochre, } \mathrm{Fe}_{2} \mathrm{O}_{3} \text { (in red) }\end{array}$} \\
\hline \multicolumn{3}{|c|}{$1 \quad \frac{1}{1600}$} \\
\hline E.8.A.2.P.E.2.1_HALITE & $\begin{array}{l}\text { 861(B) alfwillite? -consistent with COS, } \\
\text { or borates/phyllosilicates, peak at } \\
1328(B) \text { indicative of carbon }\end{array}$ & $\begin{array}{l}\text { 236(s), 298(ws), 355(s), } \\
\text { 413(ws), 483(ws), 861(B), } \\
\text { 1055(b), 1328(B), 2331(vS), } \\
\text { 2432(B), 3190(B) 3454(B) }\end{array}$ \\
\hline $\begin{array}{l}\text { E.8.A.2.P.X.2.1 (HALITE } \\
\text { NEAR IT) no diaphragm }\end{array}$ & glass and halite spectra & $\begin{array}{l}\text { 295, 483, 571(wb), 851, 1091, } \\
\text { 1555, } 3289 \text { (shoulder), } 3449\end{array}$ \\
\hline $\begin{array}{l}\text { E.8.A.2.P.X.2.1 (HALITE } \\
\text { NEAR IT) }\end{array}$ & halite & $\begin{array}{l}\text { 533(vwb), 838(vB), 1072(B), } \\
\text { 1549(wB?), 2433(B) }\end{array}$ \\
\hline E.9.A.1.P.A.3.1_HALITE & $\mathrm{n} / \mathrm{a}$ & $\begin{array}{l}\text { 238(vS), 274(B), 354(b), } \\
\text { 427(wb?), 482(vs), 850(B?), } \\
\text { 1019(S), 1558(s), 3406, 3494 }\end{array}$ \\
\hline $\begin{array}{l}\text { Mercia ISME_A.3.1_ } \\
\text { Halite }\end{array}$ & n/ae & $\begin{array}{l}127,278,352,484,1077,1555, \\
2442,3413\end{array}$ \\
\hline glass scan, no diaphragm & $\begin{array}{l}\text { glass, very good match for many peaks, } \\
\text { peaks beyond } 1100 \mathrm{~cm}^{-1} \text { do not have an } \\
\text { assignment as to what they are from. }\end{array}$ & $\begin{array}{l}\text { 478(ws), 561(B), 775(wb), } \\
\text { 993(ws), 1024(vws), 1099(B), } \\
\text { 1508(ws), 1710(ws), 2424(B), } \\
\text { 2519(B), 2644(wB), 2860(ws), } \\
\text { 3311(B), 3998(B?) }\end{array}$ \\
\hline \multirow[t]{2}{*}{$\begin{array}{l}\text { Glass scan (in black) } \\
\text { Raman spectra } \\
\text { compared with } \\
\text { reference spectra of } \\
\text { glass (in red) }\end{array}$} & \begin{tabular}{r|l}
$10000-$ & - RTX\#134; Glass \\
- & - glass scan_no diapragm_JULY16_532nm40x100intensi...
\end{tabular} & \\
\hline & 4000 & $\begin{array}{c}1 \\
1500 \\
\end{array}$ \\
\hline
\end{tabular}


Table 15. Interpretation of Raman peaks from contents of fluid inclusions from 237 to $993 \mathrm{~cm}^{-1}$. Peak strength abbreviations: $s=$ sharp, ws = weak sharp, $b=$ broad, $B=$ very broad.

\begin{tabular}{|c|c|c|}
\hline $\operatorname{peak}(\mathrm{s})\left(\mathrm{cm}^{-1}\right)$ & $\begin{array}{l}\text { suspect source: } \\
\text { liquid, vapor, } \\
\text { solid, unknown }\end{array}$ & interpretation \\
\hline$\sim 237(s)$ & unknown & $\begin{array}{l}\text { unknown - May relate to alunite, possibly anhydrite, solids } \\
\text { containing } \mathrm{Ca}, \mathrm{Mg} \text { or } \mathrm{SiO}_{2} \text { (enstatite?) or other (Frezzotti et al., } \\
\text { 2012). This peak is strongly present in spectra of Empress halite) }\end{array}$ \\
\hline 298(ws) & unknown & unknown \\
\hline$\sim 355$ & solid & halite (Frezzotti et al., 2012) \\
\hline$\sim 413(\mathrm{ws})$ & unknown & unknown \\
\hline $\begin{array}{l}\sim 470(B) \text { or } \\
472(s)\end{array}$ & solid? & $\begin{array}{l}\text { unknown - May relate to alunogen, kaolinite, quartz, 465, many } \\
\text { hydrated sulfates have strong peaks near here. Peek seen } \\
\text { (strong 472) in solids in fluid inclusions from Western Australia } \\
\text { (Jagniecki and Benison, 2010). }\end{array}$ \\
\hline$\sim 484(S)$ & equipment? & $\begin{array}{l}\text { unknown - Present in reference spectra from natural and } \\
\text { synthetic waters and inclusions (Mercia ISME, Syn. 4.2, 8, 5, 9, } \\
\text { 6; Nippewalla, Opeche, and Mormon point, not seen in spectra } \\
\text { from Mercia). Seen as a } 490 \mathrm{~cm}^{-1} \text { peak in spectra collected by } \\
\text { Eichenlaub (2016). }\end{array}$ \\
\hline$\sim 557(\mathrm{~S})$ & solid? & $\begin{array}{l}\text { unknown - may share a functional group with ammonium alunite } \\
\text { (560), seen in reference spectra (Opeche, Western Australia acid } \\
\text { sulfates, and Synthetic 5) }\end{array}$ \\
\hline$\sim 581(b)$ & unknown & unknown \\
\hline$\sim 705(s)$ & unknown & unknown \\
\hline$\sim 708,890,1180$ & liquid? unknown & $\begin{array}{l}\text { unknown - group of peaks seen in same spectra, not anhydrite } \\
\text { (890 } \mathrm{cm}^{-1} \text { is not a bisulfate peak, peaks at } 986 \text { and } 1054 \mathrm{~cm}^{-1} \text { are } \\
\text { absent). }\end{array}$ \\
\hline$\sim 735$ (ws) & unknown & unknown \\
\hline$\sim 794$ & unknown & unknown \\
\hline$\sim 845(s)$ & unknown & $\begin{array}{l}\text { unknown/uncertain - may be a cosmic ray, given its rarity and } \\
\text { lack of correlation with mineral and water references }\end{array}$ \\
\hline$\sim 861(B)$ & solid? unknown & $\begin{array}{l}\text { uncertain - carbonyl sulfite or borates/phyllosilicates, may have } \\
\text { similar functional groups to alfwillite }\end{array}$ \\
\hline -870 or 875 & unknown, solid? & $\begin{array}{l}\text { unknown - similar to aluminum sulfate }\left(872 \mathrm{~cm}^{-1}\right) \text { or rostite? (874 } \\
\left.\mathrm{cm}^{-1}\right)\end{array}$ \\
\hline$\sim 888(w B), 890$ & unknown, solid? & unknown - possibly clay, nontronite \\
\hline$\sim 930$ & unknown & unknown - seen in syn 5, and E.7 and other intervals. \\
\hline$\sim 993(S)$ & unknown, solid? & $\begin{array}{l}\text { unknown - may be from glass, may share functional group with } \\
\text { aluminite }\left(993 \mathrm{~cm}^{-1}\right) \text {, likely not sulfate- scan not from waters, also } \\
\text { sulfate peaks not seen in any spectra from any interval }\end{array}$ \\
\hline
\end{tabular}


Table 16. Interpretation of Raman spectra from 1018 to $1555 \mathrm{~cm}^{-1}$. Peak strength abbreviations: $\mathrm{s}=$ sharp, ws = weak sharp, $b=$ broad, $B=$ very broad.

\begin{tabular}{|c|c|c|}
\hline $\operatorname{peak}(\mathrm{s})\left(\mathrm{cm}^{-1}\right)$ & $\begin{array}{l}\text { suspect source: } \\
\text { liquid, vapor, } \\
\text { solid, unknown }\end{array}$ & interpretation \\
\hline $\begin{array}{l}\text { 120(ws), } 130(w s) 230(w b) \\
420(w s), 500(s), 611(s) \\
629(w s), 676(s), 860(v w b) \\
1005(s), 1018(v S), 1080(v w b) \\
1115(s), 1131(s), 1161(s)\end{array}$ & solid & $\begin{array}{l}\text { anhydrite - distinctive peaks, in several spectra } \\
\text { weak anhydrite peaks are seen, but the strong } \\
\text { peaks }\left(1018 \mathrm{~cm}^{-1}\right) \text { are not, may be a solid related to } \\
\text { anhydrite }\end{array}$ \\
\hline -1087(ws) & unknown & unknown \\
\hline $\begin{array}{l}\text { 478(ws), 561(B), 775(wb), } \\
\text { 993(ws), 1024(vws), 1099(B) }\end{array}$ & $\begin{array}{l}\text { solid, } \\
\text { background }\end{array}$ & $\begin{array}{l}\text { glass - from instrumentation (determination made by } \\
\text { scanning glass and comparing spectra with a } \\
\text { reference library) }\end{array}$ \\
\hline$\sim 1099(B)$ or $1100(B)$ & unknown & $\begin{array}{l}\text { unknown - broad peaks not seen with glass } \\
\text { contamination, no known correlation }\end{array}$ \\
\hline$\sim 1111,1180$ & unknown & unknown \\
\hline -1116(s) & unknown, solid? & $\begin{array}{l}\text { unknown - associated with anhydrite }\left(1115 \mathrm{~cm}^{-1}\right) \text {, } \\
\text { but other peaks not seen }\end{array}$ \\
\hline$\sim 1182$ & unknown & unknown \\
\hline 1237(wb), 1240, or $1254(b)$ & unknown & $\begin{array}{l}\text { unknown - may share functional group with k-alunite } \\
\left(1237 \mathrm{~cm}^{-1}\right) \text {, present in spectra from synthetic } \\
\text { references }\end{array}$ \\
\hline $\begin{array}{l}\text { 2953(wsB), 1016(ws), } \\
\text { 1272(wB), 1377(wB), }\end{array}$ & unknown & $\begin{array}{l}\text { unknown - may be a combination of unrelated peaks } \\
\text { seen in a spectrum (from E.2.E.1.P.B.9.2, a noisy } \\
\text { spectrum, so may not be significant) }\end{array}$ \\
\hline 1326(B), 431(s), 615(s) & unknown, solid? & $\begin{array}{l}\text { unknown - may relate to iron oxide, peaks like those } \\
\text { of ochre (ochre - inorganic; anhydrous iron(iii)-oxide; } \\
\text { ferric oxide; iron oxide }\left[\mathrm{Fe}_{2} \mathrm{O}_{3}\right] \text { along with clay and } \\
\text { other varied natural minerals. May be calcined } \\
\text { natural yellow oxide - hydrous iron oxide) }\end{array}$ \\
\hline$\sim 1326(B)$, or $1321(B)$ & unknown, solid? & unknown - possibly carbon (disordered graphite) \\
\hline$\sim 1375(B)$ & unknown, solid & unknown - possibly carbon (disordered graphite) \\
\hline 1380(B) and 1550(B) & uncertain & $\begin{array}{l}\text { uncertain - possibly disordered graphite, } \\
\text { amorphous carbon/diamond films (1380 and } 1550 \\
\mathrm{~cm}^{-1} \text { ) are a decent match (Wagner et al., 1989; } \\
\text { Jawhari et al., 1995). May be contamination from } \\
\text { other device users. }\end{array}$ \\
\hline$\sim 1464(s)$ & uncertain, solid? & $\begin{array}{l}\text { unknown - may share functional group with } \\
\text { aragonite }\left(1460 \mathrm{~cm}^{-1}\right) \text {, or a carbon-nitrogen bond }\end{array}$ \\
\hline$\sim 1527$ (ws) & unknown & unknown \\
\hline$\sim 1555$ & gas & oxygen gas (Frezzotti et al., 2012) \\
\hline
\end{tabular}


Table 17. Interpretation of Raman peaks from 1604 to $3070 \mathrm{~cm}^{-1}$. Peak strength abbreviations: $s=$ sharp, ws $=$ weak sharp, $b=$ broad, $B=$ very broad.

\begin{tabular}{|c|c|c|}
\hline $\operatorname{peak}(\mathrm{s})\left(\mathrm{cm}^{-1}\right)$ & $\begin{array}{l}\text { suspect source: } \\
\text { liquid, vapor, solid, } \\
\text { unknown }\end{array}$ & interpretation \\
\hline $\begin{array}{l}\text { 1604(s) or } 1600(b) \\
\text { or } 1605(B)\end{array}$ & $\begin{array}{l}\text { unknown, disordered } \\
\text { graphite? }\end{array}$ & $\begin{array}{l}\text { unknown - broad peak seen both with and without water } \\
\text { peak near } 1650 \mathrm{~cm}^{-1} \text {, disordered graphite? }\end{array}$ \\
\hline $\begin{array}{l}\sim 162,430,1581 \\
1630,2750-3900\end{array}$ & liquid & $\begin{array}{l}\text { water - several minor peaks that are components of } \\
\text { larger peaks are not listed here }\end{array}$ \\
\hline$\sim 1800$ & unknown & unknown \\
\hline$\sim 2331$ & gas & $\begin{array}{l}\text { nitrogen gas - also seen when scanning solids, likely } \\
\text { from atmosphere and not from inclusions }\end{array}$ \\
\hline $\begin{array}{l}\text { 21508(ws), 1710(ws), } \\
\text { 2424(B), 519(B), } \\
\text { 2644(wB), 2860(ws), } \\
\text { 3311(B), 3998(B?) }\end{array}$ & $\begin{array}{l}\text { instrumentation, } \\
\text { solid? }\end{array}$ & $\begin{array}{l}\text { unknown from instrumentation - currently not contributed } \\
\text { to glass, seen in spectra of surface of glass slide. }\end{array}$ \\
\hline$\sim 2424(\mathrm{~B})$ & unknown, solid? & $\begin{array}{l}\text { unknown - thiol/graphene peaks are in this area, but are } \\
\text { not good matches, possible background peak from } \\
\text { instrumentation. Seen in samples with and without } \\
\text { contamination from instrumentation. From something } \\
\text { other than glass? }\end{array}$ \\
\hline$\sim 2930(B)$ & $\begin{array}{l}\text { unknown, } \\
\text { background/ } \\
\text { equipment? }\end{array}$ & $\begin{array}{l}\text { unknown - rarely present in sharp spectra. From a } \\
\text { background source? May share functional group with } \\
\text { gaylussite }\left(2930 \mathrm{~cm}^{-1}\right) \text {, methane }\left(2917 \text { and } 3020 \mathrm{~cm}^{-1}\right) \\
\text { or ethane }\left(2954 \mathrm{~cm}^{-1}\right) \text {. }\end{array}$ \\
\hline$\sim 3070(\mathrm{~s})$ & unknown & $\begin{array}{l}\text { unknown - seen in weaker spectra, may share functional } \\
\text { group with K-alum }\left(3072 \mathrm{~cm}^{-1}\right) \text {. May also be a weak } \\
\text { water peak (Baschenko and Marchenko, 2011). }\end{array}$ \\
\hline
\end{tabular}

\section{Reference Samples}

Spectra from these samples revealed the present of sulfate and bisulfate. This shows the equipment's ability to detect these solutes. Reference spectra were also used to find sources of spectral contamination via comparison of peaks with unknown sources. Even clear halite samples and spectra collected from glass vials were occasionally noisy, indicating a machine source of noise.

\section{Raman Spectral Contamination}

There are several sources of spectral contamination. The most common source is the halite matrix (and the other minerals it contains). The second most frequent source is the 
sampling equipment. The glass sample holder has clear spectral peaks that correlate to reference spectra of glass. Other sources of spectral contamination likely originate in the equipment. Sharp peaks at $484 \mathrm{~cm}^{-1}$ were noted in every sampling interval. There is no known mineral, solute, or gas that correlates well with this strong peak (quartz has a peak near it, but corresponding peaks are not seen here). This peak was also present in reference spectra of synthetic inclusions. The same peak, shifted to $490 \mathrm{~cm}^{-1}$ is present in spectra collected from the synthetic inclusions prior to tuning the laser on the Raman spectrometer being tuned. All other peaks stayed the same (Appendix III).

\section{Solutes Found through Raman Spectroscopy}

Raman spectroscopy found water peaks consistently in fluid inclusions. No sulfate or bisulfate peaks were identified. Although peaks relating to bicarbonate were detected, they were not present in the same spectra, and were present with more likely peak sources, such as anhydrite and disordered graphite. Bicarbonate is also difficult to detect in solution unless present in high concentrations (Frezzotti et al., 2012). Therefore, this study considers bicarbonate to be absent from inclusion waters.

\section{Gases Found through Raman Spectroscopy}

Attempts to gather spectra from gas bubbles in fluid inclusions lead to more muted spectra with fewer peaks. Spectral analysis consistently detected nitrogen in all long spectra $\left(\sim 2333 \mathrm{~cm}^{-1}\right)$. Detection of an oxygen peak was more erratic, and although seen in many spectra, was more common in spectra with high noise to signal ratios. Spectra collected with the laser focused just about the glass sampling slide only yielded nitrogen and oxygen peaks. The presence of oxygen peaks in noisy spectra, indicate a peak source originating in air and not inclusions. No hydrogen sulfide or carbon dioxide peaks were detected in spectra of fluid inclusions. 


\section{Solids Identified through Raman Spectroscopy}

Several solids and suspect solids were identified in Raman spectra. The most abundant solid detected in inclusions was anhydrite (Fig. 29). In several scans, anhydrite peaks were detected when the inclusion appeared to be all-liquid. It is possible that several spectra showing the presence of anhydrite in fluid inclusions could be contamination from anhydrite in the halite matrix that was not noted during petrography, or examination via the Raman microscope.

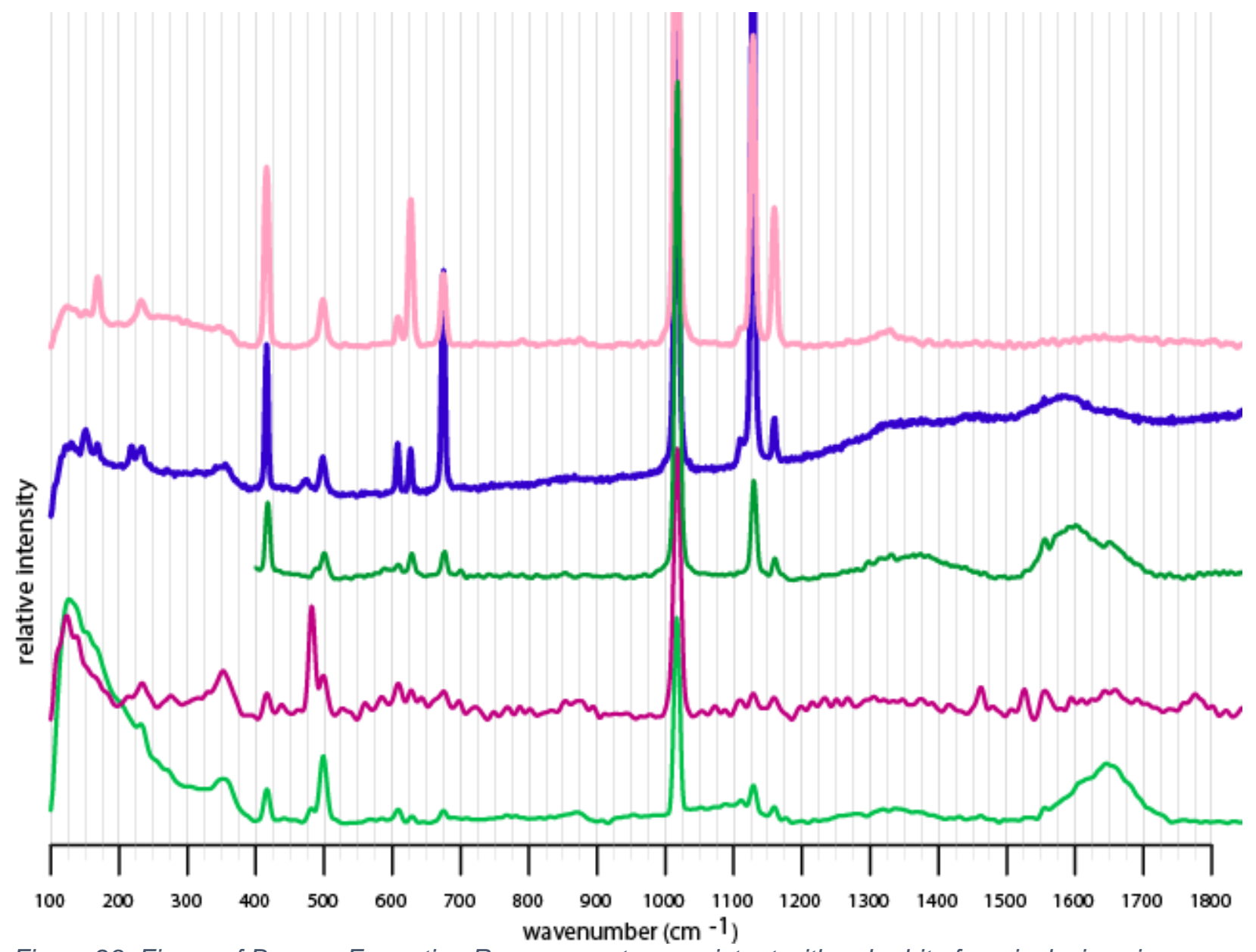

Figure 29. Figure of Browne Formation Raman spectra consistent with anhydrite from inclusions in samples from different sampling intervals. Note the variation between anhydrite specta that may be due to variation between anhydrite as well as other spectral sources. Spectra (from top to bottom) are from samples E.8.A.2.P; E.4.D.1.P; E.8.A.2.P; E.8.A.2.P; E.8.A.2.P. 
Other detected solids include halite, iron oxides, disordered graphite, and suspect quartz and phyllosilicates. Halite has poor Raman scatter; however, it does have a weak broad peak that is well documented. Iron oxide peaks $\left(\mathrm{Fe}_{2} \mathrm{O}_{3}\right)$ were found in both background spectra and spectra of fluid inclusions from many samples. These peaks in water suggest the presence of hematite as a solute, or that spectra originate from the matrix. Broad peaks that align with disordered graphite are seen in many intervals. These peaks are seen in fluid inclusion spectra where there was no solid being focused upon, indicating either spectral contamination from the matrix or the presence of very small graphite pieces in solution. Peaks that were similar to, but not perfect matches with quartz and phyllosilicates.

Many other peaks from unidentified sources are also present. Further identification of their likely functional group sources may be helpful in constraining their chemical sources (Fig. 30). No acid-metal sulfate minerals were identified through laser Raman spectroscopy.

\section{Raman spectra of solids in inclusions and halite, suspect life}

Raman spectroscopic analysis has detected microbial life and related organic compounds, such as beta-carotene and disordered graphite in modern halite deposits from Western Australia and Pleistocene halite from Death Valley (Connor and Benison, 2013; Winters et al., 2013). The Raman peaks diagnostic of the carotenoids beta-carotene ( 1010 , 1158, and $\left.1518 \mathrm{~cm}^{-1}\right)$, xanthophyll $\left(\sim 1005,1157\right.$, and $\left.1525 \mathrm{~cm}^{-1}\right)$, and lycopene $(\sim 1004,1155$, and $1519 \mathrm{~cm}^{-1}$ ) were not seen in this study. The Raman signature of kerogen from ancient life through kerogen signatures $\left(\sim 1350\right.$ and $\left.\sim 1600 \mathrm{~cm}^{-1}\right)$ has also been studied (Schopf et al., 2005). Raman spectra indicative of kerogen were found in the contemporaneous Bitter Springs Formation (Schopf et al., 2005). This thesis has also found spectra with broad peaks at $\sim 1350$ and $\sim 1600 \mathrm{~cm}^{-1}$ in the Browne Formation, which are indicative of kerogen/disordered graphite that are microbial suspects that formed through biogeochemical reactions (Benison et al., 2008). 


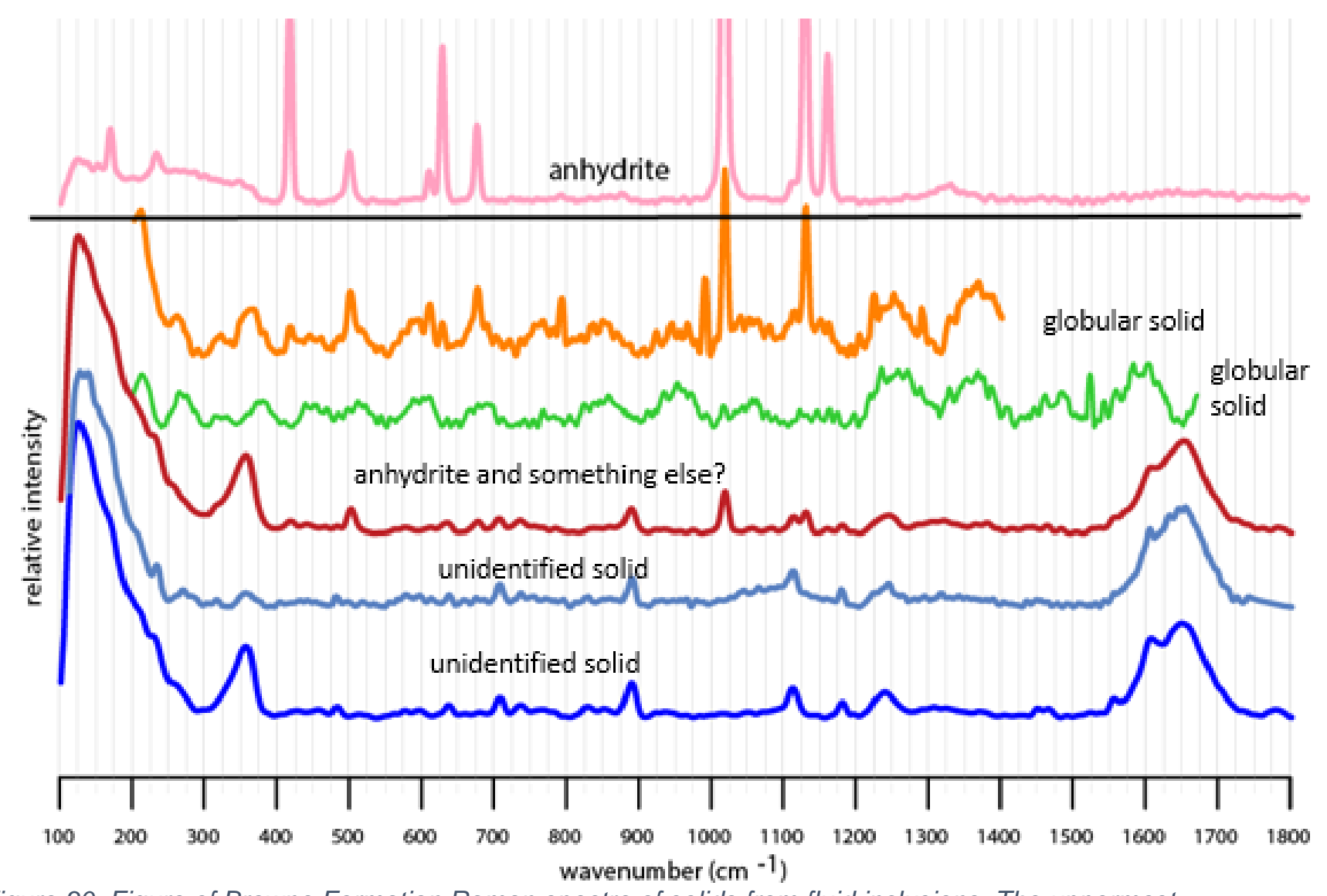

Figure 30. Figure of Browne Formation Raman spectra of solids from fluid inclusions. The uppermost figure of anhydrite is included for reference. Note that the globular solids share several peats with anhydrite. The wavy humps in the globular spectra are a spectral remnant of the data processing and are not representative of the spectra of solids within inclusions. Note that the unidentified solids are distinct from anhydrite. Spectra (from top to bottom) below the solid black line are from samples E.2.E.1.P; E.2.E.1.P; E.7.A.1.P; E.7.A.1.P; and E.7.A.1.P.

\section{Discussion}

Browne Formation fluid inclusions from bedded halite were studied to answer two questions: (1) Was its parent water marine or non-marine? If non-marine, (2) Was its parent water acid? If the Browne Formation was marine then its inclusions would behave like marine halite fluid inclusions. Browne Formation fluid inclusion behavior that differed from known marine fluid inclusions would indicate, but not be diagnostic of, a non-marine origin. If, however, parent waters were found to be acid, then the Browne Formation would be considered nonmarine. 
Modern marine inclusions contain consistent brine compositions that only vary slightly with evapoconcentration ( $\mathrm{Na}-\mathrm{K}-\mathrm{Mg}-\mathrm{Ca}-\mathrm{Cl}-\mathrm{SO}_{4}$ brine develops into a $\mathrm{Na}-\mathrm{K}-\mathrm{Mg}-\mathrm{Cl}-\mathrm{SO}_{4}$ brine; Hardie, 1984). A marine input implies little variation in inclusion chemistry over time, so large compositional fluctuations are indicative of a non-marine origin. In ancient deposits, like the Browne, marine brines must have consistent evaporation paths across contemporaneous basins. Inclusion $\mathrm{pH}$ is also indicative of parent water origin. Extreme $\mathrm{pH}$, such as $<1$, indicates non-marine origin (Benison et al., 1998).

This thesis first used petrography to determine halite suitability for analysis. Petrography identified bedded halite consisting of chevrons and cumulates, indicating that the Browne Formation was deposited in shallow saline water (such as an ephemeral lake, lagoon, or tidal flat). This bedded halite contains remnants of surface waters. Inclusions in bedded halite were appropriate for analysis because they showed no signs of alteration, such as stretching or consistent liquid-vapor rations. Large primary inclusions contained gas bubbles that were likely from the air-water interface or subaqueous gases. Inclusions have diverse solids, including accidental daughter crystals of anhydrite, and fluorescing spherules that resemble prokaryotes and Dunaleilla algae. These characteristics indicate that the Browne Formation contains unaltered bedded halite suitable for fluid inclusion analysis that was deposited in a shallow water that had anhydrite/gypsum and suspect microbes in suspension.

\section{Marine or Non-Marine?}

\section{What characteristics of parent waters does this study reveal?}

The marine vs. non-marine nature of parent waters was evaluated via the geochemical characteristics of fluid inclusion. This thesis observed that fluid inclusions from the Browne Formation do not freeze during attempted freezing-melting. Laser Raman spectroscopy identified anhydrite, disordered graphite, iron oxides, and several unknown solids in fluid 
inclusions. The mineralogy of the Browne Formation is consistent with both marine and nonmarine deposition. There are no clear depositional trends in the temporal distribution of solids in the Browne Formation.

No Raman peaks indicative of solutes, such as sulfate or bicarbonate, were detected. Therefore, inclusion fluids either (1) have no polyatomic ions, (2) have very low concentrations of these ions, or (3) have solutes that are not easily detected via laser Raman spectroscopy. With few exceptions, spectra of reference waters had sulfate peaks. The most dilute sample, modern seawater, had weak sulfate spectra, likely because of its low sulfate concentrations. Spectra of fluid inclusions from the marine Silurian Salina Formation halite did not detect sulfate, perhaps due to limited spectral collection or low sulfate. Only a minority of spectra from the Mercia Mudstone detected sulfate. Therefore the Browne Formation differs greatly from the majority of acid-saline waters studied in this thesis.

Sulfate detectable via Raman spectroscopy may vary between marine deposits. Although the marine Silurian Salina Formation halite did not detect sulfate, the Keuper halite of Lorraine, France, did have sulfate that was detectable via Raman spectroscopy (Dubessy et al., 1983). The presence of sulfate detectable via Raman spectroscopy in other marine inclusions is not known. Therefore the presence or absence of sulfate peaks is not a good indicator of marine or non-marine origin at this time.

Freezing-melting microthermometry has detected high inclusion in the Browne Formation. Other than synthetic samples with high calcium, the only other documented natural fluid inclusions with this inability to freeze during freezing-melting microthermometry are (1) modern acid-saline inclusions from Western Australia, (2) ancient acid-saline deposits from the Permian (Opeche Shale and Nippewalla Group), (3) and moderately acid-saline deposits from 
the Triassic (Mercia Mudstone). Of these natural waters, only the Mercia Mudstone and the Browne Formation contain inclusions that were wholly resistant to freezing. At least a portion of inclusions in other samples froze. This lack of freezing behavior either does not occur in marine halite deposits or it is poorly reported for these deposits.

The Raman spectral and freezing-melting data from fluid inclusions from this study reveal that these parent waters differ strongly from known acid-saline deposits as well as most halite fluid inclusions. Literature about laser Raman spectra of marine fluid inclusions is limited, so it is unknown if a lack of sulfate peaks in spectra is unusual. Laser Raman spectra of inclusions from acid saline deposits, however, typically have sulfate peaks (with the exception of the Mercia Mudstone, where only the minority of spectra contained sulfate peaks). Similarly, inclusion inability to freeze shows deviation of inclusion chemistry from most known bedded halite deposits. Limited data on the freezing-melting behavior of ancient marine halite deposits prevents further generalization of this characteristic as being marine or non-marine. Reported freezing-melting microthermometry results of a limited number of marine halite fluid inclusions indicates their ability to freeze.

\section{How does prior research affect the interpretation of data from this thesis?}

Spear found that major ion ratios of primary fluid inclusions from the Browne Formation $\left(\mathrm{Na}^{+}, \mathrm{Mg}^{2+}, \mathrm{S}, \mathrm{Cl}^{-}, \mathrm{K}^{+}\right.$, and $\left.\mathrm{Ca}^{2+}\right)$ are not consistent with brines derived from modern seawater or other Phanerozoic seawater compositions (2013). Inclusions contained depleted sulfate and potassium concentrations. These depleted sulfate levels, along with anhydrite present in the Browne Formation, indicate a parent brine with initial $\mathrm{Ca}^{2+}$ concentrations in excess of sulfate and bicarbonate concentrations. The Raman spectroscopic detection limit of sulfate is 2,000 ppm, indicating these waters have less than 2,000 ppm sulfate $(<20.8 \mathrm{mmol}$; Benison et al., 1998). This aligns with Spear's findings that the Browne Formation waters had less than 30 
mmol of sulfate (<2,900 ppm; 2014). Spear's data also indicates a water with high calcium concentrations, which impedes freezing in synthetic inclusions and aligns with observed inclusion behavior.

Prior interpretations of a marine origin for the Browne Formation are based upon nondiagnostic criteria. For an ancient deposit to be considered marine, it must be chemically similar with contemporaneous geographically separated basins. Spear used the Gillen Member of the Amadeus Basin as a contemporaneous deposit (2014). There are no primary fluid inclusion data from this member, but there are geochemical data from secondary fluid inclusions as well as sulfate isotopic composition. Brines secondary fluid inclusions in halite from this formation are chemically similar to the Browne Formation (excess of calcium). The Gillen Member's sulfur isotopic composition overlaps with values observed in the Browne Formation (Spear, 2014; Kovalevych et al., 2006). While these characteristics do not exclude these deposits from having the same parent waters, these data and criteria are limited and a marine interpretation would be strengthened with an additional contemporaneous deposit of marine origin and better preservation.

While the range of bromide concentrations in the Browne Formation are consistent with a marine origin, they are also consistent with documented non-marine concentrations (Spear, 2013; Bowen and Benison, 2009). The trend of depletion of bromide up-section is not consistent with marine deposits. Even though this depletion may be contributed the syndepositional halite recycling, it should still show an increase in bromide concentrations (Brennan et al., 2013). Bromide sampling locations come from portions of the Browne Formation that were deposited in shallow saline water, as is evidenced by chevrons. This indicates that this environment did not largely change between bromide deposition and this environment may have experienced input of dilute (non-marine?) waters. 
Are the results of this thesis and prior research diagnostic of a marine origin?

The source of Browne Formation parent waters could not be differentiated as marine or non-marine by this study. Prior studies, however, are also inconclusive (Table 18). While the Browne Formation sedimentology resembles non-marine deposits, its geochemistry is nondiagnostic of a marine or non-marine origin. Further study of the Browne Formation and contemporaneous deposits is required in order to determine whether the Browne Formation is a marine deposit.

Table 18: Browne formation characteristices compared with criteria indicative of marine or nonmarine origin. Characteristics that align with observations of the Browen Formation are highlighted in green.

\begin{tabular}{|c|c|c|c|c|c|}
\hline \multirow{2}{*}{\multicolumn{2}{|c|}{ criteria }} & \multirow[t]{2}{*}{ marine (modern) } & \multicolumn{2}{|c|}{ non-marine (diagnostic) } & \multirow{2}{*}{$\begin{array}{l}\text { Browne } \\
\text { Formation }\end{array}$} \\
\hline & & & general & acid-saline & \\
\hline \multicolumn{2}{|c|}{ sedimentology } & $\begin{array}{l}\text { marine lithofacies and/or } \\
\text { marine fossils below, } \\
\text { interbedded with, or above } \\
\text { evaporites }\end{array}$ & $\begin{array}{l}\text { continental deposits and/or } \\
\text { continental fossils below, } \\
\text { interbedded with, or above } \\
\text { evaporites }\end{array}$ & $\begin{array}{l}\text { red beds, no } \\
\text { carbonates }\end{array}$ & $\begin{array}{l}\text { indeterminate, } \\
\text { resembles acid- } \\
\text { saline }\end{array}$ \\
\hline \multicolumn{2}{|c|}{ mineralogy } & $\begin{array}{l}\text { limited by parent water (Na- } \\
\mathrm{K}-\mathrm{Mg}-\mathrm{Ca}-\mathrm{Cl}-\mathrm{SO}_{4} \text { ), minerals } \\
\text { such as } \mathrm{MgSO}_{4} \text { and } \mathrm{Na}_{2} \mathrm{SO}_{4} \\
\text { gypsum and halite }\end{array}$ & $\begin{array}{l}\text { minerals such as } \mathrm{Na}_{2} \mathrm{CO}_{3} \text {, } \\
\mathrm{KCl} \text {, and } \mathrm{CaCl}_{2} \text { in the } \\
\text { absence of } \mathrm{CaCO}_{3}, \mathrm{Na}_{2} \mathrm{SO}_{4} \text {, } \\
\text { and } \mathrm{MgSO}_{4} \text { gypsum and } \\
\text { halite }\end{array}$ & $\begin{array}{l}\text { jarosite, } \\
\text { alunite, } \\
\text { hematite } \\
\text { gypsum and } \\
\text { halite }\end{array}$ & indeterminate \\
\hline \multicolumn{2}{|c|}{$\begin{array}{l}\mathrm{Br}^{-} \text {concentration } \\
\text { of halite }\end{array}$} & $\mathrm{Br}^{-}>40 \mathrm{ppm}$ & $\mathrm{Br}^{-}<40 \mathrm{ppm}$, may be $0-3000$ & $\mathrm{Br}^{-} 0-800 \mathrm{ppm}$ & $\begin{array}{l}122 \text { to } 73 \text { ppm, } \\
\text { decrease upsection }\end{array}$ \\
\hline \multicolumn{2}{|c|}{$\begin{array}{l}\delta^{34} S \text { of waters } \\
\text { and sulfate } \\
\text { minerals }\end{array}$} & $\begin{array}{l}\delta^{34} \mathrm{~S} \text { of modern seawater is } \\
+20 \text { to }+23 \%\end{array}$ & $\begin{array}{l}\delta^{34} \mathrm{~S} \text { of sulfate minerals }<+20 \\
\text { or }>+23 \%\end{array}$ & $\begin{array}{l}17-20.4 \% \text { in } \\
\text { sulfate } \\
\text { minerals. }\end{array}$ & $\begin{array}{l}\text { 14.8-15.9\%, } \\
\text { indeterminate }\end{array}$ \\
\hline \multirow{3}{*}{ 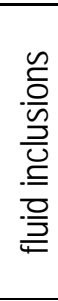 } & brines & $\begin{array}{l}\mathrm{Na}-\mathrm{K}-\mathrm{Mg}-\mathrm{Ca}-\mathrm{Cl}-\mathrm{SO}_{4} \text { to } \mathrm{Na}- \\
\mathrm{K}-\mathrm{Mg}-\mathrm{Cl}-\mathrm{SO}_{4} \text { brine in } \\
\text { modern deposits }\end{array}$ & $\begin{array}{l}\text { brines that are not } \mathrm{Na}-\mathrm{K}-\mathrm{Mg} \text { - } \\
\mathrm{Ca}-\mathrm{Cl}-\mathrm{SO}_{4} \text { to } \mathrm{Na}-\mathrm{K}-\mathrm{Mg}-\mathrm{Cl}- \\
\mathrm{SO}_{4} \text { type brines }\end{array}$ & $\begin{array}{l}\mathrm{Na}-\mathrm{Ca}-\mathrm{Cl}-\mathrm{SO}_{4}, \\
\text { elevated Al, } \mathrm{Si}, \\
\mathrm{Fe}\end{array}$ & $\begin{array}{l}\mathrm{Na}-\mathrm{Ca}-\mathrm{Cl}-\mathrm{Mg}- \\
\mathrm{SO}_{4}\end{array}$ \\
\hline & $\mathrm{pH}$ & $\begin{array}{l}\text { neutral to alkaline fluid } \\
\text { inclusion } \mathrm{pH}\end{array}$ & $\begin{array}{l}\text { non-marine waters pH may } \\
\text { range from }<1.9 \text { up to } 12.4\end{array}$ & low $\mathrm{pH}<4$. & indeterminate \\
\hline & $\begin{array}{l}\text { inter-basin } \\
\text { similarity }\end{array}$ & $\begin{array}{l}\text { overlapping evaporation } \\
\text { paths }\end{array}$ & $\begin{array}{l}\text { evaporation paths do not } \\
\text { overlap }\end{array}$ & & insufficient data \\
\hline
\end{tabular}

The unique chemistry of the Browne Formation parent waters may be due to several factors. It may have a marine source, or like modern non-marine calcium chloride brines and a number of other brines with low $\mathrm{CO}_{3} / \mathrm{HCO}_{3}{ }^{-}$and low sulfate, may have been influenced by hydrothermal waters. Seawater chemistry has varied in the Phanerozoic (Table 19; Fig. 31; 
Kovalevich et al., 1998; Brennan, et al., 2004). For example, in the early Cambrian, calcium concentrations increased over threefold (Brennan et al., 2004). The variation in chemistry observed in the Browne Formation is not outside the bounds of past changes in marine chemistry. With the exception of low potassium (possibly due to deposition and removal of potassium salts) and sulfate (low concentrations related to low Neoproterozoic atmospheric oxygen), the major ion composition of the Browne Formation is similar to those observed in the Phanerozoic.

Table 19. Past changes in seawater chemistry as compared with the modeled parent waters of the Browne Formation (Brennan and Lowenstein, 2002; Horita et al., 2002; Brennan, Lowenstein and Horita, 2004; Lowenstein et al., 2005; Timofeeff et al., 2006; Brennan, Lowenstein and Cendon, 2013; Spear, 2013). Table adapted from Spear, 2013. Note: the reported $K^{+}$concentration of the Browne Formation may not be representative of parent water composition.

\begin{tabular}{|c|c|c|c|c|c|c|c|c|}
\hline & \multirow[b]{2}{*}{ age (Ma) } & \multicolumn{6}{|c|}{ major ion (mMol/kg H2O) } \\
\hline & & & $\mathrm{Na}^{+}$ & $\mathrm{K}^{+}$ & $\mathrm{Ca}^{2+}$ & $\mathrm{Mg}^{2+}$ & $\mathrm{Cl}^{-}$ & $\mathrm{SO}_{4}{ }^{2-}$ \\
\hline $\begin{array}{l}\text { Neoproterozoic } \\
\text { (Browne Formation) }\end{array}$ & & 815 & 456 & 1 & $9-12$ & 50 & 565 & $\geq 3$ \\
\hline terminal Proterozoic & & 544 & 479 & 11 & $14(9.5-18.5)$ & 52 & 581 & $20.5(16-25)$ \\
\hline early Cambrian & & 515 & 450 & 9 & $37(33.5-40)$ & 44 & 605 & $8(4.5-11)$ \\
\hline mid-late Silurian & & $428-416$ & 445 & 12 & 35 & 48 & 601 & 11 \\
\hline mid Devonian & & 380 & $\mathrm{~N} / \mathrm{A}$ & 10 & $23-35$ & $31-41$ & $\mathrm{~N} / \mathrm{A}$ & $5-11$ \\
\hline lower Permian & & $296-283$ & 461 & 10 & 15 & 52 & 565 & 20 \\
\hline mid Permian & & $283-274$ & 439 & 10 & 17 & 60 & 565 & 19 \\
\hline late Permian & $\Phi$ & $258-251$ & 469 & 10 & 14 & 52 & 565 & 23 \\
\hline late Triassic & $\sum_{0}^{\pi}$ & 230 & $\mathrm{~N} / \mathrm{A}$ & 9.3 & $16-17$ & $28-32$ & $\mathrm{~N} / \mathrm{A}$ & $13-14$ \\
\hline late Jurassic & $\stackrel{\mathscr{D}}{\sim}$ & 150 & $\mathrm{~N} / \mathrm{A}$ & $\mathrm{N} / \mathrm{A}$ & $20-26$ & $28-33$ & $\mathrm{~N} / \mathrm{A}$ & $7-14$ \\
\hline early Cretaceous & & $121-112.2$ & 416 & 11 & 35.5 & 42 & 5665 & 8.5 \\
\hline early-late Cretaceous & & $112.2-93.5$ & 462 & 11 & 26 & 34 & 565 & 14 \\
\hline Eocene-Oligocene & & $36-34$ & 488 & 11 & $16(11-20)$ & 36 & 565 & $19(14-23)$ \\
\hline Serravallian-Tortonian & & $13.5-11.8$ & 488 & 11 & $13(8-16)$ & 44 & 565 & $24(19-27)$ \\
\hline Messinian & & $6-5$ & 486 & 11 & $12(7-15)$ & 48 & 565 & $26(21-29)$ \\
\hline modern & & 0 & 485 & 11 & 11 & 55 & 565 & 29 \\
\hline
\end{tabular}

\section{Were Browne Formation parent waters highly acidic?}

Any detected bisulfate in fluid inclusions by laser Raman spectroscopy would be diagnostic of a pH less than 1 (Benison et al., 1998; Tomikawa and Kanno, 1998). This thesis 
has found no evidence of aqueous sulfate or bisulfate in inclusion fluids from any interval of the Empress $1 \mathrm{~A}$ core. Therefore, low pH dependent upon the presence of bisulfate is not possible here.

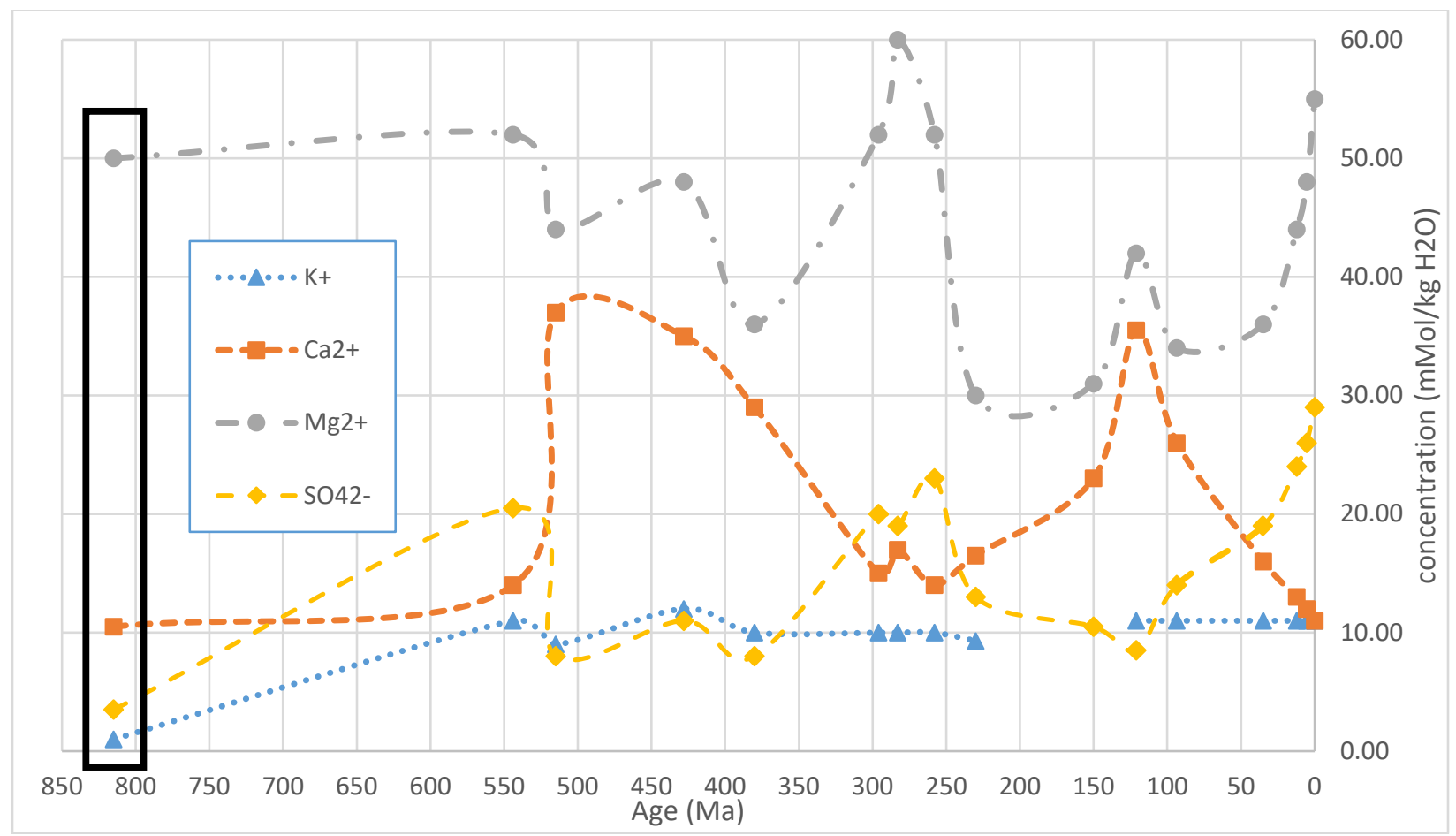

Figure 31. Chart of changes in seawater composition over time with the Browne Formation included for comparison (outlined by the black box; data from Table 19). Dashed lines show extrapolation of seawater changes. Note that Browne Formation waters, with the exception of sulfate concentrations and potassium, fall within the bounds of historical compositional fluctuations.

Raman spectra from solids in Browne Formation fluid inclusions were compared with known acid sulfate minerals that are only stable at low pH's (such as alunite and jarosite). The presence of these minerals would suggest a pH below 4 (Jagniecki and Benison, 2010; Eichenlaub, 2016). No spectra's peaks are consistent with known acid minerals or carbonates indicative of neutral to high $\mathrm{pH}$.

Freezing-melting microthermometry may be used as an indicator of low $\mathrm{pH}$. Due to inability of inclusions to freeze, Browne Formation inclusions could not be characterized via this method. There are no data indicating an extremely low pH in the Browne Formation. 


\section{Can Browne Formation parent water pH be further constrained?}

No carbonates that would be indicative of neutral to alkaline $\mathrm{pH}$ were detected in Browne Formation halite as solid inclusions, solids in inclusions, or in solution. However, the detection of aqueous carbonate is difficult to determine via laser Raman spectroscopy (Sun and Qin, 2011; Frezotti, 2012). So, there could be undetectable carbonate in Browne Formation inclusions. Evidence of bicarbonate in halite inclusions is poorly documented. Halite fluid inclusions from the alkaline Green River Formation could be good analogs to test whether bicarbonate can be detected in halite fluid inclusions (LaClair and Lowenstein, 2009).

There are no known natural acid saline systems that do not contain elevated sulfate in solution. Systems with bromic and hydrochloric acid may occur, but it would be difficult to test for this and these systems are not well studied. Geochemical modeling with iron or aluminum complexes that change with $\mathrm{pH}$ may be a useful proxy to detect inclusion $\mathrm{pH}$ via Raman spectroscopy. However, this method has yet to be shown effective (Appendix IV). Browne Formation inclusion $\mathrm{pH}$ cannot be characterized because no solutes were definitively detected by laser Raman spectroscopy.

\section{How does petrology affect interpretation of this deposit?}

Gypsum and anhydrite are commonly found in marine and many non-marine evaporites. These minerals indicate parent waters containing sulfate. However, this study did not identify sulfate in Browne Formation waters. This indicates that parent waters had sulfate which was removed as evapoconcentration increased through precipitation of gypsum.

Browne Formation mineralogy is congruent with both marine and non-marine deposits. However, red beds found in association with the Browne Formation suggest, but are not diagnostic of a continental origin (Benison and Goldstein, 2002). Dubessy analyzed of fluid inclusions the marine Keuper halite of Lorraine via Raman spectroscopy. This analysis identified 
sulfate in solution, as well as anhydrite, gypsum and suspect polyhalite within the same crystal (Dubessy et al., 1983). Both the Opeche Shale and Nippewalla Group contain anhydrite in fluid inclusions, these Permian deposits had several other minerals that were not identified in the Browne Formation (Benison, 1997). These data indicate the Browne fluid inclusion mineralogy is consistent with both marine and non-marine deposition.

The presence of only anhydrite and no gypsum in the Browne Formation may be due to its deposition as anhydrite, or later diagenesis from gypsum into anhydrite. Anhydrite precipitates from sufficiently saline and warm $\left(\sim 37^{\circ} \mathrm{C}\right)$ waters (Freyer and Voigt, 2003; Ossorio et al., 2014). If this were the case here, it would be indicative of a minimum temperature range of deposition. Modern saline lakes reach these temperatures, therefore it is reasonable to assume that this environment could have been at $\sim 37^{\circ} \mathrm{C}$ during halite deposition.

If gypsum was deposited in this environment, it probably would have altered to anhydrite as it was buried. At a burial of $\sim 500$ m, gypsum alters to anhydrite (Machel and Burton, 1991). Although there is known capacity of fluid inclusions to retain internal pressure when outside pressure differs, it is not well understood in cases of increased pressure, or in halite. If, however, it did serve as a capsule preserving depositional pressure, then gypsum deposited in an inclusion might withstand diagenetic forces.

\section{Did low Neoproterozoic atmospheric oxygen levels prevent high sulfate levels?}

Blamey (2016) analyzed gas bubbles from fluid inclusions in halite from the Browne Formation to determine atmospheric compositions. This study found atmospheric oxygen levels $(10.9 \%)$ that were half of what they are today. Petrography from this study confirms the presence of large gas bubbles in inclusions in the Browne Formation. Gas bubbles were most common in some large inclusions in cumulates and chevrons, but were also present in some small inclusions $(<15 \mu \mathrm{m})$. Inclusions did not show consistent vapor-liquid ratios; indicating gas 
was incorporated at the surface. Secondary fluid inclusion assemblages containing vapor were also abundant in the Browne Formation. Future studies may examine more inclusions through homogenization to explore the temperatures under which this formation was deposited.

There are no known natural-acid saline systems that do not contain sulfate in solution. However, all known acid systems were from water with oxygen in equilibrium with at least $20 \%$ oxygen. The parent waters of the Browne Formation contained sulfate, as is evidenced by the presence of anhydrite. Increased oxygen levels may lead to increased sulfate concentrations. Several studies indicate that marine sulfate concentrations did not increase significantly until the Ediacaran Period (Halverson and Hurtgen, 2007; Kah and Bartley, 2011).

\section{Did Browne Formation halite trap microorganisms?}

The Browne Formation depositional environment hosted unicellular life-forms. Suspect microbial remnants in fluid inclusions include (1) prokaryotes, which appear as small fluorescing spherules (<2 $\mu \mathrm{m}) ;(2)$ Dunaleilla algae, which are round, dimpled spherules $(-5-10 \mu \mathrm{m})$; and (3) suspect remnants of algal mats, which are opaque cubic solids ( $-100-600 \mu \mathrm{m})$ near primary inclusions.

Raman spectroscopy suggests the presence of disordered graphite, but has not indicated the presence of carotenoids (Schopf et al., 2002; Benison et al., 2008; Schubert, Lowenstein and Timofeeff, 2009; Winters et al., 2013). Carotenoids may not have been detected because the laser frequency was not suited for this purpose or because few scans of suspect microbes were collected (Conner and Benison, 2013; Winters, Lowenstein and Timofeeff, 2013). Organic matter may have degraded through time, leading to poor Raman spectra and UV fluorescence. These suspect prokaryotes and spherules similar to Dunaleilla algae may be in a dormant state and may be possible to revive and culture (Vreeland et al., 2000). 


\section{How does the Browne Formation compare other saline deposits?}

\section{Marginal marine, modern lagoon, South Jeddah, Saudi Arabia}

There are marginal marine lagoon salt pans on the east coast of the Red Sea in South Jeddah, Saudi Arabia (Taj and Aref, 2015). Restriction of seawater and an arid climate lead to accelerated salt deposition near the Red Sea. A lagoon near South Jeddah consistently reaches a salinity of $32 \%$ total dissolved solids. Similar to other marine deposits, it is likely alkaline (Taj and Aref, 2015). The pan consists of two sub-sections, one primarily halite, the other primarily gypsum. The gypsum sub-section has gypsum stromatolites. Unlike the Browne Formation, both sections incorporate detrital carbonates into evaporites (Taj and Aref, 2015). Similar to the Browne Formation, no active carbonate deposition is noted at the saline pan. The pan overlies lagoonal carbonate sediments. Surrounding facies consist of Pleistocene coral-reef deposits and alluvial sand (Taj and Aref, 2015).

\section{Dead Sea, Palestine, non-marine calcium-chloride brine}

The Dead Sea is a hypersaline lake with alkaline waters. These waters have an excess of calcium relative to sulfate and bicarbonate and are considered to be a calcium-chloride type brine (Hardie, 1990). Calcium-chloride brines have reduced $\mathrm{Na}^{+}, \mathrm{Mg}^{2+}, \mathrm{SO}_{4}{ }^{2-}$, and $\mathrm{K}^{+}$ratios relative to seawater, and very low $\mathrm{HCO}_{3}{ }^{-}$, they are enriched with $\mathrm{Ca}^{2+}$ and $\mathrm{Br}^{-}$relative to seawater. These brines are rare, examples include the Qaidam basin, China; Death Valley and Bristol Dry Lake, California; and Salar de Atacama, Chile (Lowenstein and Risacher, 2009). The source of these calcium chloride brines is attributed to hydrothermal fluids (Hardie, 1990). The Dead Sea brines differ from the calcium chloride brine type because they are enriched in $\mathrm{Mg}^{2+}$ and $\mathrm{K}^{+}$. In addition, the Dead Sea sedimentary structures and textures differ from those observed in the Browne Formation (it is a deep water perennial lake).

The Dead Sea brines may have formed in two phases, first as a marine lagoon, then as 
an inland saline lake (Katz and Starinksky, 2009). The lagoonal environment deposited gypsum, dolomite, aragonite, and halite. The saline lake deposited aragonite, gypsum/anhydrite, and halite. Katz and Starinsky (2009) propose a brine development whereby evaporated marine brines dolomitized adjacent limestones, creating a calcium rich brine. As the basin became isolated from the Mediterranean Sea the only source of recharge was runoff and recycled brine. Freshwater input created a stratified lake with an anoxic lower layer with sulfur reducing bacteria. Freshwater input also recharged brines until aragonite precipitated.

Thermodynamically and geochemically, this brine should precipitate anhydrite, but only gypsum is found. This is attributed to crystallization kinetics (MacDonald, 1953; Hardie, 1967). Dead Sea brine continues to evolve, the $\mathrm{Mg} / \mathrm{Ca}$ ratio in the Dead Sea has increased with precipitation of gypsum and aragonite.

The Browne Formation is chemically similar to the Dead Sea because it is a calcium rich brine. But it differs in other ways - such as hematite muds, sedimentary textures, and carbonate deposited with halite. Samples from the Dead Sea would be valuable references for freezingmelting to examine if the fluid composition here impedes freezing. Samples from of calcium chloride brines such the Qaidam basin, China; Death Valley and Bristol Dry Lake, California; and Salar de Atacama would be valuable references for both Raman spectroscopy and freezing-melting microthermometry. Raman spectra of solids in fluid inclusions from another study do not indicate the presence of either water or sulfate, further analysis of spectra from that study may be useful (Winters et al., 2013).

\section{Modern Ephemeral Acid-Saline Lakes, Western Australia}

Acid-saline lakes in Western Australia are the best documented modern cratonic natural acid-brine systems (Benison et al., 2007). Similar to the Browne Formation, they are currently forming red beds and evaporites. The most acidic lakes range in $\mathrm{pH}$ from 1.4 to 4 . Salinities 
reach more than $32 \%$ total dissolved solids. Groundwaters near these lakes have an average pH of 3 (Benison et al., 2007). Fluid inclusion study of bedded halites from these lakes has identified clear acid traits, such as an inability to freeze (Jagniecki and Benison, 2010). Even though the parent waters had pH's as low as 1.4, laser Raman spectroscopy does not detect any bisulfate (Benison, 2013). Similar to the Browne Formation, some inclusions exhibit an inability to freeze. Inclusions also contain life such as Dunaliella algae and prokaryotes (Conner and Benison, 2013). Halite from these lakes also contain suspect algal mats in conjunction with sulfate crystals. Lake waters have unusually high concentrations of iron, aluminum, and bromide (Bowen and Benison, 2009). These lakes and adjacent mudflat environments form bedded and displacive halite, bedded gypsum, hematite, kaolinite, alunite and jarosite (Benison et al., 2007). Depositional facies in this system include ephemeral lakes, saline and dry mudflats and sandflats, vegetated dunes, and desert soils.

\section{Permian Red Beds and Evaporites, Central U.S.A.}

The Permian evaporite deposits of the Nippewalla Group of Kansas and Oklahoma and the Opeche Shale of North Dakota contain evidence of extensive acid environments in the past (Benison et al., 1998; Benison and Goldstein, 2000, 2001, 2002). Similar to the Browne Formation, these deposits consist of red beds and evaporates. Fluid inclusions from the Opeche Shale contain anhydrite and other minerals (identified as alunite, jarosite, and leonite; and suspect nahcolite, polyhalite, and magnesite; Benison, 1997). The Nippewalla Group originally contained gypsum deposited as bedded swallow tail bottom growth crystals. Similar to the Browne Formation, both of these deposits contain anhydrite as solids within inclusions and as solid inclusions. Rare, disordered graphite was found in association with solids (Benison, 1997). Halite fluid inclusions in the Opeche and Nippewalla have pH's as low as -1 (Benison et al., 1998). These inclusions contain bisulfate and elevated concentrations of aluminum, iron, and 
silica (Benison et al., 1998). Similar to the Browne Formation, both the Nippewalla Group and the Opeche Shale contain bedded and displacive halite, bedded gypsum, and red beds. These deposits are interpreted as a continental ephemeral saline lake and mudflat system (Benison and Goldstein, 2000, 2001). The Opeche Shale contains more inclusions with lower pH's and fluid inclusions with daughter solids.

\section{Were Brown Formation parent waters weird?}

Browne Formation inclusions lack solutes detectable via Raman spectroscopy and contain high salinities and inclusion complexity that contribute to their rare lack of freezing capacity during freezing-melting microthermometry. Other than synthetic samples with high calcium, the only documented natural fluid inclusions that were wholly resistant to freezing are inclusions from halite in the Mercia Mudstone and Opeche Shale (Eichenlaub, 2016; Benison, 2013). This lack of freezing behavior either does not occur in marine halite deposits or it is poorly reported for these deposits.

The Raman spectral and freezing-melting data from fluid inclusions from this study show that Browne Formation halite parent waters differ strongly from known acid-saline deposits as

well as most halite fluid inclusions. As literature about laser Raman spectra of marine fluid inclusions in halite in limited, a marine characterization of spectra collected for this study is limited. Similarly, inability of inclusions to freeze exhibits a deviation of inclusion chemistry from most known bedded halite deposits. Limited data on the freezing-melting behavior of ancient marine halite deposits prevents further generalization of this characteristic as being marine or non-marine.

In comparison to known fluid inclusion chemistries and responses to analyses, Browne Formation inclusions behave unusually. Browne Formation inclusions differ from marine, non- 
marine, and acid-saline inclusions. Further characterization of marine and non-marine fluid inclusions through freezing-melting and laser Raman spectroscopy may identify an analog for this unique deposit. Current data indicates that the Browne Formation is a singular evaporite deposit on the geologic time scale.

\section{Conclusions}

This thesis was the first examination of the Browne Formation via detailed petroscopy, freezing-melting microthermometry, and laser Raman spectroscopy. Petroscopy verified that Browne Formation was deposited in a shallow waters. Primary fluid inclusions in bedded halite consisting of chevron and cumulate crystals show no sign of alteration, making this formation ideal for fluid inclusion analysis. Primary inclusions contain gas bubbles, likely from the air-water interface or subaqueous gasses. Inclusions have diverse solids including accidental daughter crystals of anhydrite, and fluorescing spherule solids that resemble prokaryotes and Dunaleilla algae. Halite crystals contain remnants of suspect algal mats. Fluid inclusions from the Browne formation do not freeze during attempted freezing melting. Laser Raman spectroscopy identified anhydrite, disordered graphite, iron oxides, and several unknown solids in fluid inclusions. No definitive solutes were detected in Browne Formation inclusions. There are no clear evaporative trends from Raman data that would indicating patterns in parent brine chemistry changes. No evidence from this study is considered diagnostic of a marine or non-marine classification. Similarly, this study did not identify any characteristics diagnostic of an acid-saline depositional environment. Data indicates that there are no known formations that share its features, making the Browne Formation a unique evaporite deposit on the geologic time scale. 


\section{Bibliography}

Andeskie, A. S. (2016) Depositional and Diagenetic History of the Triassic Redbeds and Evaporites from the Mercia Mudstone Group in the Carnduff 02 Core of County Antrim, Northern Ireland. West Virginia University.

Armbruster, T. and Micaela Danisi, R. (2015) 'The power of databases: The RRUFF project', in Highlights in Mineralogical Crystallography. Berlin, pp. 1-30. Available at: http://rruff.info/about/downloads/HMC1-30.pdf

Arthurton, R. S. (1973) 'Experimentally produced halite compared with Triassic layered halite rock from Cheshire, England', Sedimentology. Blackwell Publishing Ltd, 20(1), pp. 145160. doi: 10.1111/j.1365-3091.1973.tb01611.x.

Auer, B. M. and Skinner, J. L. (2008) 'IR and Raman spectra of liquid water: Theory and interpretation', Journal of Chemical Physics, 128(22), pp. 224511-224513. doi: 10.1063/1.2925258.

Baschenko, S. M. and Marchenko, L. S. (2011) 'On Raman spectra of water, its structure and dependence on temperature', Semiconductor Physics, Quantum Electronics \& Optoelectronics, 14(1), pp. 77-79.

Benison, K. C. (1997) Acid water deposition and diagenesis in Permian red bed-hosted evaporites, midcontinent, United States of America. University of Kansas.

Benison, K. C. (2013) 'Acid saline fluid inclusions: Examples from modern and Permian extreme lake systems', Geofluids, 13(4), pp. 579-593. doi: 10.1111/gfl.12053.

Benison, K. C. and Bowen, B. B. (2006) 'Acid saline lake systems give clues about past environments and the search for life on Mars', Icarus, 183(1), pp. 225-229. doi: 10.1016/j.icarus.2006.02.018.

Benison, K. C. and Bowen, B. B. (2013) 'Extreme sulfur-cycling in acid brine lake environments of Western Australia', Chemical Geology, 351. doi: 10.1016/j.chemgeo.2013.05.018.

Benison, K. C. and Bowen, B. B. (2015) 'The evolution of end-member continental waters: The origin of acidity in southern Western Australia', GSA Today, 25(6), pp. 4-10. doi: 10.1130/GSATG231A.1.

Benison, K. C., Bowen, B. B., Oboh-Ikuenobe, F. E., Jagniecki, E. A., LaClair, D. A., Story, S. L., Mormile, M. R. and Hong, B.-Y. (2007) 'Sedimentology of Acid Saline Lakes in Southern Western Australia: Newly Described Processes and Products of an Extreme Environment', Journal of Sedimentary Research. SEPM Society for Sedimentary Geology, 77(5), pp. 366-388. doi: 10.2110/jsr.2007.038.

Benison, K. C. and Goldstein, R. H. (1999) 'Permian paleoclimate data from fluid inclusions in halite', Chemical Geology, 154(1-4), pp. 113-132. doi: 10.1016/S0009-2541(98)001272. 
Benison, K. C. and Goldstein, R. H. (2000) 'Sedimentology of Ancient Saline Pans: An Example from the Permian Opeche Shale, Williston Basin, North Dakota, U.S.A.', Journal of Sedimentary Research, 70(1), pp. 159-169. doi: 10.1306/2dc40907-0e47-11d78643000102c1865d.

Benison, K. C. and Goldstein, R. H. (2001) 'Evaporites and siliciclastics of the Permian Nippewalla Group of Kansas, USA: A case for non-marine deposition in saline lakes and saline pans', Sedimentology, 48(1), pp. 165-188. doi: 10.1046/j.13653091.2001.00362.x.

Benison, K. C. and Goldstein, R. H. (2002) 'Recognizing acid lakes and groundwaters in the rock record', Sedimentary Geology, 151(3-4), pp. 177-185. doi: 10.1016/S00370738(02)00155-0.

Benison, K. C., Goldstein, R. H., Wopenka, B., Burruss, R. C. and Pasteris, J. D. (1998) 'Extremely acid Permian lakes and ground waters in North America', Nature, 392(6679), pp. 911-914. doi: 10.1038/31917.

Benison, K. C., Jagniecki, E. A., Edwards, T. B., Mormile, M. R. and Storrie-Lombardi, M. C. (2008) "'Hairy Blobs:" Microbial Suspects Preserved in Modern and Ancient Extremely Acid Lake Evaporites', Astrobiology, 8(4), pp. 807-821. doi: 10.1089/ast.2006.0034.

Benison, K. C. and Karmanocky, F. J. (2014) 'Could microorganisms be preserved in Mars gypsum? Insights from terrestrial examples', Geology. Geological Society of America, 42(7), pp. 615-618. doi: 10.1130/G35542.1.

Blamey, N. J. F., Brand, U., Parnell, J., Spear, N., Lecuyer, C., Benison, K., Meng, F. and Ni, P. (2016) 'Paradigm shift in determining Neoproterozoic atmospheric oxygen', Geology, 44(8), pp. 651-654. doi: 10.1130/G37937.1.

Bloch, M. (1953) 'On the $\mathrm{Cl} / \mathrm{Br}$-ratio and the distribution of $\mathrm{Br}$ ions in liquids and solids during evaporation of bromide-containing chloride solutions', Bull. Res. Council Isr.

Bowen, B. B. and Benison, K. C. (2009) 'Geochemical characteristics of naturally acid and alkaline saline lakes in southern Western Australia', Applied Geochemistry. Elsevier Ltd, 24(2), pp. 268-284. doi: 10.1016/j.apgeochem.2008.11.013.

Brennan, S. T. and Lowenstein, T. K. (2002) 'The major-ion composition of Silurian seawater', Geochimica et Cosmochimica Acta, 66(15), pp. 2683-2700. doi: 10.1016/S0016-7037(02)00870-0.

Brennan, S. T., Lowenstein, T. K. and Cendon, D. I. (2013) 'The major-ion composition of Cenozoic seawater: the past 36 million years from fluid inclusions in marine halite', American Journal of Science, 313(8), pp. 713-775. doi: 10.2475/08.2013.01.

Brennan, S. T., Lowenstein, T. K. and Horita, J. (2004) 'Seawater chemistry and the advent of biocalcification', Geology, 32(6), pp. 473-476. doi: 10.1130/G20251.1.

Carlsen, G., Simeonova, A. and Apak, S. (2003) 'New plays - petroleum systems and 
exploration potential in the Officer Basin, Western Australia', APPEA Journal-Australian Petroleum Production and Exploration Association, 43(1), pp. 473-494.

Casas, E. and Lowenstein, T. K. (1989) 'Diagenesis of saline pan halite: Comparison of petrographic features of modern, Quaternary and Permian halites', Journal of sedimentary petrology, 59(5), pp. 724-739. doi: 10.1306/212F905C-2B24-11D78648000102C1865D.

Conner, A. J. and Benison, K. C. (2013) 'Acidophilic halophilic microorganisms in fluid inclusions in halite from Lake Magic, Western Australia.', Astrobiology, 13(9), pp. 850-60. doi: 10.1089/ast.2012.0956.

Davis, D. W., Lowenstein, T. K. and Spencer, R. J. (1990) 'Melting behavior of fluid inclusions in laboratory-grown halite crystals in the systems $\mathrm{NaCl}-\mathrm{H}_{2} \mathrm{O}, \mathrm{NaCl}-\mathrm{KCl}-\mathrm{H}_{2} \mathrm{O}, \mathrm{NaC}-\mathrm{MgCl}_{2}-$ $\mathrm{H}_{2} \mathrm{O}$, and $\mathrm{NaCl}-\mathrm{CaCl}_{2}-\mathrm{H}_{2} \mathrm{O}$ ', Geochimica et Cosmochimica Acta, 54(3), pp. 591-601.

Dubessy, J., Audeoud, D., Wilkins, R. and Kosztolanyi, C. (1982) 'The use of the Raman microprobe MOLE in the determination of the electrolytes dissolved in the aqueous phase of fluid inclusions', Chemical Geology, 37(1-2), pp. 137-150. doi: 10.1016/00092541(82)90073-0.

Dubessy, J., Geisler, D., Kosztolanyi, C. and Vernet, M. (1983) 'The determination of sulphate in fluid inclusions using the M.O.L.E. Raman microprobe. Application to a keuper halite and geochemical consequences', Geochimica et Cosmochimica Acta, 47(1), pp. 1-10. doi: 10.1016/0016-7037(83)90086-8.

Eichenlaub, L. A. (2016) A fluid inclusion study of acidity in bedded halite of the Larne Halite Member Triassic Mercia Mudstone Group from the Carnduff 02 Core , County Antrim , Northern Ireland. West Virginia University.

Freyer, D. and Voigt, W. (2003) 'Crystallization and Phase Stability of CaSO4 and $\mathrm{CaSO}_{4}$ Based Salts', Monatshefte fur Chemie, 134(5), pp. 693-719. doi: 10.1007/s00706-0030590-3.

Frezzotti, M. L., Tecce, F. and Casagli, A. (2012) 'Raman spectroscopy for fluid inclusion analysis', Journal of Geochemical Exploration. Elsevier B.V., 112, pp. 1-20. doi: 10.1016/j.gexplo.2011.09.009.

Frost, R. L. and Dickfos, M. (2007) 'Hydrated double carbonates - a Raman and infrared spectroscopic study', Polyhedron, 26(15), pp. 4503-4508.

Frost, R. L., López, A., Scholz, R. and Wang, L. (2015) 'A Raman and infrared spectroscopic study of the sulphate mineral aluminite $\mathrm{Al}_{2}\left(\mathrm{SO}_{4}\right)(\mathrm{OH})_{4} \cdot 7 \mathrm{H}_{2} \mathrm{O}$ ', Spectrochimica Acta Part A: Molecular and Biomolecular Spectroscopy, 148, pp. 232-236. doi: 10.1016/j.saa.2015.04.011.

Frost, R. and Wills, R. (2006) 'A Raman specroscopic study of alunites', Journal of Molecular Structure, 785, pp. 123-132. doi: 10.1016/S0261-5177(02)00005-5. 
Goldstein, R. H. (2003) 'Petrographic analysis of fluid inclusions', in Fluid Inclusions-Analysis and Interpretation, pp. 9-54.

Goldstein, R. H. and Reynolds, T. J. (1994) Systematics of fluid inclusions in diagenetic minerals, Society for Sedimentary Geology. doi: 10.2110/scn.94.31.

Grey, K. and Blake, D. H. (1999) 'Neoproterozoic (Cryogenian) stromatolites from the Wolfe Basin, east Kimberley, Western Australia: Correlation with the Centralian Superbasin', Australian Journal of Earth Sciences, 46(3), pp. 329-341. doi: 10.1046/j.1440-0952.1999.00707.x.

Grey, K., Hill, A. C. and Calver, C. (2011) 'Biostratigraphy and stratigraphic subdivision of Cryogenian successions of Australia in a global context', Geological Society, London, Memoirs. Geological Society of London, 36(1), pp. 113-134. doi: 10.1144/M36.8.

Grey, K., Hocking, R. M., Stevens, M. K., Bagas, L., Carlsen, G. M., Irimies, F., Pirajno, F., Haines, P. and Apak, S. N. (2005) 'Lithostratigraphic nomenclature of the Officer Basin and correlative parts of the Paterson Orogen, Western Australia', Geological Survey of Western Australia, Report 93(November 2015), p. 95 pp.

Haines, P., Mory, A., Stevens, M. K. and Ghori, K. (2004) 'GSWA Lancer 1 well completion report (basic data), Officer and Gunbarrel Basins, Western Australia'. Perth, p. 39.

Halverson, G. P. and Hurtgen, M. T. (2007) 'Ediacaran growth of the marine sulfate reservoir', Earth and Planetary Science Letters, 263(1-2), pp. 32-44. doi: 10.1016/j.epsl.2007.08.022.

Hardie, L. A. (1967) 'The Gypsum-Anhydrite Equilibrium at One Atmosphere Pressure', The American Mineralogist, 52, pp. 171-200.

Hardie, L.A., 1984. Evaporites; marine or non-marine?. American Journal of Science, 284(3), pp.193-240.

Hardie, L. A. (1990) 'The roles of rifting and hydrothermal $\mathrm{CaCl}_{2}$ brines in the origin of potash evaporites: an hypothesis', American Journal of Science. American Journal of Science, pp. 43-106. doi: 10.2475/ajs.290.1.43.

Hill, A. C., Arouri, K., Gorjan, P. and Walter, M. R. (2000) 'Geochemistry of marine and nonmarine environments of a Neoproterozoic cratonic carbonate/evaporite: the Bitter Springs Formation, Central Australia', in Carbonate Sedimentation and Diagenesis in an Evolving Precambrian World, pp. 327-344. doi: 10.2110/pec.00.67.0327.

Hocking, R. M. (2002) 'Drillhole WMC NJD 1, western Officer Basin, Western Australia: Stratigraphy and petroleum geology', Geological Survey of Western Australia, 2002/18, p. 33p.

Holser, W. T. and Kaplan, I. R. (1966) 'Isotope geochemistry of sedimentary sulfates', Chemical Geology, 1(512), pp. 93-135. doi: 10.1016/0009-2541(66)90011-8.

Horita, J., Zimmermann, H. and Holland, H. D. (2002) 'Chemical evolution of seawater during 
the Phanerozoic: Implications from the record of marine evaporites', Geochimica et Cosmochimica Acta, 66(21), pp. 3733-3756. doi: 10.1016/S0016-7037(01)00884-5.

Hovorka, S. (1987) 'Depositional environments of marine-dominated bedded halite, Permian San Andres Formation, Texas', Sedimentology. Blackwell Publishing Ltd, 34(6), pp. 1029-1054. doi: 10.1111/j.1365-3091.1987.tb00591.x.

Jagniecki, E. A. and Benison, K. C. (2010) 'Criteria for the recognition of acid-precipitated halite', Sedimentology, 57(1), pp. 273-292. doi: 10.1111/j.1365-3091.2009.01112.x.

James, N. P., Models, F. and Walker, E. R. G. (1984) 'Facies Models'. Edited by R. Walker. Geological Association of Canada, pp. 229-244.

Jawhari, T., Roid, A. and Casado, J. (1995) 'Raman spectroscopic characterization of some commercially available carbon black materials', Carbon, 33(11), pp. 1561-1565. doi: 10.1016/0008-6223(95)00117-V.

Kah, L. C. and Bartley, J. K. (2011) 'Protracted oxygenation of the Proterozoic biosphere', International Geology Review. Taylor \& Francis, 53(11-12), pp. 1424-1442. doi: 10.1080/00206814.2010.527651.

Karmanocky, F. J. and Benison, K. C. (2016) 'A fluid inclusion record of magmatic/hydrothermal pulses in acid Salar Ignorado gypsum, northern Chile', Geofluids, 16(3), pp. 490-506. doi: 10.1111/gfl.12171.

Katz, A. and Starinsky, A. (2009) 'Geochemical history of the Dead Sea', Aquatic Geochemistry, 15(1-2), pp. 159-194. doi: 10.1007/s10498-008-9045-0.

Kovalevych, V.M., Peryt, T.M. and Petrichenko, O.I., 1998. Secular variation in seawater chemistry during the Phanerozoic as indicated by brine inclusions in halite. The Journal of geology, 106(6), pp. 695-712.

Kovalevych, V. M., Marshall, T., Peryt, T. M., Petrychenko, O. Y. and Zhukova, S. A. (2006) 'Chemical composition of seawater in Neoproterozoic: Results of fluid inclusion study of halite from Salt Range (Pakistan) and Amadeus Basin (Australia)', Precambrian Research, 144(1-2), pp. 39-51. doi: 10.1016/j.precamres.2005.10.004.

LaClair, D. and Lowenstein, T. (2009) 'Fluid inclusion microthermometry from halite in the Eocene Green River Formation, Piceance Creek basin, Colorado, USA: evidence for a perennial stratified saline lake', Geological Society of America, Annual Meeting.

Lindsay, J. F. (1987) 'Upper Proterozoic evaporites in the Amadeus basin, central Australia, and their role in basin tectonics', Geological Society of America Bulletin, 99, pp. 852-865.

Long, D. T. and Lyons, W. B. (1992) 'Aridity, continental weathering, and ground-water chemistry', GSA Today, p. 185-186,188.

Lowenstein, T. K. and Hardie, L. A. (1985) 'Criteria for the recognition of salt-pan evaporites', Sedimentology, 32(5), pp. 627-644. doi: 10.1111/j.13653091.1985.tb00478.x. 
Lowenstein, T. K. and Risacher, F. (2009) 'Closed basin brine evolution and the influence of Ca$\mathrm{Cl}$ inflow waters: Death Valley and Bristol Dry Lake California, Qaidam Basin, China, and Salar de Atacama, Chile', Aquatic Geochemistry, 15(1-2), pp. 71-94. doi: 10.1007/s10498-008-9046-z.

Lowenstein, T. K., Timofeeff, M. N., Kovalevych, V. M. and Horita, J. (2005) 'The major-ion composition of Permian seawater', Geochimica et Cosmochimica Acta, 69(7), pp. 17011719. doi: 10.1016/j.gca.2004.09.015.

Macdonald, F. A., Schmitz, M. D., Crowley, J. L., Roots, C. F., Jones, D. S., Maloof, A. C., Strauss, J. V., Cohen, P. A., Johnston, D. T. and Schrag, D. P. (2010) 'Calibrating the Cryogenian', Science, 327(5970), pp. 1241-1243. doi: 10.1126/science.1183325.

MacDonald, G. J. F. (1953) 'Anhydrite-gypsum equilibrium relations', American Journal of Science. American Journal of Science, 251(12), pp. 884-898. doi: 10.2475/ajs.251.12.884.

Machel, H. G. and Burton, E. A. (1991) 'Burial-diagenesis sabkha-like gypsum and anhydrite nodules.', J.Sed.Petrol., 61(3), pp. 394-405. doi: 10.1306/D4267721-2B26-11D78648000102C1865D.

Makreski, P., Jovanovski, G. and Dimitrovska, S. (2005) 'Minerals from Macedonia: XIV. Identification of some sulfate minerals by vibrational (infrared and Raman) spectroscopy', Vibrational Spectroscopy, 39(2), pp. 229-239. doi: 10.1016/j.vibspec.2005.04.008.

Maubec, N., Lahfid, A., Lerouge, C., Wille, G. and Michel, K. (2012) 'Characterization of alunite supergroup minerals by Raman spectroscopy', Spectrochimica Acta - Part A: Molecular and Biomolecular Spectroscopy, 96(July 2016), pp. 925-939. doi: 10.1016/j.saa.2012.07.094.

Mormile, M. R. and Storrie-Lombardi, M. (2012) 'The use of ultraviolet excitation of native fluorescence for identifying biomarkers in halite crystals (5906A-27)', Proceedings of the SPIE Vol. 5906, Astrobiology and Planetary Missions, 5906, pp. 246-253. doi: 10.1117/12.616906.

Munsell, A. H. (1912) 'A Pigment Color System and Notation', The American Journal of Psychology, 23(2), p. 236. doi: 10.2307/1412843.

Myers, J. S., Shaw, R. D. and Tyler, I. M. (1996) 'Tectonic evolution of Proterozoic Australia', Tectonics, 15(6), pp. 1431-1446. doi: 10.1029/96TC02356.

Nadeau, J. L., Perreault, N. N., Niederberger, T. D., Whyte, L. G., Sun, H. J. and Leon, R. (2008) 'Fluorescence microscopy as a tool for in situ life detection.', Astrobiology, 8(4), pp. 859-874. doi: 10.1089/ast.2007.0043.

Ossorio, M., Driessche, A. E. S. Van, Pérez, P. and García-ruiz, J. M. (2014) 'The gypsum anhydrite paradox revisited', Chemical Geology, 386, pp. 16-21. doi: 10.1016/j.chemgeo.2014.07.026. 
Playa, E., Cendon, D. I., Trava, A., Chivas, A. R. and Garcia, A. (2007) 'Non-marine evaporites with both inherited marine and continental signatures: The Gulf of Carpentaria, Australia, at 70 ka', Sedimentary Geology, 201(3-4), pp. 267-285. doi:

10.1016/j.sedgeo.2007.05.010.

Raman, C. V (1928) 'A new radiation', Proceedings of the Indian Academy of Sciences - Section A, 2, pp. 387-398. doi: 10.1007/BF03052651.

Retallack, G. J., Gose, B. N. and Osterhout, J. T. (2015) 'Periglacial paleosols and Cryogenian paleoclimate near Adelaide, South Australia', Precambrian Research. Elsevier B.V., 263(July), pp. 1-18. doi: 10.1016/j.precamres.2015.03.002.

Roedder, E., d'Angelo, W. M., Dorrzapf, A. F. and Aruscavage, P. J. (1987) 'Composition of fluid inclusions in Permian salt beds, Palo Duro Basin, Texas, U.S.A.', Chemical Geology, 61(1-4), pp. 79-90. doi: 10.1016/0009-2541(87)90029-5.

Ruan, H. D., Frost, R. L. and Kloprogge, J. T. (2001) 'Comparison of Raman spectra in characterizing gibbsite, bayerite, diaspore and boehmite', Journal of Raman Spectroscopy. John Wiley \& Sons, Ltd., 32(9), pp. 745-750. doi: 10.1002/jrs.736.

Rudolph, W. W. and Mason, R. (2001) 'Study of aqueous $\mathrm{Al}_{2}\left(\mathrm{SO}_{4}\right)_{3}$ solution under hydrothermal conditions: Sulfate ion pairing, hydrolysis, and formation of hydronium alunite', Journal of Solution Chemistry, 30(6), pp. 527-548. doi: 10.1023/A:1010334818580.

Satterfield, C. L., Lowenstein, T. K., Vreeland, R. H. and Rosenzweig, W. D. (2005) 'Paleobrine temperatures, chemistries, and paleoenvironments of Silurian Salina formation F-1 salt, Michigan Basin, U.S.A., from petrography and fluid inclusions in halite', Journal of Sedimentary Research, 75(4), pp. 534-546. doi: 10.2110/jsr.2005.044.

Schopf, J. W., Kudryavtsev, A. B., Agresti, D. G., Czaja, A. D. and Wdowiak, T. J. (2005) 'Raman imagery: a new approach to assess the geochemical maturity and biogenicity of permineralized precambrian fossils.', Astrobiology, 5(3), pp. 333-371. doi: 10.1089/ast.2005.5.333.

Schopf, J. W., Kudryavtsev, A. B., Agresti, D. G., Wdowiak, T. J. and Czaja, A. D. (2002) 'LaserRaman imagery of Earth's earliest fossils', Nature, 416(6876), pp. 73-76. doi: 10.1038/416073a.

Schreiber, B. C. and El Tabakh, M. (2000) 'Deposition and early alteration of evaporites', Sedimentology, 47(SUPPL. 1), pp. 215-238. doi: 10.1046/j.13653091.2000.00002.x.

Schubert, B. A., Lowenstein, T. K. and Timofeeff, M. N. (2009) 'Microscopic Identification of Prokaryotes in Modern and Ancient Halite, Saline Valley and Death Valley, California', Astrobiology, 9(5), pp. 467-482. doi: 10.1089/ast.2008.0282.

Scotese, C. R. (2009) 'Late Proterozoic plate tectonics and palaeogeography: a tale of two supercontinents, Rodinia and Pannotia', Geological Society, London, Special Publications, 326(1), pp. 67-83. doi: 10.1144/SP326.4. 
Shaw, R. D., Etheridge, M. A. and Lambeck, K. (1991) 'Development of the Late Proterozoic to Mid-Paleozoic, intracratonic Amadeus Basin in central Australia: A key to understanding tectonic forces in plate interiors', Tectonics, 10(4), pp. 688-721. doi: 10.1029/90TC02417.

Shearman, D. (1970) 'Recent halite rock, Baja California, Mexico', Institution of Mining \& Metallurgy.

Shearman, D. (1978) 'Halite in sabkha environments', Marine evaporites, pp. 30-42.

Simeonova, A. P. and lasky, R. P. (2004) Seismic mapping, salt deformation, and hydrocarbon potential of the central western Officer Basin, Western Australia, Western Basin: Geological Survey of Western Australia.

Smoot, J. P. and Castens-Seidell, B. (1994) 'Sedimentary features produced by efflorescent salt crusts, Saline Valley and Death Valley, California'.

Smoot, J. P. and Lowenstein, T. K. (1991) 'Chapter 3 Depositional Environments of Non-Marine Evaporites', in Developments in Sedimentology. 50th edn, pp. 189-347. doi: 10.1016/S0070-4571(08)70261-9.

Spear, N. (2013) A multidisciplinary analysis of evaporite rocks from the mid-Neoproterozoic Browne Formation, Officer Basin, Western Australia. University of Pennsylvania.

Spear, N., Holland, H. D., Garcia-Veigas, J., Lowenstein, T. K., Giegengack, R. and Peters, H. (2014) 'Analyses of fluid inclusions in Neoproterozoic marine halite provide oldest measurement of seawater chemistry', Geology, 42(2), pp. 103-106. doi: 10.1130/G34913.1.

Spence, G. H., Le Heron, D. P. and Fairchild, I. J. (2016) 'Sedimentological perspectives on climatic, atmospheric and environmental change in the Neoproterozoic Era', Sedimentology, 63(2), pp. 253-306. doi: 10.1111/sed.12261.

Squyres, S. W., Grotzinger, J. P., Arvidson, R. E., Bell, J. F., Calvin, W., Christensen, P. R., Clark, B. C., Crisp, J. A., Farrand, W. H., Herkenhoff, K. E., Johnson, J. R., Klingelhöfer, G., Knoll, A. H., McLennan, S. M., McSween, H. Y., Morris, R. V, Rice, J. W., Rieder, R. and Soderblom, L. A. (2004) 'In situ evidence for an ancient aqueous environment at Meridiani Planum, Mars.', Science (New York, N.Y.), 306(5702), pp. 1709-1714. doi: 10.1126/science.1104559.

Stein, C. L. and Krumhansl, J. L. (1988) 'A model for the evolution of brines in salt from the lower Salado Formation, southeastern New Mexico', Geochimica et Cosmochimica Acta, 52(5), pp. 1037-1046. doi: 10.1016/0016-7037(88)90258-X.

Stevens, M. K. and Apak, S. N. (1999) 'GSWA Empress 1 and 1A well completion report Yowalga Sub-basin, Officer Basin Western Australia', Geological Survey of Western Australia Record, 1999/4, p. 118pp.

Stewart, A. J. (1979) 'A barred-basin marine evaporite in the Upper Proterozoic of the Amadeus 
Basin, central Australia', Sedimentology, 26, pp. 33-62.

Sun, Q. and Qin, C. (2011) 'Raman OH stretching band of water as an internal standard to determine carbonate concentrations', Chemical Geology, 283(3-4), pp. 274-278. doi: 10.1016/j.chemgeo.2011.01.025.

Swanson-Hysell, N. L., Maloof, A. C., Condon, D. J., Jenkin, G. R. T., Alene, M., Tremblay, M. M., Tesema, T., Rooney, A. D. and Haileab, B. (2015) 'Stratigraphy and geochronology of the Tambien Group, Ethiopia: Evidence for globally synchronous carbon isotope change in the Neoproterozoic', Geology, 43(4), pp. 323-326. doi: 10.1130/G36347.1.

Taj, R. J. and Aref, M. A. (2015) 'Structural and textural characteristics of surface halite crusts of a supratidal, ephemeral halite pan, South Jeddah, Red Sea Coast, Saudi Arabia', Facies, 61(2). doi: 10.1007/s10347-014-0426-0.

Timofeeff, M. N., Lowenstein, T. K. and Blackburn, W. H. (2000) 'ESEM-EDS: an improved technique for major element chemical analysis of fluid inclusions', Chemical Geology, 164(3), pp. 171-181. doi: 10.1016/S0009-2541(99)00153-9.

Timofeeff, M. N., Lowenstein, T. K., da Silva, M. A. M. and Harris, N. B. (2006) 'Secular variation in the major-ion chemistry of seawater: Evidence from fluid inclusions in Cretaceous halites', Geochimica et Cosmochimica Acta, 70(8), pp. 1977-1994. doi: 10.1016/j.gca.2006.01.020.

Tomikawa, K. and Kanno, H. (1998) 'Raman Study of Sulfuric Acid at Low Temperatures', The Journal of Physical Chemistry A, 102(30), pp. 6082-6088. doi: 10.1021/jp980904v.

Valyashko, M. (1956) 'Geochemistry of bromine in the processes of salt deposition and the use of the bromine content as a genetic and prospecting criterion', Geochemistry.

Vargas Jentzsch, P., Bolanz, R. M., Ciobotă, V., Kampe, B., Rösch, P., Majzlan, J. and Popp, J. (2012) 'Raman spectroscopic study of calcium mixed salts of atmospheric importance', Vibrational Spectroscopy, 61, pp. 206-213. doi: 10.1016/j.vibspec.2012.03.007.

Vreeland, R. H., Rosenzweig, W. D. and Powers, D. W. (2000) 'Isolation of a 250 million-yearold halotolerant bacterium from a primary salt crystal', Nature, 407(6806), pp. 897-900. doi: $10.1038 / 35038060$.

Wagner, J., Ramsteiner, M., Wild, C. and Koidl, P. (1989) 'Resonant Raman scattering of amorphous carbon and polycrystalline diamond films', Physical Review B, 40(3), pp. 1817-1824. doi: 10.1103/PhysRevB.40.1817.

Winters, Y. D., Lowenstein, T. K. and Timofeeff, M. N. (2013) 'Identification of carotenoids in ancient salt from Death Valley, Saline Valley, and Searles Lake, California, using laser Raman spectroscopy.', Astrobiology, 13(11), pp. 1065-80. doi: 10.1089/ast.2012.0952. 


\section{Appendix I. Core and Fluid Inclusion Petrography}

This section highlights sampling intervals. An image of each core shows core-scale features and sampling zones. Note, the reported sampling interval and the recorded length of core may differ somewhat, both are reported with the image of the core for clarity. Each interval has a table that discusses the details of each chip sampled from the interval. The dominant fluid inclusion assemblage type (primary, secondary, or not present - massive) is listed. Comments on the contents of inclusions (vapor, solids, or lack thereof) and their optical properties are also recorded. The inclusion sizes are given as three ranges, the first is the largest primary fluid inclusion sizes seen, the second is the mid-range of fluid inclusion sizes seen, and the last is the smaller range of inclusions seen. All images that were collected during petrography were named by the convention outlined in Table 20.

Table 20. Guide to interpreting titles of image files.

\begin{tabular}{|l|l|}
\hline \multicolumn{2}{|l|}{ Image file naming explanation - example E.8.A.2.P_200um scale_40*2x } \\
\hline section of name & what it means \\
\hline E.8.A.2.P_ & Chip name and area where scanned, see prior explanation \\
\hline 200 um scale_ & length of scale in image \\
\hline $40 \star 2 x$. & magnification level \\
\hline $\begin{array}{l}\text { Note: The name may be longer, if there is something notable seen in the image, this information is usually } \\
\text { after the magnification level. }\end{array}$ \\
\hline
\end{tabular}


Empress 1A, Interval 2 (1520.22-1520.0 m)

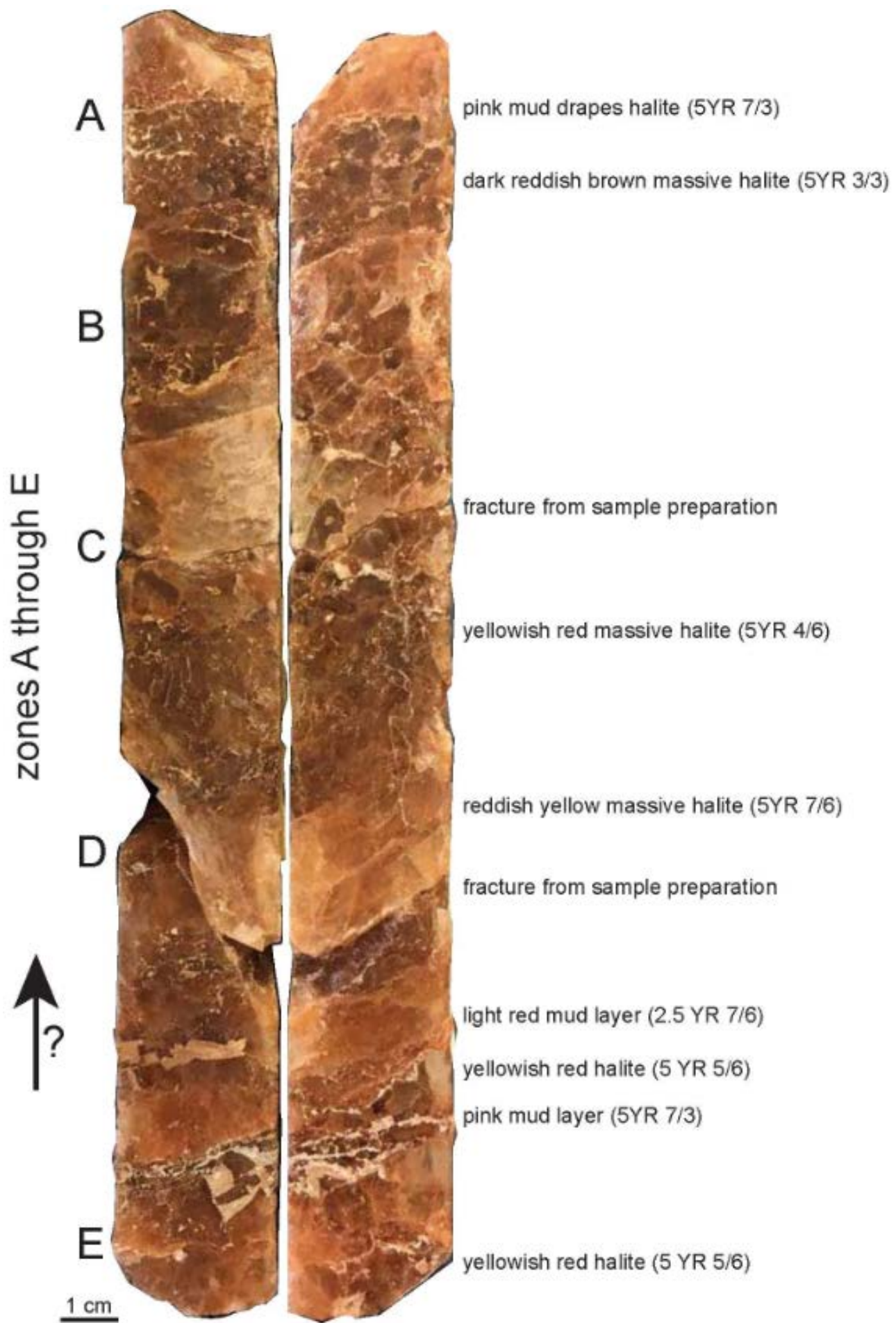

Figure 32: Image of Empress 1 A core with description, interval 2, 1520.22 - $1520.0 \mathrm{~m}(21.8 \mathrm{~cm})$, image of polished slab in daylight 
Table 21: Empress 1A, Interval 2 (1520.22 - $1520.0 \mathrm{~m})$, results of halite chip fluid inclusion examination.

\begin{tabular}{|c|c|c|c|c|c|c|c|c|c|c|c|}
\hline 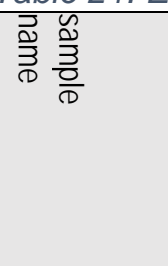 & 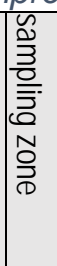 & 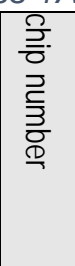 & 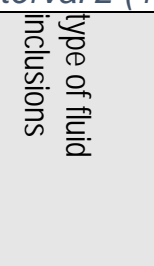 & 产. & 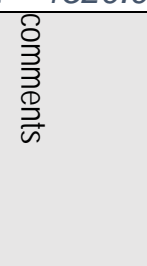 & 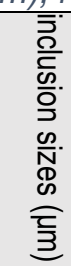 & 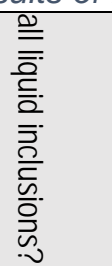 & 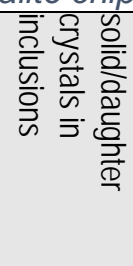 & 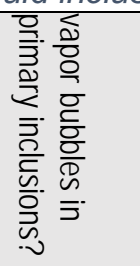 & 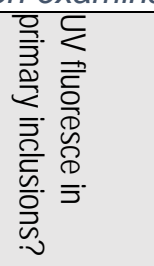 & 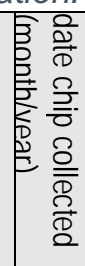 \\
\hline E.2.A.S,P? & A & $\mathrm{N} / \mathrm{A}$ & secondary & 1 & $\begin{array}{l}\text { lots of } \\
\text { secondar } \\
\text { y } \\
\text { inclusions } \\
\text {, may } \\
\text { contain } \\
\text { some } \\
\text { primaries }\end{array}$ & $\mathrm{N} / \mathrm{A}$ & $N / A$ & $\mathrm{~N} / \mathrm{A}$ & $\mathrm{N} / \mathrm{A}$ & $\begin{array}{l}\text { spherule } \\
\text { solids in } \\
\text { primary } \\
\text { inclusions } \\
\text { fluoresce } \\
\text { yellow }\end{array}$ & $\begin{array}{l}\text { Jun } \\
-16 \\
\end{array}$ \\
\hline E.2.B.S & B & $\mathrm{N} / \mathrm{A}$ & secondary & 0 & $\begin{array}{l}\text { no } \\
\text { primary } \\
\text { fluid } \\
\text { inclusions }\end{array}$ & $\mathrm{N} / \mathrm{A}$ & $N / A$ & $\mathrm{~N} / \mathrm{A}$ & $N / A$ & $\mathrm{~N} / \mathrm{A}$ & $\begin{array}{l}\text { Jun } \\
-16\end{array}$ \\
\hline E.2.C.1.P & C & 1 & primary & 2 & $\begin{array}{l}\text { primary, } \\
\text { but very } \\
\text { small, } \\
\text { some L/V } \\
\text { in the } \\
\text { larger } \\
\text { flincs }\end{array}$ & $\begin{array}{l}100 \\
-70 \\
20- \\
40 \\
<10\end{array}$ & $\begin{array}{l}\text { Some, } \\
\text { smaller }\end{array}$ & $\begin{array}{l}\text { rare, } \\
\text { seen in } \\
\text { some, } \\
\text { acicular }\end{array}$ & $\begin{array}{l}\text { yes, in } \\
\text { larger } \\
\text { inclusions }\end{array}$ & $\mathrm{N} / \mathrm{A}$ & $\begin{array}{l}\text { Jun } \\
-16\end{array}$ \\
\hline E.2.D.1.P & D & N/A & primary & 2 & $\begin{array}{l}\text { few } \\
\text { primary } \\
\text { inclusions } \\
\text { sample is } \\
\text { small }\end{array}$ & $\begin{array}{l}20- \\
50 \\
<5\end{array}$ & $\mathrm{~N} / \mathrm{A}$ & $\mathrm{N} / \mathrm{A}$ & $\mathrm{N} / \mathrm{A}$ & N/A & $\begin{array}{l}\text { Jun } \\
-16\end{array}$ \\
\hline E.2.E.1.P & $\mathrm{E}$ & 1 & primary & 5 & $\begin{array}{l}\text { large chip } \\
\text { with } \\
\text { primaries, } \\
\text { suspect } \\
\text { chevron } \\
\text { in corner }\end{array}$ & $\begin{array}{l}50- \\
150 \\
, 5- \\
20 \\
<5\end{array}$ & $\begin{array}{l}\text { some } \\
\text { are, } \\
\text { many } \\
\text { contain } \\
1 \text { or } \\
\text { more } \\
\text { small } \\
\text { globule } \\
\text { s } \\
\end{array}$ & $\begin{array}{l}\text { yes, } \\
\text { common, } \\
\text { tabular, } \\
\text { aicular, } \\
\text { globular, }\end{array}$ & $\begin{array}{l}\text { none } \\
\text { evident }\end{array}$ & $\begin{array}{l}\text { spherule } \\
\text { solids (1- } \\
2,8 \mu \mathrm{m}) \text { in } \\
\text { primary } \\
\text { inclusions } \\
\text { fluoresce } \\
\text { yellow, } \\
\text { acicular } \\
\text { solids too }\end{array}$ & $\begin{array}{l}\text { Jun } \\
-16 \\
\end{array}$ \\
\hline $\begin{array}{l}\text { E.2.E.2.P } \\
\text { (this sample } \\
\text { split into } \\
\text { E.2.E.2b.P } \\
\text { and } \\
\text { E.2.E.2a.P) }\end{array}$ & $\mathrm{E}$ & 2 & primary & 4 & $\begin{array}{l}\text { chip } \\
\text { larger } \\
\text { than } \\
\text { E.2.E.1.P } \\
\text { chip with } \\
\text { better } \\
\text { primaries }\end{array}$ & $\begin{array}{l}50- \\
200 \\
10- \\
20 \\
<2\end{array}$ & $\begin{array}{l}\text { some } \\
\text { are }\end{array}$ & $\begin{array}{l}\text { Yes, } \\
\text { acicular, } \\
\text { some } \\
\text { solid } \\
\text { inclusion } \\
\text { s are } \\
\text { opaque } \\
\text { and } \\
\text { cubic }\end{array}$ & $\begin{array}{l}\text { only in } \\
\text { large } \\
\text { isolated } \\
\text { inclusions }\end{array}$ & $\begin{array}{l}\text { globular } \\
\text { solids (1-5 } \\
\mu \mathrm{m}, \text { and } \\
12 \\
\mu \mathrm{m}[\text { rare]) } \\
\text { in primary } \\
\text { inclusions } \\
\text { fluoresce } \\
\text { yellow }\end{array}$ & $\begin{array}{l}\text { Jun } \\
-16\end{array}$ \\
\hline
\end{tabular}


The upper portion of interval 2 is largely halite with poor preservation of primary depositional features (zones A-B). The lower portions of this segment (zones C-E), especially in the area with mud layers has excellent samples with well-preserved primary fluid inclusion assemblages. Many primary fluid inclusions in this interval contain solids, vapor bubbles are not common in these inclusions. UV examination reveals primary inclusions1 enclosing globular solids that fluoresce yellow. These fluorescing solids are usually seen in inclusions that also have daughter crystals (likely accidental).

One solid on the surface of sample E.2.E.1.P was identified as a contaminant (likely from sandpaper) in zone E of interval 2 (Figure 33). This opaque irregular solid fluoresced on its edges. This characteristic is common on the edge of samples and is likely contamination from sample preparation.
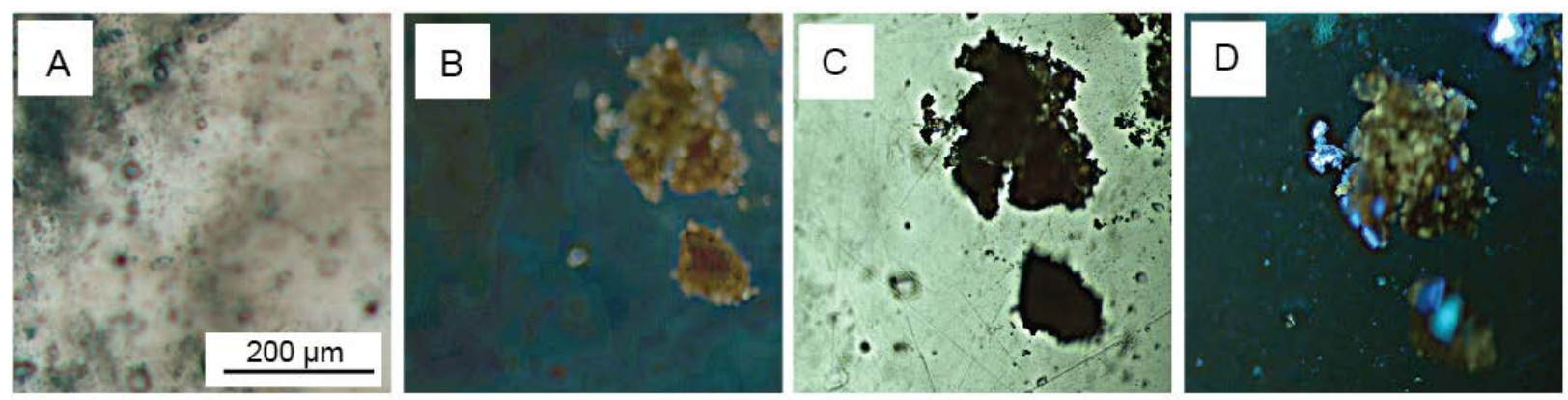

Figure 33. Images of solid contaminant (likely from sandpaper) in zone E of interval 2 (1520.22-1520.0 m; E.2.E.1.P.C). (A) white light, prior to contamination, and (B-D) after contamination, (B) XPL, (C) UV and $P P L,(D) U+V$. Not the fluorescence on the edge of the solid, this characteristic is common on the edge of samples and is likely contamination from sample preparation. 
Empress 1A, Interval 3 (1511.76- $1511.7 \mathrm{~m})$
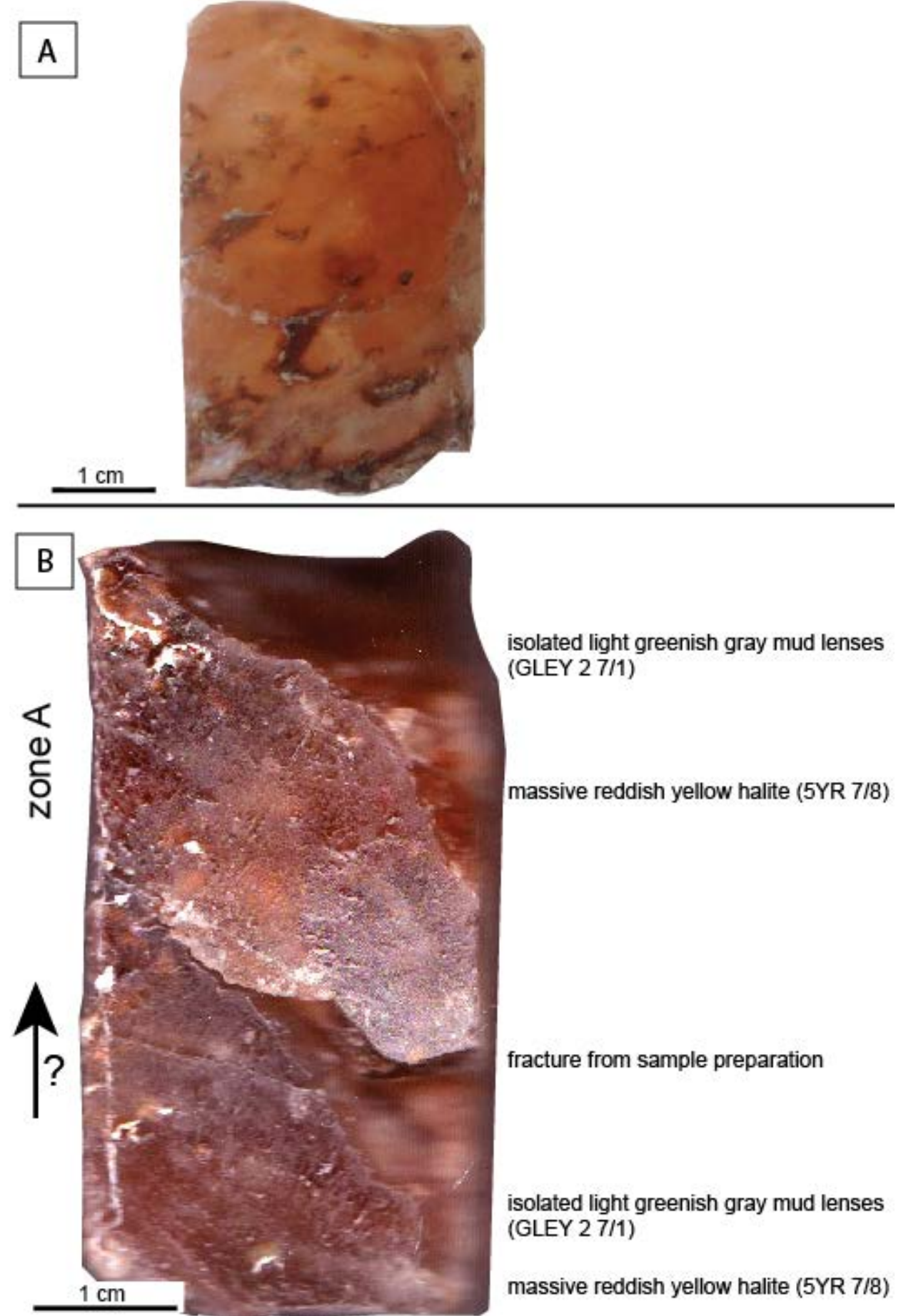

Figure 34: Image of empress 1A core, with description, interval 3, $1511.7 \mathrm{~m}(5.8 \mathrm{~cm})$. (A) Rough core, daylight, $(B)$ rough slab, image from scanner. 
Table 22: Empress 1A, Interval $3(1511.76-1511.7 m)$, results of halite chip fluid inclusion examination.

\begin{tabular}{|c|c|c|c|c|c|c|c|c|c|c|c|}
\hline 产 产 & 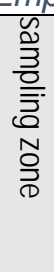 & 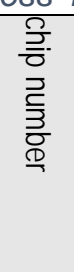 & 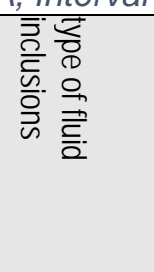 & 言. & 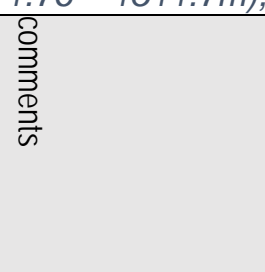 & 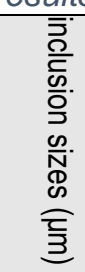 & 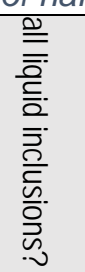 & 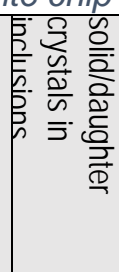 & 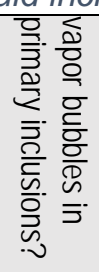 & 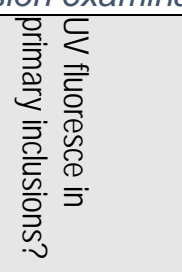 & 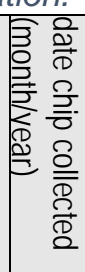 \\
\hline E.3.A.S & A & N/A & secondary & 0 & some secondary's & $\mathrm{N} / \mathrm{A}$ & N/A & $\mathrm{N} / \mathrm{A}$ & $\mathrm{N} / \mathrm{A}$ & N/A & $\begin{array}{l}\text { Jun- } \\
16\end{array}$ \\
\hline E.3.B.1.P & B & 1 & primary & 2 & $\begin{array}{l}\text { located in one } \\
\text { band, rest of } \\
\text { sample is massive. } \\
\text { Attempts at } \\
\text { collecting additional } \\
\text { sample let to } \\
\text { massive halite with } \\
\text { secondary's }\end{array}$ & $\begin{array}{l}50- \\
100 \\
10- \\
30 \\
<5\end{array}$ & most & $\begin{array}{l}\text { rare, } \\
\text { tabular }\end{array}$ & $\begin{array}{l}\text { yes, in } \\
\text { some } \\
\text { large } \\
\text { and } \\
\text { some } \\
\text { small }\end{array}$ & $\begin{array}{l}\text { no } \\
\text { fluorescence }\end{array}$ & $\begin{array}{l}\text { Jun- } \\
16\end{array}$ \\
\hline
\end{tabular}

Interval 3 consists mostly of massive reddish yellow halite with isolated mud lenses.

Only one sample had a small area with a primary fluid inclusions assemblage. These inclusions do not contain any solids, but some contain vapor bubbles. 
Empress 1A, Interval 4 (1502.7 - $1502.6 \mathrm{~m})$

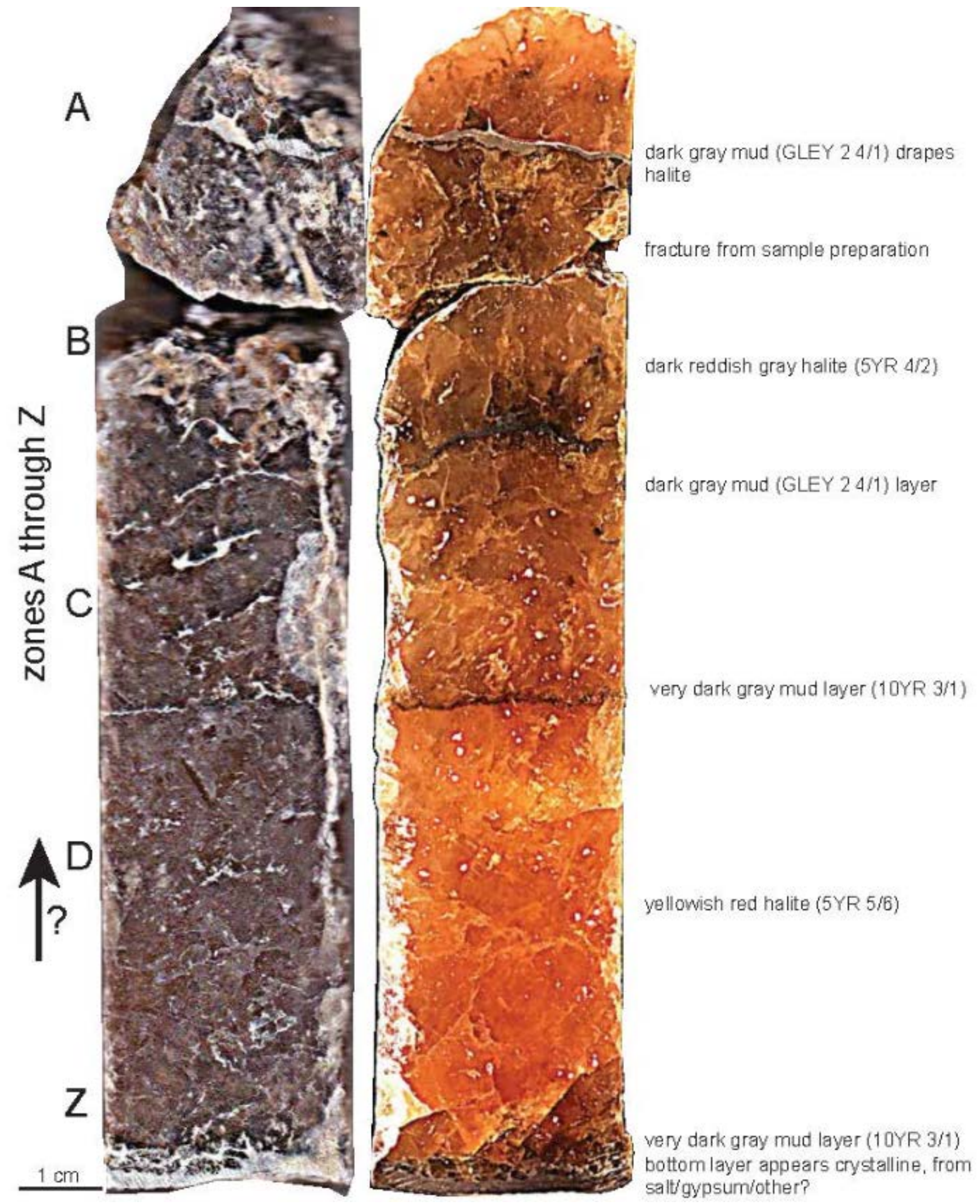

Figure 35: Image of Empress 1A core, with description, interval 4, 1502.7 - $1502.6 \mathrm{~m}$ (13.8 cm). Image of rough slab on left from scanner. Image of rough slab on right in daylight. 
Table 23: Empress 1A, Interval $4(1502.7-1502.6 \mathrm{~m})$, results of halite chip fluid inclusion examination.

\begin{tabular}{|c|c|c|c|c|c|c|c|c|c|c|c|}
\hline 离 & 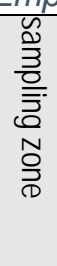 & 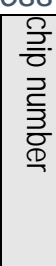 & 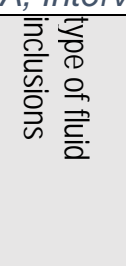 & 产. & 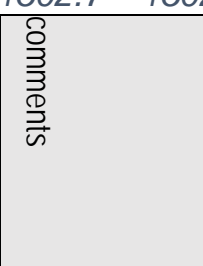 & 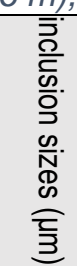 & 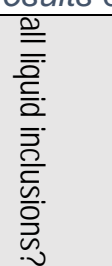 & 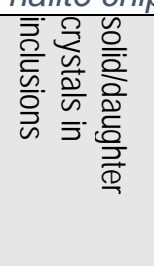 & 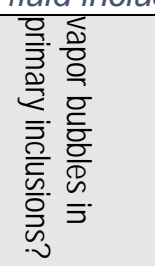 & 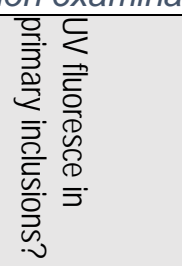 & 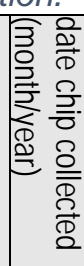 \\
\hline E.4.A.1.P & A & 1 & primary & 5 & $\begin{array}{l}\text { clear chevron } \\
\text { consisting of } \\
\text { primary } \\
\text { inclusions }\end{array}$ & $\begin{array}{l}40- \\
60 \\
10- \\
20 \\
<2 \\
\end{array}$ & rare & $\begin{array}{l}\text { yes, thin } \\
\text { tabular in } \\
\text { most }\end{array}$ & $\begin{array}{l}\text { none } \\
\text { evident }\end{array}$ & $\begin{array}{l}\text { no } \\
\text { fluorescence }\end{array}$ & $\begin{array}{l}\text { Jun- } \\
16\end{array}$ \\
\hline E.4.A.2.P & A & 2 & primary & 3 & \begin{tabular}{|l|} 
some \\
primaries, not \\
great growth \\
bands, some \\
L/S inclusions, \\
some solid \\
inclusions \\
(anhydrite? - \\
needle), no \\
fluorescence \\
in primary \\
inclusions \\
\end{tabular} & $\begin{array}{l}50- \\
100 \\
10- \\
20 \\
<5\end{array}$ & rare & $\begin{array}{l}\text { yes, } \\
\text { tabular, } \\
\text { cubic, } \\
\text { acicular, } \\
\text { in most }\end{array}$ & $\mathrm{N} / \mathrm{A}$ & $\mathrm{N} / \mathrm{A}$ & $\begin{array}{l}\text { Jun- } \\
16\end{array}$ \\
\hline E.4.B.1.P & B & 1 & primary & 5 & $\begin{array}{l}\text { some clear } \\
\text { primaries, } \\
\text { very clear } \\
\text { chevron }\end{array}$ & $\begin{array}{l}20- \\
200, \\
5- \\
20 \\
<2\end{array}$ & rare & $\begin{array}{l}\text { acicular } \\
\text { and } \\
\text { tabular in } \\
\text { many, } \\
\text { small } \\
\text { spherules } \\
\text { in small } \\
\text { inclusions }\end{array}$ & $\begin{array}{l}\text { only in } \\
\text { large fluid } \\
\text { inclusions }\end{array}$ & $\begin{array}{l}\text { no } \\
\text { fluorescence }\end{array}$ & $\begin{array}{l}\text { Jun- } \\
16\end{array}$ \\
\hline E.4.B.2.P & B & 2 & primary & 2 & \begin{tabular}{|l|} 
some clear \\
primaries, but \\
not many, not \\
a great \\
sample
\end{tabular} & $\begin{array}{l}50- \\
70 \\
<10\end{array}$ & $N / A$ & $N / A$ & $\mathrm{~N} / \mathrm{A}$ & $N / A$ & $\begin{array}{l}\text { Jun- } \\
16\end{array}$ \\
\hline E.4.C.2.P & C & 2 & primary & 2 & \begin{tabular}{|l|} 
some solid \\
inclusions, \\
some \\
primaries, \\
larger sample
\end{tabular} & $\begin{array}{l}50- \\
100, \\
10- \\
30 \\
<3\end{array}$ & some & $\begin{array}{l}\text { acicular, } \\
\text { suspect, } \\
\text { globular in } \\
\text { half }\end{array}$ & rare & $\mathrm{N} / \mathrm{A}$ & $\begin{array}{l}\text { Jun- } \\
16\end{array}$ \\
\hline E.4.C.1.P & C & 1 & primary & 1 & \begin{tabular}{|l|} 
some solid \\
inclusions, \\
small sample
\end{tabular} & $<30$ & N/A & yes & $\mathrm{N} / \mathrm{A}$ & $N / A$ & $\begin{array}{l}\text { Jun- } \\
16\end{array}$ \\
\hline E.4.D.1.P & D & 1 & primary & 4 & $\begin{array}{l}\text { some nice } \\
\text { primaries, } \\
\text { suspect } \\
\text { chevron }\end{array}$ & $\begin{array}{l}200- \\
70 \\
20- \\
40 \\
<3\end{array}$ & $\begin{array}{l}\text { rare, } \\
\text { seen in } \\
\text { section } \\
B \text { and } \\
X\end{array}$ & $\begin{array}{l}\text { majority } \\
\text { have } \\
\text { acicular or } \\
\text { tabular } \\
\text { solids }\end{array}$ & $\begin{array}{l}\text { rare, seen } \\
\text { as large } \\
\text { bubbles in } \\
\text { inclusions }\end{array}$ & $\begin{array}{l}\text { no } \\
\text { fluorescence }\end{array}$ & $\begin{array}{l}\text { Jun- } \\
16\end{array}$ \\
\hline
\end{tabular}




\begin{tabular}{|c|c|c|c|c|c|c|c|c|c|c|c|}
\hline E.4.D.2.P & D & 2 & primary & 2 & $\begin{array}{l}\text { potential } \\
\text { primaries }\end{array}$ & $\begin{array}{l}50- \\
30 \\
<10\end{array}$ & $\mathrm{~N} / \mathrm{A}$ & $\mathrm{N} / \mathrm{A}$ & $N / A$ & $N / A$ & $\begin{array}{l}\text { Jun- } \\
16\end{array}$ \\
\hline E.4.Z.1.P & Z & 1 & primary & 5 & $\begin{array}{l}\text { clear } \\
\text { inclusions, } \\
\text { can see } \\
\text { cumulate raft, } \\
\text { and fluid } \\
\text { inclusions } \\
\text { form a } \\
\text { chevron }\end{array}$ & $\begin{array}{l}70- \\
200 \\
15- \\
30 \\
<3\end{array}$ & rare & $\begin{array}{l}\text { small } \\
\text { acicular } \\
\text { solid in } \\
\text { most }\end{array}$ & $\begin{array}{l}\text { none } \\
\text { evident }\end{array}$ & $\begin{array}{l}\text { no } \\
\text { fluorescence }\end{array}$ & $\begin{array}{l}\text { Nov- } \\
15\end{array}$ \\
\hline E.4.Z.2.P & Z & 2 & primary & 5 & $\begin{array}{l}\text { good primary } \\
\text { inclusions }\end{array}$ & $\begin{array}{l}50- \\
70 \\
10- \\
20 \\
<2\end{array}$ & $\begin{array}{l}\text { some, } \\
\text { but } \\
\text { most } \\
\text { have } \\
\text { solids } \\
\end{array}$ & $\begin{array}{l}\text { yes, small } \\
\text { solids }\end{array}$ & $\begin{array}{l}\text { cannot } \\
\text { determine } \\
\text { after } \\
\text { freezing/ } \\
\text { melting }\end{array}$ & $\begin{array}{l}\text { no } \\
\text { fluorescence }\end{array}$ & $\begin{array}{l}\text { Nov- } \\
15\end{array}$ \\
\hline
\end{tabular}

The yellowish red to dark reddish gray halite in interval 4 has several thin mud layers. Most zones in this sample have well preserved primary fluid inclusions apart from interval C, which did not have many large primary inclusions. Inclusions in interval 4 have acicular to tabular solids, vapor bubbles are rare in small to medium inclusions, no solids in primary inclusions fluoresced. Sample E.4.Z.2.P was examined via freezing-melting microthermometry. Attempts to make inclusions freeze in this sample were unsuccessful.

Petrographic examination of sample E.4.B.1.P revealed several solids. An anhydrite "spine" with an iron oxide core is present (Figure 37). Further away from the "spine" the presence of anhydrite becomes more diffuse. Fluorescing solids are also seen in association with the "spine's" core. Subrounded detrital halite $(\sim 20 \mu \mathrm{m})$ was also noted in this sample (Figure 38). It is differentiated from more angular accidental halite grains from sample processing, because they lie on the surface of the sample. 


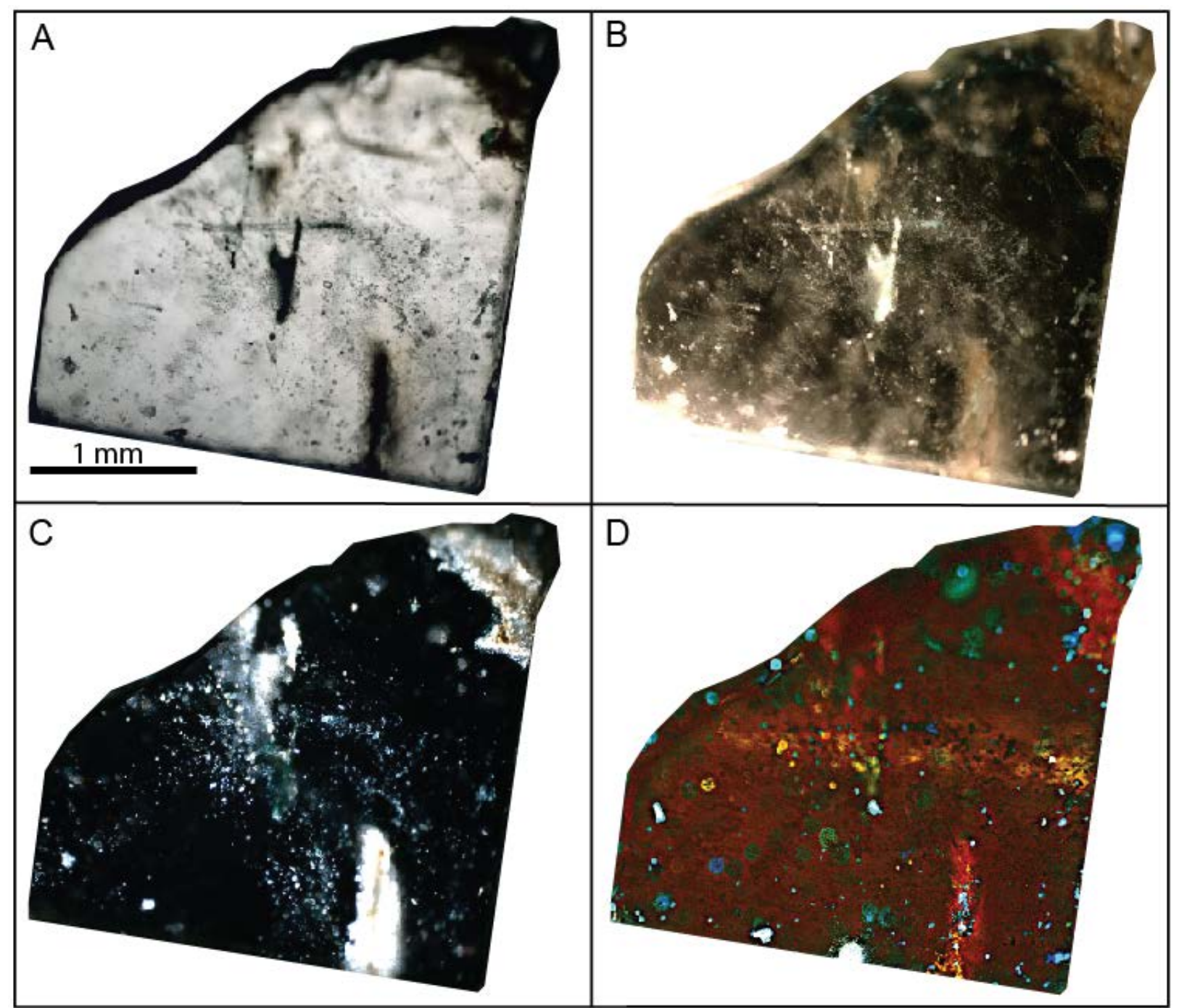

Figure 36: Images demonstrating effect of different lighting in identifying features (Sample: E.4.B.1.P). (A) Plane polarized light provides a general overview of the sample $(A)$, reflected light shows opaque reflective solids $(B)$, while cross polarized light $(C)$ enables differentiation between halite and other solids. UV illumination (D) shows areas with potential organic compounds. 


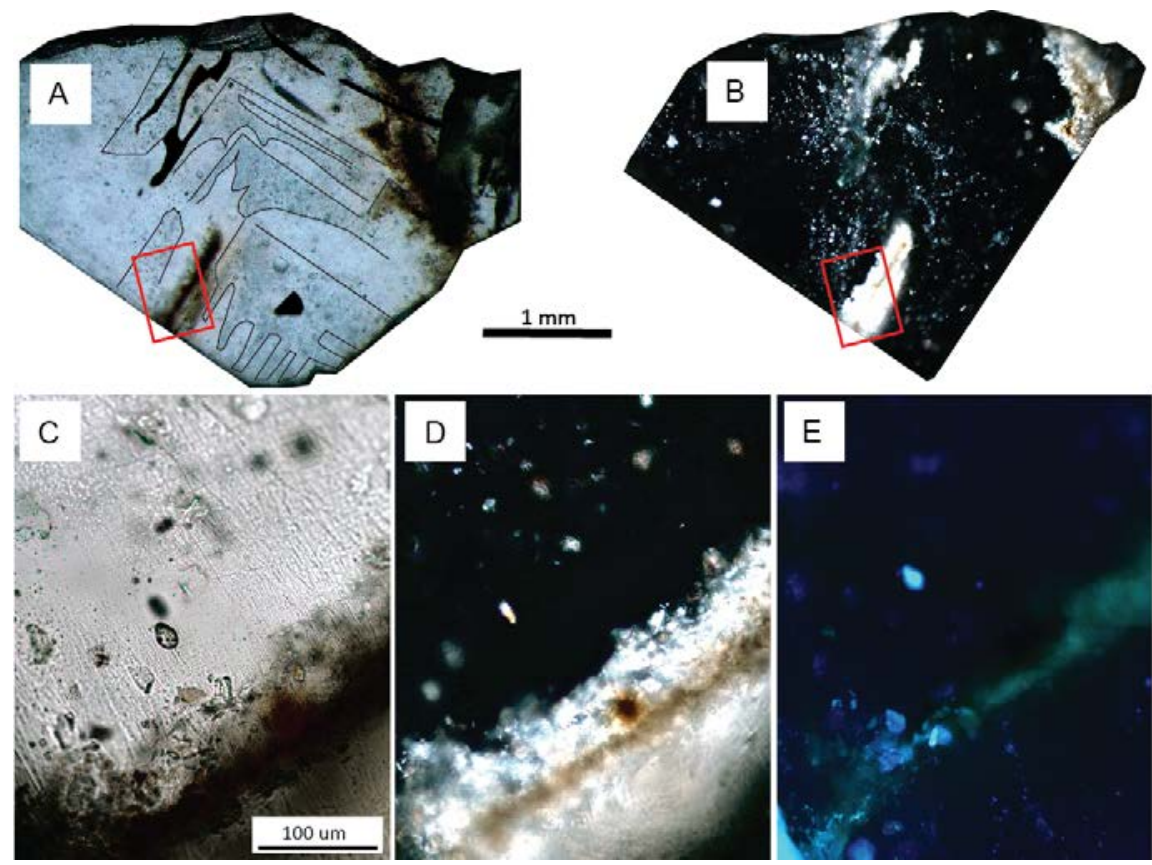

Figure 37. Images of anhydrite in sample from interval 4 under different lighting (sample E.4.B.1.P). (A) Whole sample in plane polarized light. (B) Whole sample is cross polarized light (size of sample changed because it fractured during polishing). Area outlined in red is focused upon in (C) to (E). Lighting under (C) plane polarized light, (D) cross polarized light, (E) UV illumination.

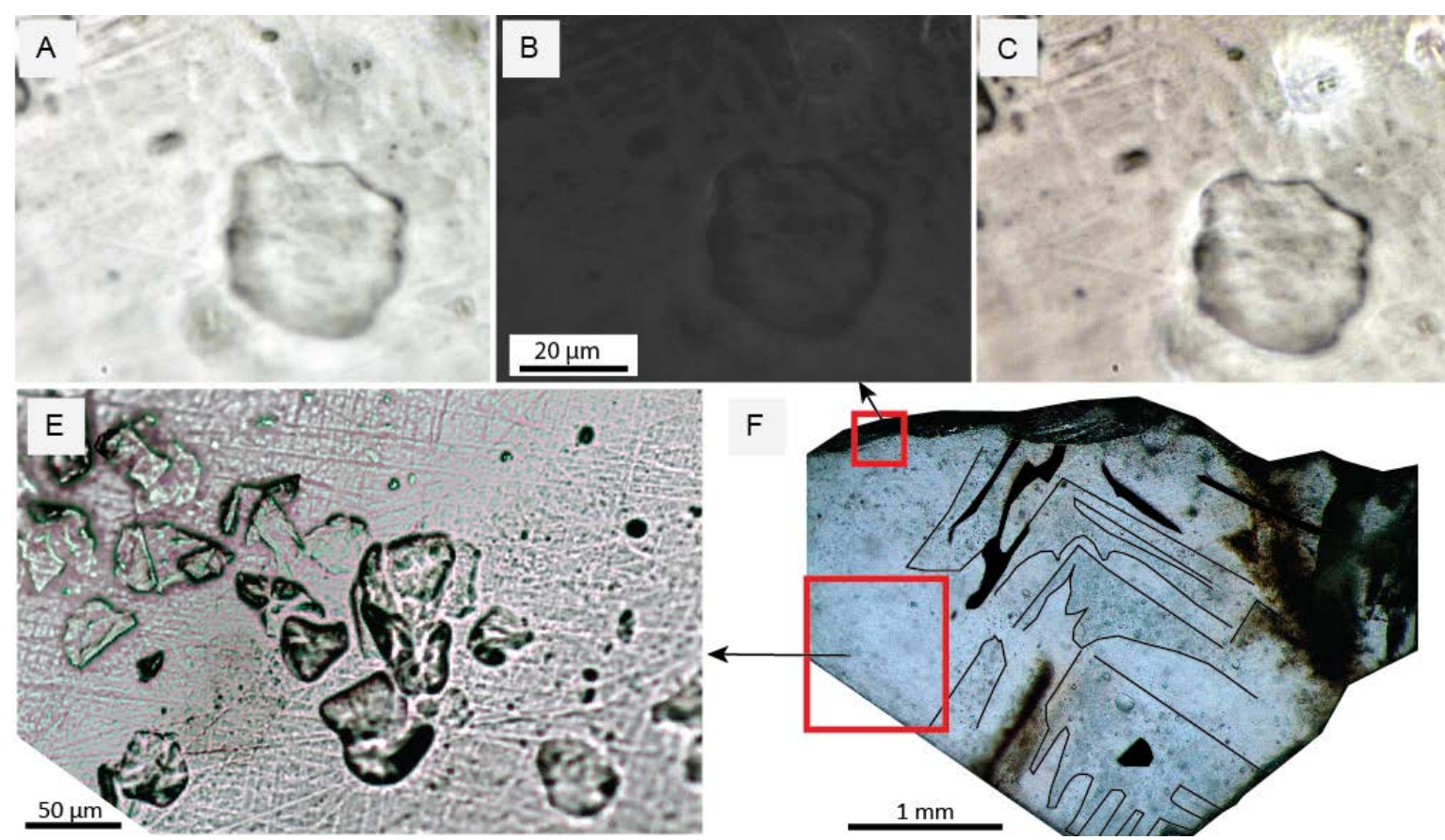

Figure 38. Images of suspect detrital halite in sample from interval 4 under different lighting (sample E.4.B.1.P). Halite "grains" are 20 to $50 \mu \mathrm{m}$ large. (F) Red boxes outline sampling areas. Suspect halite detrital halite grain under $(A)$ plane polarize light, $(B-C)$ cross polarized light. $(E)$ Halite grains on the surface of the sample that likely formed from sample processing during the polishing stage. 
Empress 1A, Interval 5 (1502.25 - $1502.2 \mathrm{~m})$

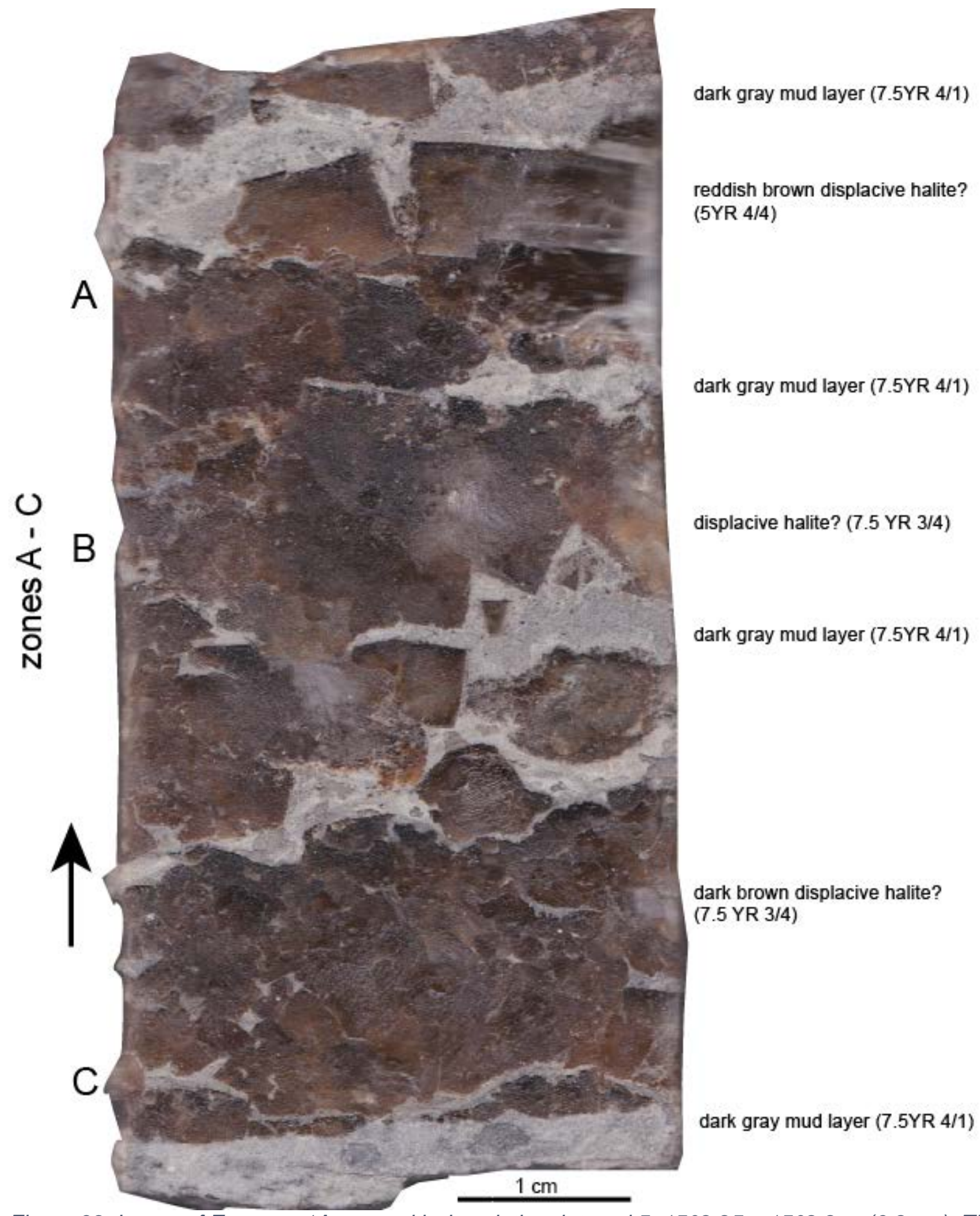

Figure 39: Image of Empress 1A core, with description, interval 5, 1502.25 - $1502.2 \mathrm{~m}(6.8 \mathrm{~cm})$. This interval largely consists of undifferentiated block halite with no inclusions. This interval is continuous with core from interval 6, 1502.29 - $1502.25 \mathrm{~m}$. Image of rough slab from scanner. 
Table 24: Empress 1A, Interval 5 (1502.25 - 1502.2), results of halite chip fluid inclusion examination.

\begin{tabular}{|c|c|c|c|c|c|c|c|c|c|c|c|}
\hline 离 & 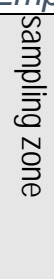 & 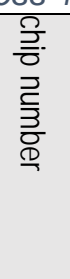 & 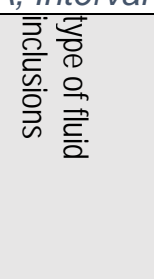 & 言. & 兽 & 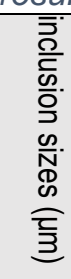 & 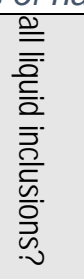 & 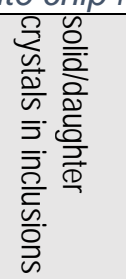 & 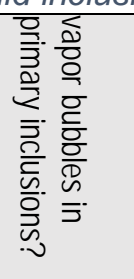 & 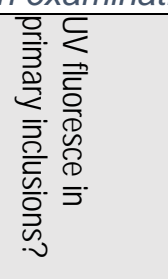 & 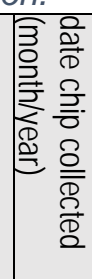 \\
\hline E.5.B.S & B & $\mathrm{N} / \mathrm{A}$ & secondary & 0 & $\begin{array}{l}\text { poor sample, } \\
\text { mostly } \\
\text { secondary's }\end{array}$ & $N / A$ & $\mathrm{~N} / \mathrm{A}$ & $\mathrm{N} / \mathrm{A}$ & $\mathrm{N} / \mathrm{A}$ & $\mathrm{N} / \mathrm{A}$ & $\begin{array}{l}\text { Jun- } \\
16\end{array}$ \\
\hline E.5.C.1.P & C & 1 & primary & 4 & $\begin{array}{l}\text { clear fluid } \\
\text { inclusion } \\
\text { assemblages, } \\
\text { small sample, } \\
\text { faint chevron } \\
\text { outlined in small } \\
\text { inclusions, 10um } \\
\text { or smaller, many } \\
\text { secondary's } \\
\text { inclusions }\end{array}$ & $\begin{array}{l}100- \\
200 \\
15- \\
40 \\
<3\end{array}$ & some & $\begin{array}{l}\text { no, solid } \\
\text { inclusion } \\
\text { in halite }\end{array}$ & $\begin{array}{l}\text { in large } \\
\text { inclusions }\end{array}$ & $\begin{array}{l}\text { no } \\
\text { fluorescence }\end{array}$ & $\begin{array}{l}\text { Jun- } \\
16\end{array}$ \\
\hline E.5.C.2.P & $\mathrm{C}$ & 2 & primary & 3 & $\begin{array}{l}\text { clear fluid } \\
\text { inclusion } \\
\text { assemblages, } \\
\text { larger sample, } \\
\text { faint chevron, } \\
\text { little dirty }\end{array}$ & $\begin{array}{l}100- \\
150 \\
10- \\
30 \\
<3\end{array}$ & $N / A$ & tabular & $\begin{array}{l}\text { rare, only } \\
\text { in large } \\
\text { inclusions }\end{array}$ & $\mathrm{n} / \mathrm{a}$ & $\begin{array}{l}\text { Jun- } \\
16\end{array}$ \\
\hline E.5.C.3.P & C & 3 & primary & 2 & $\begin{array}{l}\text { from same chip } \\
\text { as E.5.C.2.P, for } \\
\text { freezing-melting }\end{array}$ & $\begin{array}{l}50- \\
70 \\
10- \\
20 \\
<2\end{array}$ & $N / A$ & $\begin{array}{l}\text { acicular } \\
\text { in some }\end{array}$ & rare & $\mathrm{N} / \mathrm{A}$ & N/A \\
\hline E.5.Z.1.P & Z & 1 & primary & 2 & $\begin{array}{l}\text { many } \\
\text { secondary's, } \\
\text { some primary's, } \\
\text { dirty sample }\end{array}$ & $\begin{array}{l}50- \\
70 \\
10- \\
20 \\
<3\end{array}$ & some & $\mathrm{N} / \mathrm{A}$ & $\begin{array}{l}\text { rare, } \\
\text { small } \\
\text { vapor } \\
\text { bubble }\end{array}$ & $\mathrm{N} / \mathrm{A}$ & $\begin{array}{l}\text { Nov- } \\
16\end{array}$ \\
\hline
\end{tabular}

Interval 5 does not contain many areas of good halite preservation. This interval consists of blocky brown halite with gray mud draping. The upper part with blocky halite with mud may be displacive as there are only secondary fluid inclusions noted in this region. Only the lower zone (C) contains well preserved halite containing some faint primary fluid inclusion assemblages.

These inclusions do not contain daughter crystals, although there are some solid inclusions in the same zone, inclusions from this zone are small. 
Empress 1A, Interval 6 (1502.29-1502.25 m)

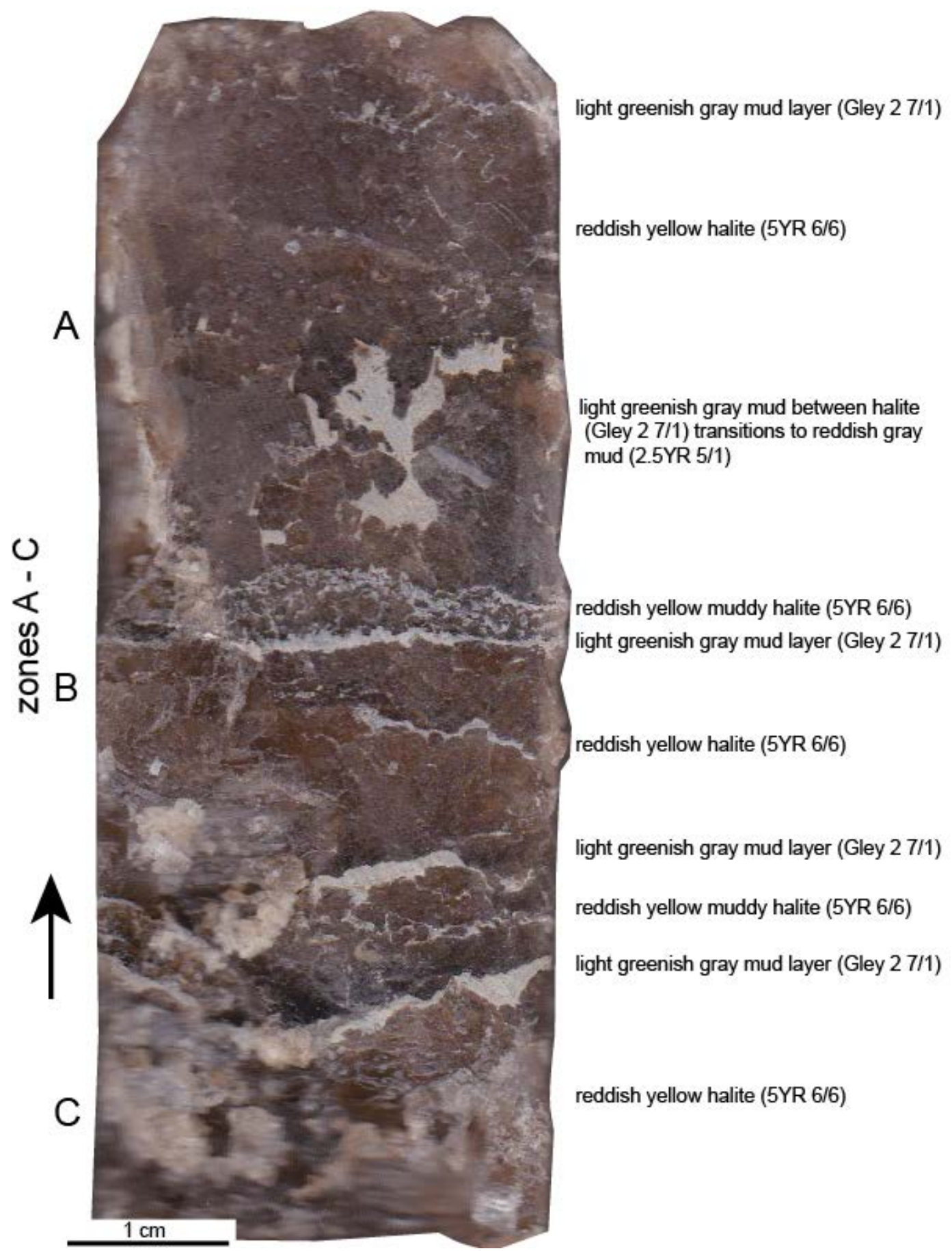

Figure 40: Image of Empress 1A core, with description, interval 6, $1502.29-1502.25 \mathrm{~m}(7.7 \mathrm{~cm})$. A portion of this interval consists of undifferentiated block halite with no inclusions. This interval is continuous with core from interval 5, 1502.25-1502.20 m. Image of rough slab from scanner. 
Table 25: Empress 1A, Interval 6 (1502.29 -1502.25), results of halite chip fluid inclusion examination.

\begin{tabular}{|c|c|c|c|c|c|c|c|c|c|c|c|}
\hline 产农 & $\begin{array}{l}3 \\
3 \\
5 \\
5 \\
5 \\
5 \\
5 \\
5 \\
5\end{array}$ & 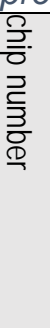 & 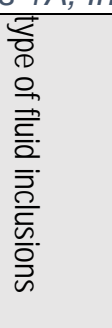 & E. & 总 & 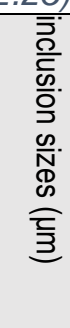 & 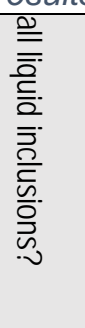 & 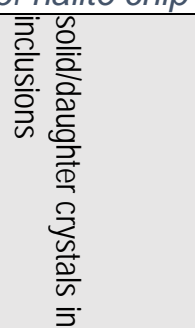 & 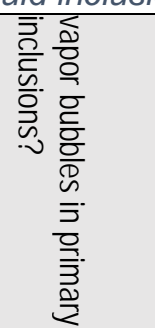 & 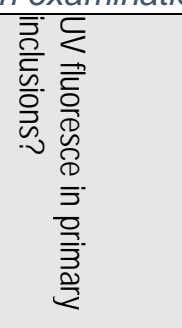 & 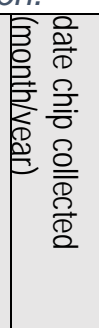 \\
\hline E.6.A.1.P & A & 1 & primary & 2 & $\begin{array}{l}\text { large sample, } \\
\text { primary fluid } \\
\text { inclusions small } \\
\text { and difficult to } \\
\text { focus upon }\end{array}$ & $\begin{array}{l}10- \\
15 \\
<3\end{array}$ & some & $\begin{array}{l}\text { tabular in } \\
\text { many }\end{array}$ & in some & $\mathrm{N} / \mathrm{A}$ & $\begin{array}{l}\text { Jun- } \\
16\end{array}$ \\
\hline E.6.A.2.P & A & 2 & primary & 3 & $\begin{array}{l}\text { small sample with } \\
\text { large vapor } \\
\text { bubble, some } \\
\text { decent fluid } \\
\text { inclusions here }\end{array}$ & $\begin{array}{l}70- \\
100 \\
10- \\
30 \\
<2\end{array}$ & some & yes & $\begin{array}{l}\text { occasional } \\
\text { in large } \\
\text { inclusions, } \\
\text { rare in } \\
\text { small } \\
\text { inclusions }\end{array}$ & $\begin{array}{l}\text { no } \\
\text { fluorescence }\end{array}$ & $\begin{array}{l}\text { Jun- } \\
16\end{array}$ \\
\hline E.6.B.1.P & B & 1 & primary & 2 & $\begin{array}{l}\text { many secondary's, } \\
\text { primary inclusions } \\
\text { are beneath large } \\
\text { secondary } \\
\text { inclusions }\end{array}$ & $\begin{array}{l}40- \\
50 \\
5- \\
20 \\
<2 \\
\end{array}$ & some & $\begin{array}{l}\text { acicular in } \\
\text { some }\end{array}$ & in some & $\mathrm{N} / \mathrm{A}$ & $\begin{array}{l}\text { Jun- } \\
16 \\
\end{array}$ \\
\hline E.6.C.1.P & C & 1 & primary & 2 & $\begin{array}{l}\text { very few primaries } \\
\text { in a very small } \\
\text { section }\end{array}$ & $\begin{array}{l}50- \\
100 \\
20- \\
40, \\
<4\end{array}$ & $\begin{array}{l}\text { major } \\
\text { ity }\end{array}$ & $\begin{array}{l}\text { acicular in } \\
\text { some, opaque } \\
\text { cubic solid } \\
\text { inclusions } \\
(100-600 \mu \mathrm{m}) \\
\text { located in or } \\
\text { near to } \\
\text { primary fluid } \\
\text { inclusions } \\
\end{array}$ & rare & $\mathrm{N} / \mathrm{A}$ & $\begin{array}{l}\text { Jun- } \\
16 \\
\end{array}$ \\
\hline
\end{tabular}

Interval 6 is contiguous with interval 5 . The lower portion of this sample has (zones B-C) very several thin layers of mud which also interfills between crystals. The upper portion (zone A) is largely halite with small mud lenses. The lower portion contains areas very few suspect primary inclusions. The upper portion is slightly better with small primary fluid inclusions containing daughter crystals, vapor is only present in large inclusions. 
Empress 1A, Interval 7 (1499.42-1499.30 m)
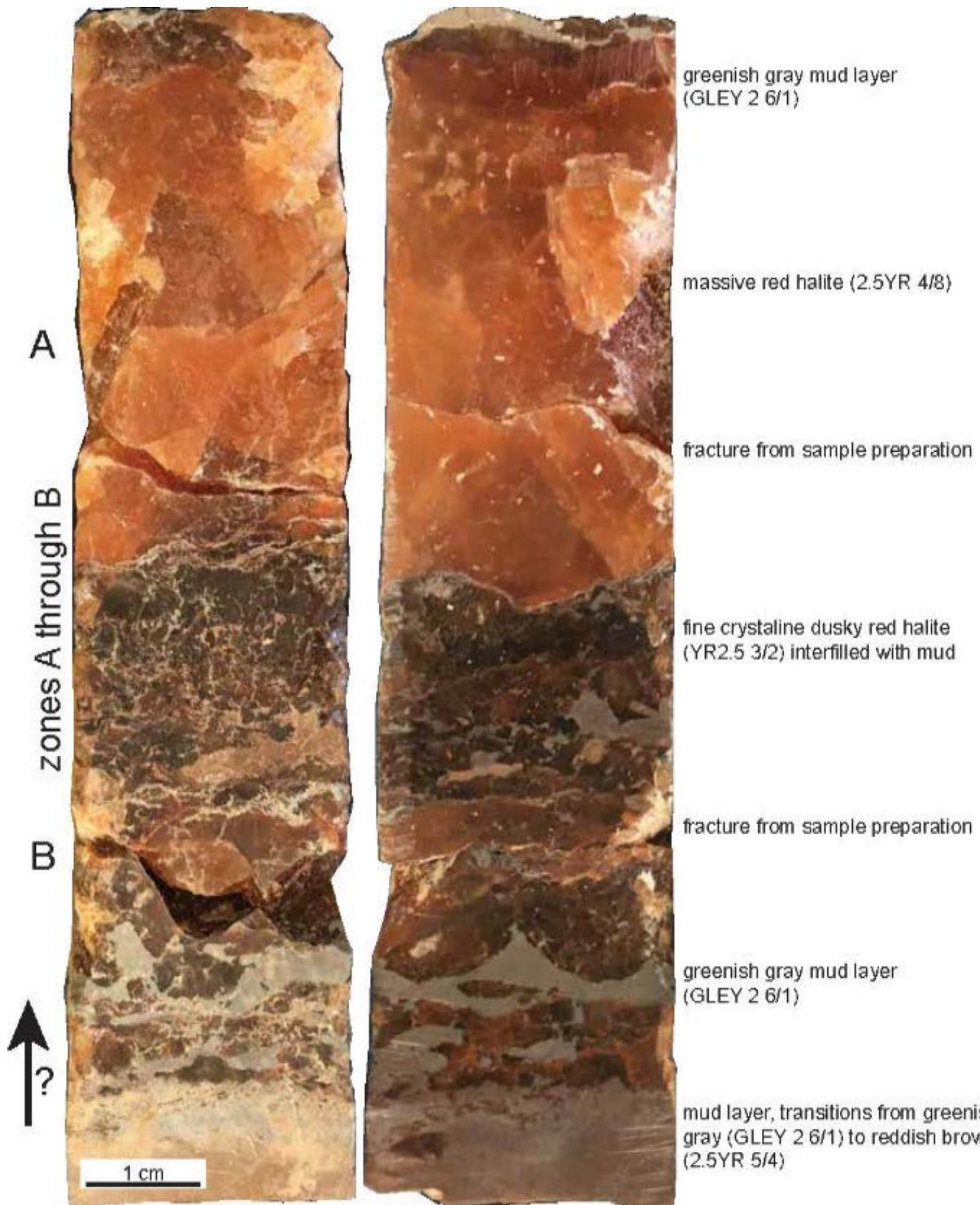

Figure 41: Image of Empress 1A core, with description, interval 7, $1499.42-1499.30 \mathrm{~m}(12.4 \mathrm{~cm})$. Rough slab on left in daylight. Polished slab on right in daylight. 
Table 26: Empress 1A, Interval $7(1499.42-1499.30 \mathrm{~m})$, results of halite chip fluid inclusion examination.

\begin{tabular}{|c|c|c|c|c|c|c|c|c|c|c|c|}
\hline 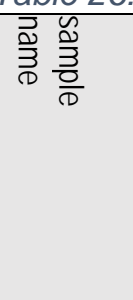 & 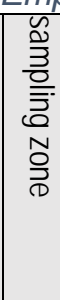 & 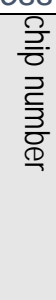 & 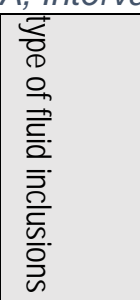 & 产. & 票 & 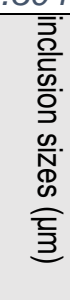 & 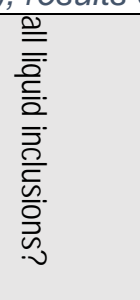 & 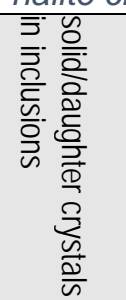 & 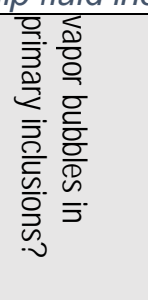 & 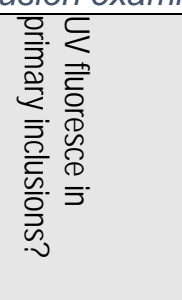 & 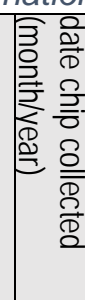 \\
\hline $\begin{array}{l}\text { E.7.A.1. } \\
\text { P }\end{array}$ & A & 1 & primary & 4 & $\begin{array}{l}\text { chevron in } \\
\text { growth band } \\
\text { easy to } \\
\text { make out, } \\
\text { great flincs, } \\
\text { small but } \\
\text { nice, }\end{array}$ & $\begin{array}{l}60- \\
40 \\
10- \\
30 \\
>3\end{array}$ & some & $\begin{array}{l}\text { acicular } \\
\text { to } \\
\text { tabular } \\
\text { in many }\end{array}$ & $\begin{array}{l}\text { only in } \\
\text { large } \\
\text { isolated } \\
\text { inclusions }\end{array}$ & $\begin{array}{l}\text { no } \\
\text { fluorescenc } \\
\text { e }\end{array}$ & $\begin{array}{l}\text { Jun- } \\
16\end{array}$ \\
\hline $\begin{array}{l}\text { E.7.A.2. } \\
\text { P }\end{array}$ & A & 2 & primary & 2 & $\begin{array}{l}\text { chevron, } \\
\text { many } \\
\text { primary } \\
\text { inclusions, } \\
\text { muddy/dirty } \\
\text { sample } \\
\text { though, may } \\
\text { make it hard } \\
\text { to get good } \\
\text { view of } \\
\text { inclusions }\end{array}$ & $\begin{array}{l}40- \\
80\end{array}$ & some & $\begin{array}{l}\text { yes, in } \\
\text { many, } \\
\text { cubic to } \\
\text { tabular } \\
\text { (some } \\
\text { tabular } \\
\text { appear } \\
\text { to be } \\
\text { striated } \\
\text { ) }\end{array}$ & $\begin{array}{l}\text { some, } \\
\text { consistent } \\
\mathrm{L}-\mathrm{V} \text { ratio } \\
\text { in large } \\
\text { fluid } \\
\text { inclusions } \\
\text { (many } \\
\text { secondary } \\
\text { inclusions } \\
\text {, some in } \\
\text { healed } \\
\text { fractures } \\
\text { with } L / V \text { ) }\end{array}$ & $\begin{array}{l}\text { no } \\
\text { fluorescenc } \\
\text { e }\end{array}$ & $\begin{array}{l}\text { Jun- } \\
16\end{array}$ \\
\hline E.7.B.S & B & $\begin{array}{l}\mathrm{N} / \\
\mathrm{A}\end{array}$ & $\begin{array}{l}\text { secondar } \\
y\end{array}$ & 0 & $\begin{array}{l}\text { some } \\
\text { secondary's } \\
\text {, massive } \\
\text { halite }\end{array}$ & $\mathrm{N} / \mathrm{A}$ & N/A & $\mathrm{N} / \mathrm{A}$ & $\mathrm{N} / \mathrm{A}$ & N/A & $\begin{array}{l}\text { Jun- } \\
16\end{array}$ \\
\hline E.7.Z.2.P & Z & 2 & primary & 3 & $\begin{array}{l}\text { primary and } \\
\text { secondary } \\
\text { inclusions } \\
\text { intermixed }\end{array}$ & $\begin{array}{l}70- \\
100 \\
1 \\
15- \\
40 \\
<3\end{array}$ & $\begin{array}{l}\text { rare, only } \\
\text { small } \\
\text { inclusion } \\
\text { s }\end{array}$ & $\begin{array}{l}\text { acicular } \\
\text { to } \\
\text { tabular } \\
\text { in over } \\
\text { half }\end{array}$ & $\begin{array}{l}\text { common, } \\
\text { in large } \\
\text { inclusions }\end{array}$ & $\begin{array}{l}\text { no } \\
\text { fluorescenc } \\
\text { e in primary } \\
\text { inclusions } \\
\text { (secondary } \\
\text { inclusion do) }\end{array}$ & $\begin{array}{l}\text { Nov } \\
-15\end{array}$ \\
\hline
\end{tabular}

Interval 7 transitions from a muddy layer at the bottom to halite interfiled with mud (zone

B) to massive red halite with isolated mud lenses in (zone A). The lower zone does not have any primary fluid inclusions and may be representative of dilute water input and dissolution followed by deposition. The upper zone consists of halite with clear growth bands consisting of small (<20 um) fluid inclusions, many contain cubic to tabular inclusions, vapor is only present in large fluid inclusions. 
Empress 1A Interval 8 (1498.74 - 1498.62 m)

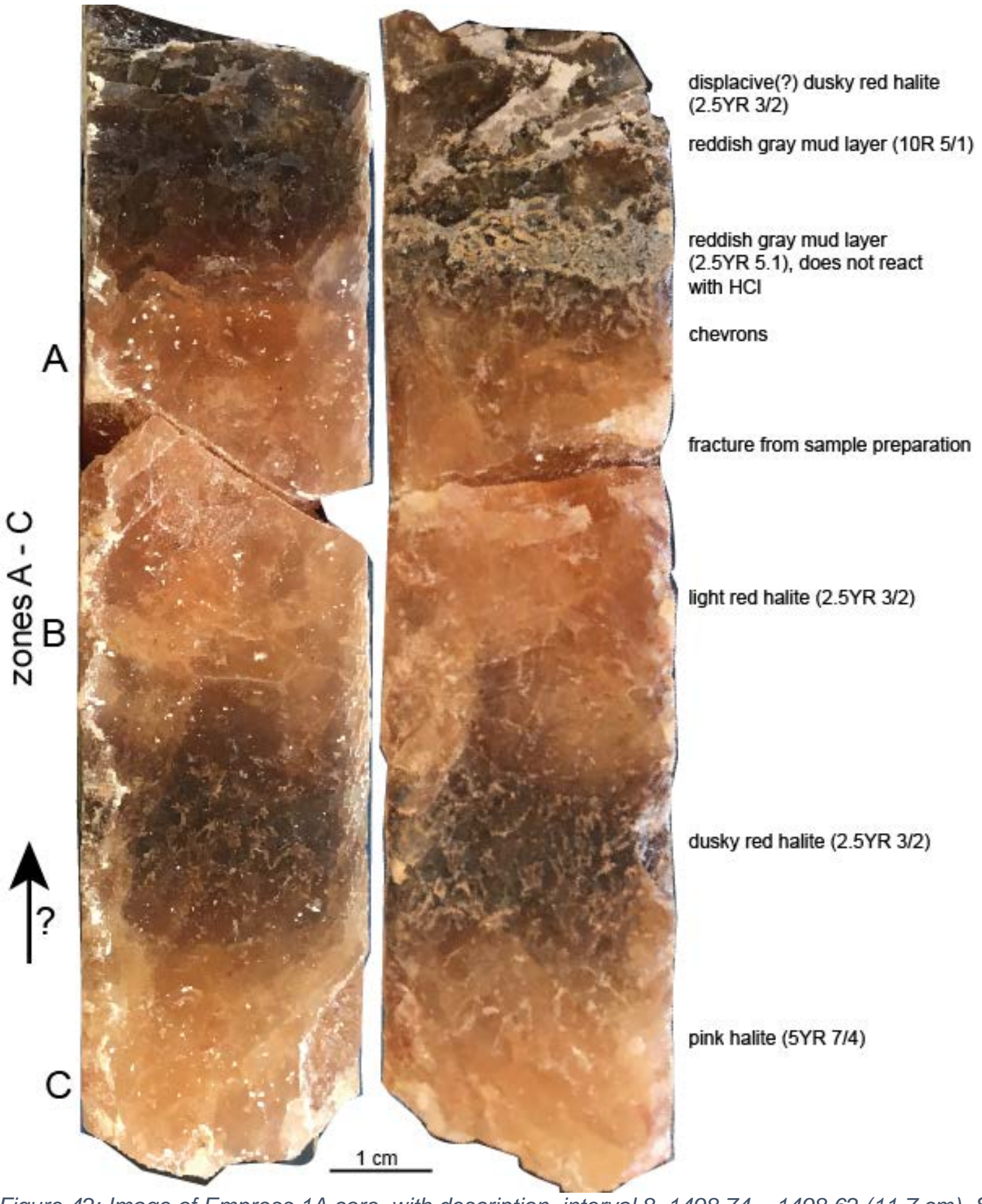

Figure 42: Image of Empress 1A core, with description, interval 8, $1498.74-1498.62(11.7 \mathrm{~cm})$. Sample has clear chevrons, which is confirmed by fluid inclusion petrography. Polished slab on left in daylight. Rough slab on right in daylight. 
Table 27: Empress 1A, Interval $8(1498.74-1498.62 \mathrm{~m})$, results of halite chip fluid inclusion examination.

\begin{tabular}{|c|c|c|c|c|c|c|c|c|c|c|c|}
\hline 产 & 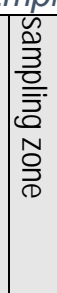 & 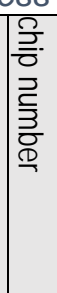 & 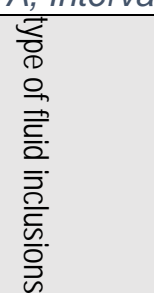 & $\begin{array}{l}\overline{\mathbf{z}} \\
\overrightarrow{\bar{c}}\end{array}$ & 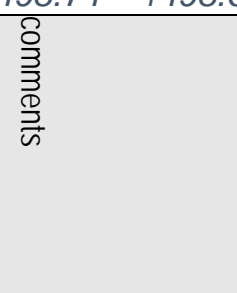 & 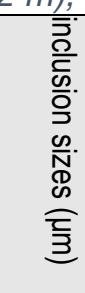 & 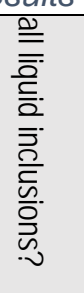 & 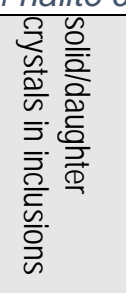 & 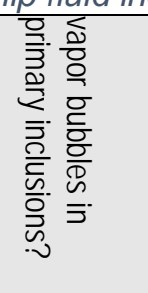 & 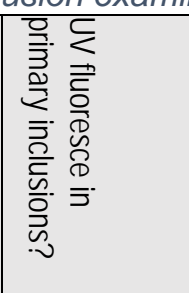 & 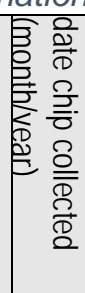 \\
\hline E.8.A.1.P & A & 1 & primary & 4 & $\begin{array}{l}\text { primary fluid } \\
\text { inclusions, some } \\
\text { chevrons, } \\
\text { decent size } \\
\text { sample, many } \\
\text { secondary } \\
\text { inclusions }\end{array}$ & $\begin{array}{l}50- \\
120 \\
10- \\
20 \\
<3\end{array}$ & some & acicular & $\begin{array}{l}\text { only in } \\
\text { large } \\
\text { isolated } \\
\text { inclusions }\end{array}$ & $\begin{array}{l}\text { no } \\
\text { fluorescence }\end{array}$ & $\begin{array}{l}\text { Jun } \\
-16\end{array}$ \\
\hline E.8.A.2.P & A & 2 & primary & 5 & $\begin{array}{l}\text { primary } \\
\text { inclusions, some } \\
\text { solid inclusions, } \\
\text { vapor present in } \\
\text { some fluid } \\
\text { inclusions }\end{array}$ & $\begin{array}{l}70- \\
150 \\
15- \\
30 \\
<2\end{array}$ & rare & $\begin{array}{l}\text { acicular } \\
\text { to } \\
\text { tabular } \\
\text { in over } \\
\text { half } \\
\end{array}$ & $\begin{array}{l}\text { present in } \\
\text { many } \\
\text { large } \\
\text { inclusions } \\
\end{array}$ & $\begin{array}{l}\text { no } \\
\text { fluorescence } \\
\text { in primary } \\
\text { inclusions, } \\
\text { solid in rare } \\
\text { large isolated } \\
\text { inclusions } \\
\text { fluoresces } \\
\text { faint blue } \\
\text { color } \\
\end{array}$ & $\begin{array}{l}\text { Jun } \\
-16 \\
\end{array}$ \\
\hline E.8.A.5.P & A & 5 & primary & 3 & $\begin{array}{l}\text { good chevron, } \\
\text { some inclusions } \\
\text { are rounded and } \\
\text { have poor } \\
\text { negative crystal } \\
\text { shape }\end{array}$ & $\begin{array}{l}50- \\
70 \\
10- \\
25 \\
<2\end{array}$ & $\mathrm{~N} / \mathrm{A}$ & $\mathrm{N} / \mathrm{A}$ & $\begin{array}{l}\text { present in } \\
\text { some } \\
\text { large } \\
\text { inclusions } \\
\end{array}$ & N/A & $N / A$ \\
\hline E.8.B.S & B & $\begin{array}{l}\mathrm{N} \\
1 \\
\mathrm{~A}\end{array}$ & secondary & 0 & poor sample & $\mathrm{N} / \mathrm{A}$ & $\mathrm{N} / \mathrm{A}$ & $\mathrm{N} / \mathrm{A}$ & N/A & $\mathrm{N} / \mathrm{A}$ & $\begin{array}{l}\text { Jun } \\
-16 \\
\end{array}$ \\
\hline E.8.C.1.P & C & 1 & primary & 2 & $\begin{array}{l}\text { some small } \\
\text { primary } \\
\text { inclusions, } \\
\text { small, no clear } \\
\text { growth areas }\end{array}$ & $\begin{array}{l}50- \\
70 \\
10- \\
20 \\
<3\end{array}$ & $N / A$ & $N / A$ & $\mathrm{~N} / \mathrm{A}$ & $N / A$ & $\begin{array}{l}\text { Jun } \\
-16\end{array}$ \\
\hline $\begin{array}{l}\text { E.8.C.P.2. } \\
\text { P }\end{array}$ & C & 2 & primary & 2 & $\begin{array}{l}\text { some primary } \\
\text { inclusions }\end{array}$ & $\begin{array}{l}50- \\
70, \\
10- \\
20, \\
<3\end{array}$ & $N / A$ & N/A & $\mathrm{N} / \mathrm{A}$ & $\mathrm{N} / \mathrm{A}$ & $\begin{array}{l}\text { Jun } \\
-16\end{array}$ \\
\hline E.8.Z.1.P & Z & 1 & primary & 4 & $\begin{array}{l}\text { area with many } \\
\text { inclusions, } \\
\text { chevron, good } \\
\text { sample }\end{array}$ & $\begin{array}{l}60- \\
90 \\
10- \\
35 \\
<3\end{array}$ & rare & $\begin{array}{l}\text { tabular } \\
\text { to } \\
\text { acicular } \\
\text { to over } \\
\text { half }\end{array}$ & rare & $\begin{array}{l}\text { no } \\
\text { fluorescence }\end{array}$ & $\begin{array}{l}\text { Nov } \\
-15\end{array}$ \\
\hline
\end{tabular}

Interval 8 consists of several halite beds with marked changed in color from pink, to dusky red, to light red halite near the top. Halite is capped by a reddish gray mud layer 
containing displacive(?) halite crystals. The lowest zone contains some primary fluid inclusions, but good growth bands are not easily evident. Zone B, near the dusky red halite layer, does not contain any primary fluid inclusions. Finally, zone A, immediately beneath the mud layer, has faint outline of chevrons. Examination of halite chips indicates that this zone consists of halite with strong growth bands. Inclusions from zone A have acicular solids, vapor bubbles are only seen in large fluid inclusions. 
Empress 1A, Interval 9 (1489.75-1489.7 m)

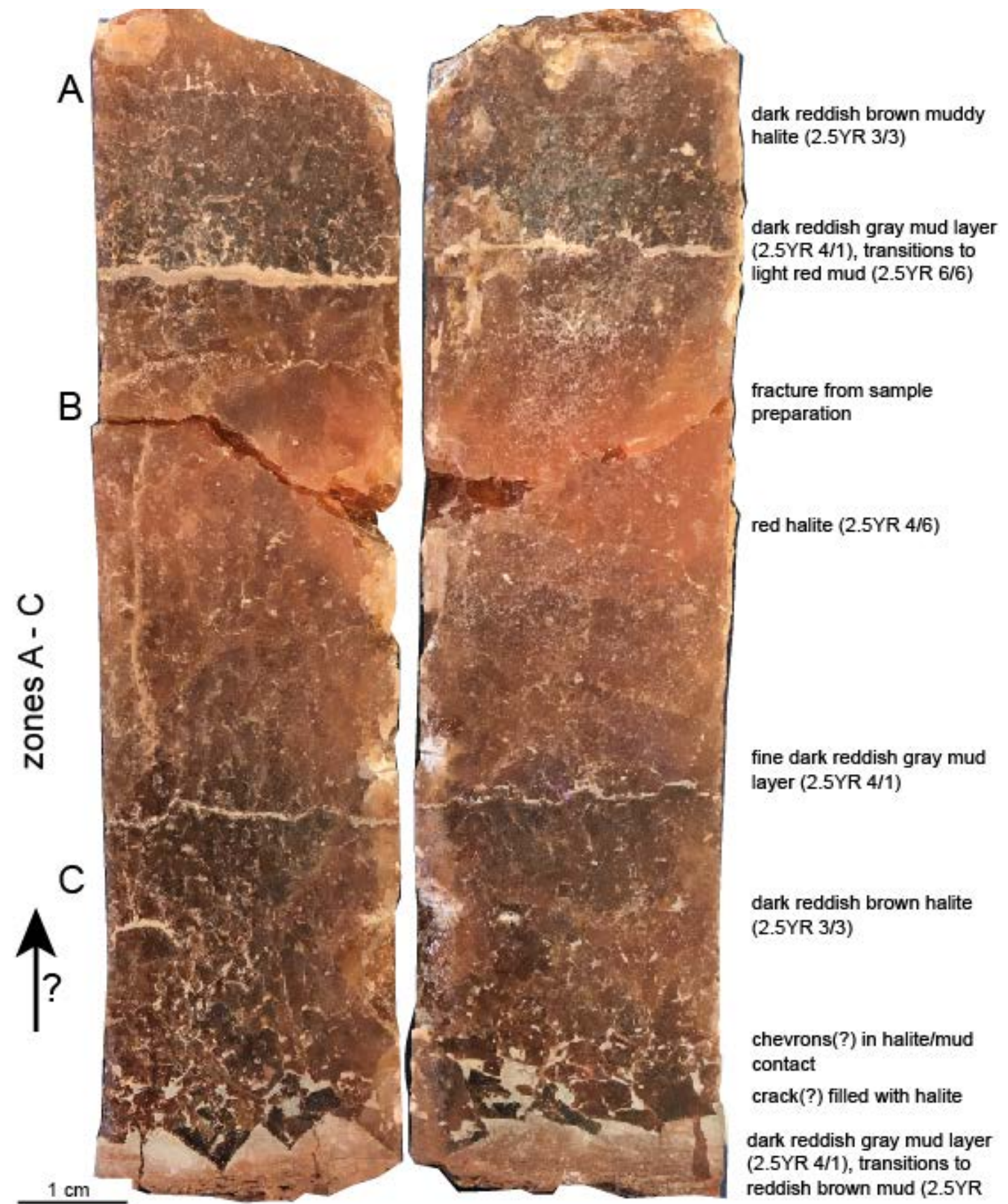

Figure 43: Image of Empress 1A core, with description, interval 9, 1498.75 - $1498.7 \mathrm{~m}(11.8 \mathrm{~cm})$. Rough slabs in daylight. 
Table 28: Empress 1A, interval $9(1489.75-1489.7 \mathrm{~m})$, results of halite chip fluid inclusion examination

\begin{tabular}{|c|c|c|c|c|c|c|c|c|c|c|c|}
\hline 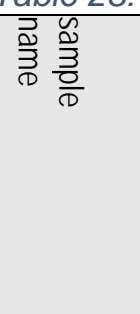 & 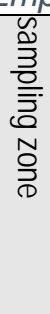 & 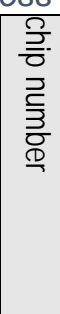 & 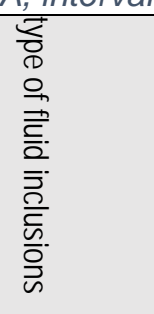 & 蔦. & $\frac{\delta}{\frac{\delta}{3}}$ & 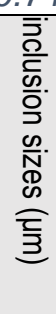 & 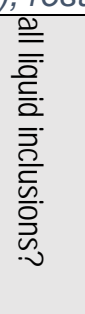 & 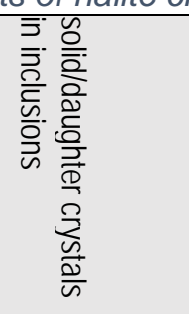 & 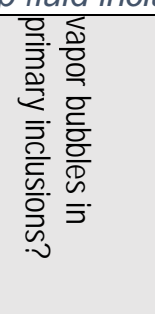 & 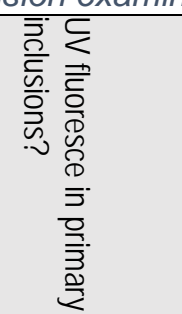 & 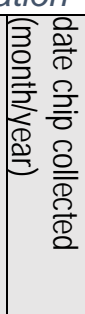 \\
\hline E.9.A.1.P & A & 1 & primary & 4 & $\begin{array}{l}\text { lots of } \\
\text { inclusions, } \\
\text { most } \\
\text { primary, } \\
\text { large } \\
\text { isolated } \\
\text { inclusions } \\
\text { also } \\
\text { present }\end{array}$ & $\begin{array}{l}40- \\
60, \\
15- \\
30, \\
<3\end{array}$ & some & $\begin{array}{l}\text { large } \\
\text { inclusions full } \\
\text { of tabular } \\
\text { (birefringent, } \\
\text { and striated) } \\
\text { and acicular } \\
\text { solids }\end{array}$ & $\begin{array}{l}\text { only in } \\
\text { large } \\
\text { inclusions }\end{array}$ & $\begin{array}{l}\text { no } \\
\text { fluorescence }\end{array}$ & $\begin{array}{l}\text { Jun- } \\
16\end{array}$ \\
\hline E.9.B.1.P & B & 1 & primary & 3 & $\begin{array}{l}\text { many } \\
\text { primary } \\
\text { fluid } \\
\text { inclusions }\end{array}$ & $\begin{array}{l}40- \\
50, \\
10- \\
20, \\
<2\end{array}$ & $N / A$ & $\begin{array}{l}\text { tabular to } \\
\text { acicular, may } \\
\text { be clumped } \\
\text { together in } \\
\text { lard inclusion, } \\
\text { birefringent } \\
\text { crystals, } \\
\text { higher relief, } \\
\text { no } \\
\text { reflectance) }\end{array}$ & $\begin{array}{l}\text { In some } \\
\text { large } \\
\text { inclusions }\end{array}$ & $\begin{array}{l}\text { no } \\
\text { fluorescence } \\
\text { in primary } \\
\text { inlusion }\end{array}$ & $\begin{array}{l}\text { Jun- } \\
16\end{array}$ \\
\hline E.9.C.1.P & C & 1 & primary & 2 & $\begin{array}{l}\text { potential } \\
\text { primary } \\
\text { inclusions, } \\
\text { small } \\
\text { primary } \\
\text { fluid } \\
\text { inclusions }\end{array}$ & $\begin{array}{l}15- \\
30, \\
<2\end{array}$ & $\mathrm{~N} / \mathrm{A}$ & $\begin{array}{l}\text { tabular to } \\
\text { acicular }\end{array}$ & in many & N/A & $\begin{array}{l}\text { Jun- } \\
16\end{array}$ \\
\hline E.9.Z.1 & Z & 1 & $\begin{array}{l}\text { solid } \\
\text { inclusions }\end{array}$ & 0 & $\begin{array}{l}\text { chaotic } \\
\text { solid } \\
\text { inclusions }\end{array}$ & & $\mathrm{N} / \mathrm{A}$ & $\mathrm{N} / \mathrm{A}$ & $\mathrm{N} / \mathrm{A}$ & $\mathrm{N} / \mathrm{A}$ & $\begin{array}{l}\text { Nov- } \\
16\end{array}$ \\
\hline
\end{tabular}

Interval 9 begins with a muddy interval at the bottom. This mud is displaced by halite crystals at the halite-mud contact. Halite crystals following this interval transition from being mud-rich to mud-poor dark reddish brown halite. This interval contains small potentially primary fluid inclusions. A thin mud layer separates zones C and B. Zone B consists of red halite with many primary fluid inclusions. These inclusions contain solids that look cocci in shape, however they do not fluoresce, this solids appear to be birefringent crystals; some inclusions contain 
vapor bubbles. Zone $A$ is separated from zone $B$ by a light red mud layer that transitions to a dark red adjacent to zone $\mathrm{A}$. This muddy halite zone contains well preserved primary inclusions with tabular and acicular daughter crystals, vapor bubbles are only present in large inclusions. 
Empress 1A, Interval 10 (1480.8-1480.7 m)

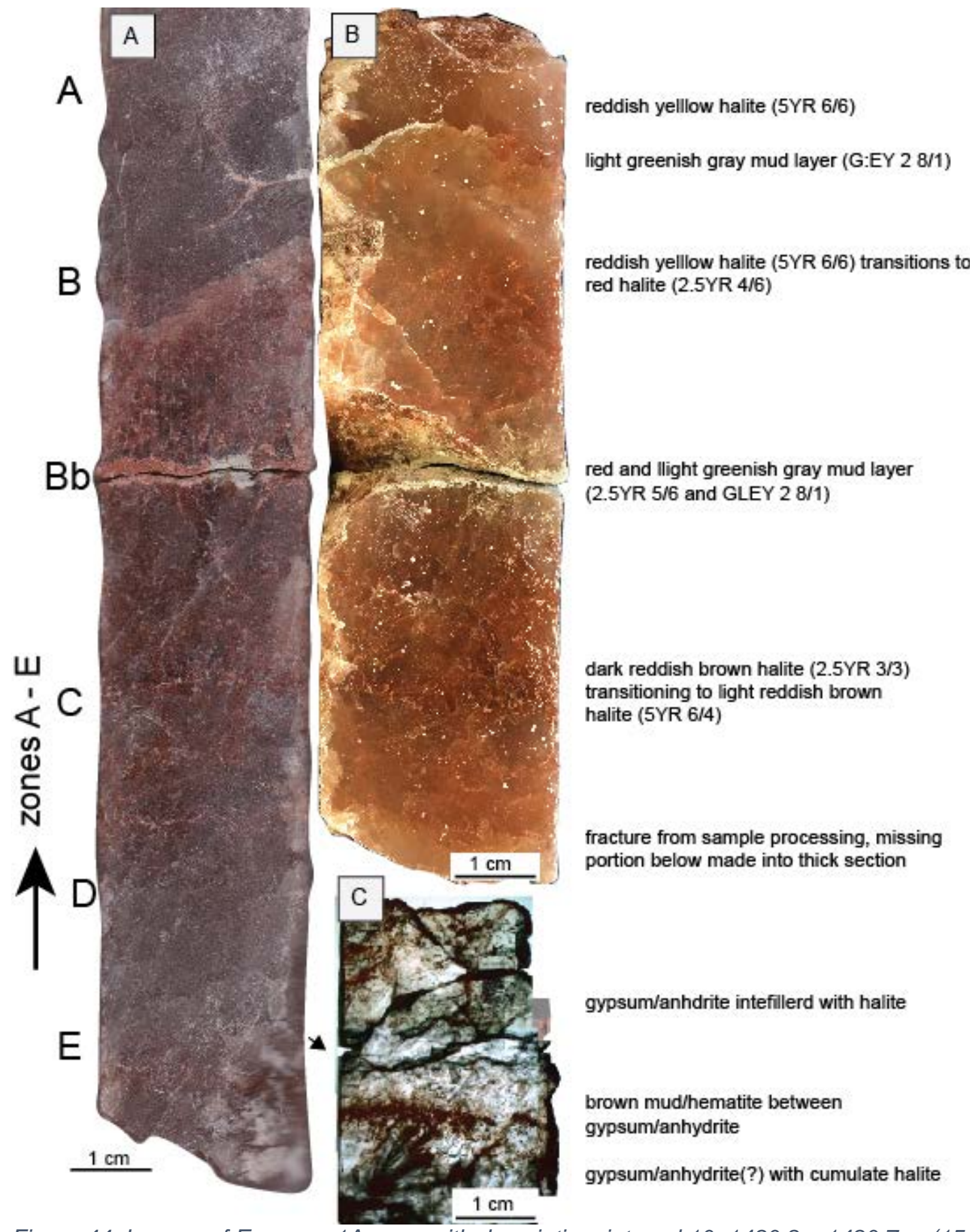

Figure 44: Images of Empress 1A core, with description, interval 10, 1480.8 - $1480.7 \mathrm{~m}(15.5 \mathrm{~cm})$. (A) Rough slab image of entire interval, image from scanner. (B) Polished slab in daylight. (C) Thick section of zone $E$ in plane polarized light. Zone $E$ contains a crystal splay, cumulate halite, and iron oxides. 
Table 29: Empress 1A, interval $10(1480.8-1480.7 \mathrm{~m})$, results of halite chip fluid inclusion examination

\begin{tabular}{|c|c|c|c|c|c|c|c|c|c|c|c|}
\hline 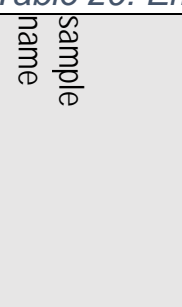 & 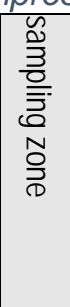 & 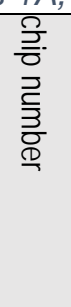 & 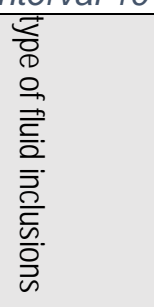 & 产. & 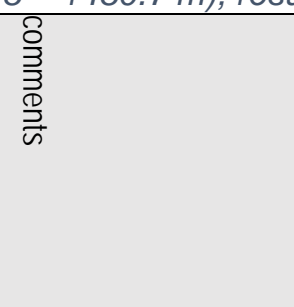 & 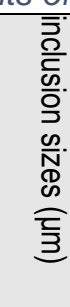 & 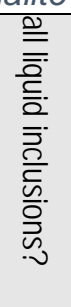 & 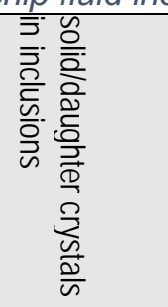 & 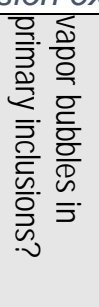 & 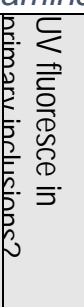 & 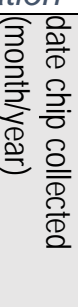 \\
\hline E.10.A.- & A & $\mathrm{N} / \mathrm{A}$ & $\begin{array}{l}\text { massive- } \\
\text { no } \\
\text { inclusions }\end{array}$ & 0 & no inclusions evident & $\mathrm{N} / \mathrm{A}$ & N/A & $\mathrm{N} / \mathrm{A}$ & $\mathrm{N} / \mathrm{A}$ & N/A & $\begin{array}{l}\text { Jun- } \\
16\end{array}$ \\
\hline E.10.B.1.P & B & 1 & primary & 2 & $\begin{array}{l}\text { very small } \\
\text { inclusions, but } \\
\text { appear like a } \\
\text { chevron and } \\
\text { primary- not suitable } \\
\text { for more research } \\
\end{array}$ & $\mathrm{N} / \mathrm{A}$ & $\mathrm{N} / \mathrm{A}$ & $\mathrm{N} / \mathrm{A}$ & N/A & N/A & $\begin{array}{l}\text { Jun- } \\
16\end{array}$ \\
\hline E.10.B.6.P & $B$ & 6 & primary & 2 & $\begin{array}{l}\text { Ok fluid inclusions, } \\
\text { very faint chevron }\end{array}$ & $\mathrm{N} / \mathrm{A}$ & $\mathrm{N} / \mathrm{A}$ & $\mathrm{N} / \mathrm{A}$ & $\mathrm{N} / \mathrm{A}$ & N/A & $\mathrm{N} / \mathrm{A}$ \\
\hline E.10.C & C & $\mathrm{N} / \mathrm{A}$ & secondary & 1 & $\begin{array}{l}\text { one inclusion area, } \\
\text { poor sample }\end{array}$ & $\mathrm{N} / \mathrm{A}$ & $\mathrm{N} / \mathrm{A}$ & $\mathrm{N} / \mathrm{A}$ & $\mathrm{N} / \mathrm{A}$ & N/A & $\begin{array}{l}\text { Jun- } \\
16\end{array}$ \\
\hline E.10,CD.1.S & $\begin{array}{l}\text { C- } \\
\text { D }\end{array}$ & 1 & secondary & 1 & $\begin{array}{l}\text { occasional possible } \\
\text { primary, mostly } \\
\text { secondary }\end{array}$ & $\mathrm{N} / \mathrm{A}$ & N/A & $\mathrm{N} / \mathrm{A}$ & $\mathrm{N} / \mathrm{A}$ & N/A & $\mathrm{N} / \mathrm{A}$ \\
\hline E.10.D.- & D & $N / A$ & $\begin{array}{l}\text { massive- } \\
\text { no } \\
\text { inclusions }\end{array}$ & 0 & $\begin{array}{l}\text { no inclusions } \\
\text { evident, no samples } \\
\text { collected }\end{array}$ & $\mathrm{N} / \mathrm{A}$ & $\mathrm{N} / \mathrm{A}$ & $\mathrm{N} / \mathrm{A}$ & $\mathrm{N} / \mathrm{A}$ & N/A & $\begin{array}{l}\text { Jun- } \\
16\end{array}$ \\
\hline $\begin{array}{l}\text { E.10.E.1. } \\
\text { P? }\end{array}$ & $E$ & 1 & primary & 1 & $\begin{array}{l}\text { small primaries, } \\
\text { interesting }\end{array}$ & $\mathrm{N} / \mathrm{A}$ & $\mathrm{N} / \mathrm{A}$ & $\mathrm{N} / \mathrm{A}$ & $\mathrm{N} / \mathrm{A}$ & N/A & $\begin{array}{l}\text { Jun- } \\
16\end{array}$ \\
\hline E.10.E slab & $N / A$ & $N / A$ & $\begin{array}{l}\text { Suspect } \\
\text { primary }\end{array}$ & 2 & $\begin{array}{l}\text { faint chevron, some } \\
\text { inclusions do not } \\
\text { have good negative } \\
\text { crystal shape }\end{array}$ & $\begin{array}{l}40- \\
80 \\
10- \\
20 \\
>3\end{array}$ & rare & $N / A$ & $\begin{array}{l}\text { In } \\
\text { some }\end{array}$ & N/A & $\begin{array}{l}\text { Nov- } \\
16\end{array}$ \\
\hline E.10.E.2. S & $E$ & 2 & $\begin{array}{l}\text { solid } \\
\text { inclusions }\end{array}$ & 0 & $\begin{array}{l}\text { cubic to tabular solid } \\
\text { inclusions-high } \\
\text { birefringence and } \\
\text { sharp relief with the } \\
\text { halite, many } \\
\text { secondary's, small } \\
\text { acicular crystals in } \\
\text { the flincs }\end{array}$ & $\mathrm{N} / \mathrm{A}$ & N/A & $\begin{array}{l}\text { high relief to } \\
\text { halite, } \\
\text { birefringent } \\
\text { tabular, 20- } \\
100 \mu \mathrm{m}\end{array}$ & $\mathrm{N} / \mathrm{A}$ & N/A & $\begin{array}{l}\text { Jun- } \\
16\end{array}$ \\
\hline E.10.Z.S & $\mathrm{Z}$ & $\mathrm{N} / \mathrm{A}$ & secondary & 0 & $\begin{array}{l}\text { big sample, many } \\
\text { secondary inclusions }\end{array}$ & $\mathrm{N} / \mathrm{A}$ & N/A & $\mathrm{N} / \mathrm{A}$ & $\mathrm{N} / \mathrm{A}$ & N/A & $\begin{array}{l}\text { Nov- } \\
15\end{array}$ \\
\hline
\end{tabular}

Interval 10 consists of several sampling zones. Despite close sampling, this interval does not have well preserved primary fluid inclusions. A thick slab made from the lower portion 
of this interval (zones E and D) indicated that this interval consists of likely gypsum/anhydrite crystal splays with cumulate halite crystals and a thin brown hematite mud intersecting this portion. Inspection reveals quartz grains $(50 \mu \mathrm{m})$ in this zone. Halite chips examined from this zone have many secondary inclusions and some solid cubic inclusions with high birefringence and sharp relief. One sample in zone E has small primary fluid inclusions. Only zone B consistently yields samples with primary fluid inclusions, these inclusions outline growth bands but are relatively small and difficult to analyze.
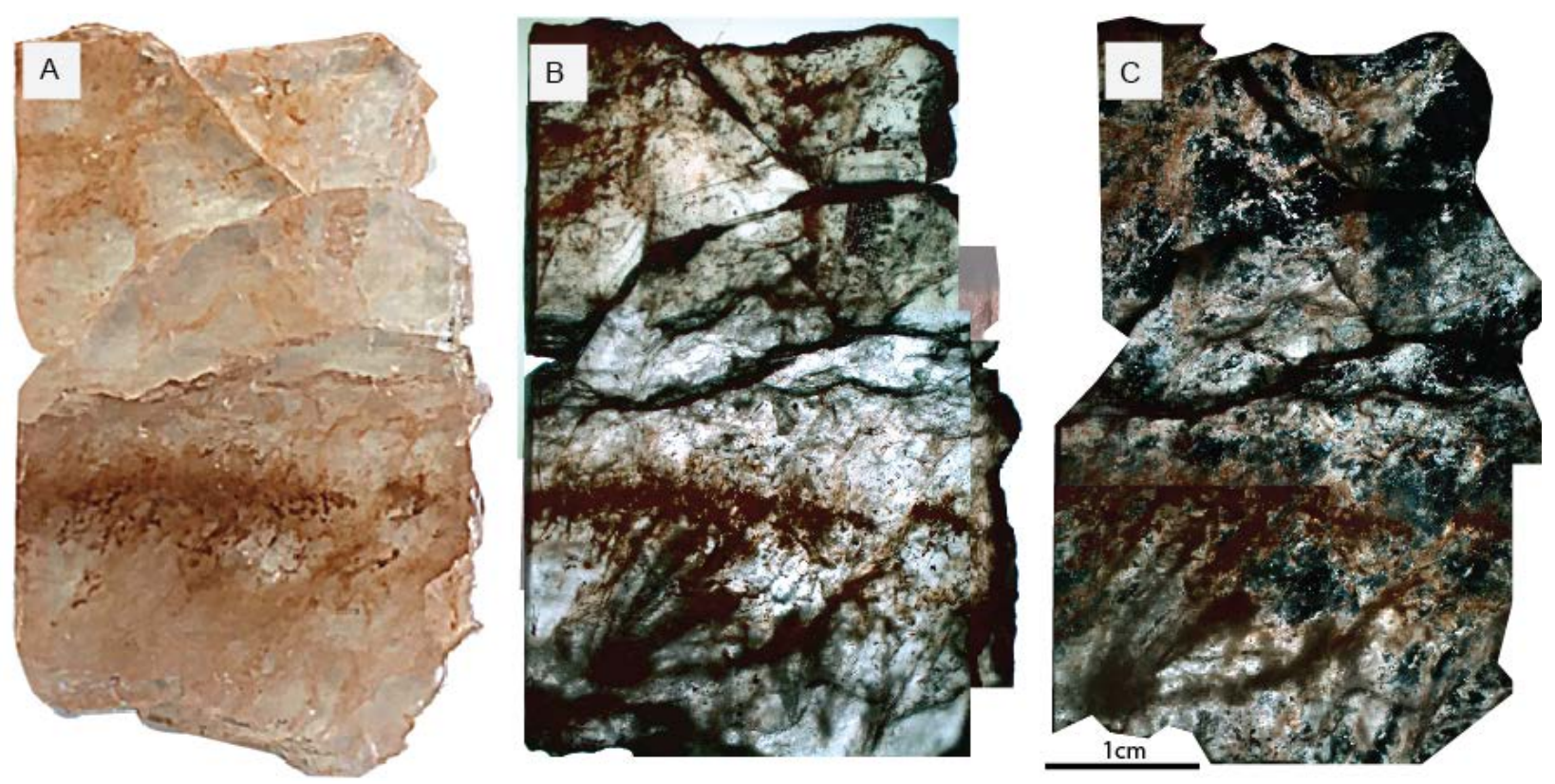

Figure 45. Images of thick slab from zone $E$ of interval 10, $1480.8-1480.7 \mathrm{~m}$ under different lighting. Different deposition features become evident under: $(A)$ daylight, $(B)$ plane polarized light, and (C) cross polarized light. Note the crystalline splay visible in XPL and PPL, but not under daylight. The upper portion of this sample is fractured. 


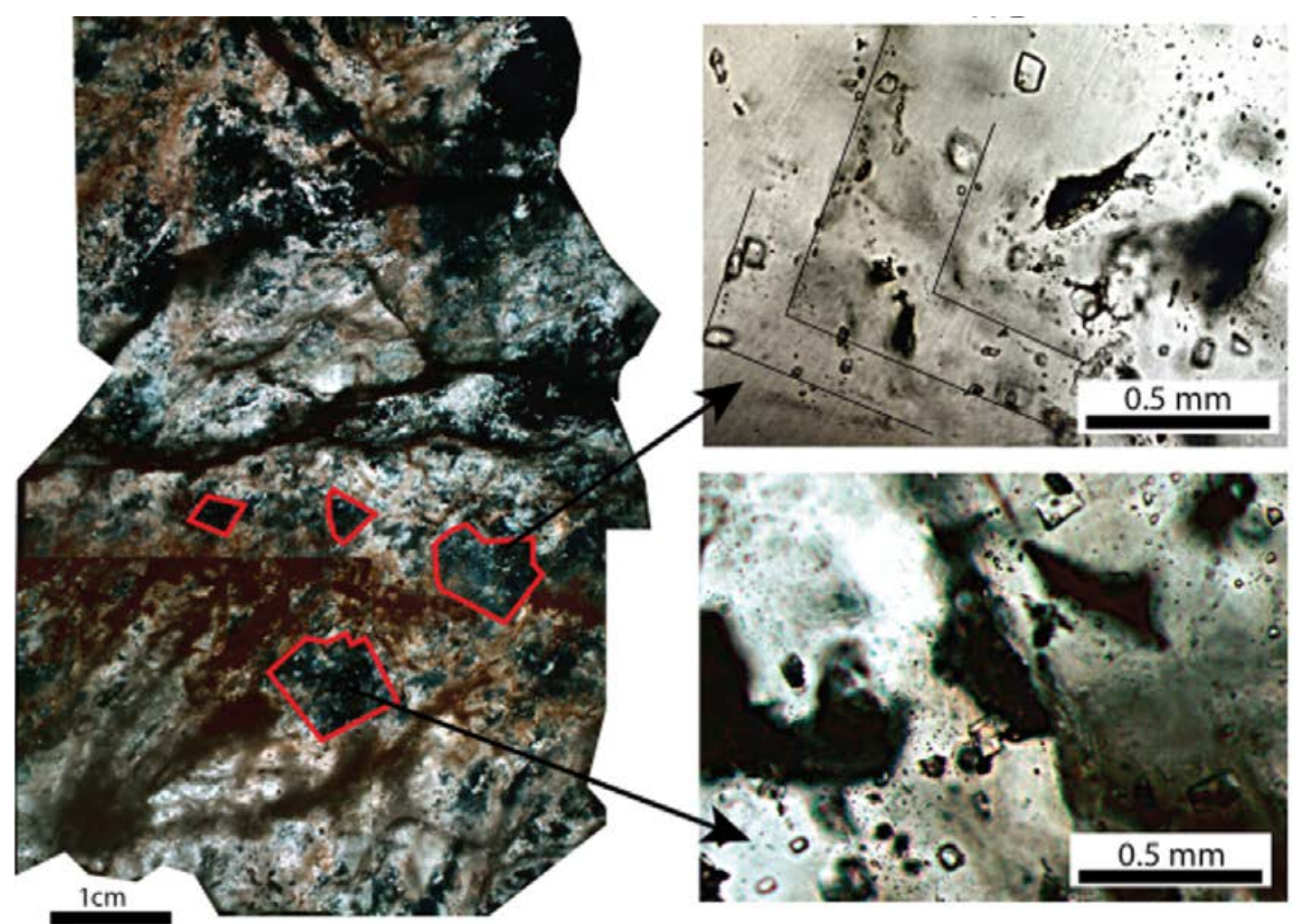

Figure 46. Images of suspect primary inclusions in E.10 slab, $1480.8-1480.7 \mathrm{~m}$. The image on the left is lit in cross polarized light. Suspect cumulate halite crystals are outlined in red. The image on the upper right is in plane polarized light, black lines added to outline suspect primary fluid inclusion growth bands. The image on the lower right is a close up of the area outlined in red.
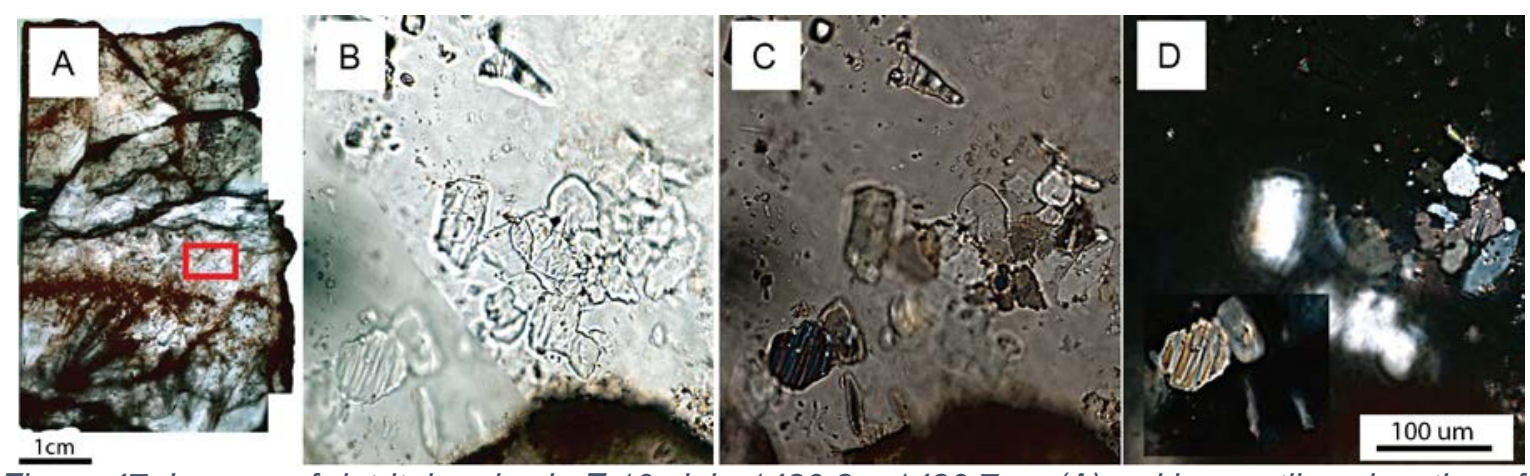

Figure 47. Images of detrital grains in E.10 slab, 1480.8 - $1480.7 \mathrm{~m}$, (A) red box outlines location of grains. (B-D) Images of grains under different lighting, (B) plane polarized light, (C) cross-polarized light, (D) cross polarized light. The grain clump appears to be quartz due to its low relief and birefringence. The grain in the lower left may be gypsum/anhydrite, however it has lower relief than anhydrite noted in other portions of this slab, and the birefringence colors are too muted. 

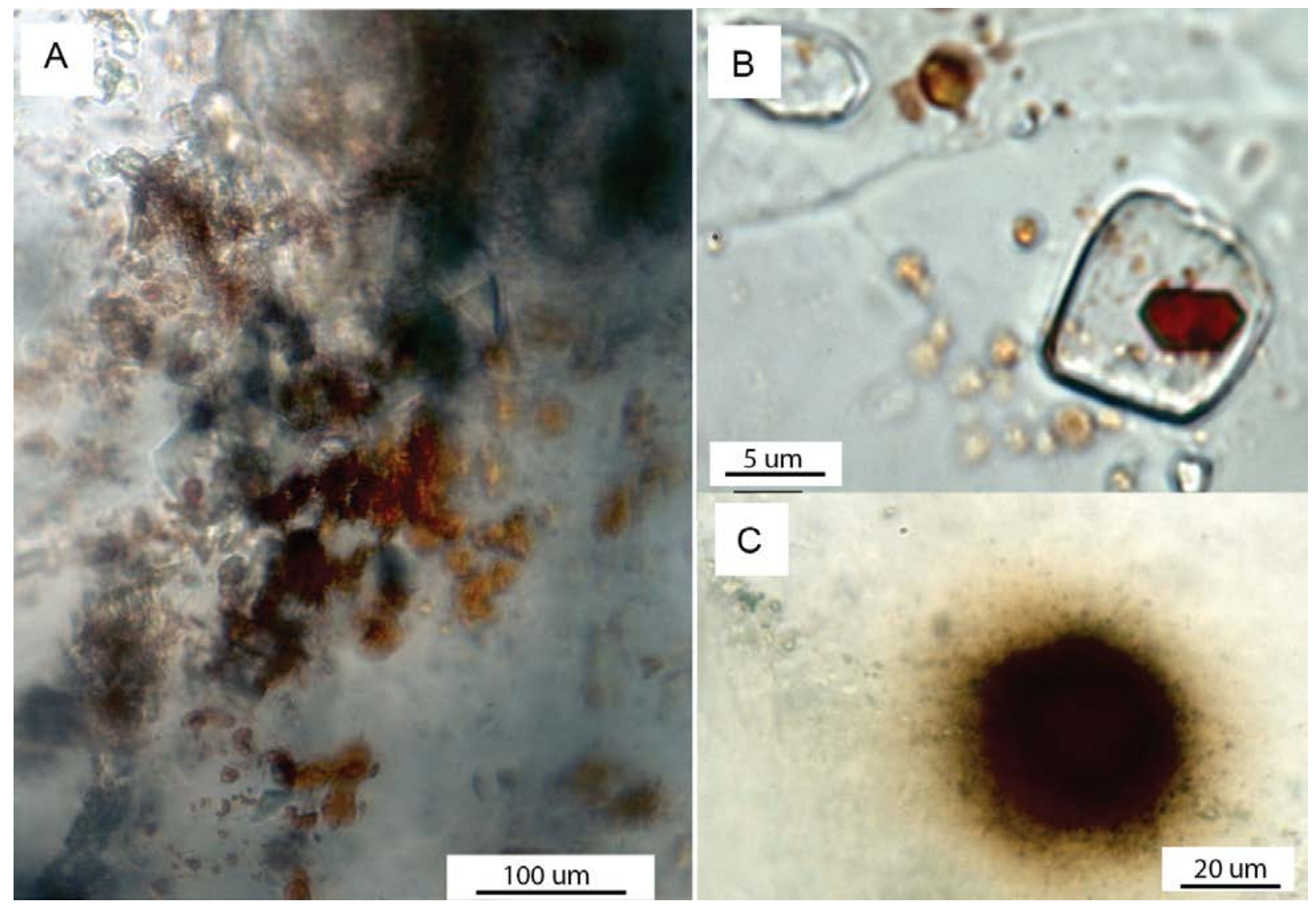

Figure 48. Images of orange-red solids in E.10 slab, 1480.8 - $1480.7 \mathrm{~m}$. (A) Subangular to globular crystals (5-30 $\mu \mathrm{m})$ in plane polarized light, suspect organic matter or iron oxides. (B) Angular burnt orange colored crystal $(4 \mu \mathrm{m})$ preserved in fluid inclusion. (C) Round iron oxide grain $(20 \mu \mathrm{m})$ with oxides dispersing into adjacent halite.

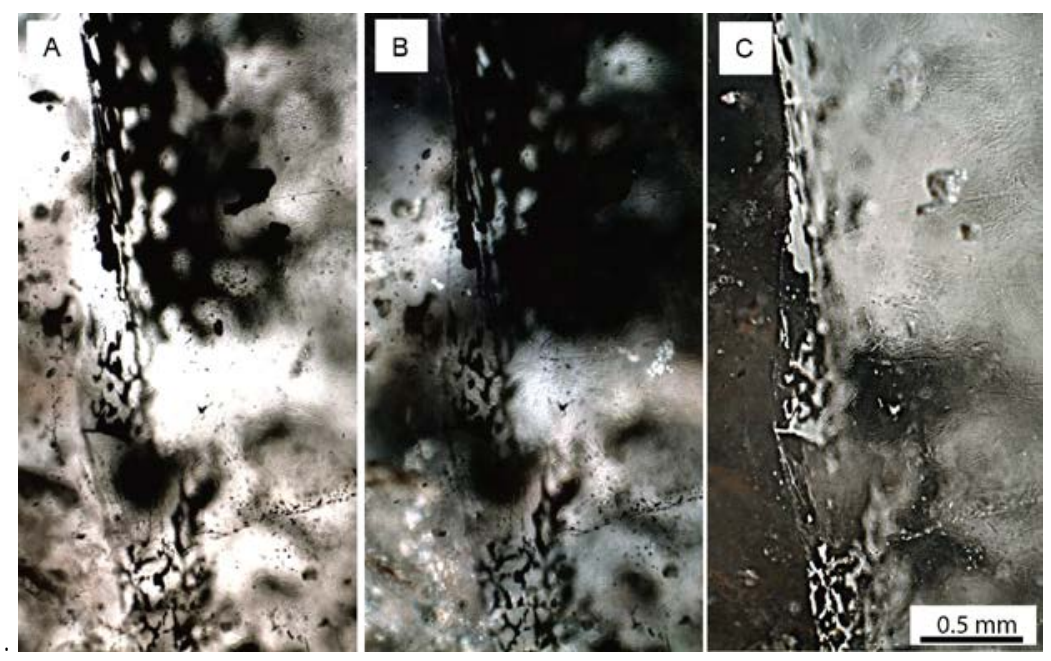

Figure 49. Images of mineralization and fluids within fractures in E.10 slab, 1480.8 - 1480.7 m, (A) plane polarized light, (B) cross polarized light, (C) reflected light. 

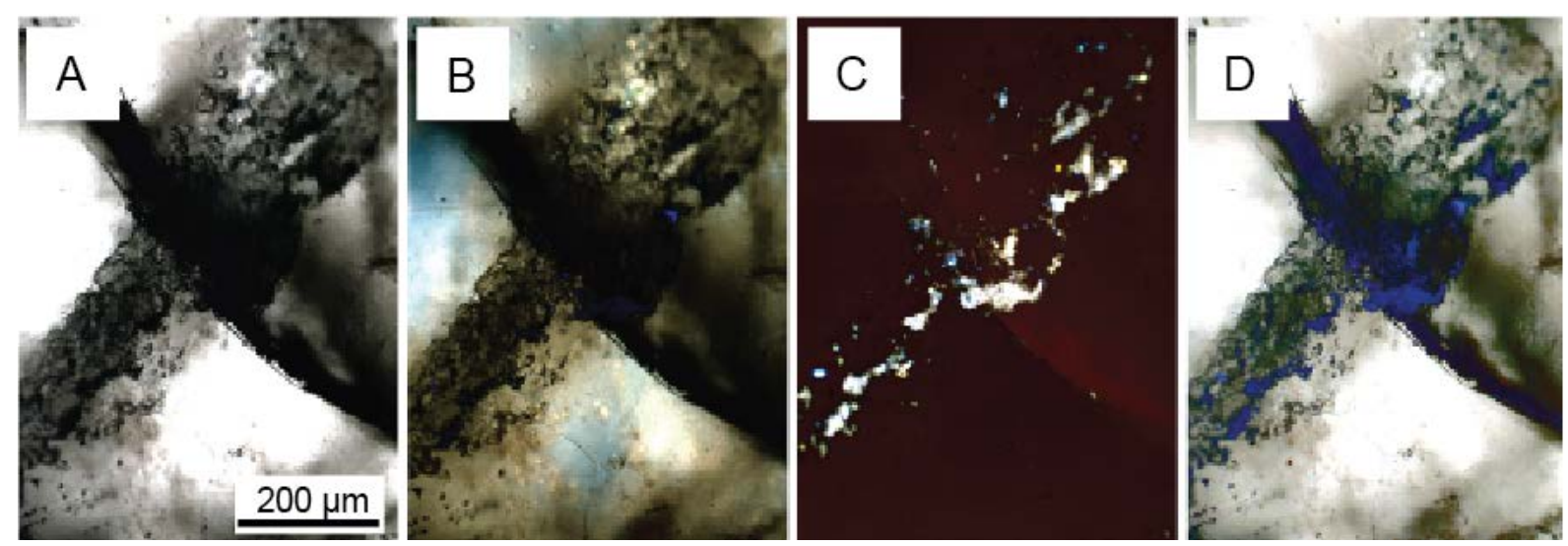

Figure 50. Images of mineralization and fluids within fractures from the upper portion of E.10 slab, 1480.8 - $1480.7 \mathrm{~m}$. Different lighting illuminates several features, (A) plane polarized light, (B) cross polarized light differentiates isotropic halite and other minerals, (C) reflected light shows opaque solids, (D) UV and plane polarized light illuminate organic fluids/solids in fracture.

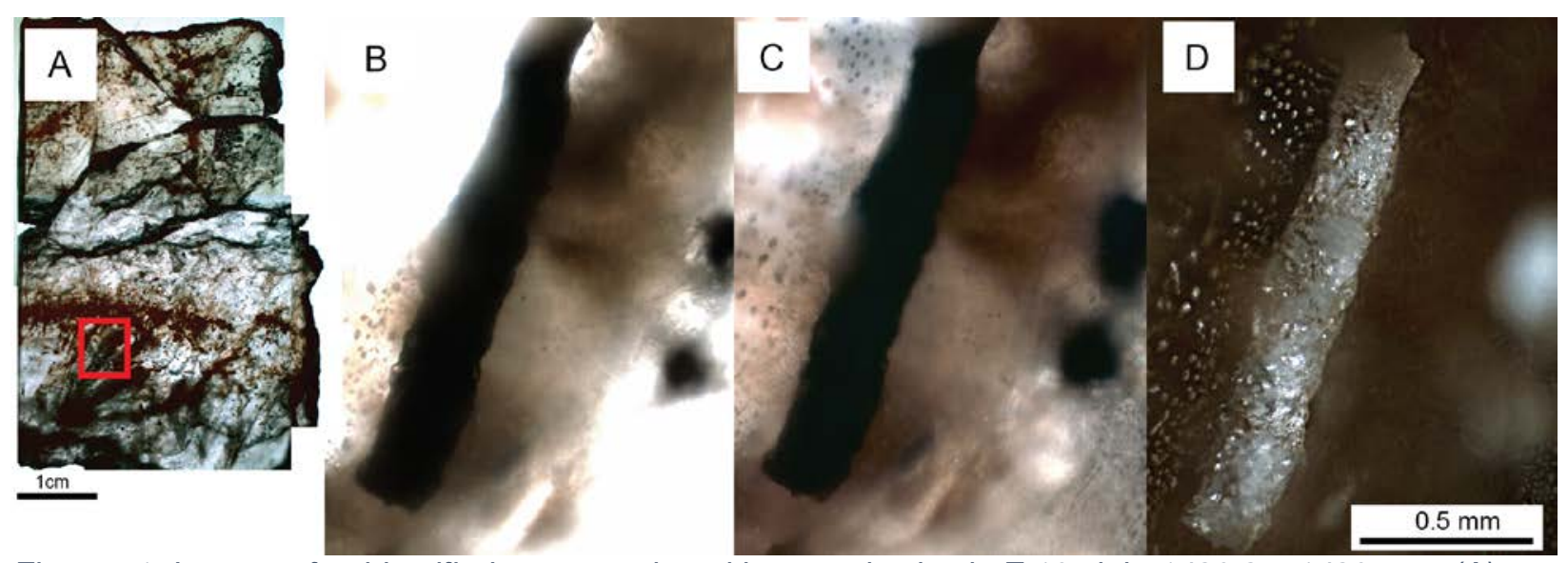

Figure 51. Images of unidentified opaque mineral in crystal splay in E.10 slab, $1480.8-1480.7 \mathrm{~m}$. (A) location of solid in slab from zone $E$ in interval 10. Solid under different lightings (B) plane polarized light, (C) cross polarized light, (D) reflected light. 


\begin{tabular}{|l|l|l|l|l|}
\hline & event & early & \multicolumn{2}{|c|}{ late } \\
\hline 1 & $\begin{array}{l}\text { deposition of } \\
\text { gypsum/anhydrite/other crystals }\end{array}$ & & & \\
\hline 2 & deposition of iron rich particles & & & \\
\hline 3 & deposition of possible chevron halite & & & \\
\hline 4 & $\begin{array}{l}\text { deposition of quartz grains- } \\
\text { aeolian/authigenic }\end{array}$ & & & \\
\hline 5 & $\begin{array}{l}\text { halite/gypsum/other mineral } \\
\text { precipitation continues }\end{array}$ & & & \\
\hline 6 & $\begin{array}{l}\text { minerals, some organic compounds } \\
\text { fractures form and fill with opaque }\end{array}$ & & & \\
\hline
\end{tabular}

Figure 52. Chart of proposed paragenetic sequence thick slab portion (zone E) of interval 10, 1480.8 $1480.7 \mathrm{~m}$ 
Empress 1A, Interval 1297 (1297.08-1297.00 m)

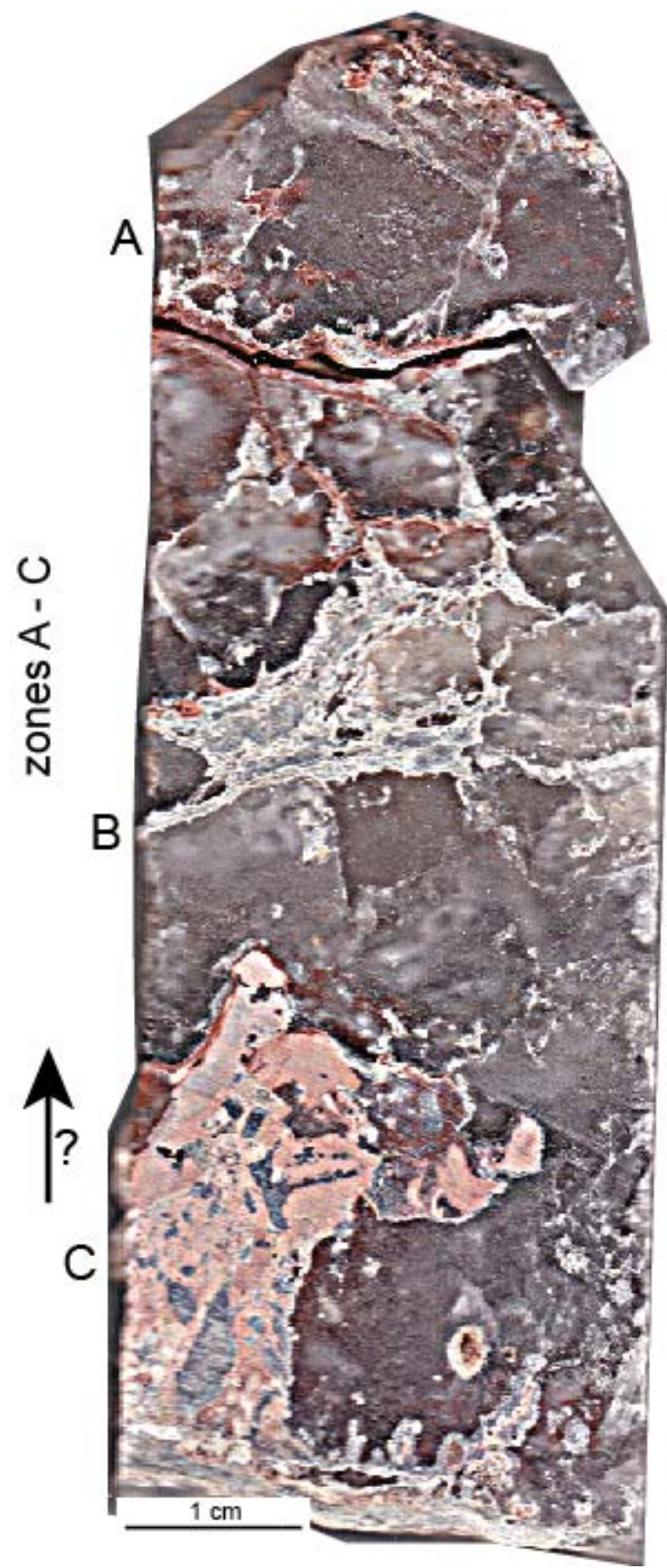

blocky light gray halite (10R 7/1)

red mud layer (2.5 YR 5/6)

light greenish gray mud layer (GLEY 2 7/2)

blocky light gray halite $(10 R 7 / 1)$

pale red mud layer with halite inclusions (10R 7/4)

blocky light gray halite (10R 7/1)

light greenish gray mud layer (GLEY $27 / 2$ ), finely laminated, does not react with $\mathrm{HCL}, \sim 0.5 \mathrm{~cm}$ of mud not shown

Figure 53: Image of Empress 1A core, with description, interval 1297, 1297 m (8.1 cm). Rough slab image from scanner. 
Table 30: Empress 1A, interval 1297 (1297.08 - 1297.0 m), results of halite chip fluid inclusion examination

\begin{tabular}{|c|c|c|c|c|c|c|c|c|c|c|c|}
\hline 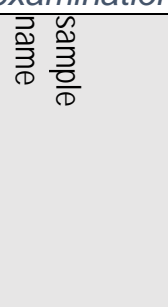 & 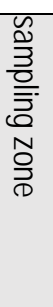 & 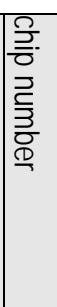 & 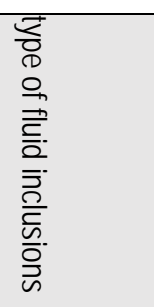 & & 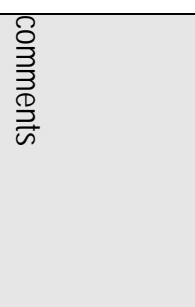 & 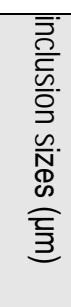 & 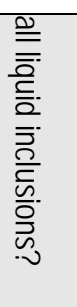 & 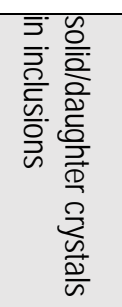 & 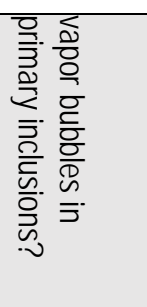 & 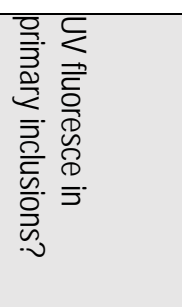 & 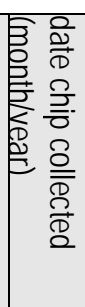 \\
\hline $\begin{array}{l}\text { E.1297.A.1. } \\
\text { S }\end{array}$ & $\mathrm{A}$ & 1 & secondary & 0 & $\mathrm{~N} / \mathrm{A}$ & $\mathrm{N} / \mathrm{A}$ & $\mathrm{N} / \mathrm{A}$ & $\mathrm{N} / \mathrm{A}$ & $\mathrm{N} / \mathrm{A}$ & $\mathrm{N} / \mathrm{A}$ & $\begin{array}{l}\text { Jun } \\
-16\end{array}$ \\
\hline $\begin{array}{l}\text { E.1297.A.2. } \\
\text { S }\end{array}$ & A & 2 & secondary & 0 & $\mathrm{~N} / \mathrm{A}$ & $\mathrm{N} / \mathrm{A}$ & $\mathrm{N} / \mathrm{A}$ & N/A & N/A & $\mathrm{N} / \mathrm{A}$ & $\begin{array}{l}\text { Jun } \\
-16\end{array}$ \\
\hline $\begin{array}{l}\text { E.1297.A.3. } \\
\text { P }\end{array}$ & A & 3 & $\begin{array}{l}\text { secondary } \\
\text { /primary }\end{array}$ & 2 & $\begin{array}{l}\text { very clear } \\
\text { sample, many } \\
\text { secondary } \\
\text { inclusions } \\
\text { near the } \\
\text { surface, } \\
\text { primary } \\
\text { inclusions } \\
\text { present }\end{array}$ & $\begin{array}{l}80- \\
120, \\
20- \\
40, \\
<3\end{array}$ & yes & rare & $\begin{array}{l}\text { in large } \\
\text { inclusions }\end{array}$ & $\mathrm{N} / \mathrm{A}$ & $\begin{array}{l}\text { Jun } \\
-16\end{array}$ \\
\hline $\begin{array}{l}\text { E.1297.B.1. } \\
\text { S }\end{array}$ & B & 1 & secondary & 0 & $\begin{array}{l}\text { all inclusions } \\
\text { appear to be } \\
\text { secondary's }\end{array}$ & $\mathrm{N} / \mathrm{A}$ & $N / A$ & $\mathrm{~N} / \mathrm{A}$ & N/A & $\mathrm{N} / \mathrm{A}$ & $\begin{array}{l}\text { Jun } \\
-16\end{array}$ \\
\hline $\begin{array}{l}\text { E.1297.C.1. } \\
S\end{array}$ & C & 1 & secondary & 0 & $\begin{array}{l}\text { large } \\
\text { secondary's }\end{array}$ & $\mathrm{N} / \mathrm{A}$ & N/A & $N / A$ & $N / A$ & $N / A$ & $N / A$ \\
\hline $\begin{array}{l}\text { E.1297.Z.1. } \\
\text { P }\end{array}$ & Z & 1 & primary & 5 & $\begin{array}{l}\text { sample I } \\
\text { already had, } \\
\text { sampled } \\
\text { earlier }\end{array}$ & $\begin{array}{l}20- \\
60 \\
10- \\
20 \\
<2\end{array}$ & most & rare & $\begin{array}{l}\text { cannot } \\
\text { determine } \\
\text { after } \\
\text { freezing/ } \\
\text { melting }\end{array}$ & $\begin{array}{l}\text { no } \\
\text { fluorescence }\end{array}$ & $\begin{array}{l}\text { Nov } \\
-15\end{array}$ \\
\hline $\begin{array}{l}\text { E.1297.Z.7. } \\
\text { P }\end{array}$ & Z & 7 & primary & 4 & $\begin{array}{l}\text { many nice } \\
\text { primary } \\
\text { inclusions }\end{array}$ & $\begin{array}{l}20- \\
60 \\
10- \\
20 \\
<2 \\
\end{array}$ & most & $\begin{array}{l}\text { rare, } \\
\text { acicular }\end{array}$ & $\begin{array}{l}\text { rare, in } \\
5 \% \text { of } \\
\text { inclusions }\end{array}$ & $\begin{array}{l}\text { no } \\
\text { fluorescence }\end{array}$ & $\begin{array}{l}\text { Nov } \\
-15 \\
\end{array}$ \\
\hline $\begin{array}{l}\text { E.1297.Z.8. } \\
\text { P }\end{array}$ & Z & 8 & primary & 4 & $\begin{array}{l}\text { sample I } \\
\text { already had, } \\
\text { sampled } \\
\text { earlier }\end{array}$ & $\begin{array}{l}30- \\
80 \\
10- \\
30 \\
<2 \\
\end{array}$ & most & $\begin{array}{l}\text { none } \\
\text { seen }\end{array}$ & $\begin{array}{l}\text { cannot } \\
\text { determine } \\
\text { after } \\
\text { freezing/ } \\
\text { melting }\end{array}$ & $\begin{array}{l}\text { no } \\
\text { fluorescence }\end{array}$ & $\begin{array}{l}\text { Oct- } \\
15\end{array}$ \\
\hline
\end{tabular}

Interval 1297 consists of blocky light gray halite and both red and light gray mud with light gray halite crystals. Large secondary fluid inclusions are present in all parts of this interval. Zone A contains some areas with primary fluid inclusion assemblages with large inclusions, 
these inclusions are primarily all liquid, a small portion contain acicular solids and vapor bubbles.

Because of the clarity of these samples and large fluid inclusion size they were examined via freezing-melting microthermometry. Samples E.1297.Z.1.P and E.1297.Z.8.P were cooled to $-190{ }^{\circ} \mathrm{C}$ for over 3 minutes. Despite this prolonged period at low temperatures, fluid inclusions never froze.

\section{Appendix II: Empress Raman Data}

\section{Detailed Raman Methods:}

1) Pre-scan

a) Focus microscope on sample.

b) Screenshot where the inclusion is scanned, record the phases seen in the inclusions, and the phases focused on in inclusions.

2) Scan collection

a) Accumulation period, as necessary to reduce the noise to signal ratio.

3) Post Scan - data processing

a) Zap cosmic ray's ( they did not increase in strength during multiple scans

b) Remove baseline (simple, subtract a simple line)

c) Smooth spectra to remove noise but maintain original significant peaks (confirmable as not noise, usually determined in examination with other spectra).

d) Record peaks using Raman software, such as built in with the spectrometer, or $3^{\text {rd }}$ party software, such as spectragryph.

4) Save as WRX (the proprietary format) and text file (can use in other programs)

5) Graph data in software (Excel, Grapher, R, other).

6) Identify through comparison with reference spectra of in peak matching software, such as BIO-Rad or Spectragryph 1.1.1 matching function with RRUFF mineral database.

Natural waters were placed in glass vials and placed on the spectrometer, the laser was 
focused through the glass and onto the waters inside it. Spectra were then collected.

\section{Raman File Naming Convention}

Table 31. Explanation of sample name scheme, signifigance of name parts.

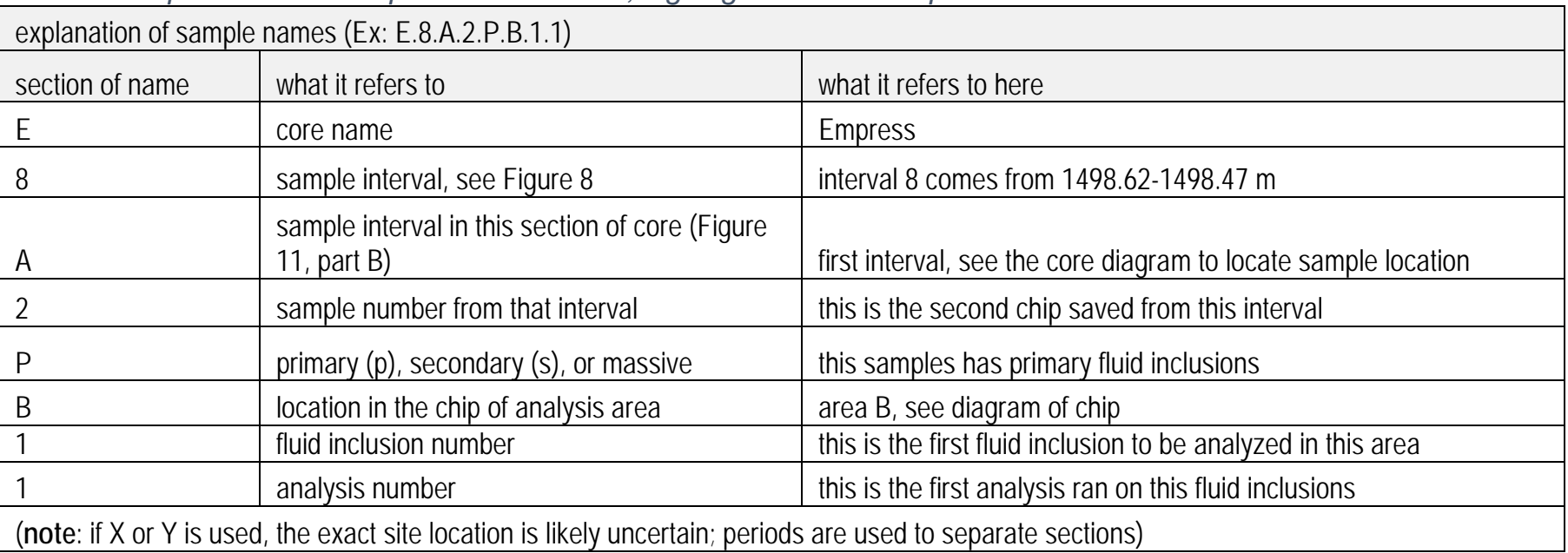

\section{Table 32. Raman file naming convention}

Raman data file naming explanation, example:

E.2.E.1.P.B.12.3_WATER_AUG.17.16_532nm40x100intensity 100-3800

\begin{tabular}{|l|l|}
\hline section of name & what it means \\
\hline E.2.E.1.P.B.12.3 & chip name and area where scanned, see Table 31 \\
\hline WWATER_ & optional section_clarifies what was measured \\
\hline AUG.17.16 & date \\
\hline $5532 \mathrm{~nm}$ & what wavelength laser was used for raman analysis \\
\hline $40 \mathrm{x}$ & what level of magnification (the objective) was used \\
\hline 100 intensity & the power of the laser \\
\hline $100-3800$ & scanned from $x$-y wavecounts \\
\hline
\end{tabular}

Empress 1A, Interval $2(1520.22-1520.00 \mathrm{~m})$

Interval $2(1520.22-1520.00 \mathrm{~m})$ has many spectral peaks without definitive identities.

The broad peak at $\sim 888 \mathrm{~cm}^{-1}$ is unaccounted for. The source of the broad peak at $\sim 1377$ and $1605 \mathrm{~cm}^{-1}$ may be organic matter such as disordered graphite. The source of the broad peak at $\sim 1272 \mathrm{~cm}^{-1}$ is unknown.

A scan of a globular solid (E.2.E.1.P.A.1.3B_gloubular) indicates the presence of anhydrite and another unknown solid (possibly aluminite) with peaks at $\sim 794, \sim 992 \mathrm{~cm}^{-1}$ (the 
fluorescence of this solid further complicates interpretation). Another scan of a globular solid yielded only water and anhydrite peaks, indicating that this solid may be another form of anhydrite. Another globular solid (E.2.E.1.P.B.12) has several anhydrite peaks ( 504, 1160 $\mathrm{cm}^{-1}$ ) but the strong characteristic peak at $\sim 1018 \mathrm{~cm}^{-1}$ is not present. This solid may be related to anhydrite while lacking the functional group causing the peak at $\sim 1018 \mathrm{~cm}^{-1}$.

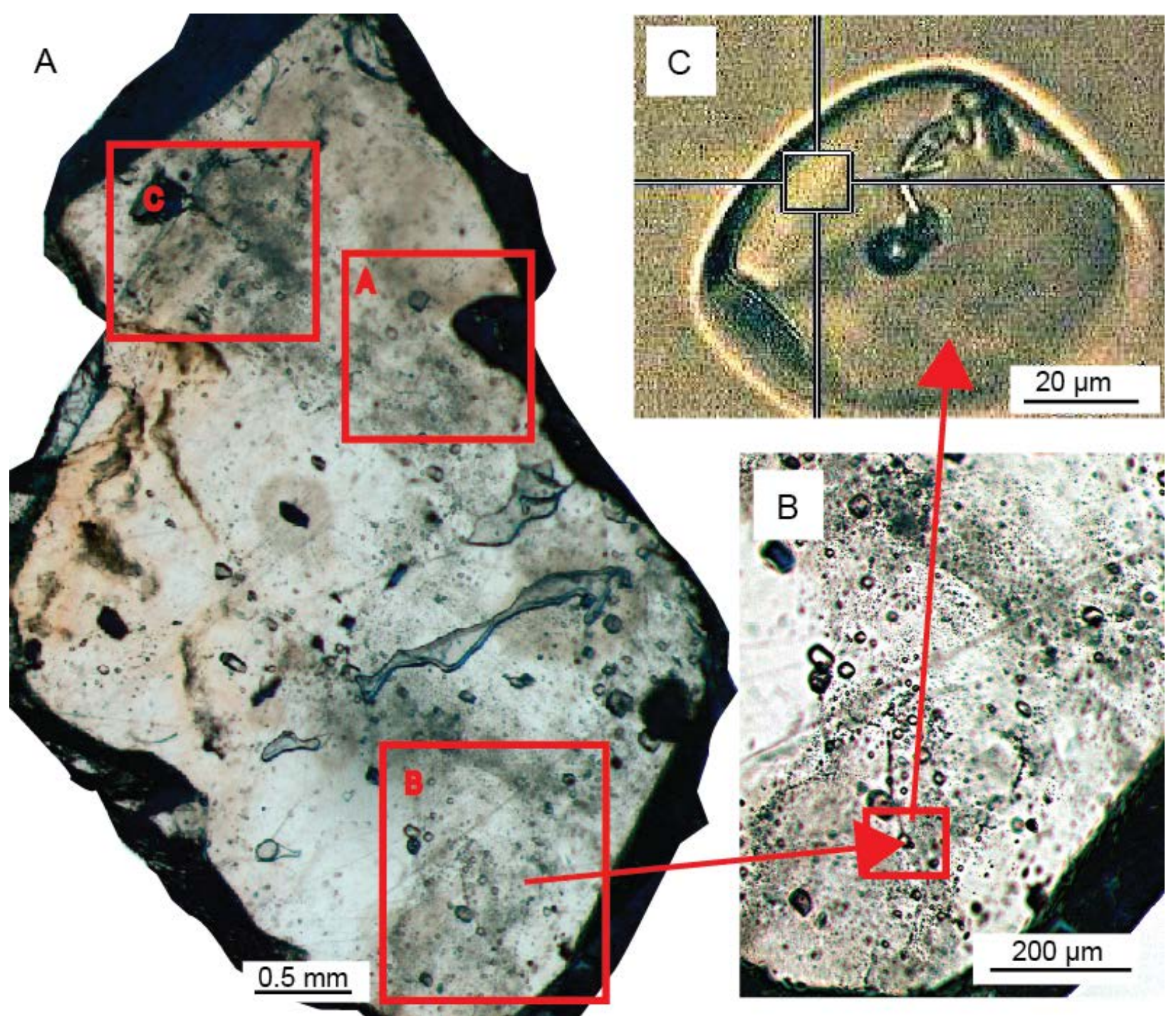

Figure 54. Images of areas of analyses in polished halite chip E.2.E.1.P. (A) Chip for Raman analysis: Empress 1A, interval 2, $1520.22-1520.0$ m, zone E, chip 1 (sample E.2.E.1.P). Areas of analysis are outlined by red boxes. (B) Area of analysis $B$, and (C) large fluid inclusion (50 $\mu$ ) with vapor bubble and acicular solids examined via laser Raman spectroscopy (scan E.2.E.1.P.B.9). 


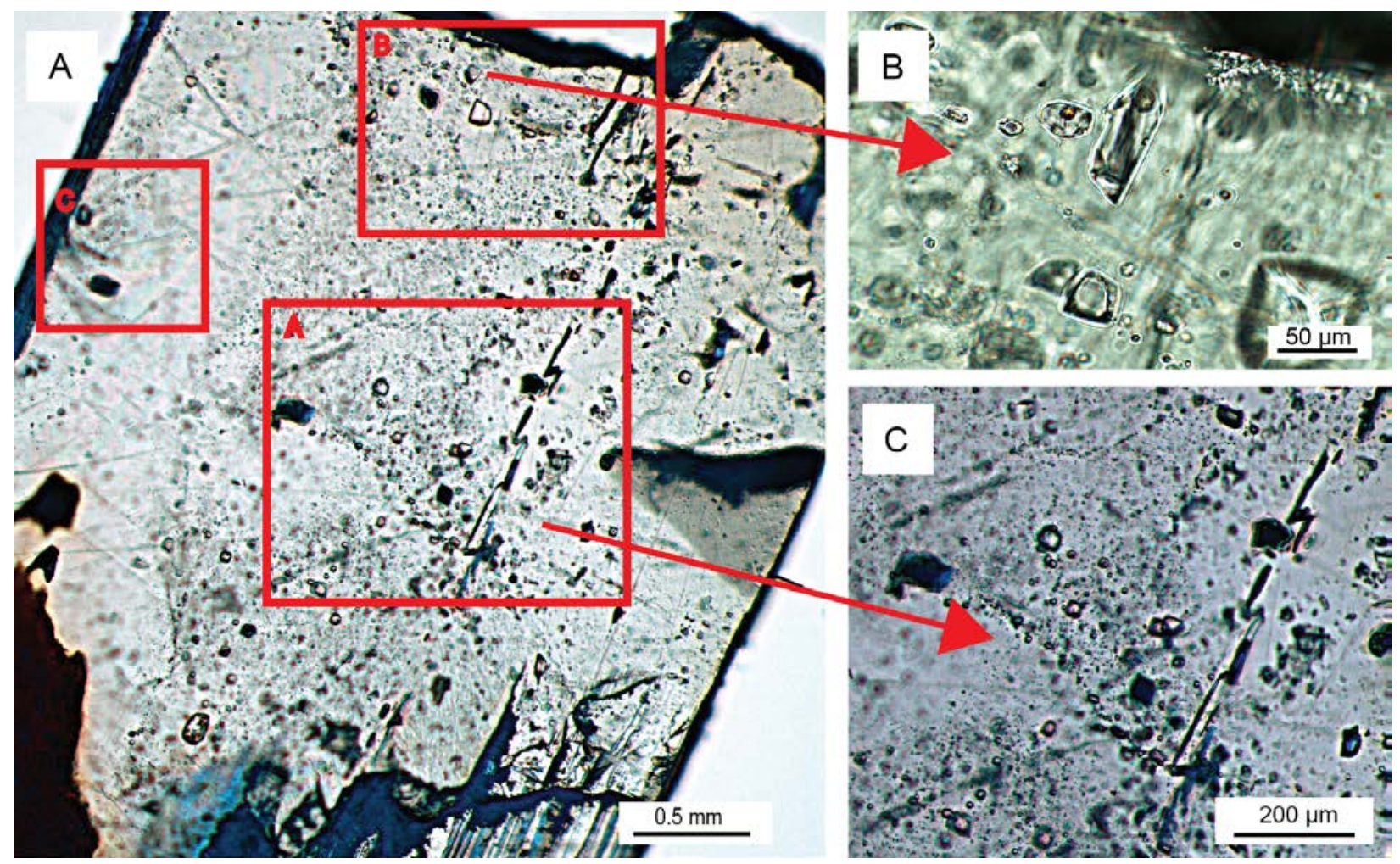

Figure 55. Images of areas of analyses in halite chip E.2.E.2.P. (A) Chip for Raman analysis: Empress 1A, interval 2, $1520.22-1520.0$ m, zone E, chip 2 (sample E.2.E.2.P). Areas of analysis are outlined by red boxes. (B) Fluid inclusions in area $B$ have opaque globular solids. (C) Area $C$ has primary and secondary fluid inclusion assemblages. 


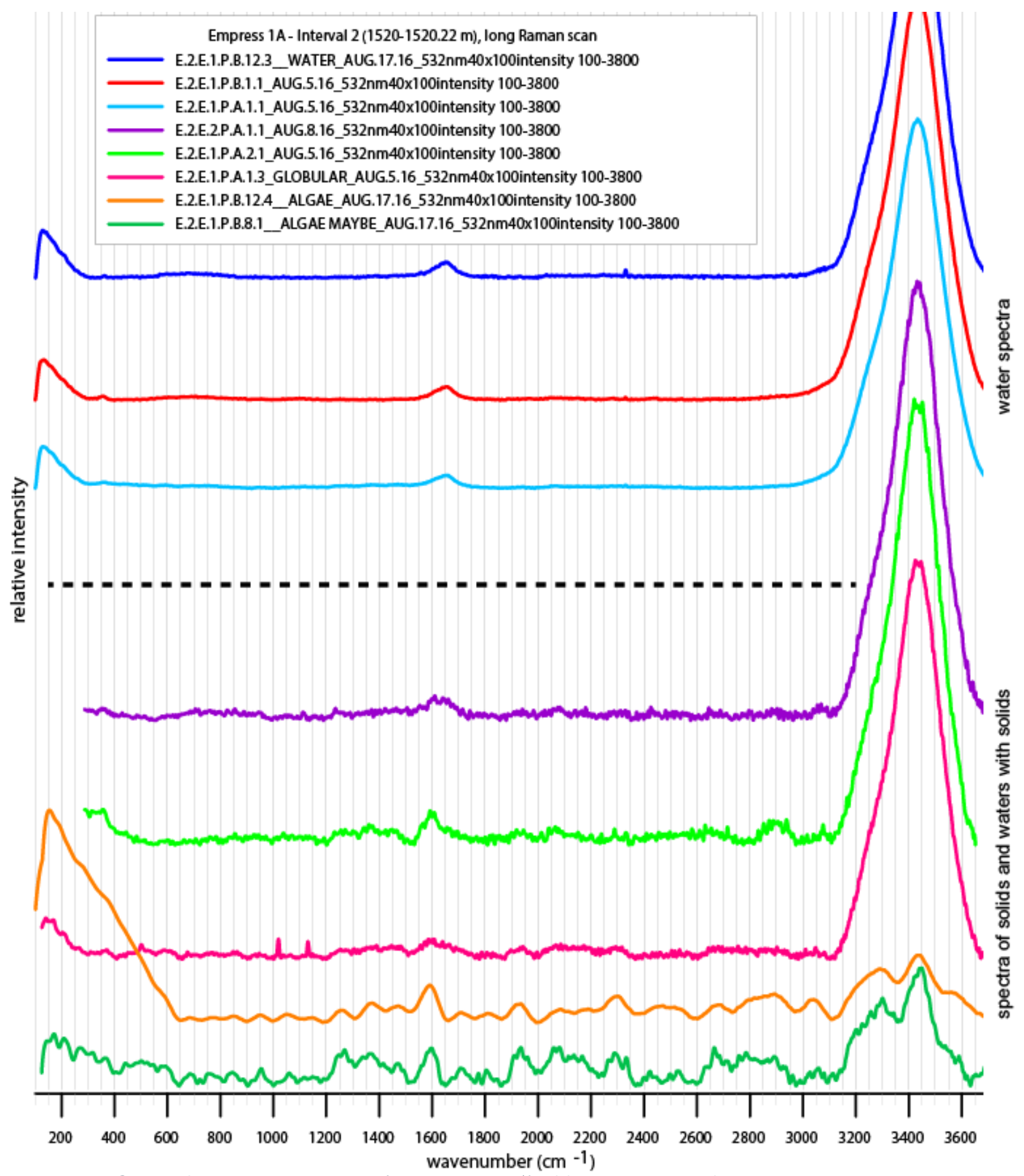

Figure 56. Chart of long Raman scans (100-3700 $\left.\mathrm{cm}^{-1}\right)$ of fluid inclusions from interval 2, 1520.22 $1520.0 \mathrm{~m}$. Spectra of solids are on the bottom, and spectra of fluids are on the top. 


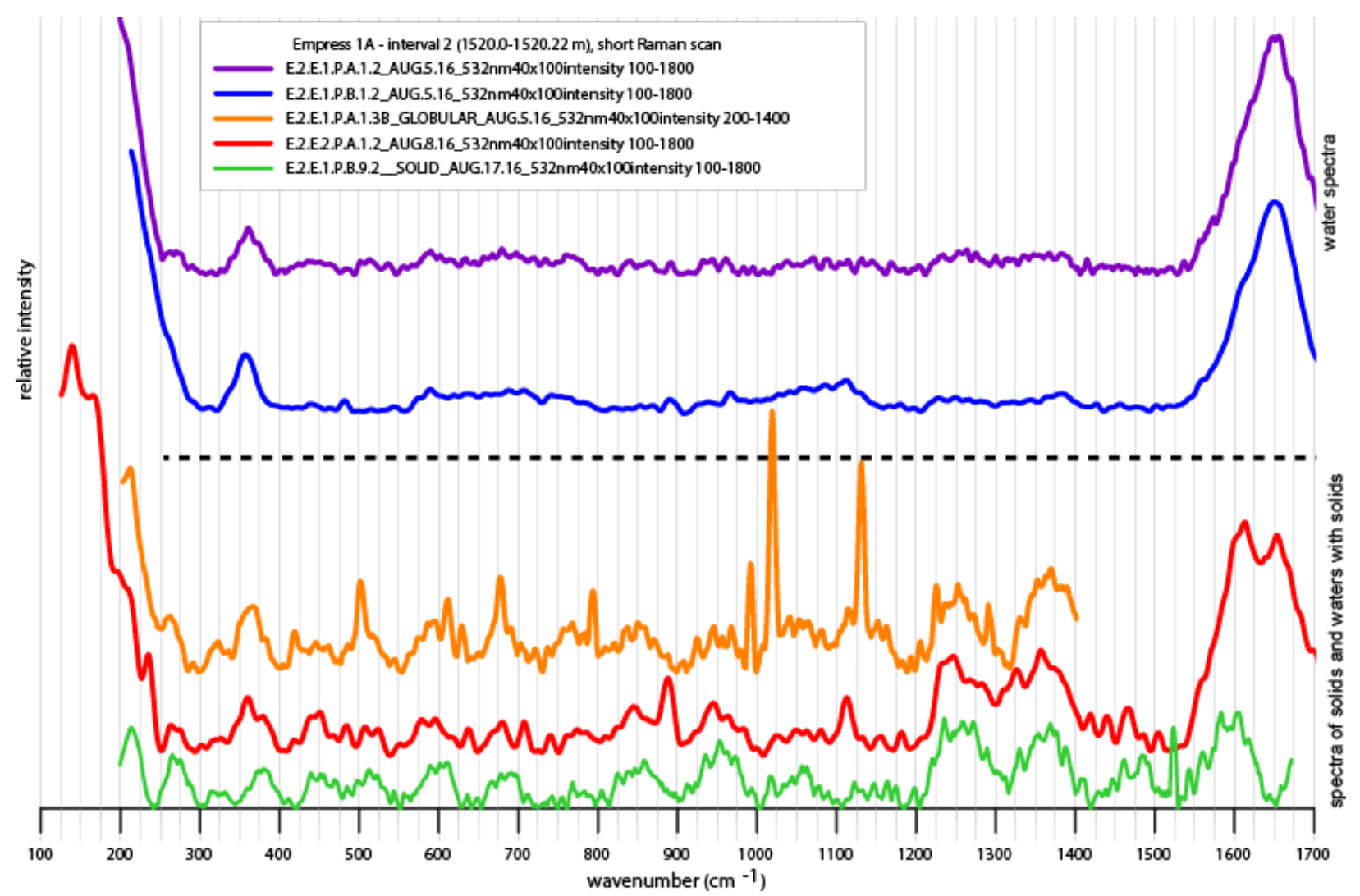

Figure 57. Chart of long Raman scans (100-1700 $\left.\mathrm{cm}^{-1}\right)$ of fluid inclusions from interval 2, 1520.22 $1520.0 \mathrm{~m}$. Spectra of solids are on the bottom, and spectra of fluids are on the top.

Table 33. Spectral peaks from Raman analysis of interval 2, $1520.22-1520.0 \mathrm{~m}$.

\begin{tabular}{|c|c|c|c|}
\hline scan name & scan target & comments & spectra peaks $\left(\mathrm{cm}^{-1}\right)$ \\
\hline E.2.E.1.P.A.1.1 & fluid & $\mathrm{n} / \mathrm{a}$ & $\begin{array}{l}\text { 146(B), 1661(B), } \\
\text { 2331(s), 3439(B) }\end{array}$ \\
\hline E.2.E.1.P.A.1.2 & fluid & $\mathrm{n} / \mathrm{a}$ & $\begin{array}{l}\text { 133(B), 360(wb), } \\
\text { 590(vwb?), 1647(B), }\end{array}$ \\
\hline $\begin{array}{l}\text { E.2.E.1.P.A.1.3 } \\
\text { GLOBULAR } \\
\text { SOLID }\end{array}$ & $\begin{array}{l}\text { solid in } \\
\text { inclusion }\end{array}$ & $\begin{array}{l}\text { this long scan picked up anhydrite and } \\
\text { water peaks, nothing else (see below) } \\
\text { came through }\end{array}$ & $\begin{array}{l}\text { 142(b), 169(wb), } \\
\text { 204(wb), 262(wb), } \\
\text { 309(vwb?), 501(ws), } \\
\text { 675(wb), 847(vwb), } 947 \\
\text { (vwb), 1019(s), } \\
\text { 1060(wb), 1130(s), } \\
\text { 1896(bw?), 3453(B) }\end{array}$ \\
\hline $\begin{array}{l}\text { E.2.E.1.P.A.1.3B } \\
\text { GLOBULAR } \\
\text { SOLID }\end{array}$ & $\begin{array}{l}\text { solid in } \\
\text { inclusion }\end{array}$ & $\begin{array}{l}\text { Strong peaks at } 992 \text { with } 1019 \text { and } \\
1113 \text { are rare. Many peaks align well } \\
\text { with anhydrite (501, } 611,677,1019 \text {, } \\
\text { and } 1131 \text { - all match with it). -Could be a }\end{array}$ & $\begin{array}{l}\text { 212(wb), 262(wb), } \\
\text { 323(vwb?), 367(B), } \\
\text { 418(ws), 501(s), } \\
\text { 600(wB?), 611(s), }\end{array}$ \\
\hline
\end{tabular}




\begin{tabular}{|c|c|c|c|}
\hline & & $\begin{array}{l}\text { combination of aluminite(not perfect, } \\
\text { and there still are unaccounted for } \\
\text { peaks ( } 794 \text { and } 992 \text { peaks)) and } \\
\text { anhydrite, good match, see image } \\
\text { below }\end{array}$ & $\begin{array}{l}\text { 677(s), 794(s), 850(wb) } \\
947(\mathrm{vwb}), 992(\mathrm{~s}) \\
1019(\mathrm{vs}), 1131(\mathrm{vs}) \\
1224(\mathrm{ws}) 1290(\mathrm{ws}) \\
1370(\mathrm{wb})\end{array}$ \\
\hline E.2.E.1.P.A.2.1 & fluid & n/a & $\begin{array}{l}\text { 360(vwb), 1593(B), } \\
\text { 2330(vwb), 2934(B) } \\
\text { 3074(s), 3443(B) }\end{array}$ \\
\hline E.2.E.1.P.B.1.1 & fluid & $\mathrm{n} / \mathrm{a}$ & $\begin{array}{l}\text { 133(b), 353(wvb), } \\
\text { 1656(B), 2333(vws), } \\
3440(B)\end{array}$ \\
\hline E.2.E.1.P.B.1.2 & fluid & $\begin{array}{l}\text { broad peaks near } 600 \text { and } 1100 \\
\text { correlate with background spectra from } \\
\text { glass (some clay minerals-nontronite- } \\
\text { have a weak-broad peak near } 888 \text {, final } \\
\text { call- unknown }\end{array}$ & $\begin{array}{l}\text { 356(b), 483(ws), } \\
\text { 587(ws), 888(ws), } \\
\text { 966(s), 1114(wb), } \\
\text { 1390(vwb?), 1507(ws), } \\
\text { 1650(B), 2330(s), } \\
\text { 3443(B) }\end{array}$ \\
\hline E.2.E.1.P.B.10.1 & fluid & water & $\begin{array}{l}142,207,266,319,348, \\
554,588,678,748,790, \\
839,863,949,1024, \\
1088,1141,1177,1267, \\
1331,1439,1472,1608, \\
1829\end{array}$ \\
\hline E.2.E.1.P.B.12.2 & $\begin{array}{l}\text { solid in } \\
\text { inclusion }\end{array}$ & $\begin{array}{l}\text { spherule solid, suspect algae- only } \\
\text { worked at 10\% laser power, } 50 \% \text { didn't } \\
\text { work }\end{array}$ & $\begin{array}{l}129,363,434,483,504, \\
571,599,654,678,850, \\
932,1160,1657,1931\end{array}$ \\
\hline E.2.E.1.P.B.12.3 & fluid & $\mathrm{n} / \mathrm{a}$ & $\begin{array}{l}\text { 130(b), 360(vwb), } \\
\sim 1650(B), 2330(s) \\
3443(B)\end{array}$ \\
\hline E.2.E.1.P.B.12.4 & fluid & n/a & $\begin{array}{l}\sim 130(b), \sim 210(w b) \\
\sim 260(w b), \sim 1600(B)\end{array}$ \\
\hline E.2.E.1.P.B.2.2 & fluid & water & $\begin{array}{l}130,232,335,354,458, \\
482,891,941,1063, \\
1091,1165,1264,1480, \\
1656\end{array}$ \\
\hline E.2.E.1.P.B.8.1 & $\begin{array}{l}\text { solid in } \\
\text { inclusion }\end{array}$ & $\begin{array}{l}\text { globular solid, noisy spectra with } \\
\text { fluorescence signal }\end{array}$ & $\begin{array}{l}\sim 130(b), 210(w b) \\
263(w b), 358,657 \\
963(w b ?), 1616(B) \\
3443(B)\end{array}$ \\
\hline E.2.E.1.P.B.9.1 & fluid & water, but peak not seen & $\begin{array}{l}\text { 168(s), 266(bw), } \\
\text { 515(ws), 578(s), } \\
\text { 945(wb), 1048(ws), } \\
\text { 1604(s), }\end{array}$ \\
\hline
\end{tabular}




\begin{tabular}{|c|c|c|c|}
\hline E.2.E.1.P.B.9.12.3 & $\begin{array}{l}\text { solid in } \\
\text { inclusion }\end{array}$ & $\begin{array}{l}\text { This noisy spectra had fluorescence } \\
\text { and other interference }\end{array}$ & $\begin{array}{l}\text { 171(ws), 210(ws), } \\
\text { 263(wb), 358(wb), } \\
657(w b), ~ 850(w b ?), \\
\text { 1014(wb), 1156(ws?), } \\
\text { 1613(B), }\end{array}$ \\
\hline E.2.E.1.P.B.9.2 & $\begin{array}{l}\text { solid in } \\
\text { inclusion }\end{array}$ & $\begin{array}{l}\text { acicular solid, did not get a strong } \\
\text { signal. Bold are the more certain signals } \\
\text { (no match seen in refs, or in other } \\
\text { signals (except for E..2.E.2.P.A.1.2) }\end{array}$ & $\begin{array}{l}\text { 130(b), 213(b), 264(b), } \\
\text { 756(ws?), 824(ws?), } \\
\text { 935(ws?), 953(wsB), } \\
\text { 1016(ws), 1063(wb), } \\
\text { 1272(wB), 1377(wB), } \\
\text { 1523(s), 1606(B), }\end{array}$ \\
\hline E.2.E.1.P.B.9.3 & fluid & $\mathrm{n} / \mathrm{a}$ & $\begin{array}{l}141,1154,1396,1605 \\
1706,2132,3429\end{array}$ \\
\hline E.2.E.2.P.A.1.1 & fluid & $\mathrm{n} / \mathrm{a}$ & $\begin{array}{l}\text { 1111(ws), 1230(wb), } \\
\text { 1610(wb), 1662(B), } \\
3444(B)\end{array}$ \\
\hline E.2.E.2.P.A.1.2 & $\begin{array}{l}\text { Solid in } \\
\text { fluid } \\
\text { inclusion, } \\
\text { fluid target }\end{array}$ & $\begin{array}{l}\text { noisy spectra, resembles } \\
\text { E.2.E.1.P.B.9.2 }\end{array}$ & $\begin{array}{l}\text { 140(b), 240(ws), } \\
\text { 262(ws), 358(vwb?), } \\
637(v w s), 705(w v s) \\
880(s), 1112(s) \\
\text { 1182(wb), 1225(wb), } \\
\text { 1357(wb), 1605(wb), } \\
\text { 1650(B), }\end{array}$ \\
\hline
\end{tabular}

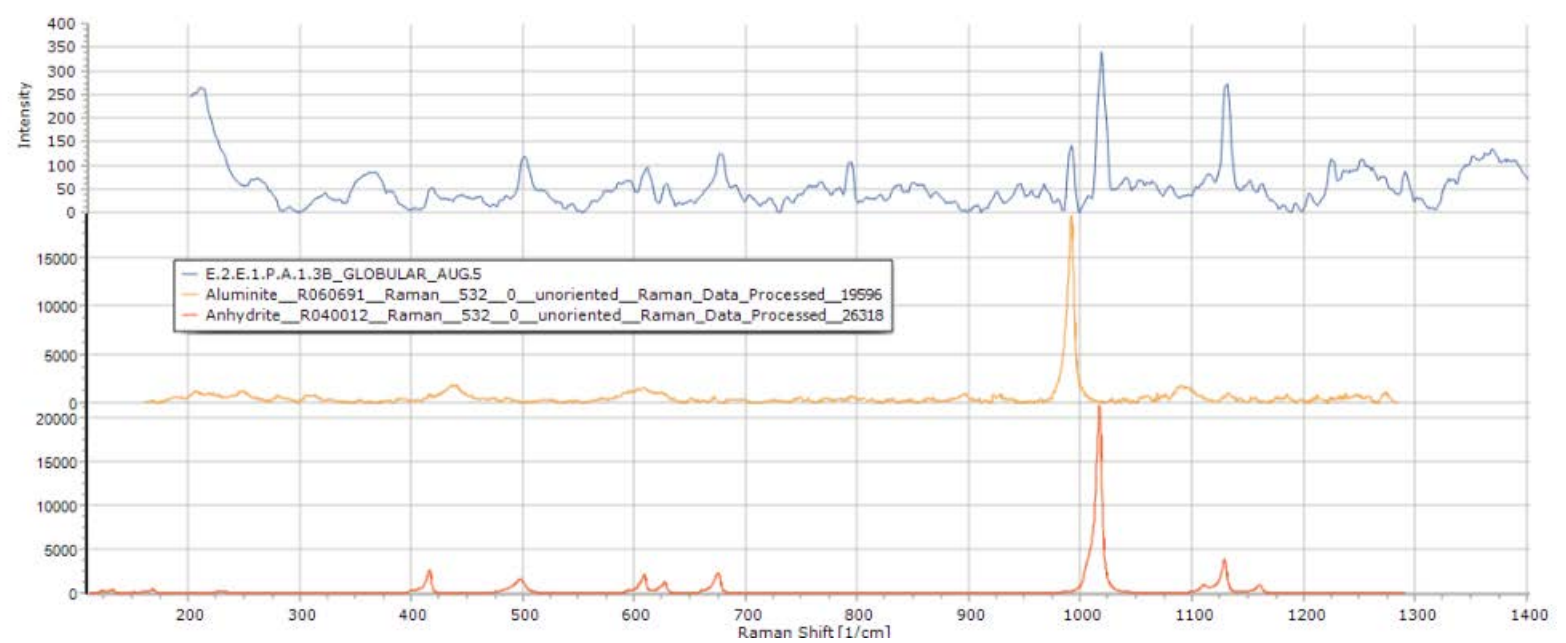

Figure 58. Chart with comparison of unidentified globular solid (Raman scan: E.2.E.1.P.A.1.3B _GLOBULAR SOLID) from interval 2, 1520.22 - $1520.0 \mathrm{~m}$, with aluminite and anhydrite. While peaks from both mineral align with observed spectra, a mineral match remains inconclusive.

Empress 1A, Interval 3 (1511.76-1511.70 m)

There are many unknowns in the interpretation of spectra from Interval 3 (1511.76 - 
$1511.70 \mathrm{~m}$ ). The sharp peak at $\sim 845 \mathrm{~cm}^{-1}$ that is only present in one scan that does not show up in other intervals is likely a cosmic ray. The source of the weak sharp peak at $\sim 880 \mathrm{~cm}^{-1}$ is unknown. The weak broad peak at $\sim 1237 \mathrm{~cm}^{-1}$ in all spectra from interval 3 may share a functional group with k-alunite. This peak is also present in synthetic samples. Two broad peaks at $\sim 1375$ and $\sim 1460 \mathrm{~cm}^{-1}$ may be a carbon compound. The broad peak at $\sim 2930 \mathrm{~cm}^{-1}$ in the noisy spectra may be related to methane (sharp $\sim 2917 \mathrm{~cm}^{-1}$ ) or ethane (sharp $\sim 2954 \mathrm{~cm}^{-1}$ ), however, neither is a good match. The source of the peak at $\sim 1605 \mathrm{~cm}^{-1}$ in this interval is unknown. The strong peak at $-3070 \mathrm{~cm}^{-1}$ is likely related to the $\mathrm{OH}$ functional group and may be related to water (Baschenko and Marchenko, 2011), or K-alum which has a moderate peak at $-3072 \mathrm{~cm}^{-1}$.

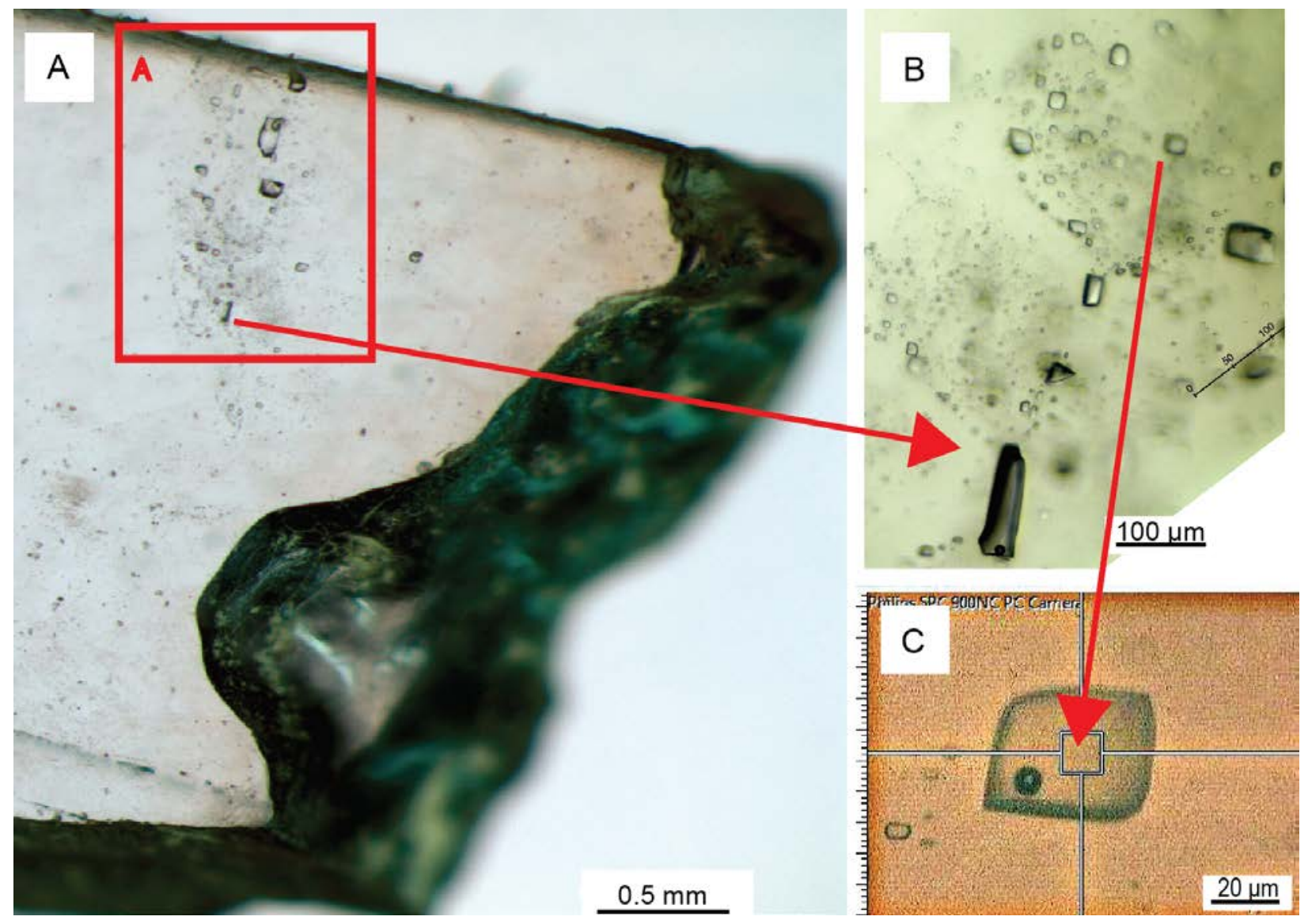


Figure 59. Image of chip for Raman analysis: Empress $1 A$, interval 3, 1511.76 - 1511.7m, from zone B, chip 1 (E.3.B.1.P). (A) This chip has one area of analysis outlined in red (B) Area A has primary and some secondary fluid inclusions, (C) some analyzed inclusions had vapor bubbles.

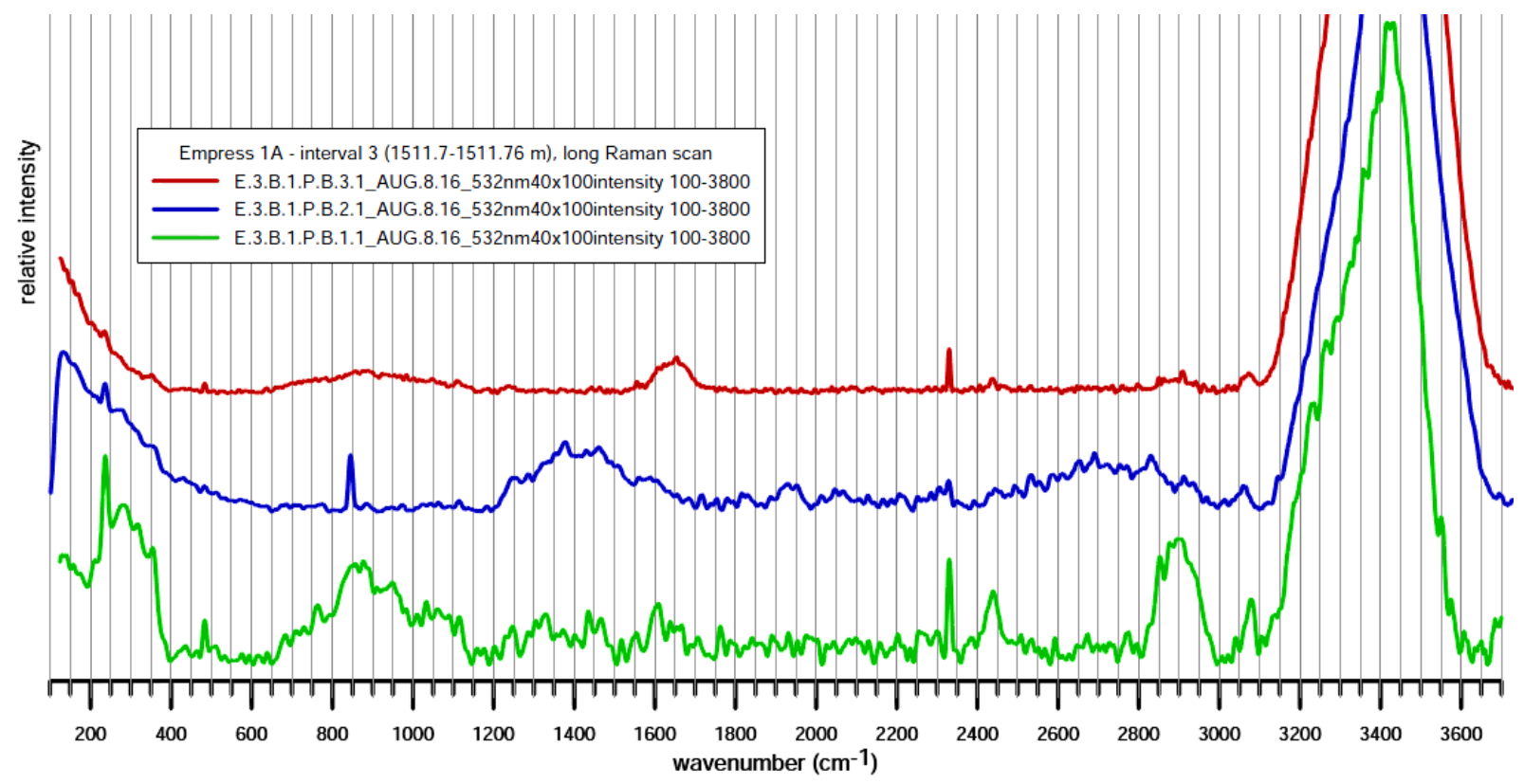

Figure 60. Chart of long Raman scans $\left(100-3700 \mathrm{~cm}^{-1}\right)$ of fluid inclusions from interval 3, 1511.76 $1511.7 \mathrm{~m}$. 

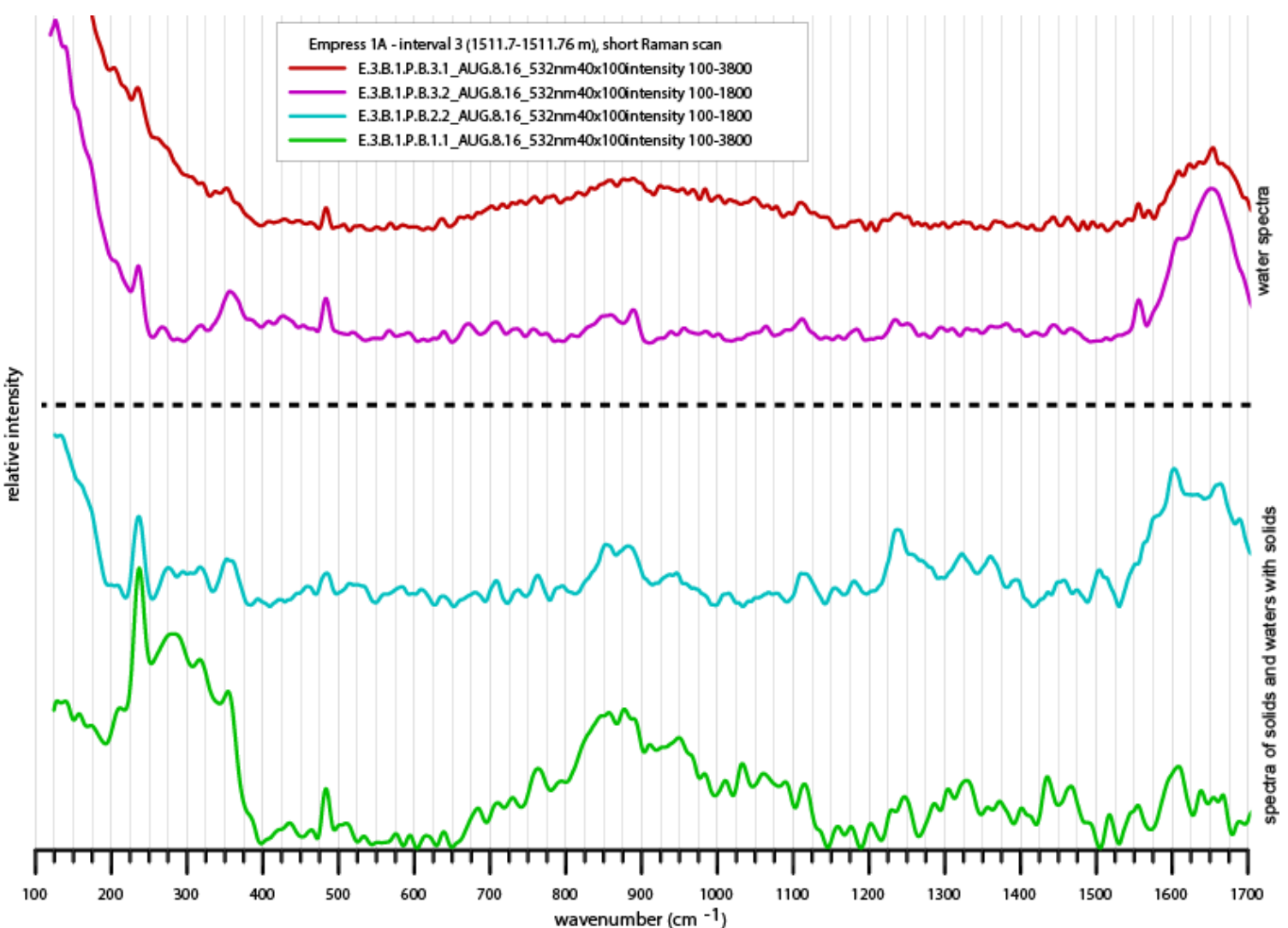

Figure 61. Chart of short Raman scans $\left(100-1700 \mathrm{~cm}^{-1}\right)$ of fluid inclusions from interval 3, 1511.76 $1511.7 \mathrm{~m}$. Spectra of solids are on the bottom, and spectra of fluids are on the top.

Table 34. Spectral peaks from Raman analysis of interval 3, 1511.76 - 1511.7m.

\begin{tabular}{|c|c|c|c|}
\hline scan name & $\begin{array}{l}\text { scan } \\
\text { target }\end{array}$ & comments & spectra peaks $\left(\mathrm{cm}^{-1}\right)$ \\
\hline E.3.B.1.P.A.1.1 & fluid & $\begin{array}{l}\text { Peak at } 237 \mathrm{~cm}^{-1} \text { are strong } \\
\text { throughout, these match best with } \\
\text { alunite, possibly anhydrite, could be } \\
\text { other, such as solids containing } \mathrm{Ca} \text {, } \\
\mathrm{Mg} \text { or } \mathrm{SiO}^{2} \text { ? }\end{array}$ & $\begin{array}{l}\text { 128(B), 237(s), 355(ws), 484, 767, } \\
1032,1114,1437,1607\end{array}$ \\
\hline E.3.B.1.P.A.2.1 & fluid & $\mathrm{n} / \mathrm{a}$ & $128,236(\mathrm{~s}), 483,1118,1925(\mathrm{~B})$ \\
\hline E.3.B.1.P.A.2.2 & fluid & $\begin{array}{l}\text { Peak at } 1237(\mathrm{wb}) \mathrm{cm}^{-1} \text { possibly k- } \\
\text { alunite? This peak in synthetic } \\
\text { samples and across other intervals, }\end{array}$ & $\begin{array}{l}\text { 126, 236(s), 345, 483, 638, 706, } \\
764,855,1012,1114,1130,1156, \\
\text { 1182, 1237(wb), 1455, 1509, } \\
\text { 1602(SH), 1662, 2332, 2408, 3245, } \\
3444\end{array}$ \\
\hline E.3.B.1.P.A.3.2 & fluid & $n / a$ & $\begin{array}{l}\text { 127, 237(s), 353, 483, 566, 705, } \\
862,940, \sim 1050,1113,1186,1235, \\
\text { 1384, 1476, 1556, 1605(sh), 1659, } \\
2331,2431(\mathrm{~B}), 3274,3444\end{array}$ \\
\hline
\end{tabular}




\begin{tabular}{|c|c|c|c|}
\hline E.3.B.1.P.B.1.1 & fluid & $\mathrm{n} / \mathrm{a}$ & $\begin{array}{l}\sim 130(\mathrm{~b}), \sim 240(\mathrm{~s}), 290(\mathrm{~B}), 360(\mathrm{ws}), \\
\sim 480(\mathrm{~s}), \sim 660(\mathrm{bw}), 870(\mathrm{vwb} ?), \\
\sim 1600(\mathrm{wb} \text { ), } 2330(\mathrm{~s}), \sim 2440(\mathrm{~b}), \\
\sim 2930(\mathrm{~B}), 3070(\mathrm{~s}), 3443(\mathrm{~B})\end{array}$ \\
\hline E.3.B.1.P.B.2.1 & fluid & $\begin{array}{l}\text { Peak at } 845 \mathrm{~cm}^{-1} \text { - does not show up in } \\
\text { other intervals, does not match up to } \\
\text { ref. minerals, believe it is cosmic, or } \\
\text { other, not in the sample. }\end{array}$ & $\begin{array}{l}\text { 130(b), } 240(\mathrm{~s}), 360(\mathrm{ws}), 484(\mathrm{ws}), \\
845(\mathrm{~S}), 1375(\mathrm{wb}), 1460(\mathrm{wb}), \\
2330(\mathrm{~s}), 3443(\mathrm{~B})\end{array}$ \\
\hline E.3.B.1.P.B.2.2 & fluid & $\mathrm{n} / \mathrm{a}$ & $\begin{array}{l}130(\mathrm{~b}), \sim 240(\mathrm{~s}), \sim 260(\mathrm{ws} ?), \\
335(\mathrm{~b}), \sim 480(\mathrm{ws}), \sim 640(\mathrm{vws}), \\
\sim 1115(\mathrm{vws}), \sim 1170(\mathrm{vws} ?), \\
1245(\mathrm{wb}), \sim 1605(\mathrm{ws}), 1655(\mathrm{wb})\end{array}$ \\
\hline E.3.B.1.P.B.3.1 & fluid & $\mathrm{n} / \mathrm{a}$ & 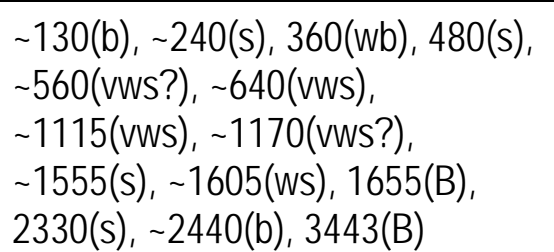 \\
\hline E.3.B.1.P.B.3.2 & fluid & $\mathrm{n} / \mathrm{a}$ & 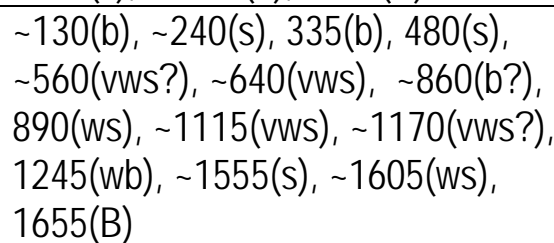 \\
\hline
\end{tabular}

\section{Empress 1A, Interval $4(1502.7-1502.6 \mathrm{~m})$}

Many spectra at Interval $4(1502.7-1502.6 \mathrm{~m})$ contain only broad peaks at $\sim 1650$ and $\sim 3440 \mathrm{~cm}^{-1}$, indicating simpler water chemistry. However, several spectra indicate the presence of other substances. The strong peaks at $\sim 417, \sim 500, \sim 1018$, and $\sim 1132 \mathrm{~cm}^{-1}$ in many of these samples are likely anhydrite. The strong broad peaks at $470 \mathrm{~cm}^{-1}$ may relate to hydrated sulfates, kaolinite, alunogen or quartz. The sharp peak at $\sim 557 \mathrm{~cm}^{-1}$ may relate to ammonium alunite $\left(\sim 560 \mathrm{~cm}^{-1}\right)$, this peak is also seen in spectra from Opeche inclusions, acid metal sulfates from Western Australia, and a synthetic inclusion (acid sulfate, syn. 5). The broad peak at $\sim 581 \mathrm{~cm}^{-1}$ is present at intervals $7(1499.42-1499.30 \mathrm{~m})$ and $1297(\sim 1297 \mathrm{~m})$, its' source is unknown. The peak at $\sim 870 \mathrm{~cm}^{-1}$ may be related to a hydrated sulfate such as aluminum sulfate $\left(\sim 870 \mathrm{~cm}^{-1}\right)$ or rostite $\left(\sim 874 \mathrm{~cm}^{-1}\right)$. The source of the peak at $930 \mathrm{~cm}^{-1}$ is unknown. It may be 
related to the peak at $870 \mathrm{~cm}^{-1}$ given its occurrence in conjunction with it.

Three broad peaks occur in the $\sim 1200-1600 \mathrm{~cm}^{-1}$ range in Interval 4 . The weak very broad peak at $\sim 1320 \mathrm{~cm}^{-1}$ may be related to iron oxide. The broad peaks at $\sim 1380$ and $\sim 1570$ $\mathrm{cm}^{-1}$ may functionally relate to amorphous carbon or other organic material (Wagner et al., 1989; Jawhari et al., 1995). The peaks that appear carbonaceous (disordered carbon peaks) only appear from one sample from scans collected in May 2016 (See Appendix II), indicating spectral contamination.

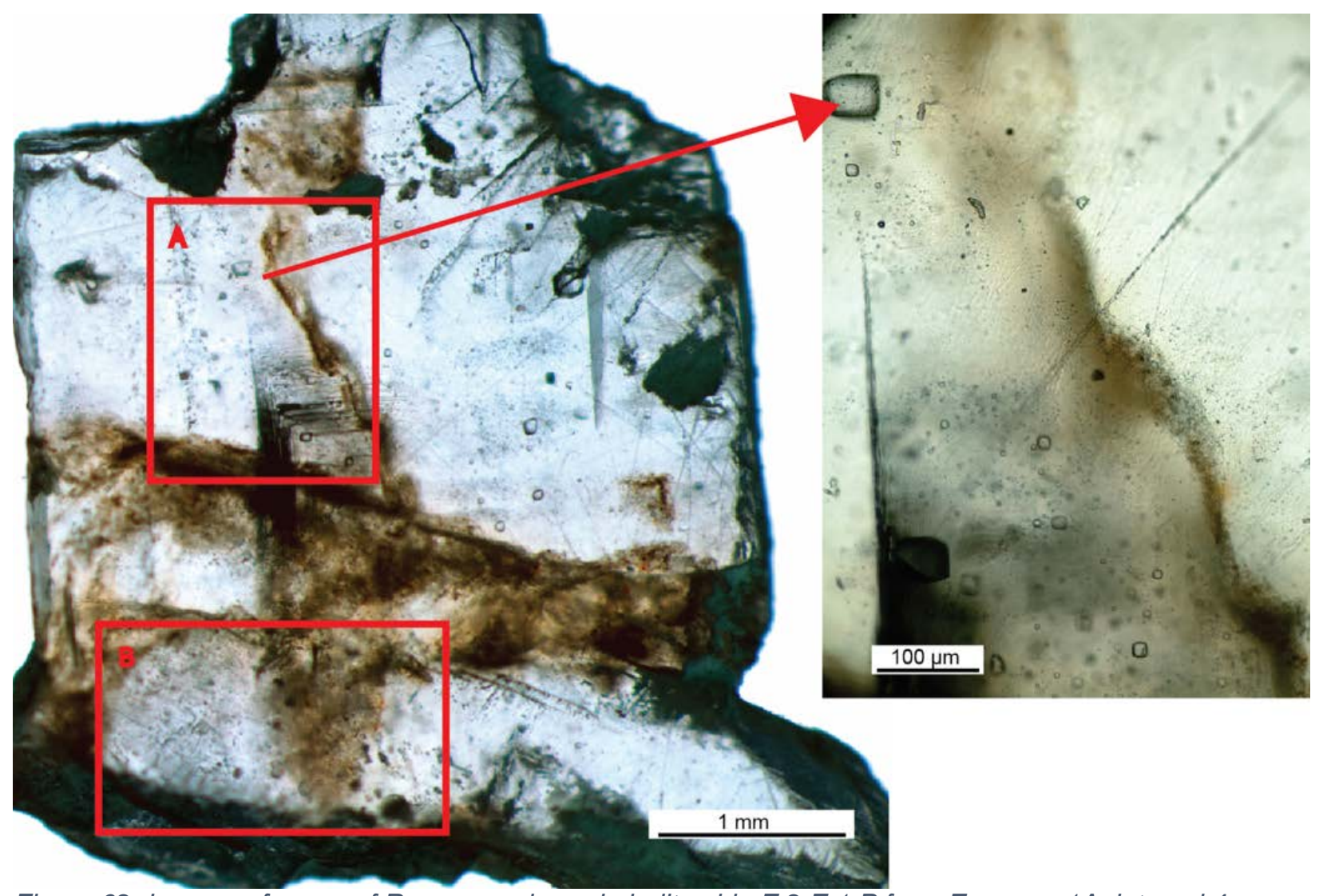

Figure 62. Images of areas of Raman analyses in halite chip E.2.E.1.P from Empress $1 A$, interval 4 $(1502.7-1502.6 \mathrm{~m})$, zone A. Areas A and B were the targets of analysis. Area $A$ is shown in greater detail on the right. 


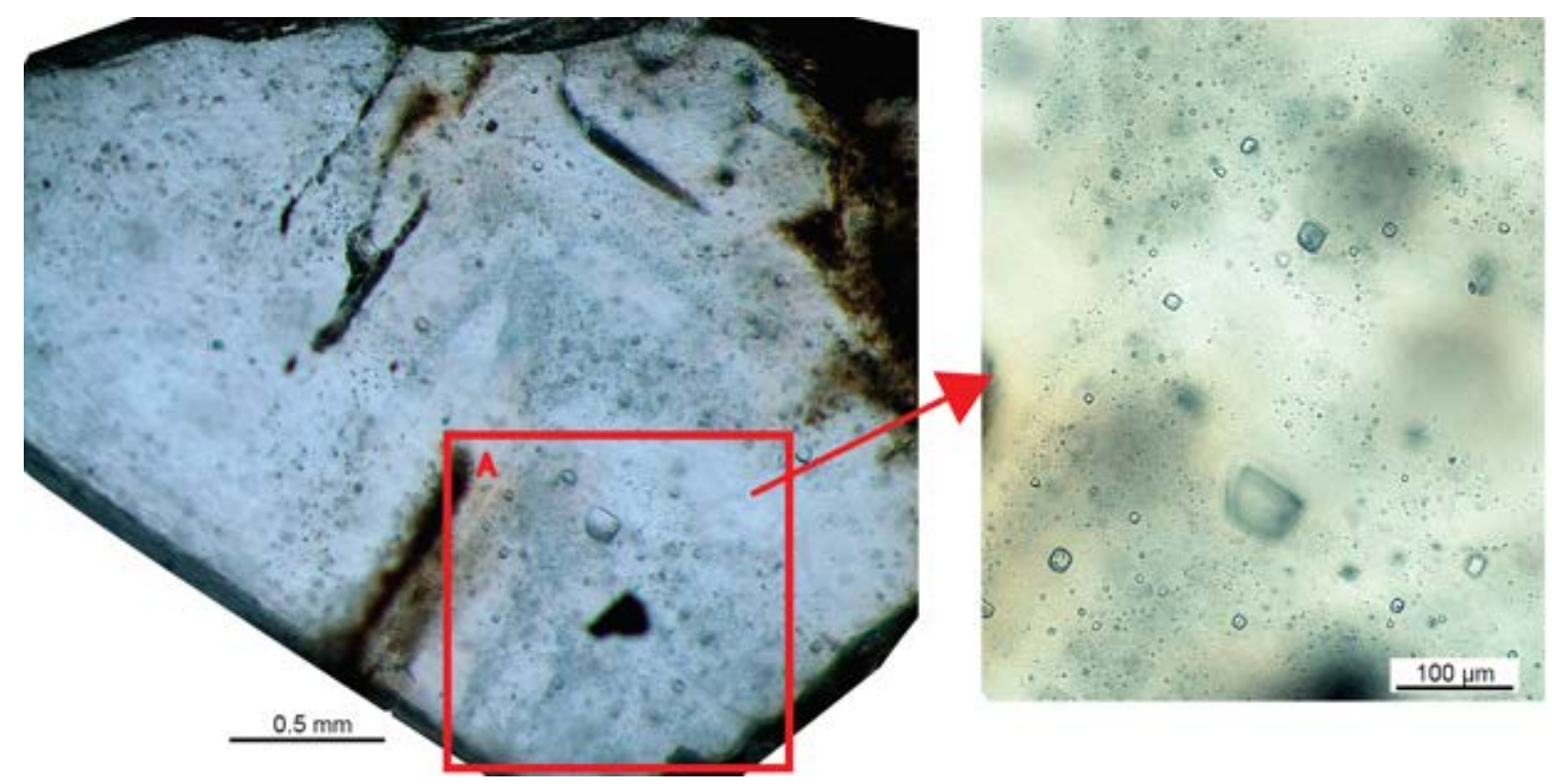

Figure 63. Images of areas of Raman analysis in halite chip E.4.B.1.P from Empress 1A, interval 4 $(1502.7-1502.6 \mathrm{~m})$, zone B. Area A was the target of analysis. Area $A$ is shown in greater detail on the right. 


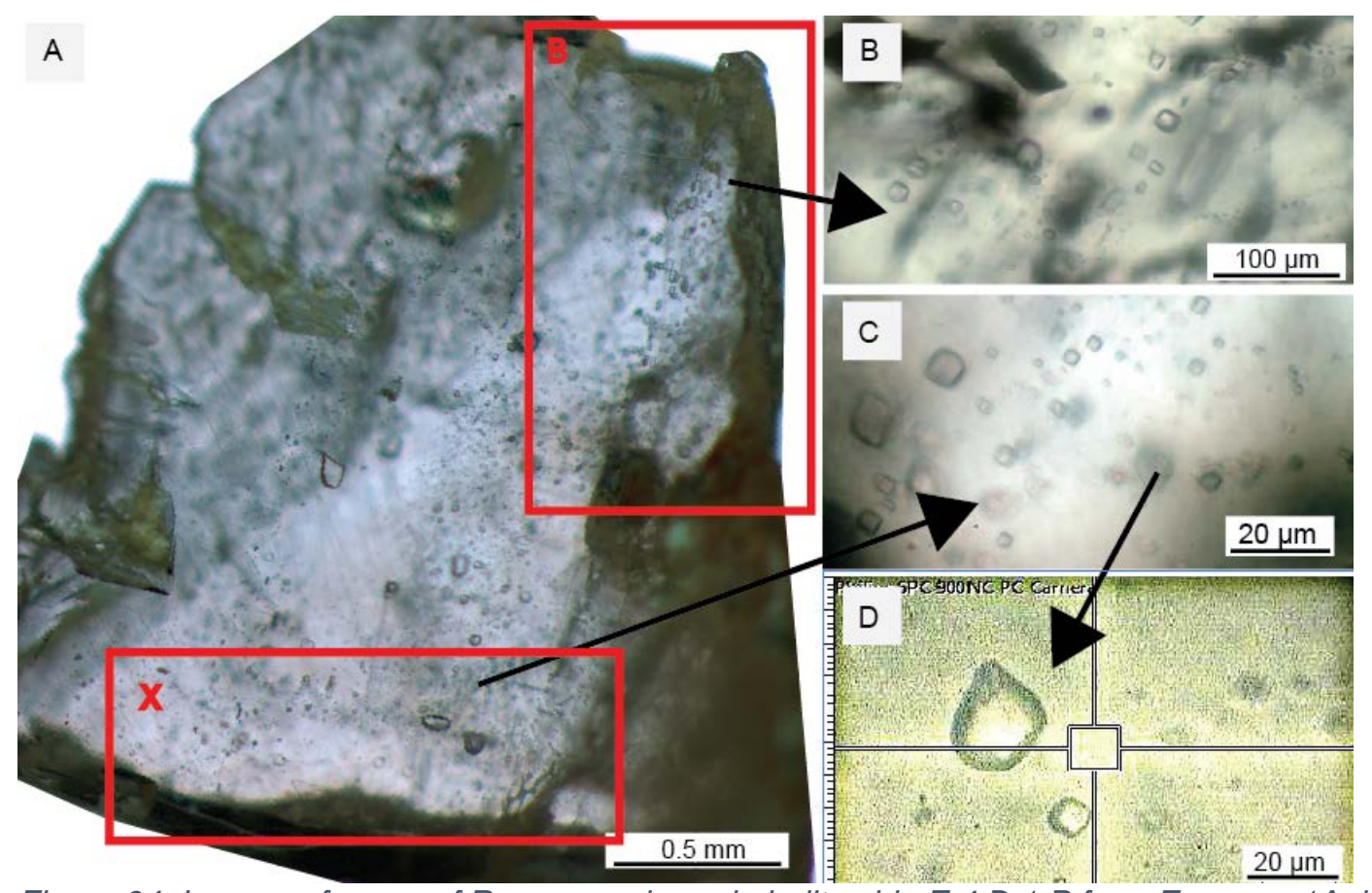

Figure 64. Images of areas of Raman analyses in halite chip E.4.D.1.P from Empress 1A, interval 4 $(1502.7-1502.6 \mathrm{~m})$, zone D. Areas of analysis are highlighted by red boxes. (B) Primary fluid inclusions in area B.(C) Primary fluid inclusions in area $X$ and (D) inclusion analyzed via Raman spectroscopy (scan E.4.D.1.P.X.2, image from laser Raman spectrometer's microscope). 


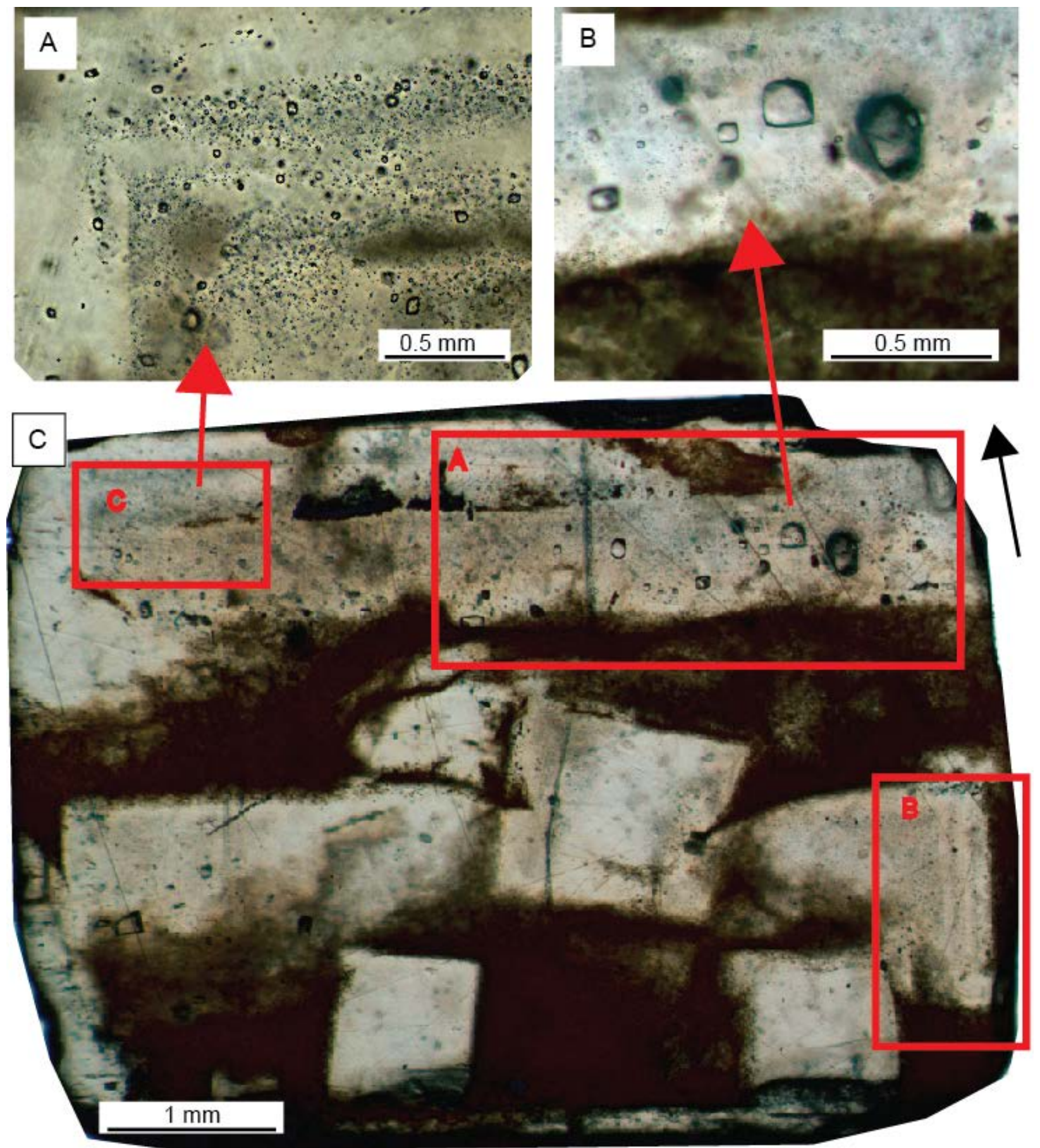

Figure 65. Image of areas of Raman analyses in halite chip E.4.Z.1.P, from Empress 1A, interval 4, 1502.7-1502.6 m, zone A. Analyzed areas outlined in red. (C) Chip contains cumulate crystal connected in a raft and sourrounded by mud. This appears to have been the nucleation point for a chevron (A) on the top part of the sample, this area is replete with primary inclusions..Another part of the chevron has very large fluid inclusions. 


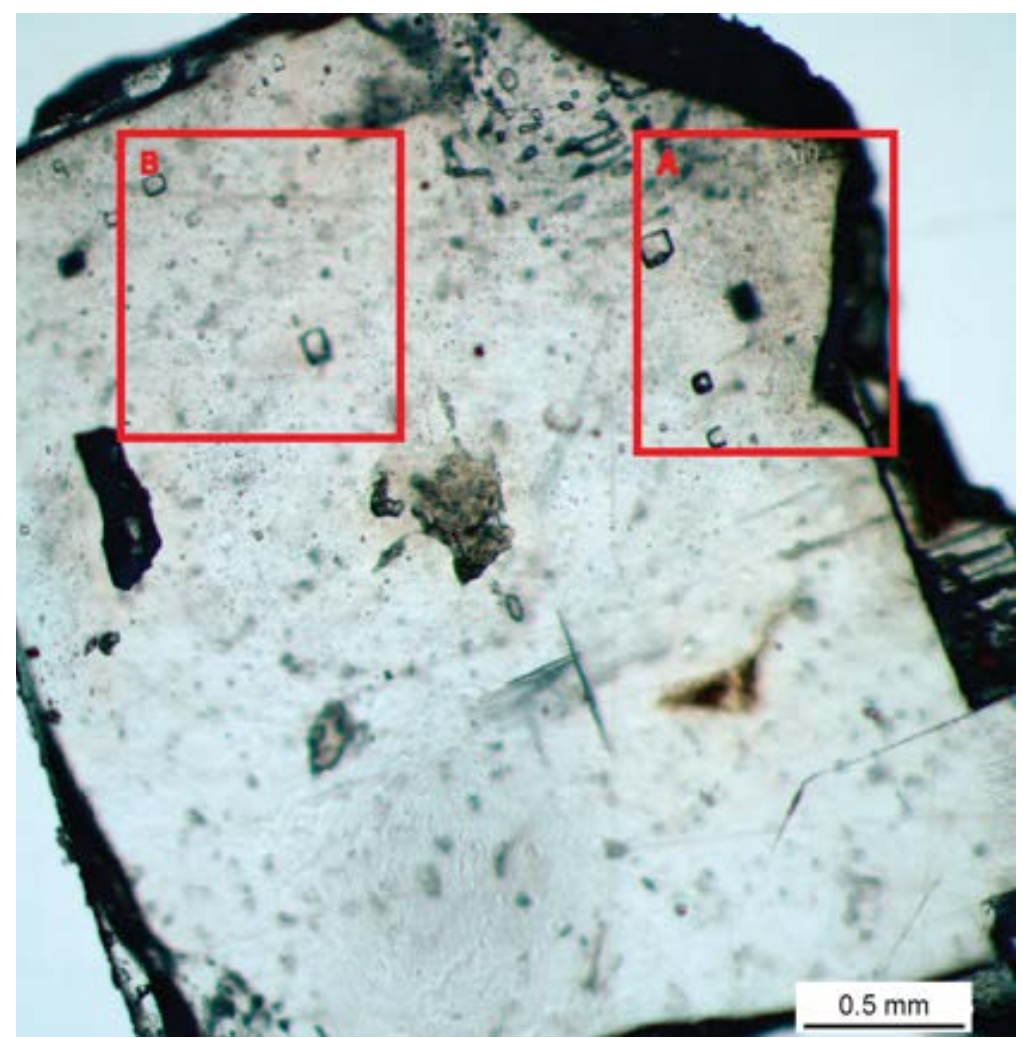

Figure 66. Image of areas of Raman analyses in halite chip E.4.Z.2.P, from Empress 1A, interval 4, 1502.7 - $1502.6 \mathrm{~m}$, zone A. Analyzed areas outlined in red.

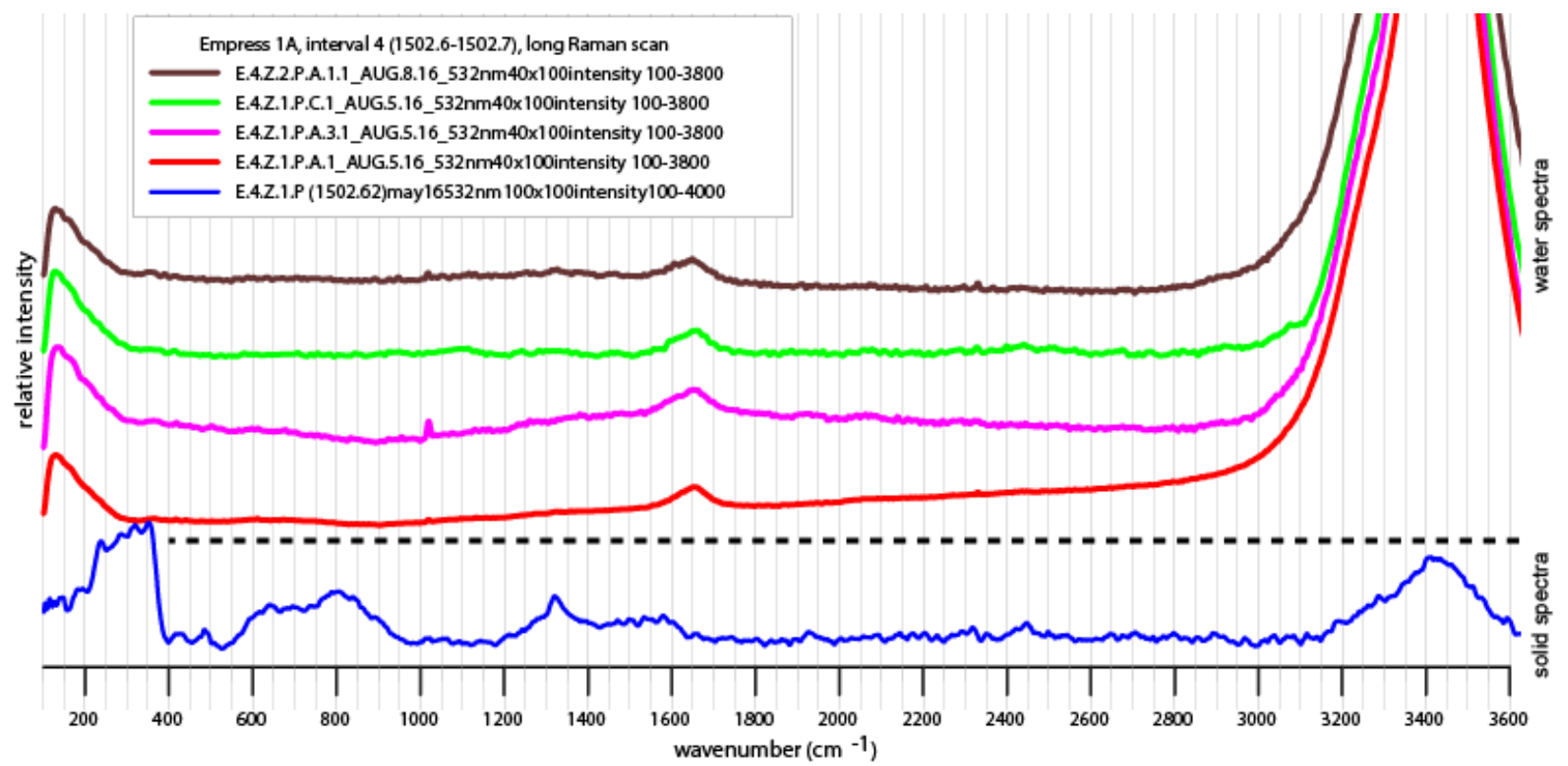

Figure 67.Chart of long Raman scans (100-3600 $\left.\mathrm{cm}^{-1}\right)$ of fluid inclusions from interval 4, 1502.7 - 1502.6 $\mathrm{m}$. Spectra of solids are on the bottom, and spectra of fluids are on the top. 


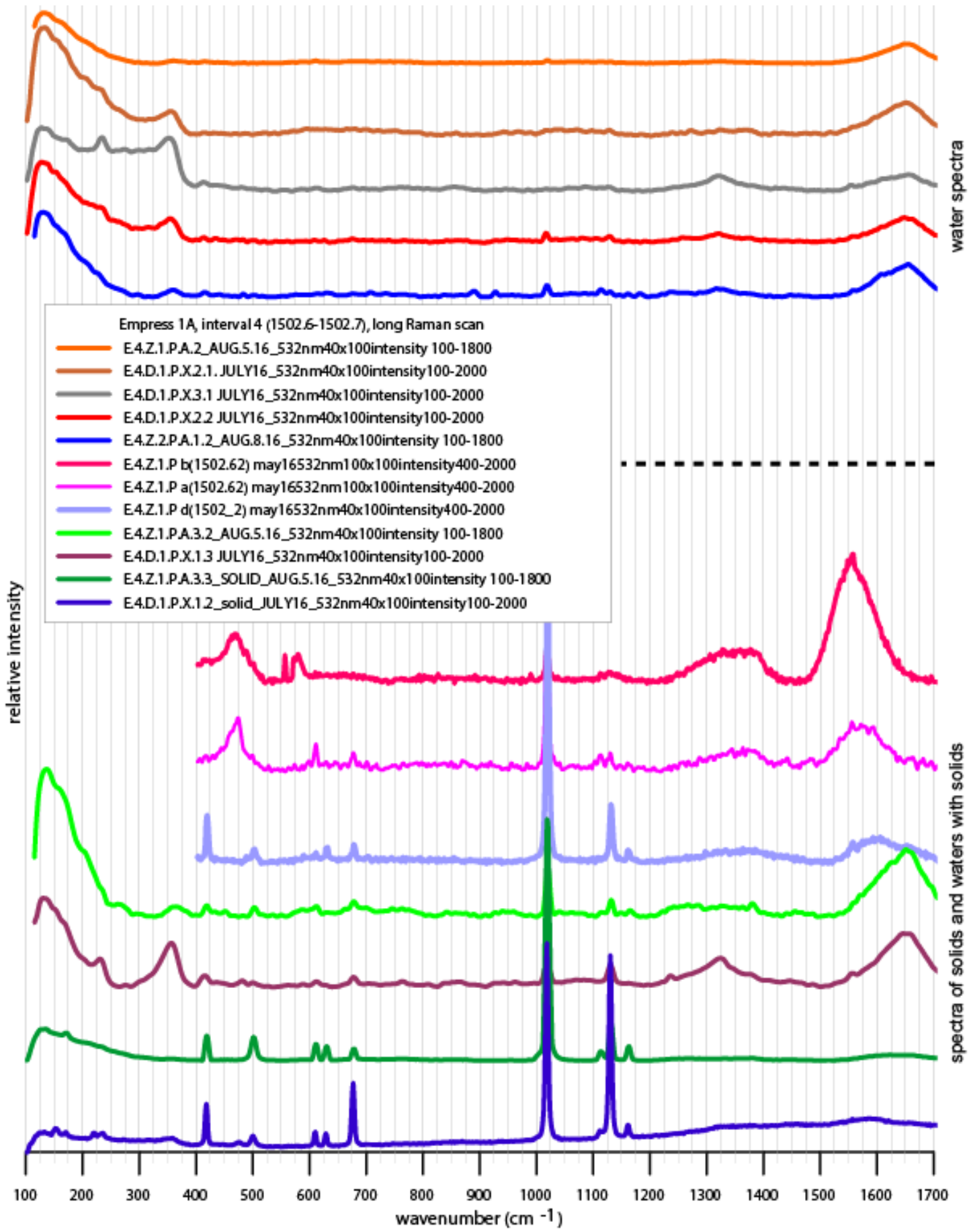

Figure 68. Chart of short Raman scans $\left(100-1700 \mathrm{~cm}^{-1}\right)$ of fluid inclusions from interval 4, 1502.7 - 1502.6 $\mathrm{m}$. Spectra of solids are on the bottom, and spectra of fluids are on the top. 


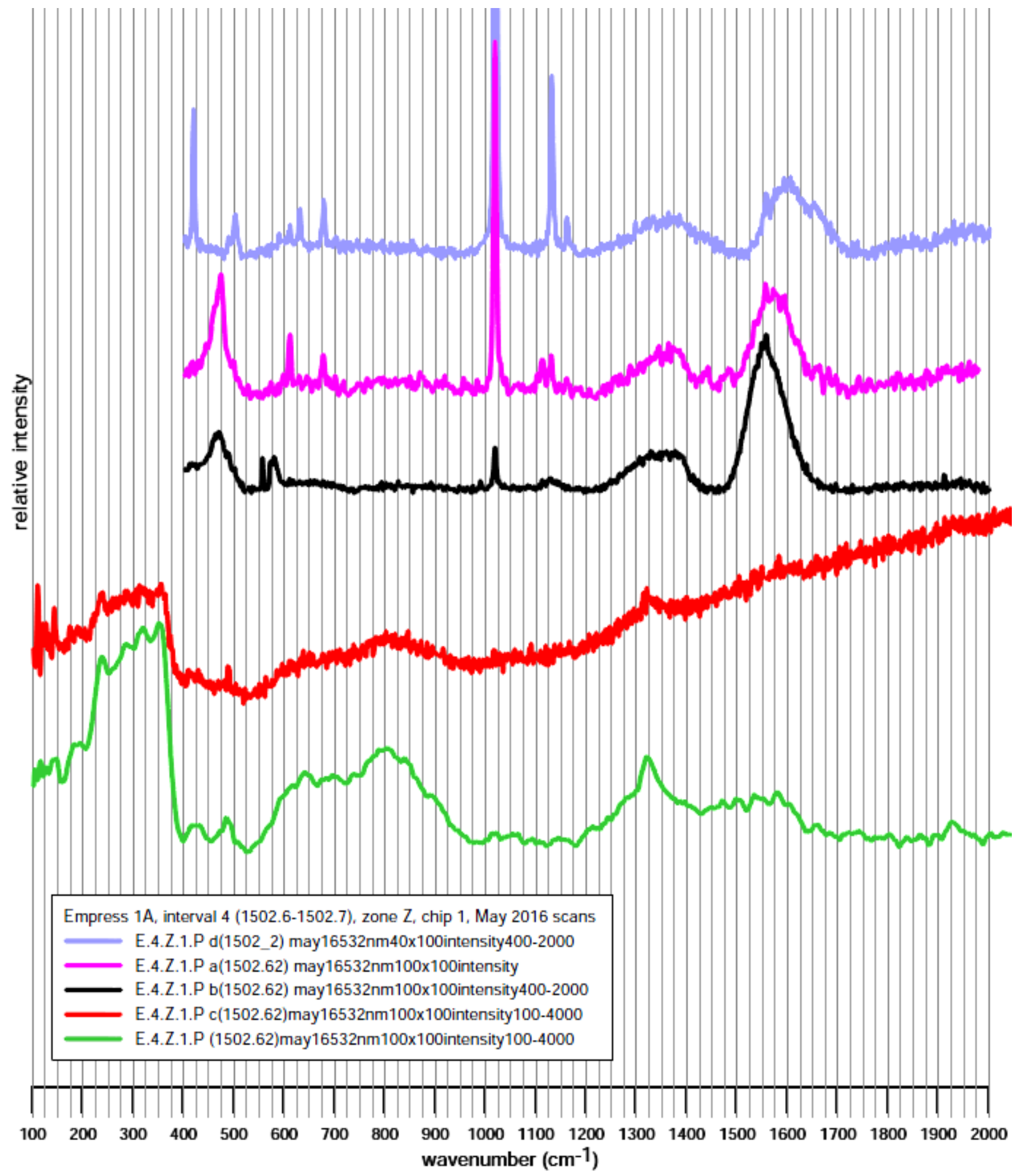

Figure 69. Chart of raman scans $\left(100-2000 \mathrm{~cm}^{-1}\right)$ of fluid inclusions from interval 4, $1502.7-1502.6 \mathrm{~m}$ collected in May 2016. These spectra differed notably from other spectra of the sale sample (Figure 68). The lower two spectra appear to be background. The upper three have unique peaks near $\sim 470,1380$, and $1570-1600 \mathrm{~cm} \mathrm{~cm}^{-1}$. 


\begin{tabular}{|c|c|c|c|}
\hline scan name & scan target & comments & spectra peaks $\left(\mathrm{cm}^{-1}\right)$ \\
\hline $\begin{array}{l}\text { E.4.A.1.P.B.1.1 } \\
(100-2000)\end{array}$ & fluid & $\mathrm{n} / \mathrm{a}$ & $\begin{array}{l}140,257,344,486, \\
744,853,1020 \\
1255,1595\end{array}$ \\
\hline E.4.B.1.P.A.2.1 & fluid & $\mathrm{n} / \mathrm{a}$ & $\begin{array}{l}266(\mathrm{mw}), 1022(\mathrm{~s}) \\
1399(\mathrm{~s}), 2900(\mathrm{~b}- \\
\text { flat) }\end{array}$ \\
\hline $\begin{array}{l}\text { E.4.B.1.P.A.4.1 } \\
(100-2000)\end{array}$ & fluid & $\mathrm{n} / \mathrm{a}$ & $1290(\mathrm{VB})$ \\
\hline $\begin{array}{l}\text { E.4.B.1.P.A.5.1 } \\
\text { solid (100- } \\
\text { 2000) }\end{array}$ & $\begin{array}{l}\text { solid in fluid } \\
\text { inclusion }\end{array}$ & acicular solid & $1250(v B)$ \\
\hline E.4.D.1.P.B.2.1 & fluid & $\mathrm{n} / \mathrm{a}$ & $\begin{array}{l}266,301,487,1075, \\
1468\end{array}$ \\
\hline E.4.D.1.P.X.1.1 & fluid & $\mathrm{n} / \mathrm{a}$ & $\begin{array}{l}\text { 132(b), 140(wb), } \\
\text { 226(wb), 352(b), } \\
\text { 1020(vws), } \\
\text { 1128(vws), } \\
\text { 1324(vwB), 1651(B), } \\
2330,32793279, \\
3449\end{array}$ \\
\hline $\begin{array}{l}\text { E.4.D.1.P.X.1.2 } \\
\text { solid }\end{array}$ & solid & solid in flinc $60 \%$ match w/anhydrous cas 04 & $\begin{array}{l}\text { 123(b) 153(ws), } \\
\text { 220(s), 235(s), } \\
357(\mathrm{wb} ?), 417(\mathrm{vS}), \\
476(\mathrm{wb}), 500(\mathrm{~s}), \\
\text { 610(s), 629(s), } \\
\text { 676(s), 1018(vS), } \\
1111(\mathrm{wb}), 1130(\mathrm{~s}), \\
1161(\mathrm{~s}), 1324(\mathrm{wB}) \\
1586(\mathrm{wB}) \\
1660(\mathrm{vwB})\end{array}$ \\
\hline E.4.D.1.P.X.1.3 & $\begin{array}{l}\text { fluid in fluid } \\
\text { inclusion with a } \\
\text { solid }\end{array}$ & inclusion contains small acicular solid & $\begin{array}{l}\text { 135(b), 227(b), } \\
\text { 350(b), 414(b), } \\
\text { 485(ws), (498(ws), } \\
\text { 610(ws?), 677(s), } \\
\text { 1018(vsS), } \\
1132(\mathrm{vS}), \\
1234 \text { (ws?), 1324(B), } \\
1651 \text { (B) }\end{array}$ \\
\hline
\end{tabular}




\begin{tabular}{|c|c|c|c|}
\hline E.4.D.1.P.X.2.1 & $\begin{array}{l}\text { fluid in fluid } \\
\text { inclusion with a } \\
\text { solid }\end{array}$ & inclusions has a small tabular solid & $\begin{array}{l}\text { 133(b), 206(vwb), } \\
351(\mathrm{~b}), 1366(\mathrm{wB}), \\
\text { 1650(B), } 22812331, \\
2435,2675(\mathrm{~B}), \\
2897,3294,3449\end{array}$ \\
\hline E.4.D.1.P.X.2.2 & $\begin{array}{l}\text { fluid in fluid } \\
\text { inclusion with a } \\
\text { solid }\end{array}$ & $\begin{array}{l}\text { scan is from a point close to solid in } \\
\text { inclusion }\end{array}$ & $\begin{array}{l}\text { 127(b), 166(ws), } \\
\text { 223(b), 352(b), } \\
\text { 412(wb), 670(wb?), } \\
\text { 860(wb), 1321(B), } \\
\text { 1655(B) }\end{array}$ \\
\hline E.4.D.1.P.X.3.1 & $\begin{array}{l}\text { solid in fluid } \\
\text { inclusion }\end{array}$ & solid in fluid inclusion & $\begin{array}{l}\text { 138(b), 165(ws), } \\
\text { 234(s), 351(b), } \\
\text { 407(ws), 1326(B), } \\
\text { 1652(B), 2275(b) } \\
2331,2439,2886, \\
3448\end{array}$ \\
\hline E.4.D.1.P.X.6.1 & fluid & $\mathrm{n} / \mathrm{a}$ & $\begin{array}{l}131,236,338,485 \\
856,927,1557 \\
1669\end{array}$ \\
\hline $\begin{array}{l}\text { E.4.Z.1.P } \\
(1502.62)\end{array}$ & $\begin{array}{l}\text { halite near } \\
\text { inclusion }\end{array}$ & $\begin{array}{l}\text { peaks not from glass contamination, strong } \\
\text { halite peak, } 1320 \text { peak present (iron } \\
\text { oxide?). }\end{array}$ & $\begin{array}{l}\sim 240(\mathrm{~s}), 360(\mathrm{~b}), \\
\sim 490(\mathrm{~s}), 645(\mathrm{wB}), \\
800(\mathrm{wB}) \\
\sim 1320(\mathrm{wB}) \\
\sim 3440(\mathrm{~B})\end{array}$ \\
\hline $\begin{array}{l}\text { E.4.Z.1.P } \\
a(1502.2) \\
\text { E.4.Z.1.P } \\
a(1502.2)\end{array}$ & $\begin{array}{l}\text { fluid target, } \\
\text { spectra does not } \\
\text { have water } \\
\text { peaks, resemble } \\
\text { solid }\end{array}$ & $\begin{array}{l}\text { 1380(b) and 1550(b)- could be related to } \\
\text { amorphous carbon/diamond films, very } \\
\text { good match(is this contamination from the } \\
\text { coal researchers?) } \\
\text { 470(b) strong peak at } 472 \text { seen in scan } \\
\text { E.7.A.1.P.D.1.2_AUG.10.16, and Western } \\
\text { Australia acid metal samples. May be } \\
\text { alunogen, quartz(s), 465, many hydrate } \\
\text { sulfates have strong peaks here, kaolinite? } \\
557(\mathrm{~s}) \text {-seen in many other intervals, } \\
\text { Opeche, and Elliot green, and synthetic } 5 \text {, } \\
560 \text { is associated with ammonium alunite } \\
581(b) \text {-unsure as to what this is (not seen } \\
\text { in ref. minerals, seen in e.1297 and e.7 } \\
\text { though. } \\
\text { no strong } 1650 \text { (b) peak seen }\end{array}$ & $\begin{array}{l}\sim 470(\mathrm{~B}), 557(\mathrm{~s}) \\
581(\mathrm{~b}), 1020(\mathrm{vS}) \\
\sim 1120(\mathrm{wb} \text { ), } \\
\sim 1380(\mathrm{~B}), 1570(\mathrm{~B})\end{array}$ \\
\hline
\end{tabular}




\begin{tabular}{|c|c|c|c|}
\hline & (10) & 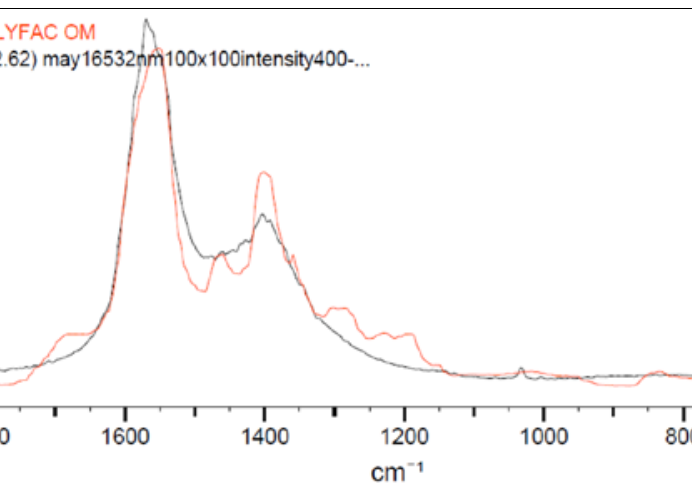 & $\frac{1}{11}$ \\
\hline E.4.Z.1.P & $\begin{array}{l}\text { fluid target, } \\
\text { spectra } \\
\text { resemble } \\
\text { multiple solids }\end{array}$ & $\begin{array}{l}\text { anhydrite, and unidentified at } 1375(b) \text { and } \\
475(\mathrm{~s}),(1360 \text { and } 1017 \text { is bicarbonate ion- } \\
1360 \text { is sharper in that though). no strong } \\
1650 \text { (b) peak seen }\end{array}$ & $\begin{array}{l}\text { 475(s), 611(s), } \\
\text { 676(ws), 1020(vS), } \\
1115(\mathrm{ws}), 1375(\mathrm{~B}) \\
1570(\mathrm{~B})\end{array}$ \\
\hline $\begin{array}{l}\text { E.Z.1.P } \\
d(1502.2)\end{array}$ & $\begin{array}{l}\text { fluid target, } \\
\text { spectra } \\
\text { resemble } \\
\text { multiple solids }\end{array}$ & $\begin{array}{l}\text { peak } 1600(b) \text { is how this differs from } \\
\text { e.z.1.p.a \& e.z.1.p.b. maybe related to } \\
\text { water? no } 1650(\text { b) peak here. this also has } \\
\text { more peaks related to anhydrite than } \\
\text { e.z.1.p.b }\end{array}$ & $\begin{array}{l}\text { 419(S), 503(ws), } \\
612(\mathrm{ws}), 631(\mathrm{ws}) \\
678(\mathrm{~s}), 1020(\mathrm{vS}) \\
1160(\mathrm{vS}), 1163(\mathrm{~s}) \\
1380(\mathrm{~B}), 1555(\mathrm{~s}) \\
1600(\mathrm{~B})\end{array}$ \\
\hline E.4.Z.1.P.A.1.1 & fluid & 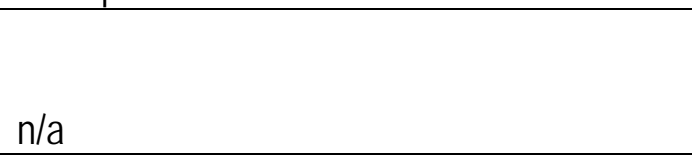 & $\begin{array}{l}\text { 131(b), 437(ws), } \\
\text { 1018(s), 1651(B), } \\
3440(\mathrm{~B})\end{array}$ \\
\hline A.1.2 & fluid & $\begin{array}{l}870 \text { and } 930 \text { peaks do not line up with any } \\
\text { mineral } \\
870 \text { - } 872 \text { is aluminum sulfate, } 874 \text { is rostite; } \\
870 \text { is also seen in sample from E.8 } \\
930-\text { no mineral match, seen in syn } 5 \text {, and } \\
\text { e.7 and other intervals. }\end{array}$ & $\begin{array}{l}128,300,360,393, \\
415,451,485,498, \\
518,592,612, \\
870 \text { (ws), } 930 \text { (ws) } \\
972(\mathrm{vs}), 1019,1091, \\
1115,1323,1650\end{array}$ \\
\hline E.4.Z.1.P.A.2.1 & $\begin{array}{l}\text { fluid in fluid } \\
\text { inclusion with a } \\
\text { solid }\end{array}$ & n/a & $\begin{array}{l}\text { 133(b), 362(b), } \\
\text { 419(ws), 612(s), } \\
\text { 1020(S), 1113(ws?), } \\
\text { 1131(ws?), } \\
\text { 1325(wB), 1652(B), } \\
\text { 2139 }\end{array}$ \\
\hline E.4.Z.1.P.A.2.2 & $\begin{array}{l}\text { fluid in fluid } \\
\text { inclusion with a } \\
\text { solid }\end{array}$ & $\mathrm{n} / \mathrm{a}$ & $\begin{array}{l}133,358,418,450, \\
502,612,661(\mathrm{~B}), \\
678,842,909,939, \\
1020,1040,1063, \\
1115,1132,1149, \\
1186,1286,1381, \\
1461(\mathrm{~B}), 1646\end{array}$ \\
\hline
\end{tabular}




\begin{tabular}{|c|c|c|c|}
\hline $\begin{array}{l}\text { E.4.Z.1.P.A.2.3 } \\
\text { SOLID, A.3.3 }\end{array}$ & $\begin{array}{l}\text { solid in fluid } \\
\text { inclusion }\end{array}$ & 94\% match with anhydrite & $\begin{array}{l}136,171,358,419 \\
502,611,630,678 \\
1020,1114,1131 \\
1162\end{array}$ \\
\hline E.4.Z.1.P.A.3.1 & fluid & $\begin{array}{l}\text { isolated } 1020 \text { peak is likely to be anhydrite, } \\
\text { other sulfates have peaks in this area, but } \\
\text { they are closer to } 1026 \text { (alunite) or } \\
1008 \text { (gypsum) }\end{array}$ & $\begin{array}{l}\sim 130(\mathrm{~b}), \sim 1020(\mathrm{~s}) \\
1650(\mathrm{~B}), 3433\end{array}$ \\
\hline E.4.Z.1.P.C.1.1 & fluid & $\mathrm{n} / \mathrm{a}$ & $\begin{array}{l}126(b), 1652(b) \\
2330(s), 3440(B)\end{array}$ \\
\hline E.4.Z.1.P.C.1.2 & fluid & $\mathrm{n} / \mathrm{a}$ & $\begin{array}{l}127,301,354,415 \\
484,515,575,708 \\
892,1028,1115 \\
1181,1320,1560 \\
1606,1648\end{array}$ \\
\hline E.4.Z.1.P.C.2 & fluid & $\begin{array}{l}\text { no very strong peaks, } 890 \text { peak is large and } \\
\text { not paired with other large peaks }\end{array}$ & $\begin{array}{l}\text { 127(S), 301, 369, } \\
415(\mathrm{~s}), 707,891(\mathrm{~s}), \\
\text { 1072(ws), 1115(s), } \\
\text { 1150, 1181, } \\
\text { 1320(B), 1605(sh,s), } \\
\text { 1649(B) }\end{array}$ \\
\hline E.4.Z.1.P? & fluid target & $400-2000 \mathrm{~cm}^{-1}$ scan & $\begin{array}{l}472,557,573,580, \\
990,1018,1389, \\
1558,1911\end{array}$ \\
\hline E.4.Z.2.P.A.1.1 & fluid & $\mathrm{n} / \mathrm{a}$ & $\begin{array}{l}170(\mathrm{~b}), 1018(\mathrm{~s}) \\
1606(\mathrm{ws}), 1645(\mathrm{~B}) \\
2330(\mathrm{~s}), 3440(\mathrm{~B})\end{array}$ \\
\hline E.4.Z.2.P.A.1.2 & fluid & $\begin{array}{l}\text { inclusion is all-liquid, but there are solids in } \\
\text { the halite. }\end{array}$ & $\begin{array}{l}130,359,415,483, \\
503,589,629,676, \\
707,733,766,837, \\
890,927,1018, \\
1060,1114,1162, \\
1182,1242,1329, \\
1411,1446, \\
1605(\mathrm{sh}), 1656\end{array}$ \\
\hline E.4.Z.2.P.A.1.2 & $\begin{array}{l}\text { solid in fluid } \\
\text { inclusion }\end{array}$ & $\mathrm{n} / \mathrm{a}$ & $\begin{array}{l}\text { 130(b), 359(wb), } \\
\text { 415(ws), 480(ws), } \\
\text { 890(b), 927(b), } \\
\text { 1018(S), 1114(b), } \\
\text { 1242(wB?), } \\
\text { 1329(wB), 1600(b?), } \\
\text { 1656(B) }\end{array}$ \\
\hline
\end{tabular}




\begin{tabular}{|c|c|c|c|}
\hline E.4.Z.2.P.B.1.1 & fluid & some solids seen in halite near inclusion & $\begin{array}{l}\text { 128(s), 358(b), } \\
\text { 639(s), 889(s), } \\
\text { 911(vws), 992(s), } \\
\text { 1111(s), 1180(s), } \\
\text { 1655(b) }\end{array}$ \\
\hline E.4.Z.2.P.B.1.2 & fluid & $\mathrm{n} / \mathrm{a}$ & $\begin{array}{l}483,500,592,639, \\
855,890,929,1010, \\
1114,1182,1246, \\
1313,1383,1420, \\
1466,1653,2869, \\
3076,3432\end{array}$ \\
\hline E.4.Z.2.P.B.2.1 & fluid & $\mathrm{n} / \mathrm{a}$ & $\begin{array}{l}124,236,358,413, \\
450,483,572,638, \\
678,708,735,854, \\
890,954,1021, \\
1067,1115,1145, \\
1182,1247,1328, \\
1327,1401,1450, \\
1533,1607,1651, \\
3436\end{array}$ \\
\hline E.4.Z.2.P.B.3.2 & fluid & $\mathrm{n} / \mathrm{a}$ & $\begin{array}{l}126,354,414,570, \\
637,707,732,890, \\
922,979,1008, \\
1060,1083,1113, \\
1160,1181,1254, \\
1329,1464,1606, \\
1653\end{array}$ \\
\hline
\end{tabular}

\section{Empress 1A, Interval 5 (1502.25 - 1502.20)}

The spectra from Interval $5(1502.25$ - 1502.20) are very noisy. One long scan had a broad peak at $\sim 3400 \mathrm{~cm}^{-1}$, this may be water, or possibly contamination. The very broad peaks at $1090 \mathrm{~cm}^{-1}$, and weak broad peaks at $\sim 570$ and $\sim 795 \mathrm{~cm}^{-1}$ are likely contamination spectra from glass (

Table 15) These spectra are not representative of the fluid inclusion. 


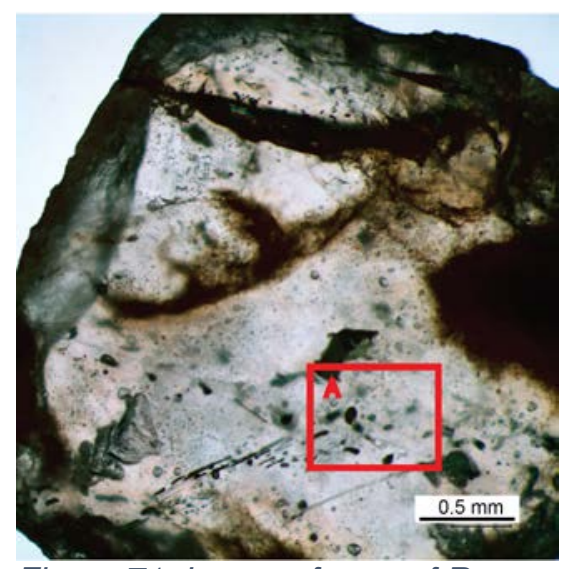

Figure 71. Image of area of Raman analyses from chip E.5.C.1.P, Empress 1A, interval 5, 1502.25 1502.20 m, zone C, chip 1. Area A, the target of Raman analysis is outlined in red.

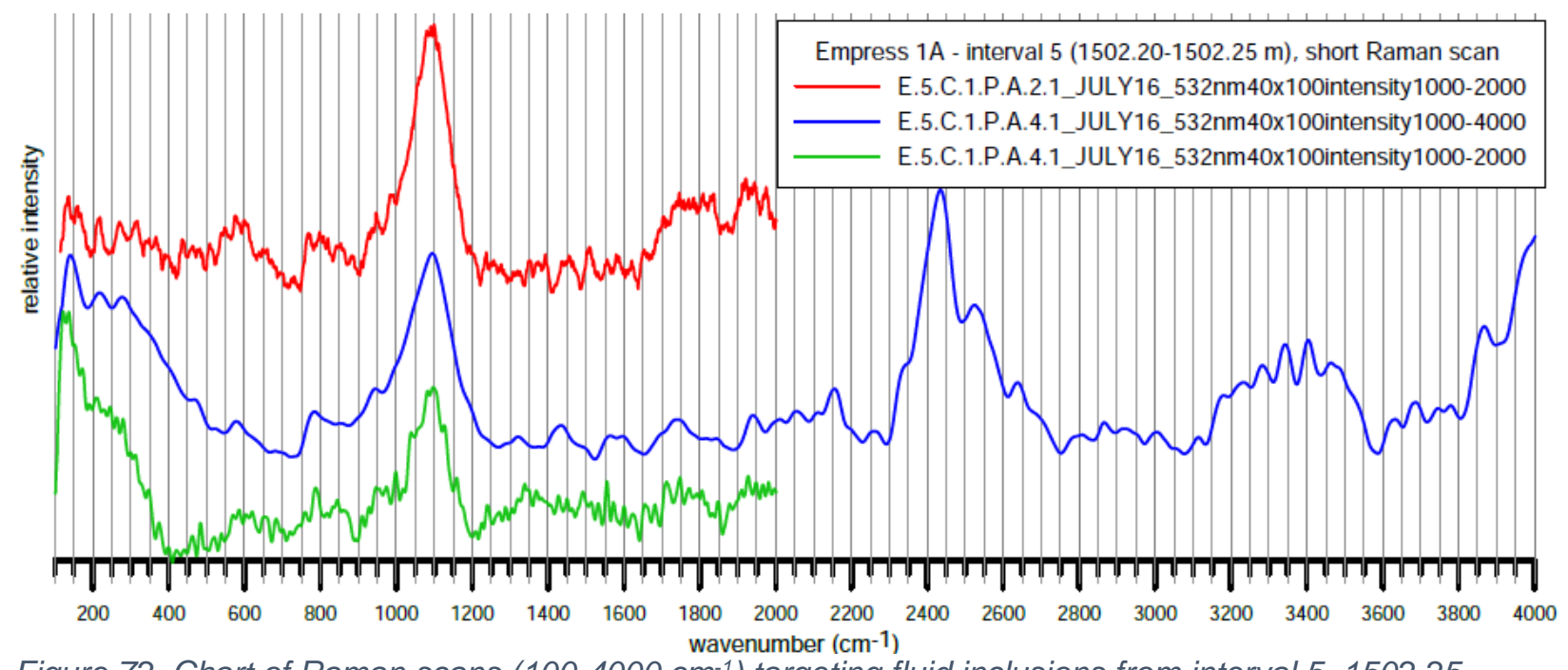

Figure 72. Chart of Raman scans (100-4000 $\left.\mathrm{cm}^{-1}\right)$ targeting fluid inclusions from interval 5, 1502.25 $1502.20 \mathrm{~m}$.

Table 35. Spectral peaks from Raman analysis of interval5, 1502.25 - $1502.20 \mathrm{~m}$.

\begin{tabular}{|l|l|l|l|}
\hline scan name & $\begin{array}{l}\text { scan } \\
\text { target }\end{array}$ & comments & spectra peaks (cm-1) \\
\hline E.5.C.P.A.2.1 & fluid & $\begin{array}{l}\text { glass contamination - } \\
\text { all peaks }\end{array}$ & $\begin{array}{l}130(\mathrm{~b} \text { ?), 570(wb?), 794(wB?), 932(wb?), 985(wb?), } \\
1090(\mathrm{vB}),\end{array}$ \\
\hline E.5.C.P.A.3.1 & fluid & $\begin{array}{l}\text { glass contamination - } \\
\text { all peaks }\end{array}$ & $1088(\mathrm{~b})$ \\
\hline & & $\begin{array}{l}\text { glass contamination - } \\
\text { all peaks }\end{array}$ & $\begin{array}{l}138(\mathrm{~b}), 348(\mathrm{wb} \text { ), 481(ws), 789(wb?), 954(wb?), } \\
\text { (B) }\end{array}$ \\
\hline E.5.C.P.A.4.1 & fluid $1740(\mathrm{~b}), 2160(\mathrm{wB}) 2428(\mathrm{vB}), 3300(\mathrm{~B}), 4000$ \\
\hline
\end{tabular}

Empress 1A, Interval 6 (1502.29-1502.25 m)

Interval 6 (1502.29 -1502.25 $\mathrm{m}$ ) has sharp peaks at $\sim 418, \sim 677, \sim 1020$ (very strong), 
$\sim 1115, \sim 1130$, and $\sim 1160 \mathrm{~cm}^{-1}$ that are likely anhydrite. The spectra with strong anhydrite peaks $\left(\sim 418, \sim 677, \sim 1115\right.$ and $\left.\sim 1131 \mathrm{~cm}^{-1}\right)$ but no strong peak at $\sim 1020 \mathrm{~cm}^{-1}$ may be functionally related to anhydrite. There is a very broad peak at $\sim 1320 \mathrm{~cm}^{-1}$ in all spectra. The source of this peak is uncertain.

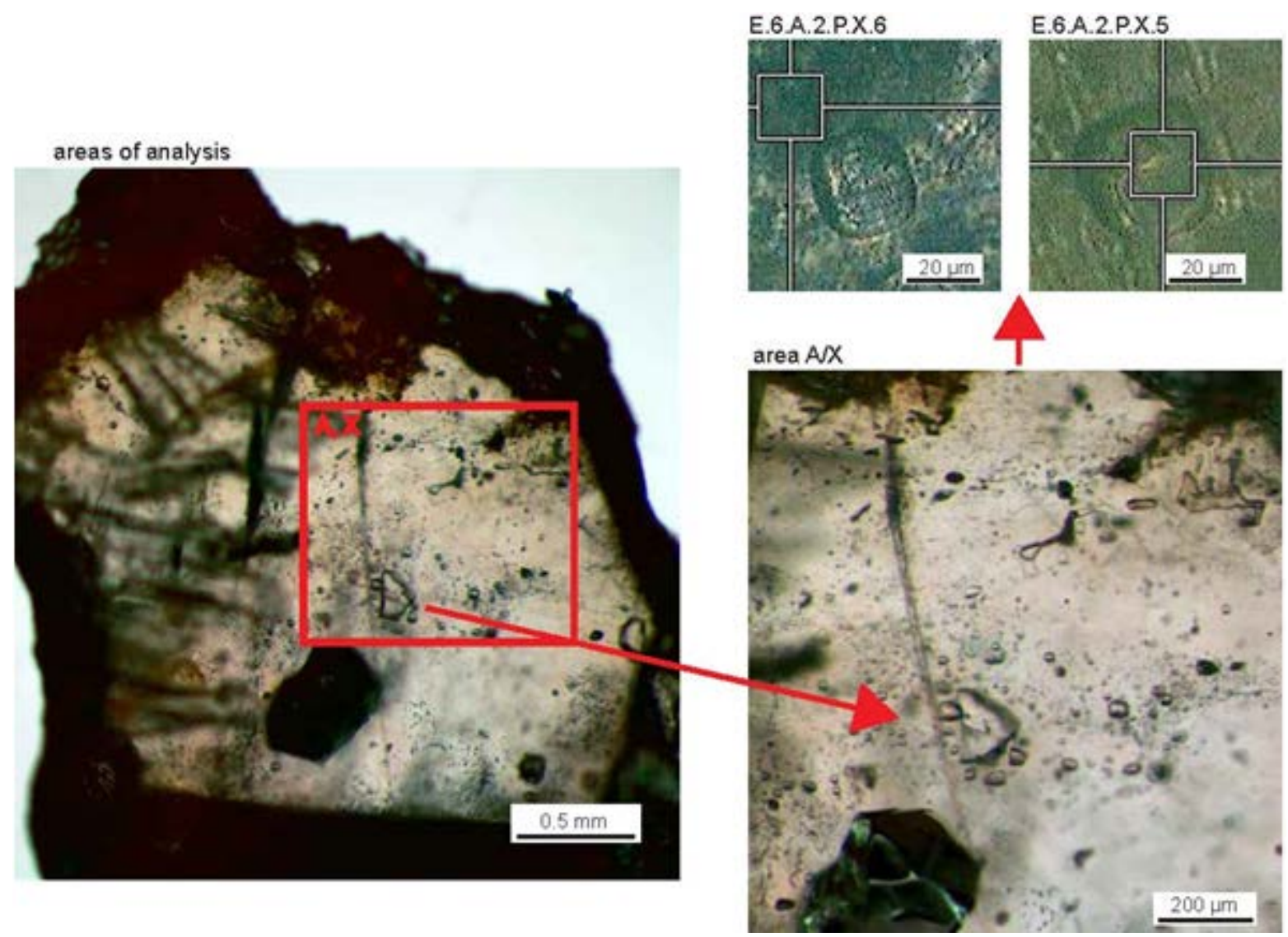

Figure 73. Images of area of Raman analyses from chip E.6.A.2.P from Empress 1A, interval 6 (1502.29 $1502.25 \mathrm{~m}$ ), zone A. Area A/X was the targets of analysis. Area A/X shown in greater detail on the right. Fluid inclusions that were analyzed via Raman Spectroscopy are shown on the upper right (inclusions E.6.A.2.P.X.6, E.6.A.2.P.X.5). 


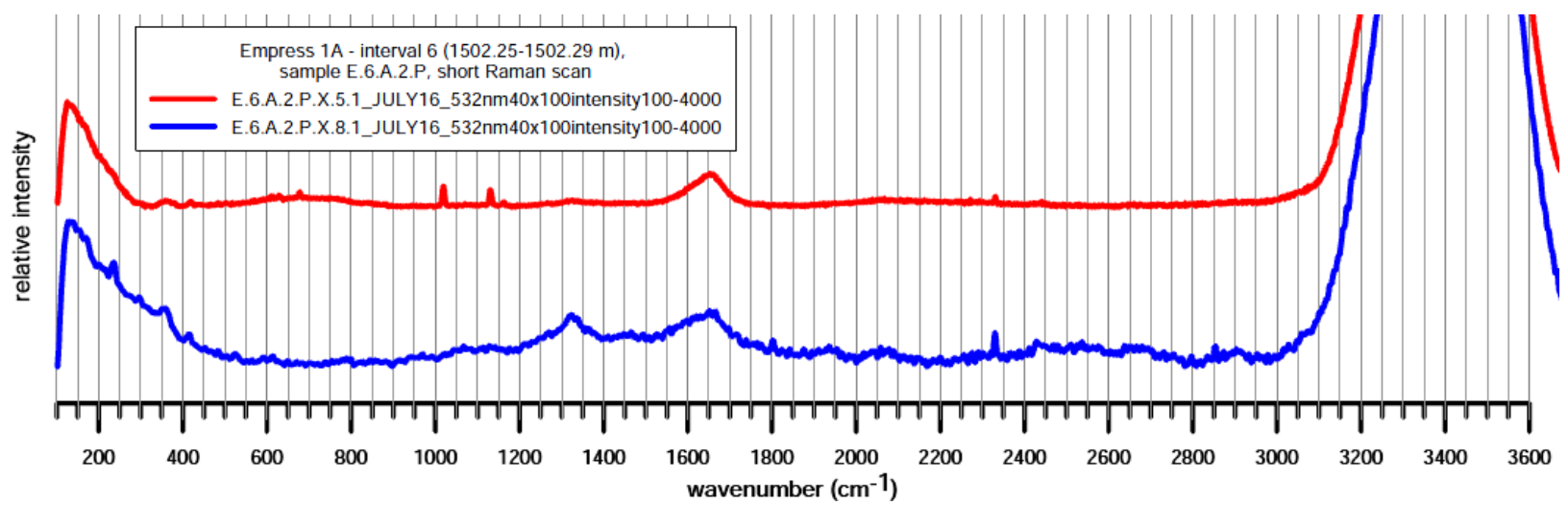

Figure 74. Chart of long Raman scans (100-3600 cm-1) of fluid inclusions from interval 6, 1502.29 $1502.25 \mathrm{~m}$. Target of scans was fluid, but appears to have hit solids. Spectra of solids are on the bottom, and spectra of fluids are on the top.

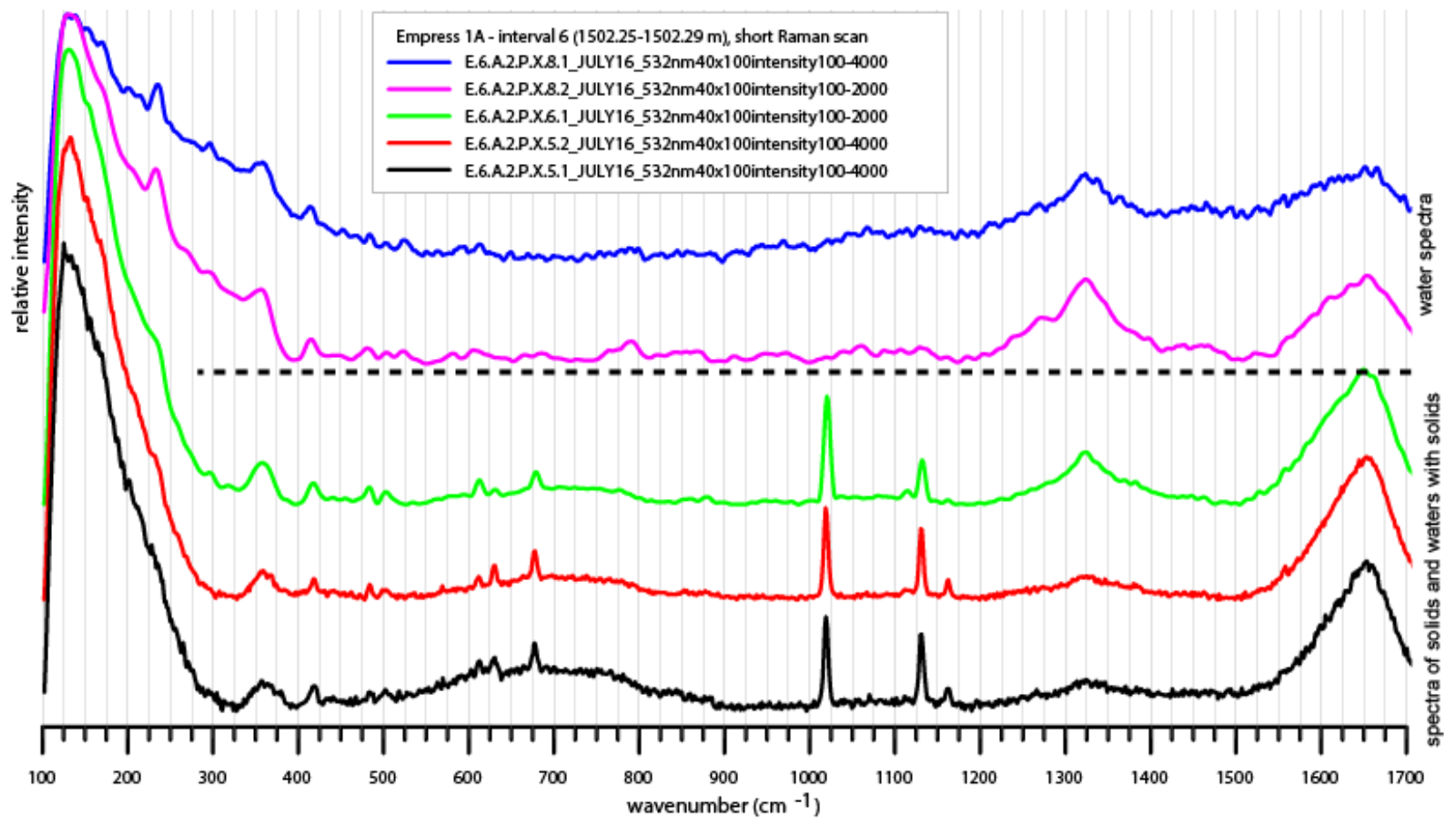

Figure 75. Short Raman scans (100-3700 $\left.\mathrm{cm}^{-1}\right)$ of fluid inclusions from interval 6, $1502.29-1502.25 \mathrm{~m}$. Spectra of solids are on the bottom, and spectra of fluids are on the top. 
Table 36. Spectral peaks from Raman analysis of interval 6, 1502.29-1502.25 m.

\begin{tabular}{|c|c|c|c|}
\hline scan name & $\begin{array}{l}\text { scan } \\
\text { target }\end{array}$ & comments & spectra peaks $\left(\mathrm{cm}^{-1}\right)$ \\
\hline E.6.A.2.P.X.5.1 & $\begin{array}{l}\text { solid in } \\
\text { fluid } \\
\text { inclusion }\end{array}$ & $\mathrm{n} / \mathrm{a}$ & $\begin{array}{l}\text { 126(b), 354(b), 419(ws), 630(ws), } \\
\text { 673(s), 1020(S), 1130(S), 1160(s), } \\
1320(w B), 1653(B), 2331(S), 3440(S)\end{array}$ \\
\hline E.6.A.2.P.X.5.2 & $\begin{array}{l}\text { solid in } \\
\text { fluid } \\
\text { inclusion }\end{array}$ & $\mathrm{n} / \mathrm{a}$ & $\begin{array}{l}\text { 145(b), 359(b), 418(ws), 484(ws), } \\
\text { 500(vws), 569(vws?), 611(ws), 630(s), } \\
\text { 677(S), 1019(vS), 1113(s), 1131(s), } \\
\text { 1162(s), 1327(wB), 1656(B), 2443, } \\
\text { 3275, 3444 }\end{array}$ \\
\hline E.6.A.2.P.X.6.1 & $\begin{array}{l}\text { solid in } \\
\text { fluid } \\
\text { inclusion }\end{array}$ & $\begin{array}{l}\text { match with anhydrite, 1325(B) } \\
\text { peak. }\end{array}$ & $\begin{array}{l}\text { 145(b), 359(b), 418(ws), 484(ws), } \\
\text { 500(vws), 611(ws), 630(ws), 677(S), } \\
\text { 1019(vS), 1113(ws), 1131(s), 1162(ws), } \\
\text { 1325(B), 1646(B), 2331, 2432, 2804, } \\
\text { 2897(b), 3265, 3454 }\end{array}$ \\
\hline E.6.A.2.P.X.8.1 & fluid & $\begin{array}{l}\text { some anhydrite peaks, } \\
\text { doesn't have the main one at } \\
1020, \text { broad peak at } 1330 \\
\text { (unknown) and peak at } 1800 \\
\text { (unknown) }\end{array}$ & $\begin{array}{l}\text { 130(b), 240(ws), 300(vws), 355(b), } \\
\text { 418(ws), 480(vws?), 520(vws?), } 1330 \\
\text { (B), 1650(B) }\end{array}$ \\
\hline E.6.A.2.P.X.8.2 & fluid & $\begin{array}{l}\text { no strong anhydrite peaks, } \\
\text { 1330(B) unknown and } \\
\text { 1650(B) water }\end{array}$ & $\begin{array}{l}\text { 130(b), 240(s), 300(vws), 340(vws), } \\
355(\mathrm{~b}), 420 \text { (ws), 480(vws?), 500(vws), } \\
520(\text { vws?), 570, } \sim 605,660,790(\mathrm{~b}), 1070 \\
\text { (bw), } 1330 \text { (B), 1470 (wB), 1650(B), } \\
2330,2440,3265,3439\end{array}$ \\
\hline
\end{tabular}

\section{Empress 1A, Interval 7 (1499.42-1499.30 m)}

Interval 7 (1499.42 - $1499.30 \mathrm{~m})$ has the strongest example of a $\sim 484 \mathrm{~cm}^{-1}$ peak, the strong peak is present in a noisy spectrum. The source of the peak at $\sim 484 \mathrm{~cm}^{-1}$ is source is uncertain (

Table 15), but may be contamination. Most of the solids from Interval 7 are likely anhydrite. Many spectra also have peaks at $\sim 705$ (strong), $\sim 735$ (weak), $\sim 890$, and $\sim 1113 \mathrm{~cm}^{-1}$. These peaks may relate to anhydrite, but their source is unclear. The source of the $\sim 1254 \mathrm{~cm}^{-1}$ peak is unknown. The source of the $-1326 \mathrm{~cm}^{-1}$ peak may relate to carbon and/or iron oxide. The peak at $\sim 1464 \mathrm{~cm}^{-1}$ may relate to a carbon functional group. 


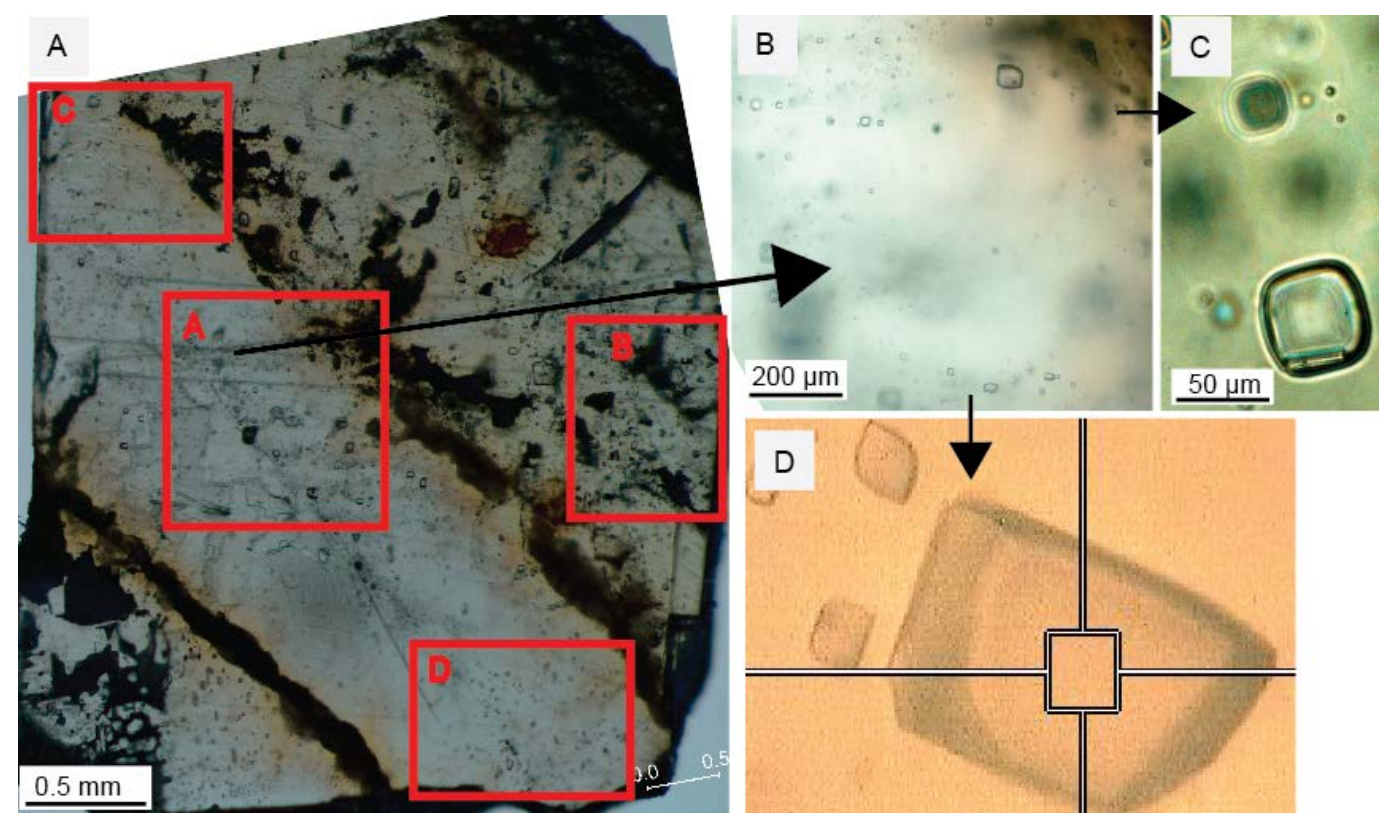

Figure 76. Images of areas of Raman analyses in halite chip E.7.A.1.P from Empress $1 A$, interval 7 (1499.42 - 1499.3 m), zone A. (A) Areas of analysis outlined in red. (B) Area A contain analyzed inclusions (C) E.7.A.1.P.A.2, and (D) E.7.A.1.P.A.7.

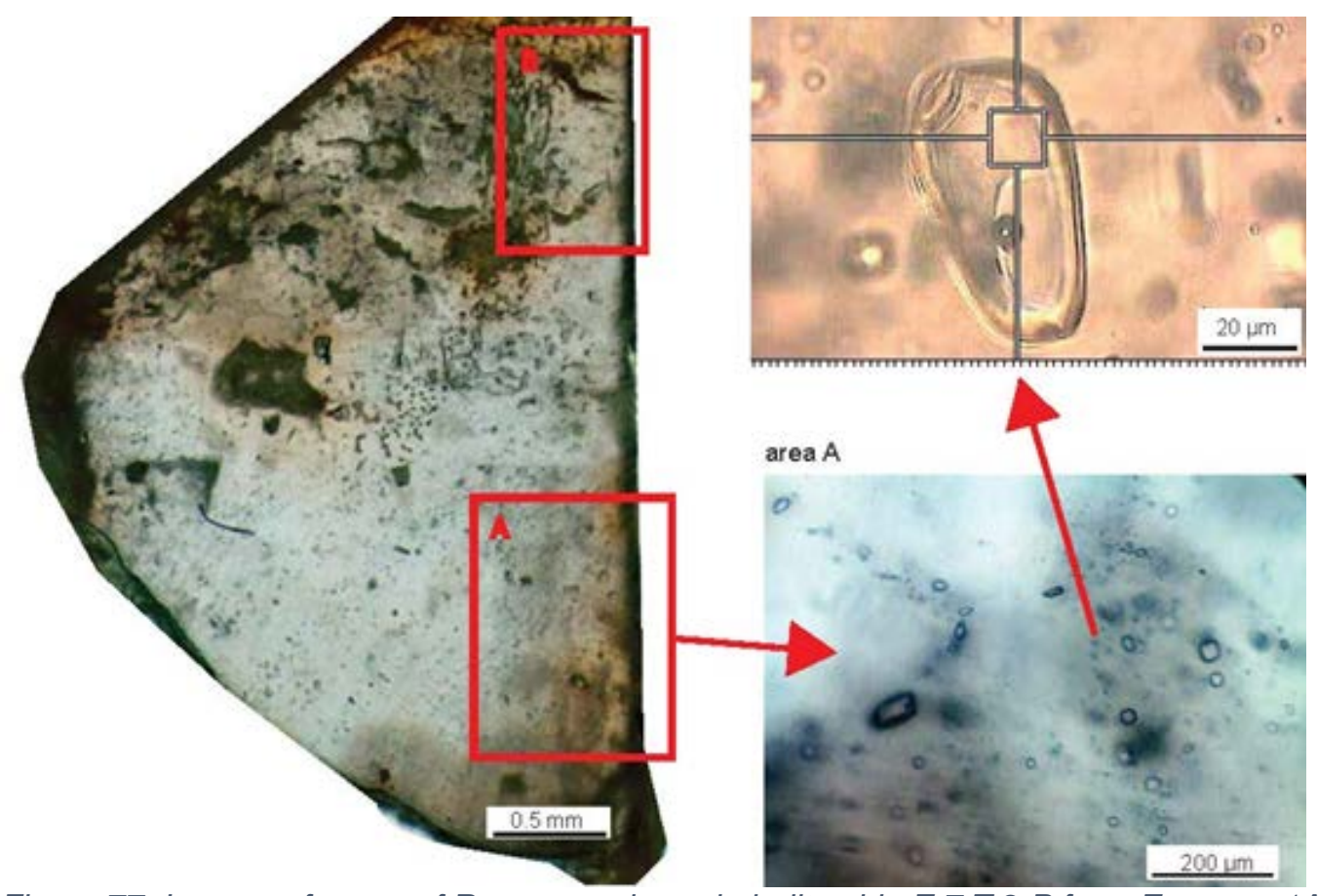

Figure 77. Images of areas of Raman analyses in halite chip E.7.Z.2.P from Empress 1A, interval 7 $(1499.42-1499.3 \mathrm{~m})$, zone Z. Areas of analysis outlined in red. Area A is shown with greater detain on the right. Inclusion E.7.Z.2.P.A.2 on the upper right was the focus of fluid inclusion analysis. 


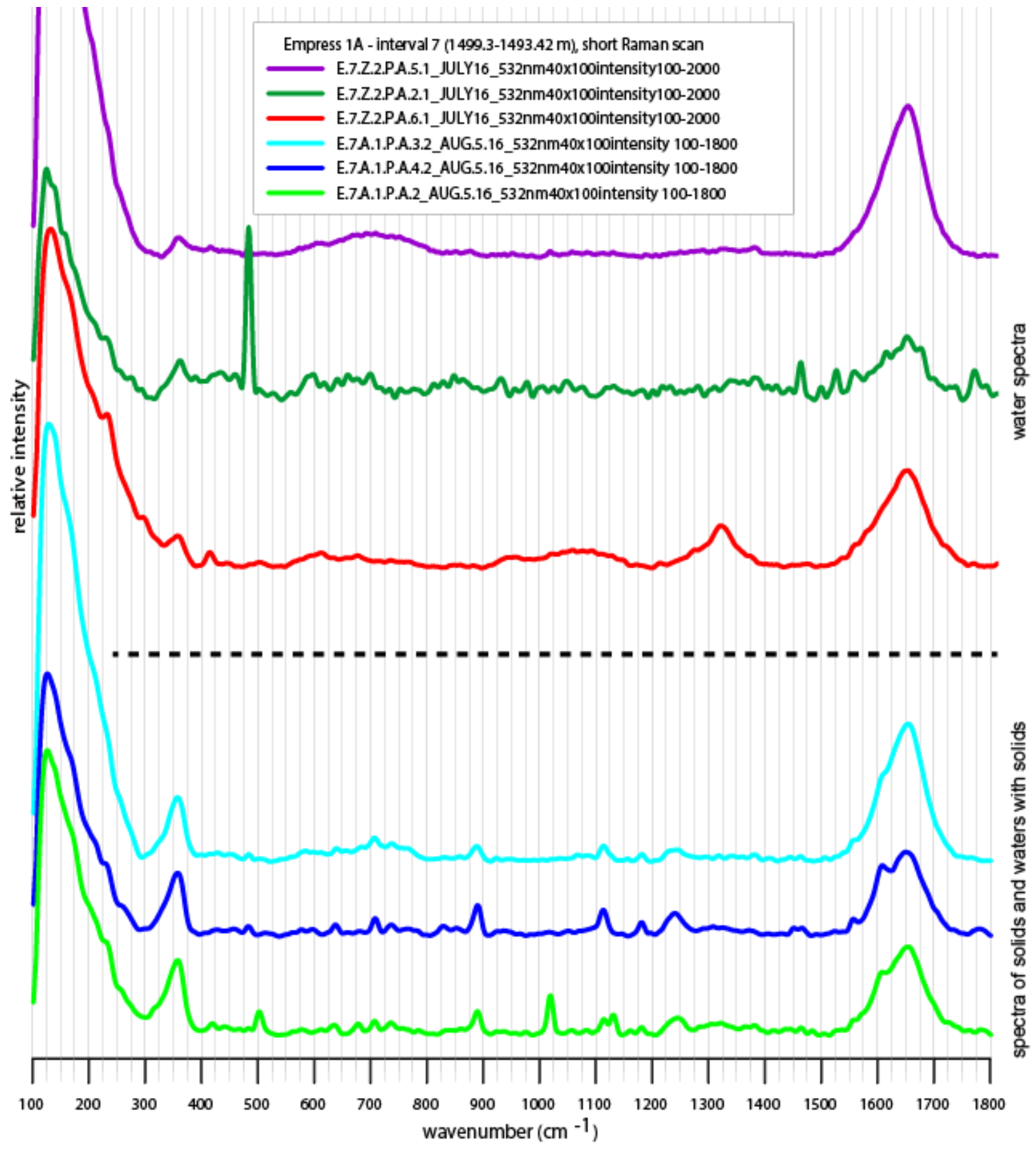

Figure 78. Short Raman scans (100-1800 $\left.\mathrm{cm}^{-1}\right)$ of fluid inclusions from interval 7, $1499.42-1499.3 \mathrm{~m}$. Spectra of solids are on the bottom, and spectra of fluids are on the top. 


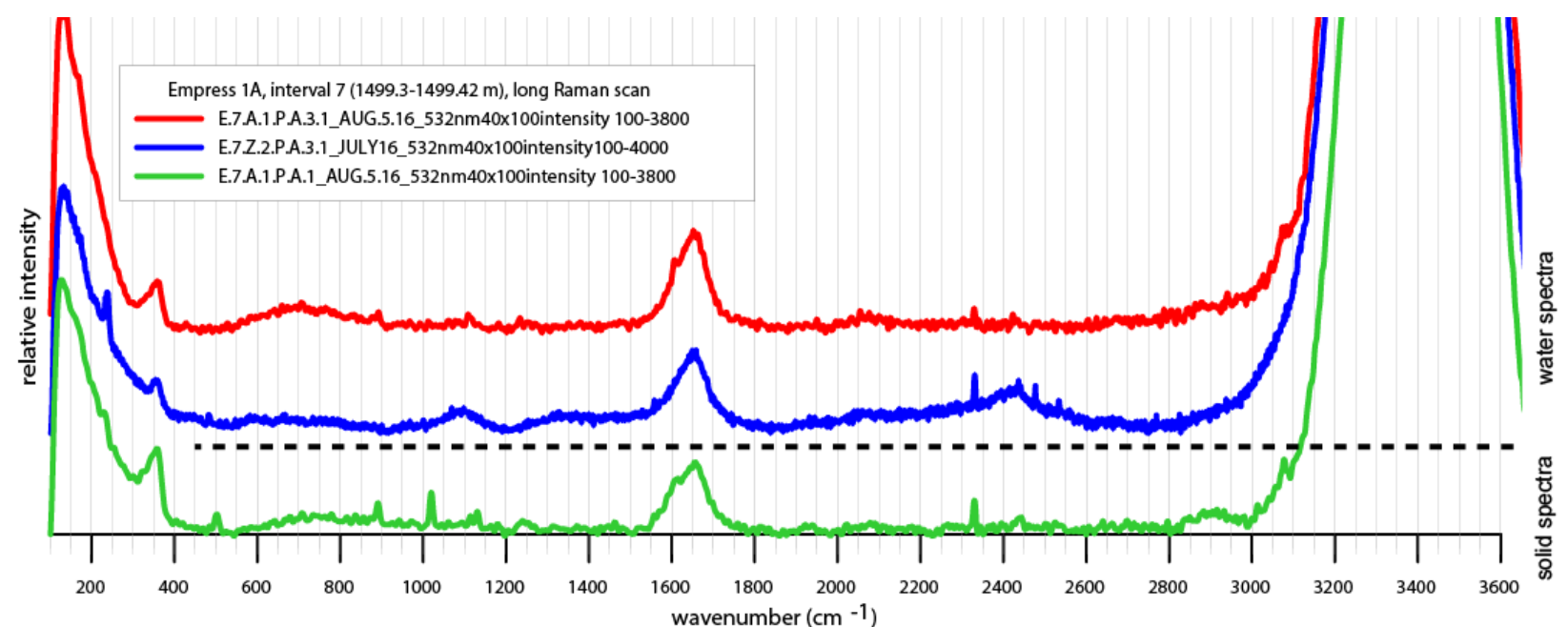

Figure 79. Long Raman scans $\left(100-3600 \mathrm{~cm}^{-1}\right)$ of fluid inclusions from interval 7, $1499.42-1499.3 \mathrm{~m}$. Spectra of solids are on the bottom, and spectra of fluids are on the top.

Table 37. Spectral peaks from Raman analysis of interval 7, 1499.42 - $1499.3 \mathrm{~m}$.

\begin{tabular}{|c|c|c|c|}
\hline scan name & scan target & comments & spectra peaks $\left(\mathrm{cm}^{-1}\right)$ \\
\hline E.7.A.1.P.A.1.1 & fluid & $\begin{array}{l}\text { strong halite signal, good } \\
\text { match for anhydrite, water } \\
\text { peak, not sure what } 891 \text { peak } \\
\text { is, or } 1240 \text { peak is. }\end{array}$ & $\begin{array}{l}\text { 126(b), 231(vws), 359(b), 501(ws), } \\
\text { 891(ws), 1019(S), 1114(vws), } \\
\text { 1131(ws), 1240(wb?), 1616(b), } \\
\text { 1656(B), 2330(S), 3440(B) }\end{array}$ \\
\hline E.7.A.1.P.A.1.2 & fluid & $\mathrm{n} / \mathrm{a}$ & $\begin{array}{l}128,231,358,419,484,504,577 \\
614,639,679,706,735,834,890 \\
975,1020,1054(w B), 1084,1114 \\
1131,1151,1183,1245,1384,1465\end{array}$ \\
\hline E.7.A.1.P.A.10.2 & $\begin{array}{l}\text { fluid } \\
\text { inclusion } \\
\text { with solid }\end{array}$ & Fluid inclusions with solid in it & $\begin{array}{l}125,230,296,356,414,484,612, \\
894,937,996,1018,1115,1323, \\
1489,1557,1606,1617,1653\end{array}$ \\
\hline E.7.A.1.P.A.2.1 & $\begin{array}{l}\text { Fluid } \\
\text { target, } \\
\text { solid } \\
\text { peaks }\end{array}$ & $\begin{array}{l}\text { good match with anhydrite } \\
\text { (other than a missing peak at } \\
611) \text {, there are additional peak } \\
\text { in this spectra that are not } \\
\text { accounted for, they are: } \\
705(\mathrm{~s}), 735(\text { ws), } 890(\mathrm{~s}), \\
\text { 1254(b), } \\
\text { Many of these peaks are seen } \\
\text { in other scans of this interval. } \\
\text { (see earlier discussion of these } \\
\text { unaccounted for peaks). }\end{array}$ & $\begin{array}{l}\text { 130(b), 230(wb), 357(b), 418(s), } \\
\text { 504(s), 635(s), 675(s), 705(s), } \\
\text { 735(ws), 890(s), 1018(S), 1114(ws), } \\
\text { 1130(s), 1151(vws), 1180(ws), } \\
\text { 1254(b), 1465(ws?), 1489(ws?), } \\
\text { 1606(b), 1652(B), 1788(wb) }\end{array}$ \\
\hline E.7.A.1.P.A.2.2 & fluid & $\mathrm{n} / \mathrm{a}$ & $\begin{array}{r}355,484,640,707,887,923,1068, \\
1114,1182,1249,1382,1654,3400\end{array}$ \\
\hline E.7.A.1.P.A.3.1 & fluid & water peaks, halite, and other. & $\begin{array}{l}\text { 126(b), 355(b), 890(ws), 1113(ws?), } \\
1605(w s), 1650(B), 2330(S), 3440(B)\end{array}$ \\
\hline
\end{tabular}




\begin{tabular}{|c|c|c|c|}
\hline E.7.A.1.P.A.3.2 & fluid & $\mathrm{n} / \mathrm{a}$ & $\begin{array}{l}\text { 126(b), 355(b), 484(ws), 640(ws), } \\
707(\text { ws), 736(ws), 890(s), 923(ws), } \\
\text { 1070(ws), 1113(s), 1180(ws), } \\
1245 \text { (wb?), 1610(ws), 1655(B) }\end{array}$ \\
\hline E.7.A.1.P.A.4.2 & $\begin{array}{l}\text { Fluid } \\
\text { target, } \\
\text { peaks } \\
\text { resemble } \\
\text { solid }\end{array}$ & $\mathrm{n} / \mathrm{a}$ & $\begin{array}{l}\text { 128(b), 356(B), 483(ws), 630(ws), } \\
\text { 709(s), 736(ws), 827(ws), 891(s), } \\
\text { 1113(s), 1181(ws), 1240(b), } \\
\text { 1450(ws), 1464(ws), 1556(ws), } \\
\text { 1608(ws), 1648(s) }\end{array}$ \\
\hline E.7.A.1.P.A.7.1 & fluid & all liquid & $\begin{array}{l}127,318,357,415,483,670,706, \\
891,1178,1358,1424,1650\end{array}$ \\
\hline E.7.A.1.P.A.7.2 & fluid & all liquid & $\begin{array}{l}482,595,609,705,735,765,890, \\
945,1020,1082,1093,1113,1181, \\
1252,1328,1379,1400,1464,1556, \\
1671,2330,3434\end{array}$ \\
\hline E.7.A.1.P.A.8.2 & fluid target & $\mathrm{n} / \mathrm{a}$ & $\begin{array}{l}483,594,638,667,707,738,761, \\
834,889,922,941,983,995(\mathrm{w}), \\
1008(\mathrm{w}), 1019,1114,1181,1245, \\
1323,1450,1606(\mathrm{~s}), 1652\end{array}$ \\
\hline E.7.A.1.P.A.9.1 & fluid target & $\mathrm{n} / \mathrm{a}$ & $\begin{array}{l}129,237,305,345,480,577,707, \\
788,823,889,936,978,1020,1066, \\
1098,1183,1235,1441,1605,1659, \\
2066,3435\end{array}$ \\
\hline E.7.A.1.P.A.9.2 & fluid & $\mathrm{n} / \mathrm{a}$ & $\begin{array}{l}\text { 833, 859, 889(s), 926, 943, 966, } \\
\text { 990(w), 1004, 1014, 1055, 1074, } \\
\text { 1092, 1114(s), 1160, 1180(s), 2331, } \\
2431,285029173046,3433\end{array}$ \\
\hline P.D.1.1 & $\begin{array}{l}\text { fluid in } \\
\text { inclusion } \\
\text { with solids }\end{array}$ & $\begin{array}{l}\text { tabular and acicular solids } \\
\text { present in inclusion }\end{array}$ & $\begin{array}{l}153,222,234,357,418,435,472 \\
505,860,888,1017,1057,1078 \\
1130,1179,1648\end{array}$ \\
\hline E.7.A.1.P.D.1.2 & $\begin{array}{l}\text { fluid in } \\
\text { inclusion } \\
\text { with solids }\end{array}$ & $\begin{array}{l}\text { tabular and acicular solids } \\
\text { present in inclusion }\end{array}$ & $\begin{array}{l}\text { 418, 437, 472(VS), 497, 611, 635, } \\
678,709,890,978(\mathrm{VW}), 1018(\mathrm{Vs}) \\
\text { 1051(vw), 1063, 1114, 1130, 1160, } \\
1182,1244,1412,1511,1556,1612, \\
1652\end{array}$ \\
\hline E.7.A.1.P.D.1.3 & $\begin{array}{l}\text { solid in } \\
\text { fluid } \\
\text { inclusion }\end{array}$ & $\begin{array}{l}\text { acicular solid in fluid inclusion } \\
\text { also containing a tabular solid }\end{array}$ & $\begin{array}{l}\text { 236, 313, 354, 418(VS), 472(m), } \\
501,612,630,678,711,763,833, \\
864,890,983(\mathrm{w}), 1018,1053(\mathrm{w}), \\
1114,1130,1337,1487,1556,1605, \\
1655\end{array}$ \\
\hline E.7.A.1.P.D.1.4 & $\begin{array}{l}\text { tabular } \\
\text { solid in } \\
\text { fluid } \\
\text { inclusions }\end{array}$ & $\begin{array}{l}\text { tabular solid in fluid inclusion } \\
\text { also containing an acicular } \\
\text { solid }\end{array}$ & $\begin{array}{l}\text { 418, 454, 501(s), 581, 611, 629, 708, } \\
736,837,861,891,954,1019,1113, \\
1163,1181,1337,1469,1557,1609, \\
1654,2329,2438\end{array}$ \\
\hline
\end{tabular}




\begin{tabular}{|c|c|c|c|}
\hline E.7.A.1.P.D.2.1 & fluid & n/a & $\begin{array}{l}140,231,355,414,1019,1108, \\
1340,1652,2330,3434\end{array}$ \\
\hline E.7.A.1.P.D.2.2 & fluid & $\mathrm{n} / \mathrm{a}$ & $\begin{array}{l}418,484,502,547,576,612,636, \\
677,707,736,852,885,970,998, \\
1019,1056(?), 1114,1130,1160, \\
1181,1254,1327,1367,1444,1471, \\
1607(s), 1648\end{array}$ \\
\hline E.7.Z.2.P.A.1.1 & fluid & n/a & $\begin{array}{l}154,277,403,484,709,762,840, \\
860,1026,1062(\mathrm{vw}), 1250,1527 \\
1670(\mathrm{w}), 1764\end{array}$ \\
\hline E.7.Z.2.P.A.1.1 & fluid & n/a & $\begin{array}{l}154,277,403,484,709,762,840 \\
860,1026,1062(\mathrm{vw}), 1250,1527 \\
1670(\mathrm{w}), 1764\end{array}$ \\
\hline E.7.Z.2.P.A.1.1 & fluid & $\begin{array}{l}\text { double rim?, very weak water } \\
\text { peak }\end{array}$ & $\begin{array}{l}154,277,403,484,709,762,840 \\
860,1026,1062(\mathrm{vw}), 1250,1527 \\
1670(\mathrm{w}), 1764,3400\end{array}$ \\
\hline E.7.Z.2.P.A.2.1 & fluid & $\begin{array}{l}\text { noisy spectra, } 484 \mathrm{~cm}^{-1} \text { peak- } \\
\text { see discussion of } 484 \mathrm{~cm}^{-1} \\
\text { peak from interval } \mathrm{E} .2 \text { or } \mathrm{E} .3 . \\
1464 \mathrm{~cm}^{-1} \text { - peak seen in } \\
\text { synthetic, natural, and other } \\
\text { intervals from the Browne } \\
\text { Formation. }\end{array}$ & $\begin{array}{l}\text { 122(b), 231(b), 365(b), 484(vS), } \\
\text { 1464(S), 1527(S), 1555(wb?), } \\
\text { 1651(B), 1770(b) }\end{array}$ \\
\hline E.7.Z.2.P.A.3.1 & fluid & $\begin{array}{l}\text { scan of fluid inclusion, and } \\
\text { glass. 238(s) peak with } \\
\text { unknown source, and halite. }\end{array}$ & $\begin{array}{l}\text { 131(b), 238(s), 357(b), 1100(wB?), } \\
\text { 1650(B), 2331(s), 2435(wB) }\end{array}$ \\
\hline E.7.Z.2.P.A.3.2 & $\begin{array}{l}\text { Fluid } \\
\text { target, } \\
\text { solid } \\
\text { peaks }\end{array}$ & same solid as E.7.A.1.P.A.2 & $\begin{array}{l}\text { 138(b), 234(s), 352(b), 481(ws), } \\
950(w b ?), 1100(w B), 1350(w b ?), \\
1554 \text { (ws), 1658(B), } 22812331 \text {, } \\
2435,2675(b), 2897,3294,3449\end{array}$ \\
\hline E.7.Z.2.P.A.4.1 & fluid & $\mathrm{n} / \mathrm{a}$ & $122,1075,1650$ \\
\hline E.7.Z.2.P.A.4.2 & fluid & n/a & $\begin{array}{l}129,229,364,478,581,771(?), \\
970,1092,1336,1555(\mathrm{vw}), 1647\end{array}$ \\
\hline E.7.Z.2.P.A.5.1 & fluid & n/a & $\begin{array}{l}\text { 127(b), 354(b), 484(ws), 600(b?), } \\
1020 \text { (vws?), 1370(wb?), 1650(B) }\end{array}$ \\
\hline D.A.6.1 & fluid & n/a & $\begin{array}{l}\text { 134(b), 236(wws), 296(ws), 359(wb), } \\
\text { 412(s), 1324(B), } 1654(\mathrm{~B})\end{array}$ \\
\hline E.7.Z.2.P.A.7.1 & $\begin{array}{l}\text { fluid in } \\
\text { inclusion } \\
\text { with solid } \\
\text { and vapor }\end{array}$ & $\begin{array}{l}\text { has a striated tabular solid and } \\
\text { a vapor bubble in inclusion }\end{array}$ & $\begin{array}{l}125,230,295,356,414,484,612, \\
894,937,995,1017,1114,1323 \\
1489,1557,1617,1653\end{array}$ \\
\hline
\end{tabular}




\begin{tabular}{|c|c|c|c|}
\hline E.7.Z.2.P.A.7.2 & $\begin{array}{l}\text { fluid in } \\
\text { inclusion } \\
\text { with solid } \\
\text { and vapor }\end{array}$ & scan from $400-1700$ & 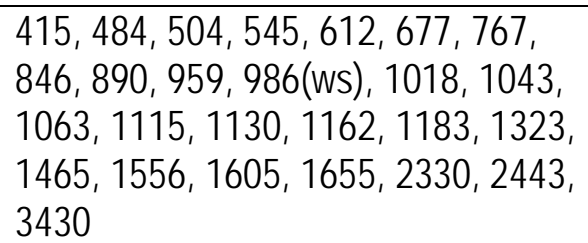 \\
\hline E.7.Z.2.P.A.7.3 & $\begin{array}{l}\text { solid in } \\
\text { fluid } \\
\text { inclusion } \\
\text { with vapor }\end{array}$ & scan from 400-1700 & $\begin{array}{l}417,485,501,611,630,678,831, \\
891,950,984(\text { ws), 1019, 1062(ws), } \\
1113,1131,1162,1325(B), 1466, \\
1556,1606,1648\end{array}$ \\
\hline E.7.Z.2.P.A.7.4 & $\begin{array}{l}\text { halite near } \\
\text { inclusion }\end{array}$ & $\begin{array}{l}\text { peaks similar to ochre(?) } \\
\text { iron(iii) oxide }\end{array}$ & $\begin{array}{l}431,460,482,503,615,670,833, \\
859,892,1017,1041,1116, \\
1326(B), 1463,1558,2329,2941 \\
3429\end{array}$ \\
\hline E.7.Z.2.P.A.8.1.1 & fluid & all liquid fluid inclusion & $\begin{array}{l}129,228,414,481,1113,1322, \\
1465,1605,1642\end{array}$ \\
\hline E.7.Z.2.P.A.8.1.2 & fluid & high noise & $\begin{array}{l}415,484,631,710,834,888,1016, \\
1038,1070,1113,1233,1323,1607, \\
1652\end{array}$ \\
\hline E.7.Z.2.P.B.1.1 & fluid & $\mathrm{n} / \mathrm{a}$ & $\begin{array}{l}140,236,360,417,500,1019,1086, \\
1115,1451,1631,1653,1926,2330, \\
2835,3425,3434\end{array}$ \\
\hline E.7.Z.2.P.B.1.2 & fluid & $\mathrm{n} / \mathrm{a}$ & $\begin{array}{l}413,483,559,585,642,707,990 \\
\text { (vws), 1018, 1053(sh), 1060, 1110, } \\
\text { 1129, 1159, 1464, 1605(sh), 1654 }\end{array}$ \\
\hline E.7.Z.2.P.B.2.2 & $\begin{array}{l}\text { fluid } \\
\text { inclusion } \\
\text { with vapor } \\
\text { bubble }\end{array}$ & $\mathrm{n} / \mathrm{a}$ & $\begin{array}{l}415,484(\mathrm{~S}), 582,610,676,707 \\
727,854,893,978,1020,1074 \\
1129,1174,1287,1486,1653\end{array}$ \\
\hline
\end{tabular}

Empress 1A, Interval 8 (1498.74-1498.62 m)

Sharp peaks at $\sim 420, \sim 1019$, and $\sim 1131 \mathrm{~cm}^{-1}$ in Interval $8(1498.74-1498.62 \mathrm{~m})$ are likely anhydrite. Very weak broad peaks at $\sim 846$ and $\sim 875$ may relate to a hydrated sulfate. Weak sharp peaks at $\sim 1465$ and $\sim 1527 \mathrm{~cm}^{-1}$ may relate to a carbon functional group, their identity is uncertain. The broad peak at $\sim 1100 \mathrm{~cm}^{-1}$ is likely glass contamination. The broad peak at $\sim 1330 \mathrm{~cm}^{-1}$ may be from an iron or carbon compound (Table 16). 


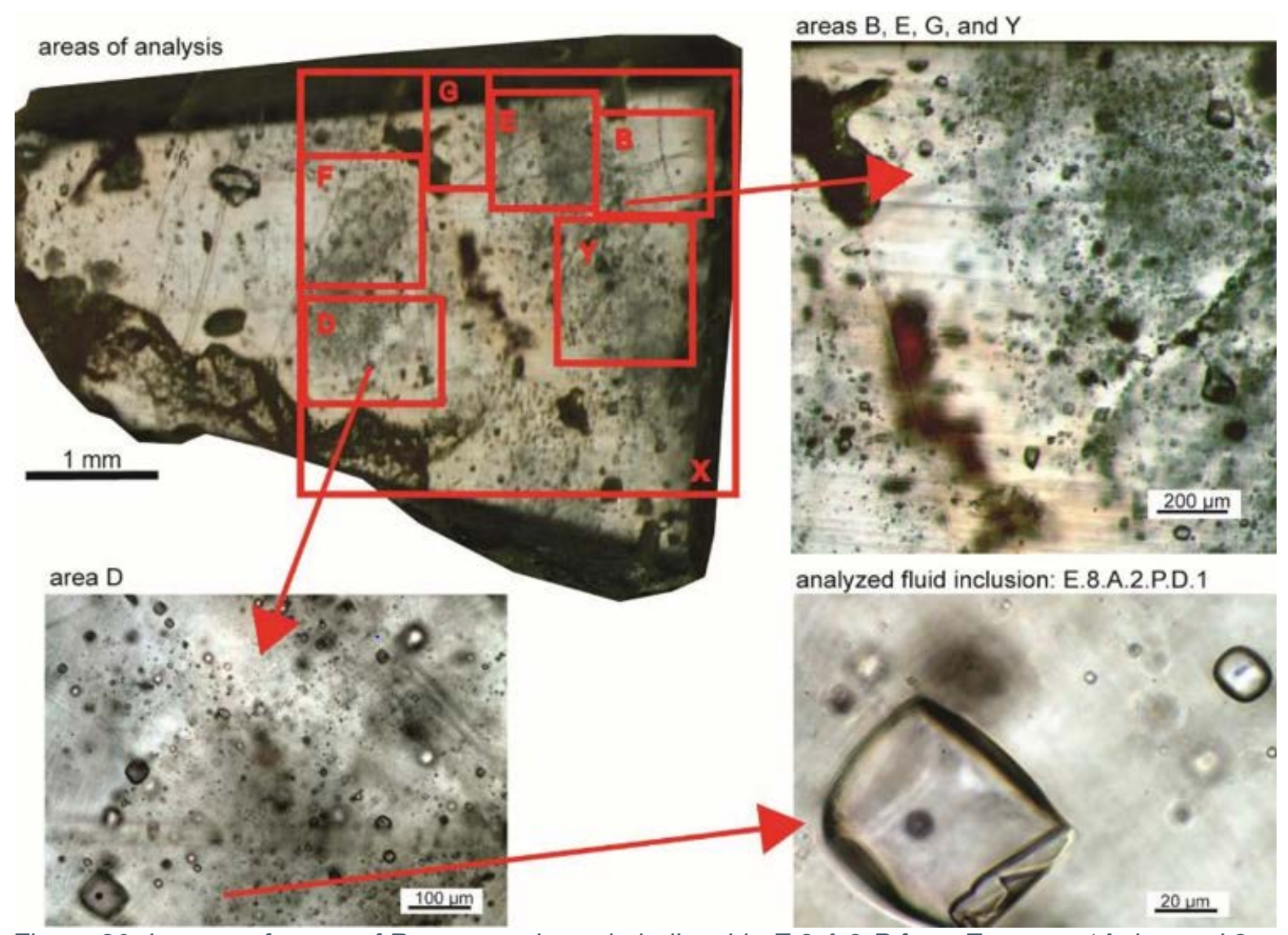

Figure 80. Images of areas of Raman analyses in halite chip E.8.A.2.P from Empress $1 A$, interval 8 $(1498.74-1498.62 \mathrm{~m})$, zone A. Areas of analyses are outlined and labeled in red on the left. Other images contain more detail of analyzed areas and inclusions. 


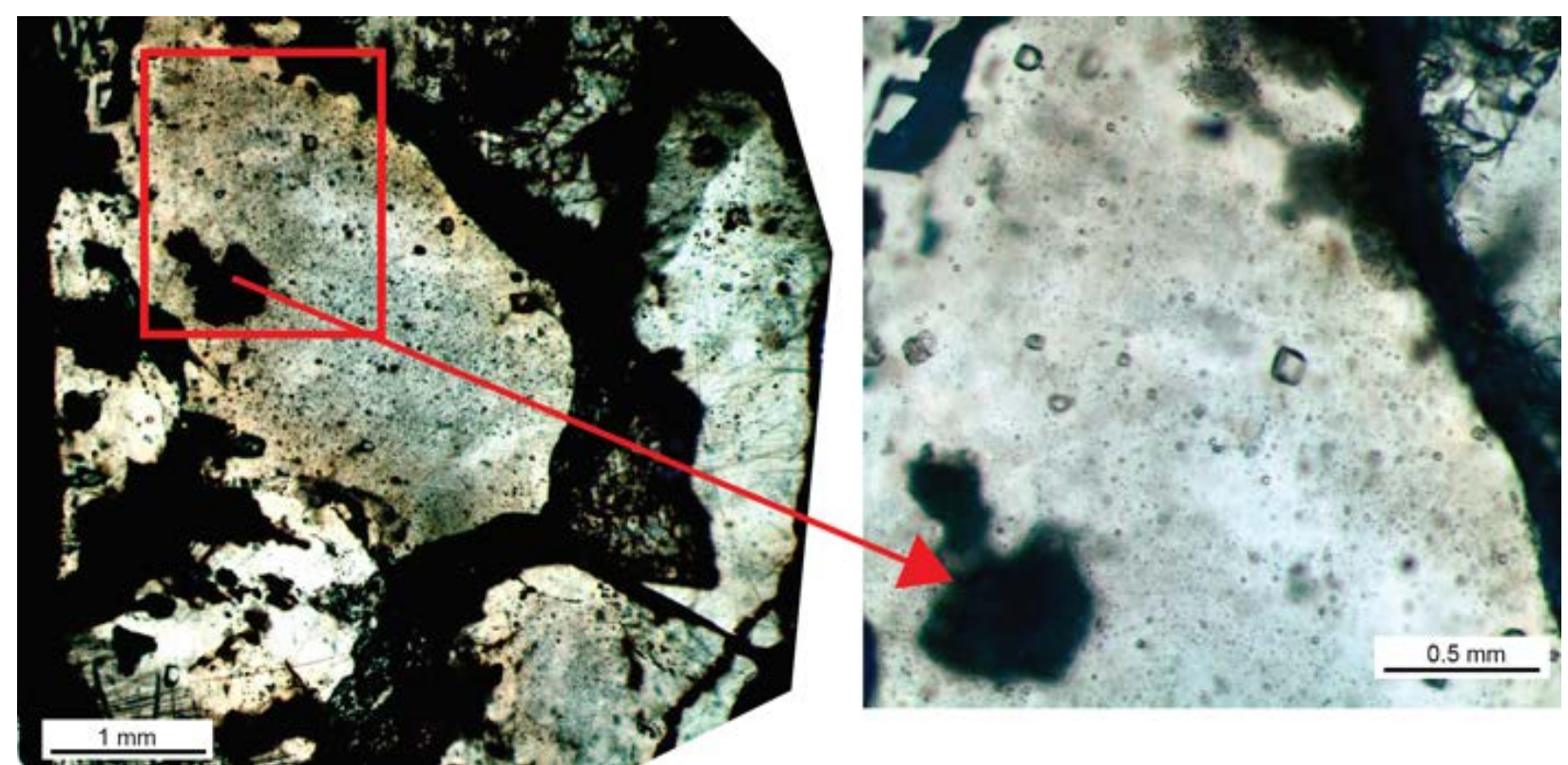

Figure 81. Images of areas of Raman analyses in halite chip E.8.Z.1.P from Empress 1A, interval 8 $(1498.74-1498.62 \mathrm{~m})$, zone Z. Chip is show on the left with area A outlined. Area A is shown in greater detail on the right.

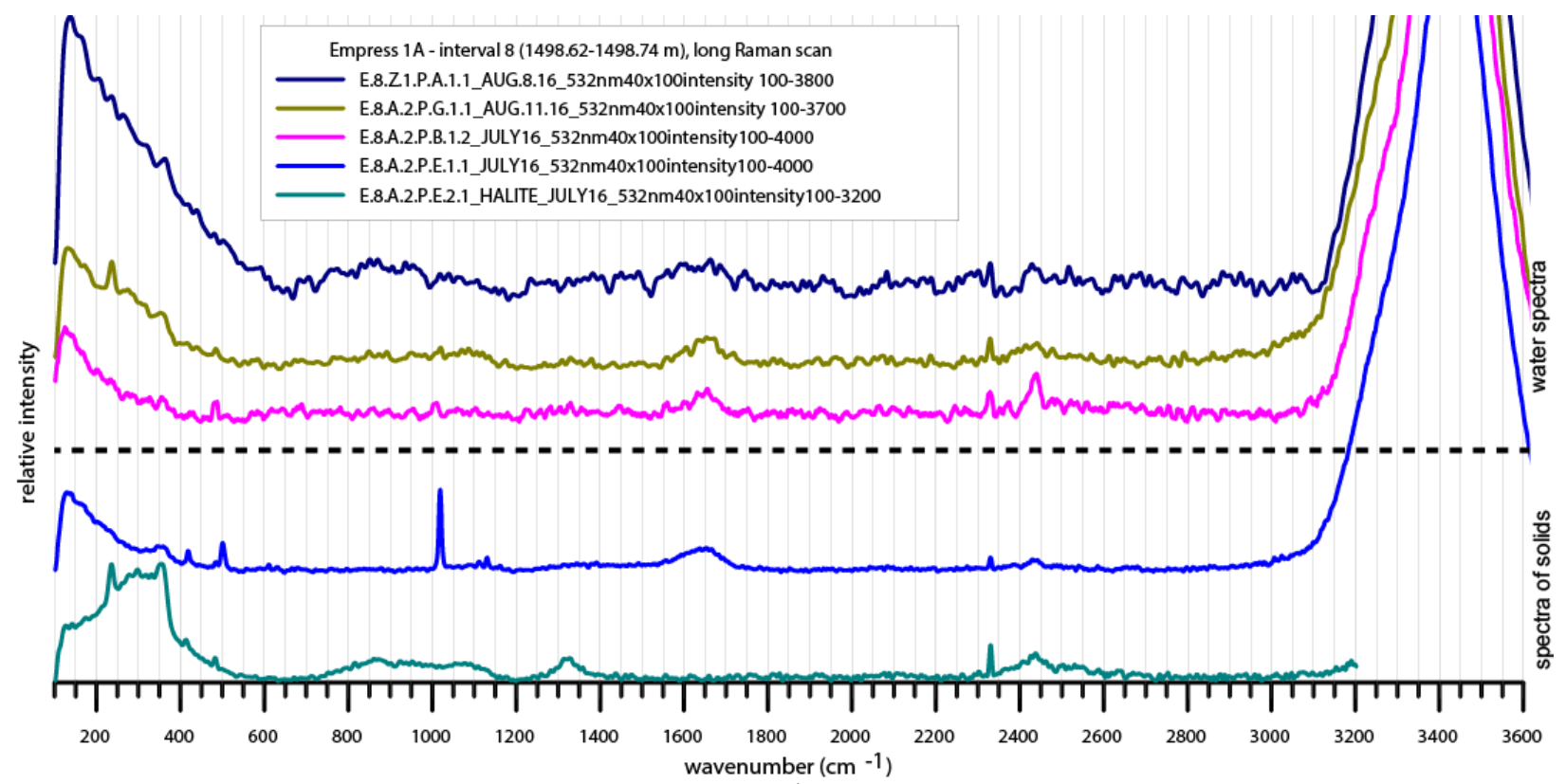

Figure 82. Chart of long Raman scans (100-3600 $\left.\mathrm{cm}^{-1}\right)$ of fluid inclusions from interval 8, 1498.74 $1498.62 \mathrm{~m}$. Spectra of solids are on the bottom, and spectra of fluids are on the top. 

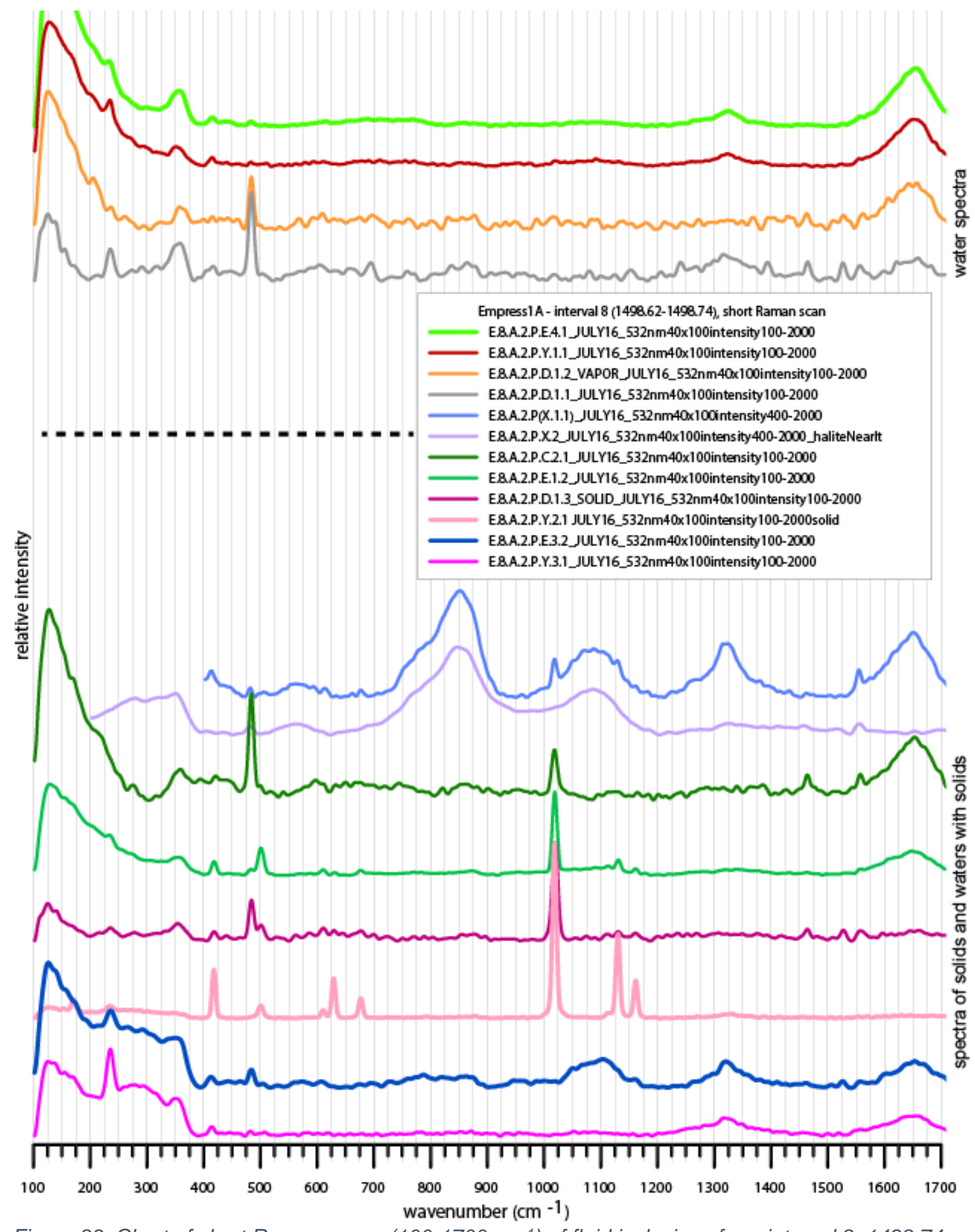

Figure 83. Chart of short Raman scans (100-1700 $\left.\mathrm{cm}^{-1}\right)$ of fluid inclusions from interval 8, 1498.74 $1498.62 \mathrm{~m}$. Spectra of solids are on the bottom, and spectra of fluids are on the top. 
Table 38. Spectral peaks from Raman analysis of interval 8, 1498.74-1498.62 m.

\begin{tabular}{|c|c|c|c|}
\hline scan name & scan target & comments & spectra peaks $\left(\mathrm{cm}^{-1}\right)$ \\
\hline E.8.A.2.P(X.1.1) & $\begin{array}{l}\text { fluid } \\
\text { inclusion } \\
\text { with solids }\end{array}$ & $\begin{array}{l}\text { with diaphragm, some solids in fluid } \\
\text { inclusion no match found }\end{array}$ & $\begin{array}{l}\text { 480(s), 549(wb), } \\
777(w b ?), 851(B), \\
\text { 1018(S), 1075(B), } \\
\text { 1323(B), 1556(s), } \\
\text { 1653(B), 2332, 2436, } \\
2873,3265,3434\end{array}$ \\
\hline E.8.A.2.P(X.1.2) & $\begin{array}{l}\text { fluid } \\
\text { inclusion } \\
\text { with solids }\end{array}$ & $\mathrm{n} / \mathrm{a}$ & $\begin{array}{l}481,556,844,1054, \\
1152,1321,1554(S) \\
1650\end{array}$ \\
\hline E.8.A.2.P.B.1.1 & fluid & $\mathrm{n} / \mathrm{a}$ & $\begin{array}{l}127,155,231,354, \\
392,448,484 \text { (vs), } \\
759,850,1092,1459, \\
1650,3406,3494\end{array}$ \\
\hline E.8.A.2.P.B.1.2 & fluid & $\mathrm{n} / \mathrm{a}$ & $\begin{array}{l}\text { 130(b), 484(s), } \\
\text { 1641(wB), 2331(s), } \\
\text { 2435(b), 3440(B) }\end{array}$ \\
\hline E.8.A.2.P.B.2.1 & fluid & $\mathrm{n} / \mathrm{a}$ & $\begin{array}{l}121,236,355,483 \\
851,974,1054(b) \\
1223,1312,1464, \\
1529,1556,1658, \\
3400\end{array}$ \\
\hline E.8.A.2.P.B.3.1 & fluid & $\mathrm{n} / \mathrm{a}$ & $\begin{array}{l}123,236,275,359, \\
483,655,692,857, \\
922,970,1089,1316, \\
1464,1661,3400\end{array}$ \\
\hline E.8.A.2.P.B.4.1 & fluid & $\mathrm{n} / \mathrm{a}$ & $\begin{array}{l}170,240,303,349, \\
409,483,502,850(b), \\
1094,1128,1326(b), \\
1555,1674(w), 1945\end{array}$ \\
\hline E.8.A.2.P.C.1.1 & fluid & $\mathrm{n} / \mathrm{a}$ & $485,1017,1021$ \\
\hline E.8.A.2.P.C.1.1 & $\begin{array}{l}\text { halite near } \\
\text { inclusion }\end{array}$ & $\mathrm{n} / \mathrm{a}$ & 484 \\
\hline E.8.A.2.P.C.2.1 & fluid & no match, analcime? & $\begin{array}{l}\text { 134(b), 236(s), } \\
\text { 358(wb), } 484(\mathrm{~s}) \\
\text { 695(ws?), 1240wb?), } \\
\text { 1396(ws), 1465(s), } \\
\text { 1527(s), 1555(ws?), } \\
\text { 1647(b) }\end{array}$ \\
\hline E.8.A.2.P.D.1.1 & $\begin{array}{l}\text { fluid } \\
\text { inclusion } \\
\text { with vapor } \\
\text { and solid }\end{array}$ & $\mathrm{n} / \mathrm{a}$ & $\begin{array}{l}\text { 126(b), 352(wb), } 484 \\
\text { (S), } 1018(\mathrm{~S}) \\
\text { 1465(ws?), 1557(s), } \\
\text { 1654(B) }\end{array}$ \\
\hline
\end{tabular}




\begin{tabular}{|c|c|c|c|}
\hline E.8.A.2.P.D.1.2 & $\begin{array}{l}\text { vapor in } \\
\text { fluid } \\
\text { inclusion } \\
\text { with solid }\end{array}$ & $\mathrm{n} / \mathrm{a}$ & $\begin{array}{l}\text { 123(b), 484(S), } \\
\text { 872(ws?), 977(ws?), } \\
\text { 1462(ws), 1767(ws?) }\end{array}$ \\
\hline E.8.A.2.P.D.1.3 & $\begin{array}{l}\text { solid in fluid } \\
\text { inclusion } \\
\text { with vapor }\end{array}$ & $\begin{array}{l}\text { Irregular tabular solid } \\
\text { Both a peak at } 1465 \text { (ws) and 1527(ws) are } \\
\text { in the D zone (these spectra are noisy but } \\
\text { the peaks are consistently present. } \\
1527 \text { peak- also seen in E.7.Z.2.P.A.1.1. } \\
\text { (no match in current mineral database) } \\
1465 \text { peak - also seen in E.4, E.7, and E.9. } \\
\text { (aragonite has a } 1460 \text { peak), but that is not } \\
\text { a good enough match. Carbon-nitrogen } \\
\text { bond? Are both from "At pH }>5 \text {, cytidine } 5^{\prime}- \\
\text { monophosphate shows three prominent } \\
\text { lines which are relatively broad at } \\
\text { 1649,1606, and } 1527 \text { cm-1 (Konig, 1970), } \\
\text { can maybe see in interval } 7 . \text { Hmm - these } \\
\text { re part of carbon rings, but the rings have } \\
\text { many more peaks that we do not see. }\end{array}$ & $\begin{array}{l}\text { 124(b), 236(b), 274(b), } \\
\text { 354(n), 484(S), } \\
\text { 502(ws), 1020(S), } \\
\text { 1465(ws), 1527(ws), } \\
\text { 1556(wb?), 1776(b?) }\end{array}$ \\
\hline E.8.A.2.P.D.2.1 & $\begin{array}{l}\text { fluid } \\
\text { inclusion } \\
\text { with vapor } \\
\text { bubble }\end{array}$ & $\mathrm{n} / \mathrm{a}$ & $\begin{array}{l}123,233,484,676 \\
874,977,1070,1462 \\
1558,1767\end{array}$ \\
\hline E.8.A.2.P.E.1.1 & $\begin{array}{l}\text { solid in } \\
\text { inclusion }\end{array}$ & $\begin{array}{l}\text { Anhydrite, very weak contamination from } \\
\text { near } 2400, \text { also seen in samples with little } \\
\text { contamination, could it be from something } \\
\text { other than the glass? }\end{array}$ & $\begin{array}{l}\text { 130(b), 350(b), } \\
\sim 420(\mathrm{~s}), 480(w s) \\
\text { 500(s), 609(ws?), } \\
\text { 1020(S), 1115(ws), } \\
\text { 1131(s), 1163(ws), } \\
\text { 1650(B), 2331(s), } \\
\text { 2434(b), 3440(B) }\end{array}$ \\
\hline E.8.A.2.P.E.1.2 & $\begin{array}{l}\text { solid in } \\
\text { inclusion }\end{array}$ & $\begin{array}{l}72 \% \text { match with anhydrite, good match to } \\
\text { me, there is anhydrite, but we also have } \\
\text { more- } 484 \text { peak, - rest appears standard. }\end{array}$ & $\begin{array}{l}\text { 129(b), 232(ws), } \\
\text { 359(b), 418(s), } \\
\text { 482(ws), 501(S), } \\
\text { 611(s), 676(ws?), } \\
\text { 873(wb?), 1019(vs), } \\
\text { 1115(ws), 1131(s), } \\
\text { 1163(ws), 1647(B) }\end{array}$ \\
\hline E.8.A.2.P.E.2.1 & $\begin{array}{l}\text { halite near } \\
\text { inclusion }\end{array}$ & $\begin{array}{l}\text { Glass noise here, but } 1330(\mathrm{~B}) \text { unknown, } \\
861(\mathrm{~B}) \text { unknown, and } 235(\mathrm{~s}) \text { unknown also } \\
\text { here. } \\
\text { The peaks } 298(w s), 355(\mathrm{~s}), 413(w s), \\
483(\text { ws) are also present here- but no }\end{array}$ & $\begin{array}{l}\text { 236(s), 298(ws), } \\
355(\mathrm{~s}), 413(\mathrm{ws}) \\
\text { 483(ws), 861(B), } \\
\text { 1055(b), 1328(B), }\end{array}$ \\
\hline
\end{tabular}




\begin{tabular}{|c|c|c|c|}
\hline & & $\begin{array}{l}\text { strong anhydrite peak, what are they } \\
\text { coming from? They are also present in other } \\
\text { long and short parts of this interval. }\end{array}$ & $\begin{array}{l}\text { 2331(vS), 2432(B), } \\
\text { 3190(B), 3454(B) }\end{array}$ \\
\hline E.8.A.2.P.E.3.1 & fluid & $\mathrm{n} / \mathrm{a}$ & $\begin{array}{l}140,158,233,316 \\
347,483,1094,1328 \\
1655\end{array}$ \\
\hline E.8.A.2.P.E.3.2 & fluid & $\begin{array}{l}\text { Has water peak and some other commonly } \\
\text { seen peaks. Does not have glass peaks! } \\
\text { The strong broad peak at } 1321(\mathrm{~B}) \text { does not } \\
\text { have an identity. There are week broad } \\
\text { peaks a } 846 \text { and } 875 \text { ish. }\end{array}$ & $\begin{array}{l}\text { 126(b), 237(s), 351(b), } \\
\text { 412(s), 484(S), } \\
\text { 864(b?), 1049(ws?), } \\
\text { 1080(B), 1161(s), } \\
\text { 1321(B), 1526(ws), } \\
\text { 1655(B), 1951(ws?), } \\
\text { 1981(ws) }\end{array}$ \\
\hline E.8.A.2.P.E.4.1 & fluid & $\mathrm{n} / \mathrm{a}$ & $\begin{array}{l}\text { 144(b), 356(b), } \\
\text { 415(ws), 483(ws), } \\
\text { 1326(B), 1657(B) }\end{array}$ \\
\hline E.8.A.2.P.G.1.1 & fluid & $\begin{array}{l}\text { similar to E.8.Z.1.P.A.1.2, but it has a water } \\
\text { peak, weak peaks from anhydrite. }\end{array}$ & $\begin{array}{l}\text { 130(b), 237(s), 356(b), } \\
\text { 484(ws?), 1019(ws?), } \\
\text { 1650(B), 2331(s), } \\
\text { 3440(B) }\end{array}$ \\
\hline E.8.A.2.P.X.2.1 & $\begin{array}{l}\text { halite near } \\
\text { inclusion }\end{array}$ & halite & $\begin{array}{l}\text { 533(vwb), 577, } \\
\text { 838(vB), 1072(B), } \\
\text { 1549(wB?), 2433(B) }\end{array}$ \\
\hline $\begin{array}{l}\text { E.8.A.2.P.X.2.1 } \\
\text { (without } \\
\text { diaphragm) }\end{array}$ & $\begin{array}{l}\text { halite near } \\
\text { inclusion }\end{array}$ & $\begin{array}{l}\text { Scan without the diaphragm in the Raman } \\
\text { microprobe }\end{array}$ & $\begin{array}{l}\text { 295, 483, 571, 851, } \\
1091,1555,3289(\mathrm{sh}) \\
3449\end{array}$ \\
\hline E.8.A.2.P.Y.1.1 & fluid & $\mathrm{n} / \mathrm{a}$ & $\begin{array}{l}\text { 128(B), 234(b), } \\
\text { 344(b), 412(ws), } \\
\text { 1090(vwB?), 1322(B), } \\
\text { 1652(vB) }\end{array}$ \\
\hline E.8.A.2.P.Y.2.1 & $\begin{array}{l}\text { solid in fluid } \\
\text { inclusions }\end{array}$ & Acicular solid in fluid inclusion- anhydrite & $\begin{array}{l}\text { 128(b), 168(S), } \\
\text { 234(wb), 415(S), } \\
\text { 501(s), 606(ws), } \\
\text { 626(S), 677(s), } \\
\text { 1018(vS), 1113(ws), } \\
\text { 1130(S), 1161(s), } \\
\text { 1319(wB), 2330, } \\
\text { 3253(sh), 3426 }\end{array}$ \\
\hline E.8.A.2.P.Y.3.1 & fluid & $\mathrm{n} / \mathrm{a}$ & $\begin{array}{l}\text { 132(b), 160(b), } \\
\text { 231(S), 277(b), } \\
\text { 354(b), 412(ws), } \\
\text { 1092(vwB), 1316(B), } \\
\text { 1658(B) }\end{array}$ \\
\hline
\end{tabular}




\begin{tabular}{|l|l|l|l|}
\hline & $\begin{array}{l}\text { Solid in fluid } \\
\text { inclusion }\end{array}$ & & $417,482,500,610$, \\
& & & $629,678,774,807$, \\
& & & $857(\mathrm{vw}), 939,957$, \\
& & $978,1018,1113$, \\
E.8.A.2A.P.F.2.2 & & anhydrite. & $1130,1160,3439$ \\
\hline & fluid & n/a & $141(\mathrm{wb}), 365(\mathrm{wb})$, \\
E.8.Z.1.P.A.1.1 & & Similar to E.8.A.2.P.E.2.1, but glass signal & $233(\mathrm{~s}), 3421(\mathrm{~B})$ \\
\hline & fluid & is weaker (hard to discern unless looking for & $856,362,483,778$, \\
& & it), peak at 1330(B) is absent, and the & $1116,1374,1463$, \\
& & 861(B) peak is present but weaker here. & $1557,1613,1662$ \\
\hline
\end{tabular}

Empress 1A, interval $9(1489.75-1489.70 \mathrm{~m})$

Interval 9 (1489.75 - $1489.70 \mathrm{~m})$ has peaks consistent with anhydrite. Sharp peaks at $\sim 708, \sim 890, \sim 1114$, and $\sim 1180 \mathrm{~cm}^{-1}$ occur in spectra without the $\sim 1019 \mathrm{~cm}^{-1}$ peak associated with anhydrite, these are likely from a solid related to anhydrite. The broad peak at $\sim 1100 \mathrm{~cm}^{-1}$ is likely from contamination from the glass slide. The broad peaks at $\sim 1325 \mathrm{~cm}^{-1}$ and $\sim 1600 \mathrm{~cm}^{-1}$ may relate to disordered graphite or another carbonaceous solid.

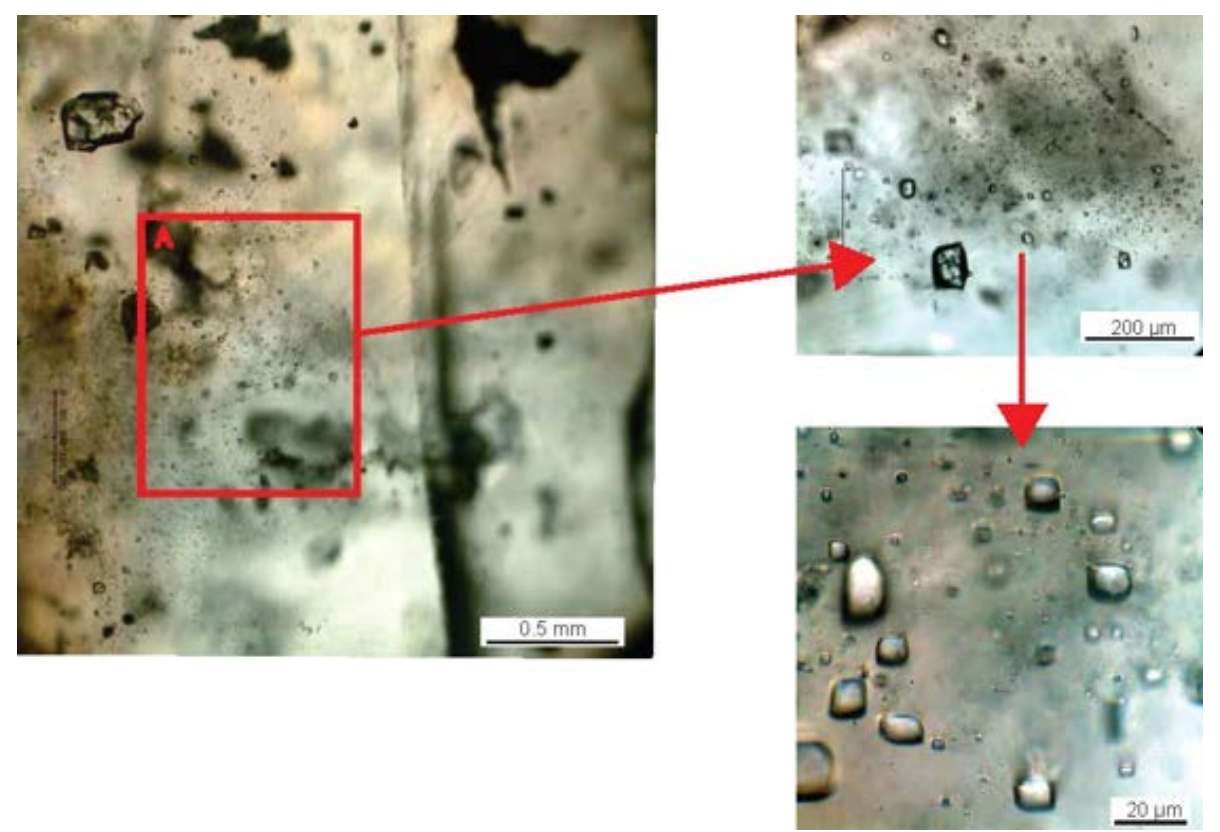

Figure 84. Images of areas of Raman analyses in halite chip E.9.A.1.P from Empress 1 A, interval 9 $(1489.75-1489.7 \mathrm{~m})$, zone A. Areas of analyses are outlined and labeled in red on the left. Primary fluid inclusions in area $A$ are highlighted on the right. 


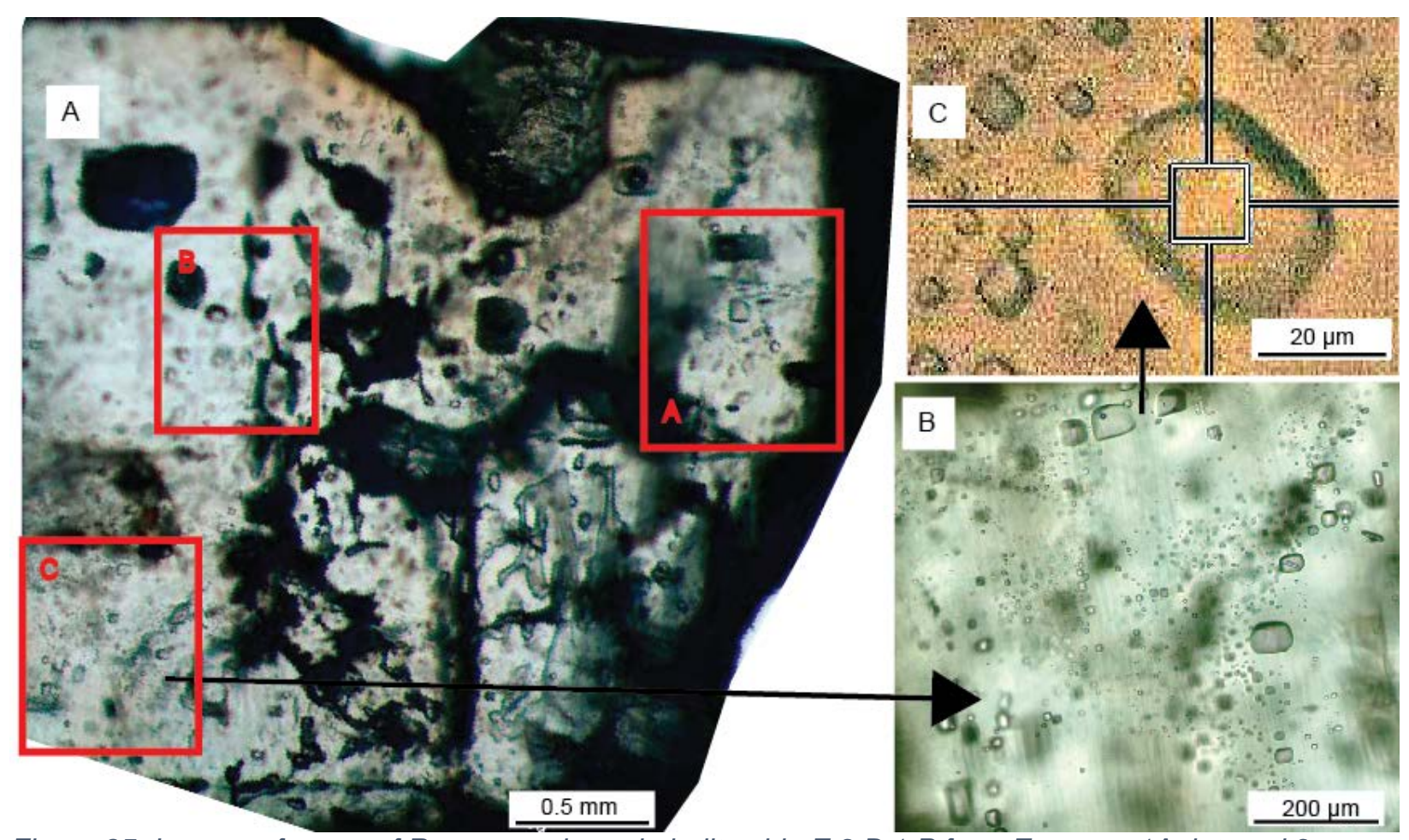

Figure 85. Images of areas of Raman analyses in halite chip E.9.B.1.P from Empress $1 A$, interval 9 $(1489.75-1489.7 \mathrm{~m})$, zone B. (A) Areas of analyses are outlined and labeled in red on the left. (B) primary fluid inclusions in area C, which has (C) inclusion E.9.B.1.P.C.3

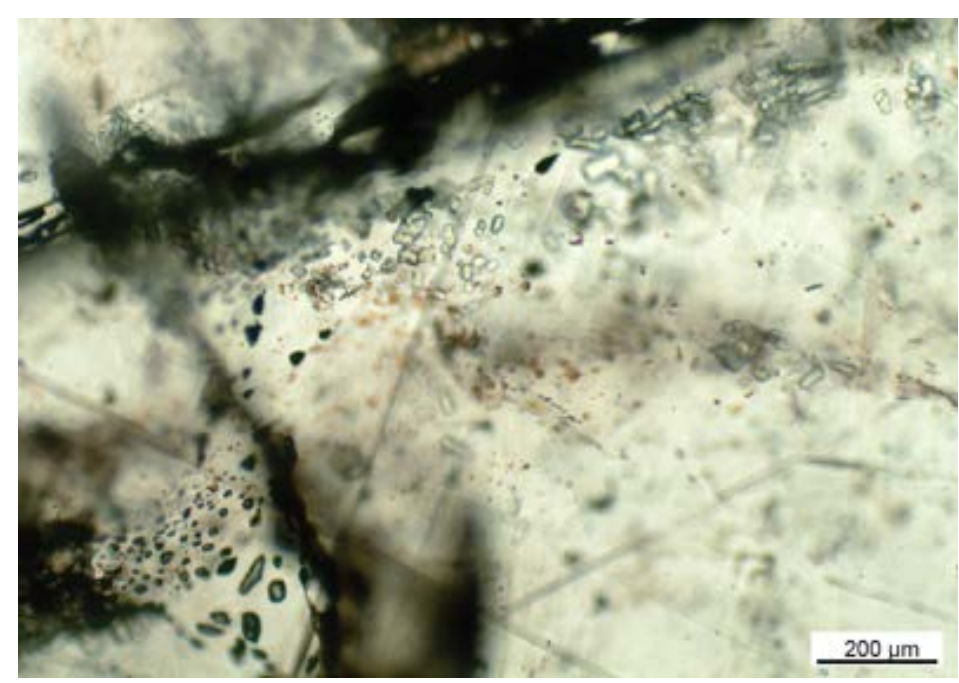

Figure 86. Image of area of Raman analyses in halite chip E.9.Z.1.S from Empress 1A, interval 9 $(1489.75-1489.7 \mathrm{~m})$, zone $Z$. This chip contains solids that were the target of Raman analysis. 


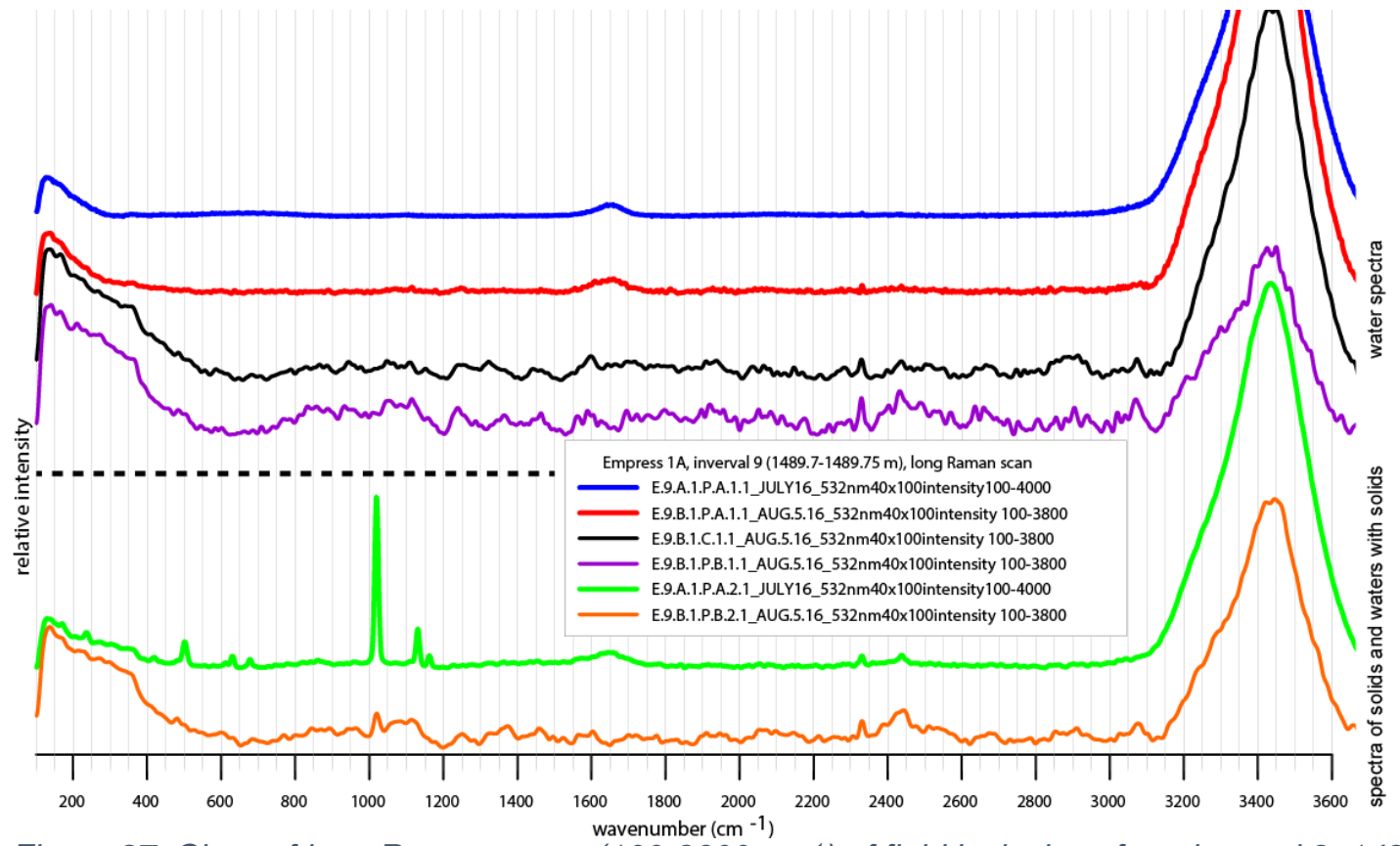

Figure 87. Chart of long Raman scans $\left(100-3600 \mathrm{~cm}^{-1}\right)$ of fluid inclusions from interval 9, 1498.75 $1498.7 \mathrm{~m}$. Spectra of solids are on the bottom, and spectra of fluids are on the top.
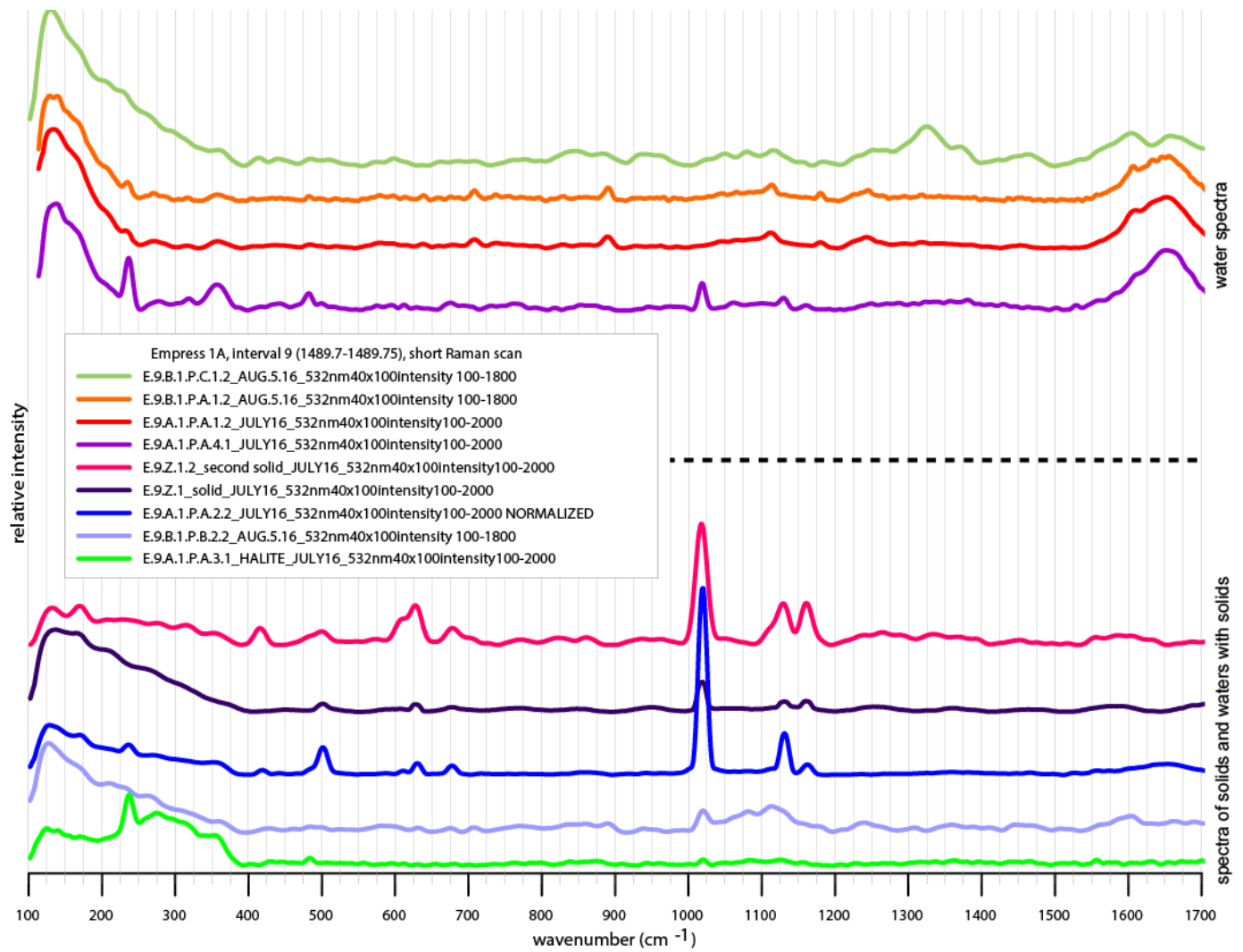

Figure 88. Chart of short Raman scans $\left(100-1700 \mathrm{~cm}^{-1}\right)$ of fluid inclusions from interval 9, 1498.75 $1498.7 \mathrm{~m}$. Spectra of solids are on the bottom, and spectra of fluids are on the top. 
Table 39. Spectral peaks from Raman analysis of interval 9, 1498.75-1498.7 m.

\begin{tabular}{|c|c|c|c|}
\hline scan name & $\begin{array}{l}\text { scan } \\
\text { target }\end{array}$ & comments & spectra peaks $\left(\mathrm{cm}^{-1}\right)$ \\
\hline E.9.A.1.P.A.1.1 & fluid & $\mathrm{n} / \mathrm{a}$ & $\begin{array}{l}\text { 130(b), 352(vwb), 1643(B), } \\
\text { 2330(ws), 3440(B) }\end{array}$ \\
\hline E.9.A.1.P.A.1.2 & fluid & $\mathrm{n} / \mathrm{a}$ & 130(b), 352(wb), 1653(B) \\
\hline E.9.A.1.P.A.2.1 & $\begin{array}{l}\text { solid in } \\
\text { inclusion }\end{array}$ & anhydrite & $\begin{array}{l}\text { 170(ws), 236(ws), 420(ws), 502(s), } \\
\text { 613(vws), 630(s), 678(ws), } \\
\text { 1019(vS), 1132(s), 1162(ws), } \\
\text { 1640(B), 2331(s), 2442(b), 3431(B) }\end{array}$ \\
\hline E.9.A.1.P.A.2.2 & $\begin{array}{l}\text { solid in } \\
\text { inclusion }\end{array}$ & $\begin{array}{l}\text { anhydrite, peak at } 265 \text { not from } \\
\text { anhydrite }\end{array}$ & $\begin{array}{l}\text { 128(b), 148(vws?), 171(s), 236(s), } \\
\text { 356(b), 419(s), 480(ws), 502(S), } \\
\text { 612(ws), 630(s), 678(s), 1019(vS), } \\
\text { 1113(vws?), 1131(S), 1162(s), } \\
\text { 1555(vws?), 1655(B), 2330, 2433, } \\
3439\end{array}$ \\
\hline $\begin{array}{l}\text { E.9.A.1.P.A.3.1 } \\
\text { HALITE }\end{array}$ & $\begin{array}{l}\text { halite near } \\
\text { inlcusion }\end{array}$ & $\mathrm{n} / \mathrm{a}$ & $\begin{array}{l}\text { 238(vS), 274(B), 354(b), 427(wb?), } \\
\text { 482(vs), 850(B?), 1019(S), 1558(s), } \\
3406,3494\end{array}$ \\
\hline E.9.A.1.P.A.4.1 & fluid target & likely anhydrite. & $\begin{array}{l}\text { 128(b), 236(S), 353(b), 483(s), } \\
\text { 1019(S), 1130(s), 1162(ws), } \\
\text { 1659(B), 2437, } 3421\end{array}$ \\
\hline E.9.B. & fluid & $\begin{array}{l}\text { water peaks, other peaks } \\
\text { unknown }\end{array}$ & $\begin{array}{l}\text { 139(b), 353(b), 1116(ws), 1248(wb), } \\
\text { 1610(ws?), 1644(B), 1813(wb?), } \\
\text { 2330(s), 3232(B) }\end{array}$ \\
\hline E.9.B.1.P.A.1.2 & fluid & $\begin{array}{l}\text { Something is here, does not } \\
\text { appear to be anhydrite (no 1019). } \\
\text { Unique peaks that may be } \\
\text { associated are } 708(\mathrm{~s}), 890(\mathrm{~s}) \text {, } \\
1114(\mathrm{~s}), 1180(\mathrm{ws}) \text { - this group of } \\
\text { peaks is also seen at intervals } \\
4,7, \text { and } 1297\end{array}$ & $\begin{array}{l}\text { 128(b), 236(ws), 358(b), 482(ws), } \\
\text { 639(ws), 708(s), 890(s), 1114(s), } \\
\text { 1180(ws), 1245(b), 1606(s), } \\
\text { 1645(B), }\end{array}$ \\
\hline P.B.1.1 & fluid & $\begin{array}{l}\text { noisy spectra, has the } 2333 \text { and } \\
2433(B), 1558 \text { is likely Oxygen. }\end{array}$ & $\begin{array}{l}\text { 141(b), 484(ws?), 1115(s), 1243(b?), } \\
\text { 1464(s?), 1558(s), 1650(wb?), } \\
\text { 2331(S), 2433(B), 3453(B) }\end{array}$ \\
\hline E.9.B.1.P.B.2.1 & fluid target & $\begin{array}{l}\text { likely anhydrite, many unknown } \\
\text { peaks }\end{array}$ & $\begin{array}{l}\text { 140(b), 364(wb), 483(ws), 501(ws), } \\
\text { 1019(S), 1251(wb?), 1374(b?), } \\
\text { 1455(wb?), 1600(ws?), 2332(s), } \\
\text { 2433(B), 3080(wb?), 3431(B) }\end{array}$ \\
\hline E.9.B.1.P.B.2.2 & fluid & $1100(B)$ - glass contamination? & $\begin{array}{l}\text { 127(b), 358(wb), 484(ws), 850(B?), } \\
\text { 1019(S), 1100(B?), 1600(B?) }\end{array}$ \\
\hline
\end{tabular}




\begin{tabular}{|c|c|c|c|}
\hline E.9.B.1.P.C.1.1 & fluid & $\begin{array}{l}\text { there is no strong water peak at } \\
1650 \text { but a notable broad peak at } \\
1600 \text {. }\end{array}$ & $\begin{array}{l}\text { 141(b), 361(b), 484(ws), } 1600(\mathrm{~b} ?) \\
\text { 2330(s), 3430(B) }\end{array}$ \\
\hline E.9.B.1.P.C.1.2 & fluid & $\begin{array}{l}1326(\mathrm{~B}) \text {, and } 1602(\mathrm{~B}) \text { at here, } \\
\text { easily seen, what are they from? }\end{array}$ & $\begin{array}{l}\text { 142(b), 230(ws), 359(b), 415(ws?), } \\
\text { 438(wb?), 483(ws?), 599(wb), } \\
\text { 1326(B), 1440(b), 1602(B) 1650(b), } \\
\text { 2330, 2890, 3417 }\end{array}$ \\
\hline E.9.B.1.P.C.3.1 & fluid & $\mathrm{n} / \mathrm{a}$ & $\begin{array}{l}\text { 140, 344, 484, 889, 1112, 1180, } \\
1239,1287,1360,1526,1557,1606, \\
1774,1847,1983,2900 \text { (B) }\end{array}$ \\
\hline E.9.B.1.P.C.3.2 & fluid & poor scan & $\begin{array}{l}835,855,891,933,962,1022,1072, \\
1113,1147,1181\end{array}$ \\
\hline E.9.B. & $\begin{array}{l}\text { vapor in } \\
\text { fluid } \\
\text { inclusion }\end{array}$ & vapor bubble, poor spectra & $\begin{array}{l}950,1110,1141,1291,1426,1442 \\
1467,1640\end{array}$ \\
\hline E.9.Z.1.2 & $\begin{array}{l}\text { solid in } \\
\text { inclusion }\end{array}$ & $\begin{array}{l}\text { solid in halite- tabular, right } \\
\text { angles, large }\end{array}$ & $\begin{array}{l}\text { 132(b), 168(s), 415(s), 606(s), } \\
\text { 629(s), 675(b), 1018(S), 1131(s), } \\
\text { 1164(s), 330, 2437, 2849, } 2891 \\
2932,32773400\end{array}$ \\
\hline E.9.Z.1_solid & $\begin{array}{l}\text { solid in } \\
\text { halite }\end{array}$ & $\begin{array}{l}\text { solid in halite- tabular, right } \\
\text { angles, large } 87 \% \text { match, } \\
\text { anhydrite }\end{array}$ & $\begin{array}{l}168,497,627,1016,1128,1161 \\
3400(B)\end{array}$ \\
\hline
\end{tabular}

\section{Empress 1A, interval $10(1480.8-1480.7 \mathrm{~m})$}

Because only solid inclusions were examined in Interval $10(1480.8-1480.7 \mathrm{~m})$ the presence of the strong peak at $\sim 484 \mathrm{~cm}^{-1}$ shows that this peak is coming from the matrix of salt or is contamination. Sharp peaks in this interval at $\sim 502, \sim 1018, \sim 1113$ and $\sim 1131 \mathrm{~cm}^{-1}$ are indicative of anhydrite. These Raman spectra show that the cubic and tabular solids in the halite matrix are likely anhydrite. The source of the weak sharp peak at $\sim 1087 \mathrm{~cm}^{-1}$ is unknown. 

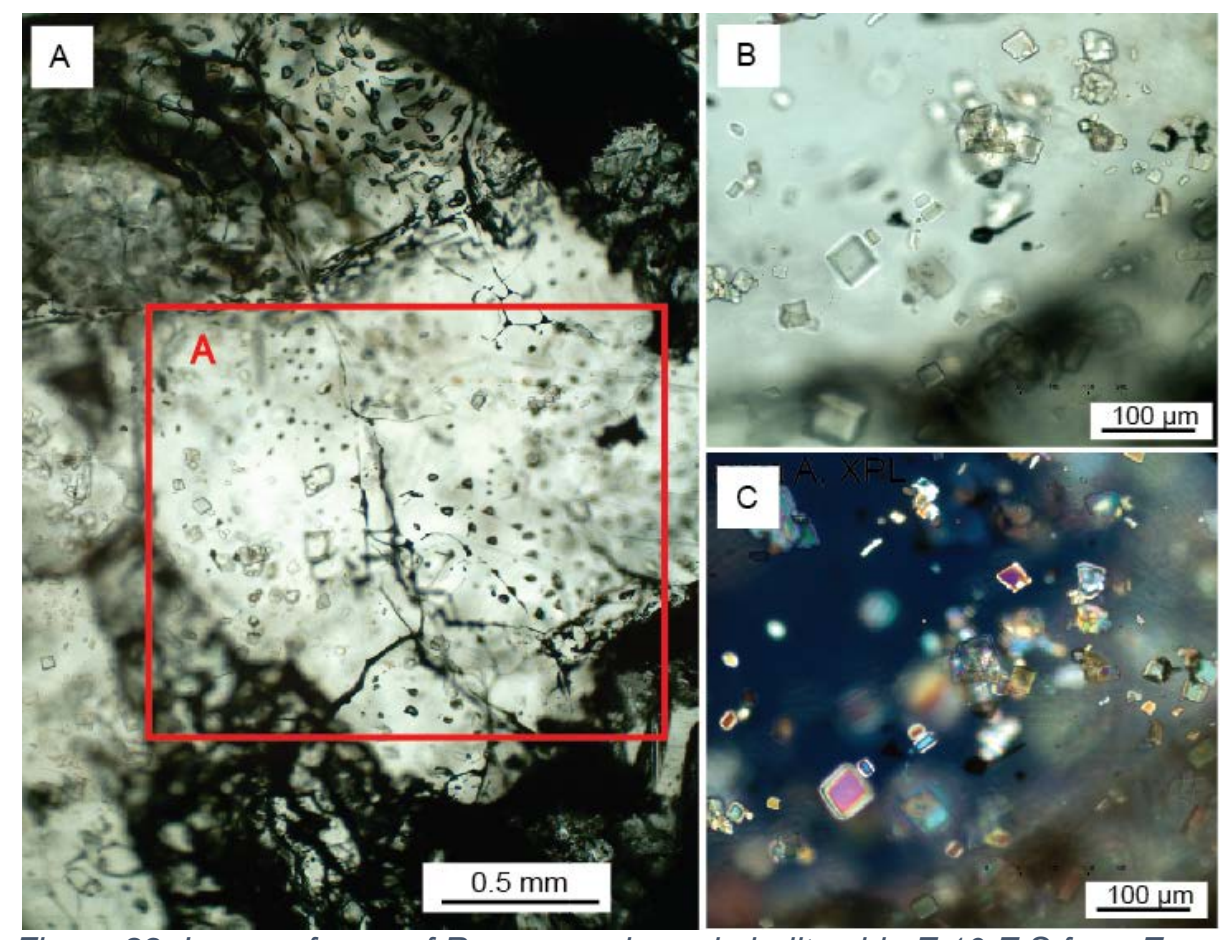

Figure 89. Image of area of Raman analyses in halite chip E.10.E.S from Empress 1A, interval 10 (1480.8 - $1480.7 \mathrm{~m}$ ), zone E.. (A) Area of analyses is outlined in red, containing (B) tabular solid in plane polarized light, (C) birefringent tabular solids in cross-polarized light.

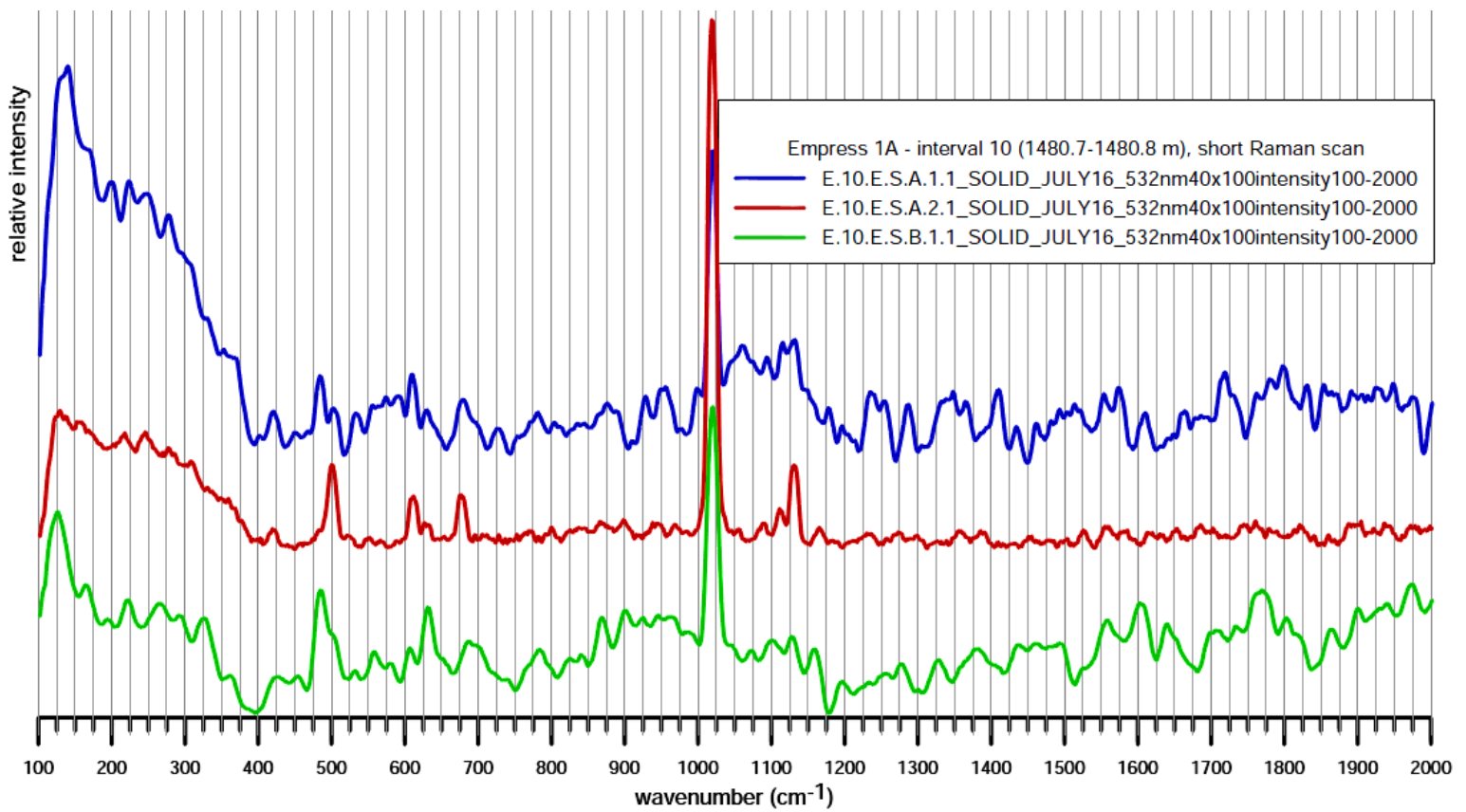

Figure 90. Raman scan (100-2000 $\left.\mathrm{cm}^{-1}\right)$ of solid tabular birefingent inclusions from interval 10, 1480.8 $1480.7 \mathrm{~m}$. 
Table 40. Spectral peaks from Raman analysis of interval 10, 1480.8-1480.7 m.

\begin{tabular}{|c|c|c|c|}
\hline scan name & $\begin{array}{l}\text { scan } \\
\text { target }\end{array}$ & comments & spectra peaks $\left(\mathrm{cm}^{-1}\right)$ \\
\hline $\begin{array}{l}\text { E.10.E.2.S.1.1 } \\
\text { Solid }\end{array}$ & $\begin{array}{l}\text { solid in } \\
\text { halite }\end{array}$ & $\mathrm{n} / \mathrm{a}$ & $\begin{array}{l}127,172,217,334,483,502,608,630, \\
782,963,1020,1130,1163,1285\end{array}$ \\
\hline $\begin{array}{l}\text { E.10.E.2.S.1.1 } \\
\text { Solid }\end{array}$ & $\begin{array}{l}\text { solid in } \\
\text { halite }\end{array}$ & $\mathrm{n} / \mathrm{a}$ & $\begin{array}{l}127,172,217,334,483,502,608,630, \\
782,963,1020,1130,1163,1285\end{array}$ \\
\hline $\begin{array}{l}\text { E.10.E.2.S.2.1 } \\
\text { Solid }\end{array}$ & $\begin{array}{l}\text { solid in } \\
\text { halite }\end{array}$ & $\mathrm{n} / \mathrm{a}$ & $\begin{array}{l}420,502,612,677,1019 \text { (vs), } \\
1087(w s), 1132(\mathrm{~m}), 2329,2438(\mathrm{~B})\end{array}$ \\
\hline $\begin{array}{l}\text { E.10.E.2.S.2.1 } \\
\text { _Solid }\end{array}$ & $\begin{array}{l}\text { solid in } \\
\text { halite }\end{array}$ & $\begin{array}{l}\text { 1087- shows up } \\
\text { consistently, source } \\
\text { unknown }\end{array}$ & $\begin{array}{l}420,502,612,677,1019(\mathrm{vs}), 1087(\mathrm{w}) \\
1132(\mathrm{~m}), 2900(\mathrm{~B})\end{array}$ \\
\hline $\begin{array}{l}\text { E.10.E.2.S.A.1.1 } \\
\text { solid }\end{array}$ & $\begin{array}{l}\text { solid in } \\
\text { halite }\end{array}$ & $\mathrm{n} / \mathrm{a}$ & $\begin{array}{l}\text { 140(wb?), 484(s), 610(s), 1018(S), } \\
\text { 1113(ws?), 1131(ws?), 1285(b?), } 1605\end{array}$ \\
\hline $\begin{array}{l}\text { E.10.E.2.S.A.2.1 } \\
\text { solid }\end{array}$ & $\begin{array}{l}\text { solid in } \\
\text { halite }\end{array}$ & good match with anhydrite & $\begin{array}{l}\text { 160(ws?), 502(s), 613(s), 677(s), } \\
\text { 1018(S), 1113(ws), 1131(s) }\end{array}$ \\
\hline $\begin{array}{l}\text { E.10.E.2.S.B.1.1 } \\
\text { solid }\end{array}$ & $\begin{array}{l}\text { solid in } \\
\text { halite }\end{array}$ & no & $\begin{array}{l}\text { 483(s), 502(ws?), 630(ws), 1020(S), } \\
\text { 1605(ws) }\end{array}$ \\
\hline
\end{tabular}

Empress 1A, interval 1297 (1297.08- $1297.00 \mathrm{~m})$

One spectrum from Interval 1297 (1297.08 - $1297.00 \mathrm{~m})$ is consistent with anhydrite, it has a very weak water peak at $\sim 1650 \mathrm{~cm}^{-1}$, as well as broad peaks at $\sim 1380 \mathrm{~cm}^{-1}$ and $\sim 1600$ $\mathrm{cm}^{-1}$ (possibly relates to disordered carbon/graphite). The source of the weak sharp peaks at $\sim 890$ and $\sim 1180 \mathrm{~cm}^{-1}$ is unknown. Because the peak for sulfate at $\sim 986 \mathrm{~cm}^{-1}$ is not present, it is unlikely that the peak at $\sim 890 \mathrm{~cm}^{-1}$ is from bisulfate. The broad peak at $\sim 1100 \mathrm{~cm}^{-1}$ is likely glass contamination. The broad peak at $\sim 1245 \mathrm{~cm}^{-1}$ may relate to a functional group share with $\mathrm{k}$ alunite $\left(\sim 1237 \mathrm{~cm}^{-1}\right)$. The broad peak at $\sim 1380 \mathrm{~cm}^{-1}$ may relate to a carbon bond. The source of the broad peak at $1600 \mathrm{~cm}^{-1}$ is unknown. The source of the broad peak at $\sim 2930 \mathrm{~cm}^{-1}$ is unknown, but this peak is present in several other intervals. 


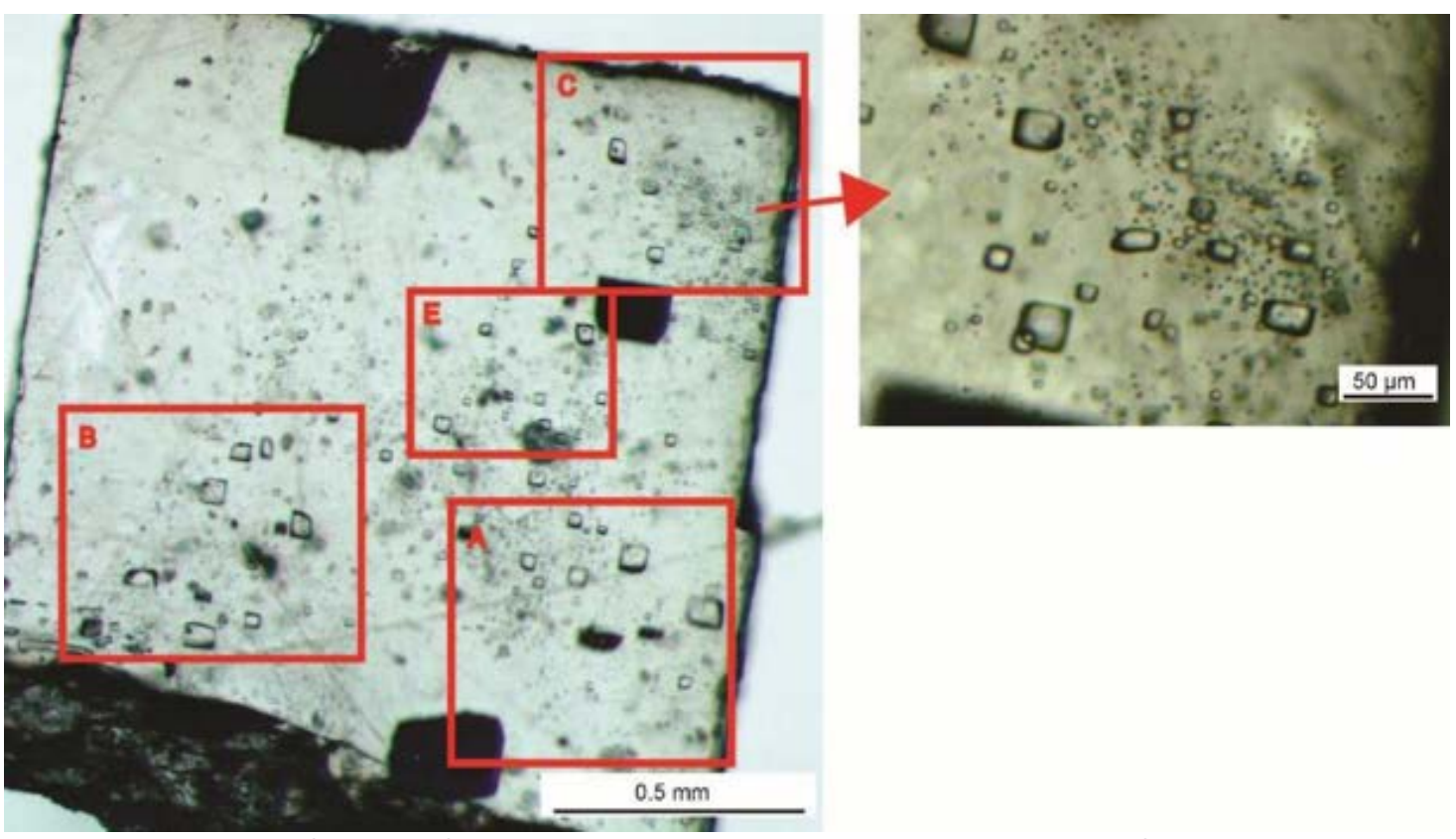

Figure 91. Images of areas of Raman analyses in halite chip E.1297.Z.1.P from Empress 1A, interval 1297 (1297.08 - $1297.0 \mathrm{~m}$ ), zone Z.. Areas of analyses are outlined and labeled in red on the left. Primary fluid inclusions in area $C$ are highlighted on the right. 


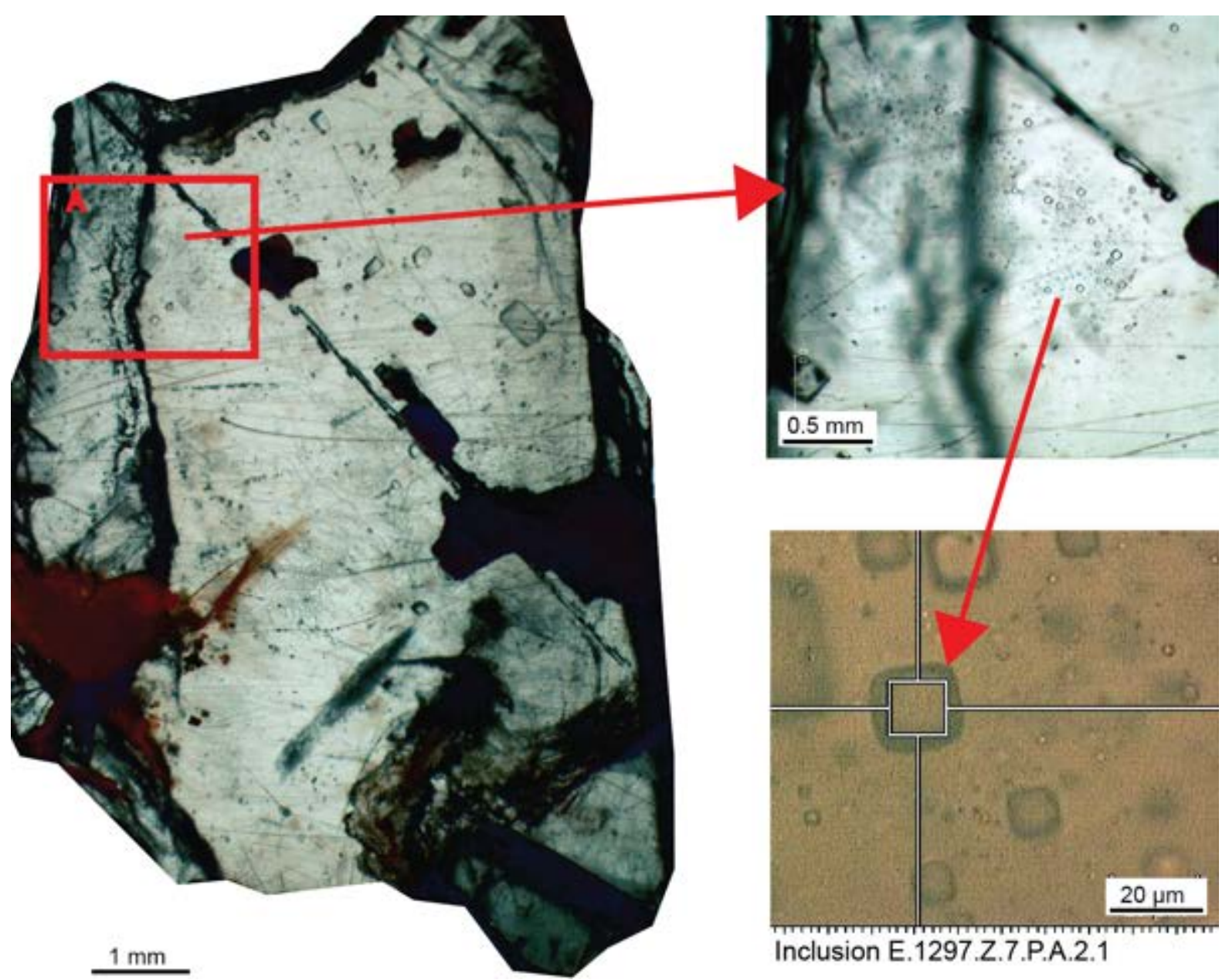

Figure 92. Images of area of Raman analyses in halite chip E.1297.Z.7.P from Empress 1A, interval 1297 $(1297.08-1297.0 \mathrm{~m})$, zone Z, for Raman analyses. Area of analyses is outlined and labeled in red on the left. Primary fluid inclusions in area $A$ are highlighted on the right. 


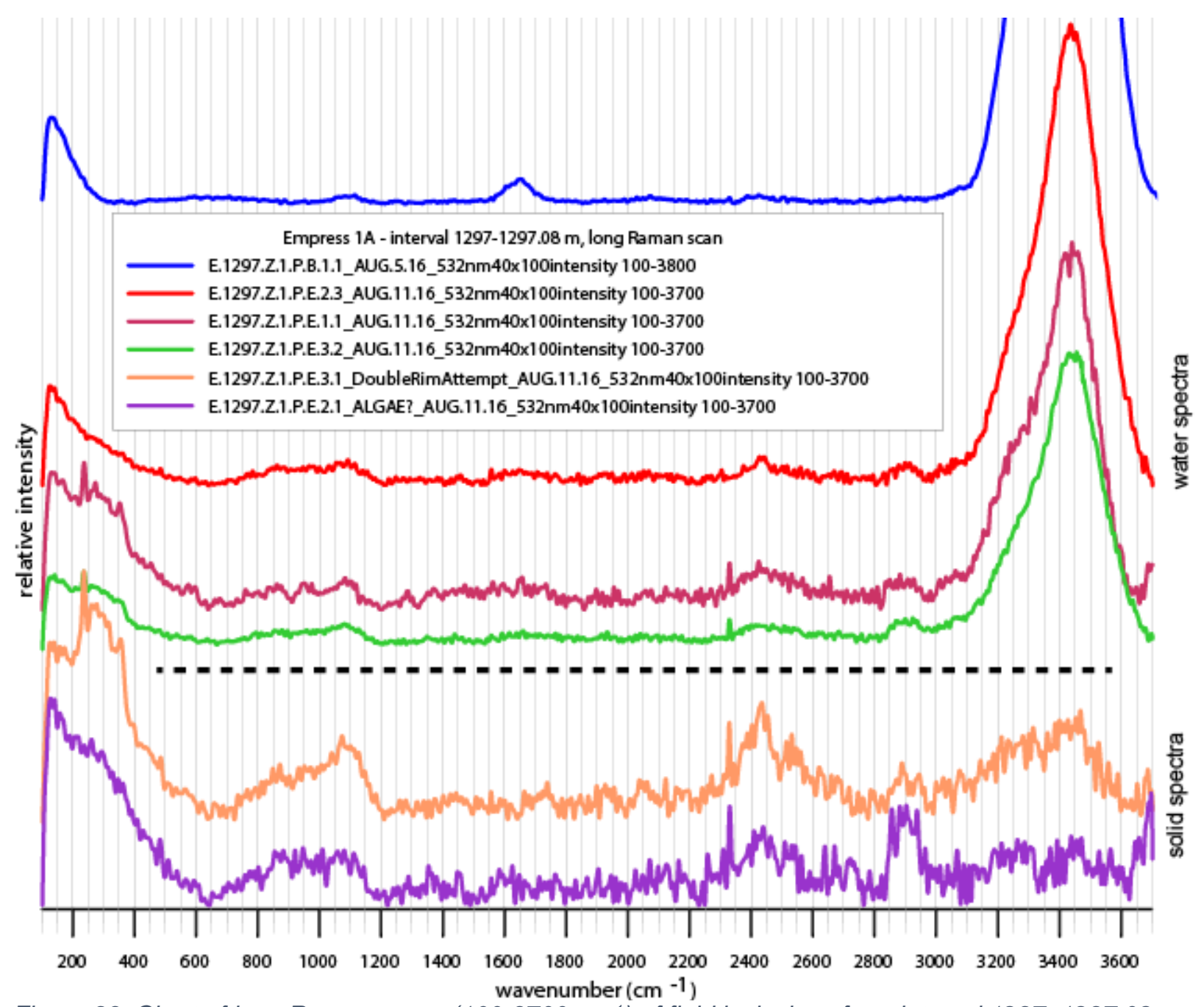

Figure 93. Chart of long Raman scans (100-3700 $\left.\mathrm{cm}^{-1}\right)$ of fluid inclusions from interval 1297, 1297.08 $1297.0 \mathrm{~m}$. Spectra of solids are on the bottom, and spectra of fluids are on the top. 


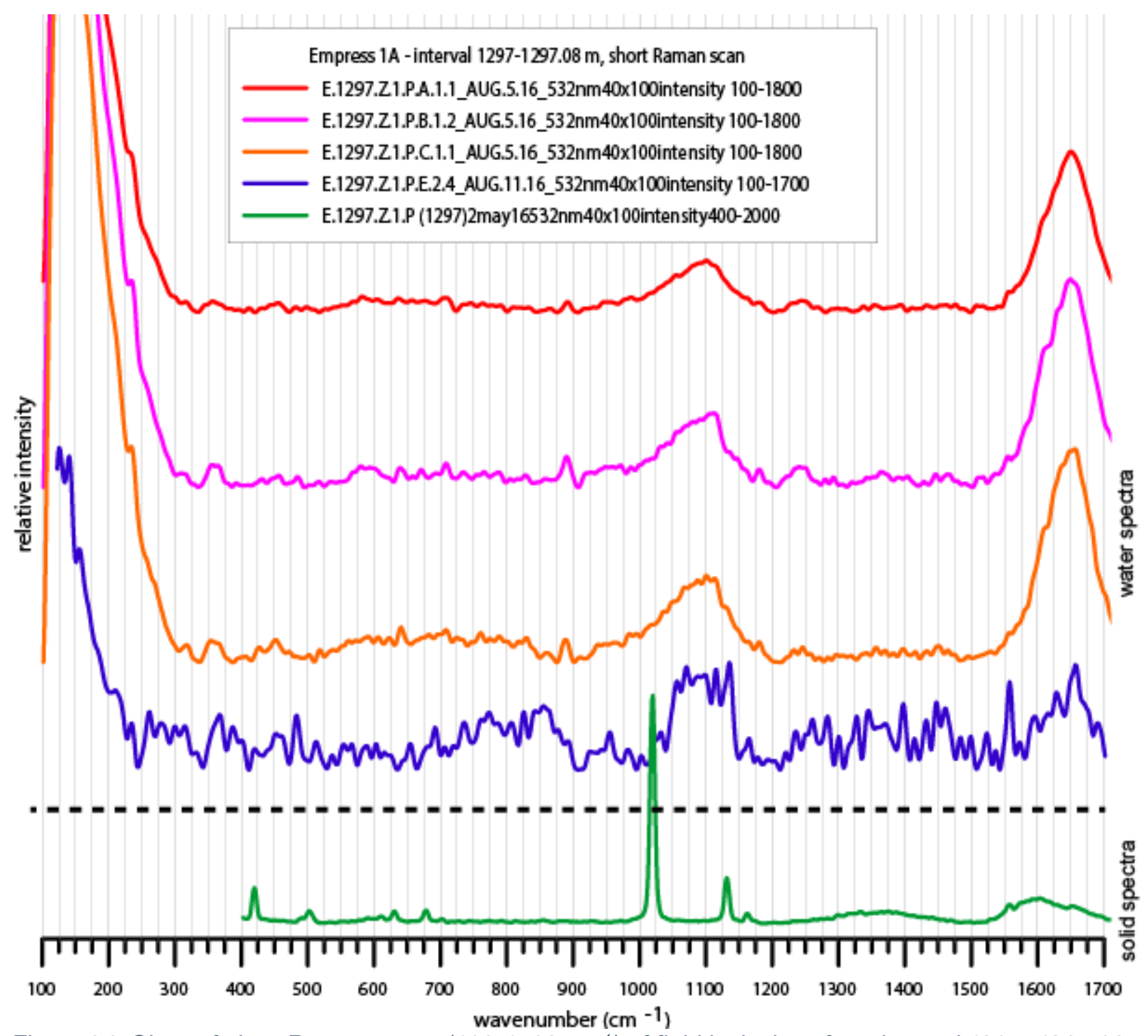

Figure 94. Chart of short Raman scans $\left(100-1700 \mathrm{~cm}^{-1}\right)$ of fluid inclusions from interval 1297, 1297.08 $1297.0 \mathrm{~m}$. Spectra of solids are on the bottom, and spectra of fluids are on the top.

Table 41. Spectral peaks from Raman analysis of interval 1297, 1297.08 - $1297.0 \mathrm{~m}$.

\begin{tabular}{|c|c|c|c|}
\hline scan name & scan target & comments & spectra peaks $\left(\mathrm{cm}^{-1}\right)$ \\
\hline $\begin{array}{l}\text { E.1297.Z.1.P } \\
(1297)\end{array}$ & $\begin{array}{l}\text { solid in } \\
\text { fluid } \\
\text { inclusion }\end{array}$ & $\begin{array}{l}\text { match with anhydrite, } \\
\text { but not with all peaks, } \\
1603(\mathrm{~b}) \& 1378(\mathrm{wb}) \\
\text { present }\end{array}$ & $\begin{array}{l}\text { 420(s), 484(ws), 502(ws), 630(ws), } \\
\text { 678(ws), 1020(S), 1113(S), 1161(ws), } \\
\text { 1333(vws), 1378(wB), 1555(ws), } \\
\text { 1603(B), 1653(b,sh) }\end{array}$ \\
\hline E.1297.Z.1.P.A.1.2 & fluid & very noisy spectra & $\begin{array}{l}132,234,357,412,455,581,703,892, \\
945,987,1058,1100,1161,1181,1242, \\
1395,1476,1555,1648\end{array}$ \\
\hline E.1297.Z.1.P.B.1.1 & fluid & n/a & $\begin{array}{l}\text { 120(b), 1078(vB), 1639(vB), 2420(B), } \\
\text { 3440(B) }\end{array}$ \\
\hline
\end{tabular}




\begin{tabular}{|c|c|c|c|}
\hline E.1297.Z.1.P.B.1.2 & fluid & $\begin{array}{l}708,890,1180 \text { peak } \\
\text { group is present. } \\
1115(b) \text { or } 1100(b) \text { or } \\
1090(b) \text { peak (glass) is } \\
\text { present in many of these } \\
\text { zones. }\end{array}$ & $\begin{array}{l}\text { 131, 356, 484, 580, 636, 708, 890, } 972 \text {, } \\
1115(B), 1181,1251,1292,1650\end{array}$ \\
\hline E.1297.Z.1.P.C.1.1 & fluid & $\mathrm{n} / \mathrm{a}$ & $\begin{array}{l}234,318,354,426,452,518,640,707 \\
760,889,1100,1181,1246,1452,1658\end{array}$ \\
\hline E.1297.Z.1.P.E.1.1 & fluid & noisy & $\begin{array}{l}\text { 130(b), 235(s), 275(ws?), 355(b), } \\
\text { 2330(S), 2655(s?), 2930(B?), 3440(B) }\end{array}$ \\
\hline E.1297.Z.1.P.E.2.1 & $\begin{array}{l}\text { solid in } \\
\text { fluid } \\
\text { inclusion }\end{array}$ & algae? & $\begin{array}{l}\text { 130(b), 484(ws?), 2330(S), 2930(B?), } \\
\text { 3440(B) }\end{array}$ \\
\hline E.1297.Z.1.P.E.2.2 & $\begin{array}{l}\text { solid in } \\
\text { fluid } \\
\text { inclusion }\end{array}$ & algae?, noisy signal & $\begin{array}{l}483,511,584,802,858,965,1020, \\
1050(B), 1065,1095,1133,1265,1347, \\
1453,1557,1596,1670\end{array}$ \\
\hline E.1297.Z.1.P.E.2.3 & fluid & n/a & $\begin{array}{l}\text { 126(b), 484(s), 848(b?), 1458(B?), } \\
\text { 1558(S), 1647(wB), 2428(vB), 2879(vB), } \\
\text { 3460(B) }\end{array}$ \\
\hline E.1297.Z.1.P.E.2.4 & fluid & very noisy, poor scan & $\begin{array}{l}142,233,260,361,386,483,555,655, \\
836,893,956,1056,1071,1346,1462, \\
1558,1622,1658,2331,2836,3062, \\
3445\end{array}$ \\
\hline E.1297.Z.1.P.E.3.1 & fluid & $\mathrm{n} / \mathrm{a}$ & $\begin{array}{l}\text { 236(s), 261(B), 355(b), 486(ws), } \\
\text { 1073(b), 1644(s), 2330(s), 2452(B) }\end{array}$ \\
\hline E.1297. & fluid & $\begin{array}{l}\text { 2930(b) peak is present } \\
\text { in many parts of this, } \\
\text { noisy spectra }\end{array}$ & $\begin{array}{l}\text { 130(b), 235(s), 355(b), 1070(wB), } \\
\text { 2450(B), 2880(wB) 2930(B), 3440(B) }\end{array}$ \\
\hline E.1297.Z.8.P.A.1.1 & fluid & all liquid & $\begin{array}{l}127,213,238,279,317,358,419,489, \\
1281,1472,1556,1617,1670\end{array}$ \\
\hline E.1297.Z.8.P.A.1.2 & fluid & all liquid & $\begin{array}{l}439,484,599,702,970,1060,1084, \\
1133,1153,1204,1319,1440,1559, \\
1586,1657,2328,3429\end{array}$ \\
\hline E.1297.Z.8.P.A.2.1 & fluid & all liquid & $\begin{array}{l}125,238,279,345,484(\mathrm{vS}), 523,597, \\
694,791,866,909,933,969,989,1041 \\
1057,1126,1153,1196,1237,1326, \\
1352,1466,1538,1588,1683,\end{array}$ \\
\hline E.1297.Z.8.P.A.2.2 & fluid & all liquid & $\begin{array}{l}128,173,238,286,357,485,542,950, \\
990,1052,1130,1318,1464,1445, \\
1522,1616,1644,3027\end{array}$ \\
\hline
\end{tabular}




\section{Appendix III. Raman Spectra of Supplementary Samples}

\section{Reference Mineral Spectra}

Table 42. Reference mineral and solute Raman spectra....

\begin{tabular}{|c|c|c|}
\hline $\begin{array}{l}\text { mineral name - } \\
\text { chemical formula }\end{array}$ & Raman peaks (cm-1) & $\begin{array}{l}\text { sourcel } \\
\text { reference }\end{array}$ \\
\hline $\begin{array}{l}\text { actinolite - } \\
\mathrm{Ca} 2(\mathrm{Mg}, \mathrm{Fe}) 5 \mathrm{Si} 8 \mathrm{O} 2 \\
2(\mathrm{OH}) 2\end{array}$ & $\begin{array}{l}\text { 158, 177, 222, 249, 368, 392, 413, 672, 748, 929, 1028, 1058, } \\
1067\end{array}$ & RRUFF \\
\hline $\begin{array}{l}\text { afwillite - } \\
\text { Ca3(SiO3OH)2·2(H } \\
\text { 2O) }\end{array}$ & not available & $\begin{array}{l}\text { not } \\
\text { available }\end{array}$ \\
\hline $\begin{array}{l}\text { alum }(\mathrm{K})- \\
\mathrm{KAl}(\mathrm{SO}) 2 \cdot 12(\mathrm{H} 2 \mathrm{O}\end{array}$ & 455(mw), 614(mw), 974(s), 989(vs), 1130(mw), 3072(m), 3396(vs) & $\begin{array}{l}\text { (Frezzotti et } \\
\text { al., 2012) }\end{array}$ \\
\hline $\begin{array}{l}\text { aluminite - } \\
\text { Al2SO4(OH)4·7(H2 } \\
\text { O) }\end{array}$ & $\begin{array}{l}\text { 165(b), 210(b), 252(s), 285(wb), 440(s), 607(s), 793(wB), 993(S), } \\
\text { 1094(b) }\end{array}$ & $\begin{array}{l}\text { (Frost, } \\
\text { López, et } \\
\text { al., 2015) }\end{array}$ \\
\hline $\begin{array}{l}\text { aluminum sulfate - } \\
\mathrm{Al}(\mathrm{SO} 4) 3\end{array}$ & $872,980,1010,1033,1044,1054,, 1141,1245$ & $\begin{array}{l}\text { (Rudolph } \\
\text { and Mason, } \\
\text { 2001) }\end{array}$ \\
\hline $\begin{array}{l}\text { alunite (ammonium } \\
\text { alunite) - } \\
\text { NH4AI6(S04)2(OH) } \\
6\end{array}$ & $\begin{array}{l}201.4,219.9,235,241,251,259,296,347,357,381,453,486 \\
508,560,564,605,635,655,981,985,1023,1026,1078,1152 \\
1170,1189,1258,1424,439,34843511,3517\end{array}$ & $\begin{array}{l}\text { (Frost and } \\
\text { Wills, 2006) }\end{array}$ \\
\hline $\begin{array}{l}\text { alunite (hydronium } \\
\text { alunite) - } \\
\mathrm{H} 3 \mathrm{O}+\mathrm{Al} 3(\mathrm{SO} 4) 2(\mathrm{OH}) \\
6\end{array}$ & $\begin{array}{l}160,181,238,250,352,383,488,504,560,590,648,880,1035,1072 \\
1110,1161,1192,1600,1635,2250,2700,3400,3478,3500\end{array}$ & $\begin{array}{l}\text { (Rudolph and } \\
\text { Mason, } \\
\text { 2001) }\end{array}$ \\
\hline $\begin{array}{l}\text { alunite (k-alunite) - } \\
\mathrm{KAI} 3(\mathrm{SO} 4) 2(\mathrm{OH}) 6\end{array}$ & $\begin{array}{l}\text { 200(ws), 235(s),248, 373, 389, 481, 489, , 505, 563, 608, 644, 644.3 } \\
773,961,989,999,1014,1026,1049,1051,1083,1194,1228\end{array}$ & $\begin{array}{l}\text { (Frost and } \\
\text { Wills, 2006) }\end{array}$ \\
\hline $\begin{array}{l}\text { alunite (natroalunite) } \\
\text { - } \mathrm{NaAl} 3(\mathrm{SO} 4) 2(\mathrm{OH}) 6 \\
\end{array}$ & $163,234,345,392,483,519,572,652,1024,1085,1163,1183$ & $\begin{array}{l}\text { (Maubec et } \\
\text { al., 2012) } \\
\end{array}$ \\
\hline $\begin{array}{l}\text { alunogen - } \\
\text { Al2(SO4)3·17(H2O) }\end{array}$ & $465,612,992,1067$ (shoulder),1086, 1126 & $\begin{array}{l}\text { (Kahlenberg, } \\
\text { Braun and } \\
\text { Orlova, 2015) }\end{array}$ \\
\hline ammonia - NH3 & 3336 & $\begin{array}{l}\text { (Frezzotti et } \\
\text { al., 2012) }\end{array}$ \\
\hline
\end{tabular}




\begin{tabular}{|c|c|c|}
\hline $\begin{array}{l}\text { analcime - } \\
\text { NaAlSi2O6 } \cdot \mathrm{H} 2 \mathrm{O}\end{array}$ & $191,297,384,481,1098,1104$ & RRUFF \\
\hline anhydrite - CaSO4 & $\begin{array}{l}\sim 120 \text { (ws), } \sim 130(w s), 230(w b), 420 \text { (ws), 500(s), 611(s), 629(ws), 676(s), } \\
860 \text { (vwb), 1005(s), 1018(vs), 1080(vwb), 1115(s), 1131(s), 1161(s) }\end{array}$ & $\begin{array}{l}\text { (Frezzotti et } \\
\text { al., 2012) }\end{array}$ \\
\hline aragonite - $\mathrm{CaCO} 3$ & $\begin{array}{l}\text { 140(ws), 165(ws), 185(ws), 213(ws), 270(wb), 278(vwb), 701(s), } \\
\text { 1083(S), 1460(vws), 1573(vws) }\end{array}$ & $\begin{array}{l}\text { (Buzgar and } \\
\text { Apopei, } \\
\text { 2009) }\end{array}$ \\
\hline \multicolumn{2}{|c|}{ basaluminite, same as felsőbányaite $-\mathrm{Al}_{4}(\mathrm{OH})_{10} \cdot 4\left(\mathrm{H}_{2} \mathrm{O}\right)$} & not available \\
\hline $\begin{array}{l}\text { bassanite - } \\
\text { CaSO4.0.5(H2O) }\end{array}$ & not available & not available \\
\hline $\begin{array}{l}\text { bicarbonate ion - } \\
\mathrm{HCO} 3\end{array}$ & 1017(vs), 1360(m) & $\begin{array}{l}\text { (Frezzotti et } \\
\text { al., 2012) }\end{array}$ \\
\hline $\begin{array}{l}\text { bischofite - } \\
\mathrm{MgCl} 2 \cdot 6(\mathrm{H} 2 \mathrm{O})\end{array}$ & not available & not available \\
\hline bisulfate - HSO4 & $422,586,890,1053,1202$ & $\begin{array}{l}\text { Rudolph and } \\
\text { Mason, } \\
\text { 2001) } \\
\end{array}$ \\
\hline $\begin{array}{l}\text { blödite - } \\
\mathrm{Na} 2 \mathrm{Mg}(\mathrm{SO} 4) 2 \cdot \\
4(\mathrm{H} 2 \mathrm{O})\end{array}$ & $454,617,992,1188$ & RRUFF \\
\hline boric acid - $\mathrm{B}(\mathrm{OH}) 3$ & 495,877 & $\begin{array}{l}\text { (Frezzotti et } \\
\text { al., 2012) }\end{array}$ \\
\hline calcite - $\mathrm{CaCO} 3$ & 156(s), 284(s), 711(s), 1085(S), 1435 & $\begin{array}{l}\text { (Frezzotti et } \\
\text { al., 2012) }\end{array}$ \\
\hline carbon dioxide - $\mathrm{CO} 2$ & $1265,1388,3300$ (strongSh) -when dissolved in water & $\begin{array}{l}\text { (Frezzotti et } \\
\text { al., 2012) }\end{array}$ \\
\hline $\begin{array}{l}\text { carbon monoxide - } \\
\text { CO }\end{array}$ & 2143 & $\begin{array}{l}\text { (Frezzotti et } \\
\text { al., 2012) }\end{array}$ \\
\hline carbonate ion - $\mathrm{CO} 3$ & 684,1064 & $\begin{array}{l}\text { (Frezzotti et } \\
\text { al., 2012) }\end{array}$ \\
\hline $\begin{array}{l}\text { carbonyl sulfide - } \\
\text { COS }\end{array}$ & 857 & $\begin{array}{l}\text { (Frezzotti et } \\
\text { al., 2012) }\end{array}$ \\
\hline $\begin{array}{l}\text { carnallite - } \\
\mathrm{KCl} \cdot \mathrm{MgCl} 2 \cdot 6(\mathrm{H} 2 \mathrm{O})\end{array}$ & 202(b), 300(b), 365(wb), 655(bw) & $\begin{array}{l}\text { (Dubessy et } \\
\text { al., 1982) }\end{array}$ \\
\hline \multicolumn{2}{|c|}{ copaipite - Fe2+(Fe3+)4(SO4)6(OH)2·20(H2O) } & not available \\
\hline $\begin{array}{l}\text { dickite (kaolinite) - } \\
\text { Al2Si2O5(OH)4 }\end{array}$ & not available & not available \\
\hline $\begin{array}{l}\text { dolomite - } \\
\text { CaMg(CO3)2 }\end{array}$ & 176(s), 299(S), 337(ws), 725(b), 880(vws), 1097(vS), 1443(vws) & $\begin{array}{l}\text { (Frezzotti et } \\
\text { al., 2012) }\end{array}$ \\
\hline
\end{tabular}




\begin{tabular}{|c|c|c|}
\hline $\begin{array}{l}\text { epsomite - } \\
\text { MgSO } 4 \cdot 7 \mathrm{H} 2 \mathrm{O}\end{array}$ & $\begin{array}{l}120(\mathrm{vw}), 139(\mathrm{~m}), 173(\mathrm{vw}), 220(\mathrm{~s}), 298(\mathrm{~m}), 351(\mathrm{w}), 376(\mathrm{w}), 433(\mathrm{~m}) \\
460(\mathrm{~s}), 562(\mathrm{~m}), 623(\mathrm{~m}), 662(\mathrm{vw}), 1004(\mathrm{~s}), 1100(\mathrm{~s}), 1148(\mathrm{~m})\end{array}$ & $\begin{array}{l}\text { (Makreski, } \\
\text { Jovanovski } \\
\text { and } \\
\text { Dimitrovska, } \\
\text { 2005) } \\
\end{array}$ \\
\hline ethane - $\mathrm{C} 2 \mathrm{H} 6$ & 2954 & $\begin{array}{l}\text { (Frezzotti et } \\
\text { al., 2012) }\end{array}$ \\
\hline $\begin{array}{l}\text { felsőbányaite (same } \\
\text { as basaluminite) - } \\
\text { Al4(SO4)(OH)10.4(H } \\
\text { 20) }\end{array}$ & not available & not available \\
\hline $\begin{array}{l}\text { gaylussite - } \\
\mathrm{Na} 2 \mathrm{Ca}(\mathrm{CO} 3) 2 \cdot 5(\mathrm{H} 2 \\
\text { O) }\end{array}$ & 165(s), 255(s), 708(ws), 1070(S), 2944(vs) & $\begin{array}{l}\text { (Frost and } \\
\text { Dickfos, } \\
2007 \text { ) } \\
\end{array}$ \\
\hline $\begin{array}{l}\text { gibbsite (same as } \\
\text { norstrandite) - } \\
\mathrm{Al}(\mathrm{OH}) 3\end{array}$ & 242(mw), 255(m), 322(m), 380(vs), 538(vs), 569(vs) & $\begin{array}{l}\text { (Frezzotti et } \\
\text { al., 2012) }\end{array}$ \\
\hline $\begin{array}{l}\text { Glass scan_no } \\
\text { diapragm - N/A }\end{array}$ & $458,561,775,934,1024,1093,2330,2900$ (B, flat), 3260, 3448 & J. Bernau \\
\hline $\begin{array}{l}\text { glauberite - } \\
\mathrm{Na} 2 \mathrm{Ca}(\mathrm{SO} 4) 2\end{array}$ & $452,469,484,616,621,632,642,647,998,1104,1138,1154,1167$ & $\begin{array}{l}\text { (Vargas } \\
\text { Jentzsch et } \\
\text { al., 2012) }\end{array}$ \\
\hline $\begin{array}{l}\text { goethite - } \\
\text { Fe3+O(OH) }\end{array}$ & 224(w), 299(mw), 389(vs), 546(m), 681(mw) & $\begin{array}{l}\text { (Frezzotti et } \\
\text { al., 2012) }\end{array}$ \\
\hline graphite - C & $\sim 1350, \sim 1600, \sim 2450$ & $\begin{array}{l}\text { (Wagner et } \\
\text { al., 1989) }\end{array}$ \\
\hline $\begin{array}{l}\text { gypsum - } \\
\text { CaSO4-2(H2O) }\end{array}$ & $\begin{array}{l}320 \text { (wB- from H2O), 415(s-SO4), 495(s-SO4), 572(vwB-H2O), 623(s- } \\
\text { SO4), 671(vws-SO4), 1006(S-SO4), 1132(s-SO4) }\end{array}$ & $\begin{array}{l}\text { (Frost and } \\
\text { Kloprogge, } \\
2000 \text { ) } \\
\end{array}$ \\
\hline halite - $\mathrm{NaCl}$ & $\sim 350(w b)$ & $\begin{array}{l}\text { (Frezzotti et } \\
\text { al., 2012) }\end{array}$ \\
\hline $\begin{array}{l}\text { halotrichite - } \\
\text { FeAl2(SO4)4.22 } \\
(\mathrm{H} 2 \mathrm{O})\end{array}$ & $420,427,456,462,611,620,974,993$ & RRUFF \\
\hline hematite - Fe2O3 & 223(vws), 310, 390, 404(s), 497, 539, 615(ws), 721 & $\begin{array}{l}\text { (Aramendia } \\
\text { et al., 2014) }\end{array}$ \\
\hline $\begin{array}{l}\text { hydrobasaluminite } \\
\text { (similiar to } \\
\text { felsobayanite) - } \\
\text { Al4(SO4)(OH)10.15( } \\
\mathrm{H} 2 \mathrm{O})\end{array}$ & not available & not available \\
\hline $\begin{array}{l}\text { hydrobromic acid } 23 \\
\mathrm{~mol} \% \text { - } \mathrm{HBr}\end{array}$ & $460,730,1220,1625,3180,3390$ & $\begin{array}{l}\text { (Giguere and } \\
\text { Guillot, 1982) }\end{array}$ \\
\hline
\end{tabular}




\begin{tabular}{|c|c|c|}
\hline hydrogen gas - H2 & $354,586,813,1032,4126,4143,4156,4161$ & $\begin{array}{l}\text { (Frezzotti et } \\
\text { al., 2012) }\end{array}$ \\
\hline $\begin{array}{l}\text { hydrogen sulfate - } \\
\mathrm{HS} \text { and } \mathrm{H} 2 \mathrm{~S}\end{array}$ & $2570-2590$ & $\begin{array}{l}\text { (Frezzotti et } \\
\text { al., 2012) }\end{array}$ \\
\hline $\begin{array}{l}\text { hydrogen sulfide - } \\
\text { H2S }\end{array}$ & 2611(Sb), slight 3300 shoulder on $\mathrm{H} 20$ peak & $\begin{array}{l}\text { (Frezzotti et } \\
\text { al., 2012) }\end{array}$ \\
\hline hydronium - $\mathrm{H} 3 \mathrm{O}+$ & 1060 ( 32 mol \% H3O), 1110 ( 32 mol \% H3O), 1220 (23 mol\% H3O) & $\begin{array}{l}\text { (Giguere and } \\
\text { Guillot, 1982) }\end{array}$ \\
\hline hypochlorite - $\mathrm{ClO}$ & 645,928 & $\begin{array}{l}\text { (Frezzotti et } \\
\text { al., 2012) }\end{array}$ \\
\hline $\mathrm{FeCl} 3$ & $165(w), 315(s), 430(w)$ & $\begin{array}{l}\text { (Kanno and } \\
\text { Hiraishi, } \\
\text { 1982) }\end{array}$ \\
\hline $\begin{array}{l}\text { jarosite (k-jarosite) - } \\
\mathrm{KFe} 3+3(\mathrm{SO} 4) 2(\mathrm{OH}) 6\end{array}$ & $\begin{array}{l}\text { 170, 223, 301, 354, 434, 454, 551(ws),573(b), 636(s), 643(vws), } \\
\sim 800(\mathrm{~b}), \sim 830(\mathrm{ws}), \sim 890(\mathrm{wb}), 1008(\mathrm{~S}), 1102(\mathrm{~S}), 1156(\mathrm{~s})\end{array}$ & $\begin{array}{l}\text { (Maubec et } \\
\text { al., 2012) }\end{array}$ \\
\hline $\begin{array}{l}\text { jarosite } \\
\text { (natrojarosite) - } \\
\text { NaFe3(SO4)2(OH)6 }\end{array}$ & $227,298,367(w), 444(s), 451(s h), 570,625,1012,1113,1154(w)$ & $\begin{array}{l}\text { Sasaki, } \\
\text { Tanaike and } \\
\text { Konno, 1998) }\end{array}$ \\
\hline $\begin{array}{l}\text { jurbanite - } \\
\text { AlSO4}(\mathrm{OH}) \cdot 5(\mathrm{H} 2 \mathrm{O})\end{array}$ & not available & not available \\
\hline $\begin{array}{l}\text { kaolinite } \\
\text { - Al2Si2O5(OH)4 }\end{array}$ & $\begin{array}{l}\text { 130, 141, 201, 244, 271, 392, 431, 461, 512, 637, 700, 750, 790, 915, } \\
940,1048,1105\end{array}$ & $\begin{array}{l}\text { (Johnston, } \\
\text { Sposito and } \\
\text { Birge, 1985) }\end{array}$ \\
\hline $\begin{array}{l}\text { kieserite - MgSO4 } \\
\mathrm{H} 2 \mathrm{O}\end{array}$ & 436(s), 481(w), 629(m), 1046(vS), 1117(mv), 1215(w), 3297(vS) & $\begin{array}{l}\text { (Frezzotti et } \\
\text { al., 2012) }\end{array}$ \\
\hline $\begin{array}{l}\text { leonite - } \\
\mathrm{K} 2 \mathrm{Mg}(\mathrm{SO} 4) 2 \cdot 4(\mathrm{H} 2 \mathrm{O})\end{array}$ & not available & not available \\
\hline $\begin{array}{l}\text { lepidocrocite - } \\
\text { Fe3+O(OH) }\end{array}$ & $216,250,303,380,420,427,525,650$ & RRUFF \\
\hline magnesite - MgCO3 & 210(ws), 325(s), 730(b), 1097(S) & $\begin{array}{l}\text { (Krishnamurti } \\
\text {, 1956) }\end{array}$ \\
\hline $\begin{array}{l}\text { magnetite - } \\
\mathrm{Fe} 2+\mathrm{Fe} 3+2 \mathrm{O} 4\end{array}$ & $163,179,187,531,661$ & RRUFF \\
\hline $\begin{array}{l}\text { melanterite - } \\
\text { FeSO4.7(H2O) }\end{array}$ & not available & not available \\
\hline methane - $\mathrm{CH} 4$ & $2917(\mathrm{~s}) 3020(w)$ & $\begin{array}{l}\text { (Frezzotti et } \\
\text { al., 2012) }\end{array}$ \\
\hline $\begin{array}{l}\text { mirabilite - } \\
\mathrm{Na2SO} 4 \cdot 10(\mathrm{H} 2 \mathrm{O})\end{array}$ & $447,458,616,627,989,1086,1108,1120,1129,1671,3092$ & $\begin{array}{l}\text { (Hamilton } \\
\text { and Menzies, } \\
\text { 2010) }\end{array}$ \\
\hline $\begin{array}{l}\text { monmorillionite - } \\
(\mathrm{Na}, \mathrm{Ca}) 0.3(\mathrm{Al}, \mathrm{Mg}) 2 \mathrm{~S} \\
\mathrm{i} 4 \mathrm{O} 10(\mathrm{OH}) 2 \cdot \mathrm{nH} 2 \mathrm{O}\end{array}$ & $\begin{array}{l}173,199,289,384,426,515,605,628,638,708,794,840,920,929 \\
1096,1109,1195,1215\end{array}$ & RRUFF \\
\hline nahcolite - NaHCO3 & $165,203,225,659,685,1046$ & RRUFF \\
\hline
\end{tabular}




\begin{tabular}{|c|c|c|}
\hline nitrate - NO3 & $450,690,1049$ & $\begin{array}{l}\text { (Frezzotti et } \\
\text { al., 2012) }\end{array}$ \\
\hline nitrogen - N2 & 2331 & $\begin{array}{l}\text { (Frezzotti et } \\
\text { al., 2012) }\end{array}$ \\
\hline $\begin{array}{l}\text { nontronite (clay) - } \\
(\mathrm{CaO} 0.5, \mathrm{Na}) 0.3 \mathrm{Fe} 3+ \\
2(\mathrm{Si}, \mathrm{Al}) 4 \mathrm{O} 10(\mathrm{OH}) 2 \cdot \mathrm{n} \\
(\mathrm{H} 2 \mathrm{O})\end{array}$ & $239,287,363,429,450,487,879,972,1032,1092$ & Frost 2000 \\
\hline $\begin{array}{l}\text { nordstrandite same } \\
\text { as gibbsite - } \mathrm{Al}(\mathrm{OH}) 3\end{array}$ & mw 242(mw), 255(m), 322(m), 380(vw), 538(vs), 569(vs) & $\begin{array}{l}\text { (Frezzotti et } \\
\text { al., 2012) }\end{array}$ \\
\hline opal - SiO2·n(H2O) & $377,394,456,466,555,567,786,792,830,947,956,966,1064,1075$ & RRUFF \\
\hline oxygen - O2 & 1555 & $\begin{array}{l}\text { (Frezzotti et } \\
\text { al., 2012) }\end{array}$ \\
\hline $\begin{array}{l}\text { paulingite-k - } \\
(\mathrm{Na2}, \mathrm{K} 2, \mathrm{Ca}, \mathrm{Ba}) 5 \mathrm{Al} 1 \\
\text { 0Si35O90.45(H2O) }\end{array}$ & 183(ws), 238(b), 490(S) & \\
\hline $\begin{array}{l}\text { pentahydrite - } \\
\text { MgSO4.5H2O }\end{array}$ & 447(m), 602(vw), 1005(vS), 1106(vw), 1159(vw), 3341(vS), 3391(vS) & $\begin{array}{l}\text { (Frezzotti et } \\
\text { al., 2012) }\end{array}$ \\
\hline $\begin{array}{l}\text { polyhalite - } \\
\mathrm{K} 2 \mathrm{Ca} 2 \mathrm{Mg}(\mathrm{SO} 4) 4 \cdot 2( \\
\mathrm{H} 2 \mathrm{O})\end{array}$ & $\begin{array}{l}\text { 436, 448, 464, 477(sh), 620(sh), 626, 641, 652, 987, 1014, 1069, 1094, } \\
\text { 1130, 1144, 1165, } 1181\end{array}$ & $\begin{array}{l}\text { (Vargas } \\
\text { Jentzsch et } \\
\text { al., 2012) }\end{array}$ \\
\hline propane - C3H8 & 2890 & $\begin{array}{l}\text { (Frezzotti et } \\
\text { al., 2012) }\end{array}$ \\
\hline pyrite - FeS2 & 350(ws), 385(s), 570(wB) & $\begin{array}{l}\text { MenaghandT } \\
\text { rudu_1993 }\end{array}$ \\
\hline quartz - SiO2 & $128,204,264,355,464,508,808,1082$ & $\begin{array}{l}\text { (Frezzotti et } \\
\text { al., 2012) }\end{array}$ \\
\hline $\begin{array}{l}\text { rostite - } \\
\mathrm{Al}(\mathrm{SO} 4)(\mathrm{OH}) 0.8 \mathrm{~F} 0.2 . \\
5(\mathrm{H} 2 \mathrm{O})\end{array}$ & $\begin{array}{l}\text { 169(s), 295(s), 420(s), 434(sh), 504(s), 570(ws), 590(s), 625(s), 874(b), } \\
\text { 991(s), 1083(ws), 1131(ws), 1227(ws), 1312(ws) }\end{array}$ & $\begin{array}{l}\text { (Frost, } \\
\text { Scholz, et al., } \\
\text { 2015) }\end{array}$ \\
\hline $\begin{array}{l}\text { rozenite - } \\
\text { Fe2+SO4.4(H2O) }\end{array}$ & 615(ws), 991(wb) & $\begin{array}{l}\text { (Aramendia } \\
\text { et al., 2014) }\end{array}$ \\
\hline $\begin{array}{l}\text { schlossmacherite - } \\
(\mathrm{H} 3 \mathrm{O}) \mathrm{Al} 3(\mathrm{SO} 4) 2(\mathrm{OH} \\
) 6\end{array}$ & not available & not available \\
\hline $\begin{array}{l}\text { schwertmannite - } \\
\text { Fe8O8(OH)6(SO4).n } \\
(\mathrm{H} 2 \mathrm{O})\end{array}$ & $\begin{array}{l}\text { 416(s), 480(sh), 612(m), 701(s), 840(wb), 979(m), 1040(sh), 1125(s), } \\
\text { 1180(sh) }\end{array}$ & $\begin{array}{l}\text { (Bingham, } \\
\text { 1980) }\end{array}$ \\
\hline $\begin{array}{l}\text { Starkeyite - } \\
\text { MgSO4.4(H2O) }\end{array}$ & $\begin{array}{l}\text { 401(vw), 462(vw), 565(vw), 606(vw), 664(vw), 1000(vS), 1086(w), } \\
\text { 1116(vw), 1156(w) }\end{array}$ & $\begin{array}{l}\text { (Frezzotti et } \\
\text { al., 2012) }\end{array}$ \\
\hline sulfate - SO4 & 620,986 & $\begin{array}{l}\text { (Benison et } \\
\text { al., 1998; } \\
\text { Frezzotti et } \\
\text { al., 2012) }\end{array}$ \\
\hline sulfur - S & $157,187,220,246,437,462$ & $\begin{array}{l}\text { (Frezzotti et } \\
\text { al., 2012) }\end{array}$ \\
\hline
\end{tabular}




\begin{tabular}{|c|c|c|}
\hline sulfur dioxide - SO2 & 1151 & $\begin{array}{l}\text { (Frezzotti et } \\
\text { al., 2012) }\end{array}$ \\
\hline sulfuric acid - HSO4 & $\begin{array}{l}70(\mathrm{OH}), 140 \text { (weak, glassy 50\% H2SO4), } 210(\mathrm{OH}), 890 \text { (HSO4), } 982 \\
\text { (HSO4), } 1040 \text { (HSO4), } 1100 \text { (shoulder- HSO4), 1200 (weak band that } \\
\text { gets stronger with H3O), } 2500-3000 \text { continuum- stronger at } 3000 \text { (H5O2) } \\
\text { - common to acid solutions }\end{array}$ & $\begin{array}{l}\text { (Tomikawa } \\
\text { and Kanno, } \\
\text { 1998) }\end{array}$ \\
\hline sylvite - $\mathrm{KCl}$ & 213(wb), 280(vwb) & $\begin{array}{l}\text { (Frezzotti et } \\
\text { al., 2012) }\end{array}$ \\
\hline $\begin{array}{l}\text { tachyhydrite - } \\
\text { CaMg2Cl6.12(H2O) }\end{array}$ & not available & not available \\
\hline thenardite - $\mathrm{Na} 2 \mathrm{SO} 4$ & 451.8, 466.6, 620.5, 6323.8, 647.2, 993.1, 1102, 1132, 1153 & $\begin{array}{l}\text { (Hamilton } \\
\text { and Menzies, } \\
\text { 2010) }\end{array}$ \\
\hline water - $\mathrm{H} 2 \mathrm{O}$ & $162,430,1581,1630,2750-3900$ & $\begin{array}{l}\text { (Frezzotti et } \\
\text { al., 2012) }\end{array}$ \\
\hline $\begin{array}{l}\text { zaherite - } \\
\text { Al12(OH)26(SO4)5.2 } \\
0(\mathrm{H} 2 \mathrm{O})\end{array}$ & not available & not available \\
\hline
\end{tabular}




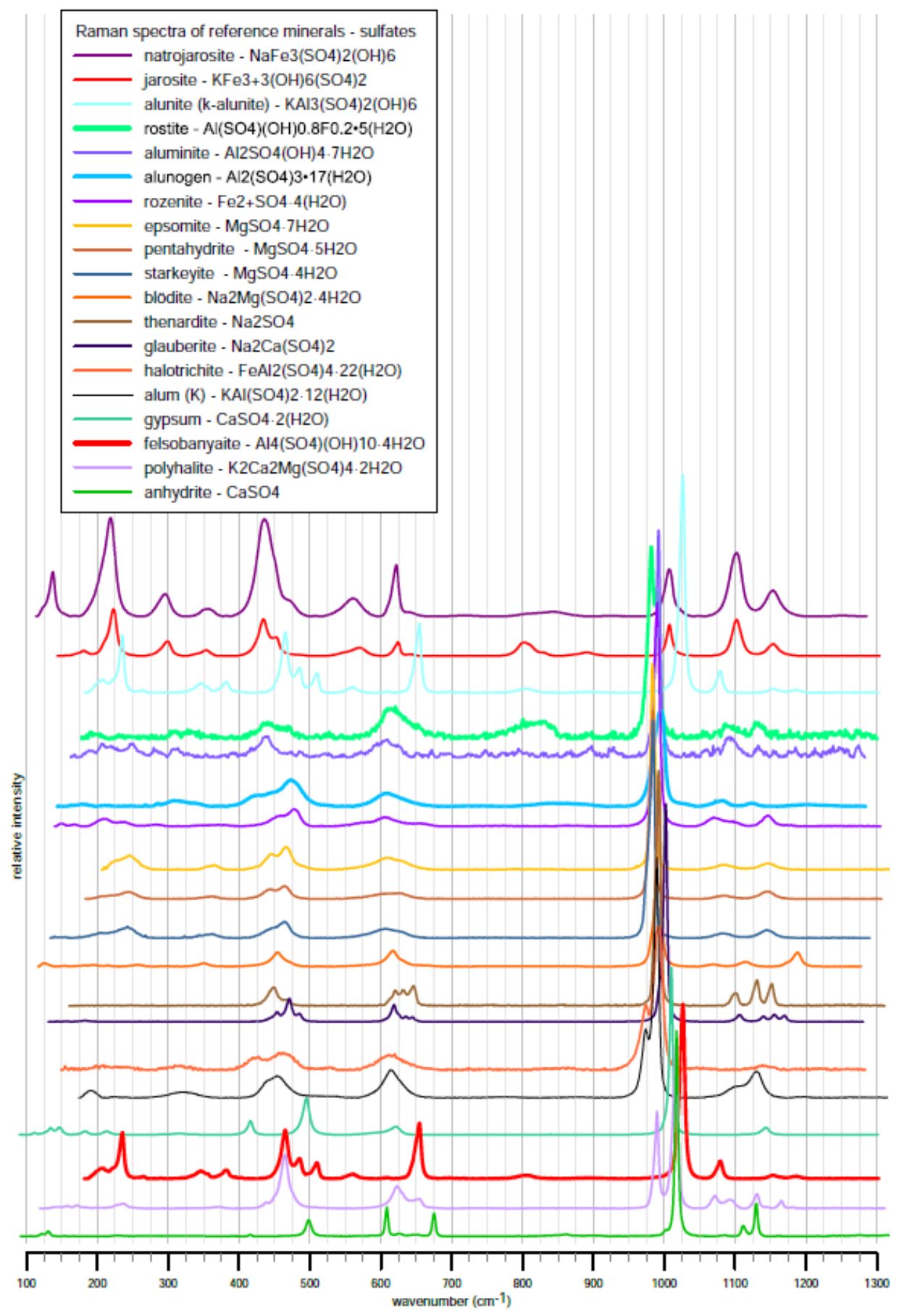

Figure 95. Chart of reference sulfate mineral Raman spectra. Spectra from RRUFF database (Armbruster and Micaela Danisi, 2015). 


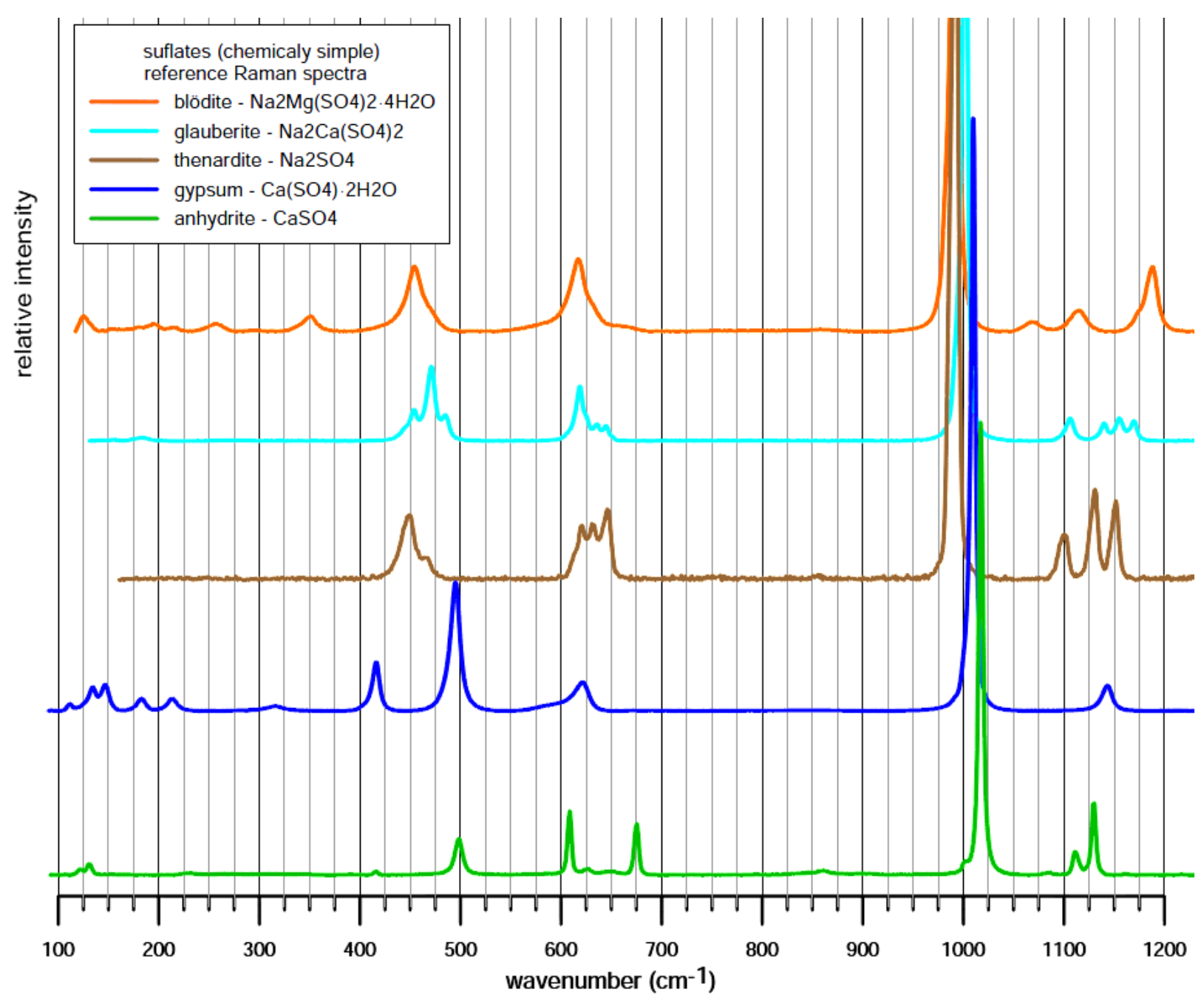

Figure 96. Chart of reference sulfate mineral Raman spectra, chemically simple. Spectra of blodite, glauberite, thenardite, gypsum, and anhydrite. Spectra from RRUFF database (Armbruster and Micaela Danisi, 2015). 


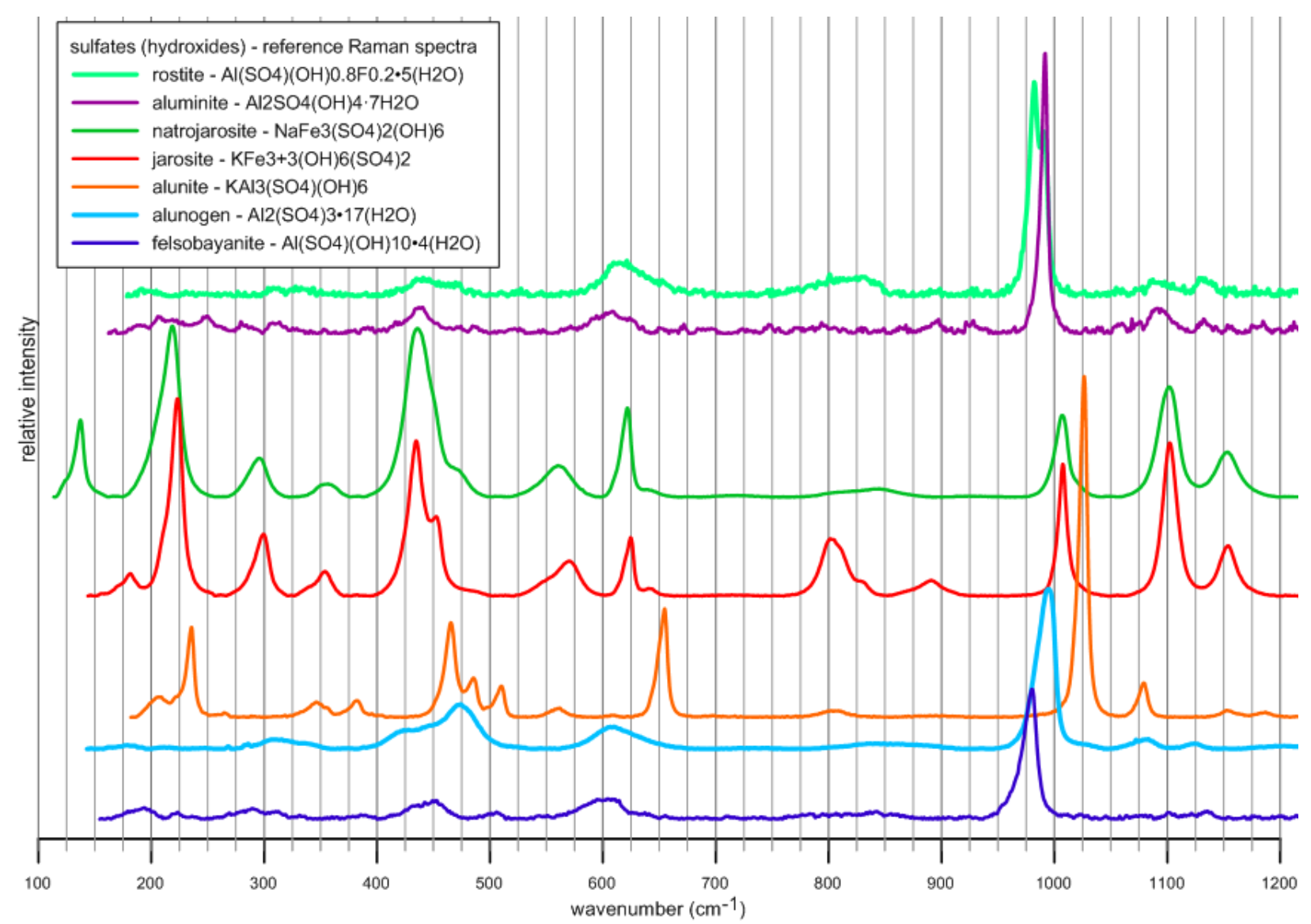

Figure 97. Chart of Raman spectra of sulfate hydroxide minerals: rostite, aluminite, natrojarosite, jarosite, alunite, alunogen, felsobayanite. 


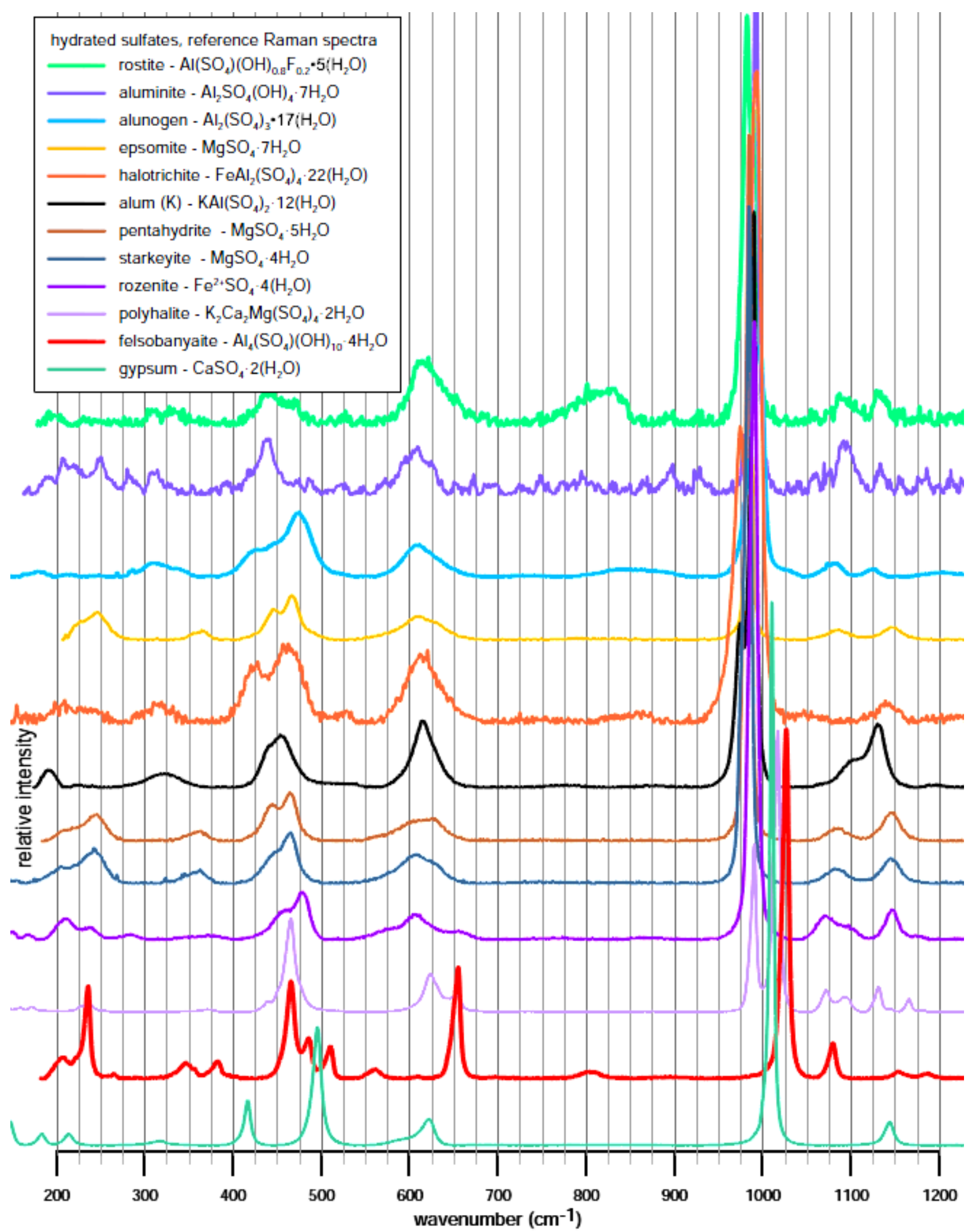

Figure 98. Chart of Raman spectra of reference minerals, hydrated sulfates: rostite, aluminite, alunogent, epsomite, halotrichite, alum, pentahydrate, starkeyite, rozenite, polyhalite, felsobayanite, gypsum. Spectra from RRUFF database (Armbruster and Micaela Danisi, 2015). 


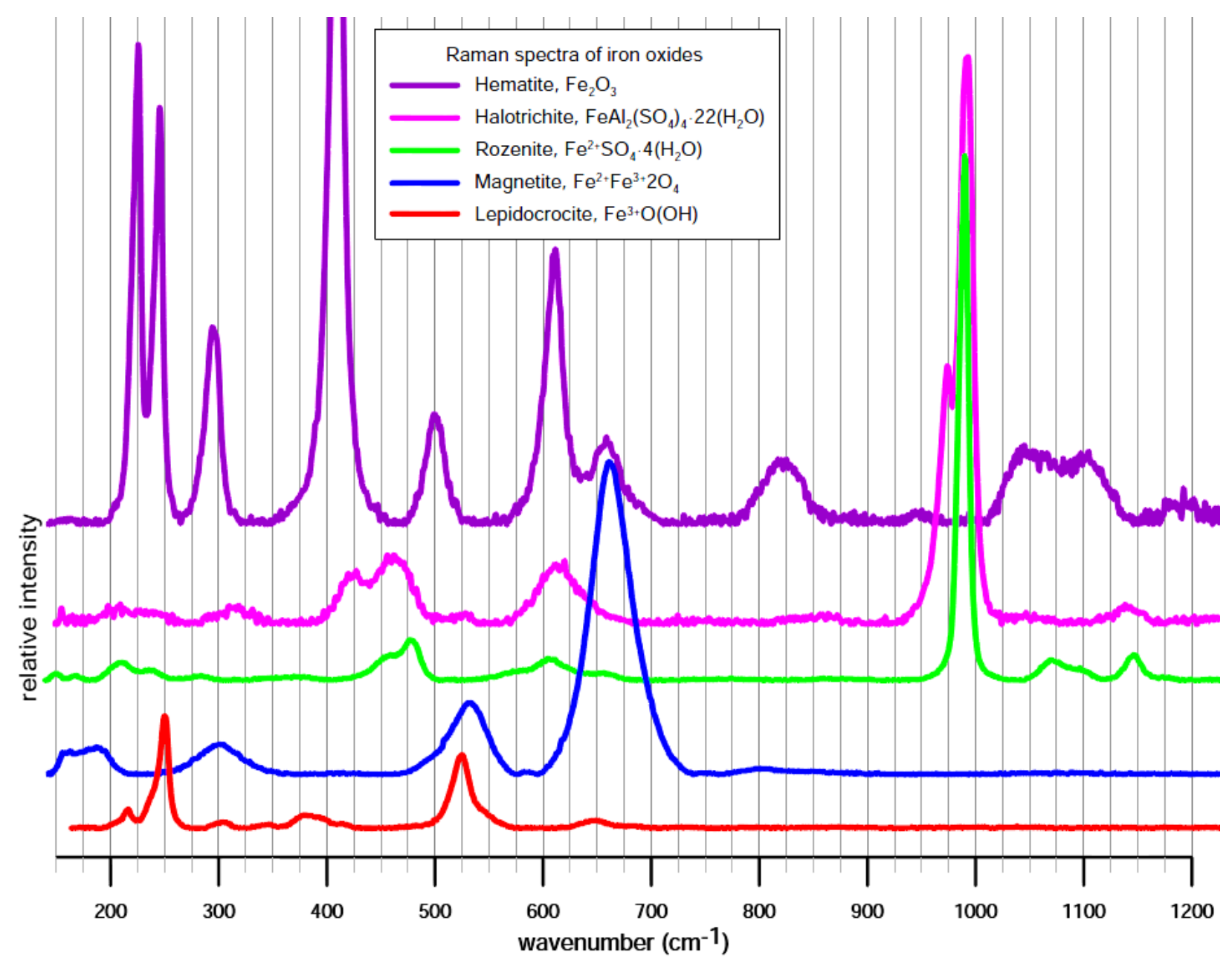

Figure 99. Chart of Raman spectra of iron oxides, and iron containing evaporite minerals: hematite, halotrichite, rozenite, magnetite, lepidocrocite. Spectra from RRUFF database (Armbruster and Micaela Danisi, 2015). 


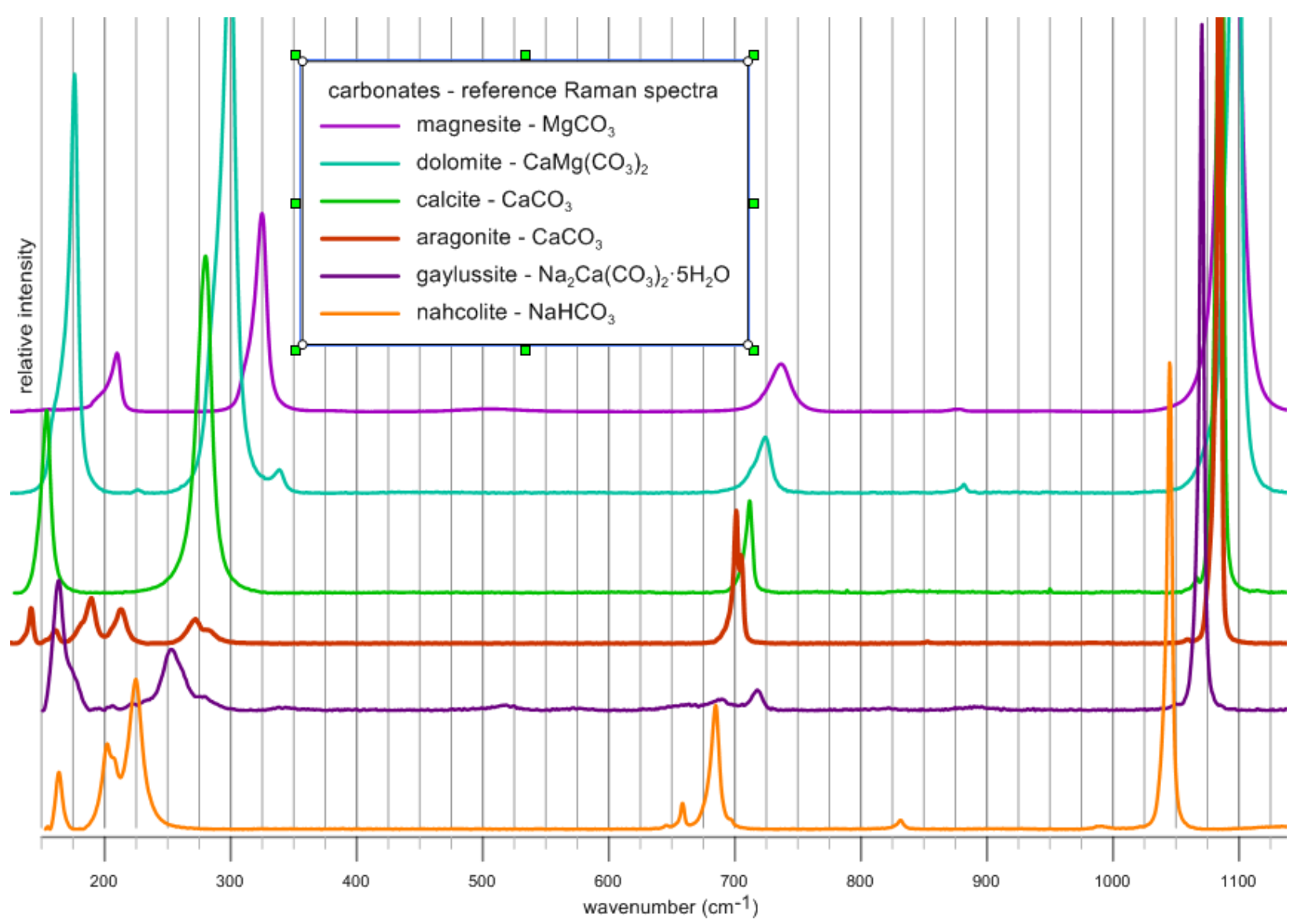

Figure 100. Chart of Raman spectra of carbonate minerals: magnesite, dolomite, calcite, aragonite, gaylussite, nahcolite. Spectra from RRUFF database (Armbruster and Micaela Danisi, 2015). 


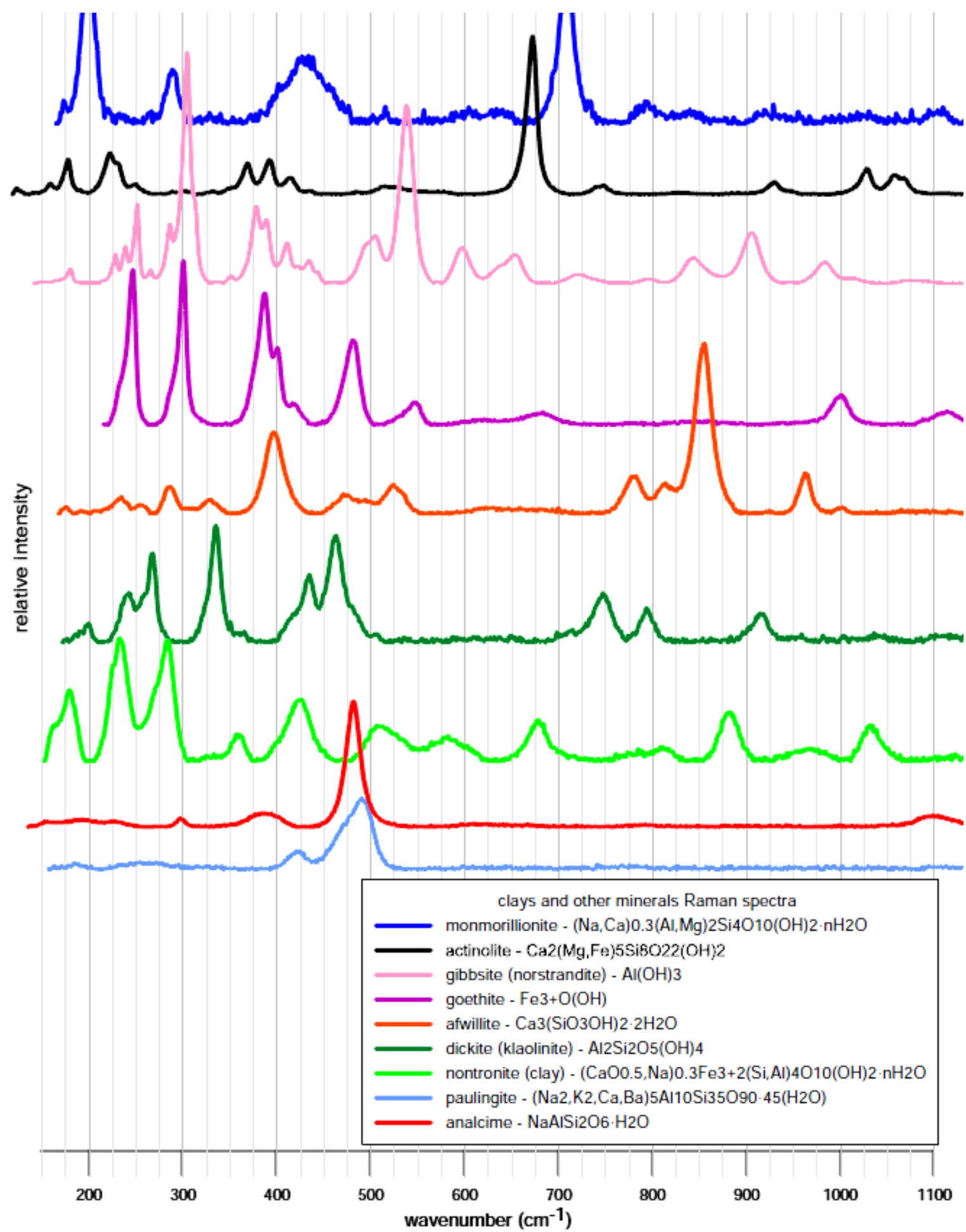

Figure 101. Chart of Raman spectra of clay minerals and related minerals: monmorillionite, actinolite, gibbsite, goethite, afwillite, dickite, nontronite, paulingite, analcime. Spectra from RRUFF database (Armbruster and Micaela Danisi, 2015). 


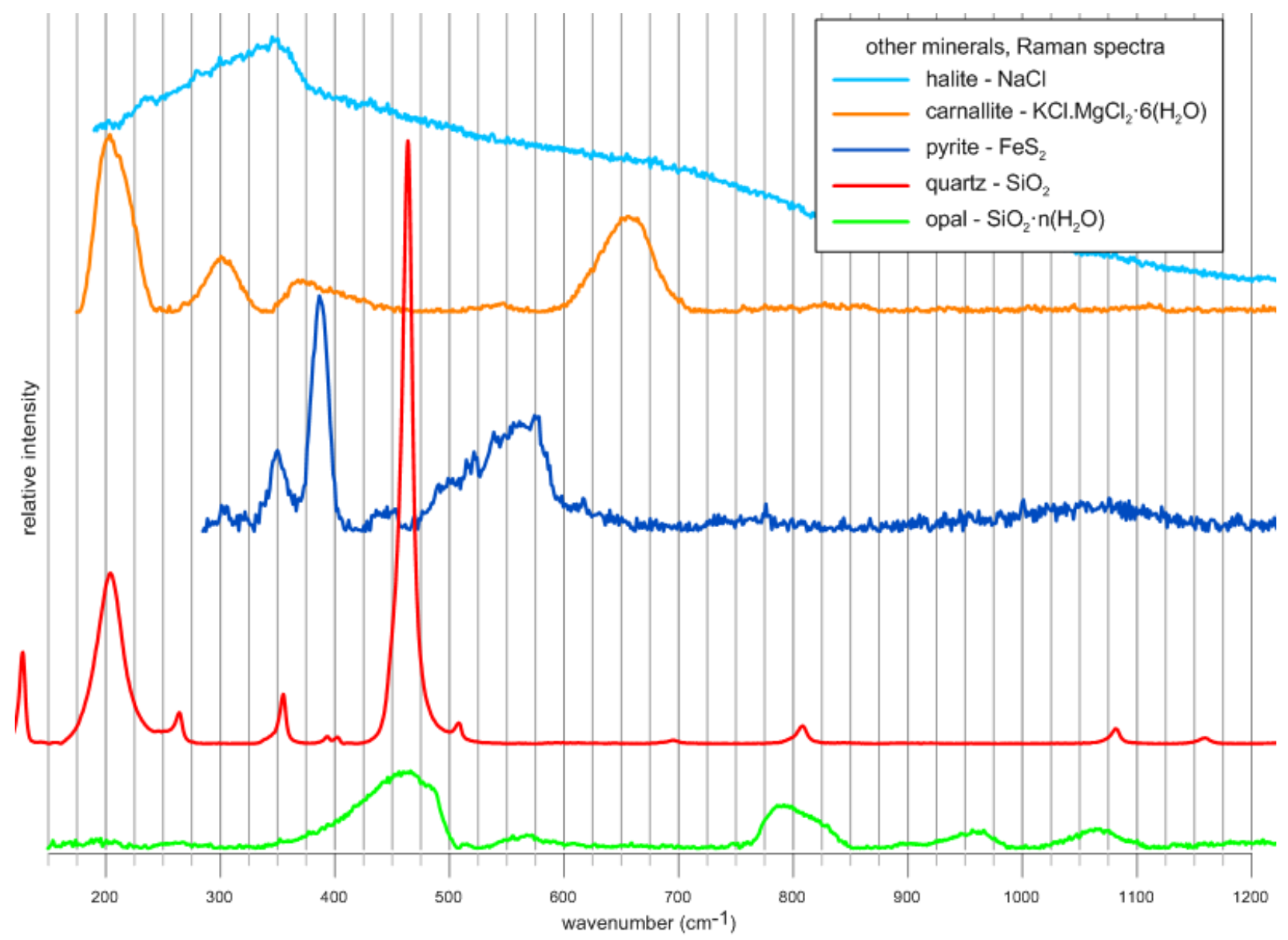

Figure 102. Chart of Reference Raman Spectra of the minerals halite, carnallite, pyrite, quartz, and opal. The opal spectra resembles the background spectra from the glass slide. Spectra from RRUFF database (Armbruster and Micaela Danisi, 2015).

Synthetic Waters Spectra 


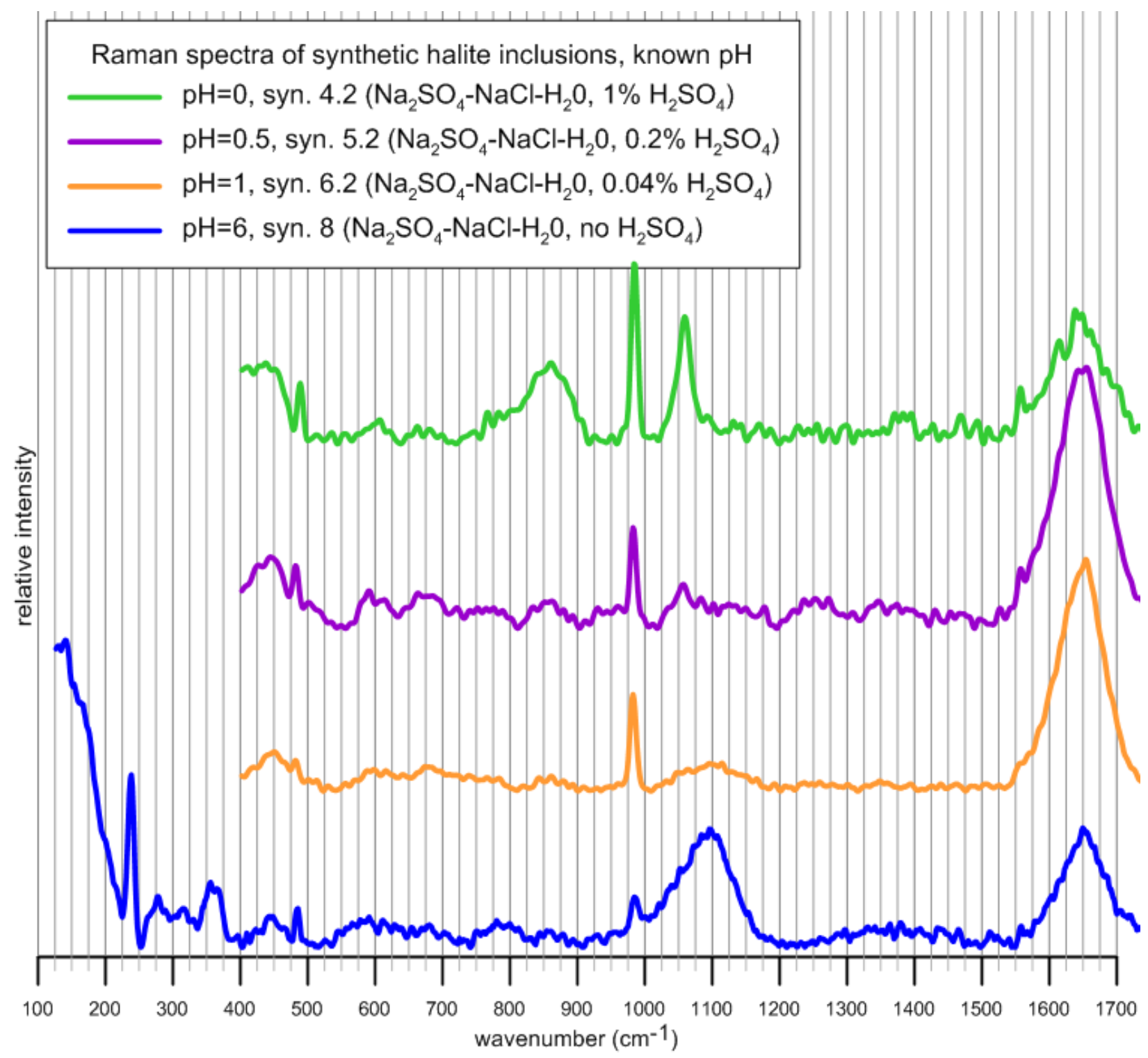

Figure 103. Chart of Raman spectra of synthetic fluid inclusions with $\mathrm{pH}$ ranging from 0 to 6 (Benison, 1997). Peaks $\sim 986$ and $\sim 620 \mathrm{~cm}^{-1}$ are indicative of sulfate in solution. Peaks at $\sim 422, \sim 586, \sim 890, \sim 1053$, and $\sim 1202 \mathrm{~cm}^{-1}$ are indicative of bisulfate in solution (Rudolph and Mason, 2001). The presence of a peak at $\sim 1054 \mathrm{~cm}^{-1}$ is indicative of a pH below 1. If an additional peak at $\sim 890 \mathrm{~cm}^{-1}$ is present, it is indicative of a pH below 0 (Benison, et al., 1998). This technique will not detect sulfate in concentrations below 2000 ppm. 


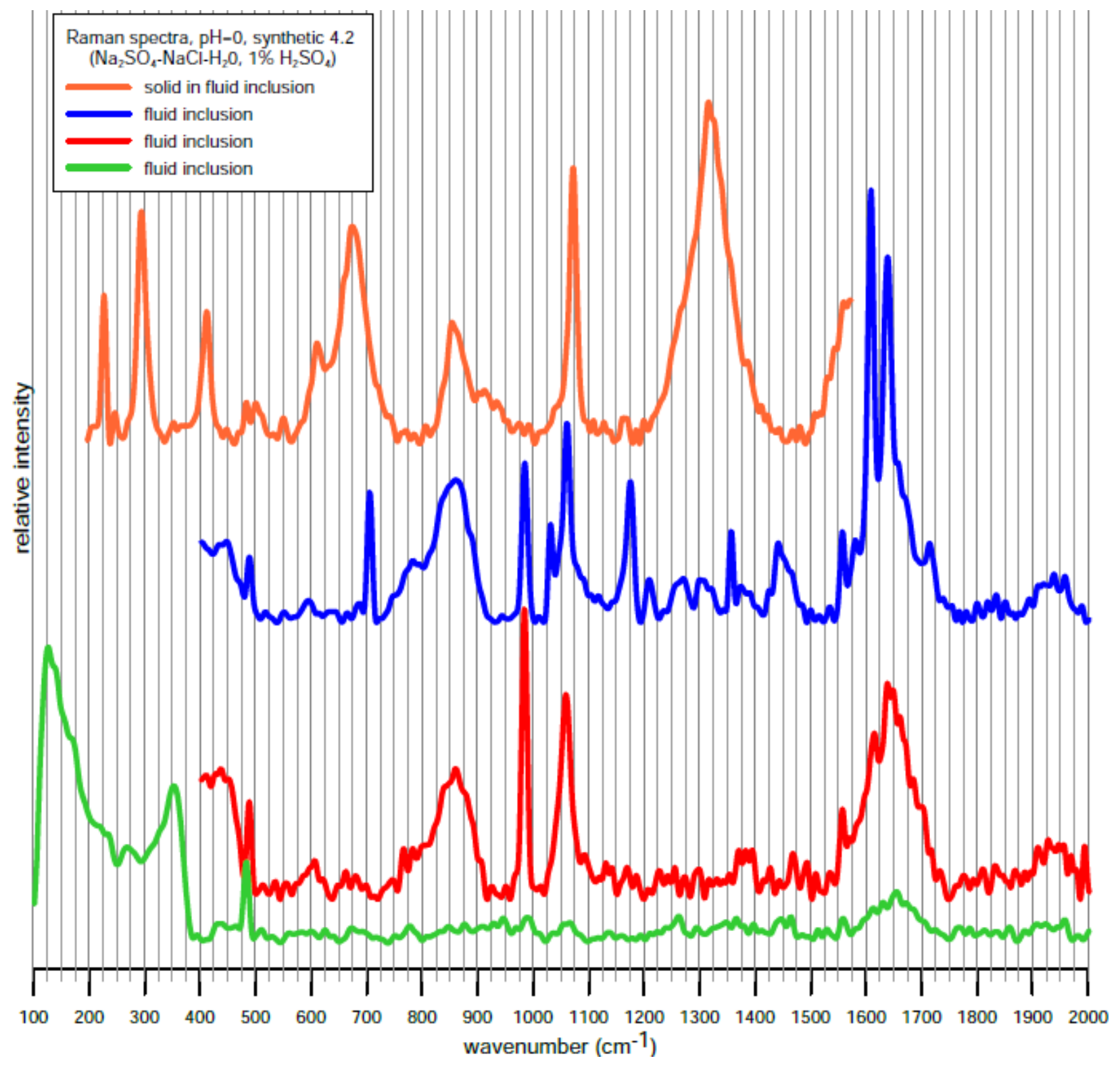

Figure 104. Chart of Raman spectra from halite fluid inclusions, synthetic solution 4.2, $\mathrm{pH}=\mathrm{O}\left(\mathrm{Na}_{2} \mathrm{SO}_{4^{-}}\right.$ $\mathrm{NaCl}-\mathrm{H}_{2} \mathrm{O}, 1 \% \mathrm{H}_{2} \mathrm{SO}_{4}$; Benison, 1997). These spectra have sulfate and bisulfate peaks at 890, 986, $\sim 1053$, and $\sim 1202 \mathrm{~cm}^{-1}$. The lowest, green spectra, has a strong signature from the host salt. Note that the strong peak at $\sim 484 \mathrm{~cm}^{-1}$ is shifted to the right to $\sim 490 \mathrm{~cm}^{-1}$ in the blue and red spectra. The blue and red spectra were collected by Lynnette Eichenlaub in May 2016 (Eichenlaub, 2016). It may be that differences in spectral collection between Lynnette Eichenlaub and this study, and changes in the equipment lead to this slight shift. Note that the broad water peaks at $\sim 1650 \mathrm{~cm}^{-1}$ are shifted to the left slightly in the blue and red spectra relative to the green spectra. The orange spectra, representing a solid in inclusions resembles iron oxide spectra $\left(\mathrm{Fe}_{2} \mathrm{O}_{3}\right)$, see Figure 105. 

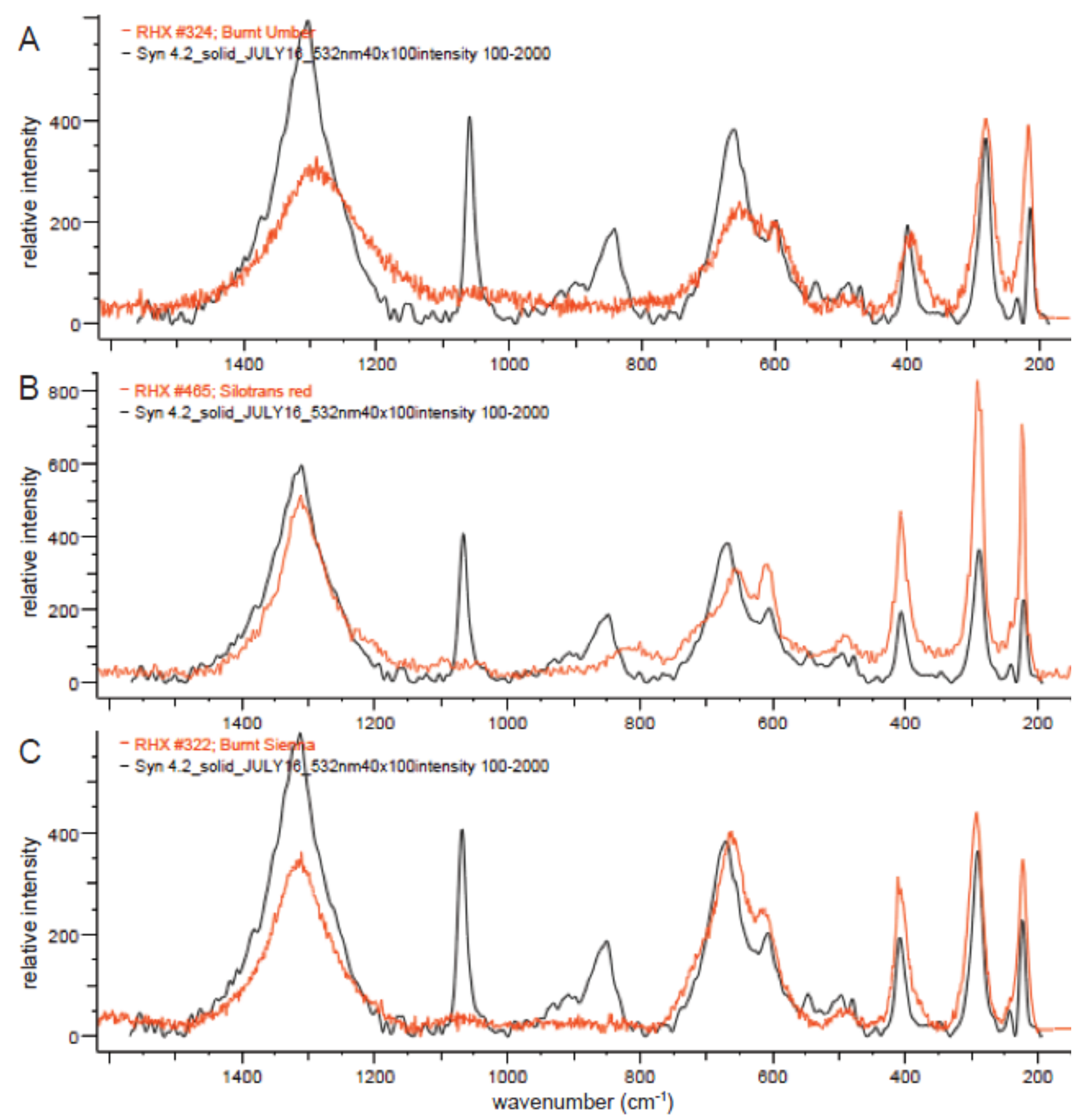

Figure 105. Illustration of Raman spectral Identification of solid in fluid inclusion from Synthetic 4.2 solution, $\mathrm{pH}=\mathrm{O}\left(\mathrm{Na}_{2} \mathrm{SO}_{4}-\mathrm{NaCl}-\mathrm{H}_{2} \mathrm{O}, 1 \% \mathrm{H}_{2} \mathrm{SO}_{4}\right)$. Spectral matching (synthetic sample in question in black, match in red) indicates it is likely related to the pigments $(A)$ burnt umber - $\mathrm{Fe}_{2} \mathrm{O}_{3}$ and $\mathrm{MnO}$; $(B)$ solitrans red - $\mathrm{Fe}_{2} \mathrm{O}_{3} ;(\mathrm{C})$ burnt sienna $-\mathrm{Fe}_{2} \mathrm{O}_{3}{ }^{+}$and $\mathrm{Fe}_{3} \mathrm{O}_{4}$. All of these pigments have iron oxide in common, therefore observed peaks are likely from an iron oxide, likely hematite. Spectral matches identified with BIO-RAD Know-it-all spectral software. 


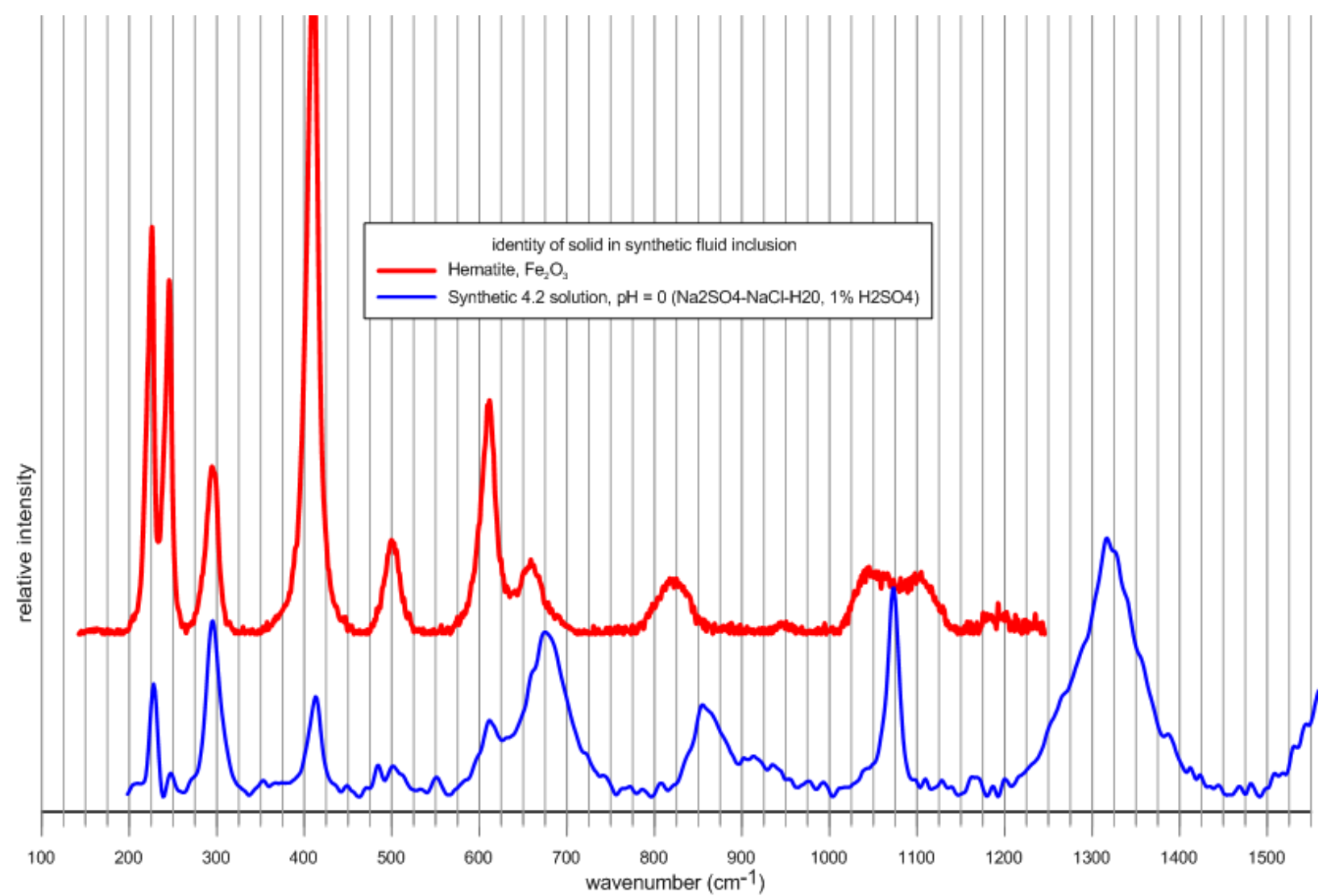

Figure 106. Chart of Raman spectra from solid in inclusion from synthetic 4.2 and hematite reference spectra. The spectra align well, and when other source of spectra are accounted for in the synthetic inclusion solid's spectra, are a match (Armbruster and Micaela Danisi, 2015).

Analog Spectra 


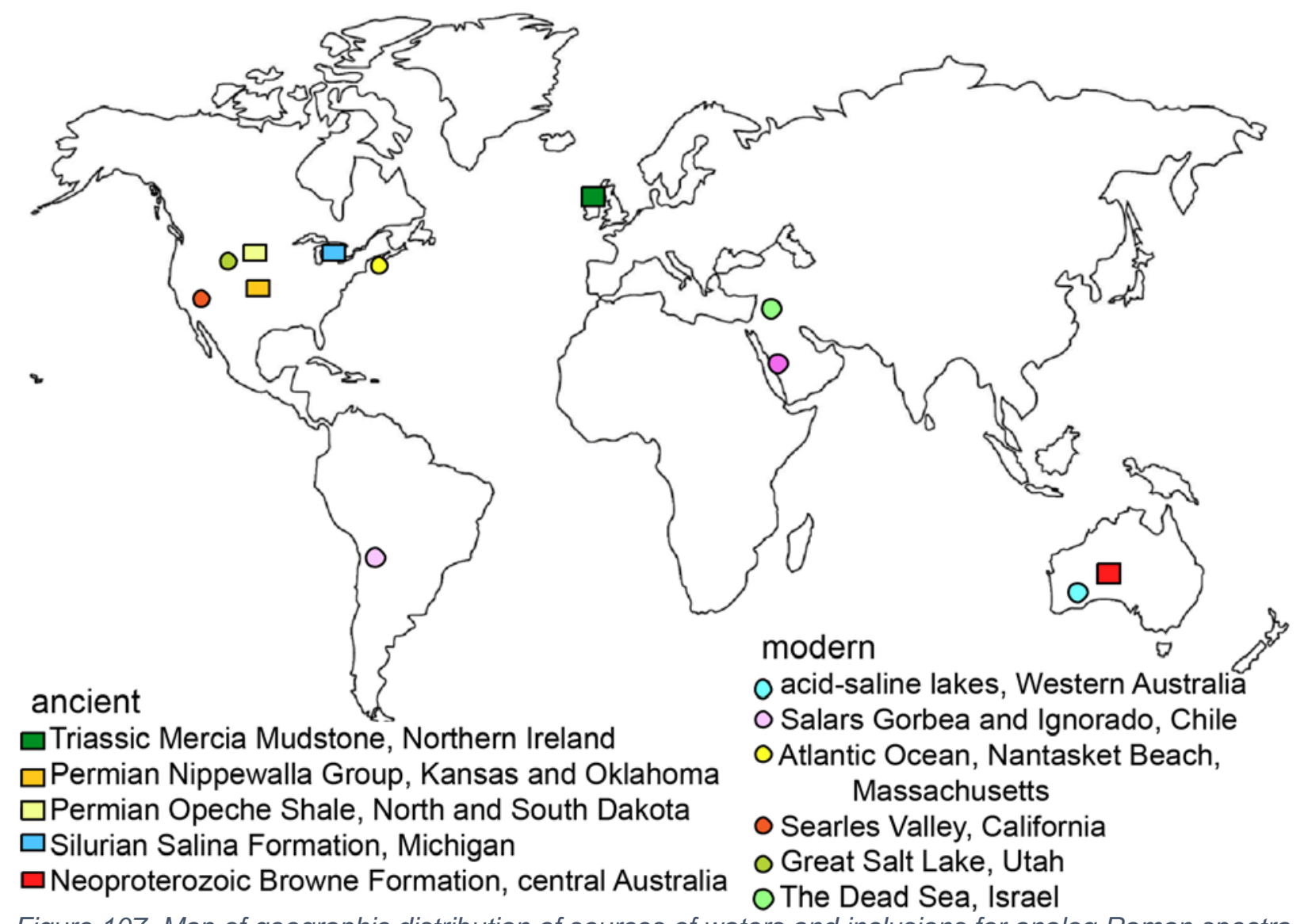

Figure 107. Map of geographic distribution of sources of waters and inclusions for analog Raman spectra.

\section{Triassic Mercia Mudstone Laser Raman Spectra}

These spectra were collected on the same laser Raman spectrometer that was used for this study. However, they were collected over a different times period and by a different user. Therefore they give another angle of understanding into the spectra and their possible influences. 


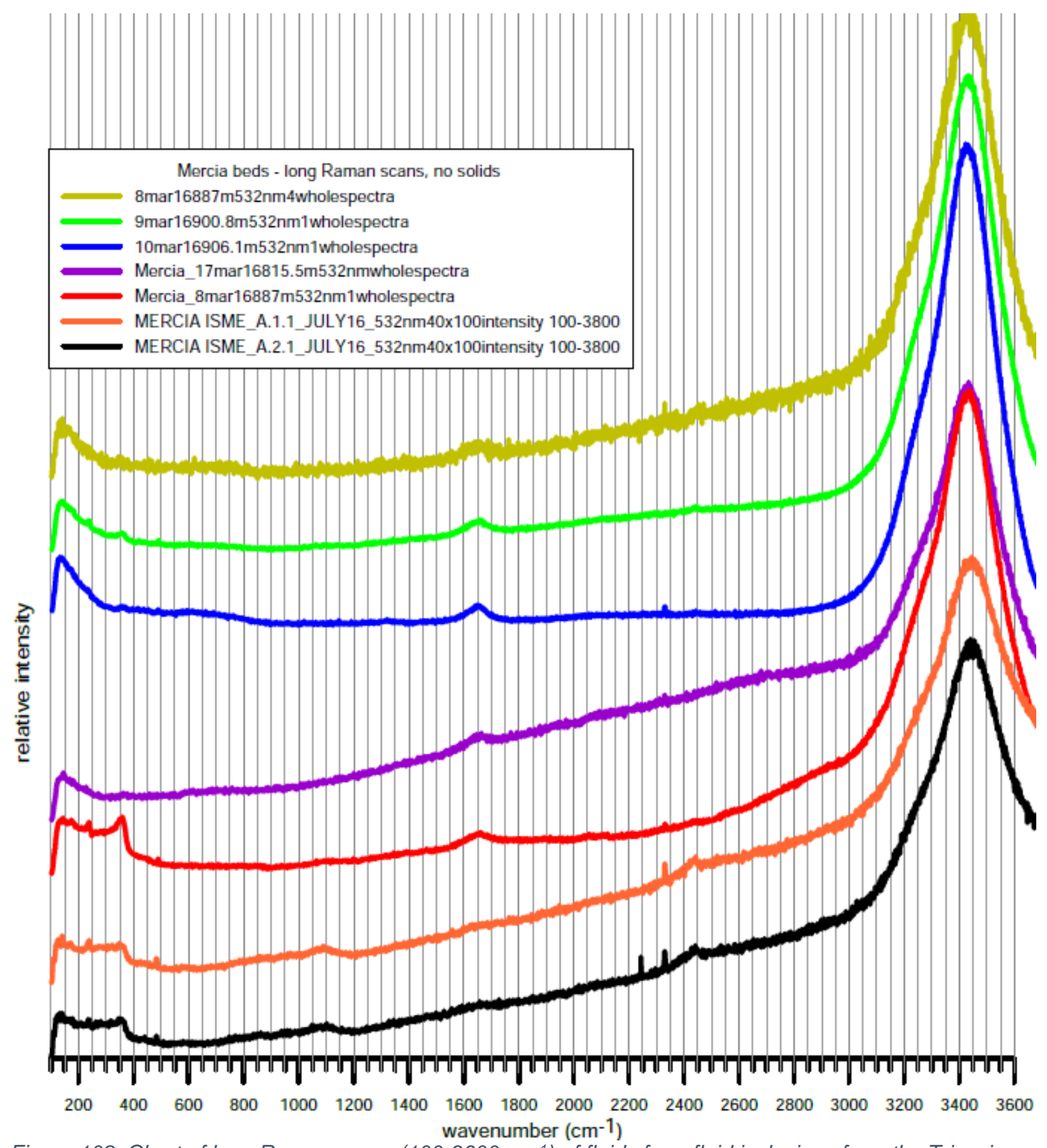

Figure 108. Chart of long Raman scans $\left(100-3600 \mathrm{~cm}^{-1}\right)$ of fluids from fluid inclusions from the Triassic Mercia Mudstone (Eichenlaub, 2016). 


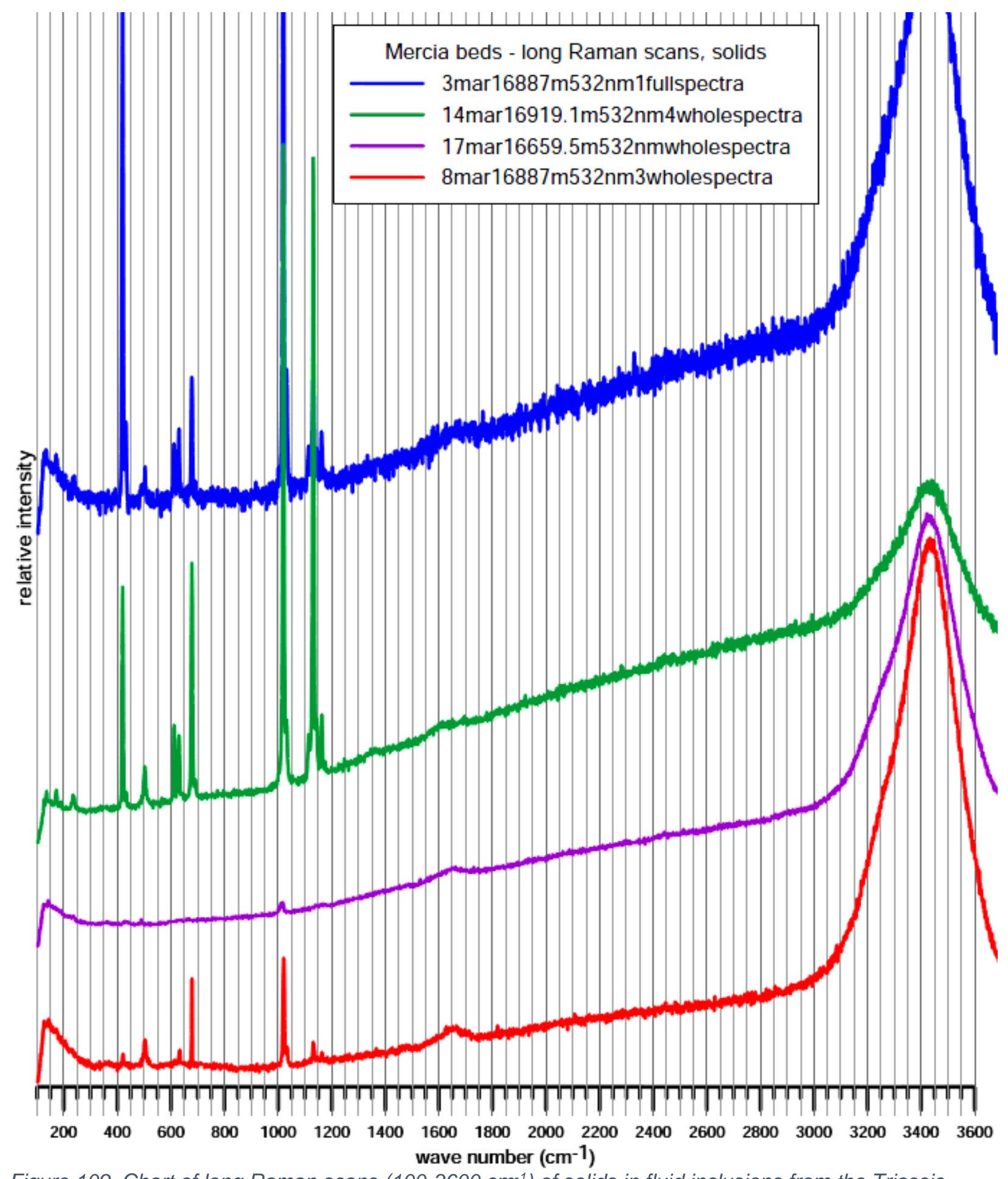

Figure 109. Chart of long Raman scans $\left(100-3600 \mathrm{~cm}^{-1}\right)$ of solids in fluid inclusions from the Triassic Mercia Mudstone (Eichenlaub, 2016). Solids are identified as anhydrite and suspect alunite. 


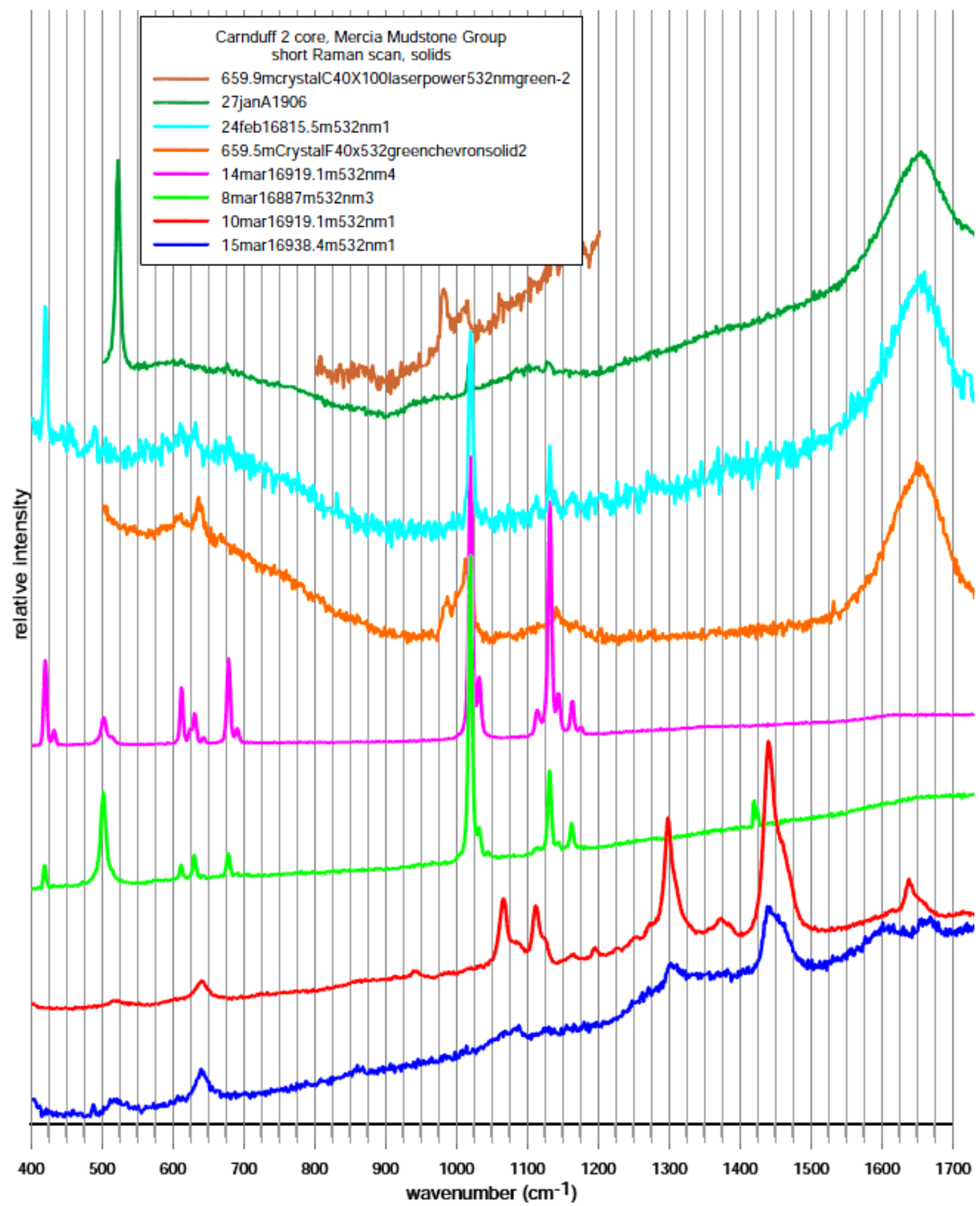

Figure 110. Chart of short Raman scans $\left(400-1700 \mathrm{~cm}^{-1}\right)$ of solids in fluid inclusions from the Triassic Mercia Mudstone (Eichenlaub, 2016). Solids are identified as anhydrite, suspect alunite, and suspect Poly(dodecyl vinyl ether-alt-maleic anhydride) [Figure 111], other solids remain unidentified. 

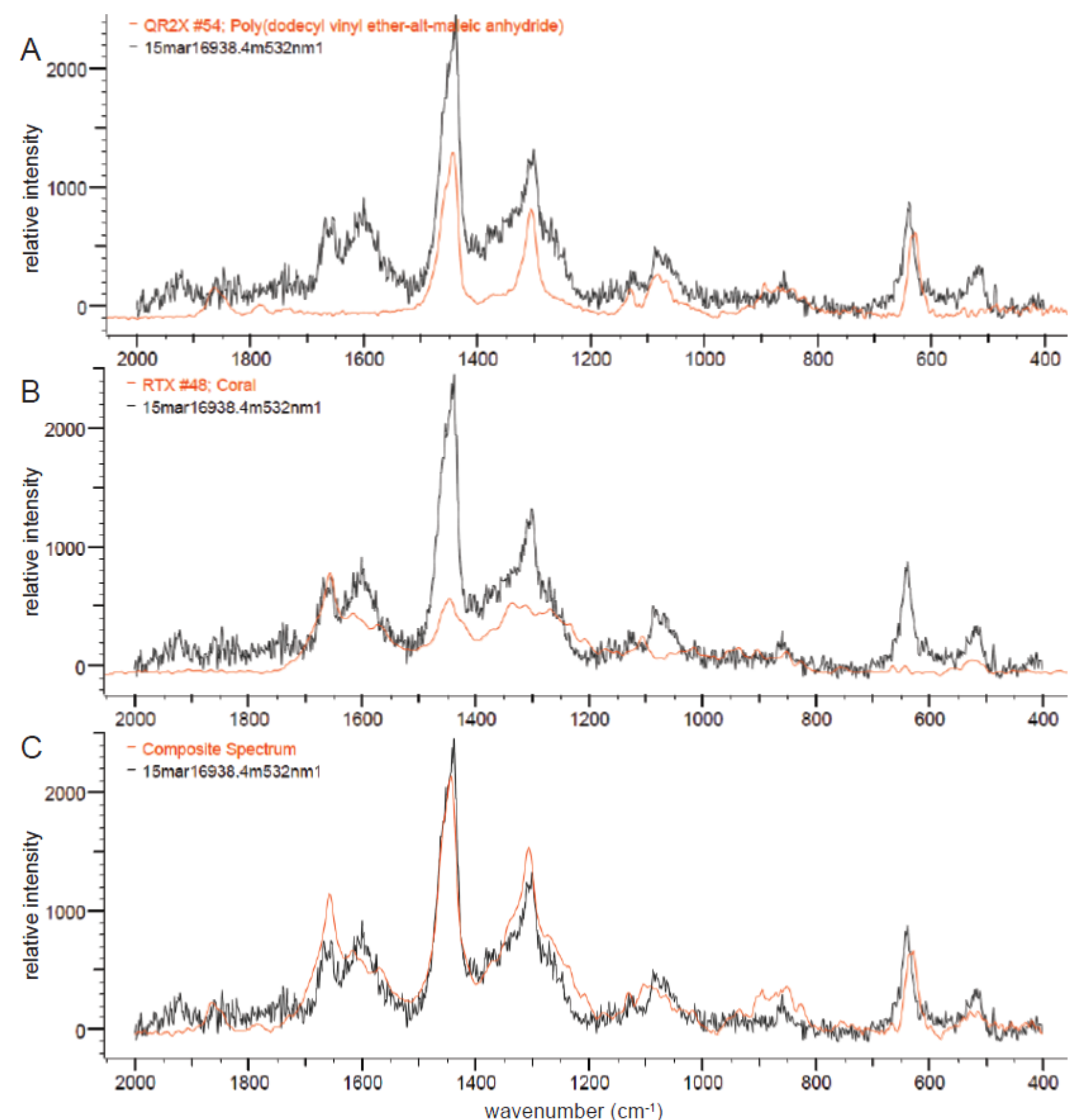

Figure 111. Illustration of Raman spectral Identification of solid in fluid inclusion from Triassic Mercia Mudstone (Eichenlaub, 2016), Spectral matching (synthetic sample in question in black, match in red) indicates it is likely related to (A) a polymer - poly(dodecyl vinyl ether-alt-maleic anhydride), (B) coral, or (C) a combination of the two. Spectral matches identified with BIO-RAD Know-it-all spectral identification software. 


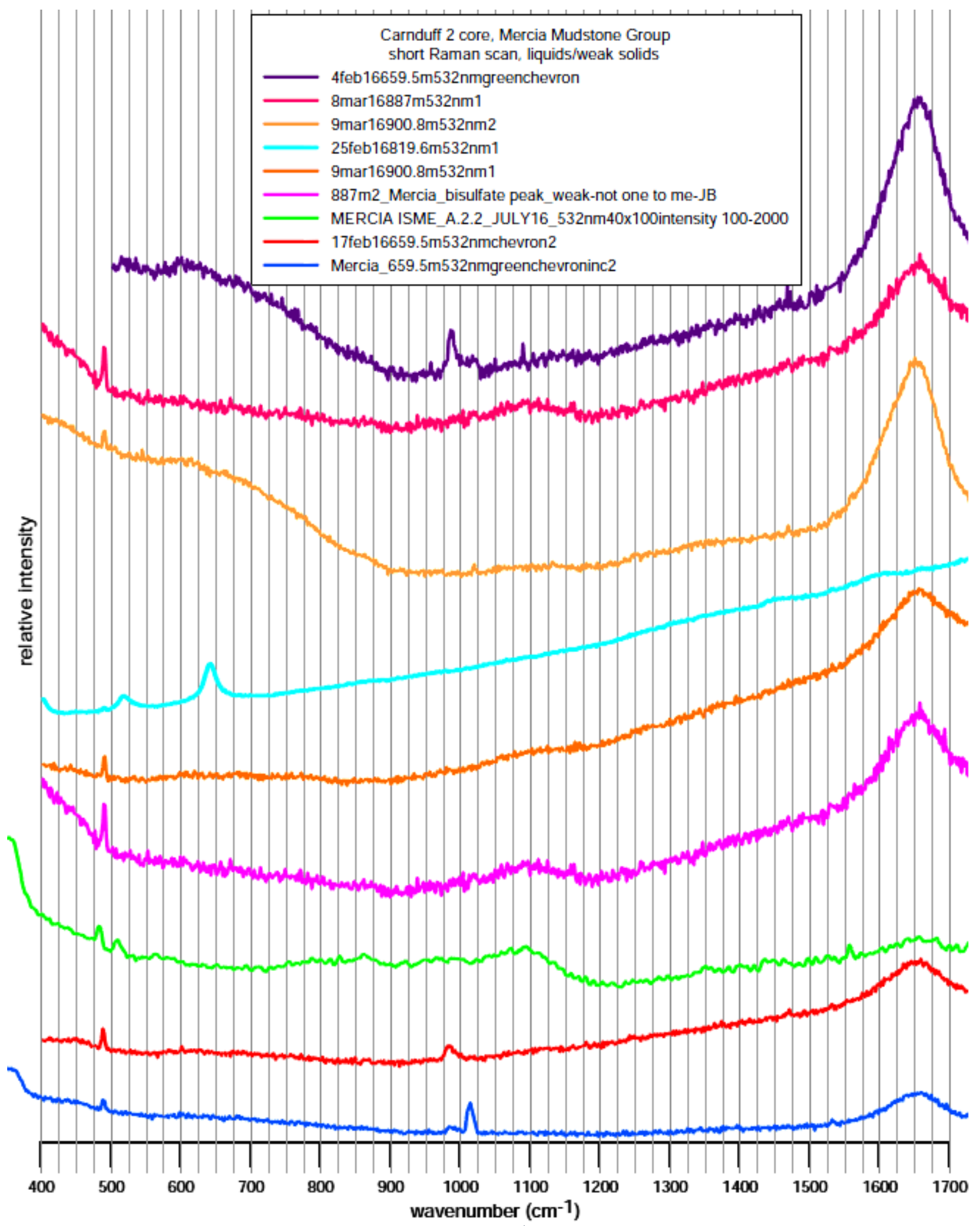

Figure 112. Chart of short Raman scans (400-1700 $\left.\mathrm{cm}^{-1}\right)$ of fluid inclusions, some of which may contain solids, from the Triassic Mercia Mudstone (Eichenlaub, 2016). The peaks at 984 in these spectra indicate the presence of sulfate. The source of other peaks is uncertain. 


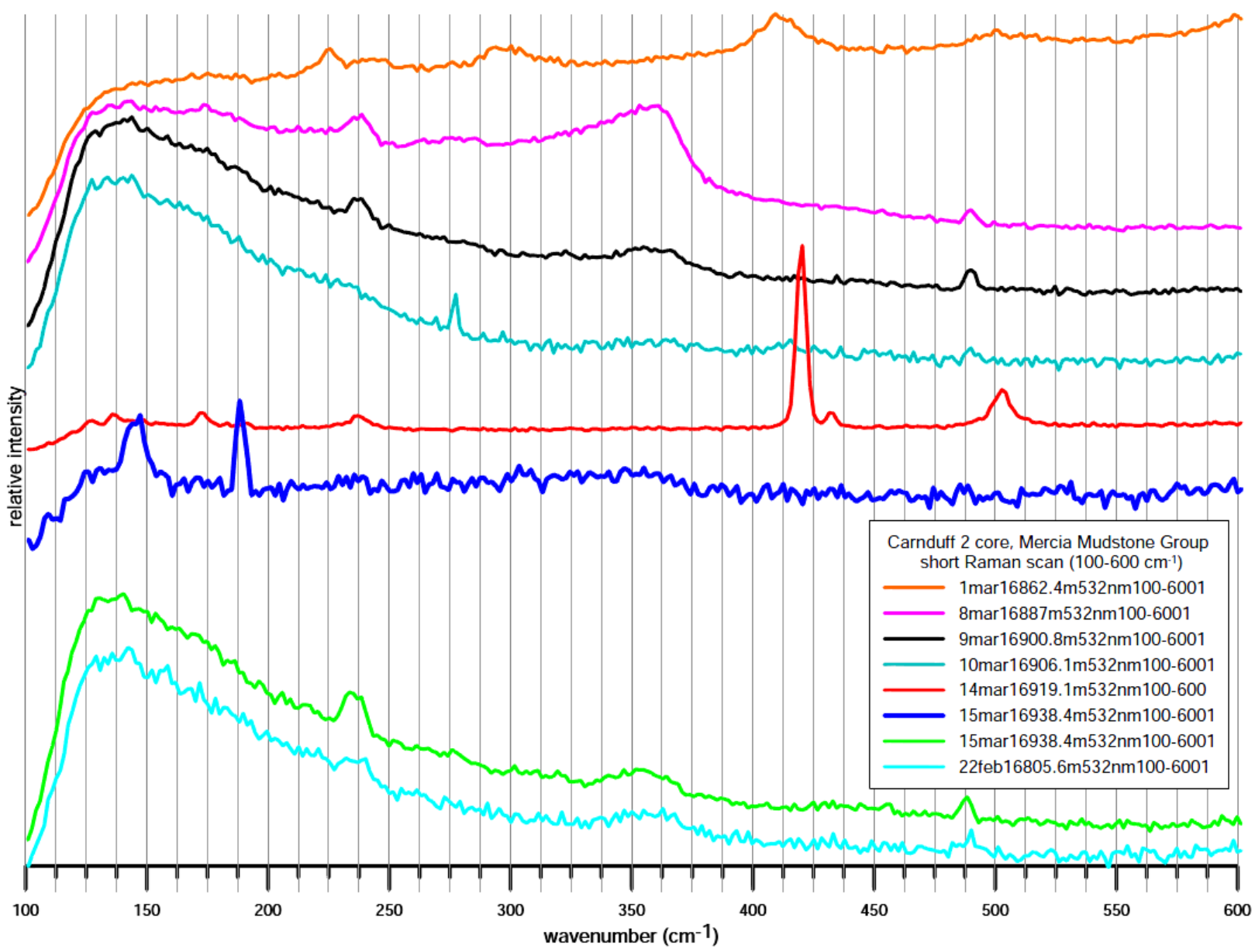

Figure 113. Chart of short Raman scans $\left(400-1700 \mathrm{~cm}^{-1}\right)$ of fluid inclusions, some of which may contain solids, from the Triassic Mercia Mudstone (Eichenlaub, 2016). The peaks at $~ 984$ in these spectra indicate the presence of sulfate. The source of other peaks is uncertain. 
Fluid inclusion Laser Raman Spectral Analogs

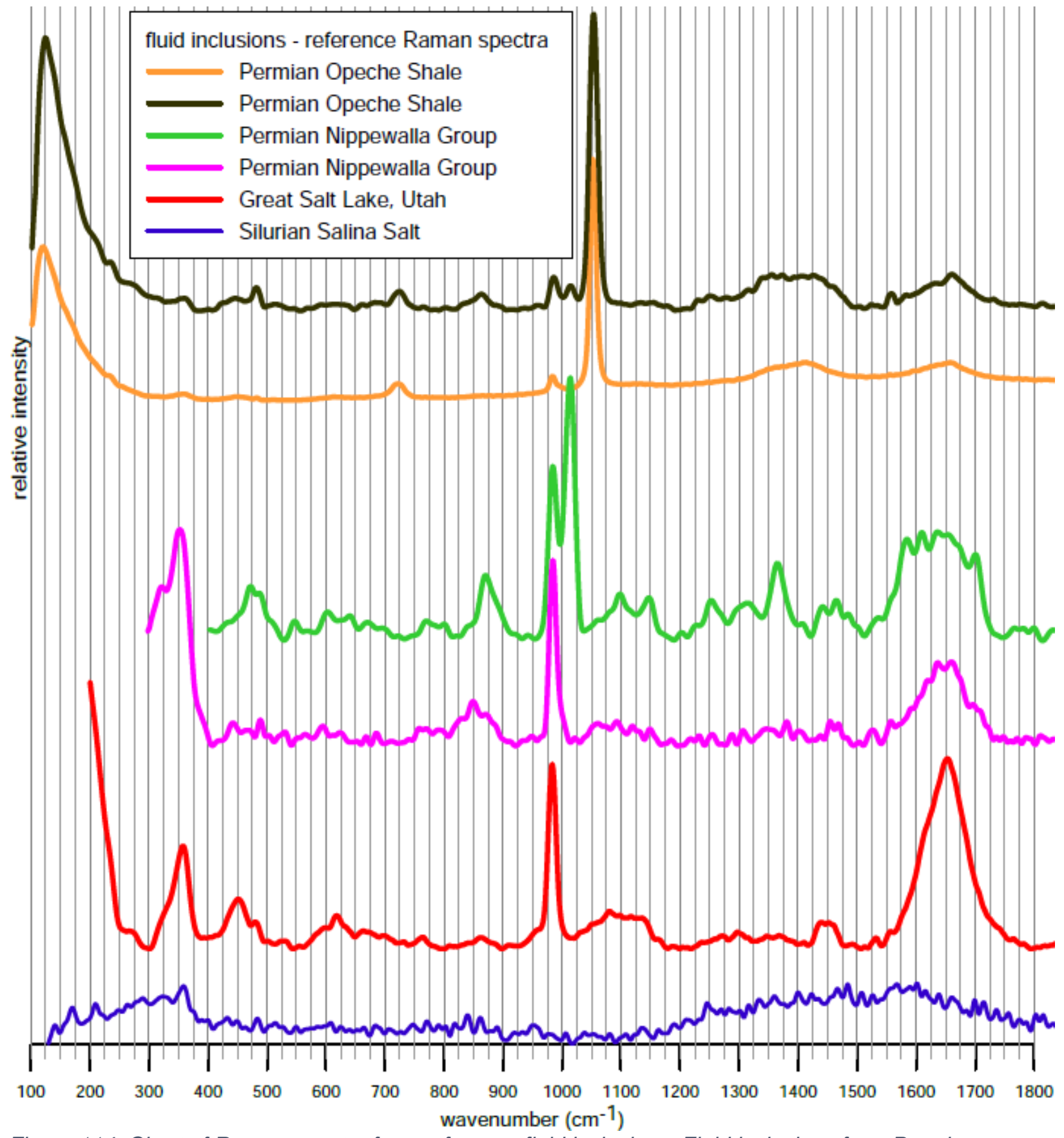

Figure 114. Chart of Raman spectra from reference fluid inclusions. Fluid inclusions from Permian Opeche Shale and Nippewalla group show evidence of high sulfate the low $\mathrm{pH}$. Fluid inclusion from Great Salt Lake, Utah, contains high sulfate. Inclusion from Silurian Salina Formation does not indicate the presence of sulfate. Note: some of these spectra may be influenced by solids in adjacent halite, or in the fluid inclusion. Some spectra collected by Eichenlaub (2016). 
Table 43. Solids observed in Opeche Shale fluid inclusions and tentative identity from Raman analysis (Benison, 1997; 1998)

\begin{tabular}{|l|l|l|}
\hline Formation & Mineral Shape & Potential mineral ID \\
\hline Opeche & elongated solid & alunite or jarosite \\
\hline Opeche & small round solid & leonite \\
\hline Opeche & $\begin{array}{l}\text { bladed solid, large } \\
\text { solid, }\end{array}$ & small round solid \\
anhydrite
\end{tabular}


Modern saline lakes and ephemeral saline lakes

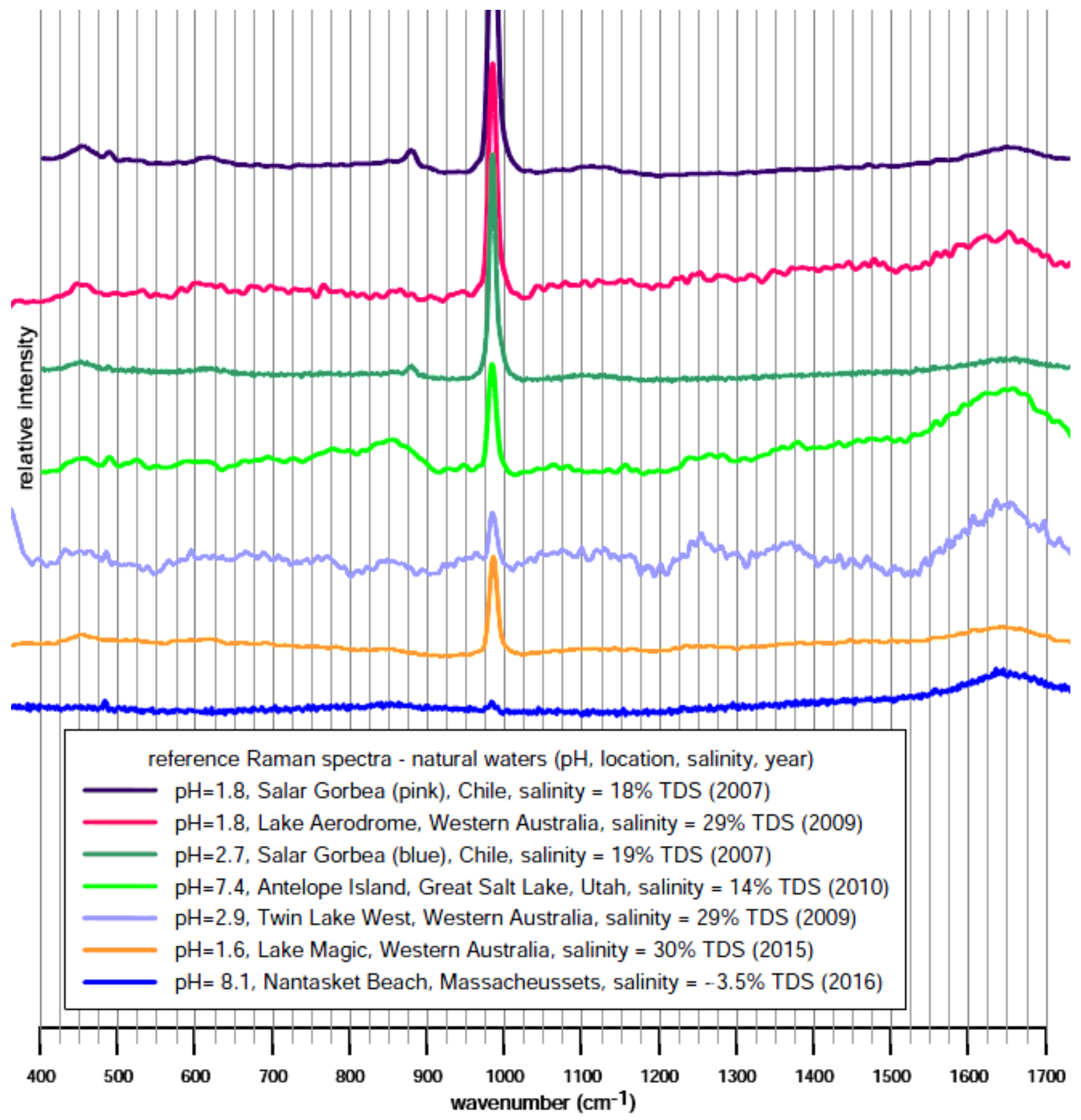

Figure 115. Chart of reference Raman spectra of natural modern waters from locations with varying $\mathrm{pH}$ and salinity. Some spectra collected by Eichenlaub (2016) 


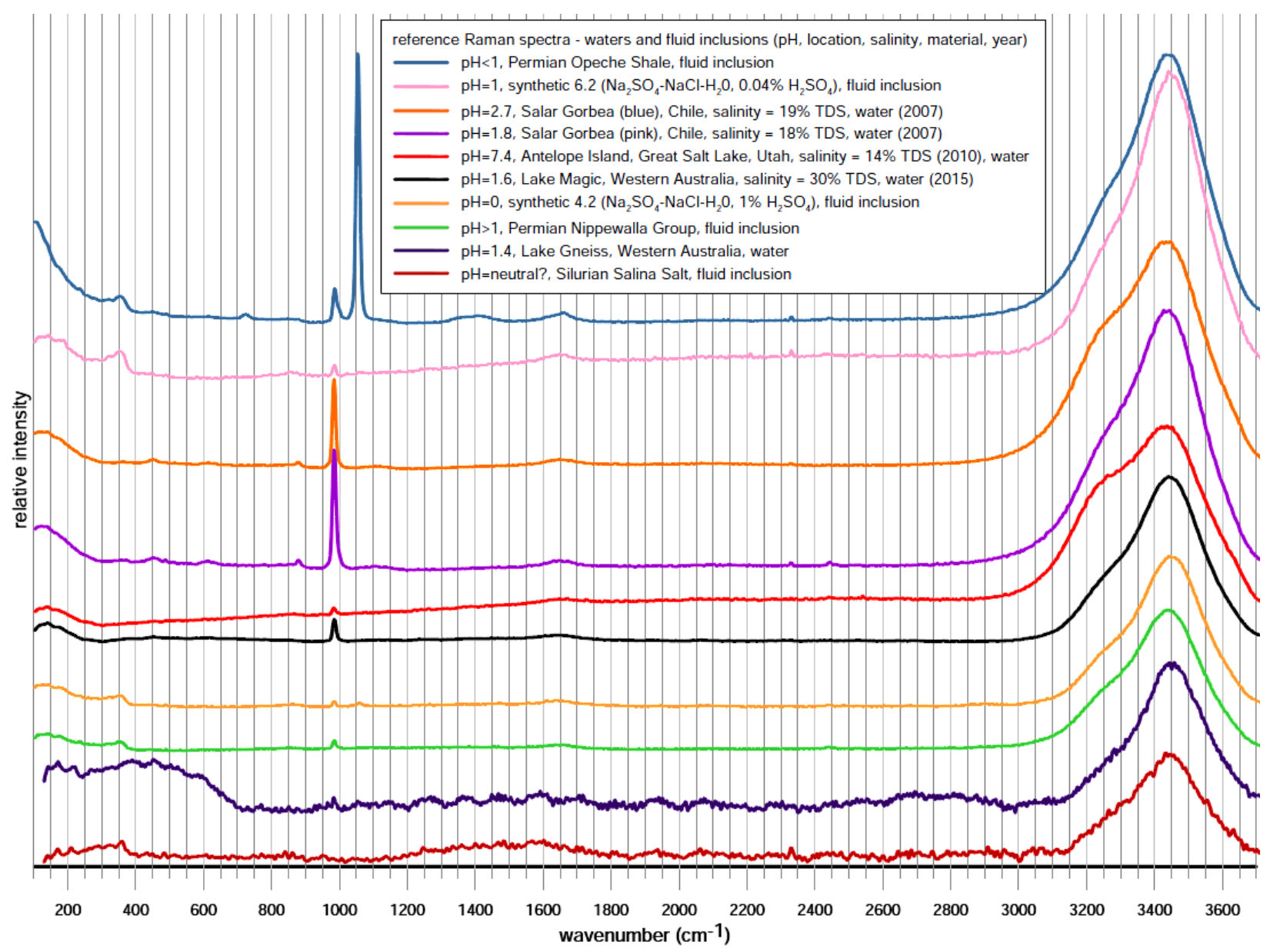

Figure 116. Chart of long Raman scans (100-3700 $\left.\mathrm{cm}^{-1}\right)$ of reference waters and fluid inclusions. Some spectra collected by Eichenlaub (2016)

Appendix IV. Can Raman spectra of aqeous iron complexes be a $\mathrm{pH}$ proxy?

Intro

Project goal: to test if Raman Spectroscopy may determine the presence of different iron complexes and thus delineate the $\mathrm{pH}$. 
Background

\section{Fe III speciation}

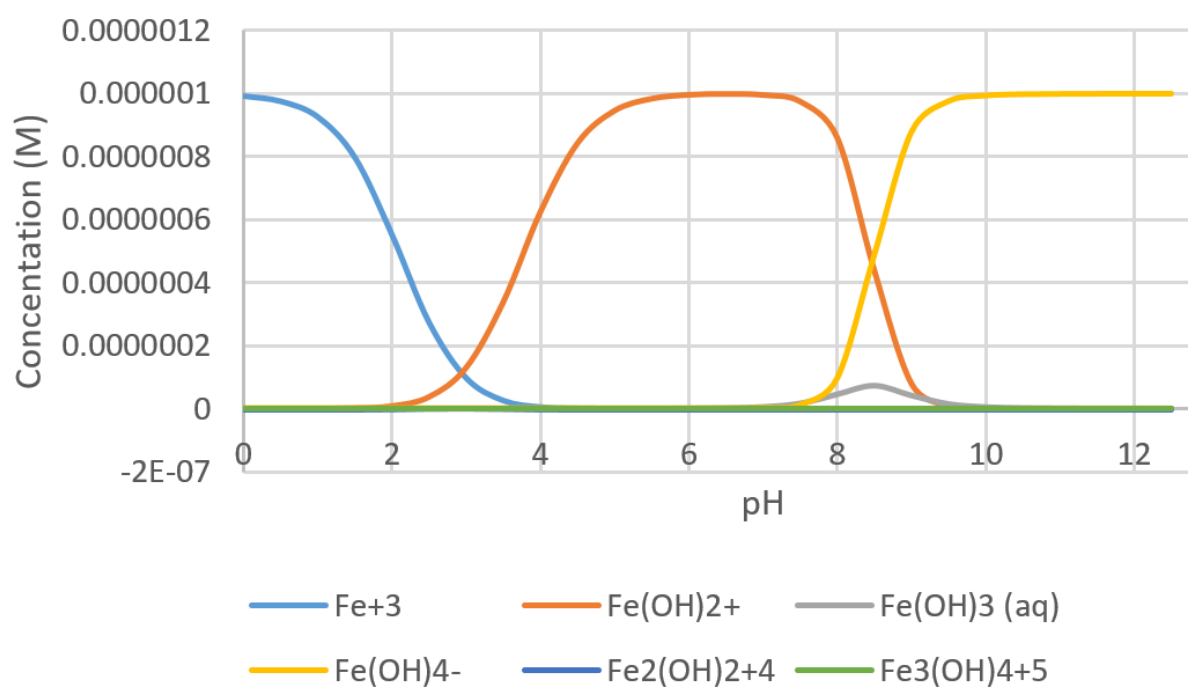

Figure 117. Chart of $\mathrm{Fe}^{3+}$ speciation with changing $\mathrm{pH}$. The possible species here are limited and not representative of all possible iron species.

\section{Fe III - lonic strength 5}

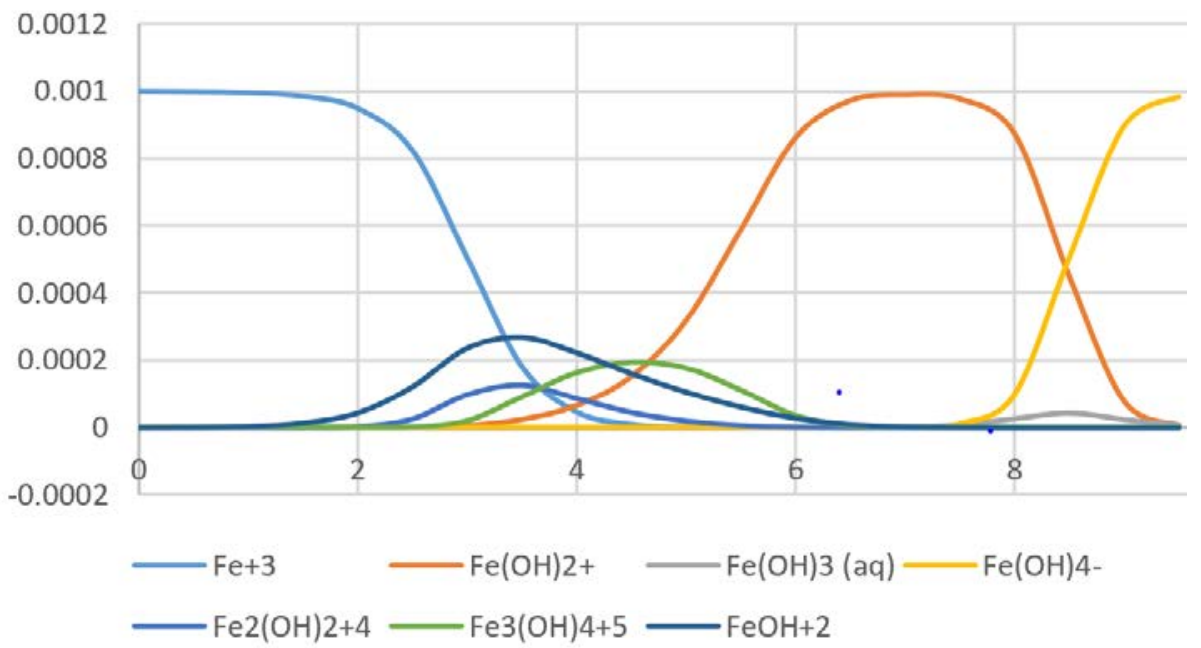

Figure 118. Chart of $\mathrm{Fe}^{3+}$ at an ionic strength of 5 with changing $\mathrm{pH}$. The possible species here are limited and not representative of all possible iron species 


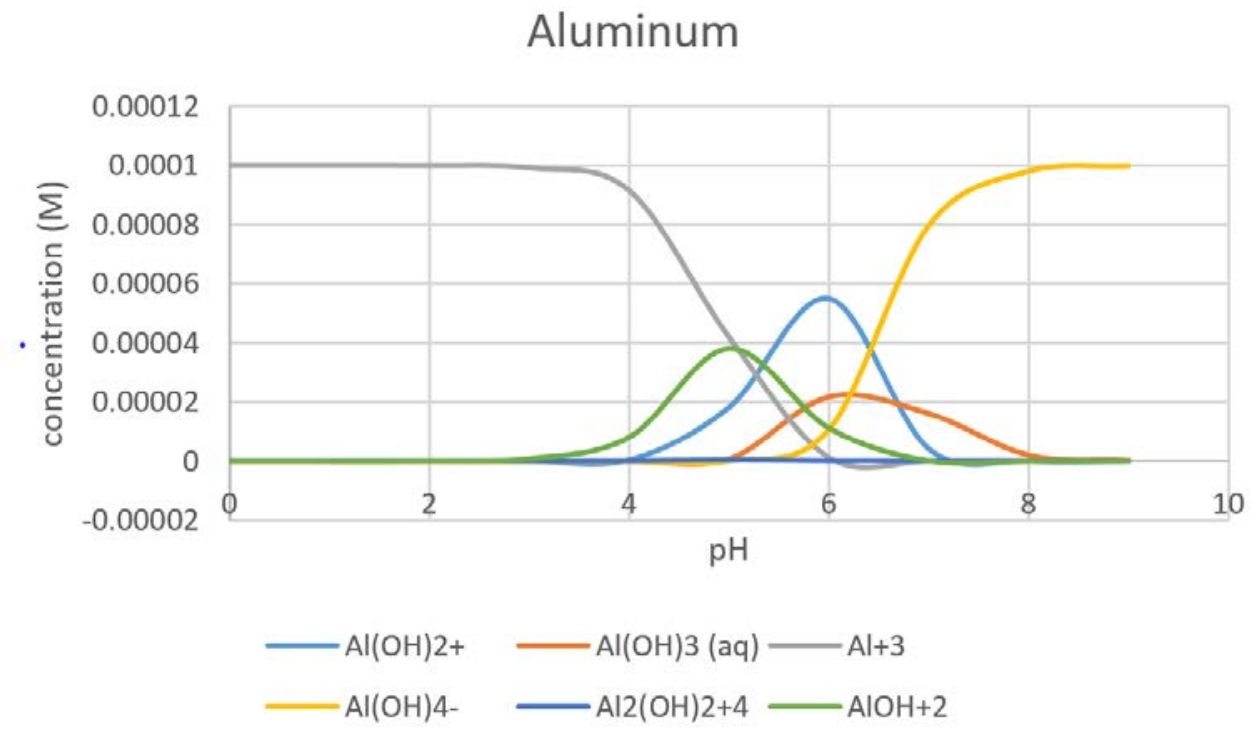

Figure 119. Chart of aluminum speciation with changing $\mathrm{pH}$, not that most change in specied occur between $\mathrm{pH} 4$ and 8.

Methods

Ingredients and amounts needed for $250 \mathrm{ml}$ solution (note: will be making two of these, as well as one saline nitric solution).

\begin{tabular}{|l|c|}
\hline \multicolumn{1}{|c|}{ substance } & grams \\
\hline $\mathrm{Fe}(\mathrm{NO} 3) 3 \cdot 9 \mathrm{H} 2 \mathrm{O}$ & \\
\hline $\mathrm{NaCl}$ & \\
\hline $\mathrm{HCl}$ & $\mathrm{X}$ \\
\hline $\mathrm{NaOH}$ & $\mathrm{X}$ \\
\hline distilled water & \\
\hline
\end{tabular}

Equipment needed

- $\quad 2-250 \mathrm{ml}$ volumetric flasks

- 1 -desiccator

- pH strips

- several water vials

- stir bar and plate

- hot plate

- salinity refractometer and eyedropper 
Note: will be preparing two solutions of $\mathrm{pH}: 1$, and one solution of $\mathrm{pH}$ : 5

At least $\mathbf{2 4}$ hours prior to preparing solution

1. Place at least 5 times the needed mass of $\mathrm{Fe}(\mathrm{NO} 3) 3 \cdot 9 \mathrm{H} 2 \mathrm{O}\left(\mathrm{g}\right.$ ) in oven at $105{ }^{\circ} \mathrm{C}$ for at least an hour, remove from oven and cool in desiccator

After $\mathrm{Fe}(\mathrm{NO} 3) 3 \cdot 9 \mathrm{H} 2 \mathrm{O}$ has been desiccated

2. Weigh out__ g of $\mathrm{Fe}(\mathrm{NO} 3) 3 \cdot 9 \mathrm{H} 2 \mathrm{O}$

a. Place plastic boat or tare paper on a balance sensitive to 0.01 grams

b. Tare boat/paper

c. Add $\mathrm{Fe}(\mathrm{NO} 3) 3 \cdot 9 \mathrm{H} 2 \mathrm{O}$ until

3. Add $50 \mathrm{ml}$ of water to $250 \mathrm{~mL}$ volumetric flask

4. Add ___ g of Fe(NO3)3.9H2O to the $250 \mathrm{~mL}$ volumetric flask

5. Add ___ g of NaCl to the $250 \mathrm{~mL}$ volumetric flask

6. Fill flask to $180 \mathrm{ml}$ volume

7. Stir/heat(?) flask to dissolve $\mathrm{Fe}(\mathrm{NO} 3) 3 \cdot 9 \mathrm{H} 2 \mathrm{O}$ and $\mathrm{NaCl}$

8. Use $\mathrm{pH}$ strip to determine $\mathrm{pH}$

9. Add $\mathrm{HCl} / \mathrm{NaOH}$ to solution dropwise and test with $\mathrm{pH}$ strips until desired $\mathrm{pH}$ is reached

10. Fill flask to $250 \mathrm{~mL}$ volume

11. If needed, stir/heat(?) flask to dissolve $\mathrm{Fe}(\mathrm{NO} 3) 3 \cdot 9 \mathrm{H} 2 \mathrm{O}$ and $\mathrm{NaCl}$

12. Use salinity refractometer to determine final salinity

13. Place water sample in labeled vial

14. Use normal procedure in Raman spectrometer to determine presence of desired spectra

\begin{tabular}{|l|r|}
\hline goal volume & $0.25 \mathrm{~L}$ \\
\hline Fe (min) (g) & 0.018 \\
\hline $\mathrm{Fe}(\max )(\mathrm{g})$ & 0.90425 \\
\hline $\mathrm{NaCl}(\min )(\mathrm{g})$ & 51.135 \\
\hline $\mathrm{NaCl}(\max )(\mathrm{g})$ & 70.128 \\
\hline
\end{tabular}

$\mathrm{Fe}(\mathrm{NO} 3) 3.9 \mathrm{H} 2 \mathrm{O}$ (final mass) : 2 grams, (get 5 grams for the desiccator to ensure sufficient material).

$\mathrm{NaCl}: 150$ grams

Results

Notes: 
A. Attempted to heat the ferric nitrate at $66^{\circ} \mathrm{C}$ in oven for several hours, the compound melted and turned into a brown gelatinous jelly like substance, took out, cooled, and disposed off

B. This experiment was performed with non-desiccated $\mathrm{Fe}(\mathrm{NO} 3) 3 \cdot 9 \mathrm{H} 2 \mathrm{O}$ (so greater than called for amount of that substance was added).

C. Added Nitric acid to reference container for nitric.

D. Had to use $\mathrm{KOH}$ instead of $\mathrm{NaOH}$ to adjust the $\mathrm{pH}$.

E. Solution \#2 had an iron floculant in it, this was filtered out using syringe filter, the remaining liquid was then lowered in $\mathrm{pH}$ to create solution \#4

F. Iron in solution at low $\mathrm{pH}$ had a bright uranium yellow color, as $\mathrm{pH}$ raised, the solution color became orange to rust red.

Raman information

a. Used the $5 x$ objective

b. Calibrated the Silicon wafer to $522 \mathrm{~nm}$

Table 44. Chemical composition of iron-complex solutions used for laser Raman analysis. Note peak strength abbreviations: $s$ = sharp, $S=$ very sharp, ws = weak sharp, $b=$ broad, $w b=$ weak broad, $B=$ very broad.

\begin{tabular}{|c|c|c|c|c|}
\hline Solution & 1 & 2 & 3 & 4 \\
\hline description & FeNO3, low pH & FeNO3 high(er) pH & nitric reference & $\begin{array}{l}\text { FeNO3, moderate pH, } \\
\text { iteration of \#2, unfiltered, } \\
\text { poor spectra }\end{array}$ \\
\hline $\mathrm{pH}$ & $\sim 1$ & 5 & $\sim>1$ & $<5$ \\
\hline salinity (\%TDS) & 27.8 & 28.1 & 27.4 & 28.1 \\
\hline ionic strength & 4.88 & 4.91 & 4.82 & 4.93 \\
\hline $\mathrm{Fe}(\mathrm{mol} / \mathrm{L})$ & 1.07E-02 & 1.03E-02 & $0.00 \mathrm{E}+00$ & 1.03E-02 \\
\hline NO3 (mol/L) & $3.21 \mathrm{E}-02$ & 3.09E-02 & 2.63E-02 & $5.72 \mathrm{E}-02$ \\
\hline $\mathrm{K}(\mathrm{mol} / \mathrm{L})$ & $0.00 \mathrm{E}+00$ & 4.40E-02 & $0.00 \mathrm{E}+00$ & 4.40E-02 \\
\hline $\mathrm{Na}(\mathrm{mol} / \mathrm{L})$ & 4.81 & 4.83 & 4.81 & 4.83 \\
\hline $\mathrm{CL}(\mathrm{mol} / \mathrm{L})$ & 4.82 & 4.83 & 4.81 & 4.83 \\
\hline $\begin{array}{l}\text { observed spectral } \\
\text { peaks }\left(\mathrm{cm}^{-1}\right)\end{array}$ & $\begin{array}{l}\text { 140(b), 365(wb), } \\
\text { 435(b), 484(s), } \\
\text { 1053(S), 1468(wb), } \\
1653(B)\end{array}$ & $\begin{array}{l}140(\mathrm{~b}), 365(\mathrm{wb}) \\
435(\mathrm{~b}), 484(\mathrm{~s}) \\
1052(\mathrm{~S}), 1651(\mathrm{~B})\end{array}$ & $\begin{array}{l}\text { 140(b), 365(wb), } \\
435(\mathrm{~b}), 484(\mathrm{~s}) \\
1052(\mathrm{~S}), 1652(\mathrm{~B})\end{array}$ & $\begin{array}{l}\text { 125(b), 140(b), 365(wb), } \\
\text { 484(s), 1058(ws?), 1463(s), } \\
\text { 1528(s), 1598(s), 1650(B) }\end{array}$ \\
\hline
\end{tabular}




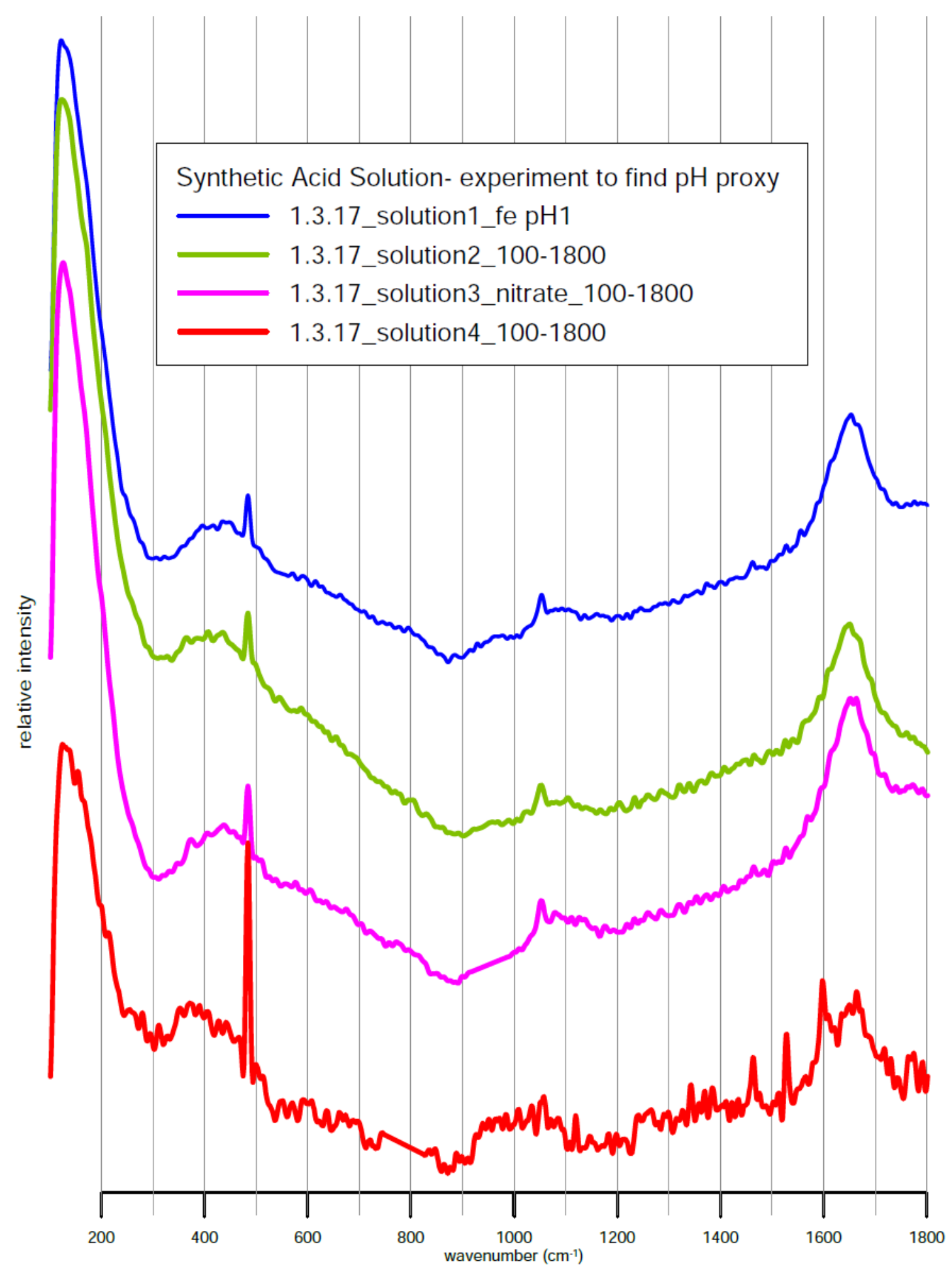

Figure 120: Chart of Raman spectra of iron solutions at different pH's. Solutions 1, 2, and 4, which contain iron, nearly match the spectra of solution 3, which contains only $\mathrm{NaCl}$ and nitric acid. 


\section{Discussion/Conclusion}

Conclusion: the $\sim 484,1053$, and $1650 \mathrm{~cm}^{-1}$ Raman peaks to not change markedly with a change in the $\mathrm{pH}$. This indicates that iron complexes may not be a good Raman proxy for constraining $\mathrm{pH}$.

\section{References}

Andrieux, F. P. L., Boxall, C. and Taylor, R. J. (2008) ‘Determination of the Constants of Formationyof Complexes of Iron ( III ) and Acetohydroxamic Acid', Intech, (Iii), pp. 1-18.

Kanno, H. and Hiraishi, J. (1982) 'A Raman study of aqueous solutions of ferric nitrate, ferrous chloride and ferric chloride in the glassy state', Journal of Raman Spectroscopy, 12(3), pp. 224-227. doi: 10.1002/jrs.1250120305.

Liu, X. and Millero, F. J. (1999) 'The solubility of iron hydroxide in sodium chloride solutions', Geochimica et Cosmochimica Acta, 63(19-20), pp. 3487-3497. doi: 10.1016/S00167037(99)00270-7.

Perkins, R. S. and Garber, J. D. (2003) ‘Raman Spectroscopy of Iron in Aqueous Carbonate Solutions', Journal of Solution Chemistry, 32(3), pp. 265-272. doi:

10.1023/A:1022990402530. 